\title{
Le choix de la CEE par la France
}

L’Europe économique en débat de Mendès France à de Gaulle (1955-1969)

Laurent Warlouzet
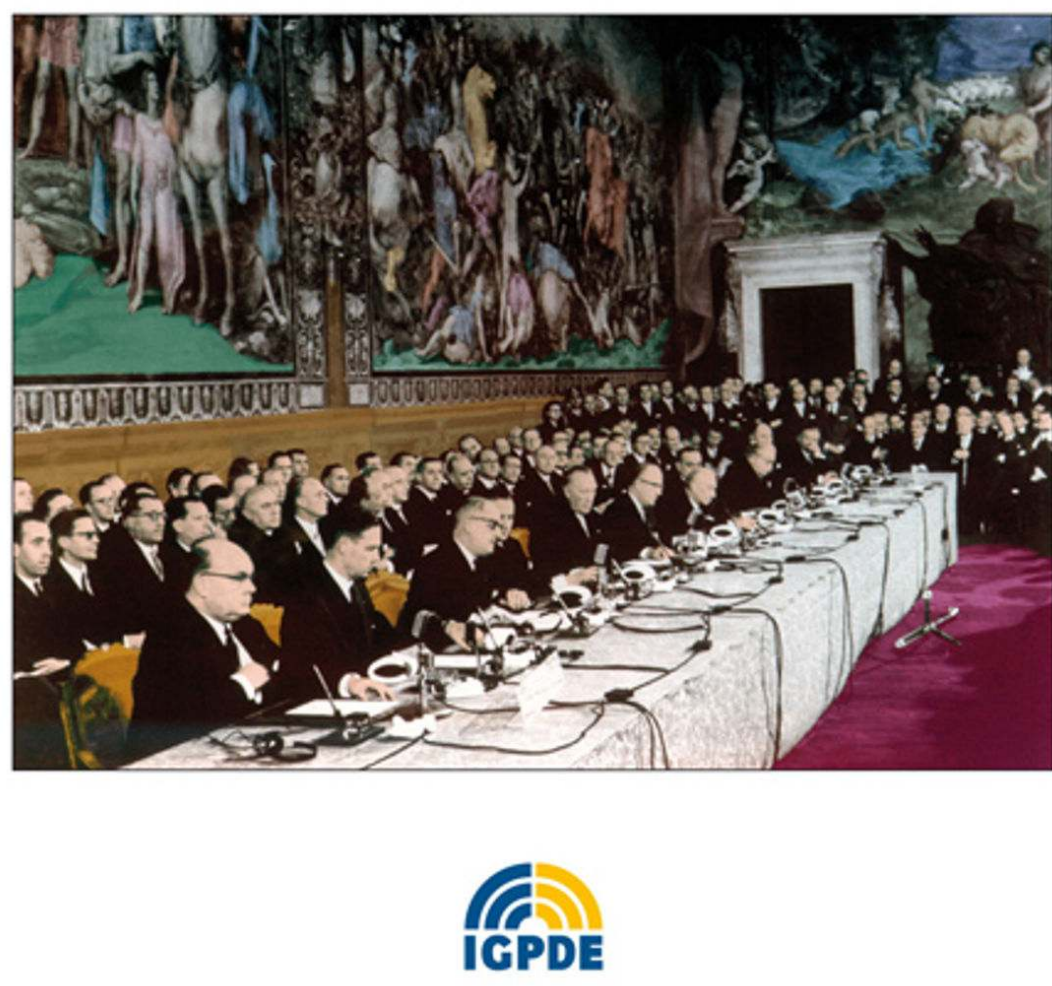

COMITÉ POUR L'HISTOIRE ÉCONOMIQUE ET FINANCIÈRE DE LA FRANCE 


\section{Le choix de la CEE par la France}

L'Europe économique en débat de Mendès France à de Gaulle (1955-1969)

France's choice of the EEC. The debate on economic Europe from Mendès France to de Gaulle (1955-1969) La elección de la CEE por parte de Francia. El debate en torno a la Europa económica, de Mendès France a de Gaulle (1955-1969)

\section{Laurent Warlouzet}

DOI : 10.4000/books.igpde.102

Éditeur : Institut de la gestion publique et du développement économique, Comité pour l'histoire économique et financière de la France

Lieu d'édition : Paris

Année d'édition : 2011

Date de mise en ligne : 27 octobre 2011

Collection : Histoire économique et financière - XIXe-XX

ISBN électronique : 9782111287570

\section{Sbooks}

http://books.openedition.org

\section{Édition imprimée}

Date de publication : 1 janvier 2011

ISBN : 9782110975171

Nombre de pages : 588

Ce document vous est offert par Université Paris 1 Panthéon-Sorbonne

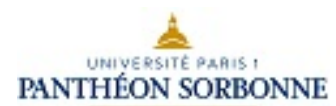

Référence électronique

WARLOUZET, Laurent. Le choix de la CEE par la France : L'Europe économique en débat de Mendès France à de Gaulle (1955-1969). Nouvelle édition [en ligne]. Paris : Institut de la gestion publique et du développement économique, 2011 (généré le 13 septembre 2019). Disponible sur Internet : <http:// books.openedition.org/igpde/102>. ISBN : 9782111287570. DOI : 10.4000/books.igpde.102. 
Études générales

\section{Le choix de la CEE par la France}

L’Europe économique en débat de Mendès France à de Gaulle

(1955-1969)

Laurent Warlouzet
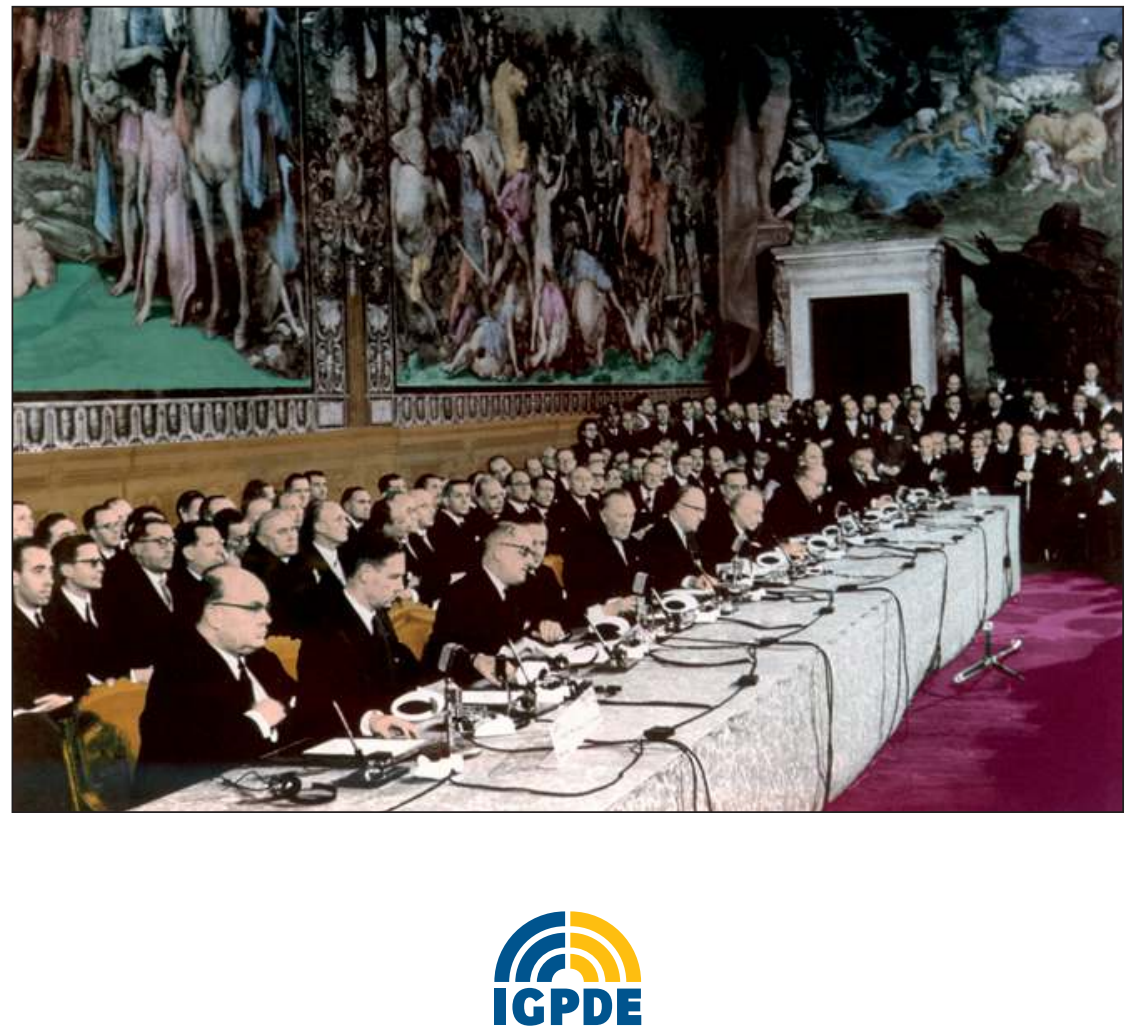

COMITÉ POUR L'HISTOIRE ÉCONOMIQUE ET FINANCIÈRE DE LA FRANCE 


\section{Histoire économique et financière de la France}


Dans la collection « Histoire économique et financière de la France », la série Études générales est destinée à la publication de thèses universitaires ou de travaux scientifiques de synthèse.

Couverture : 25 mars 1957 : signature du traité de Rome Source : Médiathèque de la Commission européenne. Référence P-001321/00-05

(C) Union Européenne, 2010

(C) Comité pour l'histoire économique et financière de la France - IGPDE

Ministère de l'Économie, des Finances et de l'Industrie,

Ministère du Budget, des Comptes publics

et de la Réforme de l'État - Paris 2011

ISBN 978-2-11-097517-1 
MINISTĖRE DE L'ÉCONOMIE, DES FINANCES ET DE L'INDUSTRIE

MINISTĖRE DU BUDGET, DES COMPTES PUBLICS

ET DE LA RÉFORME DE L'ÉTAT.

\title{
Le choix de la CEE par la France
}

\section{L'Europe économique en débat de Mendès France à de Gaulle (1955-1969)}

\section{Laurent Warlouzet}

\author{
Avant-propos d'Éric Bussière \\ Préface de Michel Albert
}

\author{
COMITÉ POUR L'HISTOIRE ÉCONOMIQUE \\ ET FINANCIËRE DE LA FRANCE
}


L'Institut de la gestion publique et du développement économique soutient la recherche universitaire en publiant des ouvrages en gestion publique et en histoire économique et financière dans sa collection « Histoire économique et financière de la France »"

Dans le cadre de ses activités de recherche, l'Institut de la gestion publique et du développement économique est assisté d'un Comité pour l'histoire économique et financière de la France.

Sont membres de ce comité :

Edward Arkwright, Marc-Olivier Baruch, Françoise Bayard, Philippe Bezes, Christian de Boissieu, Éric Bussière, Florence Descamps, Christian Descheemaeker, Olivier Feiertag, Patrick Fridenson, Pascal Griset, PierreCyrille Hautcœur, Jean-Noël Jeanneney, Jean Kerhervé, Michel Lescure, Christine Manigand, Michel Margairaz, Olivier Mattéoni, Philippe Minard, François Monnier, Frédérique Pallez, Albert Rigaudière, Guy Thuillier, Mireille Touzery, Jean Tulard. 


\section{AVANT-PROPOS}

Le livre de Laurent Warlouzet nous invite à repenser sous de nombreux aspects le rapport de la France au projet européen. C'est le fait d'une étude bien centrée sur un objet essentiel, l'Europe économique, et mettant en æuvre de multiples angles d'attaque.

Espérons-le, ce livre règlera de façon définitive la question du rapport du gaullisme, celui du Général, à l'Europe, rapport fondé sur une série d'incompréhensions et d'erreurs. Certes le Général a assumé politiquement l'ouverture de l'économie française sur l'Europe et le monde, notamment à travers les réformes économiques de décembre 1958. Il a donc permis à la France de respecter ses engagements européens. Mais Laurent Warlouzet démontre son incompréhension des fondements du projet communautaire et des potentialités qu'il comporte. D'où des erreurs successives dans la stratégie suivie consistant notamment à faciliter la mise en place de dynamiques institutionnelles au début des années 1960 que l'on cherche maladroitement à bloquer quelques années après. Il est vrai que de Gaulle avait été précédé dans ce jeu de dupes par plusieurs présidents du Conseil de la IV République, quelles que soient par ailleurs leurs intentions sur le fond. Ce défaut de lucidité sur le projet européen montre combien ce dernier resta longtemps incertain et flou aux yeux de la plupart et notamment d'une partie des hauts fonctionnaires chargés de conseiller les politiques en la matière.

Mais au-delà du cas spécifique de la France du Général, c'est une série de lectures binaires parce qu'artificiellement politisées et instrumentalisées que remet en cause Laurent Warlouzet en nous montrant que la réalité des positions des acteurs face à l'Europe économique relève en fait d'une série de positionnements transversaux. Le débat entre Europe arbitre et Europe volontaire, entre Europe du marché ou Europe organisée se situe au sein même de la Commission en même temps qu'il génère des rapprochements sousestimés jusqu'il y a peu notamment entre Français et Italiens. Mais ce même débat traverse aussi le monde des entreprises et du patronat et il est vain, ici encore, pour qui veut comprendre, d'organiser l'analyse selon de simples logiques comparatives à base nationale qui négligent les cultures de branche par définition transnationales.

Laurent Warlouzet met enfin en valeur une série de schémas et d'inflexions dont la portée ne se révélera, dans toute leur amplitude, que parfois bien 
plus tard. Les Français de la Commission, à la tête desquels se détache le personnage de Robert Marjolin, ont tenté de promouvoir à l'échelle communautaire un modèle de politique économique proche par plusieurs aspects du modèle français dont quelques fonctionnaires parisiens seulement ont perçu toute la portée sans avoir pour autant la possibilité de le relayer à l'échelon national. La "crise de la chaise vide " a de ce point de vue affaibli leurs initiatives et les chances réelles qu'eut alors la France de promouvoir son modèle d'Europe économique. Il faudra attendre les années 1980 pour qu'une seconde chance soit donnée à ce modèle.

Dès lors, comme le fait très justement remarquer l'auteur, les années 1960 ne constituent pas une sorte d'âge d'or pour le projet européen. Mais pour la France plus encore que pour d'autres, ce premier temps de la construction européenne apparaît bien comme celui des occasions manquées.

Éric BUSSIÈRE

Professeur à l'Université Paris-Sorbonne 


\section{PRÉFACE}

Laurent Warlouzet, maître de conférences en histoire contemporaine à l'Université d'Artois (Arras) a soutenu en 2007 sa thèse de doctorat à Paris IV-Sorbonne sous la direction d'un jury particulièrement prestigieux qui lui a accordé mention " très bien » avec félicitations du jury à l'unanimité. Cette thèse est intitulée Quelle Europe économique pour la France ? La France et le Marché commun industriel, 1956-1969.

Aujourd'hui, les Éditions du Comité pour l'histoire économique et financière de la France publient le livre que Laurent Warlouzet vient de tirer de sa thèse, sous un titre quelque peu différent : Le choix de la CEE par la France. L'Europe économique en débat de Mendès France à de Gaulle (1955-1969). Son premier mérite est de présenter une bibliographie actualisée et bien exploitée, dans un esprit critique libéré des substrats idéologiques habituels en la matière.

La première partie du livre, chronologique, éclaire le grand débat qui a précédé la création du Marché commun. D’un côté, un petit nombre de militants européistes, inspirés notamment par Jean Monnet et Robert Schuman. Ils bénéficient en France de l'autorité intellectuelle de Robert Marjolin pour défendre le projet d'intégration économique tant auprès de l'administration que du patronat. D'autre part les adversaires du traité du Marché commun s'appuient notamment sur deux personnalités politiques majeures, Paul Ramadier et Pierre Mendès France, ce dernier redoutant les risques d'une immigration italienne massive en France ainsi que la perte de nos préférences coloniales. Ils sont paradoxalement alliés à un establishment qui refuse l'ouverture des frontières parce qu'il est profondément persuadé que l'économie française serait incapable d'affronter sans protection la concurrence de l'économie allemande.

Entre ces deux thèses, c'est finalement le général de Gaulle qui arbitrera en appliquant pleinement ce traité de Rome qu'il avait refusé de soutenir. Ce ralliement a été fortement inspiré par Jacques Rueff. D'ailleurs le traité de Rome, contrairement à son appellation courante de traité de "Marché commun », est en réalité intitulé "Traité instituant la Communauté économique européenne ". Entre les deux formulations, il y a le résultat de tout un effort de compromis qui permit, en regard de la libération des échanges, d'instituer un processus d'élimination des distorsions de concurrence les plus flagrantes et un début de coordination des politiques économiques notamment avec une 
politique régionale pouvant bénéficier tout particulièrement au moins développé des six pays membres, l'Italie.

Les controverses n'ont pas pris fin pour autant. C'est même à leur élucidation que Laurent Warlouzet consacre toute la seconde partie de son ouvrage, dont l'intérêt ne cesse de grandir à mesure qu'il s'avance sur les terrains de l'économique et du social, beaucoup moins défrichés que l'histoire politique et diplomatique.

Ces controverses sont dans une large mesure suscitées et animées par le " messianisme français » du général de Gaulle, qui va jusqu'à provoquer la crise de la chaise vide en 1965, pour combattre les risques d'évolution de la CEE vers la supranationalité et promouvoir au contraire une Europe intergouvernementale dominée par la France et protégée par le droit de veto. Face à cette conception française, la Commission européenne, particulièrement active sous la présidence de Walter Hallstein, se rattache à une vision fédéraliste de la construction européenne et promeut surtout, faute de pouvoir faire mieux, une politique de la concurrence inspirée par l'ordolibéralisme, philosophie économique largement inconnue en France et qui ne s'est pleinement incarnée que dans le " modèle rhénan » du capitalisme.

Tout cela est très sérieusement étudié et solidement présenté, en particulier ce qui concerne la priorité des priorités pour la France, à savoir la politique agricole commune (PAC). En outre, l'auteur est parvenu à rédiger avec autant de finesse que de compétence les aspects les plus délicats de son étude. C'est particulièrement vrai des deux derniers chapitres

Le chapitre VI intitulé "L'Europe "organisée" de Marjolin » comporte des guillemets qui suggèrent opportunément que les conceptions françaises en matière d'organisation économique n'ont été que modérément acceptées. Pour avoir été responsable, successivement sous la vice-présidence de Robert Marjolin et de Raymond Barre, de la politique économique à moyen terme, je peux témoigner que, pour nos collègues allemands, le mot " planification », même atténué par l'adjectif « indicative » était proprement insupportable, tant il évoquait pour eux des souvenirs de la période hitlérienne.

De même, le chapitre VII sur la politique industrielle est prudemment intitulé "Les projets de politique industrielle communautaire ». En effet, quand nous préconisions, nous Français, une politique industrielle européenne, nous n'étions pas toujours conscients de ce que cette expression avait de détestablement dirigiste aux yeux de la plupart de nos partenaires, qui ne manquaient pas de nous rappeler les mécomptes de la politique sidérurgique, du plan calcul ou $d u$ Concorde. C'est pourquoi je me réjouis que l'auteur parle prudemment de projets plutôt que de politique. 
On comprend ainsi que Laurent Warlouzet ne s'est pas contenté d'exploiter des points de vue français. Il a aussi tenu compte de conceptions exprimées par nos partenaires. C'est pourquoi ce livre si important mériterait de faire école et de susciter le lancement d'une collection européenne croisant d'autres ouvrages sur les mêmes sujets.

Michel ALBERT

Membre de l'Institut 



\section{REMERCIEMENTS}

Ce livre est issu d'une thèse de doctorat soutenue en 2007 à l'Université Paris IV-Sorbonne (Quelle Europe économique pour la France? La France et le Marché commun industriel, 1956-1969, 2007,1107 p.). Par rapport à cette dernière, cet ouvrage est deux fois plus court et bénéficie d'une bibliographie actualisée.

Mes remerciements s'adressent en premier lieu à mon directeur de thèse, Éric Bussière, qui m'a permis de mener ce projet à bien, ainsi qu'aux membres du jury de soutenance : Gérard Bossuat, Bernard Bruneteau, Pascal Griset, Piers Ludlow et Sylvain Schirmann. Je remercie également Michel Dumoulin, Robert Frank, Michel Margairaz, Kiran Patel et George-Henri Soutou pour leurs suggestions et leur soutien à divers moments de ce travail. Je suis également reconnaissant au Bureau de la Recherche de l'Institut de la gestion publique et du développement économique, en particulier à Anne de Castelnau, Catherine Guillou et Garance Valin, pour leur appui et pour avoir permis à cette recherche d'être publiée aux Éditions du Comité pour l'histoire économique et financière de la France.

La recherche ne saurait être un exercice solitaire. Mon engagement dans la création et le développement de l'association RICHIE (Réseau international de jeunes chercheurs en histoire de l'intégration européenne : http://www. europe-richie.org/index-fr.html) avec un groupe de chercheurs provenant d'horizons variés a été une contribution décisive à l'européanisation de ce sujet de recherche. Plus généralement, de très nombreux collègues m'ont aidé à trouver des sources et de nouvelles idées. Je remercie plus particulièrement pour leurs commentaires et leurs apports bibliographiques : Alain Chatriot, François Denord, Wolfram Kaiser, Christina Knudsen, Ivo Maes, Michel Mangenot, Sigfrido Ramirez, Katja Seidel et Frédéric Turpin.

Développer un projet de recherche en histoire est bien sûr impossible sans le recours à de très nombreux archivistes. Je suis tout particulièrement redevable à Jocelyne Collonval et Jean-Marie Palayret (archives de l'Union européenne), à Dominique Parcollet (archives de Sciences Po), à Pascal Geneste (Archives nationales) et à Laurent Fournié (archives économiques et financières) qui m'ont permis de découvrir de nouveaux fonds. De même, en termes d'archives orales, je suis reconnaissant à tous ceux qui ont bien voulu m'accorder leur témoignage, en particulier à Michel Albert qui a accepté de rédiger une préface. Enfin, je ne saurais oublier d'associer à ces remerciements mes amis, mes parents et Florence pour leur soutien constant. 



\section{LISTE DES ABRÉVIATIONS}

\section{ABRÉVIATIONS UTILISÉES \\ DANS LE CORPS DU TEXTE}

- AELE : Association européenne de libre-échange.

- AME : Accord monétaire européen.

- BKA : Bundeskartellamt.

- CECA : Communauté européenne du charbon et de l'acier (créée en 1951).

- CED : Communauté européenne de défense (projet de 1952-1954).

- CEE : Communauté économique européenne (créée en 1957).

- CEEP : Centre européen de l'entreprise publique.

- CPE : Communauté politique européenne (projet de 1953-1954).

- CIFE : Conseil des fédérations industrielles européennes.

- CJCE : Cour de justice des communautés européennes.

- CNPF : Conseil national du patronat français.

- CPEMT : Comité de politique économique à moyen terme.

- DAEF : Direction des Affaires économiques et financières (ministère des Affaires étrangères).

- DREE : Direction des Relations économiques extérieures (ministère des Affaires économiques).

- FIB : Fédération des industries belges.

- FIMTM : Fédération des industries mécaniques et transformatrices de métaux.

- FMI : Fonds monétaire international (créé en 1944).

- GATT : General agreement on tariffs and trade (conclu en 1947).

- IDE : Investissements directs étrangers.

- LECE : Ligue européenne de coopération économique.

- OCDE : Organisation pour la coopération et le développement économique (née en 1960). 
- OECE : Organisation européenne de coopération économique (née en 1948).

- PAC : Politique agricole commune.

- PEMT : Politique économique à moyen terme.

- PRST : Politique de la recherche scientifique et technique.

- REP : Représentation permanente de la France auprès de la CEE à Bruxelles.

- SGCI : Secrétariat général du Comité interministériel pour les questions de coopération économique européenne.

- UNICE : Union des industries de la Communauté européenne.

- ZLE : Zone de libre-échange (projet britannique de 1956-1958).

\section{ABRÉVIATIONS DANS LES NOTES DE BAS DE PAGE}

- AAPD : Akten zur Auswärtigen Politik der Bundesrepublik Deutschland (documents diplomatiques allemands).

- ACNPF : Archives du CNPF déposées à Roubaix.

- AFJM : Archives de la Fondation Jean Monnet à Lausanne.

- AHUE : Archives historiques de l'Union européenne déposées à Bruxelles et Florence.

- AINDUS : Archives du ministère de l'Industrie déposées à Fontainebleau.

- ALECE : Archives de la Ligue européenne de coopération économique déposées à l'Université catholique de Louvain (UCL/Louvain-la-Neuve).

- AN : Archives nationales françaises, fonds de Paris.

- AMAE : Archives du ministère des Affaires étrangères français déposées à Paris.

- AMAE/DECE : Archives du ministère des Affaires étrangères français/ fonds « Direction économique-Coopération économique ».

- AMAE/RPUE : Archives du ministère des Affaires étrangères français/ fonds de la représentation permanente auprès de l'Union européenne déposé à Nantes.

- AMINEFI : Archives du ministère de l'Économie et des Finances déposées à Savigny-le-Temple.

- AO : Archives orales 
- ARAM : Archives du fonds Ramadier déposées à Rodez.

- ASGCI : Archives du SGCI déposées à Fontainebleau.

- DDF : Documents diplomatiques français.

- PRO : Public Record Office, aujourd'hui National Archives. Archives nationales britanniques déposées à Londres. 



\section{INTRODUCTION GÉNÉRALE}

La Communauté économique européenne (CEE) est aujourd'hui, à travers l'Union européenne (UE), une organisation économique majeure. Elle a un impact considérable sur les politiques publiques, tant en termes d'équilibres économiques et sociaux que sur le plan institutionnel. Pourtant sa réussite n'est pas évidente à ses débuts. Lorsque les négociations à Six sur le projet de " Marché commun » sont lancées, en juin 1955 à la conférence de Messine, peu de décideurs ont anticipé l'importance de la future organisation européenne issue de ces discussions. Le 25 mars 1957, lorsque le traité de Rome est signé, rien n'indique que la France sera capable de l'appliquer, et que la CEE s'imposera face aux autres formes de coopération économique internationale envisagées alors. À cette date, la France subit une crise financière et commerciale grave qui rend très difficile l'application d'accords fondés sur le libre-échange comme le traité de Rome. Par ailleurs, de nombreuses autres possibilités d'organisation de la coopération économique sont mises en œuvre ou discutées à d'autres échelles comme celle de la Grande Europe (OECE, projet de zone de libre-échange négocié depuis 1956), ou celle du monde (GATT, FMI). Le semi-échec du Conseil de l'Europe, le demi-succès de la première communauté européenne, la Communauté européenne du charbon et de l'acier (CECA), la faillite de la Communauté européenne de défense (CED), et la fin annoncée de l'OECE - victime de son succès ${ }^{1}$ - peuvent d'ailleurs faire penser que l'intégration européenne n'est utile que pour une période limitée, celle de la reconstruction de l'Europe après la seconde guerre mondiale. Une fois celle-ci terminée, vers 1955, une coopération sur une base universelle, ou, à défaut, occidentale, pourrait naturellement prévaloir. Pourtant, c'est bien la CEE qui s'impose rapidement comme le forum de coopération économique de référence en Europe. À l'échelle de la France, c'est cet engagement qui sanctionne l'abandon définitif des bases de la prospérité française définies à la fin du XIX ${ }^{\mathrm{e}}$ siècle et confirmées dans les années trente : un développement économique en partie autocentré, reposant sur des marchés nationaux et coloniaux protégés et un poids relatif important de l'agriculture.

1. Née en 1948 pour assurer deux missions, la répartition de l'aide Marshall et le retour à la libération des échanges en Europe occidentale, l'OECE est affectée par l'arrêt de la première et la quasi-réalisation de la seconde à partir de 1955. 
Deux questions s'imposent pour comprendre cette double rupture : pourquoi le modèle de la CEE s'est imposé face aux autres possibilités de coopération économique européenne et pourquoi les décideurs français l'ont choisi et soutenu ? La première interrogation impose de caractériser le modèle de la CEE, à la fois en terme de fonctionnement institutionnel et en terme de dynamique économique, afin de comprendre sa spécificité. La seconde implique de mesurer l'influence des décideurs français sur la construction économique de la CEE.

Pour répondre à ces deux questions, il est nécessaire de revenir sur la négociation du traité de Rome. Le modèle de ce qui est encore appelé le « Marché commun » émerge progressivement avec la conférence de Messine de juin 1955 qui manifeste un premier engagement des gouvernements des six pays membres de la CECA (France, RFA, Italie, Belgique, Luxembourg, Pays-Bas). Signé en mars 1957, le traité de Rome commence à être appliqué en 1958 (clauses institutionnelles) et en 1959 (début du processus de libération des échanges). Ce sont donc les gouvernements de la $\mathrm{IV}^{\mathrm{e}}$ République finissante et surtout du général de Gaulle, au pouvoir entre juin 1958 et avril 1969, qui portent la principale responsabilité dans les débuts de la CEE. L'année 1969 est une coupure profonde dans l'histoire de la construction européenne avec l'arrivée au pouvoir de nouveaux leaders (Pompidou, Brandt) et la relance de La Haye de décembre 1969 qui autorise l'élargissement à la Grande-Bretagne. Pour embrasser cette période de quatorze années (1955-1969), deux prismes sont privilégiés, le processus de décision et les modèles économiques, tous deux étudiés aux échelles française et européenne.

\section{LE PROCESSUS DE DÉCISION À PARIS ET BRUXELLES : ACTEURS ET RÉSEAUX}

Trois types d'acteurs sont privilégiés, les responsables politiques, administratifs et économiques. Sur le plan politique, s'il est indispensable d'étudier les grands acteurs de la période, de Pierre Mendès France à Charles de Gaulle, il ne faut pas se limiter à eux et sombrer dans une histoire héroïque, conduite par des affrontements homériques entre des grands hommes prométhéens. Il est nécessaire de faire preuve de réalisme : aucun individu n'a le temps de se prononcer sur tous les dossiers multiples et complexes qui façonnent les choix de la France en matière d'intégration économique européenne.

Au-delà des grands hommes, les autres responsables politiques doivent donc être étudiés tout comme les principaux décideurs administratifs. Dans un secteur relativement neuf et surtout extrêmement technique comme la coopération 
économique européenne, les hauts fonctionnaires jouent un rôle crucial. L'histoire administrative de la construction européenne est d'ailleurs un domaine de recherche en plein renouvellement, en particulier autour de la thématique des cultures spécifiques à une administration en termes de méthodes de travail, de fonction économique ou de doctrine européenne ${ }^{2}$. L'étude ne doit pas se limiter à Paris mais concerner aussi Bruxelles, c'est-à-dire inclure les Français présents à la Commission européenne et dans son administration. Ces derniers ne doivent pas être considérés comme les prolongements naturels des premiers car ils sont soumis à des allégeances multiples, tant politiques (socialistes, démocrates-chrétiens, gaullistes, etc.), qu'économiques (keynésiens, néolibéraux, libéraux, etc.) ou encore en termes de projets européens (fédéralistes ou intergouvernementalistes, etc.). Ces Français s'insèrent dans des réseaux d'alliances transnationaux qu'ils peuvent former à la Commission avec des collègues issus de pays voisins et qui peuvent défendre une même vision de l'intégration économique européenne ${ }^{3}$.

Enfin, les milieux économiques doivent être pris en compte car ils représentent bien souvent une source d'expertise indispensable pour les responsables publics. De plus, ils peuvent avoir une influence directe dans le processus de décision communautaire. Les milieux économiques se sont d'ailleurs structurés plus rapidement à l'échelle européenne que les milieux syndicaux, minés par les divisions politiques pendant cette période ${ }^{4}$. Les dossiers prioritaires des syndicats de travailleurs (politique sociale) restent traités à l'échelle nationale alors que des pans entiers de politiques publiques fondamentales pour les entreprises (libération des échanges, politique de la concurrence) passent rapidement à l'échelle communautaire.

L'approche choisie insiste sur l'interpénétration entre ces trois types d'acteurs, politiques, administratifs et économiques. Elle refuse l'hypothèse de l'unicité de l'acteur étatique. Dans le domaine de la coopération économique européenne, les États sont divisés entre des réseaux nationaux ou transnationaux concurrents,

2. Laurence Badel, Stanislas Jeannesson, Piers Ludlow (dir.), Les administrations nationales et la construction européenne, Peter Lang, Bruxelles, 2005 ; Michel Mangenot, Une Europe improbable. Les hauts fonctionnaires français dans la construction européenne, 1948-1992, thèse de sciences politiques, dir. Brigitte Gaïti, IEP Strasbourg, 2001.

3. Sur l'approche par les réseaux transnationaux : Wolfram Kaiser, "Transnational networks in European governance. The informal politics of integration », in Wolfram Kaiser, Brigitte Leucht, Morten Rasmussen (éd.), The History of the European Union. Origins of a trans-and supranational polity, 1950-1972, Routledge, Londres, 2008, p. 12-33.

4. Dès 1949 est créé le CIFE (Conseil des fédérations industrielles européennes), puis en 1952 une organisation à l'échelle des Six appelée par la suite UNICE (Union des industries de la Communauté européenne) ; au contraire la Confédération européenne des syndicats (CES) ne date que de 1973. 
porteurs de visions différentes de l'intégration économique européenne. Dès lors, parler de « la France » ou de « la RFA » comme d'une entité homogène est impossible et revient en fait à réifier un concept. Le même raisonnement peut s'appliquer à la Commission européenne, qui apparaît souvent unie de l'extérieur alors qu'elle est en réalité extrêmement divisée.

C'est bien une histoire supranationale de la politique européenne de la France qui doit être privilégiée. Dans le domaine de l'Europe communautaire, les acteurs agissent nécessairement à plusieurs échelles, nationales et supranationales, même s'ils ne sont censés représenter qu'un État. Le système institutionnel de la CEE doit être envisagé comme un espace qui est à la fois le lieu d'expression des États-nations et des dynamiques communautaires, mais aussi de réseaux transnationaux qui défendent des modèles d'intégration européenne différents, complémentaires ou concurrents. À rebours d'interprétations partisanes se bornant à considérer la CEE soit comme une simple enceinte d'États-nations (interprétation intergouvernementale), soit aboutissant inéluctablement à une fédération (vision téléologique), il est nécessaire de faire preuve de pragmatisme. Le recours aux outils de la science politique est utile non pour développer une théorie qui se voudrait globale ${ }^{5}$, mais pour mieux comprendre la spécificité du système institutionnel communautaire ${ }^{6}$. En particulier, le recours aux trois grilles d'explication classiques, intergouvernementale, fédéraliste et néofonctionnaliste, reste toujours utile ${ }^{7}$. Elle peut se combiner avec des approches plus récentes comme l'institutionnalisme historique, qui met l'accent sur les conséquences de long terme non anticipées des décisions prises dans le contexte communautaire ${ }^{8}$. Le recours aux démarches constructivistes, qui met en valeur le poids des idées, des représentations dans des réflexions qui ne sont pas toujours strictement utilitaires, est également utile ${ }^{9}$. Une série d'études

5. Donald J. Puchala, « Of Blind Men, Elephants and International Integration », in Journal of Common Market Studies, 10/3, 1972, p. 267.

6. Morten Rasmussen, « Supranational governance in the making. Towards a European political system », in W. Kaiser, B. Leucht, M. Rasmussen (éd.), The History of the European Union..., op. cit., p. 34-55.

7. La théorie intergouvernementale insiste sur le rôle directeur des États-nations dans le système communautaire tandis que les deux autres mettent l'accent sur les institutions communautaires. Sur la différence entre fédéralisme et néofonctionnalisme et leur application à un problème historique, voir dans le chapitre VI le passage consacré à la crise de la chaise vide vue par la Commission.

8. Paul Pierson, «The Path to European Integration : A Historical Institutionalist Analysis », in Comparative Political Studies, 29 (2), 1996, p. 123-163.

9. Cette approche a déjà été appliquée à la politique de la France envers la CEE : Craig Parsons, A certain Idea of Europe, Cornell UP, Ithaca, 2003. 
historiques récentes, portant sur l'histoire globale de la CEE dans les années soixante ${ }^{10}$, sur les politiques communautaires ${ }^{11}$ ou sur son système institutionne $1^{12}$ porte la marque de cette approche à la fois pragmatique et sensible à l'interdisciplinarité. Elle doit être appliquée aux modèles économiques en débat aux échelles française et européenne.

\section{UNE HISTOIRE DES POLITIQUES ÉCONOMIQUES FRANÇAISES ET EUROPÉENNES}

La CEE met en œuvre une dynamique d'intégration économique particulièrement ambitieuse. Elle s'oppose à la simple coopération. Elle peut se définir comme la fusion des marchés tant sur le plan des acteurs économiques, que sur celui des formes de la régulation publique. L'intégration négative désigne la simple suppression des obstacles aux échanges (par exemple la diminution des droits de douane), tandis que l'intégration positive évoque des formes plus ambitieuses comme la coordination des politiques nationales, leur harmonisation (des législations, des systèmes fiscaux, des pratiques de politiques publiques, etc.) ou même leur fusion, par la création d'une politique commune.

Ces débats sur l'intégration économique européenne s'inscrivent dans des dynamiques de long terme identifiées par une série de recherches ${ }^{13}$. Depuis

10. Piers Ludlow, The European Community and the Crises of the 1960's. Negotiating the Gaullist challenge, Routledge, Londres, 2005.

11. Voir une série de thèses récentes : Lucia Coppolaro, Trade and Politic across the Atlantic: the European Economic Community (EEC) and the United States of America in the GATT Negotiations of the Kennedy Round (1962-1967), thèse, dir. A. Milward, Institut universitaire européen de Florence, 2006 ; Ann-Christina Knudsen, Farmers on Welfare. The Making of Europe's Common Agricultural Policy, Cornell UP, Ithaca, 2009 (tiré d'une thèse soutenue à l'Institut universitaire européen de Florence en 2001) ; Brigitte Leucht, Transatlantic policy networks and the formation of core Europe, thèse, dir. W. Kaiser, Portsmouth, 2008 ; Katja Seidel, Administering Europe. Community officials and the bureaucratic integration of Europe (1952-1967), thèse, dir. W. Kaiser, Portsmouth, 2008 (publiée sous le titre : The Process of Politics in Europe : The Rise of European Elites and Supranational Institutions, IB Tauris, Londres, 2010) ; Guia Migani, La France et l'Afrique subsaharienne, 1957-1963 : histoire d'une décolonisation entre idéaux eurafricains et politique de puissance, Peter Lang, Bruxelles, 2007.

12. Voir les contributions réunies dans la Revue d'histoire de l'intégration européenne, 2008/2 (Piers Ludlow coord.).

13. Éric Bussière et Michel Dumoulin, «L'émergence de l'idée d'identité économique européenne d'un après-guerre à l'autre ", in René Girault (dir.), Identité et conscience européenne au XXe siècle, Hachette, Paris, 1994, p. 67-105 ; Laurence Badel, Éric Bussière, Michel Dumoulin, Ruggero Ranieri, «Cercles et milieux économiques » in Robert Frank, Gérard Bossuat (dir.), Les identités européennes au $X X^{e}$ siècle. Diversités, convergences, solidarités, Publications de la Sorbonne, Paris, 2004, p. 13-45. 
les années vingt, le débat s'articule autour de l'opposition entre l'Europe du marché et l'Europe organisée, la première reposant exclusivement sur l'intégration négative et la seconde souhaitant accompagner l'ouverture des marchés par des mesures de coordination des différents acteurs ${ }^{14}$. Ces débats se recomposent en permanence, la CEE développant à la fois une Europe arbitre, fondée essentiellement sur la régulation neutre des activités économiques, et une Europe volontariste, qui ne refuse pas les interventions directes d'orientation et de stimulation. Les controverses étant à la fois permanentes et s'inscrivant dans des tendances de long terme, il est nécessaire d'étudier tant les réussites que les projets avortés. Ces derniers traduisent la vigueur d'une conception économique de l'intégration européenne et peuvent d'ailleurs être à la base de nouveaux projets développés dix ou vingt ans plus tard.

Le lien entre intégration économique et construction de l'Europe politique est réel mais leur relation n'est pas mécanique. Les partisans de l'Europe organisée ne sont pas forcément fédéralistes et peuvent très bien défendre une voie intergouvernementale. Les dynamiques économiques suivent donc une logique propre, mise en valeur par une histoire économique en plein renouvellement ${ }^{15}$. Il est impossible de comprendre les rapports de force au sein des institutions communautaires sans prendre en compte la réalité des dossiers économiques qui sont au cœur de leurs compétences. D'un autre coté, il est indispensable de tenir compte des dynamiques politiques et culturelles, tant sur le plan des relations internationales (guerre froide, décolonisation, rapports francoallemands et franco-britanniques essentiellement) que du cadre national (échéances politiques, situation économique, financière et sociale, voire socioculturelle comme dans le cas de Mai 1968).

L'intégration économique est donc un processus vaste et ambitieux. Il ne faut pas le réduire à la seule dimension commerciale, ni à la $\mathrm{PAC}$, qui répond d'ailleurs plus à des logiques politiques et sociales qu'économiques comme

14. Voir la série de colloques publiés par les trois animateurs du groupe de recherche, Éric Bussière, Michel Dumoulin, Sylvain Schirmann : Europe organisée, Europe du libre-échange? Fin XIXe siècleannées 1950, Peter Lang, Bruxelles, 2006 ; Milieux économiques et intégration européenne au XX siècle. La crise des années 1970. De la conférence de La Haye à la veille de la relance des années 1980, Peter Lang, Bruxelles, 2006 ; Milieux économiques et intégration européenne au XX siècle. La relance des années quatre-vingt (1979-1992), Comité pour l'histoire économique et financière de la France, Paris, 2007.

15. Jean-Claude Daumas, « Redynamiser l'histoire économique française », in Entreprises et histoire, $\mathrm{n}^{\circ}$ 52, septembre 2008, p. 7-17; pour l'histoire des entreprises à une échelle internationale : Dominique Barjot, «Introduction », in Revue économique, vol. 58, n 1, janvier 2007, p. 5-30. 
l'ont montré des études récentes ${ }^{16}$. Le lien entre les débats français, européens et mondiaux doit être pris en compte, en particulier en s'appuyant sur des études menées par exemple sur la politique monétaire ${ }^{17}$ ou la politique de coopération ${ }^{18}$. Il est nécessaire de privilégier des politiques publiques transversales. Elles sont les plus révélatrices sur le plan de la conception globale de l'intégration économique européenne, comme la régulation de la libération des échanges et du comportement des acteurs économiques (politique de la concurrence, politique industrielle) ou la coordination des politiques macroéconomiques. En d'autres termes, il faut dépasser la conception réductrice de la CEE, celle qui en fait un simple échange entre des exportations agricoles françaises et des exportations industrielles allemandes.

Ainsi se définit une méthode globale croisant les échelles françaises et européennes, les acteurs politiques, administratifs et économiques, pour étudier les différents modèles d'intégration économique européenne développés entre 1955 et 1969. Refusant les clivages artificiels (entre déterminants politiques et économiques, entre idées et acteurs, entre motivations idéalistes et considérations réalistes), elle s'inscrit dans une démarche déjà développée dans une étude de la politique européenne de la France qui croise ces différentes approches ${ }^{19}$. Elle s'appuie sur des sources diversifiées.

\section{DES SOURCES NATIONALES ET EUROPÉENNES}

Les archives s'établissant sur une base nationale, les documents provenant des acteurs politiques et administratifs gouvernementaux français sont nombreux. Cependant, les comptes rendus des Conseils des ministres sont quasi inexistants. Le processus de décision ne peut être reconstitué sans le recours à des sources complémentaires comme les fonds privés déposés par Maurice Couve de Murville et surtout par Michel Debré à la Fondation nationale des

16. A.-C. Knudsen, Farmers on Welfare..., op. cit. ; Kiran Patel (éd.), Fertile Ground for Europe? The History of European Integration and the Common Agricultural Policy since 1945, Nomos Verlag, Baden-Baden, 2009.

17. Olivier Feiertag, Wilfrid Baumgartner. Un grand commis des finances à la croisée des pouvoirs (1902-1978), Comité pour l'histoire économique et financière de la France, Paris, 2006.

18. Guia Migani, La France et l'Afrique subsaharienne..., op. cit. ; Frédéric Turpin, La politique française de coopération avec l'Afrique subsaharienne francophone au prisme de la volonté de puissance. 1960-1974, habilitation à diriger des recherches, Université Paris IV-Sorbonne, 2007, chapitre VI.

19. Gérard Bossuat, L'Europe des Français, 1943-1959: la Quatrième République aux sources de l'Europe communautaire, Publications de la Sorbonne, Paris, 1996. Gérard Bossuat prend cependant plus en compte les dimensions stratégiques et militaires que notre étude. 
sciences politiques. Les archives administratives sont abondantes. Celles du ministère des Affaires étrangères (à Paris et à Nantes) représentent une source essentielle car le Quai d'Orsay a en charge la représentation permanente de la France auprès des Communautés européennes et joue un rôle important dans la définition de la position française, en relation avec le $\mathrm{SGCI}^{20}$, un service interministériel dont les fonds sont déposés aux Archives nationales (Fontainebleau). Les archives du ministère des Finances à Savigny-le-Temple sont tout aussi utiles mais parfois difficiles à exploiter en raison de la diversité des services en charge des questions européennes. Toutefois, un certain nombre d'études monographiques existe sur ces directions et permet de trouver des repères ${ }^{21}$, d'autant que leur rapport à la construction européenne est parfois étudié ${ }^{22}$. Les archives du commissariat général au Plan et du ministère de l'Industrie livrent également des renseignements utiles, mais de second ordre.

Pour tenter de reconstituer le processus de décision communautaire et les éventuels réseaux transnationaux, les très volumineux fonds de l'Union européenne, déposés à Florence et Bruxelles, ont été dépouillés. Là aussi, les comptes rendus des réunions officielles majeures (Conseil des ministres CEE et Commission) sont très succincts, d'où le recours à divers fonds privés déposés à Florence et à Lausanne (Jean Monnet, Émile Noël, Pierre Uri), le plus utile étant celui du commissaire européen Robert Marjolin. Enfin, les Archives nationales britanniques livrent des renseignements très intéressants pour comprendre le

20. Secrétariat général du comité interministériel pour les questions de coopération économique européenne ; voir : Anne de Castelnau, "Le rôle du SGCI dans les relations de la France avec le Marché commun, 1956-1961 ", in Le rôle des ministères des Finances et de l'Économie dans la construction européenne (1957-1978), Comité pour l'histoire économique et financière de la France, Paris, 2002, p. 207-228.

21. Pour la période considérée : Frédéric Tristram, Une fiscalité pour la croissance. La direction générale des Impôts et la politique fiscale en France de 1948 à la fin des années 1960, Comité pour 1'histoire économique et financière de la France, Paris, 2005 ; Laure Quenouëlle-Corre, La direction du Trésor 1947-1967. L'État-banquier et la croissance, Comité pour l'histoire économique et financière de la France, Paris, 2000 ; Aude Terray, Des francs-tireurs aux experts. L'organisation de la prévision économique au ministère des Finances. 1948-1968, Comité pour l'histoire économique et financière de la France, Paris, 2002.

22. Laurence Badel, « La direction des Relations économiques extérieures (DREE). Origines, culture, logique (1920-1970) », in Laurence Badel et al. (dir.), Les administrations nationales..., op. cit., p. 169-206 ; Gérard Bossuat, «Les hauts fonctionnaires du ministère des Finances français et la construction européenne, 1948-1974», in Le rôle des ministères des Finances et de l'Économie dans la construction européenne (1957-1978), tome I, Comité pour l'histoire économique et financière de la France, Paris, 2002, p. 142-187. 
déroulement de la négociation sur la zone de libre-échange en 1956-1958, mais aussi sur l'histoire de la CEE pendant les années soixante ${ }^{23}$.

L'étude des milieux économiques dans la construction européenne est plus difficile même si elle a donné lieu à des travaux importants ${ }^{24}$, en particulier pour le secteur automobile ${ }^{25}$. Cependant, les archives du CNPF, déposées à Roubaix, sont particulièrement utiles pour étudier la position patronale à l'échelle française, mais aussi européenne. De nombreux documents de l'UNICE, le syndicat patronal européen, y figurent.

Outre les sources imprimées et la bibliographie, très abondantes sur la période, une attention particulière doit être accordée aux témoignages. La période étudiée a été très exaltante pour deux groupes d'acteurs, les collaborateurs du général de Gaulle d'un côté, et les pionniers de la construction européenne de l'autre, les deux ensembles se recoupant parfois. Dès lors, si ces sources sont tout à fait fondamentales pour tenter de reconstituer l'état d'esprit de l'époque et identifier les réseaux de relations, elles doivent être maniées avec précaution ${ }^{26}$. Des mémoires et des archives orales ont donc été consultées et un petit nombre d'interviews a été conduit pour éclairer certaines zones d'ombre.

\section{PLAN DE L'ÉTUDE}

L'étude du processus de décision imposant une trame plutôt chronologique et celles des modèles d'Europe une approche thématique, il a été nécessaire de croiser les deux approches en mettant l'accent sur l'une puis sur l'autre de manière successive.

Une première période, de juin 1955 à l'extrême fin 1958, est en effet marquée par deux négociations globales parallèles et interconnectées, celle relative à la

23. L'intérêt de ces archives pour l'histoire de la CEE sans la Grande-Bretagne a déjà été souligné in : Piers Ludlow, Negotiating the Gaullist Challenge..., op. cit., p. 9.

24. Jean-François Eck, Les entreprises françaises face à l'Allemagne de 1945 à la fin des années 1960, Comité pour l'histoire économique et financière de la France, Paris, 2003.

25. Sigfrido Ramirez, Public Policies, European Integration and Multinational Corporations in the Automobile Sector. The French and Italian Cases in a comparative perspective 1945-1973, thèse, dir. Bo Strath, Institut universitaire européen, 2007. Dans une perspective française mais avec une prise en compte de la dimension européenne, voir: Jean-François Grevet, Au cour de la révolution automobile : l'industrie du poids lourd du plan Pons au regroupement Berliet-Saviem. Marchés, industrie et État en France, 1944-1974, thèse dir. Jean-Pierre Hirsch, Université Lille III, 2005.

26. Robert Frank, «Du bon usage de l'homme illustre par l'historien », in Gérard Bossuat, Andreas Wilkens (dir.), Jean Monnet, l'Europe et les chemins de la paix, Publications de la Sorbonne, Paris, 1999, p. 451-454. 
négociation puis à l'application du traité de Rome d'une part, et celle portant sur la zone de libre-échange d'autre part. Un plan chronologique s'impose donc pour étudier ces négociations par ailleurs très dépendantes des soubresauts de la crise financière et politique que connaît la France en cette fin de IV ${ }^{\mathrm{e}}$ République. Une seconde période, de janvier 1959 à avril 1969, est marquée par l'application du traité de Rome seul, sans négociation concurrente. Une trame thématique s'impose alors car des projets d'intégration économique européenne différents se développent en parallèle, en relation avec des réseaux transnationaux spécifiques. En dehors du projet européen gaulliste, qui marque l'ensemble de la période, une certaine continuité chronologique s'observe entre les trois modèles d'Europe développés de manière largement concurrente, à savoir l'Europe ordolibérale, l'Europe « organisée » du commissaire français Robert Marjolin, et les projets d'Europe de la politique industrielle. 


\section{PREMIÈRE PARTIE}

\section{LA FRANCE FACE À LA RÉORGANISATION DE L'EUROPE : LES DÉFIS DU MARCHÉ COMMUN ET DE LA ZLE (1955-1958)}



Les historiens de la construction européenne se sont longtemps interrogés sur les raisons qui ont poussé la France à accepter le traité de Rome. Les Anglo-Saxons en particulier se sont affirmés dans ce débat avec des thèses très tranchées. D'un côté, certains estiment que la France choisit le Marché commun par pur intérêt économique, afin d'ouvrir progressivement son économie à l'extérieur et pour renouveler les bases de sa prospérité ${ }^{\text {. D'un autre }}$ côté, c'est l'idéalisme européen d'un petit groupe d'acteur qui est mis en valeur, soit celui du président du Conseil Guy Mollet ${ }^{2}$, soit celui d'un groupe transnational chrétien-démocrate ${ }^{3}$, qui prime sur les considérations de contraintes extérieures ou intérieures. Cette partie met en avant trois types d'explications : la logique institutionnelle des négociations européennes, le poids de la contrainte extérieure - représentée notamment par le projet de zone de libre-échange (ZLE), et le rôle décisif d'un petit groupe d'acteurs qui impose le choix du Marché commun face à des élites françaises extrêmement sceptiques, pour des raisons à la fois économiques et politiques.

Dans un premier temps, la France négocie un traité de Rome qu'elle signe sans enthousiasme en mars 1957. Ensuite, entre avril 1957 et avril 1958, la France s'enfonce dans une crise financière et politique grave qui semble menacer l'avenir même de la CEE, et ce alors que s'ouvre la négociation de la ZLE. C'est finalement le retour au pouvoir du général de Gaulle en mai 1958 qui impose une rupture profonde dans les négociations européennes, avec le rejet de la ZLE et la mise en œuvre pleine et entière de la CEE.

1. Alan Milward The European Rescue of the Nation-State, Routledge, Londres 1992, p. 196223 ; Andrew Moravcsik, The Choice for Europe. Social Purpose and State Power from Messina to Maastricht, UCL Press, Londres, 1999, p. 103-122 ; Frances Lynch, France and the international economy. From Vichy to the Treaty of Rome, Routledge, Londres, 1997.

2. Craig Parsons, A certain Idea of Europe, Cornell UP, Ithaca, 2003.

3. Wolfram Kaiser, Christian Democracy and the Origins of European Union, Cambridge UP, Cambridge, 2007. 



\section{CHAPITRE PREMIER}

\section{LA CEE SANS ENTHOUSIASME (1955-MARS 1957)}

La négociation du Marché commun fait parfois figure de miracle tant elle a réussi à concilier des objectifs très éloignés. La convergence des positions s'est effectuée, du point de vue français, en trois étapes. Dans un premier temps, après la conférence de Messine de juin 1955, les discussions restent ouvertes et débouchent sur de nombreux projets. C'est le rapport Spaak d'avril 1956, qui constitue la véritable base de la négociation. Dans un second temps, à l'été 1956, le gouvernement français s'efforce de surmonter l'opposition de l'administration française pour définir une position réaliste. Cependant, le modèle du Marché commun reste toujours menacé jusqu'à la fin des négociations, en mars 1957 , soit en interne par les nombreux décideurs français sceptiques, soit en externe par l'affirmation progressive du projet de ZLE. Finalement, le traité de Rome du 25 mars 1957 met en place une organisation originale et dynamique.

\section{L'INVENTION D'UN MARCHÉ COMMUN HYPOTHÉTIQUE (JUIN 1955-AVRIL 1956)}

La négociation du Marché commun commence en 1955 alors que les décideurs peinent à définir une position cohérente en matière de construction européenne. Le rapport Spaak d'avril 1956 les oblige pourtant à réagir, et à manifester une grande hostilité à ce projet d'Europe libérale et supranationale.

\section{A. LA FRANCE FACE À LA CONSTRUCTION EUROPÉENNE : OPPORTUNITÉS ET CONTRAINTES}

En 1955, la France entre dans un nouveau cycle européen, la période de l'après-reconstruction. Les décideurs français sont à la recherche de nouvelles sources de puissance car les leviers anciens sont contestés, tant sur le plan politique, avec l'accélération du mouvement de décolonisation (début des « événements » d'Algérie en 1955, indépendances marocaines et tunisiennes en 1956, affaire de Suez), que sous l'angle économique. Sur le plan international, les 
pressions à la libération des échanges et au retour à la libre convertibilité se font plus fortes à partir du milieu des années cinquante car les pays d'Europe occidentale ont également terminé leur reconstruction. À partir de 1955, le retour à la convertibilité de la livre sterling, qui risque d'entraîner celle d'autres monnaies européennes comme le deutschmark, est de nouveau à l'ordre du jour ${ }^{1}$. De même, à partir de janvier 1955, l'extension des mesures de libéralisation commerciale de l'OECE au GATT est demandée par les Américains et les Britanniques ${ }^{2}$. Le nouvel ordre mondial libre-échangiste ébauché par les États-Unis dans l'immédiat après-guerre avec le système de Bretton Woods et le GATT commence à se concrétiser.

Or la France a des difficultés à s'adapter à cette nouvelle réalité en raison de ses problèmes récurrents de balance commerciale, qui l'ont conduit à être l'un des pays les plus protectionnistes de l'OECE $^{3}$. La France est ainsi la seule parmi les Six à ne pas tenir l'objectif de libération des échanges de l'OECE fixé en $1955^{4}$ et à instaurer un système de taxes à l'importation et d'aides à l'exportation pour éviter de dévaluer ${ }^{5}$. Même si la situation s'améliore en 1955, elle redevient problématique dès 1956 en raison de la fin de l'aide américaine, de l'aggravation du conflit en Algérie, et de la politique de soutien de la demande du nouveau gouvernement Mollet. La France peine à tenir ses engagements européens, alors même qu'une réorganisation de la coopération économique européenne se profile.

\section{La France au cœur des constructions européennes.}

La construction européenne se développe à partir de 1948-1950 selon deux voies complémentaires qui ont toutes deux le plein soutien du gouvernement français.

L'Europe intergouvernementale tout d'abord, est une voie très sérieusement prise en considération en 1955. Elle a connu un certain succès avec l'OECE

1. Alan Milward, «The European Monetary Agreement », in Gilbert Trausch (éd.), Die Europaïsche Integration vom Schuman-Plan bis zu den Verträgen von Rom, Nomos Verlag, Baden-Baden, 1993, p. 117 et 123 .

2. Frances Lynch, France and the international economy..., op. cit. p. 143.

3. Frances Lynch, France and the international economy..., op. cit., p. 128-9.

4. Au début de 1956 , la France passe à $82,3 \%$ de libération contre $99,1 \%$ pour l'Italie et $91,5 \%$ pour la RFA par exemple. L'objectif fixé en janvier 1955 à l'OECE était de libérer $90 \%$ du commerce (sur la base de 1948). Voir : L'année politique, 1956, PUF, Paris, 1957, p. 129. 105.

5. André de Lattre, La politique économique française, Les cours de droit, Paris, 1970, p. 104- 
et l'UEP, qui permettent de revenir à une libération des échanges et des paiements de manière progressive. De plus, cette coopération renforce l'unité du camp occidental sans remettre en cause de manière décisive les souverainetés nationales. Cependant, la finalité proprement européenne de ces coopérations reste incertaine. Pour de nombreux décideurs, l'OECE et l'UEP ne sont que des organismes provisoires, qui ont vocation à s'effacer, une fois leur mission effectuée, devant le GATT et le FMI.

En complément de cette "Grande Europe » se développe depuis la déclaration Schuman du 9 mai 1950 une voie communautaire au sein d'une «Petite Europe », celle des Six. Elle repose sur la création d'institutions supranationales dotées de pouvoirs importants. Elle est soutenue par les européistes mais aussi par de nombreux décideurs français car elle apporte des avantages objectifs en termes de rétablissement de la puissance française. Elle permet de renforcer la réconciliation franco-allemande sans remettre en cause la supériorité française sur le plan diplomatique. Sur le plan économique, elle complète l'Europe libérale par la mise en œuvre d'une Europe plus organisée. Ainsi, dans le cadre de la CECA, les mesures d'ouverture des marchés sont complétées par de très nombreuses clauses d'harmonisation des conditions de concurrence et de sauvegarde. Si les mesures de libération des échanges sont réclamées par un nombre croissant de pays européens (et extra-européens comme les États-Unis), la France est l'un des seuls pays en Europe à réclamer autant de mesures d'accompagnement de ce processus. Elle a donc un intérêt objectif à obtenir des engagements de nature communautaires, et pas simplement intergouvernementaux, pour être sûr qu'ils soient appliqués.

Ainsi en 1955 la France reste engagée dans deux formes de coopération européenne, l'une intergouvernementale et l'autre communautaire, qui présentent toutes deux des avantages pour elle. Si la première forme d'Europe est plus que jamais d'actualité depuis le rejet de la CED, c'est pourtant la seconde dynamique qui s'impose sur l'agenda des décideurs français à la faveur de la conférence de Messine de juin 1955.

\section{Les décideurs français méfiants face au projet de Marché commun.}

La construction de l'Europe communautaire est relancée par la réunion des ministres des Affaires étrangères des Six à Messine, du $1^{\text {er }}$ au 3 juin 1955. La France est le seul des Six à n'avoir pas clarifié sa position avant Messine car elle reste traumatisée par le souvenir du 30 août 1954 qui l'empêche de prendre une position trop affirmée. Deux types de coopération européenne sont discutés, des projets sectoriels - sur le modèle de la CECA, et une intégration horizontale par le « Marché commun ». Ce dernier est fondé sur une 
réactualisation du «plan Beyen » de 1952, fondé sur la suppression des obstacles aux échanges entre les Six.

Cette logique libérale se heurte à l'attachement français au protectionnisme et au repli sur la sphère protégée de l'empire colonial. En 1955, la France n'a pas connu le libre-échange depuis plus de vingt ans, ce qui incite beaucoup de décideurs français à la prudence. Face au projet de Marché commun, le débat porte sur les mesures de complément à cette dynamique d'ouverture des marchés. Deux positions se développent dans l'administration. Tout d'abord, certains décideurs français se montrent favorables par principe au Marché commun s'il est accompagné des mesures correctrices à mettre en œuvre en parallèle. C'est le cas par exemple de Bernard Clappier, le directeur de la DREE et ancien directeur de cabinet de Robert Schuman lorsque celui lança le projet CECA. Il rédige une note favorable au Marché commun ${ }^{6}$. Sur le fond, il demande un processus d'harmonisation des charges, mais il affirme explicitement que la libération des échanges est un processus favorable à la France.

La seconde attitude est plus restrictive et s'impose finalement. Deux diplomates s'illustrent dans la définition de cette position, le secrétaire général, René Massigli, et le nouveau directeur des Affaires économiques et financières, Olivier Wormser. Le premier dirige deux réunions interministérielles sur la " relance européenne » en avril 1955 où il se montre très sceptique $^{7}$. Lors de ces réunions, seuls les aspects sectoriels sont évoqués. Le projet de Marché commun général est ignoré. Le second rédige en mai 1955 une note très critique envers les propositions du Benelux destinées à être discutées à la conférence de Messine ${ }^{8}$. Il part du présupposé que la libération des échanges serait néfaste pour la France. Il plaide pour une harmonisation des conditions de concurrence préalable à la libération des échanges, et la création d'un fonds d'investissement destiné à remédier aux déséquilibres entraînés par le mouvement de libération des échanges. Sur le plan politique, il craint que l'intégration économique générale n'aboutisse à l'intégration politique. Il conseille donc de se concentrer sur les projets d'intégration sectorielle (notamment dans les transports et l'énergie atomique) et de n'accepter de discuter du projet de Marché commun que sous des conditions très strictes. Cette conception restrictive s'impose. La position officielle de la France pour la conférence

6. AN, F60, 3083, note de Bernard Clappier, DREE, transmise par Étienne Hirsch au ministre le 21 juin 1955.

7. AN, F60, 3082, compte-rendu des réunions au ministère des Affaires étrangères des 22 et 25 avril 1955.

8. AN, F60, 3082, note d'Olivier Wormser du 25 mai 1955 ; voir aussi : DDF, 1955-I, document $\mathrm{n}^{\circ} 288$, note de la DAEF du 18 mai 1955. 
de Messine consiste à privilégier l'intégration sectorielle face à un projet concurrent d'ailleurs dénommé « plan Beyen ${ }^{9} »$. Si le projet de Marché commun s'avère politiquement incontournable, des adaptations devront être demandées pour accompagner, voire contrarier, le processus de libération des échanges.

\section{Les ambiguïtés de la conférence de Messine.}

Réunis à Messine du $1^{\text {er }}$ au 3 juin 1955, les ministres des Affaires étrangères des six pays de la CECA se mettent d'accord sur une procédure originale pour l'étude de divers projets européens. Un comité d'experts présidé par une personnalité à la fois indépendante et dotée d'une autorité politique suffisante pour lui permettre de faire avancer les travaux est créé. C'est le ministre belge des Affaires étrangères Paul-Henri Spaak qui est désigné pour prendre la tête de ce qui fut appelé le premier " comité Spaak ${ }^{10}$ ». Le comité Spaak est une assemblée d'experts et pas de délégués nationaux négociant au nom de leur gouvernement. Les discussions sont donc très libres. Deux ambiguïtés pèsent toutefois sur ces travaux : d'une part le caractère contraignant des discussions envisagées n'est pas précisé et d'autre part les résolutions de la conférence de Messine sont très nombreuses.

Certains membres de la délégation française, comme Olivier Wormser, n'ont accepté que le principe de l'étude d'un marché commun, et pas un engagement politique ferme ${ }^{11}$. Pour eux, le Marché commun n'est qu'une hypothèse parmi d'autres et pouvait donc être rejeté. C'est d'ailleurs le sens des instructions à la délégation française participant au comité Spaak. La note se refuse à employer le terme d' « instructions » à propos du projet de marché commun car il ne s'agit que d'études et pas d'une véritable négociation intergouvernementale $^{12}$. Cependant, ces directives tiennent compte du caractère spécifique de ces discussions. Ainsi, les Français considèrent que la participation britannique aux travaux devrait être remise en question car ils doivent déboucher non pas sur de simples accords intergouvernementaux, mais sur des projets plus ambitieux $^{13}$. De fait, les Britanniques quittent les travaux du comité Spaak en novembre 1955.

9. DDF, 1955-I, document n 301, note du département, « plan Beyen », 26 mai 1955.

10. Spaak n'est pas désigné pendant la conférence mais un peu après ; voir Michel Dumoulin, Spaak, Racine, Bruxelles, 1999, p. 510.

11. Michel Dumoulin, «Les travaux du comité Spaak (juillet 1955-avril 1956) », in Enrico Serra (dir.), La relance européenne et les traités de Rome, Bruylant, Bruxelles, 1989, p. 199-200.

12. AN, F60, 3083, instructions à la délégation française issues du comité interministériel du 5 juillet 1955,12 juillet 1955 .

13. AN, F60, 3083, instructions à la délégation française du 12 juillet 1955, ministère des Affaires étrangères à Gaillard, délégation française auprès du comité Spaak. 
D'autre part, la résolution finale de la conférence de Messine ouvre de très nombreuses pistes de coopération européenne. Trois sont explicitement évoquées : l'intégration sectorielle dans de nombreux domaines (transport et énergie surtout), la création d'un marché commun et de nombreuses mesures d'accompagnement de la libération des échanges (harmonisation des politiques nationales, fonds d'investissement et de réadaptation, etc.). Les travaux du comité Spaak restent donc soumis à une grande incertitude et se développent dans de très nombreuses directions ${ }^{14}$. La France s'emploie cependant à clarifier sa doctrine par le mémorandum d'octobre 1955.

\section{Le mémorandum français d'octobre 1955.}

Dès l'automne 1955 les diplomates français constatent avec dépit que les négociations au comité Spaak s'orientent de plus en plus vers le projet de marché commun général ${ }^{15}$. Ils soutiennent alors la publication d'un mémorandum français destiné à éviter un nouveau " glissement » de la négociation ${ }^{16}$.

Le mémorandum français est publié le 14 octobre $1955^{17}$. Il part de l'acceptation du principe du Marché commun mais avec une application limitée à une première étape de quatre ans. À la libération des échanges devraient correspondre des engagements précis en matière d'harmonisation sociale et de mise en place d'un fonds d'investissement. Ce dernier pourrait intervenir pour soutenir des opérations de rationalisation et de spécialisation des entreprises afin de les aider à s'adapter à la libération des échanges. À l'issue de cette première étape, une nouvelle négociation intergouvernementale aurait lieu.

Les aspects institutionnels restent vagues car il est difficile pour ces décideurs français, sceptiques envers la construction européenne, de définir une organisation garantissant l'exécution par les partenaires de la France d'un processus d'harmonisation très contraignant, tout en préservant la souveraineté nationale. Le mémorandum se contente donc d'insister sur des procédures négatives : un engagement limité à une première étape et une clause de sauvegarde unilatérale.

14. Sur les postes par exemple, les discussions sont assez ambitieuses : Léonard Laborie, « Les grands réseaux techniques et l'intégration européenne. Le cas des Postes et des Télécommunications (1945-1959) », in Katrin Rücker, Laurent Warlouzet (éd.), Quelle(s) Europe(s). Nouvelles approches en histoire de l'intégration européenne, Peter Lang, Bruxelles, 2006, p. 328-335.

15. DDF, 1955-II, doc $n^{\circ} 297$, note de François Valéry du 13 octobre 1955.

16. DDF, 1955-II, doc n 297, note de François Valéry du 13 octobre 1955.

17. AN, F60, 3112, mémorandum de la délégation française du 14 octobre 1955. 
Ce mémorandum semble traduire la forte influence du Quai d'Orsay, et en particulier de la DAEF (direction des Affaires économiques et financières) dirigée par Olivier Wormser, dont le rôle s'accroît ${ }^{18}$. Il bénéficie en particulier de liens avec son oncle Georges Boris ${ }^{19}$, un proche de Pierre Mendès France. Wormser cherche peut-être à reprendre la main face à un chef de la délégation française, Félix Gaillard, trop européiste. Le directeur de la DAEF demande en effet explicitement au gouvernement des instructions pour obliger Gaillard à se montrer plus ferme ${ }^{20}$.

Les décideurs français sont donc dominés par une frange très sceptique envers le Marché commun, qui s'exprime à travers le mémorandum d'octobre 1955. En décembre 1955, Olivier Wormser, estime toujours que le Marché commun a de fortes chances de ne jamais voir le jour ${ }^{21}$. Sur toute cette période, c'est surtout l'absence de position claire et officielle, émanant du sommet de l'État, qui frappe et qui permet à des hauts fonctionnaires comme Wormser de jouer un rôle central. Paris va toutefois devoir clarifier ses conceptions pour se positionner face un nouveau document incontournable, le rapport Spaak.

\section{B. LE RAPPORT SPAAK : LES ÉQUILIBRES DU MARCHÉ COMMUN}

Déposé le 21 avril 1956, le « rapport des chefs de délégation aux ministres des Affaires étrangères » est bientôt connu sous le nom de « $\operatorname{rapport~Spaak}^{22}$ ». Il a été rédigé par un petit groupe d'européistes convaincus en particulier le Français Pierre Uri, un proche de Jean Monnet, et l'Allemand Hans von der Groeben $^{23}$. Il est particulièrement ambitieux en matière d'intégration économique car il veut créer une « vaste zone de politique économique commune » qui s'appuie sur une " fusion des marchés ${ }^{24} »$. Le Marché commun est donc à la base de ce projet, l'énergie atomique ou les autres formes de coopérations

18. Laurent Warlouzet, « Le Quai d'Orsay face au traité de Rome. La direction des Affaires économiques et financières (DAEF) de 1957 à 1975 », in Laurence Badel, Stanislas Jeannesson, Piers Ludlow (dir.), Les administrations nationales et la construction européenne, Peter Lang, Bruxelles, 2005, p. 139-168.

19. André de Lattre, Servir aux finances, Comité pour l'histoire économique et financière de la France, Paris, 1999, p. 225-226.

20. AMAE, PA-AP 314, carton 1, note d'Olivier Wormser pour le président, 10 octobre 1955.

21. AMAE, PA-AP 314, carton 1, notes d'Olivier Wormser des 13 et 14 décembre 1955.

22. Rapport des chefs de délégation aux ministres des Affaires étrangères (Bruxelles, 21 avril 1956), ci-après : « Rapport Spaak ». Disponible sur le site Internet ena.lu.

23. G. Bossuat, L'Europe des Français..., op. cit., p. 315. Pierre Uri, Penser pour l'action. Un fondateur de l'Europe, Odile Jacob, Paris, 1991, p. 121-125.

24. Rapport Spaak, avant-propos. 
sectorielles n'intervenant que dans un second temps. Sur le plan économique, le rapport Spaak est un projet mettant en œuvre un libéralisme régulé.

Comme son nom l'indique le «Marché commun » repose avant tout sur une dynamique libérale d'ouverture des marchés, par la mise en place d'une union douanière. La période transitoire de suppression des obstacles internes aux échanges doit durer de 12 à 15 ans. Elle est constituée de trois étapes. Les modalités du passage de la première étape de quatre ans à la seconde ne sont pas précisées mais aucune renégociation de traité ne sera permise à la différence de ce que demande la France dans son mémorandum d'octobre 1955. Il ne peut donc être question d'un engagement conditionnel.

Par rapport à l'OECE, le rapport Spaak entend aller plus loin ${ }^{25}$. Le système utilisé par l'OECE repose sur la suppression totale de contingents. Au lieu de cela, le rapport Spaak propose un système qui combine élargissement des contingents et diminution des tarifs douaniers, pour éviter toute compensation de l'un par l'autre. Cette libéralisation interne doit être complétée par une unification des politiques commerciales extérieures, avec la création d'un tarif extérieur commun (TEC). Le rapport Spaak évoque d'ailleurs l'impossibilité de choisir la solution de la zone de libre-échange ${ }^{26}$. Sur le plan technique, une zone de libre-échange se cantonne à la suppression des obstacles douaniers et contingentaires, sans harmonisation des tarifs extérieurs. Dès lors, dans une zone de libre-échange, un tarif douanier élevé dans un pays A peut être contourné par une importation venant d'un pays $B$ à tarif bas, qui entre librement dans le pays $\mathrm{A}$ dans la mesure où les obstacles internes entre $\mathrm{A}$ et $\mathrm{B}$ ont été abolis. Les pays à tarifs élevés comme la France pourraient donc souffrir particulièrement de l'importation par l'intermédiaire de pays voisins à tarifs bas, comme la Belgique. Ce phénomène de détournement de trafic ne peut être circonscrit que par une surveillance de l'origine des produits. Mais cette dernière est parfois difficile à établir sans procédures administratives lourdes. Par ailleurs, la libération des échanges de marchandises doit être complétée par une libération des mouvements de capitaux et de travailleurs, ainsi que la libre prestation de services, formant ainsi les « quatre libertés » de circulation. Pour éviter de trop grands déséquilibres issus de cette large ouverture des marchés, des mesures de régulations sont prévues.

Le rapport Spaak prévoit de réguler l'ouverture des marchés par deux dynamiques. Tout d'abord, une harmonisation progressive des conditions de concurrence doit être développée, tant par la création d'une politique de la

25. Rapport Spaak, titre I, chapitre II.

26. Rapport Spaak, introduction, point III.B. 
concurrence (lutte contre les pratiques discriminatoires des entreprises comme les cartels) que par des harmonisations ciblées des conditions de formation des coûts de production. Le rapport Spaak affirme clairement que les différences de prix ne posent pas de problèmes de principe ${ }^{27}$. Elles favorisent la concurrence et peuvent être compensées par les taux de change ou le niveau de productivité. Le rapport Spaak s'oppose donc à une volonté d'harmonisation systématique qui est réclamée par de nombreux décideurs français. Les harmonisations sont acceptables lorsqu'elles sont limitées aux distorsions de concurrence les plus flagrantes. Le rapport cite plusieurs exemples de législation sociale, financière ou fiscale comme les trois harmonisations sociales réclamées par la France (égalité des salaires masculins et féminins, durée des congés payés, rémunération des heures supplémentaires) ${ }^{28}$.

Ainsi, le rapport Spaak reconnaît que la dynamique libérale de suppression des obstacles aux échanges n'est pas suffisante pour aboutir à une fusion des économies des Six. Il prévoit même de compenser d'éventuels déséquilibres entraînés par l'ouverture des marchés. D'une part, un fonds d'investissement, fonctionnant selon les mêmes modalités qu'une banque, devrait financer à la fois des projets dans des régions en retard de développement, et la reconversion d'entreprises dont l'activité serait condamnée. D'autre part, une assistance est prévue en cas de déséquilibres de balance des paiements. Le rapport Spaak le justifie par la nécessité d'éviter toute dévaluation compétitive. Toutes les procédures sont communautarisées. C'est bien évidemment la France qui est visée par cette dernière proposition. Elle cherche à apporter une aide éventuelle à ce pays, s'il connaissait des difficultés, tout en insérant cette action dans un cadre institutionnel contraignant, afin d'éviter toute action unilatérale.

Ainsi le rapport Spaak contribue à mettre le Marché commun au cœur de la relance européenne, au détriment des autres projets de coopération proposés à Messine. Il vise en effet à fusionner les économies des Six par une dynamique triple : une libéralisation aboutie des échanges, une régulation forte des conditions de concurrence et une correction des déséquilibres spécifiques. Ce compromis audacieux s'inscrit en faux par rapport à la position française définie jusqu'alors, d'où la réaction négative d'une majorité des décideurs de l'administration française.

27. Rapport Spaak, titre II, chapitre II, section I.

28. Rapport Spaak, titre II, chapitre II, section II. 


\section{LA SURPRISE ET L'HOSTILITÉ DE L'ADMINISTRATION FRANÇAISE}

Le contenu du rapport Spaak est une surprise pour l'administration française. Une réunion interadministrative se tient dans la nuit du 24 avril 1956. L'heure même de la réunion traduit l'urgence du débat et sa conclusion est sans appel : " les conclusions auxquelles aboutit ce rapport d'unanimité étaient ignorées des services des ministères et en règle générale ne paraissent pas devoir avoir leur agrément, loin de là̀ ${ }^{29}$ ». En effet, le rapport Spaak s'inscrit en faux par rapport au mémorandum français d'octobre 1955.

\section{Le rapport Spaak et le mémorandum français d'octobre 1955.}

Par rapport au mémorandum français d'octobre 1955, le rapport Spaak est plus libéral et plus supranational. Sur le plan économique, la mise en place d'une union douanière fondée sur le libre-échange est à la base du rapport Spaak comme du mémorandum français. Mais ce dernier reposait sur un engagement conditionnel, avec une renégociation du traité entre la première et la deuxième étape. Sur le plan institutionnel, les contreparties régulatrices et correctrices à cette libéralisation sont nombreuses mais communautarisées. Ainsi, c'est la Commission qui sera à l'initiative des diverses mesures d'harmonisation. Face à elle, le Conseil décidera à l'unanimité puis à la majorité qualifiée dès la deuxième étape. Au bout de quatre ans, la France n'aurait donc pas affaire à un marché commun à renégocier, comme elle le prévoyait en octobre 1955 , mais à un marché commun communautarisé, dans lequel elle pourrait être mise en minorité. De même, la mise en œuvre de la clause de sauvegarde en cas de difficultés de balance des paiements et l'octroi du concours mutuel reposent sur une procédure communautaire et exigent que l'État en difficulté adopte une politique de rigueur.

Enfin, le rapport Spaak tourne le dos au dirigisme français qui pouvait s'exprimer dans des documents antérieurs. Le fonds d'investissement du rapport Spaak fonctionne comme une banque. D'une manière plus générale, la place des coopérations sectorielles s'est largement réduite et est reléguée à la toute fin du rapport. C'est bien le Marché commun, au sens commercial et libéral, qui s'impose comme base de cette relance européenne.

\section{L'hostilité de l'administration au rapport Spaak.}

Les réactions aux choix économiques du rapport Spaak sont largement négatives en raison de son postulat libéral. Cette méfiance s'explique par

29. ARAM, 52 J 114, note G. Plescoff et G. Paul-Boncour pour le président Ramadier, 25 avril 1956. 
des considérations structurelles, la prégnance du protectionnisme et du repli sur l'empire colonial, mais aussi par des facteurs conjoncturels : la balance commerciale française redevient largement déficitaire au début de 1956, tandis que l'aggravation des « événements 》 en Algérie relance le déficit budgétaire et l'inflation ${ }^{30}$. Comme le gouvernement Mollet refuse de dévaluer pour des raisons politiques (ne pas grever le pouvoir d'achat), la compétitivité française se dégrade. Dès lors, il paraît de plus en plus difficile à la France de profiter du libre-échange international.

La méfiance envers le rapport Spaak est générale. À la DAEF du Quai d'Orsay, tout d'abord, le directeur Olivier Wormser envoie une note très critique au secrétaire d'État Maurice Faure ${ }^{31}$. Constatant l'inflexion libérale du rapport, alors que les obligations d'harmonisations sont mal définies, il estime que la France ne peut, politiquement, que s'engager sur une première étape conditionnelle. Son adjoint, François Valéry, après une analyse précise du rapport Spaak, aboutit à la même conclusion, tout comme Francis Gutmann, un autre diplomate de la DAEF ${ }^{32}$.

La méfiance envers la libération des échanges est aussi très répandue au sein du ministère des Finances et des Affaires économiques. Le 4 mai 1956, le ministre Paul Ramadier demande leur avis sur le rapport Spaak à ses directeurs $^{33}$. Hormis Goetze au budget, et Sadrin aux finances extérieurs, tous les autres directeurs manifestent leur sourde hostilité. C'est d'abord la puissante direction du Trésor qui condamne le libéralisme du traité : «Toute la philosophie du rapport est d'inspiration libérale, dans la mesure où elle admet comme un postulat les avantages d'un marché commun et les mérites de la libre concurrence ${ }^{34}$. La direction du Trésor est très attachée au dirigisme national, en raison de son rôle éminent dans l'orientation des investissements français (le " circuit du Trésor » décrit par Laure Quenouëlle ${ }^{35}$ ). Elle critique très vivement le fonds d'investissements proposé dans le rapport Spaak ${ }^{36}$ qui risque de menacer ses prérogatives. Cela montre bien les limites du projet français d'intégration européenne. Les demandes en terme d'interventions sectorielles ou

30. André de Lattre, La politique économique française..., op. cit., p. 103, 136 et 138.

31. DDF, 1956-I, doc n ${ }^{\circ} 293$, note d'Olivier Wormser pour Maurice Faure, 3 mai 1956.

32. DDF, 1956-I, doc n ${ }^{\circ} 269$, note de François Valéry, 25 avril 1956 ; DDF 1956-I, doc n 251 , note de François Gutmann, 17 avril 1956 ; AMAE, DECE 613-138, note de Francis Gutmann diffusée par François Valéry du 7 mai 1956.

33. ARAM, 52 J 114, lettre de Paul Ramadier à ses directeurs, 4 mai 1956.

34. ARAM, 52 J 114, note de la direction du Trésor du 7 mai 1956.

35. Laure Quenouëlle, La direction du Trésor 1947-1967. L'État banquier et la croissance, Comité pour l'histoire économique et financière de la France, Paris, 2000.

36. ARAM, 52 J 114, note de la direction du Trésor, 7 mai 1956. 
d'harmonisation législatives ou fiscales sont séduisantes en théorie, mais inapplicables de facto, en raison des délégations de souveraineté qu'elles impliquent. De son côté, la direction des Douanes estime que la libération des échanges n'aura pas de conséquences positives notables ${ }^{37}$. Enfin, à la direction des Prix, c'est le directeur Louis Franck qui semble avoir inspiré la note du 18 mai $1956^{38}$. Selon lui, la France ne doit pas s'engager pour l'ensemble du processus devant conduire à la réalisation d'un marché commun, mais seulement sur une « étape probatoire » où ne seraient libérés que les produits ne posant pas de problèmes, c'est-à-dire les matières premières, les produits semi-finis et, inversement, les produits à très forte valeur ajoutée comme les produits de luxe, où la France est compétitive. La France devrait donc imposer à ses partenaires le libre-échange dans les secteurs où elle bénéficie d'un avantage comparatif. De son côté, le ministère des Affaires sociales demande une harmonisation très large dans son domaine, allant jusqu'à la fixation d'un salaire minimum ${ }^{39}$.

Seuls des fonctionnaires isolés sont favorables au rapport Spaak. C'est notamment le cas de deux directeurs de la rue de Rivoli, Jean Sadrin aux Finances extérieures et Roger Goetze au Budget, mais pour des raisons différentes. Le premier défend le rapport Spaak par conviction européiste. Le directeur des Finances extérieures est un ancien négociateur de la partie financière de la CED, à laquelle il était favorable ${ }^{40}$. Dans sa note d'avril $1956^{41}$, il se montre particulièrement enthousiaste envers cette dynamique d'intégration économique, qui devrait selon lui entraîner le développement d'une véritable union monétaire, voire d'une union politique. Au contraire, le directeur du Budget Roger Goetze soutient le rapport Spaak non par européisme mais par libéralisme. Il commence sa note de mai 1956 par un constat clair : « À long terme, les préoccupations qui ont guidé les rédacteurs du rapport sur le Marché commun rejoignent, en majeure partie, des préoccupations traditionnelles de la direction du Budget ${ }^{42}$. Le retour au libre-échangisme permettrait en effet de supprimer les coûteuses subventions aux exportations contre lesquelles il se bat

37. ARAM, 52 J 114, note du directeur général des Douanes et Droits indirects, 7 mai 1956.

38. ARAM, 52 J114, note du secrétaire d'État aux Affaires économiques, Jean Masson, qui semble rédigée par Louis Franck, le directeur des Prix, 18 mai 1956 ; la note du 18 mai 1956 ressemble beaucoup à une note de la direction des Prix sans date qui se trouve également dans le dossier ARAM, $52 \mathrm{~J} 114$.

39. AMAE, DECE 613, n 156, note Françis Gutmann du 12 mai 1956.

40. Témoignage d'André de Lattre in Le rôle des ministères des Finances et de l'Économie dans la construction européenne (1957-1968), Comité pour l'histoire économique et financière de la France, Paris, 2002, p. 192.

41. ARAM, 52 J 114, note de Jean Sadrin, directeur des Finances extérieures, 28 avril 1956.

42. ARAM, 52 J 114, note de Roger Goetze du 7 mai 1956. 
depuis de longues années ${ }^{43}$. D'une manière générale, pour Goetze, le rapport Spaak inscrirait la France dans un processus de libéralisation de l'économie qui permettrait de supprimer de nombreuses interventions inefficaces de l'État dans l'économie.

Face à cette hostilité très majoritaire à l'égard du rapport Spaak, la réunion interministérielle du 24 avril demande soit le rejet pur et simple du rapport Spaak, soit un remaniement profond à partir d'un futur mémorandum français ${ }^{44}$. Cependant, le temps presse car il a été convenu que les négociations reprendraient à la prochaine conférence des Six prévue pour le 29 mai 1956, soit un mois plus tard.

\section{La contre-proposition de l'administration française en mai 1956.}

Le mémorandum français est préparé par deux types de travaux. D'un côté, des notes montrent l'attachement des décideurs français à l'Europe contractuelle des ententes. Olivier Wormser, dans une note de mai 1956 critiquant le rapport Spaak, préconise d'intégrer les marchés européens non par le libre-échange mais par des ententes sectorielles supervisées par l'État ${ }^{45}$. Dans cette optique, en facilitant la pénétration des marchés étrangers par des accords, les ententes seraient un moyen de construire l'intégration européenne de manière réaliste, sans compter sur les seules forces du marché. Elles permettraient de rationaliser les structures. Le patronat soutient cette orientation : le mémorandum de la Fédération des industries mécaniques et transformatrices de métaux (FIMTM) du 7 juin 1956 remarque que l'objectif d'augmentation de la taille des entreprises à la base du Marché commun peut être obtenu par des ententes plus facilement que par la libération des échanges ${ }^{46}$. Cet attachement à la logique de l'Europe contractuelle, à l'organisation des marchés par des ententes, est ancien ${ }^{47}$. Après 1945, il est renouvelé par une revalorisation du rôle de l'État. Les entreprises ne doivent plus agir seules mais sous le contrôle des États.

D'un autre côté, des notes s'attachent à définir une contre-proposition fondée sur un processus d'harmonisation très poussée pour atténuer la dynamique de

43. Marc Duchassin, «La direction du Budget et les subventions à l'exportation, 1950-1958 », in La direction du Budget face aux grandes mutations des années cinquante, acteur... ou témoin ?, Paris, Comité pour l'histoire économique et financière de la France, 1998, p. 534-35.

44. AFJM, ARM 13/5, compte rendu de la « Commission Verret » du 24 avril 1956.

45. DDF, 1956-I, doc. ${ }^{\circ} 293$, note Olivier Wormer pour Maurice Faure, 3 mai 1956.

46. ACNPF, 72 AS 1505, mémorandum de la FIMTM, 7 juin 1956 : «Les industries mécaniques et transformatrices de métaux et l'intégration européenne ».

47. É. Bussière et M. Dumoulin, «L'émergence de l'idée d'identité économique européenne... », op. cit., p. 67-105. 
libéralisation. Un projet de mémorandum circule au sein de l'administration française en mai $1956^{48}$. Il a été préparé par des fonctionnaires peu favorables au Marché commun comme Francis Gutmann du Quai d'Orsay et Claude Beaurepaire du ministère de l'Industrie ${ }^{49}$. Par rapport au rapport Spaak, trois différences apparaissent. Tout d'abord, sur le plan institutionnel, le mémorandum se montre beaucoup plus intergouvernemental. Ensuite, il reprend l'idée d'une libéralisation conditionnelle. La France ne souhaite s'engager que sur une première étape de quatre années, à l'issue de laquelle une nouvelle négociation intergouvernementale devra avoir lieu ${ }^{50}$. Enfin, le mémorandum affirme très clairement une position très dirigiste. Il soutient l'idée de fonds d'investissement et en ajoute une nouvelle, celle de la planification indicative, qui devra être à la base de la coordination des politiques économiques des Six. Il est en effet prévu que le Conseil devra « examiner les plans et les programmes généraux de développement à long terme établis par chacun des gouvernements » et fixer des objectifs de production communs ${ }^{51}$. Surtout, il envisage de généraliser le système français de taxes à l'importation et d'aides à l'exportation, qui avaient été mis en place pour éviter une dévaluation, refusée par principe par le gouvernement Mollet. Ils constituent des expédients contraires au mouvement de libération des échanges, mais pourtant tolérés par les partenaires de la France en raison de ses difficultés financières. Le mémorandum va donc plus loin que la demande de reconnaissance de ce système car il exige sa généralisation et sa communautarisation, pour gérer de manière courante les différences de compétitivité : «Les pays qui auront à souffrir de l'existence d'une source de disparité de prix établiront les éléments du calcul de cette disparité et mettront en application les mécanismes de compensation correspondants... ${ }^{52}$. La libre concurrence est donc niée car tous les coûts doivent être égalisés a priori par un système de taxes, et ne sont donc pas soumis aux lois du marché.

Les réflexions de l'administration française telles qu'elles se développent en mai 1956 sont donc en complet décalage avec l'esprit même du Marché commun. La libération des échanges est acceptée uniquement si elle n'accroît pas la concurrence, ce qui est paradoxal. Protégées derrière des rideaux de

48. AN, F60, 3112, «projet de document de travail sur l'établissement d'un marché présenté par la délégation française », date manuscrite : « mai $1956 »$.

49. AN, F60, 3112, note SGCI pour Donnedieu de Vabres, 15 mai 1956.

50. AN, F60, 3112, « projet de document de travail sur l'établissement d'un marché présenté par la délégation française », date manuscrite : «mai $1956 »$.

51. AN, F60, 3112, «projet de document de travail sur l'établissement d'un marché présenté par la délégation française », date manuscrite : « mai $1956 »$.

52. AN, F60, 3112, « projet de document de travail sur l'établissement d'un marché présenté par la délégation française », date manuscrite : « mai $1956 »$. 
taxes de compensation, les entreprises françaises n'auraient aucune incitation à augmenter leur productivité, ruinant ainsi tous les bénéfices attendus de la mise en place d'un marché commun. Par rapport au mémorandum français d'octobre 1955, une radicalisation des positions peut s'observer, sans doute en raison de la dégradation de la situation financière française. Face à cette résistance de l'administration, le pouvoir politique réagit vigoureusement.

\section{LE CHOIX DE LA CEE PAR LE GOUVERNEMENT MOLLET}

Face à une négociation difficile, c'est le pouvoir politique qui impose le choix du Marché commun à l'été 1956. Une position constructive est définie dans la négociation à Six en septembre 1956 et confirmée lors des événements de Suez en novembre 1956. Ce volontarisme dans le choix de la CEE est facilité par le soutien du CNPF au projet de marché commun.

\section{A. LE DIFFICILE CHOIX POLITIQUE DU MARCHÉ COMMUN (AVRIL-AOÛT 1956)}

Un trio de décideurs politiques se mobilise au printemps 1956 pour imposer la perspective du Marché commun à une administration qui reste longtemps réticente.

\section{Un trio gouvernemental engagé.}

L'arrivée au pouvoir d'un nouveau gouvernement en janvier 1956 permet à un trio favorable à l'Europe communautaire de prendre en charge les négociations. Le premier est le président du Conseil Guy Mollet, dont l'œuvre en matière de construction européenne a été longtemps ignorée ${ }^{53}$. Ministre chargé du Conseil de l'Europe dans les cabinets Pléven et Queuille (juillet 1950-août 1951), il devient président de l'Assemblée consultative du Conseil de l'Europe en $1954^{54}$. Selon Christian Pineau, il a été choisi contre Pierre Mendès France pour occuper le poste de président du Conseil par le président de la République

53. Gérard Bossuat, L'Europe des Français..., op. cit., p. 292 ; dans le colloque de référence sur Guy Mollet, sur les 34 contributions, aucune ne traite spécifiquement de la construction européenne : Bernard Ménager et al. (éd.), Guy Mollet. Un camarade en République, PUL, Lille, 1987.

54. Sur les réseaux européens de Guy Mollet : Gérard Bossuat, «Les euro-socialistes de la SFIO», in Gérard Bossuat (dir.), Georges Saunier (collab.), Inventer l'Europe. Histoire nouvelle des groupes d'influence et des acteurs de l'unité européenne, Peter Lang, Bruxelles, 2003, notamment p. 410. 
René Coty justement en raison de cet engagement européen ${ }^{55}$. Membre du Comité d'action pour les États-Unis d'Europe, Guy Mollet voulait relancer la construction européenne après l'échec de la CED par idéalisme mais aussi par réalisme, afin d'adapter la France à un monde nouveau, celui des grandes puissances et de la décolonisation ${ }^{56}$. Il refuse de donner le poste de ministre des Affaires étrangères à Pierre Mendès France, considéré comme trop réservé envers la construction européenne, pour l'offrir à Christian Pineau, un ancien résistant et déporté favorable à la réconciliation franco-allemande et à la construction européenne ${ }^{57}$.

Le trio gouvernemental est complété par Maurice Faure, jeune secrétaire d'État aux Affaires étrangères. Député radical, Maurice Faure représente ce parti au Comité d'action pour les États-Unis d'Europe de Jean Monnet. Il est proche de Guy Mollet, qu'il a côtoyé dans de nombreux combats proeuropéens, de la CECA à la CED ${ }^{58}$. À ce titre, le président du Conseil lui laisse une grande marge de manœuvre dans les affaires européennes par rapport au ministre Christian Pineau, il est vrai largement préoccupé par la lourde actualité internationale de l'année $1956^{59}$.

Au-delà des mémoires et des témoignages, les sources d'archives livrent des traces de l'influence de ce trio gouvernemental dans les négociations, et en premier lieu en mai 1956 pour imposer le rapport Spaak à une administration méfiante.

\section{Le primat du pouvoir politique sur l'administration.}

La réunion interministérielle du 28 mai 1956 doit préparer la conférence des Six à Venise du lendemain ${ }^{60}$. Alors que le mémorandum français a justement été préparé pour cette réunion, il est immédiatement mis de côté. Une position beaucoup plus modérée est définie. Elle consiste à prendre le rapport Spaak comme base de travail, tout en réclamant des accompagnements en terme

55. Témoignage de Christian Pineau in Enrico Serra (dir.), La relance européennes..., op. cit., p. 281.

56. Gérard Bossuat, L’Europe des Français..., op. cit., p. 294-296 et p. 352-358. Sur la modération de Mollet par rapport aux plus fervents européistes : Michel Debré, Trois républiques pour une France, Mémoires, t. II, 1946-1958, Agir, Albin Michel, Paris, 1988, p. 184.

57. Gérard Bossuat, «Christian Pineau face aux crises internationales (1956-1958)», in Alya Aglan, Denis Lefebvre (dir.), Christian Pineau : de Buchenwald aux traités de Rome, B. Leprince, Paris, 2004, p. 71-75.

58. Bruno Riondel, Maurice Faure, un artisan de la construction européenne, thèse de doctorat, dir. Robert Frank, Paris I, 1997, p. 125.

59. Bruno Riondel, Maurice Faure..., op. cit., p. 166.

60. AN, F60, 3112, résumé des décisions du comité interministériel du 28 mai 1956. 
d'harmonisation sociale et fiscale, ainsi que l'institution d'un Comité monétaire. Ce dernier constituerait une instance au sein de laquelle les Six devraient s'efforcer de coordonner leurs politiques économique et monétaire. Il concrétiserait la solidarité financière des Six tout en restant intergouvernemental. Enfin, le problème des territoires d'outre-mer, négligé dans le rapport Spaak, devra être pris en compte.

Cette réunion manifeste l'influence très forte du pouvoir politique, et notamment des principaux promoteurs du Marché commun comme Guy Mollet et Christian Pineau, sur l'administration, mobilisée tardivement et en majorité réticente envers le rapport Spaak. Sur le plan politique, un arbitrage interne au gouvernement s'est également produit car Paul Ramadier, le ministre des Affaires économiques et financières, était également hostile au rapport Spaak, mais il n'a pu faire prévaloir ses vues ${ }^{61}$. Un autre membre influent du gouvernement, Pierre Mendès France, lui aussi sceptique envers l'intégration européenne, aurait pu s'opposer au rapport Spaak mais il quitte le gouvernement à cette époque, en raison d'un désaccord sur la politique algérienne du gouvernement ${ }^{62}$.

Ainsi, à la conférence de Venise, le ministre des Affaires étrangères Christian Pineau peut accepter de prendre le rapport Spaak comme base de négociation ${ }^{63}$. Il émet un certain nombre de réserves, notamment la prise en compte du problème des territoires d'outre-mer et de la spécificité de la situation économique et financière française. La grande novation de la position française porte sur la nature conditionnelle de l'engagement dans le Marché commun. Alors que la France n'avait, jusqu'alors, envisagé qu'un accord limité à une première étape, Christian Pineau affirme une position audacieuse : « fixer, dès à présent, les objectifs et le processus de réalisation de la première étape, sans toutefois arrêter un délai trop rigide pour cette dernière, mais étant entendu que la réalisation de toutes les mesures prévues pour la première étape - par exemple, en matière d'abaissement des droits de douane et d'harmonisation concomitante des charges sociales - entraînerait automatiquement le passage à la deuxième étape dont le traité aurait déjà défini les grandes lignes ${ }^{64} \gg$. Cette affirmation représente une évolution considérable car, si elle est suivie à la lettre, elle signifie que la France accepte d'abandonner toute garantie

61. ARAM, 52 J 114, note du ministre des Affaires économiques et financières, 24 mai 1956.

62. Lettre de Pierre Mendès France à Guy Mollet du 23 mai 1956, in Pierre Mendès France, Euvres complètes, tome IV, Pour une République moderne, 1955-1962, Gallimard, Paris, 1987, p. 187.

63. AN, F60, 3083, projet de procès-verbal de la conférence des Six à Venise, 29 et 30 mai 1956.

64. DDF, 1956-I, doc n ${ }^{\circ} 377$, projet de procès-verbal de la conférence des Six à Venise des 29 et 30 mai 1956,8 juin 1956. 
intergouvernementale pour le passage d'étape, en s'en remettant à une procédure communautaire. De fait, l'accord trouvé dans le traité de Rome s'avère être en retrait par rapport à cette position - le traité prévoit un vote à l'unanimité qui pouvait retarder pendant deux ans le passage d'étape. Sa portée ne fut toutefois pas bien mesurée à l'époque, en raison du poids des réticences exprimées par ailleurs par Pineau dans les autres dossiers (Euratom, agriculture, territoires d'outre-mer).

Ainsi, il apparaît que dès la conférence de Venise, les dirigeants français européistes ont accepté l'essentiel, c'est-à-dire la base libre-échangiste du Marché commun industriel. En interne, le pouvoir politique et ses relais doivent convaincre l'administration française de se mobiliser pour une issue positive de cette négociation du Marché commun.

\section{La reprise en main de l'administration.}

Pour mieux contrôler l'administration, le président du Conseil créé un comité présidé par un proche, Alexandre Verret ${ }^{65}$, qui doit définir la position française en coordonnant les travaux des administrations ${ }^{66}$. Cette même réunion du 3 juillet 1956 définit la délégation française ${ }^{67}$. Elle est dirigée par Maurice Faure, assisté par deux vice-présidents, Robert Marjolin pour les questions économiques, et Georges Vedel pour les questions institutionnelles. Ainsi, le trio gouvernemental favorable au Marché commun contrôle la définition et l'exécution de la position française, directement dans le cas de Faure, ou indirectement par le biais de membres des cabinets (Alexandre Verret pour le cabinet de Guy Mollet et Robert Marjolin au cabinet de Christian Pineau).

Dans un second temps, les hauts fonctionnaires trop hostiles au Marché commun sont écartés. Ainsi, le secrétaire général du ministère des Affaires étrangères René Massigli est poussé à la retraite en grande partie à cause de son hostilité aux négociations du Marché commun ${ }^{68}$. Au sein de la délégation française, le sceptique Olivier Wormser, proche de Massigli, est remplacé par Jacques Donnedieu de Vabres, considéré comme plus souple, à la tête du groupe

65. Proche de Mollet selon Franck : Louis Franck, 697 Ministres. Souvenir d'un directeur général des prix, 1947-1962, Comité pour l'histoire économique et financière de la France, Paris, 1990, p. 7.

66. AFJM, ARM 13/1, compte rendu de la réunion du 3 juillet 1956.

67. AFJM, ARM 13/1, compte rendu de la réunion du 3 juillet 1956.

68. Raphä̈le Ulrich-Pier, René Massigli (1888-1988). Une vie de diplomate, Peter Lang, Bruxelles, 2004, p. 1324. 
chargé de la négociation du Marché commun ${ }^{69}$. Face à cette reprise en main de l'administration par l'exécutif se développe un débat de fond sur l'intérêt économique du projet de marché commun.

\section{L'échec sur le fond des opposants internes au Marché commun.}

Les opposants au Marché commun tentent de reprendre la main à l'été 1956 en menant des études destinées à démontrer l'impossibilité pour la France de profiter de la dynamique libre-échangiste. Au sein du comité Verret, Beaurepaire, du ministère de l'Industrie, et Juvigny, du ministère des Affaires sociales, demandent des études sur un nombre important de secteurs ${ }^{70}$. En parallèle, à Bruxelles, Olivier Wormser tente, sans succès, de faire adopter la même procédure au niveau des $\operatorname{Six}^{71}$.

Les premières études sur les prix donnent cependant des résultats contradictoires. Certes, celle effectuée en urgence par la direction des Prix le 23 mai 1956, conclut de manière pessimiste sur la non-compétitivité de la très grande majorité des produits français ${ }^{72}$. Mais d'autres études sont beaucoup plus nuancées. Une note émanant du même ministère, le secrétariat aux Affaires économiques, minore les décalages de charges salariales entre la France et ses voisins ${ }^{73}$. La France reste le pays où le coût de la main-d'œuvre est le plus élevé mais seulement à hauteur de $10 \%$ par rapport à la RFA et de 7,5\% par rapport à la Belgique. Et la note de conclure : «On peut attirer l'attention sur le fait que si l'on tient compte des sur - ou sous - évaluations de certaines monnaies [...] on trouve de nouveaux indices sensiblement équivalents (à moins de $10 \%$ près) ». Ainsi le handicap français paraît faible et de toute façon lié à la surévaluation du franc français. De même, le SGCI transmet une étude de l'OIT (Organisation internationale du travail) dans laquelle il apparaît que l'indice du coût de la main-d'œuvre français est supérieur de seulement $4 \%$ par rapport à celui de

69. Hanns Jürgen Küsters, Fondements de la CEE, Office de publication des communautés, Luxembourg, 1990 [1982], p. 168 ; Ghislain Sayer, «Le Quai d'Orsay et la construction de la Petite Europe : l'avènement de la Communauté économique européenne (1955-1957)», in Relations Internationales, $\mathrm{n}^{\circ} 101$, printemps 2000, p. 100.

70. AFJM, ARM 13/1, note Industrie, Affaires extérieures, Claude Beaurepaire, 9 juillet 1956 ; AFJM, ARM 13/1, réunion du comité Verret du 12 juillet 1956.

71. AFJM, ARM 13/1, réunion du comité Verret du 7 juillet 1956 qui décide de la diffusion d'un questionnaire auprès des Six ; AN, F60, 3112, note d'Olivier Wormser du 23 juillet 1956 sur la réunion à Six du 20 juillet 1956 .

72. ARAM, 52 J 114, note de la direction des Prix et des Enquêtes économiques, 23 mai 1956.

73. AN, F60, 3112, note de Menahem, secrétariat d'État aux Affaires économiques, 12 juillet 1956. 
la Belgique, grand pays exportateur ${ }^{74}$. Spaak lui-même utilise ces statistiques dans un entretien avec Maurice Faure ${ }^{75}$. Finalement, la Haute Autorité de la CECA entre dans le débat et souligne que la thèse française d'un coût salarial supérieur à celui de ses partenaires n'est pas fondée ${ }^{76}$. Elle souligne notamment que les situations sont très différenciées. Ainsi, si certains mineurs sont mieux payés en France qu'en Allemagne, la situation est inversée pour la sidérurgie. De plus, les différences entre deux régions d'un même pays sont bien souvent supérieures à celles qui existent entre deux pays voisins.

Cette étude déclenche une contre-offensive des opposants au Marché commun. Olivier Wormser la critique directement et une démarche est effectuée auprès de la chambre syndicale de la sidérurgie française pour obtenir des statistiques qui permettraient de contredire ces chiffres ${ }^{77}$. En août 1956, le ministère de l'Industrie diffuse au sein du comité Verret une étude de la FIMTM qui met en évidence les handicaps salariaux français ${ }^{78}$.

Ces conclusions contradictoires ne sont pas étonnantes car il est très difficile d'évaluer le niveau de compétitivité des prix français pour des raisons macroéconomiques (surévaluation du franc français) et méso-économiques (diversité des situations en fonction des secteurs). Déjà le rapport Nathan de 1954, chargé d'enquêter sur les causes de la disparité des prix français avec les prix étrangers, avait conclu sur l'extrême diversité des situations sectorielles ${ }^{79}$.

D'une manière générale, l'impossibilité pour les hauts fonctionnaires opposés au Marché commun de fonder leurs arguments sur une démonstration solide s'explique en partie par une peur irraisonnée - sur le plan économique - de la libération des échanges. Elle s'exprime par exemple dans la revendication sur l'harmonisation sociale qui est ancienne. Elle faisait déjà partie des arguments que la France avait opposés au plan Beyen en $1953^{80}$. Cela explique que le mémorandum du Benelux du 18 mai 1955 envisageait une harmonisation

74. AN, F60, 3112, note SGCI du 9 juillet 1956.

75. DDF, 1956-I, doc n ${ }^{\circ} 432$, note sur l'entretien entre Maurice Faure et Paul-Henri Spaak à Bruxelles, 26 juin 1956.

76. AN, F60, 3112, note CECA du 27 juin 1956.

77. AN, F60, 3112, note d'Olivier Wormser du 23 juillet 1956 et lettre d'Armengaud à Jacques Ferry, Chambre syndicale de la sidérurgie française, du 5 juillet 1956.

78. AN, F60, note de Valabrègues, ministère de l'Industrie, du 11 août 1956.

79. Ministère des Finances, Rapport général de la commission créée par arrêté du 6 janvier 1954 pour l'étude des disparités entre les prix français et étrangers, 1954 ; cité in Frances Lynch, France,... op. cit., p. 138-140.

80. Lise Rye, The Rise and Fall of the French Demand for Social Harmonization in the EEC, 1955-1966, n ${ }^{\circ} .48$, Trondheim Studies in History, NTNU, 2004, p. 36 et 39. 
de la durée du travail, de la rémunération des heures supplémentaires et de la durée des congés payés ${ }^{81}$.

$\mathrm{Au}$ cours de la négociation, la France demande dans un premier temps l'harmonisation préalable des régimes sociaux. Puis, consciente de l'irréalisme de ses propositions, elle exige ensuite une harmonisation sociale parallèle au processus de libération sur quatre points : l'harmonisation des régimes de sécurité sociale, l'égalité des salaires masculins et féminins, le paiement des heures supplémentaires et la durée des congés payés. Finalement, le mémorandum de septembre 1956 ne retient que les trois derniers points, qui figureront dans le traité de Rome. Dans ces trois domaines, la législation sociale française est censée être la plus avancée des Six, ce qui peut entraîner une distorsion de la concurrence. Ainsi, dans la branche de la construction électrique où la main-d'œuvre féminine est nombreuse et l'exportation importante, la revendication d'une égalisation des salaires masculins et féminins est très forte ${ }^{82}$. Mais cette avancée française ne semble pas effective dans le cas des congés payés car le traité de Rome stipule que «Les États membres s'attachent à maintenir l'équivalence existante des régimes de congés payés » (article 120).

En fait, alors que les handicaps français en termes de législation sociale ont dû s'accroître sous le gouvernement Mollet (troisième semaine de congés payés), les exigences françaises décroissent. La négociation conduite entre mai 1955 et mars 1957 montre que l'exigence française d'harmonisation sociale n'est pas corrélée à l'évolution de la législation sociale. Cela s'explique en fait car cette revendication est essentiellement politique, comme le montrent les analyses du Quai d'Orsay ${ }^{83}$.

Dès les instructions françaises pour le comité Spaak du 12 juillet 1955, il est précisé que les revendications dans ce domaine sont liées au «point de vue de l'opinion française ${ }^{84} »$. Une note de la DAEF de février 1956 est plus claire encore : «...les milieux économiques français sont convaincus, à tort ou à raison, de la nécessité de tenir compte de l'inégalité des charges sociales et fiscales ». En septembre 1956, une autre note estime que la cause des disparités

81. Mémorandum des trois pays du Benelux du 18 mai 1955 ; voir www.ena.lu; texte tiré de : Pour une Communauté politique européenne, Travaux préparatoires (1955-1957). tome II, 1955-1957. Bruylant, Bruxelles, 1987, p. 25-29.

82. Janos Szokoloczy-Syllaba, Les organisations professionnelles françaises et le Marché commun, Colin, Cahiers de la FNSP n ${ }^{\circ}$ 133, Paris, 1965, p. 154.

83. Lise Rye, The Rise and Fall..., op. cit., p. 28 et 38-41.

84. AN, F60, 3083, instructions pour la délégation française au comité Spaak (Gaillard), 12 juillet 1955. 
entre les prix français et les prix étrangers ne réside que pour une faible part dans les divergences de législations sociales ${ }^{85}$. C'est plutôt l'ensemble de la politique économique et des structures industrielles françaises qui sont à mettre en cause comme le refus de dévaluer. Le 29 novembre 1956, le même auteur remarque finalement que « les discussions de Bruxelles, comme les travaux du Comité Verret, ont mis en évidence le caractère plus politique qu'écono-mique du problème de l'harmonisation des charges sociales ${ }^{86} »$. Le directeur de la DAEF, Olivier Wormser, estime également que l'harmonisation sociale sera " fictive $^{87}$ » mais qu'elle doit être demandée pour des raisons politiques : elle permet à la France de justifier ses demandes de dérogations au sein de $1^{\prime} O E C E^{88}$. Si la France abandonnait cette revendication, elle reconnaîtrait ainsi qu'elle ne souffre pas d'un handicap réel et qu'elle peut donc supporter la libération des échanges prônée par l'OECE. Enfin, le caractère économiquement peu justifié de ces revendications est reconnu implicitement par l'ambassadeur de France en Allemagne, Maurice Couve de Murville. Il souligne dans ses notes l'ampleur des avancées sociales réalisées récemment en RFA, tout en reconnaissant qu'elles sont parfois peu visibles car elles se développent autant par les négociations entre partenaires sociaux que par la $1 \mathrm{loi}^{89}$.

Finalement, l'étude de cet argument de l'harmonisation sociale met en lumière les difficultés de l'émergence d'une Europe sociale. Tout d'abord, le processus d'harmonisation en lui-même est plus difficile car les systèmes sociaux nationaux sont très spécifiques, tout comme leurs acteurs (les syndicats), par ailleurs soumis à des divisions idéologiques beaucoup plus importantes que les milieux économiques (problème de la position des syndicats communistes). Il est donc très difficile de développer des approches communes, alors que, dans le domaine économique, les consensus sont plus faciles à trouver autour de mesures techniques et moins chargées politiquement. Ensuite, le différentiel entre la France et ses partenaires du Marché commun en la matière est faible et, s'il existe, lié à la surévaluation du franc. Les six pays de la future CEE ont tous développé un État-providence généreux, et profitent tous d'une croissance élevée et d'un chômage faible. La réalisation d'une Europe sociale est donc à la fois plus compliquée et moins urgente que l'Europe économique.

85. AMAE, DECE 711, folio ${ }^{\circ} 43$, note Francis Gutmann du 15 septembre 1956.

86. DDF, 1956-III, $n^{\circ} 262$. Note de Francis Gutmann du 29 novembre 1956.

87. AMAEF, POW 31, folio $n^{\circ} 155$, note d'Olivier Wormser du 20 octobre 1956.

88. AMAEF, PA-AP 314, note d'Olivier Wormser du 10 octobre 1955.

89. AMAE, DECE 629, n 34, télégramme de Maurice Couve de Murville à la direction Europe, 19 octobre 1956. 
Sur le plan du processus de décision, ces débats montrent à la fois les lacunes de l'administration française en terme d'information économique, l'importance du patronat pour combler ces lacunes, mais aussi la faiblesse conceptuelle des conceptions françaises. Sans que des études sérieuses et contradictoires ne soient réalisées, il est admis comme un axiome que les charges sociales de la France sont supérieures à celle de ses voisins en raison de son modèle social avancé, les Français étant supposés être les seuls en Europe à bénéficier du Welfare State. Cette position traduit l'incertitude qui règne en France sur la capacité du pays à supporter une pleine libération des échanges, que le pays n'a plus connu depuis près de trente ans, hormis une courte période au début des années cinquante. Cet échec sur le fond des opposants au Marché commun permet au gouvernement de définir une position de négociation plus modérée en septembre 1956.

\section{B. L'ÉVOLUTION VERS UNE POSITION FRANÇAISE PLUS MODÉRÉE (SEPTEMBRE-NOVEMBRE 1956)}

Après avoir accepté le rapport Spaak comme base de négociation en mai 1956, les décideurs français favorables au Marché commun définissent une position de négociation réaliste en septembre 1956, et l'imposent partiellement aux Six en novembre 1956.

\section{La définition d'une position réaliste en septembre 1956.}

À la rentrée 1956, la négociation intergouvernementale pour l'élaboration d'un traité de Marché commun reprend après l'interruption estivale. Guy Mollet sort renforcé des débats à l'Assemblée nationale sur Euratom, du 6 au 11 juillet 1956, au cours desquels il a développé des arguments également valables pour le Marché commun ${ }^{90}$. Enfin, le CNPF, qui est un acteur important pour attester de l'intérêt économique du Marché commun, développe une position modérée $^{91}$. C'est l'occasion pour Guy Mollet d'engager pleinement l'administration et le gouvernement français dans la négociation en imposant une position constructive.

Mollet convoque pour le 4 septembre 1956 un comité interministériel décisif $^{92}$. Il est préparé par une note de synthèse de Robert Marjolin, qui abandonne

90. Il évoque notamment la nécessité « d'intégrer l'Allemagne à l'Europe et d'échapper à une entente germano-russe », in L'année politique, 1956, PUF, Paris, 1957, p. 71.

91. Voir ci-après.

92. Évoqué dans Gérard Bossuat, L’Europe des Français..., op. cit., p. 328. 
la position traditionnelle consistant à refuser de vouloir fixer un terme final au Marché commun et à ne s'engager que pour une première étape ${ }^{93}$. De plus, il se montre assez favorable à la délégation de pouvoirs aux organes communautaires dans la détermination des objectifs de chaque étape et dans la gestion des clauses de sauvegarde ${ }^{94}$.

Lors du comité interministériel tenu sous la présidence de Guy Mollet le 4 septembre 1956, Maurice Faure présente la nouvelle position française proposée dans la note de Marjolin ${ }^{95}$. Il définit une position acceptable de négociation : la France demandera l'harmonisation des charges sociales, la possibilité de conserver le système de taxes à l'importation et d'aides à l'exportation, une clause de sauvegarde partiellement unilatérale, des engagements précis ne portant que sur les quatre premières années et enfin une mise en œuvre du Marché commun retardée jusqu'à la fin des troubles en Afrique du Nord. En dehors des deux dernières conditions, quasiment léonines et que la France ne parviendra d'ailleurs pas à imposer à ses partenaires, le reste de la position française constitue un compromis qui se révélera acceptable par les Six. L'harmonisation des charges sociales ne signifie plus une égalisation préalable et complète mais concerne juste des points spécifiques.

En termes de rapport de force, Maurice Faure souligne le danger du « droit de sécession » que les Cinq auraient offert à la France, c'est-à-dire la possibilité pour la France de se retirer du processus unilatéralement ${ }^{96}$. Cette « clause de sécession » avait notamment été évoquée par Spaak dans une conversation avec Faure ${ }^{97}$. Elle consistait à offrir à la France la possibilité de se retirer du Marché commun au bout de quatre ou cinq ans. Ainsi, la position française consistant à ne s'engager que pour quatre années est discréditée par Spaak qui en démontre la conséquence concrète : le risque pour la France de voir la construction du Marché commun continuer, mais sans elle. Faure utilise cette menace pour démontrer que la France doit s'engager pleinement si elle ne veut pas finir isolée.

93. ARAM, 52 J115, « Mémorandum Marjolin » du 3 septembre 1956 diffusé par le SGCI avec l'indication : « Note destinée à servir de base aux discussions du comité interministériel du mardi 4 septembre $1956 »$.

94. AFJM, ARM 13/5/20, note pour le ministre, 4 septembre 1956.

95. Les paragraphes sur ce comité interministériel sont fondés sur : AN, F60, 3112, compte rendu du 5 septembre 1956 du comité interministériel du 4 septembre 1956 ; notes manuscrites sur ce même comité.

96. AN, F60, 3112, notes manuscrites du comité interministériel du 4 septembre 1956.

97. DDF, 1956-I, doc n ${ }^{\circ} 432$, notes sur l'entretien entre MM. Faure et Spaak à Bruxelles 26 juin 1956. 
Lors de cette réunion, si le garde des Sceaux François Mitterrand soutient cette position, les opposants au Marché commun sont nombreux. Le gaulliste Jacques Chaban-Delmas se montre actif mais c'est surtout Paul Ramadier, le ministre des Affaires économiques et financières, qui intervient. Il estime que la France ne peut entrer dans le Marché commun maintenant. Il prévoit que les difficultés financières françaises vont s'aggraver en 1957 et 1958. Allant plus loin, il considère que la France, à cause des troubles en Algérie, devra entrer dans une « ère d'économie fermée et peut-être d'économie de guerre ». Il défend donc une politique qui est à l'opposé de la libération des échanges, marquée par le protectionnisme, le dirigisme et un certain fatalisme.

C'est alors que le président du Conseil intervient pour faire basculer le débat : « Il faut se convaincre que le Marché commun est un bien en soi, même pour la France. Il [Guy Mollet] ne nie pas les difficultés actuelles. Nous sommes en suremploi et en déficit budgétaire, c'est-à-dire dans les meilleures conditions d'inflation ; mais si nous restons en autarcie, cette situation ne fera qu'empirer. Si nous songeons en outre à tous les problèmes que nous posent les territoires d'outre-mer nous ne savons pas où nous pourrons chercher les moyens et trouver les solutions ». Dès lors, le Marché commun n'est plus une contrainte mais une solution. Il apparaît à la fois, pour le présent, comme un garde-fou indispensable pour ne pas mener une politique encore plus déficitaire et, pour l'avenir, comme la seule solution pour financer le développement des territoires d'outre-mer, et donc, in fine, le maintien de leurs liens avec la France.

Finalement, la position présentée par Maurice Faure est acceptée. Un nouveau mémorandum doit être rédigé. Il est diffusé aux Cinq deux semaines plus $\operatorname{tard}^{98}$. Par rapport au projet de mémorandum de mai 1956, il est beaucoup plus conciliant sur trois points tout en ajoutant une condition léonine supplémentaire. Tout d'abord, la France accepte de signer un traité qui l'engage pour toute la durée de la période transitoire, même si le passage de la première à la deuxième étape doit se faire à l'unanimité. Ensuite, la France demande une régulation de la logique libre-échangiste plus spécifique. Ainsi, le maintien du régime d'aide à l'exportation et de taxes à l'importation est demandé mais sa généralisation n'est plus envisagée. Bien plus, la France prend l'engagement de le supprimer si les décalages de prix venaient à disparaître. En matière d'harmonisation sociale, seules les trois exigences spécifiques (égalité des salaires masculins et féminins, congés payés, heures supplémentaires) sont reprises. Enfin,

98. AN, F60, 3112, « Mémorandum de la délégation française remis au Marché commun », « date : environ 18 septembre 1956 »; AN, F60, 3093, « Note présentée par la délégation française », note Ch. Del. 29, 19 septembre 1956. 
l'exigence d'éviter à tout prix la dévaluation n'est plus indiquée. La France réclame maintenant l'instauration d'un "Comité monétaire ", déjà évoqué lors de la réunion du 28 mai 1956. Organe consultatif, il devra intervenir dans l'application des clauses de sauvegarde ${ }^{99}$. Il permettra d'assurer une certaine solidarité monétaire et financière dans un cadre intergouvernemental. Dernier élément, le mémorandum stipule que : « La France se réserve, au moment où l'on discutera la date d'entrée en vigueur du traité, de demander un ajournement de la mise en application, si l'effort militaire qu'elle est obligée d'accomplir pour assurer la pacification de l'Algérie continue à peser lourdement sur ses ressources ». Les concessions antérieures se voient donc remise en question par l'épée de Damoclès que constituent les troubles en Algérie.

Ce mémorandum, issu des arbitrages définis au cours du comité interministériel du 4 septembre 1956, constitue cependant une évolution considérable de la position française. La logique générale de la libéralisation des échanges est dorénavant perçue moins comme une menace que comme une opportunité, conformément à la position exprimée par Mollet. Les aménagements sont conçus comme étant temporaires, en dehors d'une harmonisation sociale qui est limitée à des législations spécifiques. La négociation communautaire peut reprendre sur de nouvelles bases, mais elle doit également tenir compte de la relance de l'Europe intergouvernementale avec le projet de zone de libreéchange (ZLE).

\section{La ZLE et la place de la Grande-Bretagne dans la coopération européenne.}

Si la négociation à Six entre dans une phase avancée à partir de l'été 1956, les autres pays d'Europe ne restent pas inactifs. La Grande-Bretagne en particulier cherche à compléter le Marché commun par un accord à l'échelle des dix-sept pays de l'OECE, le projet de zone de libre-échange (ZLE). Elle est motivée à la fois par des raisons économiques (prolonger l'expérience réussie de l'OECE en l'étendant au-delà des seuls contingents) et politiques (éviter un isolement britannique en cas de succès du Marché commun).

Par ailleurs, pour certains responsables britanniques, la ZLE semble être un outil pour briser le Marché commun. À la fin de 1955 déjà, le gouvernement britannique avait entamé une campagne à l'OECE hostile aux travaux des

99. AN, F60, 3099, mémorandum français relatif à l'institution d'un Comité monétaire, 15 octobre 1956, doc Mar. Com. 79 ; AN, F60, 3100, mémorandum français du 21 novembre 1956 sur le Comité monétaire. 
$\operatorname{Six}^{100}$. Harold Macmillan avait joué un rôle fondamental dans cette offensive, en sollicitant directement les Américains ${ }^{101}$. Le soutien de Dulles, secrétaire d'État américain, aux Six condamne finalement cette offensive britannique. Macmillan reprend alors le combat un peu plus tard avec le projet de ZLE, connu sous le nom de «Plan $G$ » dans l'administration britannique, pour briser le Marché commun et assurer le leadership de la Grande-Bretagne en Europe ${ }^{102}$. $\mathrm{Au}$ contraire, de nombreux décideurs britanniques soutiennent la ZLE pour des raisons plus positives, analogues à celles des Européens " modernisateurs " français : stimuler l'économie britannique par la libération des échanges ${ }^{103}$.

Le projet de ZLE est défini lors d'une réunion interministérielle du 31 mai 1956, en réaction à l'accélération des négociations à Six permise par le rapport Spaak ${ }^{104}$. C'est donc le succès du Marché commun, encore en négociation, qui est à l'origine de cette proposition britannique car Londres ne croyait plus à l'utilité de l'OECE jusqu'à ce qu'elle l'utilise pour contrer le Marché commun ${ }^{105}$. C'est finalement René Sergent, le secrétaire général de l'OECE, qui, sous l'impulsion des Britanniques ${ }^{106}$, présente le projet de ZLE lors la réunion des 17, 18 et 19 juillet 1956 de l'OECE. Mais le projet de ZLE ne fait pas l'unanimité à Londres. Il n'est discuté au sein du cabinet britannique qu'à partir de septembre $1956^{107}$, du fait de l'hostilité d'un certain nombre d'administrations comme le Commonwealth Office ${ }^{108}$.

Par ailleurs, d'un autre côté, le cabinet britannique étudie en parallèle les projets de coopération bilatérale étroite entre la France et la Grande-Bretagne. Lors de sa rencontre avec Eden le 27 septembre 1956, Mollet souligne en effet qu'il veut renforcer considérablement la coopération bilatérale francobritannique $^{109}$. Il aurait également affirmé dans ses entretiens, qui ne nous

100. DDF, 1956-I, doc. $n^{\circ} 62$, note du service de coopération économique, janvier 1956 ; Michel Dumoulin confirme cela grâce à des documents d'archives belges : Michel Dumoulin, Spaak, op. cit., p. 511-12.

101. Wolfram Kaiser, Using Europe, abusing the Europeans. Britain and European Integration, 1945-1963, Macmillan Press, Basingstoke, 1996, p. 48-49.

102. Wolfram Kaiser, Using Europe..., op. cit., p. 53 et p. 61.

103. Wolfram Kaiser, Using Europe..., op. cit., p. 73.

104. Alan Milward, The Rise and Fall of a National Strategy, 1945-1963, Whitehall History Publishing, Londres, 2002, p. 246.

105. Alan Milward, The Rise and Fall..., op. cit., p. 247-8.

106. Wolfram Kaiser, Using Europe..., op. cit., p. 77.

107. Alan Milward, The Rise and Fall..., op. cit., p. 246. Wolfram Kaiser, Using Europe..., op. cit. p. 75 .

108. PRO, CAB 130/120, réunion du cabinet « Future commercial policy », 3 septembre 1956, note du 4 octobre 1956.

109. PRO, PREM 11/1352, « Meeting at the Hotel Matignon, September 27. 1956 ». 
sont connus que par les archives britanniques : « The United Kingdom and France must draw closer together; he for his part would have liked to join the Commonwealth on the terms proposed in Sir Winston Churchill's 1940 offer ». Cette référence au projet d'union franco-britannique de 1940 a provoqué une certaine émotion à Londres. Eden a demandé à son administration d'étudier sérieusement l'hypothèse de l'entrée de la France dans le Commonwealth ${ }^{110}$. Les conclusions de ces études ont finalement été négatives. Un fonctionnaire a même souligné, en reprenant les minutes de la rencontre, que Mollet n'avait pas manifesté explicitement une telle intention ${ }^{111}$, ce qui semble être le cas. Ces projets sont définitivement rejetés par Londres au début d'octobre $1956^{112}$. La réaction d'Eden montre en tout cas combien la Grande-Bretagne surestime l'importance du Commonwealth et son pouvoir d'attraction.

Du côté français, ces offres de Mollet montrent que le Marché commun n'est pas considéré comme un cadre de coopération européenne unique et suffisant pour lui. La négociation à six reste en effet difficile, en particulier jusqu'au « tournant » de Suez.

\section{Le « tournant » de Suez.}

La rencontre entre Adenauer et Mollet à Paris le 6 novembre 1956 alors que l'opération de Suez bat son plein fait souvent figure de tournant dans les négociations européennes. De fait, malgré les concessions françaises de septembre 1956, les négociations à six piétinent lors de la conférence des ministres des Affaires étrangères des 20 et 21 octobre $1956^{113}$. Le délégué allemand Alfred Müller-Armack affiche une position très restrictive envers les demandes françaises, ce qui bloque la négociation. Müller-Armack est un proche d'Erhard, assez sceptique envers le Marché commun, alors que le ministre des Affaires étrangères, Von Brentano, se montre plus modéré. Il est lié au réseau chrétien-démocrate favorable à l'Europe communautaire comme Hallstein ${ }^{114}$. Cette intransigeance du ministre allemand de l'Économie s'expliquerait par le

110. PRO, CAB 130/120, réunion du cabinet « Franco british Union », $1^{\text {er }}$ octobre 1956, compte rendu du 2 octobre 1956.

111. PRO, PREM 11/1352, réunion de fonctionnaires, "Political Association with Europe », 4 octobre 1956.

112. Alan Milward, The Rise and Fall..., op. cit., p. 259.

113. AN, F60, 3091, projet de procès-verbal de la conférence des ministres des Affaires étrangères des 20-21 octobre 1956, doc MAE 460f/56 du 13 novembre 1956 ; note de Jean François-Poncet du 25 octobre 1956.

114. Wolfram Kaiser, Christian Democray..., op. cit., p. 284 ; Alfred Müller-Armack, Auf dem Weg nach Europa. Erinnerungen und Ausblicke, Poeschel, Stuttgart, 1971, p. 111. 
lancement récent du projet de ZLE, plus séduisant pour lui ${ }^{115}$. Après le règlement du dossier sarrois par l'accord du 27 octobre 1956, c'est justement pour lever ces contentieux communautaires qu'Adenauer se rend à Paris le 6 novembre $1956^{116}$.

Les discussions de Paris entre Adenauer et Mollet ont été très fructueuses. Elles ont été encouragées par l'échec de l'opération de Suez, qui intervient au moment même où le chancelier allemand est à Paris, le 6 novembre 1956. En effet les opérations militaires terrestres franco-britanniques commencent le 5 novembre 1956 et l'ultimatum de Khrouchtchev intervient dans la nuit du 5 au 6. Les Britanniques annoncent dès le 6 novembre 1956 à 13 heures, sous la pression américaine, qu'ils stoppent l'opération ${ }^{117}$. Le contraste est rude avec le dossier du Marché commun, ou l'entente franco-allemande est retrouvée, grâce à un compromis trouvé par un petit groupe de hauts fonctionnaires dirigés par le Français Marjolin et l'Allemand Carstens ${ }^{118}$.

Sur l'harmonisation sociale tout d'abord, la France obtient ce qu'elle réclamait avec l'acceptation par la RFA des trois harmonisations spécifiques. Lise Rye souligne la bonne volonté allemande car Bonn estimait que la France ne souffrait pas d'un handicap spécifique dû à sa législation sociale ${ }^{119}$. Du côté allemand comme du côté français, ce problème était donc avant tout perçu comme politique.

Ensuite, la France obtient le maintien de son système de taxes à l'importation et d'aides à l'exportation. Mais, en contrepartie, elle doit soumettre ce régime à l'examen du Conseil des ministres des Six qui pourra en demander la modification à la majorité qualifiée. Ce régime devra disparaître dès que l'équilibre de la balance des paiements française sera rétabli. La France obtient donc la reconnaissance de ses difficultés financières et commerciales, mais uniquement en raison de leur caractère conjoncturel et, de plus, leur surveillance s'inscrit dans un cadre communautaire.

115. Gérard Bossuat, L'Europe des Français..., op. cit., p. 329 ; Georges-Henri Soutou, L'Alliance incertaine. Les rapports politico-stratégiques franco-allemands, 1954-1996, Paris, Fayard, 1996, p. 62-63 ; Hanns Jürgen Küsters, Fondements..., op. cit., p. 199-204.

116. DDF, 1956-III, doc $\mathrm{n}^{\circ} 75$, télégramme de Christian Pineau à Maurice Couve de Murville, 31 octobre 1956.

117. Georges-Henri Soutou, La guerre de Cinquante Ans. Les relations Est-Ouest, 1943-1990, Paris, Fayard, 2001, p. 340.

118. Hanns Jürgen Küsters, Fondements..., op. cit., p. 213.

119. Sources : archives allemandes in Lise Rye, The Rise and Fall..., op. cit., p. 60. 
Le 6 novembre 1956, la France accepte donc officiellement le principe de base du Marché commun industriel : le rôle stimulateur de la libération des échanges. Les deux concessions obtenues sur l'harmonisation sociale et le régime spécial sont des mesures respectivement spécifiques et provisoires. Elles correspondent globalement à la position définie par Mollet en septembre 1956, en dehors de la clause léonine du report de l'application du Marché commun en raison des événements d'Algérie. Le compromis est proche de celui défini dans le rapport Spaak d'avril 1956 : une harmonisation sociale limitée aux distorsions spécifiques de la concurrence, donc excluant les harmonisations générales, et la reconnaissance du régime spécial de la France mais sous une surveillance communautaire.

Cependant, l'idée de « rupture » de Suez doit être nuancée. Sur le plan français, la rupture date plutôt de septembre $1956^{120}$. La rencontre du 6 novembre 1956 n'apporte pas de novation fondamentale à la position du gouvernement français. La rupture concerne plutôt l'opinion publique française - pour qui Suez renforce la nécessité de la construction européenne, ainsi que l'engagement du gouvernement allemand et donc les négociations à Six. Un texte résultant du compromis franco-allemand (harmonisation sociale, passage à la deuxième étape, régime spécial pour la France) est rapidement diffusé aux six en novembre $1956^{121}$, et permet d'obtenir un accord sur le Marché commun industriel, en dehors du dossier épineux de la fixation du tarif extérieur commun. Entre novembre 1956 et mars 1957, les négociations portent donc sur ce dernier point ainsi que sur trois autres sujets sensibles, les institutions et les régimes spéciaux à accorder à l'agriculture et aux territoires d'outre-mer ${ }^{122}$. Une fois ce cadre établi pour le Marché commun industriel, le patronat cherche alors à influencer les négociations finales.

\section{LE PATRONAT DIVISÉ FACE AU MARCHÉ COMMUN : LE RÔLE DE GEORGES VILLIERS}

Dans la définition de la position française sur le Marché commun industriel, le rôle du patronat apparaît déterminant. Les principaux arguments avancés à l'encontre du Marché commun portent en effet sur le manque de compétitivité

120. Gérard Bossuat, L'Europe des Français..., op. cit., p. 296 ; Alan Milward, The Rise and Fall..., op. cit., p. 261 ; Andrew Moravcsik, The Choice for Europe..., op. cit., p. 119-120.

121. AN, F60, 3093, projet de procès-verbal de la réunion des chefs de délégation du 16 novembre 1956, doc Ch. del. 60 du 21 novembre 1956.

122. DDF, 1957-I, doc $\mathrm{n}^{\circ} 102$, télégramme de Raymond Bousquet aux représentants diplomatiques chez les Cinq, 2 février 1957. 
des industries françaises, d'où l'intérêt de connaître leur point de vue pour disposer d'arguments solides dans la négociation. De plus, le patronat joue un rôle actif, cherchant à promouvoir ses intérêts dans la négociation, mais il est très divisé, en dépit de la position volontariste du CNPF.

\section{Le soutien du CNPF au Marché commun.}

Le CNPF, principale organisation représentative du patronat français, s'impose dans ce débat en adoptant très rapidement une position relativement favorable au Marché commun ${ }^{123}$. Son président, Georges Villiers, écrit au président du Conseil Guy Mollet pour lui livrer ses premières impressions sur le rapport Spaak ${ }^{124}$. Cette lettre prudente insiste sur les garanties nécessaires à obtenir (parallélisme entre harmonisation et libération des échanges, association des pays et territoires d'outre-mer) mais ne se montre pas hostile par principe au Marché commun, à la différence de nombreux documents internes à l'administration ou à la FIMTM. La position du CNPF est en fait définie par deux notes des 9 et 10 août 1956 publiées dans la revue du $\mathrm{CNPF}^{125}$. Ces notes, ainsi que les documents publiés par le CNPF jusqu'en mars $1957^{126}$, mais aussi les archives internes du $\mathrm{CNPF}^{127}$, définissent une position exigeante mais pas hostile au Marché commun. Trois éléments saillants en ressortent.

Tout d'abord et de manière classique en France, le CNPF insiste sur l'équilibre entre le processus de libération des échanges et celui d'harmonisation des conditions de concurrence. Ensuite, le CNPF entend défendre le rôle des accords entre les entreprises (ententes) dans le processus d'intégration économique européenne. Les ententes sont particulièrement utiles pour préparer et

123. Les sources utilisées sont les archives du CNPF, la publication officielle du CNPF (Bulletin $d u$ CNPF) et plusieurs études : Janos Szokoloczy-Syllaba, Les organisations professionnelles françaises et le Marché commun, Paris, Colin, 1965; Philippe Mioche, « Le patronat français et les projets d'intégration économique européenne dans les années cinquante », in Gilbert Trausch (éd.), Die Europaïsche Integration..., op. cit., p. 241-257 ; Béatrice Touchelay, « Le CNPF et l'internationalisation des entreprises françaises entre 1946 et le début des années 1960 » in $4^{\mathrm{e}}$ congrès de l'AEHE, Bordeaux, 15-16 septembre 2000.

124. ARAM, 52 J 114, lettre de Georges Villiers à Guy Mollet, 7 mai 1956.

125. Georges Villiers, «Euratom et Marché commun » in Bulletin du CNPF, $\mathrm{n}^{\circ} 150$, août 1956 ; «Le projet de marché commun européen » in Bulletin du CNPF, $\mathrm{n}^{\circ} 153$, novembre 1956 ; textes cité in Éric Bussière et Michel Dumoulin (textes réunis par), Les cercles économiques et l'Europe, Louvain-Paris, 1992, p. 205-216.

126. Déclarations de Georges Villiers lors des assemblées générales du 10 juillet 1956 et du 15 janvier 1957, respectivement dans les numéros n 150, d'août 1956, et n 157 de février 1957, et ACNPF, 72 AS 846.

127. ACNPF, 72 AS 1505, document de travail de la commission des affaires européennes du 11 juin 1956. 
accompagner l'ouverture des marchés. Il ne s'agit plus, comme dans les années 1920 et 1930, de demander une cartellisation généralisée, mais de favoriser la coopération entre les entreprises d'une part pour adapter les industries françaises à la concurrence internationale (c'est l'aspect défensif) et d'autre part pour favoriser une véritable intégration des marchés (dimension offensive). L'accès à un marché étranger est en effet relativement difficile sans partenaire local. L'organisation des marchés ne s'oppose pas à la libération des échanges mais doit au contraire en maximiser les effets positifs selon le CNPF.

La troisième idée est de contrôler les interventions excessives et prédatrices des États nationaux par l'intégration européenne. Le CNPF refuse absolument les évolutions dirigistes de la construction européenne, comme un contrôle étatique trop étroit des ententes, ou un fonds d'investissement public. Dans un discours de janvier 1957, il demande une « coordination intérieure des politiques économiques et sociales [...] efficace de façon que le gouvernement ne s'engage pas isolément dans des mesures économiques ou sociales nouvelles ${ }^{128} \ldots$ »" L'intégration économique communautaire doit donc permettre d'encadrer le gouvernement français, en le contraignant à cesser de prendre des mesures isolées qui mettent en danger la compétitivité de son économie.

L'influence personnelle du président du CNPF, Georges Villiers, paraît déterminante dans cette prise de position ${ }^{129}$. Patron lyonnais d'une entreprise métallurgique de taille moyenne, il devint maire de Lyon à partir de 1941. Révoqué en 1943, il est arrêté puis condamné à mort, avant d'être finalement envoyé à Dachau ${ }^{130}$. Il échappe donc au discrédit qui touche une grande partie des milieux économiques à la Libération et devient, à ce titre, le premier président du CNPF en 1946. Il promeut à la tête du CNPF une doctrine européenne en créant dès 1948, une commission des affaires allemandes confiée à l'ancien ambassadeur André François-Poncet ${ }^{131}$. C'est également lui qui est à l'origine de la formation, en 1949, du CIFE, le Conseil des fédérations industrielles européennes, créé après une réunion à Paris des organisations patronales des

128. Exposé général de Georges Villiers, président du CNPF, AG du CNPF du 17 janvier 1957 in Bulletin du CNPF, février 1957, $\mathrm{n}^{\circ} 157$ et ACNPF, 72 AS 846.

129. Sur Georges Villiers (1899-1982), voir sa notice, in : Jean-Claude Daumas (dir.), Dictionnaire historique et critique des patrons et du patronat français de 1880 à nos jours, Flammarion, Paris, à paraître en 2011.

130. Georges Villiers, Témoignages, France-Empire, Paris, 1978, p. 81 et 85.

131. Matthias Kipping, Neil Rollings, « Networks of Peak Industrial Federations. The Council of Directors of European Industrial Federations and the Council of European Industrial Federations », in Michel Dumoulin (éd.), Réseaux économiques et construction européenne, Peter Lang, Bruxelles, 2004, p. 283. 
pays membres de l'OECE ${ }^{132}$. Sur le plan économique, Georges Villiers cherche à revaloriser les règles du marché face au dirigisme triomphant en soutenant diverses associations libérales et néolibérales ${ }^{133}$. Son engagement européen est donc logique car il s'inscrit dans des convictions antitotalitaires et libérales, deux caractéristiques majeures de l'intégration européenne depuis ses débuts en 1948. Son activisme proeuropéen est particulièrement remarqué au CNPF car il est loin d'être majoritaire ${ }^{134}$.

Georges Villiers mobilise le CNPF juste après l'adoption du rapport Spaak comme base de négociation par les Six, les 29 et 30 mai 1956 à Venise. Il crée une commission des affaires européennes avec à sa tête Jean Louis et Robert Lemaignen ${ }^{135}$. Ce dernier est un membre du patronat colonial engagé depuis longtemps dans la promotion de l'idée européenne ${ }^{136}$. Cette rupture chronologique est tout à fait logique car elle correspond à la prise de conscience du caractère irréversible de la décision politique ${ }^{137}$. C'est bien l'acceptation du rapport Spaak comme base des négociations intergouvernementales qui marque l'engagement des six pays fondateurs, plus encore que la conférence de Messine. La création de cette commission répond aussi à une logique interne au CNPF, le décès de Pierre Ricard permettant à Georges Villiers de s'imposer définitivement dans les questions européennes ${ }^{138}$.

Le rôle d'entraînement de ce petit groupe est réel car les premières réunions de la commission des affaires européennes montrent que le patronat n'était pas acquis au principe du Marché commun à la mi-1956 ${ }^{139}$. Cette méfiance dure pendant de longs mois. Le comité directeur du CNPF du 7 janvier 1957 ainsi, est divisé entre partisans et adversaires du Marché commun ${ }^{140}$. Villiers

132. Jean-François Eck, Les entreprises françaises face à l'Allemagne de 1945 à la fin des années 1960, Comité pour l'histoire économique et financière de la France, Paris, 2003, p. 335-336.

133. François Denord, Néolibéralisme version française. Histoire d'une idéologie politique, Démopolis, Paris, 2007, p. 200-201 et p. 233.

134. AO, entretien de l'auteur avec Robert Pelletier, à cette époque chef du service des affaires financières du CNPF (de 1957 à 1966) le 4 avril 2005; entretien de l'auteur avec François Ceyrac le 10 mai 2004, François Ceyrac est, à cette époque, secrétaire général de la commission sociale du CNPF. Il fut le président du CNPF de 1972 à 1981.

135. ACNPF, 72 AS 1509, lettre de Georges Villiers du 31 mai 1956, lettre de Bertrand Hommey du 4 juin 1956.

136. Catherine Hodeir, Stratégies d'Empire. Le grand patronat colonial face à la décolonisation, Belin, Paris, 2003, p. 272 et p. 284.

137. Janos Szokoloczy-Syllaba, Les organisations professionnelles françaises... op. cit., p. 294-95.

138. Yohann Morival, L'intégration européenne du Conseil national du patronat français (19491966), mémoire de master 1, dir. Michel Offerlé, EHESS-ENS, 2009, p. 21-26.

139. ACNPF, 72 AS 1505, réunion de la commission des affaires européennes du 6 juin 1956.

140. Philippe Mioche, « Le patronat français... », op. cit., p. 254-255. 
est notamment soutenu par un proche, Henri Lafond, et des membres du grand patronat colonial, comme Edmond Giscard d'Estaing et Paul Bernard. Lors de l'assemblée générale de janvier 1957, Georges Villiers est obligé de recourir à la dramatisation de la situation pour convaincre son auditoire, dont certaines interventions montrent qu'il n'est pas entièrement acquis à la cause du Marché commun $^{141}$.

Cette conversion rapide de l'organe officiel du patronat au Marché commun est relevée par l'administration. Le Quai d'Orsay, lorsqu'il analyse les positions du CNPF exprimées dans une note d'août 1956 souligne qu'elles correspondent globalement à celle de l'administration, sauf sur le plan du fonds d'investissement, dont le dirigisme suscite l'hostilité du patronat. Surtout, la note remarque : «Il convient enfin de noter que le document établi par le CNPF ne mentionne pas la question des clauses de sauvegarde et des mesures de compensation ». Or ces points sont capitaux pour les négociateurs français du Quai d'Orsay, dans la mesure où ils permettent à la France de se soustraire de facto à des engagements juridiques et de briser toute la dynamique de la libération des échanges par un système permanent de taxes à l'importation et d'aides à l'exportation. Mais pour le CNPF, elles manifestent surtout l'impossibilité pour le gouvernement français d'abandonner les excès de son dirigisme en acceptant un cadre européen contraignant. Le CNPF ne se place donc pas dans la perspective d'un refus de la libération des échanges mais dans celle d'une régulation du libéralisme. Le CNPF insiste sur la nécessité d'une harmonisation parallèle à la libération des échanges ${ }^{142}$. Or cette exigence est en retrait par rapport à certains hauts fonctionnaires qui réclament toujours une harmonisation préalable à la libération ${ }^{143}$. Dès lors, le CNPF développe une position plus favorable au Marché commun qu'une grande partie des milieux économiques, mais aussi de l'administration.

Cette position explique la modération du CNPF lors des négociations du traité de Rome. L'organisation patronale insiste sur des demandes assez classiques, comme l'association de représentants patronaux au processus de décision communautaire ${ }^{144}$, la surveillance d'éventuelles pratiques

141. ACNPF, 72 AS 846, exposé général de Georges Villiers, assemblée générale du 15 janvier 1957.

142. Rapport de Georges Villiers en tant que président de la commission des relations économiques internationales, assemblée générale du CNPF du 10 juillet 1956 in Bulletin du CNPF, août 1956, n 150 et ACNPF, 72 AS 846. ARAM, 52 J 114, lettre de Georges Villiers à Guy Mollet du 7 mai 1956.

143. Par exemple : AINDUS, 1977.1386, article 52, projet de lettre du ministre de l'Industrie au ministre de l'Intérieur, 24 août 1956.

144. Lettre de Villiers à Maurice Faure du 5 mars 1957 reproduite in Bulletin du CNPF, avril 1957, $\mathrm{n}^{\circ} 159$. 
discriminatoires des partenaires de la France ${ }^{145}$, ou la nécessité d'avoir un tarif extérieur commun assez élevé ${ }^{146}$. L'influence patronale passe également par un canal sectoriel, comme l'illustre l'exemple de l'automobile.

\section{Le lobbying d'experts de l'automobile dans la négociation finale.}

L'industrie automobile française est particulièrement dynamique à cette époque. Elle bénéficie à la fois d'une forte expansion tant de la production que de ses exportations (elles doublent entre 1951 et 1957), et de structures fortement concentrées ( 4 constructeurs assurent $97 \%$ de la production) ${ }^{147}$. Dans ce secteur marqué par le mode de production fordiste, les investissements sont très lourds et nécessitent de longues séries pour pouvoir être rentables, d'où l'importance de disposer d'un marché large.

Les deux organisations représentant les constructeurs automobiles français publient rapidement des documents de synthèse sur le projet de Marché commun $^{148}$. Ils insistent sur le problème des investissements directs étrangers dans le Marché commun, et notamment de ceux provenant des firmes américaines ${ }^{149}$. Ces dernières étant beaucoup plus grandes, elles profitent de coûts de production plus faibles, en raison du caractère fortement standardisé de la production automobile. Si elles investissent massivement en Europe continentale, elles pourront produire à des prix très bas. Dès lors, le Groupement syndical des constructeurs français d'automobile demande la création d'une commission de contrôle des investissements étrangers, à caractère paritaire (comprenant des représentants des États et des industriels), avec droit de veto possible ${ }^{150}$. La Chambre syndicale des constructeurs d'automobiles formule des revendications

145. ACNPF, 72 AS 1590, note de Hommey, 27 mars 1957 ; ASCGI, 1991.004, volume 2, lettre de Maurice Faure à Georges Villiers du 4 juin 1957.

146. AMAE, DECE 661, lettre de Georges Villiers à Maurice Faure, 25 janvier 1957.

147. Janos Szokoloczy-Syllaba, Les organisations professionnelles françaises..., op. cit., p. 209211.

148. AN, F60, 3114, mémorandum sur le problème de l'implantation des firmes étrangères, décembre 1956 ; AMAE, DECE 628, folio 33, lettre de François Valéry accusant réception pour la DAEF le 21 décembre 1956 ; AN, F60, 3114, lettre de Pierre Lemaigre au SGCI, 15 janvier 1957.

149. Pour plus de détails sur l'action des constructeurs automobiles français mais aussi italiens, voir : Sigfrido Ramirez, Public Policies, European Integration and Multinational Corporations in the Automobile Sector. The French and Italian Cases in a comparative perspective 1945-1973, thèse, Institut universitaire européen, 2007, p. 485-525.

150. AN, F60,3114, mémorandum sur le problème de l'implantation des firmes étrangères, décembre 1956 ; AMAE, DECE 628, folio 33, lettre de François Valéry accusant réception pour la DAEF le 21 décembre 1956. 
équivalentes, mais sous une forme plus modérée ${ }^{151}$. Elle regroupe d'ailleurs des constructeurs plus tournés vers l'exportation comme Renault et Simca ${ }^{152}$. Elle les intègre en effet dans une note d'ensemble sur le Marché commun qui souligne les bénéfices attendus de cet accord de libéralisation des échanges.

Une deuxième forme d'intervention plus directe apparaît progressivement, avec des interventions directes de Renault. Les archives laissent en effet apparaître des traces directes de contacts entre la régie automobile et les négociateurs français ${ }^{153}$. Renault est dirigée à l'époque par Pierre Dreyfus, proche de Robert Marjolin depuis les années $1930^{154}$. La correspondance avec l'administration s'effectue par l'intermédiaire du directeur des relations extérieures de Renault, Maurice Bosquet, lui-même ancien fonctionnaire de l'OECE au moment où Marjolin en était le secrétaire général ${ }^{155}$. Renault entreprend une action auprès de Robert Marjolin et de Jean-François Deniau (SGCI) en leur transmettant des documents émanant de l'OECE démontrant que tous les pays ont des procédures de contrôle des investissements directs étrangers ${ }^{156}$. L'idée serait de mettre en place un système communautaire de surveillance. Par ailleurs, Renault demande à être consulté lorsque le problème du tarif extérieur commun des pièces détachées sera négocié. En effet, s'il est beaucoup plus bas que le tarif des voitures complètes, ce sera une incitation pour une entreprise extracommunautaire à installer une usine de montage très compétitive au sein de la CEE. De plus, le 18 mars 1957, soit une semaine avant la signature du traité de Rome, la régie nationale distribue à ses cadres une fiche explicative sur l'automobile et le Marché commun ${ }^{157}$. L'attitude favorable de Renault à une libération des échanges

151. AN, F60, 3114, lettre de Pierre Lemaigre, président de la Chambre syndicale des constructeurs d'automobile à Jacques Donnedieu de Vabres, SGCI, 15 janvier 1957.

152. Janos Szokoloczy-Syllaba, Les organisations professionnelles..., op. cit.

153. AN, F60, 3114, Telex Alby (SGCI) à Donnedieu de Vabres (SGCI), 21 janvier 1957 ; ASGCI 1991.004, art 1, lettre de M. Bosquet (Renault) à Donnedieu de Vabres du 26 janvier 1957. Pour plus de détails sur les interventions de Renault, voir : Sigfrido Ramirez, Public Policies..., op. cit. p. 485486, 501-504, 508-518.

154. Robert Marjolin, Le travail d'une vie. Mémoires, 1911-1986, Robert Laffont, Paris, 1986, p. 33 ; Stéphane Clouet, De la rénovation à l'utopie socialiste. Révolution constructive, un groupe d'intellectuels socialistes des années 1930, Presses Universitaires de Nancy, Nancy, 1991.

155. Maurice Bosquet (né en 1914) est inspecteur de la Société de contrôle des coopératives de consommation (1936-1943). Il est affecté à la direction des Industries mécaniques au ministère de la Production industrielle (1943-1948) puis devient secrétaire du comité de l'équipement de l'OECE (48-54). Il est ensuite attaché à la direction générale puis directeur des relations extérieures de Renault (1954-1959).

156. ASGCI 1991.004, art 1, lettre de Renault (M. Bosquet) à Deniau du 7 février 1957.

157. ASGCI 1991.0004, article 1, note de 32 P. : «L'automobile et le Marché commun. Modalités techniques de réalisation de l'union douanière européenne »; note du 18 mars 1957 adressée aux cadres de Renault, et transmise à Jean-François Deniau par Maurice Bosquet. 
dans le cadre communautaire des Six s'était déjà exprimée avec la CECA, qui il est vrai ne concernait pas directement le secteur de l'automobile, car le PDG de l'époque, Pierre Lefaucheux, voulait obtenir une baisse du prix de l'acier ${ }^{158}$. L'intégration économique à Six est donc perçue depuis ses débuts comme un levier de modernisation des structures industrielles. C'est moins la concurrence européenne qu'américaine qui est crainte. Un lobbying se met en place auprès des négociateurs français dans une démarche d'expertise. Au contraire, d'autres secteurs se montrent beaucoup plus méfiants envers le Marché commun.

\section{La force de l'opposition patronale à la libération des échanges.}

Les opposants au Marché commun restent très influents jusqu'à la signature du traité de Rome. Leur méfiance est fondée avant tout sur une opposition à la libération des échanges, comme le montrent le cas du coton et celui des industries métallurgiques et minières (FIMTM).

Peu compétitive, en difficulté depuis la première guerre mondiale, l'industrie du coton profitait d'une forte protection douanière, tout en étant très peu exportatrice en dehors des marchés protégés de l'outre-mer ${ }^{159}$. Elle nourrissait donc une très forte appréhension envers toute libération des échanges. L'influence de cette branche sur le débat européen tient à son importance économique mais surtout à sa bonne organisation. Elle est, en effet, représentée par le Syndicat général de l'industrie cotonnière française (SGICF) dont l'influence est importante car ce secteur est surtout constitué d'entreprises de taille moyenne ${ }^{160}$. Son vice-président délégué est Pierre de Calan. Inspecteur des finances, il a été le directeur de cabinet du ministre de la Production industrielle Jean Bichelonne en 1942, puis directeur du Commerce intérieur au ministère de la Production industrielle en 1943-1944. Blanchi après la Libération, il quitte néanmoins l'administration puis est recruté par le syndicat pour lui donner un style plus offensif selon son témoignage ${ }^{161}$.

Face au rapport Spaak, le SGICF demande une harmonisation forte des conditions de production au sein du Marché commun, et une politique commerciale

158. Matthias Kipping, La France et les origines de l'Union européenne. Intégration économique et compétitivité internationale, Comité pour l'histoire économique et financière de la France, Paris, 2002, p. 352.

159. Janos Szokoloczy-Syllaba, Les organisations professionnelles..., op. cit., p. 70, voir aussi p. 25-27 et 67-68.

160. AO/Comité pour l'histoire économique et financière de la France, entretiens de Pierre de Calan avec Aude Terray, retranscrits, tome II, p. 136.

161. AO/Comité pour l'histoire économique et financière de la France, entretiens de Pierre de Calan avec Aude Terray, retranscrits, tome II, p. 136. 
extérieure protectionniste envers les pays à bas salaires ${ }^{162}$. Pierre de Calan défend encore en janvier 1957 un engagement dans le Marché commun conditionnel et limité à quatre années ${ }^{163}$, alors que même l'administration a abandonné cette position. Des démarches directes auprès des administrations sont entreprises comme une rencontre avec le ministre concerné en juillet $1956^{164}$, au moment même où les parties les plus hostiles de l'administration française cherchent à s'appuyer sur les professionnels pour soutenir une position de fond hostile au rapport Spaak.

Cette position de la branche cotonnière peut trouver un écho auprès d'autres secteurs. Ainsi, la FIMTM publie dès le 7 juin 1956 un mémorandum très complet contre le rapport Spaak, destiné au CNPF ${ }^{165}$. Refusant la dynamique libérale, la FIMTM préfère organiser les structures de production par une généralisation des ententes.

L'opposition au Marché commun se nourrit donc d'une défiance envers une libération des échanges perçue comme déstabilisatrice pour des industries peu compétitives. D'un autre côté, les milieux économiques les plus libéraux ne sont pas forcément très favorables au Marché commun.

\section{Les libéraux peu enthousiastes envers le Marché commun.}

Le courant libéral du patronat français est ancien ${ }^{166}$. Il s'exprime en particulier dans certaines organisations représentatives des chambres de commerce. Dans le débat sur le Marché commun, la Chambre de commerce de Paris (CCIP) adopte une position sur le rapport Spaak assez voisine de celle du CNPF, plutôt positive sur le principe ${ }^{167}$. Surtout, elle se sert de l'argument des négociations européennes pour réclamer des réformes internes, sans défendre spécifiquement le projet issu du rapport Spaak en tant que te ${ }^{168}$. Par la suite, au cours de l'année 1958, les débats de la CCIP s'orientent dans une direction plus libérale

162. Industrie cotonnière française, septembre-octobre 1956, p. 9, cité in Janos Szokoloczy-Syllaba, Les organisations professionnelles..., op. cit., p. 40.

163. Philippe Mioche, «Le patronat français... », op. cit., p. 254-255 ; Janos Szokoloczy-Syllaba, Les organisations professionnelles..., op. cit., p. 55.

164. Janos Szokoloczy-Syllaba, Les organisations professionnelles..., op. cit., p. 56.

165. ACNPF, 72 AS 1505, «Les industries mécaniques et transformatrices de métaux et l'intégration européenne », 7 juin 1956.

166. Voir l'étude du CAED in Laurence Badel, Un milieu libéral et européen. Le grand commerce français, 1925-1948, Comité pour l'histoire économique et financière de la France, Paris, 1999.

167. Éric Bussière, «La Chambre face à l'intégration européenne de l'après-guerre à la relance des années 1980 », in Paul Lenormand (éd.), La Chambre de commerce et d'industrie de Paris, 18032003, II, Droz, Genève 2008, p. 433-438.

168. ACNFP, 72 AS 132, rapport sur les activités de 1956 de la Chambre de commerce de Paris. 
que ceux du CNPF ; le projet de ZLE en particulier est mieux vu qu'au CNPF ${ }^{169}$. Au début de 1957, l'assemblée des présidents des chambres de commerce propose qu'une rationalisation des institutions européennes soit opérée, regroupant la CECA, la CEE et l'Euratom dans une seule organisation économique d'un côté, l'UEO et l'OTAN dans une seule organisation militaire de l'autre ${ }^{170}$. L'argument principal est celui de la diminution des frais de gestion. L'idéal européiste est absent, tout comme la compréhension des spécificités du projet d'intégration économique du Marché commun.

\section{De l'influence de l'acteur patronal.}

À l'image des décideurs administratifs et politiques, les milieux économiques sont divisés à l'encontre du Marché commun. Le prisme sectoriel joue particulièrement pour définir une position économiquement rationnelle mais il n'est pas le seul. Une part d'idéalisme européiste motive également certains patrons comme le montre la position de Georges Villiers.

En terme d'influence, l'acteur patronal est forcément secondaire par rapport au pouvoir politique. Cela ne l'empêche pas d'avoir des divergences avec l'administration. Ainsi, pendant toute l'année 1956, même si une convergence globale peut être observée en apparence ${ }^{171}$, Georges Villiers est en réalité plus favorable au Marché commun que ne l'est la majorité de l'administration, surtout si on le compare à son ministère de tutelle, l'Industrie. Le président du CNPF a eu un rôle personnel majeur pour porter un message beaucoup plus européen et communautaire que le patronat n'en avait l'habitude, notamment en interne. Il a utilisé des arguments économiques mais aussi politiques, montrant ainsi que le patronat, même s'il s'en défend, n'hésite pas à prendre des engagements qui dépassent parfois sa stricte logique fonctionnelle.

Se pose alors le problème de l'influence patronale sur les réflexions administratives. Les traces directes sont évidemment très difficiles à trouver. Une mobilisation forte s'observe à la fin de la négociation autour de dossiers précis. Le travail d'influence du secteur automobile sur le problème des investissements américains a eu un certain écho dans la mesure où Pierre Mendès France évoque longuement ce problème dans son célèbre discours du 18 janvier $1957^{172}$. De

169. Éric Bussière, « La Chambre... », op. cit., p. 439-443.

170. ACNFP, 72 AS 132, «Voeu émis par la chambre de commerce de Tulle et Ussel et adopté par l'assemblée des présidents des chambres de commerce de l'Union française dans sa séance du 19 février $1957 »$.

171. Marine Moguen, L'ouverture des frontières européennes dans les années cinquante. Fruit d'une concertation avec les industriels?, Peter Lang, Bruxelles, 2002, p. 208.

172. Voir ci-après. 
même, le problème des taxes compensatoires a été soulevé par le CNPF semblet-il avec un certain succès car il s'incarne dans l'article 97 du traité de Rome.

D'une manière générale, les hauts fonctionnaires ne peuvent ignorer l'opinion patronale lorsqu'ils définissent l'intérêt de la France en matière industrielle. Le fait de voir le CNPF et des secteurs importants comme l'automobile accepter la logique libre-échangiste du Marché commun a pu aider à faire approuver ce projet. Il a pu inciter les négociateurs français à se concentrer non plus sur des clauses léonines qui remettent en cause l'intérêt de l'ouverture des marchés, mais sur des clauses assurant une harmonisation des conditions de concurrence en interne, et une protection contre les concurrents extérieurs. Par contre, l'action du CNPF reste essentiellement nationale, d'autant que l'organisation patronale européenne établie à l'échelle des Six, l'UNICE, vient juste d'être remise en fonction ${ }^{173}$. Sur un plan français, malgré cette conversion à l'Europe communautaire d'une partie du patronat, et le fort soutien du sommet de l'exécutif français, le Marché commun reste toujours menacé.

\section{UN MARCHÉ COMMUN TOUJOURS MENACÉ (NOVEMBRE 1956-MARS 1957)}

Si les négociations du Marché commun semblent se débloquer après Suez, son succès paraît toujours hypothétique. À l'extérieur, le projet de ZLE se développe tandis qu'au sein des décideurs français, les réticences restent fortes.

\section{A. LA ZLE : COMPLÉMENT OU ALTERNATIVE ?}

La crise de Suez assure une relance parallèle des négociations du Marché commun et du projet de ZLE. Cette dernière s'impose rapidement comme un projet incontournable, complément naturel de l'accord à Six chez la majorité des décideurs français. Une minorité commence toutefois à s'inquiéter de ce projet par attachement au Marché commun.

\section{La ZLE relancée par Suez.}

À Londres, les événements dramatiques de Suez conduisent également à une relance de la construction européenne. Harold Macmillan, le chancelier de

173. Laurent Warlouzet, Quelle Europe économique pour la France?..., op. cit., p. 152-3 ; Yohann Morival, L'intégration européenne..., op. cit., p. 52-60. 
l'Échiquier, parvient à imposer la ZLE à un cabinet auparavant très réticent ${ }^{174}$. Quels que soient ses objectifs - briser ou compléter le Marché commun, la ZLE constitue une rupture certaine dans la politique britannique. Elle manifeste la réorientation commerciale et industrielle de la Grande-Bretagne du Commonwealth vers l'Europe continentale, selon un mouvement déjà entamé par la France. Le mouvement était cependant plus facile pour les Français tant pour des raisons politiques (le traumatisme de 1940 sanctionne le déclin de la France) qu'économique (marché préférentiel colonial plus étroit).

Les deux conséquences de Suez, l'échec de l'opération militaire et la relance de la négociation du Marché commun, poussent la Grande-Bretagne à s'engager pleinement dans la promotion de son projet de ZLE car, auparavant, Londres comptait toujours sur la possibilité d'une rupture des négociations par Paris ${ }^{175}$. Ainsi c'est bien le succès du Marché commun qui relance les projets d'intégration économique de l'Europe. La ZLE ne peut se comprendre sans le Marché commun, car elle constitue une réponse du principal perdant de cet accord, la Grande-Bretagne, qui se sent isolée économiquement et politiquement.

Concrètement, cette relance se manifeste par une lettre de Macmillan à son homologue français, Ramadier, demandant l'ouverture de discussions sur la ZLE avant la conclusion du traité de Marché commun, pour être sûr que ce dernier soit compatible ${ }^{176}$. Cette lettre suscite un débat au sein de l'administration française sur la réponse à y apporter. Robert Marjolin estime qu'il faut se contenter d'une réponse dilatoire ${ }^{177}$. Au contraire Bernard Clappier, le directeur de la DREE, propose d'engager des conversations approfondies pour faciliter ce qu'il perçoit comme une possibilité « d'inclure les Anglais dans le Marché commun ${ }^{178} \gg$. Clappier estime donc que le projet de ZLE ne menace pas le Marché commun. Au contraire, Marjolin paraît s'inquiéter de la perspective de la conclusion prochaine d'une ZLE et estime vraisemblablement qu'il faut donner la priorité à la négociation sur le Marché commun. Finalement, aucune suite n'est donnée à cette proposition britannique qui s'inscrit d'ailleurs dans une offensive plus générale, le ministre des Affaires étrangères italien Gaetano Martino recevant également le même courrier ${ }^{179}$.

174. Wolfram Kaiser, Using Europe..., op. cit., p. 78 et p. 83. ; Alan Milward, The Rise and Fall..., op. cit., p. 262.

175. Alan Milward, The Rise and Fall..., op. cit., p. 246.

176. AMAE, PA-AP 314, lettre de Macmillan à Ramadier, 30 novembre 1956.

177. ARAM, 52 J 115, projet de réponse de Robert Marjolin, pas de date.

178. ARAM, $52 \mathrm{~J} 115$, note manuscrite de Bernard Clappier, pas de date.

179. Francesca Fauri, «Italy and the Free Trade Area Negotiations, 1956-1958 », in Revue d'histoire de l'intégration européenne, 1998-2, p. 49. 
Sur le fond, la Grande-Bretagne définit une position fondée sur l'exclusion du champ de la ZLE de l'agriculture et des relations commerciales avec le Commonwealth. C'est la seule solution possible que les promoteurs de la ZLE ont trouvée pour convaincre un cabinet et une administration longtemps réticents ${ }^{180}$. La Grande-Bretagne développe ainsi un projet de coopération européenne qui satisfait ses seuls intérêts, alors que le rapport Spaak était issu d'une confrontation des positions des Six. La ZLE reste toutefois très vague, tant sur le plan économique qu'institutionnel.

Lors du conseil OECE des 12 et 13 février 1957, il est décidé de créer des groupes d'experts issus des différents gouvernements pour étudier le projet de ZLE, qui entre ainsi dans une nouvelle phase ${ }^{181}$. La Grande-Bretagne profite de son statut de partenaire incontournable en Europe pour imposer son projet. Elle s'appuie sur l'anglophilie de nombreux responsables européens, notamment les Français Mollet et Pineau, mais aussi de la déception qu'a pu représenter le Marché commun chez certains responsables des Six comme le ministre de l'Économie allemand Ludwig Erhard. Ce dernier a d'ailleurs critiqué publiquement un futur traité de Marché commun trop peu libéral à son goût au début de $1957^{182}$.

Par rapport à la négociation du Marché commun, trois différences sont visibles dans le cas de la ZLE. Tout d'abord, la méthode de négociation n'est pas définie, alors que la résolution de Messine avait suscité la création du comité Spaak. Ensuite, aucune base commune n'existe, à la différence du rapport Spaak. Enfin, la ZLE n'est pas, selon les termes du communiqué de l'OECE de février 1957, une négociation entre des pays considérés de manière individuelle, mais entre six pays réunis en un marché commun, et les autres pays membres de l'OECE. La ZLE se définit donc par rapport au Marché commun, comme une réponse et un complément à ce dernier. Ainsi, alors même que le traité de Rome est signé, le 25 mars 1957, un autre projet de coopération économique européenne est lancé.

180. Wolfram Kaiser, Using Europe..., op. cit., p. 75. ; Alan Milward, The Rise and Fall..., op. cit., p. 243-4.

181. DDF, 1957-I, doc $\mathrm{n}^{\circ} 155$, télégramme de Christian Pineau aux représentants diplomatiques français à l'étranger, 20 février 1957.

182. DDF, 1957-I, doc ${ }^{\circ} 127$, télégramme de Christian de Margerie (Bonn) à Christian Pineau, 12 février 1957 ; idem, doc $n^{\circ} 212$, télégramme de Maurice Couve de Murville (Bonn) à Christian Pineau, 6 mars 1957, idem doc n 242, télégramme de Maurice Couve de Murville (Bonn) à Christian Pineau, 15 mars 1957. 


\section{Une mobilisation naturelle en faveur de la ZLE.}

La plupart des décideurs français ne différencient pas clairement le Marché commun et la ZLE en terme d'opportunité pour la France. Deux types d'arguments, politiques et économiques, sont développés en faveur de la ZLE.

Tout d'abord, l'aspect stratégique de la ZLE est particulièrement mis en valeur par les diplomates de la DAEF. François Valéry souligne la bonne volonté britannique car « c'est en effet la première fois que la Grande-Bretagne semble disposée à participer à une autre zone préférentielle que celle constituée par le Commonwealth ${ }^{183} »$. Cet argument politique est complété par une considération à la fois stratégique et économique : la création de la ZLE permettra de diluer la formidable puissance industrielle exportatrice allemande dans une zone préférentielle plus vaste que celle des $\mathrm{Six}^{184}$. Cet argument démontre la persistance de la peur de la domination allemande. Les relations commerciales sont appréhendées sous l'angle des rapports de puissance plus que sous celui d'une vision libérale optimiste, assignant au libre-échange une fonction de pacification des relations internationales et de stimulateur de la prospérité.

Les responsables politiques sont particulièrement sensibles à la nécessité de ne pas s'éloigner de la Grande-Bretagne. Dès le mois de janvier 1957, l'opposant au Marché commun Paul Ramadier demande à ses services des notes sur la ZLE, alors même que le traité de Rome n'est pas encore signé ${ }^{185}$. De même, lors de son grand discours à l'Assemblée nationale, Pierre Mendès France critique le Marché commun pour de multiples raisons et notamment en raison de l'absence de la Grande-Bretagne ${ }^{186}$. La résolution finale des débats de l'Assemblée insiste sur la nécessité de compléter le Marché commun par une zone de libre-échange permettant d'associer la Grande-Bretagne ${ }^{187}$. Christian Pineau, le ministre des Affaires étrangères se montre très volontaire sur la ZLE lors des entretiens franco-britanniques du 9 mars 1957, soulignant les difficultés de la négociation mais proposant, avant même la conclusion du traité de Rome, des entretiens bilatéraux acceptés par Macmillan ${ }^{188}$. Il utilise d'ailleurs à cette occasion des chiffres pourtant basiques - la part de la production française

183. AMAE, DECE 740, folio 29, note de François Valéry du 26 juillet 1956.

184. AMAE, DECE 740, folio 48, note de François Valéry, 9 octobre 1956 ; AMAE, DECE 614, folio 78 et DECE 740, folio 119, note de Michel Warenghien du 8 décembre 1956.

185. AMAE, DECE 740, $\mathrm{n}^{\circ} 207$, note NN, DREE, note pour le ministre du $1^{\text {er }}$ février 1957.

186. Pierre Mendès France, CEuvres complètes, tome IV : Pour une République moderne, 19551962, Gallimard, Paris, 1987, p. 250-275.

187. AMAE, DECE 751, folio 31, note de René de Saint-Légier du 25 janvier 1957.

188. PRO, FO 371/128338, doc. 611/278, réunion à Matignon le 9 mars 1957. 
consacrée à l'agriculture - qui se révèlent très éloignés de la vérité ${ }^{189}$, ce qui est étonnant compte tenu de sa formation et de ses expériences économiques ${ }^{190}$. Cela démontre que la réflexion de Pineau est de nature plutôt politique à cette date. Par ailleurs, Pineau propose de réunir des groupes d'experts de manière bilatérale pour aplanir les différents de nature technique. Cette suggestion est immédiatement acceptée par Macmillan. François Valéry, pourtant favorable à la ZLE, est très étonné de cette offre qui est particulièrement avantageuse pour la Grande-Bretagne ${ }^{191}$. De même, dans le discours qu'il prononce à Rome à l'occasion de la signature des traités, le 25 mars 1957, Pineau souligne que la tâche immédiate des Six est dorénavant d'étudier la ZLE afin de ne pas se couper de la Grande-Bretagne ${ }^{192}$. L'argumentation de Pineau est donc essentiellement politique - il s'agit de progresser dans l'unification de l'Europe - et insère le Marché commun dans la négociation globale sur la réorganisation de la coopération en Europe qui doit aussi inclure la Grande-Bretagne.

Cette réaction s'explique par une deuxième caractéristique des conceptions françaises de la ZLE, l'absence de compréhension de la spécificité du modèle d'intégration économique de la CEE. Pour les diplomates de la DAEF le Marché commun ne permet pas d'obtenir pour la France plus de garanties que la ZLE et sa négociation ne sera pas plus difficile que celle du Marché commun ${ }^{193}$. Naturellement, Olivier Wormser cherche à préparer sérieusement la négociation sur la ZLE à venir, en la plaçant dans la continuité directe de la CEE. Il demande à un de ses adjoints d'étudier la possibilité d'appliquer les trois harmonisations sociales accordées à la France dans le cadre de la négociation à Six, au projet de $\mathrm{ZLE}^{194}$.

189. Christian Pineau assure que la part de la production agricole sur la production totale est de $40 \%$ en France contre $10 \%$ en Grande-Bretagne, ce qui suscite une note de l'ambassade de France à Londres. Selon elle, les chiffres réels, tirés des statistiques françaises, sont respectivement de $14 \%$ et de $5 \%$ : PRO, FO 371/128338, note du département commercial, 18 mars 1957.

190. Michel Margairaz, «Christian Pineau et son expérience des Finances et de l'Économie : un modernisateur réformateur et réformiste (1934-1950)», in Alya Aglan, Denis Lefebvre (dir.), Christian Pineau : de Buchenwald aux traités de Rome, B. Leprince, Paris, 2004, p. 53-70.

191. PRO, FO 371/128338, doc. 611/287, note pour F. E. Figgures, Treasury, 11 mars 1957 : «He [François Valéry] was obviously a little shaken at their Ministers having proposed such bilateral...»».

192. Discours de Christian Pineau lors de la signature des traités de Rome, 25 mars 1957, texte issu des archives historiques de l'Union européenne (fonds CM3/NEGO/098), disponible sur : www. ena.lu.

193. AMAE, DECE 740, folio 48, note de François Valéry, 9 octobre 1956 ; AMAE, DECE 614, folio 1, note de Françis Gutmann du 2 novembre 1956.

194. AMAE, DECE 740, folio 114, note manuscrite d'Olivier Wormser à Francis Gutmann du 30 novembre 1956. 
Cette attitude des diplomates de la DAEF paraît logique. Attachés à l'alliance britannique pour des raisons stratégiques, ils considèrent que le projet de ZLE permet de satisfaire à la fois la nécessaire participation de la France à la coopération économique européenne tout en évitant la supranationalité. Leur position est d'ailleurs partagée par d'autres spécialistes des négociations économiques européennes comme Bernard Clappier et Alexandre Kojève de la DREE ${ }^{195}$.

Ainsi le projet de ZLE apparaît comme politiquement incontournable et s'inscrivant directement dans la continuité du Marché commun sur le plan économique. Très naturellement, juste après la conclusion du traité de Marché commun, un second comité Verret est constitué, cette fois sur la ZLE ${ }^{196}$. Le parallèle entre les négociations CEE et ZLE est explicite. La différenciation entre CEE et ZLE est rarement effectuée. Cela tient d'une part à l'imprécision du projet de ZLE mais aussi au manque de perception de la spécificité du modèle économique de la CEE. C'est justement la défense de cette spécificité du Marché commun qui mobilise les premiers opposants à la ZLE.

\section{L'émergence d'un groupe hostile à la ZLE.}

La relance des négociations du Marché commun et de la ZLE explique que les premières réactions hostiles à ce dernier projet se manifestent à partir de la fin de 1956. Elles commencent à se percevoir d'abord dans les groupes les plus susceptibles de percevoir l'intérêt de l'intégration économique par le Marché commun, comme le patronat et certains hauts fonctionnaires spécifiquement chargés de ce dossier comme Robert Marjolin.

Le CNPF tout d'abord, avait défini une doctrine fondée sur une intégration économique exigeante qui l'a amené à défendre le modèle du Marché commun, certes amendé pour tenir compte de la situation de la France. Par contre la ZLE ne comporte pas les mêmes garanties pour la France. La relance de la ZLE après l'échec de Suez oblige la direction du CNPF à prendre position, par un article de novembre $1956^{197}$. Sans critiquer explicitement le modèle de la ZLE, en raison du flou du projet, la note du CNPF dénonce cependant en faux un projet strictement opportuniste, fondé sur la peur britannique de l'isolement et du déclin, et non pas sur un idéal modernisateur européen.

195. AMAE, DECE 613, folio 401, note d'Alexandre Kojève, DREE, 19 octobre 1956.

196. ASGCI, 1977.1471, article 60, note H. Barbier du $1^{\text {er }}$ avril 1957, réunion du 27 mars 1957.

197. "L'Angleterre découvre l'Europe », in Bulletin du CNPF, n' 153, novembre 1956, p. 21-22; cité in Éric Bussière, Michel Dumoulin (textes réunis par), Les cercles économiques et l'Europe au $X X^{e}$ siècle, Louvain-Paris, 1992, texte ${ }^{\circ} 27$, p. 217-219. 
Après cette première note, la réflexion sur le contenu même du projet de ZLE progresse en interne, au sein de la commission des affaires européennes du CNPF. Une note développe ainsi deux types d'arguments très hostiles à la $Z_{L E}{ }^{198}$. Elle relève tout d'abord qu'il serait quasiment impossible pour la France d'obtenir dans le cadre de la ZLE les garanties accordées par les Six dans le cadre du Marché commun. Les garanties désignent à la fois, sur le plan négatif, le caractère conditionnel de la libération des échanges (procédures de passages d'étapes, clauses de sauvegarde, reconnaissance du système français de taxes à l'importation et d'aides à l'exportation) et, sur le plan positif, les diverses mesures d'harmonisation et de coordination prévues (tarif extérieur commun, harmonisations sociales, etc.). Cette note s'inscrit donc en faux avec certaines analyses de l'administration (à la DAEF notamment) qui estimaient que la négociation ZLE ne serait pas plus dure que celle du Marché commun. Au contraire, l'étude de la ZLE permet de mettre en valeur les avantages économiques spécifiques du Marché commun.

À l'assemblée générale du CNPF de janvier 1957, Georges Villiers, après avoir souligné les garanties obtenues par la France dans le cadre du Marché commun remarque que le projet de zone de libre-échange présentera vraisemblablement « plus encore de menaces pour une économie non préparée ${ }^{199}$ ». Un débat a eu lieu au sein du CNPF sur la ZLE. Selon Philippe Mioche, Jean Louis, l'un des animateurs de la commission des affaires européennes, aurait souhaité profiter de la ZLE pour enlever au Marché commun ses aspects les plus supranationaux $x^{200}$. La publication de la note de novembre 1956 et les déclarations de Georges Villiers en janvier 1957 montrent que cette opinion n'a pas prévalu et que l'engagement personnel du président du CNPF dans la construction d'une Europe ambitieuse comme celle du Marché commun, et pas seulement d'une vague coopération économique promise par la ZLE, s'est imposé.

D'autres milieux patronaux commencent d'ailleurs à se mobiliser en faveur du Marché commun et contre la ZLE. C'est par exemple le cas d'un syndicat régional qui écrit une lettre dans ce sens au Quai d'Orsay ${ }^{201}$. La DAEF (Francis Gutmann), dans sa réponse, s'emploie à lui démontrer à l'inverse que la ZLE ne s'oppose pas au Marché commun mais le complète naturellement ${ }^{202}$. De même,

198. ACNPF, 72 AS 1505, lettre du 11 décembre 1956, Bertrand Hommey, commission des affaires européennes du CNPF.

199. ACNPF, 72 AS 846, AG du 17 janvier 1957, exposé général de Georges Villiers.

200. Comité directeur de novembre 1956 évoqué par Philippe Mioche, «Le patronat français... », op. cit., p. 252.

201. AMAE, DECE 628, folio 35, lettre FICA (Fédération des groupements et syndicats des industriels, commerçants et artisans de la Sarthe) à Christian Pineau, 19 janvier 1957.

202. AMAE, DECE 628, folio 39, lettre de Francis Gutmann, 30 janvier 1957. 
une partie du secteur automobile s'inquiète dès janvier 1957 du projet de ZLE et conseille de le refuser si la France n'obtient pas de garanties suffisantes, et de se contenter du seul Marché commun ${ }^{203}$.

$\mathrm{Au}$ sein de l'administration, la principale opposition provient de Robert Marjolin, comme en témoigne sa réaction hostile à la lettre de Macmillan proposant l'ouverture de discussions pour la conclusion d'un traité de ZLE ${ }^{204}$. Peu de temps après, Robert Marjolin annonce que le gouvernement a déclaré une nouvelle accélération de la négociation du Marché commun au cours du comité interministériel du $1^{\mathrm{er}}$ décembre $1956^{205}$. La note de Claude Beaurepaire relatant cette réunion lie directement la volonté de relance, assez considérable car il s'agit de gagner six mois sur le calendrier initial, au projet de ZLE ${ }^{206}$. Elle s'en inquiète vivement car elle risque de laisser de nombreux points mal définis dans le traité.

Le 9 février 1957, c'est Robert Marjolin qui fixe la position provisoire de la France sur la ZLE ${ }^{207}$. Il la calque sur la défense du modèle du Marché commun. La France demandera donc une zone de libre-échange avec le contrôle de l'origine (à défaut du tarif extérieur commun), l'inclusion des produits agricoles et des " garanties équivalentes à celles du Marché commun » sous forme de mesures de « coopération économique » et d' " harmonisation sociale ». De même, lors de la première réunion interadministrative sur la ZLE qui se tient au lendemain même de la signature du traité de Rome, il est le seul à exposer clairement une position méfiante envers la ZLE en demandant le respect intégral des équilibres du traité de Marché commun ${ }^{208}$. Cette position est en effet très isolée au sein de l'administration française. À cette date, elle n'est partagée que par le directeur des Finances extérieures, Jean Sadrin, un autre défenseur précoce du Marché commun ${ }^{209}$. Ces exigences maximalistes témoignent de la volonté de protéger à toute force la jeune Communauté économique européenne.

203. AN, F60, 3114, lettre de Pierre Lemaigre, président de la Chambre syndicale des constructeurs d'automobiles à Jacques Donnedieu de Vabres, 15 janvier 1957. Sigfrido Ramirez, Public Policies..., op. cit., p. 519-520 et p. 527.

204. Voir plus haut; ARAM, 52 J 115, lettre de Harold Macmillan à Paul Ramadier, 30 novembre 1956 ; ARAM, 52 J 115, projet de réponse de Robert Marjolin.

205. ARAM, 52 J 115, note de Claude Beaurepaire, Industrie, pour le ministre Ramadier, 6 décembre 1956.

206. ARAM, $52 \mathrm{~J} 115$, note de Claude Beaurepaire, Industrie, pour le ministre Ramadier, 6 décembre 1956.

207. DDF, 1957-I, doc $n^{\circ} 120$ et DECE 619, folio 118, télégramme de Raymond Bousquet (Bruxelles) à Christian Pineau, 9 février 1957.

208. AINDUS, 1997.1520, article 49, note manuscrite sur la réunion ZLE du 28 mars 1957.

209. AMINEFI, B 44.246, note Finex, $1^{\text {er }}$ bureau, RG, signé Sadrin 10 avril 1957. 
Pour tous ces acteurs, la ZLE s'avère à la fois peu avantageuse pour la France, et dangereuse pour la dynamique du Marché commun. L'opposition à ce projet reste encore très minoritaire car ce projet est largement considéré comme politiquement incontournable et économiquement proche du Marché commun. La spécificité de ce dernier est mal perçue car le soutien à la future CEE reste très faible chez les décideurs français.

\section{B. DeS OPPOSANTS AU MARCHÉ COMMUN TRÈS INFLUENTS}

Les décideurs français de premier plan restent largement hostiles au Marché commun, tant chez les décideurs politiques que chez les « fonctionnaires modernisateurs $\gg$.

\section{Les décideurs politiques : Ramadier et Pierre Mendès France.}

Le projet de traité de Marché commun suscite de vives critiques au sein même de la coalition gouvernementale, chez deux personnalités majeures, Paul Ramadier et Pierre Mendès France.

Le ministre des Affaires économiques et financières Paul Ramadier est une figure importante du personnel politique français de la $\mathrm{IV}^{\mathfrak{e}}$ République ${ }^{210}$, plusieurs fois ministre et ancien président du Conseil. Deux raisons peuvent expliquer son hostilité au Marché commun. Sur le plan économique tout d'abord, Ramadier est un socialiste favorable aux formes de gestion collective de l'économie (coopérative, entreprises nationalisées, planification indicative) ${ }^{211}$, et foncièrement hostile au libéralisme économique qui imprègne le rapport Spaak ${ }^{212}$. Sur le plan européen, Ramadier est partisan d'une Europe intergouvernementale et avec la Grande-Bretagne. Il a participé au congrès de La Haye de 1948 en se montrant hostile aux fédéralistes ${ }^{213}$. Il a ensuite accepté le traité de Paris tout en multipliant les critiques envers la CECA, jugée trop supranationale et

210. Les sources sur Paul Ramadier sont relativement abondantes en raison de la richesse de son fonds privé, déposé aux archives départementales de l'Aveyron (indiqué en note de bas de pages par le sigle ARAM). Une biographie de Paul Ramadier consacrée essentiellement à ses réseaux locaux existe : Aline Fonvieille-Vojtovic, Paul Ramadier (1888-1961), élu local et homme d'État, Publications de la Sorbonne, Paris, 1993. L'ouvrage de référence est le collectif dirigé par Serge Berstein : Serge Berstein (dir.), Paul Ramadier, la République, le socialisme, Complexe, Bruxelles, 1990.

211. Lucette Le Van-Lemesle, «La pensée économique de Paul Ramadier », in Serge Berstein (dir.), Paul Ramadier, op. cit., p. 65.

212. ARAM, Ramadier $52 \mathrm{~J} 114$, notes sur le Marché commun du ministre des Affaires économiques et financières, 2 et 24 mai 1956.

213. Pierre Guillen, « Paul Ramadier et l'Europe », in Serge Berstein (dir.), Paul Ramadier..., op. cit., p. 389-390. 
technocratique ${ }^{214}$. D'ailleurs, lorsque le gouvernement français d'Edgar Faure envisage, en 1955, de le nommer à la tête de la Haute Autorité, les milieux européens communautaires ont obtenu le retrait de sa candidature ${ }^{215}$.

Face au Marché commun, Ramadier persiste dans son opposition même après avoir été mis en minorité lors du conseil interministériel du 4 septembre 1956. Lors d'une réunion interadministrative du 10 décembre 1956, Ramadier a proposé de proportionner les charges à payer par chacun des Six pour l'outre-mer au niveau des exportations vers l'outre-mer atteint ${ }^{216}$. La logique reste entièrement contractuelle et très peu libérale dans la mesure où elle repose sur une démarche de troc contingentaire. L'opposition de Ramadier représente donc celle d'un socialiste français hostile à la dynamique libre-échangiste, et à une Europe trop étroite et trop supranationale.

L'autre opposant principal au Marché commun au sein de la coalition gouvernementale est Pierre Mendès France, une autre figure majeure de la $\mathrm{IV}^{\mathfrak{T}}$ République. Ministère d'État sans portefeuille dans le gouvernement Mollet, il reprend sa liberté en mai 1956. Sur le plan européen, le député radical reste attaché à un mode de coopération souple et à grande échelle comme l'OECE et l'UEO $^{217}$. Face à la future CEE, Pierre Mendès France se montre très hostile, en particulier dans son célèbre discours prononcé à l'Assemblée nationale le 18 janvier $1957^{218}$.

Tout d'abord, Pierre Mendès France s'attache à démontrer que le Marché commun menace le modèle économique et social français. Il reprend l'argument classique du handicap spécifique de la France en raison de son modèle social avancé ${ }^{219}$. Plus loin, Mendès France souligne l'équilibre de la structure économique française par rapport à son homologue d'outre-Rhin : «Jusqu'à présent, nous faisions face aux grandes crises économiques internationales mieux que d'autres pays, mieux que les pays industrialisés [...] grâce à la structure de notre économie ${ }^{220} »$. Dans le même ordre d'idée, il souligne l'intérêt de préserver la zone commerciale préférentielle de 1'Union française ${ }^{221}$.

214. Pierre Guillen, « Paul Ramadier et l'Europe », in Serge Berstein (dir.), Paul Ramadier..., op. cit., p. 395-397.

215. Gérard Bossuat, L'Europe des Français..., op. cit., p. 270.

216. AN, F60, F 3112, note pour Alby et Morin (SGCI) du 11 décembre 1956.

217. Gérard Bossuat, " Pierre Mendès France, une volonté pour l'Europe », in Michel Margairaz, (dir.), Pierre Mendès France et l'économie. Pensée et action, Odile Jacob, Paris, 1989, p. 175.

218. Pierre Mendès France, Euvres complètes, tome IV, Pour une République moderne, 1955-1962, Gallimard, Paris, 1987, p. 250-275.

219. Ibid., p. 255.

220. Ibid., p. 252.

221. Ibid., p. 274. 
L'ancien président du Conseil décrit bien ici les bases du modèle traditionnel français qu'il défend : une structure économique reposant sur une agriculture forte et des marchés protégés, comme ceux de l'outre-mer, qui sont perçus comme des éléments stabilisateurs.

Mais la menace que représente le Marché commun n'est pas seulement économique, elle est aussi démographique. La première critique que Pierre Mendès France adresse au traité, celle par laquelle il commence son discours, porte sur l'immigration économique. L'ancien président du Conseil a peur d'une immigration italienne, mais il a surtout peur d'un départ massif des Français de régions pauvres (Languedoc, Auvergne, Bretagne) vers l'Allemagne puis, dans un second temps, d'un afflux massif de travailleurs allemands vers la France lorsque la crise économique, inévitable et plus forte qu'en France selon lui, touchera ce pays. Il conclut sur la nécessité pour la France d'obtenir le droit " de limiter l'immigration en France » et « des sauvegardes contre le risque d'un chômage et d'un abaissement du niveau de vie importé du dehors $\gg{ }^{222}$.

L'ancien président du Conseil radical développe ensuite une contreproposition fondée sur trois éléments. Tout d'abord et de manière classique, Pierre Mendès France reprend la position française traditionnelle qui reposait sur un engagement conditionnel pour quatre années, à l'issue desquelles tout serait décidé à l'unanimité. Il refuse la conclusion d'un traité cadre qui laisserait aux institutions communes de très vastes pouvoirs d'interprétation ${ }^{223}$.

Ensuite et de manière plus positive, il développe sa vision de l'intégration économique industrielle : « Je crois que toute la reconstruction de l'Europe, tout son développement d'après-guerre auraient dû être conçus sur la base d'investissements européens coordonnés selon des plans d'intérêt commun, évitant les doubles emplois, les investissements excessifs ou superflus, les concurrences ruineuses et aussi les pénuries communes ${ }^{224} \gg$. Une approche volontariste, voire même dirigiste, de l'intervention de l'État dans l'économie est ainsi développée. Cette vision permet de défendre le modèle français de la planification indicative et du circuit du Trésor. Elle souffre cependant de trois lacunes. Tout d'abord, aucune différenciation entre la période de la reconstruction et une période ultérieure où le rôle de l'État aurait pu être repensé n'est effectuée. Ensuite, un tel volontarisme économique impliquerait nécessairement le développement d'institutions supranationales fortes, ce qui contredit l'attrait de Mendès France

222. Ibid., p. 253.

223. Ibid., p. 269.

224. Ibid., p. 266-67. 
pour une Europe intergouvernementale avec la Grande-Bretagne. Enfin, cette vision est difficilement acceptable par les partenaires de la France.

Enfin, Mendès France demande l'élargissement du cadre de la coopération européenne à la Grande-Bretagne. Il estime que la France devrait considérer avec beaucoup plus d'attention qu'elle ne le fait le projet de ZLE ${ }^{225}$. Cependant, les arguments avancés par Pierre Mendès France sont contradictoires. Dans le domaine agricole, 1 'ancien président du Conseil estime que la Grande-Bretagne représente un débouché important pour les produits agricoles français alors qu'il défend le système britannique des préférences impériales, fondé sur des importations agricoles du Commonwealth, juste avant ${ }^{226}$. La note du Quai d'Orsay commentant ce discours relève d'ailleurs cette incohérence ${ }^{227}$. En matière industrielle ensuite, s'il s'inquiète de la concurrence de l'industrie allemande, il n'évoque pas la position de l'industrie britannique, elle-même très puissante et bénéficiant à la fois du marché privilégié du Commonwealth et d'investissements américains. C'est d'ailleurs elle, ainsi que son homologue américaine, qui est visée par certaines études du secteur automobile sur les investissements américains que Pierre Mendès France cite $^{228}$. Enfin, sur le plan politique, l'ancien président du Conseil radical souligne que la Grande-Bretagne a fait un grand pas en avant en proposant la ZLE ${ }^{229}$. Mais le modèle de la ZLE est plus éloigné que celui du Marché commun de l'harmonisation sociale ou de la coopération économique volontariste qu'il appelle de ses vœux, car elle ne constitue qu'un projet strictement commercial.

Pierre Mendès France livre par ce discours une analyse documentée du traité de Rome. Il manifeste la permanence d'un idéal économique et social français fondé à la fois sur des éléments traditionnels (poids de l'agriculture, préférences coloniales) et sur une modernisation étatique dirigiste, issue d'un idéal développé dans l'immédiat après-guerre (orientation des investissements par l'État). En matière de construction européenne, comme le remarque Gérard Bossuat, sa position traduit « la permanence du rêve français d'une Grande Europe sous direction franco-britannique ${ }^{230} »$. Mais les contradictions relevées sur le rôle de la Grande-Bretagne ne permettent pas de considérer comme crédibles les propositions de l'ancien président du Conseil radical. Son opposition s'atténue

225. Ibid., p. 270-71.

226. Ibid., respectivement p. 272 et p. 271.

227. DDF, 1957-I, doc $n^{\circ} 63$, note du service de coopération économique, 19 janvier 1957.

228. AN, F60, 3114, lettre de Pierre Lemaigre à Jacques Donnedieu de Vabres, 15 janvier 1957.

229. Pierre Mendès France, CEuvres complètes, tome IV..., op. cit., p. 270.

230. Gérard Bossuat, L'Europe des Français..., op. cit., p. 351. 
au cours de l'année 1957 à la faveur d'une correspondance avec Pierre Uri ${ }^{231}$, avant de disparaître à la fin de $1958^{232}$.

Mendès France et Ramadier ont en commun de reprocher au projet de Marché commun à la fois son libéralisme économique, son échelle inadaptée et les délégations de souveraineté insupportable qu'il entraîne. Certes, les réflexions économiques, politiques et européennes de Mendès France et de Ramadier ne sont pas similaires, mais elles traduisent toutes deux la force, au sein de la gauche, d'une vision idéalisée d'une Grande Europe chimérique. Celle-ci reposerait sur des délégations de souveraineté modérées, qui préserverait le modèle économique et social français, la participation d'une GrandeBretagne, toujours très prestigieuse (notamment du fait du souvenir des réformes économiques et sociales des travaillistes), et le refus de la libération des échanges. La Petite Europe des Six, centrée sur l'axe franco-allemand, reposant sur des institutions supranationales et une ambition d'union économique fondée sur la dynamique libre-échangiste, sert de repoussoir. Cette vision est irréaliste car la Grande-Bretagne soutient avant tout des coopérations strictement libérales et commerciales, sans régulation ni compensation à l'ouverture des marchés. Toutefois, ces conceptions nourrissent l'opposition de la majorité des hauts fonctionnaires au Marché commun.

\section{Le Marché commun en porte-à-faux face à la logique des « fonctionnaires modernisateurs ».}

Le Marché commun suscite une opposition très largement majoritaire au sein de la haute fonction publique car il semble remettre en cause un modèle économique fondé sur un très fort interventionnisme de l'État pour guider la modernisation économique du pays. Ainsi, dans son rapport sur la réforme de l'organisation du ministère des Finances et des Affaires économiques rendu le 31 décembre 1956, François Bloch-Lainé développe, selon Florence Descamps une réflexion « fortement interventionniste, dirigiste, bureaucratique, centralisatrice et planificatrice », qui «peut paraître en porte à faux par rapport au mouvement de libération de l'économie ${ }^{233} \gg$, notamment parce que le Marché commun en est très largement absent alors même que sa négociation est déjà proche de son terme. Plus directement, Claude Gruson, le directeur du SEEF

231. « Le débat Mendès France-Uri sur les traités de Rome (juillet 1957) », texte $n^{\circ} 45$ in Gérard Bossuat, Faire l'Europe sans défaire la France..., op. cit., p. 368-373.

232. Gérard Bossuat, L'Europe des Français..., op. cit., p. 360.

233. Florence Descamps, « François Bloch-Lainé et la réforme de l'État : de l'action au magistère moral, 1946-1996», in Michel Margairaz (dir.), François Bloch-Lainé, fonctionnaire, financier, citoyen, Comité pour l'histoire économique et financière de la France, Paris, 2005, p. 182-184. 
(Service des études économiques et financières) du ministère des Affaires économiques et financières s'oppose à la CEE en raison de son postulat « libéral », et en raison de l'absence de mécanismes de planification européenne ${ }^{234}$. La planification indicative s'entendait, pour Claude Gruson, comme contraire à la libération des échanges. Frances Lynch avait déjà remarqué la tendance de certains milieux planificateurs à minimiser l'effet dynamisant de la libération des échanges comme en témoigne leur action visant à encourager les productions de substitutions d'importation ${ }^{235}$.

Le caractère consensuel du rôle directeur de la planification indicative française est prouvé par les nombreuses références positives que l'on trouve dans les archives patronales. Ainsi, la FIMTM dans son mémorandum du 7 juin $1956^{236}$ plaide pour un rôle fort de l'État dans l'organisation de l'économie, en collaboration avec les représentants patronaux. Pour la définition de la politique économique européenne de la France, la FIMTM préconise de suivre la solution des procédures d'élaboration du Plan, fondées sur la multiplication des commissions sectorielles associant fonctionnaires et représentants syndicaux. D'une manière générale, une partie des milieux économiques de la $I V^{\mathcal{E}}$ République s'est accommodée du rôle directeur des autorités publiques dans l'économie ${ }^{237}$. Le mépris des parlementaires et la tradition du pantouflage les rapprochent des fonctionnaires.

Un bilan de l'opinion des hauts fonctionnaires face au Marché commun, telle qu'elle s'exprime dans les archives, fait apparaître une très nette domination des opposants au modèle du rapport Spaak. Au Quai d'Orsay, le secrétaire général René Massigli est très sceptique mais il part en retraite en juillet 1956. Il laisse cependant derrière lui un service des affaires économiques, la DAEF, très méfiant envers la CEE (Olivier Wormser), voire séduit par la ZLE (François Valéry).

Au ministère des Affaires économiques et financières, le scepticisme envers le projet de Marché commun est lui aussi général ${ }^{238}$. Seuls Jean Sadrin, par européisme, et Roger Goetze, par attachement aux mécanismes libéraux,

234. AFJM, ARM 15/1/2, Note Claude Gruson pour le président, 17 janvier 1957 ; Aude Terray, Des francs-tireurs aux experts. L'organisation de la prévision économique au ministère des Finances. 1948-1968, Comité pour l'histoire économique et financière de la France, Paris, 2002, p. 210.

235. Frances Lynch, France and the International Economy..., op. cit., p. 130-131.

236. ACNPF, 72 AS 1505, mémorandum de la FIMTM, 7 juin 1956 : «Les industries mécaniques et transformatrices de métaux et l'intégration européenne ».

237. Henry W. Erhmann, Organized Business in France, Princeton UP, Princeton, 1957, p. 226. Voir aussi le témoignage de Pierre de Calan : AO/Comité pour l'histoire économique et financière de la France, Pierre de Calan, interview par Aude Terray, 1988, retranscrits : tome IV, p. 54-55.

238. Gérard Bossuat, "Les hauts fonctionnaires français et le processus d'unité en Europe occidentale d'Alger à Rome » in Revue d'histoire de l'intégration européenne, 1995-1, p. 104. 
réservent un accueil favorable au rapport Spaak. Laurence Badel évoque le scepticisme de la DREE envers le traité de Rome lors de sa négociation ${ }^{239}$. À la Banque de France le sous-gouverneur Jean Saltes se montre particulièrement inquiet envers la capacité de la France de profiter de la dynamique libreéchangiste du traité de Rome ${ }^{240}$. Le ministère de l'Industrie apparaît comme un bastion du dirigisme et du protectionnisme, demandant parfois plus de protection que les industriels eux-mêmes. Cette vision qui peut paraître caricaturale du ministère de l'Industrie, est pleinement confirmée par les archives.

Comment interpréter cette opposition majoritaire ? Dans des témoignages, des hauts fonctionnaires des Finances, appartenant d'ailleurs à la génération suivante, ont tenté d'expliquer ce qu'ils considéraient moins comme des réticences que comme une certaine lenteur dans la conversion des Finances à l'Europe ${ }^{241}$. Certains mettent l'accent sur la logique de fonction : les directions les plus puissantes du ministère n'avaient pas intérêt à remettre en cause un système qui était à leur avantage en soutenant un projet hasardeux ${ }^{242}$.

En fait, l'étude des archives écrites et des sources imprimées montre clairement que le Marché commun ne s'inscrit pas dans la stratégie de modernisation économique de la France développée par les élites dominantes, c'est-à-dire les « fonctionnaires modernisateurs » étudiés par Emmanuel Chadeau ${ }^{243}$ et Michel Margairaz ${ }^{244}$, et les figures considérées comme les plus « réformatrices » du débat public comme Pierre Mendès France, qui jouissait d'ailleurs d'un grand prestige chez les fonctionnaires « modernisateurs ${ }^{245}$ ». Ces « fonctionnaires

239. Laurence Badel, « La direction des relations économiques extérieures (DREE). Origine, culture, logique (1920-1970) » in Laurence Badel et alii (dir.), Les administrations nationales et la construction européenne..., op. cit., p. 205.

240. Note du 24 février 1957 citée in Olivier Feieratg, Wilfrid Baumgartner. Un grand commis des finances à la croisée des pouvoirs (1902-1978), Comité pour l'histoire économique et financière de la France, Paris, 2006, p. 522.

241. Intervention d'André de Lattre, in Le rôle des ministères des Finances et de l'Économie dans la construction européenne (1957-1978), tome I, Comité pour l'histoire économique et financière de la France, Paris, 2002, p. 191-92.

242. Intervention de Dominique de la Martinière, in Le rôle des ministères des Finances..., op. cit., p. 196-97.

243. Emmanuel Chadeau, «Les modernisateurs de la France et l'économie du XX ${ }^{\mathrm{e}}$ siècle. Note sur quelques ouvrages d'histoire immédiate », in Bulletin de l'IHTP, septembre 1982, p. 22-35.

244. Michel Margairaz, L'État, les finances et l'économie. Histoire d'une conversion, 1932-1952, Comité pour l'histoire économique et financière de la France, Paris, 1991, notamment p. 1338-1340. Voir aussi : Richard F. Kuisel, Le capitalisme et l'État en France. Modernisation et dirigisme au $X X^{e}$ siècle, Gallimard, Paris, 1984 [1981].

245. Particulièrement révélateur de l'association entre les fonctionnaires qu'il appelle les « modernistes » et la pensée de Pierre Mendès France : André Gauron, Histoire économique et sociale de la $V^{R}$ République, tome I, Le temps des modernistes, Maspéro, Paris, 1983. 
modernisateurs » se sont largement mis en scène à partir des années 1980 pour mettre en avant leur rôle fondamental dans la reconstruction, face à des élites politiques inconstantes ${ }^{246}$. Ils développent une vision fondée sur le pouvoir supérieur du technocrate fonctionnaire, guidé par l'intérêt général et qui «éclaire » les gouvernants et les milieux économiques aux compétences plus limitées. Sur le plan économique, leur doctrine « expanso-atlantique » est fondée sur un fort accroissement des investissements, notamment publics et parapublics, en réaction avec l'« austéro-dirigisme » des années $1930^{247}$. Leur discours s'articule autour de la rupture de 1944-1945 et de la nécessité de créer une France nouvelle ${ }^{248}$. À partir de cette date, les anciennes élites qui n'avaient pas su tirer les conséquences de la crise de 1929 étaient discréditées et remplacées par de nouvelles, qui tirent leur pouvoir d'une vulgate keynésienne qui leur sert à légitimer l'intervention de l'État ${ }^{249}$. Or si ce modèle a pu fonctionner dans l'immédiat après-guerre car la reconstruction exigeait une forte centralisation étatique, il n'est plus adapté à une économie où l'offre comme la demande se diversifient et s'internationalisent, évolution amplifiée et symbolisée par le Marché commun. De plus, le modèle expanso-atlantique tel qu'il est compris par les acteurs européens - mais pas par les « fonctionnaires modernisateurs »-est lui-même fondé sur le retour à la libération internationale des échanges, et ce pour les mêmes raisons qui ont justifié un rôle accru de l'État dans l'économie, la volonté de tirer les leçons des années 1930. En effet, le protectionnisme a été l'un des moteurs du nationalisme économique et, in fine, politique, conduisant à la seconde guerre mondiale.

Si les « modernisateurs » ont bien pris conscience des ruptures de 1929 et 1945, ils n'ont pas pris le tournant de la fin de la reconstruction en Europe qui s'impose à partir de 1955 environ. De nombreuses analyses opposent toujours, selon une vision dichotomique, deux politiques, celle de l'austérité et

246. Sur leur mise en scène : Brigitte Gaïti, « Les modernisateurs dans l'administration d'aprèsguerre. L'écriture d'une histoire héroïque "), in Revue française d'administration publique, $\mathrm{n}^{\circ} 102$, avril-juin 2002, p. 295-306. Le principal ouvrage mettant en valeur le rôle des fonctionnaires modernisateurs est : Jean Bouvier, François Bloch-Lainé, La France restaurée, 1944-1954 : dialogue sur le choix d'une modernisation, Fayard, Paris, 1986.

247. Michel Margairaz, L'Etat, les finances et l'économie..., op. cit.

248. Emmanuel Chadeau, «Les modernisateurs... », op. cit., p. 25-28; sur cette coupure pour Bloch-Lainé par exemple : Margairaz, "Conclusions », in Michel Margairaz (dir.), François BlochLainé, fonctionnaire, financier, citoyen, Comité pour l'histoire économique et financière de la France, Paris, 2005, p. 250.

249. Pierre Rosanvallon, « Histoire des idées keynésiennes en France », in Revue française d'économie, vol. 2-4, automne 1987, p. 47 ; Olivier Dard, «Économie et économistes des années trente aux années cinquante : un tournant keynésien ? », in Historiens et géographes, $\mathrm{n}^{\circ} 361$, mars-avril 1998, p. 189. 
du libre-échangisme classique d'un côté, celle de l'expansion couplée au protectionnisme de l'autre. Le consensus « modernisateur » de 1945 paraît ainsi associer dans une synthèse consensuelle des éléments de long terme, la France protectionniste, agricole et impériale de Méline à une dynamique de moyen terme, fondée sur le développement de l'État-providence et d'une société industrielle par l'action déterminante des autorités publiques. À partir de 1955, ce consensus ne peut plus se prolonger tel quel : la fin de la reconstruction pousse les partenaires de la France à réclamer avec toujours plus d'insistance un retour à la libération des échanges et des paiements. Par ailleurs, les déséquilibres financiers croissant à partir de 1956 traduisent l'inefficacité d'une économie trop protégée. Face à cette évolution, symbolisée par le Marché commun, les fonctionnaires « modernisateurs » n'ont pas pu, ou pas voulu, adapter leurs projets de modernisation internes à l'intégration économique européenne en proposant un contre-projet réaliste après le rapport Spaak. À l'époque de la négociation du traité de Rome, en 1956-1957, la France n'a pas connu de véritable libération internationale des échanges depuis près de vingt-cinq ans, de nombreux responsables administratifs sont donc légitimement effrayés par ce mouvement. Ils se replient sur une attitude défensive. Face à cette opposition majoritaire, un petit groupe de décideurs se mobilise pour défendre le Marché commun.

\section{LA COMPLÉMENTARITÉ DES PROMOTEURS DU MARCHÉ COMMUN}

Le Marché commun bénéfice du soutien d'un ensemble d'acteurs qui ne le défendent pas toujours pour les mêmes raisons. L'attachement de Guy Mollet au Marché commun tout d'abord, se révèle équivoque, à la différence de la position de Robert Marjolin, qui joue un rôle central dans sa promotion avec un petit nombre de hauts fonctionnaires.

\section{L'ambiguïté de la défense du Marché commun par Mollet.}

Le président du Conseil Guy Mollet joue un rôle fondamental pour faire accepter le Marché commun. Lors du comité interministériel du 4 septembre 1956 , c'est lui qui l'impose à ses ministres réticents ${ }^{250}$. Il doit manifester à nouveau son engagement personnel lors des comités interministériels des 9 octobre

250. Éric Kocher, Le rôle de la France dans les négociations des traités de Rome. Un aspect de la relance 1954-1957, maîtrise, dir. René Girault, 1989, p. 111. 
$1956^{251}$ et 13 février 1957, où l'hostilité au projet persiste ${ }^{252}$. En parallèle, Mollet organise un nouveau débat à l'Assemblée nationale le 17 janvier 1957. En dépit de l'intervention de Pierre Mendès France, les parlementaires soutiennent majoritairement les orientations européennes du gouvernement Mollet ${ }^{253}$. Le travail de conviction des parlementaires est essentiel pour éviter une répétition du 30 août 1954. Dans un témoignage Christian Pineau insiste sur l'implication de Guy Mollet dans cette action essentielle et cite l'exemple d'Alain Savary, hostile à la CED mais qui est devenu favorable au Marché commun ${ }^{254}$. Enfin, Mollet cherche à promouvoir ce projet auprès de l'opinion publique. Des émissions de radio exposant les bénéfices quotidiens sont réalisées ${ }^{255}$.

Cependant la doctrine économique européenne de Mollet est difficile à reconstituer. À travers ses interventions dans les comités interministériels émerge l'idée d'une dynamique de libération des échanges inévitable. Le Marché commun s'impose donc comme un cadre indispensable, à la fois pour forcer la France à s'adapter à la libre concurrence internationale, et pour obtenir des garanties pour contrôler ce processus. Le cadre des Six n'est toutefois pas l'unique enceinte de coopération européenne possible comme en témoignent ses propositions de coopération avec la Grande-Bretagne de septembre $1956^{256}$. Cette attitude prouve que Mollet était peu attaché à l'intégration économique qui faisait la spécificité du Marché commun. Dans les débats des années 1950, Gérard Bossuat souligne d'ailleurs que Mollet s'était rallié à la CECA sans enthousiaste, car les liens entre la SFIO et le parti travailliste étaient beaucoup plus forts qu'avec le $\mathrm{SPD}^{257}$. De même, les nombreuses déclarations de Pineau favorables à la ZLE semblent démontrer que le ministre des Affaires étrangères nourrit, comme son président du Conseil, un attachement plus politique qu'économique de la CEE.

251. AMAE, POW $31, \mathrm{n}^{\circ} 123$, notes manuscrites sur une réunion qui semble être ce comité interministériel, également évoqué par Éric Kocher, Le rôle de la France..., op. cit., p. 122.

252. Éric Kocher, Le rôle de la France..., op. cit., p. 127.

253. L'année politique, 1957, PUF, Paris, 1958, p. 8-11.

254. Témoignage de Christian Pineau in Enrico Serra (dir), La relance européenne..., op. cit., p. 284.

255. AN, F60, 3112, note du cabinet de la présidence du Conseil, Jean Piat, 8 février 1957. Voir sur le site ina.fr des émissions de promotion du Marché commun auxquelles participent Robert Marjolin et Georges Vedel.

256. Voir plus haut et notamment : PRO, PREM 11/1352 CR « Meeting at the Hotel Matignon, September 27. $1956 »$; Frances Lynch, France and the International Economy..., op. cit., p. 178-9; Alan Milward, The Rise and Fall..., op. cit., p. 251-7.

257. Gérard Bossuat, «Les eurosocialistes de la SFIO », in Gérard Bossuat (dir.), Georges Saunier (collab.), Inventer l'Europe. Histoire nouvelle des groupes d'influence et des acteurs de l'unité européenne, Peter Lang, Bruxelles, 2003, p. 425-227. 
Cette orientation peut expliquer les contradictions de la politique européenne de Guy Mollet en matière économique. D'une part, il soutient tout autant la ZLE que la CEE alors que la première aggraverait bien plus que la seconde les difficultés commerciales et financières françaises. D'autre part il met en œuvre une politique économique intérieure qui ne permet pas à la France d'appliquer le Marché commun. Ce qui compte pour Mollet est de faire l'Europe plus que le seul Marché commun à Six.

On retrouve la même ambiguité chez d'autres défenseurs du Marché commun comme Bernard Clappier, le directeur de la DREE. Ancien directeur de cabinet de Robert Schuman à l'époque du lancement de la CECA, le directeur de la DREE est fréquemment cité comme un des principaux soutiens à l'Europe communautaire de l'administration française. Il est vrai qu'il est l'un des rares à s'exprimer en faveur du Marché commun dès juin $1955^{258}$ et au moment de l'examen du rapport Spaak ${ }^{259}$. Cependant, comme pour Guy Mollet ou Christian Pineau, son attachement au Marché commun n'est ni militant ${ }^{260}$, ni exclusif car il paraît avoir une opinion très favorable du projet britannique de ZLE. Dans les archives britanniques, il apparaît également, en novembre 1956, comme un partisan de la ZLE ${ }^{261}$.

Ainsi, l'attitude favorable de Guy Mollet, Christian Pineau ou Bernard Clappier envers le Marché commun ne traduit pas une adhésion véritable à sa dynamique d'intégration économique mais plutôt un soutien de principe aux initiatives européennes. Au contraire, Robert Marjolin joue un rôle central pour faire accepter le projet économique du Marché commun.

\section{Le rôle central de Robert Marjolin.}

Robert Marjolin, conseiller au cabinet du ministre des Affaires étrangères Christian Pineau chargé des questions économiques européennes, est un acteur charnière de la négociation. Bénéficiant de larges réseaux de relations de par son expérience double de haut fonctionnaire français (directeur de la DREE et commissaire adjoint au plan) et européen (secrétaire général de l'OECE de 1948 à 1955), c'est aussi un professeur d'économie qui développe une réflexion

258. AN, F60, 3083, note de Bernard Clappier, DREE, transmise par Étienne Hirsch au ministre le 21 juin 1955 .

259. Robert Marjolin, Le travail d'une vie..., op. cit., p. 283.

260. Laurence Badel, « La direction des relations économiques extérieures (DREE)... », op. cit., p. 203.

261. PRO, FO 371/122039, folio 107, doc 611/396, note FEF du 16 novembre 1958, entretien avec Bernard Clappier. 
personnelle sur l'intégration européenne. Dans des articles parus en 1955, il explique clairement son soutien au projet de marché commun pour des raisons avant tout économiques, moderniser le pays en l'insérant dans une dynamique libre-échangiste stimulante, tout en bénéficiant des protections apportées par l'échelle communautaire ${ }^{262}$.

Fort de ces convictions, Marjolin s'emploie à mobiliser l'opinion publique et surtout les milieux économiques, industriels et agricoles en faveur du Marché commun $^{263}$. Les archives du CNPF témoignent ainsi de ses bons rapports avec Bertrand Hommey, le président de la commission des relations internationales du $\mathrm{CNPF}^{264}$. Surtout, Robert Marjolin orchestre l'évolution de la position française en arrière-plan, particulièrement à trois moments décisifs lors de cette première période. Tout d'abord, il joue un rôle majeur pour infléchir les positions françaises dans un sens plus conciliant à l'été 1956. Ainsi, son mémorandum du 3 septembre 1956 propose une novation de la position française par l'abandon de la revendication consistant à ne s'engager que pour une première étape, remplacée par l'acceptation d'un engagement pour l'ensemble du processus devant conduire au Marché commun ${ }^{265}$. Cette position est celle que défend Maurice Faure le lendemain, lors de la réunion interministérielle tenue le 4 septembre $1956^{266}$. Il est difficile de savoir qui est à l'origine de cette décision mais c'est Robert Marjolin qui est chargé de rédiger le texte de compromis. François Duchêne, biographe de Jean Monnet, insiste sur le rôle de Marjolin pour convaincre Guy Mollet de l'intérêt propre du Marché commun face à Euratom ${ }^{267}$. Bruno Riondel, biographe de Maurice Faure, confirme cette version car il affirme qu'à cette date, Faure impose à la délégation française de privilégier le projet de Marché commun sur celui d'Euratom en particulier sous l'influence de Robert Marjolin et ce malgré la déception de nombre de ses collaborateurs ${ }^{268}$.

Ensuite, dans un second temps, Robert Marjolin apparaît comme l'un des artisans de l'accélération de la négociation à la fin de l'année 1956. Lors de la

262. ARAM, 52 J 92, article : « Le programme économique français », in Banque et Bourse, décembre 1955, p. 67-76 ; Robert Marjolin, Le travail d'une vie..., op. cit., p. 247-251.

263. Robert Marjolin, Le travail d'une vie. Mémoires, 1911-1986, Robert Laffont, Paris, 1986, p. 291.

264. ACNPF, 72 AS 1590, note de Bertrand Hommey pour le président Georges Villiers, 27 mars 1957.

265. ARAM, 52 J 115, « Mémorandum Marjolin » du 3 septembre 1956.

266. Éric Kocher, Le rôle de la France..., op. cit., p. 111.

267. François Duchêne, Jean Monnet, The first statesman of interdependence, Norton \& Company, Londres, 1994, p. 56.

268. B. Riondel, Maurice Faure..., op. cit., p. 219-21. Voir aussi le témoignage de Maurice Faure in : Enrico Serra (dir.), La relance européenne..., op. cit., p. 282-3. 
rencontre franco-allemande cruciale du 6 novembre 1956, c'est lui qui définit, avec son homologue allemand Carstens, certains compromis techniques sur les garanties à accorder à la France ${ }^{269}$. Ensuite, le 30 novembre 1956, c'est Marjolin qui conseille à Ramadier une réponse dilatoire à Macmillan sur la ZLE, alors que Clappier est plus conciliant ${ }^{270}$. Peu après, le 6 décembre 1956, Beaurepaire, chef du service des Affaires extérieures du ministre de l'Industrie, informe son secrétaire d'État que Robert Marjolin, lors d'une réunion interministérielle tenue le $1^{\text {er }}$ décembre 1956, a transmis la volonté du gouvernement d'accélérer la négociation ${ }^{271}$. Persuadé que tous les litiges ne pourront être réglés dans le détail, Robert Marjolin estime que c'est à la future autorité supranationale que reviendra le soin de les régler. Aucune raison de cette accélération n'a été avancée mais Beaurepaire estime que le projet de ZLE fait peur. De fait, et c'est la dernière contribution majeure de Robert Marjolin à la position française, ce dernier est l'un des rares à avoir une position précise sur la ZLE, qu'il différencie nettement du Marché commun ${ }^{272}$. Il met en relief son importance cardinale, car il correspond mieux à sa conception exigeante de l'intégration économique européenne.

Ainsi, Robert Marjolin a un rôle crucial pour défendre le projet de l'intégration économique par le Marché commun auprès de l'administration et des milieux économiques. Il apparaît comme le relais majeur du pouvoir dans les dossiers industriels. En sens inverse, il peut profiter de la conversion à l'Europe communautaire de la direction du CNPF pour convaincre ses interlocuteurs de l'intérêt de la CEE.

D'une manière générale, s'il est difficile de savoir qui est à l'origine des inflexions dans la doctrine française en matière économique, l'apparition constante de Marjolin aux moments cruciaux permet de supposer qu'il a joué un rôle déterminant dans la définition d'une position française acceptable par ses cinq partenaires. Cette idée est étayée par le fait que Marjolin a une doctrine propre, fondée sur une intégration économique européenne exigeante. Il défend spécifiquement le modèle d'intégration économique de la CEE, y compris face à la ZLE, alors même que d'autres promoteurs de la CEE, comme Guy Mollet, avaient en même temps promu des projets de coopération européenne

269. H.-J. Küsters, Fondements..., op. cit., p. 213-214.

270. ARAM, $52 \mathrm{~J} 115$, projet de réponse de Robert Marjolin.

271. ARAM, 52 J 115, note Beaurepaire pour le ministre, 6 décembre 1956.

272. Télégramme de Raymond Bousquet citant la position de Marjolin, 9 février 1957 in DDF, 1957-II, n 120 ; AINDUS, 1977,1520, vol 49, note manuscrite sur une réunion sur la ZLE du 28 mars 1957. 
fondamentalement différents, par exemple sur base franco-britannique. Il s'affirme comme un relais indispensable entre les sphères politiques, administratives et économiques, ainsi que les réseaux européistes. Son influence est complémentaire de celle des autres promoteurs du Marché commun dans l'administration.

\section{Les autres promoteurs du Marché commun dans l'administration.}

D'autres figures d'intermédiaires entre les sphères administratives, politiques et intellectuelles ont joué un rôle de premier plan dans la négociation du traité de marché commun. Cependant, elles jouent un rôle moins important que Robert Marjolin dans le dossier spécifique de la négociation des clauses économiques du Marché commun entre le rapport Spaak et le traité de Rome.

Félix Gaillard et Pierre Uri ont joué un rôle important entre Messine et le rapport Spaak. Le premier est le chef de la délégation française au comité Spaak en 1955. Ancien collaborateur de Monnet et Marjolin, il apparaît lié aux mêmes milieux européens et modernisateurs, mais il disparaît des négociations européennes sous le gouvernement de Guy Mollet.

Pierre Uri a un profil proche de Robert Marjolin. Comme lui, il a commencé par des études littéraires - mais en suivant la voie plus classique de l'ENS et de l'agrégation de philosophie, avant de s'orienter vers l'économie. Les deux hommes ont tous deux effectué un séjour d'étude aux États-Unis avantguerre $^{273}$. Enfin, ils ont tous les deux été des collaborateurs de Jean Monnet au Plan. Alors que Marjolin est parti pour l'OECE, Pierre Uri a rejoint la CECA. Il prit ensuite une part très active à la relance de Messine en rédigeant une synthèse entre les projets sectoriels de Monnet et ceux de marché commun général de Beyen qui est à la base du mémorandum présenté par le Benelux avant Messine ${ }^{274}$. De même, il fut l'un des principaux rédacteurs du rapport Spaak. Par la suite, il joua un rôle important dans la négociation du Marché commun mais comme conseiller de Paul-Henri Spaak et pas du gouvernement français ${ }^{275}$. Très bon technicien, son caractère trop tranché - qui apparaît bien

273. Robert Marjolin séjourna à Yale. Voir Robert Marjolin, Le travail d'une vie..., op. cit., p. 40. Pierre Uri séjourna à Princeton et rencontra après la guerre l'économiste américain Robert Nathan, proche de F. D. Roosevelt. Voir Jérôme Wilson, «Aux origines de l'ordre juridique communautaire » in Annales d'études européennes de l'université catholique de Louvain, volume 7, 2003-2004, p. 20.

274. Michel Dumoulin, Spaak, Racine, Bruxelles, p. 505.

275. Robert Marjolin, Le travail d'une vie..., op. cit., p. 296 et Hanns Jürgen Küsters, Fondements..., op. cit., p. 168. 
dans ses mémoires ${ }^{276}$ - rendait toutefois difficile son affectation à une fonction diplomatique ou politique ${ }^{277}$.

Des proches collaborateurs du président du Conseil et de ses ministres ont, par contre, joué un rôle très important dans la négociation intergouvernementale du traité de Rome. Le premier, Émile Noël est à la fois un Européen militant et un proche de Guy Mollet, qu'il assista dans ses fonctions de président de l'Assemblée consultative du Conseil de l'Europe ${ }^{278}$. Ses archives laissent entrevoir sa fonction de proche conseiller du président du Conseil pour un nombre de dossier impressionnant mais pas l'intégration économique ${ }^{279}$.

Enfin, Georges Vedel, professeur de droit et membre du cabinet de Maurice Faure, a joué un grand rôle dans les questions institutionnelles, même si les témoins sont partagés sur son influence dans ce domaine ${ }^{280}$.

Le reste des décideurs de l'administration française est très majoritairement hostile au Marché commun, à deux exceptions près, les hauts fonctionnaires européistes mais isolés, et ceux qui sont favorables au Marché commun non par européisme, mais par simple libéralisme. Le premier camp est animé notamment par le directeur des Finances extérieures, Jean Sadrin ${ }^{281}$. Une autre personnalité à la fois libérale et europhile apparaît dans les archives, Jean-François Deniau. Très jeune (il est né en 1928), il n'a d'influence que par sa coopération

276. Par exemple sur sa responsabilité dans la création de la CEE : «Pour moi, j'ai usé les circonstances pour introduire ce Marché commun dans la résolution de Messine, j'ai conçu et écrit le rapport Spaak, j'ai réalisé tous les accords difficiles dans la négociation du traité de Rome. Alors, père du Marché commun ? [...] C'est en France qu'on commence maintenant à le reconnaître, il arrive qu'on me présente comme l'auteur du traité de Rome ou qu'on me demande comment j'apprécie les conséquences lointaines de ce que j'ai fait. Il y a des jours où j'ai besoin de me dire qu'il s'agit, après tout, du plus grand événement du demi-siècle », in Pierre Uri, Penser pour l'action. Un fondateur de l'Europe, Odile Jacob, Paris, 1991, p. 137.

277. Katja Seidel, « Gestalten statt Verwalten : Der Beitrag von Europabeamten zur Europäischen Integration », in Jürgen Elvert und Michael Salewski, Historische Mitteilungen, Band 18. 2005, Franz Steiner verlag, Stuttgart, 2006, p. 141.

278. Gérard Bossuat, «Émile Noël : un grand serviteur de 1'Europe communautaire », in Michel Dumoulin (dir.), La Commission européenne, 1958-1972. Histoire et mémoire d'une institution, Communautés européennes, Bruxelles, 2007, p. 213-227.

279. Le fonds Émile Noël est déposé aux archives de l'UE à Florence. Les documents concernant ses fonctions de directeur de cabinet de Guy Mollet sont peu nombreux. Un seul concerne le Marché commun (EN 2704) et ne comprend pas de documents sur l'intégration économique européenne, en dehors de l'agriculture.

280. Témoignage minorant le rôle de Georges Vedel par Pierre Pescatore in : Pierre Pescatore, «Les travaux du "groupe juridique" dans la négociation des traités de Rome », in Studia Diplomatica, 1-4 (1981), p. 163, cité in : Corinne Schröder et Jérôme Wilson, «Europam Esse Construendam : Pierre Pescatore und die Anfänge der Europaïschen Rechtsordnung », in Jürgen Elvert, Michael Salewski (éd.), Historische Mitteilungen, (HRMG Band $18: 2005$ ), Franz Steiner Verlag, Stuttgart, 2006, p. 169.

281. ARAM, 52 J 114, note de Jean Sadrin, directeur des Finances extérieures, 28 avril 1956. 
avec Marjolin, qu'il assiste dans son travail de promotion du Marché commun tant auprès du patronat, que de l'administration ou de l'opinion publique. Il s'impose rapidement comme un des spécialistes incontesté du traité de Marché commun en rédigeant le Que sais-je ? sur le Marché commun à la demande de Robert Marjolin ${ }^{282}$. Il y met en valeur les spécificités et les aspects stimulants de l'intégration économique européenne.

D'autres décideurs administratifs sont favorables au Marché commun non par européisme mais par attachement au retour aux mécanismes du libre marché. C'est le cas notamment de Roger Goetze, le directeur du Budget, dans sa note d'analyse du rapport Spaak ${ }^{283}$, mais aussi d'un jeune inspecteur des finances membre du cabinet de Paul Ramadier, Claude Pierre-Brossolette, qui est sur la même ligne ${ }^{284}$. En mai 1956, il n'hésite pas à critiquer vigoureusement la thèse classique de l'impossibilité pour la France de profiter de l'ouverture des marchés en raison du niveau de ses charges sociales et fiscales ${ }^{285}$. Il montre que d'autres pays exportateurs ont des salaires plus élevés que la France (États-Unis, Grande-Bretagne). Il conseille enfin de pratiquer une dévaluation véritable et complète, et d'arrêter de subventionner les industries les moins compétitives. Le projet de Marché commun n'est donc pas défendu par européisme mais pour la logique de stimulation par la libéralisation des échanges qu'il apporte. Par ailleurs, d'autres types de coopérations européennes sont envisagés.

\section{LES AUTRES MODÈLES D'EUROPE}

Le modèle du Marché commun, qui repose à la fois sur l'échelle des Six et l'intégration totale des économies, ne fait pas l'unanimité parmi les promoteurs de la construction européenne. Ainsi, Jean Monnet, le principal promoteur de la CECA, s'intéressait plus au projet d'Euratom qu'à celui de Marché commun. Lors de la négociation des futurs traités de Rome, Jean Monnet

282. ASGCI, 1991.004, art. 4, lettre du PDG des Presses universitaires françaises, Paul Angoulvent à Jean-François Deniau du 3 avril 1957 faisant référence à Robert Marjolin. Réponse positive le 8 avril 1957.

283. Voir plus haut ; ARAM, 52 J 114, note de Roger Goetze du 7 mai 1956.

284. Né en 1928, fils du résistant Pierre Brossolette, inspecteur des finances, chargé de mission au cabinet de Paul Ramadier (1956). Collaborateur de Valéry Giscard d'Estaing, il fut par la suite secrétaire général de la présidence de la République (1974-1976) puis président du Crédit lyonnais (1976-1982).

285. ARAM, 52 J 114, note du ministre du 2 mai 1956 et note de Claude Pierre-Brossolette du 4 mai 1956. 
mobilise son Comité d'action pour les États-Unis d'Europe exclusivement vers l'Euratom. Jean Monnet a d'ailleurs choisi d'exclure les milieux industriels de son comité d'action, qui ne regroupe que des représentants des partis politiques et des syndicats de travailleurs, alors même que le Marché commun intéresse au premier chef les industriels. Son désintérêt pour le Marché commun dans un premier temps est confirmé par ses mémoires ${ }^{286}$, les biographies de son ancien collaborateur François Duchêne et du journaliste Éric Roussel ${ }^{287}$, comme par d'autres témoins ${ }^{288}$. Ainsi, en septembre 1956, alors que la négociation sur le Marché commun est dans une grave impasse, Jean Monnet tente de convaincre Adenauer de la nécessité d'accélérer la négociation d'Euratom, pour conclure ce traité avant celui du Marché commun ${ }^{289}$.

De plus, Jean Monnet ne perçoit pas bien l'intérêt économique spécifique de ce projet. Il a donc une opinion très positive du projet britannique de ZLE à ses débuts. En octobre 1956, le Comité d'action salue l'initiative britannique de $Z_{L E}{ }^{290}$. En mars 1957 encore, Jean Monnet écrit une lettre révélatrice à Bernard Clappier $^{291}$. Il y interprète la ZLE comme une simple association à la CEE, qu'il faut encourager, alors que des observateurs plus attachés à la dynamique d'intégration économique du Marché commun se méfient du projet britannique dès cette époque. Monnet reste cependant l'un des principaux promoteurs de l'Europe des Six, forme d'organisation qui n'est cependant pas naturelle, tant l'échelle de la Grande Europe reste prégnante.

L'OECE manifeste le succès d'une coopération économique à l'échelle de la « Grande Europe », qui se définissait à cette époque comme l'ensemble des pays européens du bloc occidental. Cette organisation est particulièrement défendue à la DAEF du ministère des Affaires étrangères, elle-même chargée des relations avec l'OECE. L'attachement de son directeur, Olivier Wormser, au modèle de l'OECE par rapport à celui de la CECA avait déjà été observéén

286. Jean Monnet, Mémoires, Fayard, livre de poche, volume 2, 1976, chapitre XVI : Le Comité d'action pour les États-Unis d'Europe (1955-1975), p. 603-644.

287. François Duchêne, Jean Monnet..., op. cit., p. 292 et 306 ; Éric Roussel, Jean Monnet, Fayard, Paris, 1996, p. 689 et 709.

288. Christian Pineau in Enrico Serra (dir.), La relance européennes... op. cit., p. 282.

289. François Duchêne, Jean Monnet..., op. cit., p. 297.

290. Jean Monnet, Mémoires, Fayard, livre de poche, volume 2, 1976, p. 673. On peut mettre en parallèle les déclarations pessimistes sur la ZLE tenu au même moment par Marjolin à ses interlocteurs britanniques : PRO, FO 371/122037, folio 16, doc 611/310, note de RF Bretherton du 18 octobre 1956, entretien avec Robert Marjolin du 17 octobre 1956.

291. AFJM, AMK C 14/3/48, lettre de Jean Monnet à Bernard Clappier, 5 mars 1957.

292. Gérard Bossuat, «La vraie nature de la politique européenne de la France (1950-1957) », in Gilbert Trausch (éd.), Die Europaïsche Integration..., op. cit., p. 195. 
Wormser semble s'inscrire dans la ligne de celui qui a lancé sa carrière au Quai d'Orsay, René Massiglii ${ }^{293}$, lui-même hostile à toute forme de construction européenne négligeant l'axe franco-britannique. Face au Marché commun, c'est surtout l'adjoint de Wormser, François Valéry qui se distingue par une défense précoce et assidue du projet britannique de ZLE. Le raisonnement de François Valéry repose sur une mise en valeur de l'alliance traditionnelle avec la Grande-Bretagne au détriment d'une Allemagne toujours menaçante ${ }^{294}$. Cette orientation se percevait déjà dans les postes précédents occupés par Valéry au Quai d'Orsay. Lorsqu'il s'occupait des objectifs économiques français en Allemagne, il a représenté la ligne dure, insistant sur la permanence de la menace allemande ${ }^{295}$. Par la suite, il a suivi les débuts de la CECA par le biais du prisme du contrôle sur l'industrie allemande que la Haute Autorité pouvait exercer ${ }^{296}$. Valéry représente donc la vision traditionnelle qui assigne à la construction européenne une fonction de surveillance de l'encombrant voisin allemand.

L'autre diplomate défendant un attachement à la logique de l'OECE est Alain Peyrefitte. Le futur ministre et académicien est chargé, au sein de la sousdirection des organisations européennes de la direction d'Europe, de suivre la négociation du Marché commun. Dans une note du 27 décembre 1956, il défend, comme François Valéry, le modèle de la « Grande Europe », tout en soulignant le caractère incontournable du Marché commun ${ }^{297}$. Hostile à une concentration exclusive sur la « Petite Europe » toujours suspecte de prétentions fédérales, il défend une organisation européenne fondée sur le duo Marché commun-ZLE. Le Marché commun est perçu comme une étape nécessaire pour aboutir à un autre type d'organisation européenne plus large.

Ainsi existe au sein du ministère des Affaires étrangères une ligne favorable à une coopération européenne poussée, mais dans un cadre plus vaste et moins supranational que celui de la CECA ou du futur Marché commun. Pour ces diplomates, l'échelle des Six offre deux inconvénients. D'abord elle implique

293. Raphaële Ulrich-Pier, René Massigli..., op. cit., p. 1295 ; René Massigli, Une comédie des erreurs, 1943-1956. Souvenirs et réflexions sur une étape de la construction européenne, Plon, Paris, 1978, p. 505.

294. AMAE, DECE 740, n 29, note de François Valéry, 26 juillet 1956 ; AMAE, DECE 740, $\mathrm{n}^{\circ} 48$, note de François Valéry, 9 octobre 1956 ; AMAE, DECE 614, n 107, note François Valéry, 22 décembre 1956.

295. Sylvie Lefèvre, Les relations économiques franco-allemandes de 1945 à 1955. De l'occupation à la coopération, Comité pour l'histoire économique et financière de la France, Paris, 1998, p. 158.

296. AMAE, DECE 544, nº 98, note François Valéry, 5 mai 1953.

297. AMAE, DECE 740, folio n 149, note d'Alain Peyrefitte du 27 décembre 1956. 
un éloignement de la Grande-Bretagne et un rapprochement avec la RFA dont la puissance industrielle effraie. Ensuite, elle tend à diviser l'Europe occidentale, ce qui est inacceptable dans un contexte de guerre froide.

\section{E. CONCLUSION : DES PROMOTEURS DU TRAITÉ DE ROME PEU NOMBREUX ET DIVISÉS}

Le Marché commun à Six n'est pas la seule voie possible de coopération économique en Europe. Pour certains partisans de l'Europe communautaire comme Monnet, ou les socialistes très attachés à l'Europe franco-britannique (Mollet, Pineau), ce projet est perçu comme intéressant mais insuffisant, tandis que sa dynamique d'intégration économique n'est pas comprise. Pour d'autres, comme les libéraux purs, seule une réforme d'un dirigisme étatique perçu comme inefficace compte. Dans ce cadre, le Marché commun peut être utile. Enfin, un troisième groupe, très important au sein des décideurs politiques (Mendès France, Ramadier) et administratifs (DAEF du Quai d'Orsay), estime que la dynamique de l'OECE doit rester première, car elle manifeste la permanence de l'alliance préférentielle entre la France et la Grande-Bretagne, face à une RFA toujours menaçante, si ce n'est militairement, du moins économiquement. Ce dernier groupe est renforcé par la grande méfiance des « fonctionnaires modernisateurs » envers une dynamique de libéralisation de l'économie qui menace les bases essentiellement dirigistes de leur projet réformateur pour la France.

Cet attachement à l'OECE explique la bonne réception du projet britannique de ZLE, qui s'impose naturellement dans l'agenda des décideurs français alors même que ce projet ne comporte aucune des garanties négociées âprement par la France dans le cadre des Six (tarif extérieur commun, harmonisations, etc.). Seule une minorité souligne les défauts économiques de ce projet, pour mieux défendre les avantages du traité de Marché commun pour la France. La CEE seule permet en effet un retour à la libéralisation des échanges dans un cadre protecteur. Ce groupe de partisans du Marché commun et d'opposants à la ZLE est animé par Robert Marjolin, qui occupe un rôle charnière entre des décideurs politiques favorables au Marché commun mais qui en comprennent mal la dynamique économique (Mollet, Pineau), des décideurs administratifs très majoritairement hostiles et des milieux économiques divisés. En leur sein, l'engagement en faveur du traité de Rome d'un petit groupe à la tête du CNPF, derrière Georges Villiers, est décisif pour donner des arguments aux partisans du Marché commun. Les partisans du Marché commun sont donc à la fois peu nombreux et divisés. Ils parviennent toutefois à faire accepter un traité de Rome original. 


\section{LE TRAITÉ DE ROME FACE AUX POSITIONS FRANÇAISES}

Le traité de Rome du 25 mars 1957 créant la CEE repose sur deux compromis, en matière institutionnelle et dans le domaine économique. Cet équilibre définit l'originalité du traité CEE qui s'inscrit en décalage par rapport à la position française.

\section{A. L'ÉQUILIBRE DU TRAITÉ DE ROME}

Le traité de Rome établit une Communauté économique européenne qui repose sur un double équilibre, institutionnel et économique.

\section{Un système institutionnel mixte.}

L'objectif de la CEE est d'éviter à la fois les insuffisances de l'OECE, dont l'efficacité est minée par une structure strictement intergouvernementale, et les excès supranationaux de la CECA - qui s'est révélée peu efficace dans certains domaines - et surtout de la CED-CPE - qui a fait craindre une disparition des États-nations. Pour cela, la CEE repose sur un moteur, dont les deux organes, la Commission européenne et le Conseil des ministres, fonctionnent de manière interdépendante. La Commission est constituée de neuf personnalités indépendantes des États membres mais nommés par ces derniers. Elle doit représenter l'intérêt de la Communauté dans son ensemble et est la gardienne des traités. Le Conseil des ministres est constitué de représentants des États membres. Leur interdépendance est manifestée par une relation étroite : la Commission a le monopole du pouvoir de proposition, et le Conseil celui de les voter, et de les transformer en décision. Il délègue ensuite leur application à la Commission européenne, qui s'appuie en général sur les administrations nationales. Les pouvoirs législatifs et exécutifs sont donc inextricablement partagés et liés.

Par rapport à la CECA, la logique intergouvernementale des institutions est renforcée. Le Conseil CEE a beaucoup plus de pouvoirs par rapport à la Commission européenne que le Conseil CECA n'en avait par rapport à la Haute Autorité. La Haute Autorité avait un pouvoir de décision propre important et elle cooptait son neuvième membre. Cependant, la Commission peut compter sur une dynamique supranationale car le recours au vote à la majorité qualifiée au sein du Conseil doit s'accroître de manière progressive, au fur et à mesure du passage d'étape.

En plus de cet exécutif double, à la fois supranational et intergouvernemental, la $\mathrm{CEE}$ constitue une communauté juridique propre, grâce à la $\mathrm{CJCE}$, qui 
est reprise de la CECA en étant renforcée ${ }^{298}$. Arbitre entre les institutions communautaires, elle constitue aussi un tribunal suprême pour l'application d'un droit interne qui, contrairement au droit international, est directement applicable et n'a pas besoin de transposition. En effet, la CJCE de la CECA a été fondée non pas sur le droit international mais sur le droit administratif français, en raison du rôle des conseillers d'État français dans sa conception ${ }^{299}$. Le traité de Rome introduit une prérogative supplémentaire avec l'article 177. Il n'établit pas seulement un droit pour la CJCE d'interpréter le traité pour les institutions de la CEE (Conseil, Commission), mais aussi pour les tribunaux nationaux, qui doivent la consulter sous forme de questions préjudicielles. Un lien direct est ainsi établi entre le système judiciaire national et son homologue communautaire, sans l'écran des administrations nationales. La CJCE n'est donc pas qu'une juridiction de dernier ressort (comme la Cour de cassation), elle crée un ordre juridique propre. D'ailleurs, l'article 189 permet à la Commission de prendre des règlements qui sont directement applicables, tandis que l'article 192 autorise la Commission à prendre des décisions individuelles, envers un État membre ou un particulier, y compris avec des sanctions pécuniaires. Ce sont des actes juridiques directement applicables sans interventions nationales.

Ainsi, la CJCE participe à la formation d'un ordre juridique communautaire directement applicable. Aux côtés du Conseil des ministres et de la Commission européenne, elle constitue une institution essentielle car les deux autres (l'Assemblée parlementaire européenne et le Comité économique et social) ont des fonctions essentiellement consultatives. Le traité de Rome assure donc, sur le plan institutionnel, un équilibre entre les logiques intergouvernementales et supranationales, dont la balance n'est pas fixée de manière irréversible et dépendra largement de son interprétation ultérieure. Ce dispositif institutionnel mixte est complété par une dynamique économique ambitieuse.

\section{Une union économique potentielle.}

L'intégration économique repose sur la fusion des économies. La CEE compte mettre en œuvre cette dynamique à la fois par l'intégration négative

298. Morten Rasmussen, «The Origins of a Legal Revolution. The Early History of the European Court of Justice », in Revue d'histoire de l'intégration européenne, 2008/2, p. 83-91.

299. Jérôme Wilson, « Jurisconsultes et conseillers d'État : aux origines de l'ordre juridique communautaire ", in Revue d'histoire de l'intégration européenne, 2008/2, p. 35-55 ; Michel Mangenot, « Le Conseil d'Etat et l'institutionnalisation du système juridique communautaire ", intervention au colloque CRPS-CURAPP/groupe Polilexes, Les juristes et la construction d'un ordre politique européen, Amiens, 2004. 
(la suppression des obstacles) et l'intégration positive (les mesures volontaires d'harmonisation, de coordination ou de mise en commun). Mais cette union économique n'est que potentielle dans la mesure où elle n'est définie que dans ses grandes lignes dans le traité, à travers trois mécanismes déjà présents dans le rapport Spaak : un véritable marché commun libéral, un processus d'harmonisation des distorsions de concurrence les plus flagrantes, et une coordination des politiques économiques.

Tout d'abord, la CEE repose sur la conviction que la libération des échanges augmente la croissance et la productivité tout en diminuant les risques de conflits par l'interpénétration commerciale des États. Le contre-exemple des années trente joue à plein pour soutenir cette doctrine libérale, tant sur les plans économiques (ouverture des marchés) que politiques (préservation des libertés individuelles).

Techniquement, la solution adoptée par la CEE est celle de l'union douanière, c'est-à-dire d'une zone où tous les obstacles douaniers et contingentaires sont supprimés en interne, tandis qu'une politique commerciale commune (tarif douanier commun notamment) lie les États membres dans leurs rapports avec le reste du monde. L'union douanière est établie lors d'une période transitoire de douze à quinze années, divisée en trois étapes. Le passage entre la première et la deuxième étape se fait par décision à l'unanimité, puis à la majorité qualifiée s'il est retardé de plus de deux ans. Ainsi, même si la France voulait bloquer la libération des échanges, elle ne pourrait le faire de manière unilatérale que pendant deux années. La libération des échanges de marchandises est complétée par des clauses sur la libre circulation des travailleurs et des capitaux, ainsi que la libre prestation de services. Par ailleurs, le développement d'une politique de la concurrence doit empêcher que les entreprises ou les États n'établissent de nouvelles restrictions aboutissant à augmenter les prix.

Enfin, exception à la libération des échanges, la situation spécifique de la France est reconnue. Elle peut conserver son régime de taxes à l'importation et d'aides à l'exportation mais il fait l'objet d'une étroite surveillance communautaire. D'une manière générale, aucune dérogation unilatérale aux obligations du traité de Rome n'est possible, sauf clauses de sauvegardes avec procédure communautaire (articles 108, 109 et 226).

Deuxième aspect, complémentaire de la logique libérale, une harmonisation des conditions de concurrence doit être établie dans des cas spécifiques. Ainsi, en matière sociale, l'article 119 prévoit l'application du principe d'égalité de rémunérations entre hommes et femmes. L'article 120 se borne à prévoir que : «Les États membres s'attachent à maintenir l'équivalence existante des régimes de congés payés ». L'harmonisation est donc déjà censée exister 
dans ce domaine, ce qui revient à nier toutes les prétentions françaises à fonder leur handicap de compétitivité sur un système social plus avancé. Enfin, l'harmonisation de la base de rémunération des heures supplémentaires ne fait pas l'objet d'un article mais d'un protocole, qui accorde à la France une clause de sauvegarde sectorielle sous le contrôle de la Commission en cas de défaut d'harmonisation ${ }^{300}$. Les harmonisations du cadre fiscal et législatif sont limitées car elles ne peuvent se faire qu'après un vote à l'unanimité des membres du Conseil.

Sur le plan macroéconomique, la coordination des politiques économiques et monétaires est limitée aux seuls éléments susceptibles de menacer la libération des échanges. L'équilibre de la balance des paiements doit donc être recherché (article 105) et, en cas de problèmes graves susceptibles de remettre en cause l'ouverture des marchés, des procédures d'aides fortement communautarisées sont prévues en cas de difficultés de balances des paiements (article 108 et 109), de difficultés sectorielles (article 226) ou de troubles liés à la libération des mouvements de capitaux (article 73). Un comité monétaire est toutefois institué pour coordonner les politiques monétaires. L'essentiel de l'harmonisation des conditions de production est laissé à la dynamique concurrentielle issue de l'ouverture des marchés, dont la régulation doit être assurée par une politique de la concurrence commune. Elle exprime donc un libéralisme régulé de l'« Europe arbitre ».

Dernier élément, le traité de Rome prévoit des clauses d'exception à cette dynamique libre-échangiste, en particulier dans deux dossiers intéressants la France, l'agriculture et les pays et territoires d'outre-mer. Pour ces derniers, l'accord d'association prévoit un transfert financier des Six vers des territoires qui sont majoritairement français (ou en passe de devenir indépendant mais sous influence française). Les négociations ont d'ailleurs été particulièrement difficiles, les partenaires de la France étant très peu intéressés par une solidarité coûteuse avec des colonies et ex-colonies françaises représentant des marchés peu solvables ${ }^{301}$. Sur un plan plus général, deux instruments la BEI (Banque européenne d'investissement) et le FSE (Fonds social européen), sont créés pour concrétiser les projets de « fonds d'investissement » et du « fonds de réadaptation » du rapport Spaak. Ils sont destinés à prendre en charge des fonctions que le marché ne peut pas assurer : le financement de certains investissements pour

300. Traité de Rome, « Protocole relatif à certaines dispositions intéressant la France », point 2.

301. Sur ces difficiles négociations : Guia Migani, La France et l'Afrique Subsaharienne..., op. cit., p. 52-63. 
la BEI, et la mobilité géographique et professionnelle des travailleurs pour le FSE. La BEI doit cependant fonctionner comme une banque, et se concentrer sur des projets rentables ${ }^{302}$. La CEE a donc une ambition économique importante, qui se traduit par l'appellation "Communauté économique européenne ", qui remplace au début de 1957 celle, plus exclusivement libre-échangiste, de « Marché commun ${ }^{303}$ ».

Le traité de Rome est donc un traité-cadre dans le domaine de l'union économique. Il définit un équilibre entre les deux formules d'unification économique de l'Europe, l'« Europe arbitre » du libéralisme régulé d'un côté, et l'Europe volontariste, plus timide mais visible à travers les clauses d'harmonisation des politiques économiques ou d'exceptions à la dynamique libérale d'un autre côté. La conception générale est proche de celle développée dans le rapport Spaak, même si certains aspects sont moins ambitieux. L'objectif central reste la libération des échanges, au service de laquelle une intégration négative très aboutie est mise en œuvre. L'intégration positive, c'est-à-dire les processus d'harmonisation, de coordination et de création d'action commune, est circonscrite aux distorsions de concurrence les plus flagrantes ou aux secteurs en marge par rapport aux lois du marché. Les potentialités d'intégration économique restent importantes, surtout si elles se combinent avec les dynamiques institutionnelles décrites précédemment. Cet équilibre entre Europe arbitre et Europe volontariste d'une part, Europe intergouvernementale et Europe supranationale d'autre part, définit l'originalité de la CEE. Elle manifeste la pertinence de l'échelle de la « Petite Europe », la seule possible pour une coopération si ambitieuse, et de la voie économique, après l'échec de la CED et de la CPE. Ces équilibres définissent un traité original, issu de compromis défini à Six qui est forcément insatisfaisant par rapport à la position initiale de chacun. C'est particulièrement le cas pour la France.

\section{B. LE DÉCALAGE FACE AUX REVENDICATIONS FRANÇAISES}

L'équilibre défini par le traité de Rome est certes original mais il ne répond que très partiellement aux demandes françaises en matière d'intégration économique.

302. Éric Bussière, Michel Dumoulin, Émilie Willaert (dir.), La Banque de l'Union européenne. La BEI, 1958-2008, Imprimerie Centrale, Luxembourg, 2008.

303. Ce changement intervient après la conférence des 19 et 20 février 1957 à Paris ; AN, F60, 3112, note DG politique Europe, sous-direction des organisations européennes, 19 mars 1957. 


\section{L'absence de contre-proposition française.}

Dans la négociation du traité de Rome, la France a concentré une grande partie de ses efforts sur des objectifs extérieurs au Marché commun proprement dits comme l'association des territoires d'outre-mer, ou sur l'obtention de garanties négatives largement illusoires. Les trois concessions principales obtenues par la France sont temporaires et, de toute façon, gérées de manière communautaire. La première concerne le passage de la première à la seconde étape. La France a obtenu l'unanimité mais elle ne peut jouer que pendant deux ans, à l'issue desquels la majorité qualifiée s'impose. La seconde est constituée par l'ensemble des clauses de sauvegarde mais elles sont toutes gérées de manière communautaire. La troisième concession, enfin, concerne le protocole accordé à la France concernant le système de taxes à l'importation et d'aides à l'exportation. Là aussi, c'est une procédure communautaire qui s'applique pour sa gestion. Les décideurs français n'ont donc pas réussi à se soustraire à la dynamique libre-échangiste du Marché commun car ils se sont concentrés sur un combat défensif.

Les décideurs français n'ont pas pu développer une contre-proposition crédible. Chronologiquement, la première forme de marché commun industriel volontariste que la France avait mis en avant était le fonds d'investissement dirigiste. Transposition à l'échelle européenne de l'interventionnisme français, cette proposition était non seulement difficilement acceptable par les partenaires de la France, mais également par la France elle-même en raison des transferts importants de souveraineté qu'elle impliquait. Le fait que le traité de Rome contienne une BEI peut difficilement être perçu comme une concession importante faite à la France dans la mesure où tous les mémorandums présentés avant la conférence de Messine, y compris celui de la RFA ${ }^{304}$, comprenaient la nécessité de prévoir un organisme de ce type. Les décideurs français ont également évoqué, dans le projet de mémorandum français de mai 1956, l'adoption par les instances européennes de méthodes proches de la planification française mais cette exigence n'est plus défendue par la suite.

La coopération en matière monétaire n'avait pas fait l'objet de beaucoup de développement dans le rapport Spaak. Cela avait été remarqué notamment par de nombreux hauts fonctionnaires ${ }^{305}$. Dans ce domaine, la France a obtenu de

304. Mémorandum des trois pays du Benelux du 18 mai 1955 ; mémorandum du gouvernement italien sur la poursuite de l'intégration du 27 mai 1955 ; mémorandum du gouvernement fédéral sur la poursuite de l'intégration du $1^{\text {er }}$ juin 1955 ; voir www.ena.lu ; textes tirés de : Pour une Communauté politique européenne, Travaux préparatoires (1955-1957). Tome II, 1955-1957, Bruylant, Bruxelles, 1987.

305. ARAM, 52 J 115, note finex, signée Sadrin, du 16 janvier 1957 ; AFJM, ARM 15/1/2, note de Claude Gruson, SEEF, pour le président Ramadier, 17 janvier 1957 ; Jean-François Deniau, Le Marché commun, PUF, Que sais-je ?, Paris, 1958, chapitre 2.5. 
véritables concessions avec la création du Comité monétaire et les clauses de sauvegarde de l'article 108, incluant un « concours mutuel » qui peut prendre la forme d'une aide financière. Cependant, le problème de fond subsiste : si les partenaires européens de la France reviennent à une libre convertibilité de leur monnaie sans la France, toujours paralysée par ses déséquilibres de balance des paiements, cette dernière sera isolée en Europe.

Comment expliquer cette absence de contre-proposition française crédible et défendue de manière constante en matière d'intégration positive ? Trois éléments peuvent être avancés. Tout d'abord, l'échec de la CECA dans ses ambitions les plus volontaristes a dû inciter les négociateurs français à une certaine modestie. Le traité de Paris a accordé de très larges prérogatives économiques et sociales à la Haute Autorité mais son action a été jugée relativement modeste ${ }^{306}$. Un autre argument réside dans les spécificités du modèle économique et financier français, difficilement applicable au plan européen sans de très lourdes délégations de souveraineté.

Enfin, dernier élément, au-delà des aspects structurels, l'opposition majoritaire de l'administration française au traité de Marché commun l'a sans doute empêché de bâtir une alternative crédible en termes de modèle positif d'intégration économique et industrielle. Le Marché commun n'était qu'un projet de coopération européenne parmi d'autres, qui n'est pas destiné à un avenir plus brillant que l'OECE ou la CECA, et peut même sombrer comme la CED ou la CPE. Au moment de la signature du traité de Rome, sa mise en œuvre paraît en effet très aléatoire.

\section{Une difficile application de la CEE.}

Depuis le début de l'année 1956, si l'activité économique est soutenue, les équilibres financiers, tant internes (budgétaires) qu'externes (balance des paiements) sont précaires en raison de la politique économique du gouvernement fondée sur le soutien à la demande intérieure. Ces déséquilibres ont pu être supportables pendant un temps, dans la mesure où la France disposait de réserves en devises confortables. Mais la guerre d'Algérie provoque des dépenses exceptionnelles, sources de déficit budgétaire, et une tension sur le marché du travail. Sous la menace d'une inflation excessive, le gouvernement pratique alors une politique des prix coûteuse, fondée sur une subvention des prix de certaines denrées qui entrent dans le calcul de l'indice. Ainsi, des tendances

306. Raymond Poidevin, Dirk Spierenburg, Histoire de la Haute Autorité de la CECA, Bruylant, Bruxelles, 1993, p. 865. 
structurelles - les difficultés de la balance commerciale, une politique fondée sur la demande - se conjuguent avec des difficultés conjoncturelles - Suez, la guerre d'Algérie - pour grever lourdement la balance des paiements française. Cette situation a des répercussions sur le système institutionnel. Ainsi, c'est le rejet d'un programme massif d'économie budgétaire qui provoque la chute du gouvernement Mollet le 21 mai $1957^{307}$.

Au-delà, la position internationale de la France souffre d'un creusement des déficits de la balance commerciale et des comptes publics. Bien plus, le 14 mars 1957, des mesures de restriction des échanges sont prises. La taxe de $15 \%$ à l'importation est généralisée, alors qu'auparavant des taux différents étaient en vigueur. L'OECE accepte ces mesures mais estime que les causes structurelles du déficit, une politique trop favorable à la demande, doivent être corrigées $^{308}$. La contrainte extérieure devient ainsi plus concrète. Le directeur de la DAEF, Olivier Wormser, demande d'ailleurs des réformes profondes de la politique économique française justement pour restaurer l'autorité internationale de la France ${ }^{309}$. À défaut les créanciers de la France pourront faire pression sur elle, et notamment les États-Unis dans le règlement du problème algérien. Cette position de faiblesse accentue la menace que peut représenter la ZLE sur l'application de la CEE.

\section{La menace de la ZLE sur la vision française de la CEE.}

La CEE offre des avantages objectifs à la France si elle est appliquée conformément à ses intérêts. Les analyses du traité de Rome par le Quai d'Orsay en mars 1957 sont ainsi beaucoup plus modérées que les positions qui se sont exprimées au cours de la négociation. La direction politique reconnaît que les institutions sont plus intergouvernementales que pour la CECA, et donnent globalement satisfaction à la France ${ }^{310}$. La DAEF souligne que la France a obtenu de nombreuses concessions économiques ${ }^{311}$. Cependant la note remarque que dans de nombreux domaines qui intéressent la France, seuls les principes

307. Jean-Paul Brunet, «La politique économique et sociale du gouvernement de Guy Mollet », in Bernard Ménager et alii (éd.), Guy Mollet. Un camarade en République, PUL, Lille, 1987, p. 437.

308. AMAE, POW 78, folio 2, secrétariat du Conseil OECE, rapport sur la situation économique, 25 mars 1957.

309. AMAE, POW 77, folio 172, note d'Olivier Wormser du 22 février 1957.

310. AMAE, DECE 636, folio 37, note AP, direction Générale politique, sous-direction des organisations européennes, 19 mars 1957.

311. DDF, 1956-III, doc $n^{\circ} 262$, note de la DAEF, sans doute de François Valéry, sur le projet de traité de marché commun, 5 décembre 1956. 
sont définis. Des négociations ultérieures sont donc nécessaires et peuvent se révéler difficiles. Pour pouvoir bénéficier des contreparties à la libération des échanges, la France doit d'abord ouvrir ses marchés, sinon les Cinq ne seront pas intéressés par la poursuite d'une coopération préférentielle avec elle. Cette hypothèque sur l'application du traité de Rome est renforcée par le développement du projet de ZLE.

Si la ZLE est considérée comme un projet incontournable, elle ne comporte pas de mécanismes régulateurs et compensateurs de la libération des échanges qui intéressent la France. Elle exclut de son champ de compétence à la fois le Commonwealth et l'agriculture ce qui désavantage la France pour trois raisons. Sur le plan industriel en premier lieu, le fait pour l'industrie britannique de disposer d'un énorme marché préférentiel comme le Commonwealth, beaucoup plus important que l'ex-Empire colonial français, lui permet de produire en grande série et donc de diminuer ses coûts de revient. Sur le plan agricole en second lieu, la France ne pourrait obtenir dans le cadre de la ZLE les mêmes avantages que dans le Marché commun. Enfin et surtout, la France a obtenu dans le traité de Rome des compensations financières pour les charges que lui imposent ses territoires d'outre-mer. Il lui serait impossible d'obtenir les mêmes concessions dans le cadre de la ZLE.

Dès lors se profile le risque que la ZLE infléchisse la CEE dans un sens moins favorable à la France si ses cinq partenaires se lassent de sa mauvaise volonté. Le problème de la compatibilité entre la CEE et la ZLE se pose ainsi. Si certains des Cinq estiment qu'une ZLE est suffisante, ils ne s'investiront pas dans les mécanismes les plus intégrateurs de la CEE dont la France attend beaucoup. D'ailleurs, les plus fervents promoteurs de la ZLE comme Harold Macmillan pensaient que la ZLE pourrait être conclue sans la France ${ }^{312}$. La ZLE risque donc au minimum de faire évoluer les mécanismes de coopération économique européenne - OECE, CEE et ZLE - dans un sens plus éloigné des préoccupations françaises, et au pire de menacer la CEE voire d'isoler la France, murée dans son protectionnisme.

Au moment de sa signature, le 25 mars 1957, l'application du traité de Rome selon les intérêts de la France est donc menacée à la fois par ses difficultés financières et par le projet complémentaire, ou alternatif, de ZLE.

312. Document britannique du 6 novembre 1956 cité par Wolfram Kaiser, Using Europe..., op. cit., p. 94. 


\section{CONCLUSION : LA FRANCE ET LA NÉGOCIATION DU TRAITÉ DE ROME}

Trois explications complémentaires peuvent être avancées pour expliquer le choix du traité de Rome par les décideurs français : le poids de la contrainte extérieure, le rôle décisif d'un petit groupe d'acteurs et les qualités intrinsèques du projet de marché commun pour la France.

\section{A. LA CONTRAINTE EXTÉRIEURE IMPOSE L'OPTION EUROPÉENNE}

À partir de 1955, la plupart des pays européens et les États-Unis envisagent un retour rapide à une libéralisation internationale des échanges car le processus de reconstruction semble terminé. Malgré des difficultés commerciales récurrentes, les décideurs français sont donc confrontés à une volonté croissante d'ouverture des marchés européens, à la fois dans le cadre de l'OECE et dans celui des Six. Dans le même temps, l'empire colonial français s'érode.

C'est dans ce contexte de déclin que le « Marché commun » s'impose sur l'agenda des décideurs français à partir de 1955. La France n'a en effet pas le choix, tant sur le plan économique - car l'exigence d'ouverture des marchés est quasi unanime dans le camp occidental, que sur le plan institutionnel. En effet, le cadre des Six s'impose comme incontournable depuis le succès relatif de la CECA, et ce malgré l'échec de la CED. La solution d'institutions supranationales reste valide d'autant plus que les excès fédéralistes sont dorénavant condamnés. Ce cadre des Six n'est pas exclusif, comme en témoigne l'invitation de la Grande-Bretagne aux travaux du comité Spaak en 1955 ou le soutien au projet de ZLE en 1956. Mais le refus des Britanniques de participer activement aux discussions du comité Spaak légitime une nouvelle fois cette échelle de coopération. La France doit donc se positionner face à une relance d'une construction européenne à la fois libérale et supranationale.

Tous ces éléments externes tendent à remettre en cause une partie des bases de la puissance française, encore largement fondée en 1955-1956, si ce n'est dans les faits du moins dans les représentations, sur le protectionnisme colonial et un rôle directeur de l'État dans l'économie. Cela explique l'opposition très large que suscite le projet de marché commun et donc, a contrario, l'importance de la mobilisation d'un petit groupe de décideurs.

\section{B. LE RÔLE DÉCISIF DES PROMOTEURS DU MARCHÉ COMMUN}

Face au projet de marché commun, le sentiment de méfiance, voire d'hostilité domine chez de nombreux hauts fonctionnaires « modernisateurs » et 
d'hommes politiques influents, notamment dans la majorité élue en 1956, comme Mendès France ou Ramadier. De plus, une grande partie d'entre eux reste attachée à d'autres modèles de construction européenne, en particulier la coopération intergouvernementale à base franco-britannique.

Face à ces opposants, un certain nombre de décideurs français se mobilisent tant dans le monde politique, qu'au sein du patronat ou de l'administration. Les hommes politiques ont l'autorité indispensable pour surmonter les réticences de l'administration. Ainsi, le pouvoir politique a imposé le rapport Spaak comme base de négociation en mai 1956, puis une position française de compromis en septembre 1956. De leur côté, les patrons favorables au Marché commun ont nourri les décideurs publics d'arguments économiques. C'est justement pour faire comprendre cette dynamique du Marché commun que Robert Marjolin joue un rôle majeur d'intermédiaire entre un pouvoir politique soucieux de renouveler les bases de la puissance française, une administration réticente et un patronat divisé mais qui se mobilise partiellement pour le Marché commun.

La cohérence de ce groupe ne doit pas être surestimée. Les déterminants politiques jouent un rôle très grand chez Mollet et Pineau, qui semblent négliger la dynamique d'intégration économique, comme en témoigne leur attitude face à la Grande-Bretagne. Cet aspect économique est au contraire fondamental dans la réflexion de certains hauts fonctionnaires comme Marjolin, Sadrin ou Deniau. Au sein de l'administration, certains s'accommodent du Marché commun non par européisme mais par libéralisme (Goetze). Au sommet du $\mathrm{CNPF}$, la défense du Marché commun se combine avec la rénovation du projet d'Europe contractuelle et la volonté d'encadrer l'interventionnisme de l'État français. La dimension économique est indispensable pour comprendre la spécificité de la CEE, et donc les défauts de la ZLE. Les premiers défenseurs de l'intégration économique par le Marché commun sont donc logiquement les premiers opposants à la ZLE. Cette hostilité se fonde sur un choix de modèle économique et pas sur un rejet a priori de la Grande-Bretagne au profit de l'Allemagne.

Par rapport aux autres projets de construction européenne, le rôle d'une minorité éclairée apparaît toujours aussi déterminant. Cependant, à l'exception de la première période (entre Messine et le rapport Spaak), ce sont les élites officielles qui ont joué le premier rôle : Guy Mollet est le président du Conseil, Georges Villiers le président du CNPF et Robert Marjolin le principal négociateur pour la partie économique. Jean Monnet n'a pas pesé de manière déterminante dans cette négociation tandis que de très nombreux hauts fonctionnaires occupant les postes les plus prestigieux n'ont pas fait ce choix du Marché commun, car il tend à remettre en cause leurs prérogatives. 
Ce rôle fondamental des toutes premières autorités françaises a été déjà été mis en valeur par Gérard Bossuat puis Craig Parsons ${ }^{313}$. Cependant, si Mollet et Pineau ont défendu le Marché commun face à une administration réticente, ils ne semblent pas en avoir compris tous les déterminants économiques. Confrontés à d'autres dossiers plus brûlants comme les « événements » d'Algérie, ils ne paraissent avoir accordé une attention particulière aux spécificités du processus d'intégration économique de la CEE. Ce malentendu explique à la fois les propositions audacieuses faites aux Britanniques par Mollet en septembre 1956 et par Pineau en mars 1957. Il permet de comprendre l'incompatibilité entre une politique extérieure fondée sur le libre-échange et une politique intérieure aggravant les déséquilibres structurels. Il explique enfin l'absence de réflexion sur les conséquences à long terme de certains choix institutionnels, déjà observée par Paul Pierson ${ }^{314}$. En effet, Mollet s'engage dans le Marché commun pour forcer la France à s'adapter à la libre concurrence internationale, mais sans pouvoir anticiper l'ensemble des obligations qui pèseront sur son pays, d'abord parce que l'application du traité de Rome est incertaine, et ensuite parce que le projet de ZLE redistribuera une nouvelle fois les cartes de la coopération économique européenne. Au contraire, certains des partisans du traité de Rome comme Marjolin avaient mieux compris ses implications économiques, et l'intérêt objectif qu'il présentait pour la France.

\section{L'INTÉRÊT ÉCONOMIQUE ET INSTITUTIONNEL DE LA CEE POUR LA FRANCE}

La CEE n'a pas été acceptée que pour des raisons de politique extérieure (la pression de ses partenaires) ou intérieure (les rapports de force entre le président du Conseil et sa majorité parlementaire, la versatilité de l'opinion publique). Elle représente aussi un compromis objectivement plus équilibré et plus intéressant pour la France que de nombreux projets alternatifs.

Le traité de Rome offre en effet une solution pour adapter progressivement la France à la libéralisation des échanges, tout en préservant les éléments du consensus économique et social français. L'ouverture des marchés est complétée par une harmonisation des distorsions de concurrence les plus sévères et par des clauses d'exception ou de compensation de la dynamique libérale. L'indépendance nationale est préservée par un système institutionnel ingénieux,

313. Gérard Bossuat, L'Europe des Français..., op. cit., p. 291-377 ; Craig Parsons, A Certain Idea of Europe..., op. cit., p. 90-116.

314. Paul Pierson, «The Path to European Integration. A Historical Institutionalist Analysis », in Comparative Political Studies, vol. 29, avril 1996, p. 137. 
qui associe étroitement dynamiques supranationales et intergouvernementales. Même les éléments de la puissance française qui semblaient le plus difficilement compatibles avec ce projet de Marché commun, l'agriculture et le lien colonial, trouvent leur place dans le traité de Rome.

L'équilibre et la flexibilité de la CEE sont à la source de son succès. Elle est à la conjonction de plusieurs modèles d'Europe. Les partisans de l'Europe politique, prudents (Mollet) ou ambitieux (Monnet) y sont favorables. Ceux qui restent attachés à la Grande-Bretagne peuvent espérer l'y associer par le biais de la ZLE. Les défenseurs de l'Europe intégrée, c'est-à-dire d'une intégration économique forte permettant à la fois à la France de s'insérer de manière inéluctable dans la dynamique libérale tout en obtenant des assurances et des compensations, sont également satisfaits (Marjolin, Deniau, Sadrin). Enfin, les milieux économiques peuvent espérer y recycler leur projet d'Europe contractuelle.

Certes, la CEE ne représente pas un accord idéal pour la France mais les accords internationaux sont toujours des compromis entre les États. Le modèle du Marché commun tel qu'il est esquissé à Messine et présenté dans le rapport Spaak n'émerge pas ex nihilo. Il s'inscrit dans un certain nombre de réflexions anciennes portant sur l'équilibre nécessaire à trouver entre des dynamiques libérales (OECE, plan Beyen, etc.) et des politiques d'organisation des marchés (discussions sur les pools sectoriels, etc.). Le même constat peut être dressé en matière institutionnelle : la CEE a tiré les leçons des insuffisances de certaines organisations (OECE, Conseil de l'Europe) et des excès de la CED-CPE. Elle reprend certaines institutions de la CECA (CJCE, APE) tout en corrigeant certains de ses défauts (pouvoirs de la Haute Autorité). Les acteurs de la négociation ne partent donc pas d'une feuille blanche mais sont contraints par les négociations antérieures, les «path depencies» décrites par les institutionnalistes historiques ${ }^{315}$.

C'est le rôle de Marjolin et de certains éléments du patronat (Villiers, Dreyfus) de mettre en valeur ces éléments objectifs qui différencient le Marché commun de projets antérieurs ou concurrents. Tout ne peut donc pas s'expliquer par le rôle des idéologies politiques ${ }^{316}$, les déterminants proprement économiques jouent aussi leur rôle même s'ils ne sont pas les seuls.

Cependant, une fois le traité de Rome signé, tout reste à faire. Alors que la France paraît de plus en plus incapable de supporter le processus de libéralisation des échanges, la CEE doit être appliquée et la ZLE doit être négociée.

315. Paul Pierson, «The Path...», op. cit., p. 130-135.

316. C'est la thèse de Craig Parsons : Craig Parsons, A Certain Idea of Europe..., op. cit. 



\section{CHAPITRE II}

\section{LA CRISE FRANÇAISE, LA CEE ET LA ZLE \\ (AVRIL 1957-MAI 1958)}

Après la signature du traité de Rome en mars 1957, la situation politique et financière de la France se dégrade et son crédit international s'en trouve affecté. Cela entraîne paradoxalement une acceptation rapide de la CEE. Dans la négociation ZLE, la France est confrontée à des choix difficiles et à un risque d'isolement.

\section{LA CRISE DE LA IV RÉPUBLIQUE}

Après la chute du gouvernement Mollet, les difficultés financières s'aggravent et touchent le crédit international de la France. Le gouvernement BourgèsMaunoury et surtout le gouvernement Gaillard tentent de réagir, tandis que le CNPF se mobilise de manière exceptionnelle pour tenter de peser sur l'adaptation de la France à la CEE. Les événements d'Algérie précipitent toutefois la crise finale de la $I V^{e}$ République.

\section{A. LES DIFFICULTÉS FINANCIÈRES ET LE CRÉDIT INTERNATIONAL DE LA FRANCE}

Les déficits croissants de la balance des paiements inquiètent les décideurs français car ils la rendent plus dépendante de la bonne volonté de ses partenaires extérieurs de deux manières. À l'échelle mondiale tout d'abord, le directeur de la DAEF Olivier Wormser dénonce régulièrement le risque d'épuisement des réserves françaises et la perspective de devoir recourir à des crédits américains ou allemands ${ }^{1}$. Dans le cadre des Six ensuite, Wormser et Marjolin (représentant français au comité intérimaire des Six) observent que si la France n'ouvre pas ses marchés au premier janvier 1959 comme il est prévu dans le traité

1. AMAE, POW 78, folio 24, 38 et 43, notes d'Olivier Wormser des 2 mai 1957, 20 juillet 1957 et 30 juillet 1957 . 
CEE, et recourt aux clauses de sauvegarde, elle ne se met pas dans l'illégalité mais pourra difficilement réclamer la bonne volonté de ses partenaires dans l'application des clauses du traité de Rome qui l'intéressent le plus ${ }^{2}$.

Pour tenter de remédier à cette situation, le gouvernement Bourgès-Maunoury, qui est investi en juin 1957, prend une série de mesures radicales. Tout d'abord, il suspend la libération des échanges le 17 juin 1957. L'ensemble du commerce extérieur redevient contingenté, c'est-à-dire soumis à une autorisation administrative. La part du commerce extérieur français libéré passe donc de $82 \%$, chiffre déjà faible par rapport aux $90 \%$ requis par l'OECE, à $0 \%$. De plus, le gouvernement pratique une dévaluation masquée. Le 10 août 1957, après une intense spéculation contre le franc, toutes les aides à l'exportation et taxes à l'importation sont supprimées, pour être remplacées par un versement unique de $20 \%$. De nombreuses exceptions sont prévues, notamment pour les produits importés servant à réaliser des produits réexportés. Cette mesure particulièrement protectionniste est vivement critiquée par l'OECE qui obtient la généralisation de ce qui fut appelé l' « opération $20 \%$ » le 26 octobre 1957, sans que la dévaluation soit reconnue officiellement, et ce jusqu'au 15 juin 1958, sous le gouvernement de Gaulle ${ }^{3}$.

Cependant, l'impact de ces mesures est limité par la renaissance d'une profonde instabilité ministérielle. Après trois mois d'activité, le gouvernement Bourgès-Maunoury est renversé le 30 septembre 1957. Il faut ensuite attendre plus de deux mois avant qu'un nouveau gouvernement, dirigé par Félix Gaillard, obtienne la confiance. Cette situation s'explique par l'aggravation de la crise en Algérie, qui accentue les difficultés financières comme l'instabilité gouvernementale car elle crée de nouveaux clivages au sein des partis politiques existants. À la crise financière et algérienne s'ajoute donc bientôt une crise institutionnelle, que le nouveau gouvernement Gaillard tente de surmonter.

\section{B. LE VOLONTARISME DU GOUVERNEMENT GAILLARD}

Le gouvernement Gaillard est investi le 5 novembre 1957 en partie grâce au souffle rénovateur porté par la personnalité même du nouveau président du Conseil ${ }^{4}$. Âgé de seulement 38 ans, c'est à la fois un homme politique (ancien ministre), un technicien (inspecteur des finances et ancien du commissariat au

2. AMAE, POW 78, folio 38, note d'Olivier Wormser du 20 juillet 1957 ; AFJM, ARM 13/1, note manuscrite de Robert Marjolin, « Exposé Robert Marjolin », 3 juillet 1957.

3. AMAE, POW 78, folio 97, recommandations du Conseil OECE du 22 novembre 1957 ; A. de Lattre, La politique économique..., op. cit., p. 126-128.

4. Année politique, 1957, PUF, Paris, 1958, p. 112. 
Plan) et un expert des questions européennes. Il fut chef de cabinet de Jean Monnet en 1944, puis chef de la délégation française au comité Spaak de 1955, où il manifeste une bonne volonté qui irrite notamment Wormser ${ }^{5}$.

Très rapidement, le nouveau président du Conseil prépare une loi-cadre sur l'adaptation de la France au Marché commun. Elle est adoptée lors du Conseil des ministres du 29 janvier 1958 après une déclaration du ministre des Finances Pflimlin condamnant le protectionnisme ${ }^{6}$. Selon lui : «Le traité de Rome ne fait que donner une forme juridique à une nécessité économique impérieuse », c'est-à-dire la libération des échanges. La perspective change complètement car l'ouverture des marchés n'est plus considérée comme une contrainte, mais comme une nécessité impérative pour moderniser le pays.

Au-delà de cette action structurelle, le gouvernement Gaillard obtient des crédits internationaux importants en janvier 1958, pour combler ses déficits. Cet accord intervient à la suite de démarches nombreuses entreprises en 1956 et $1957^{7}$. Jean Monnet est chargé de finaliser ce travail, qui aboutit en janvier 1958 à une série d'accords. Les États-Unis accordent à la France environ 150 millions de dollars pour 1958 et le FMI accorde un droit de tirage de 131 millions de dollars. Surtout, la France obtient 250 millions de dollars de crédits de l'UEP, dont 150 millions de dollars de crédits « spéciaux » (hors du quota normal), très largement financés - à hauteur de 100 millions de dollars - par la RFA. En tout, la France obtient environ 530 millions de dollars de concours divers pour 1958. L'aide est conditionnée à l'adoption d'une politique économique et financière plus rigoureuse et à un retour à la libération des échanges. Certains documents prévoient également l'abandon par la France de ses systèmes d'aides à l'exportation et une limitation du nombre d'hommes sous les drapeaux ${ }^{8}$, impliquant ainsi une limitation claire de l'indépendance française. Par ailleurs, pour la première fois, la France obtient presque autant de crédits de ses voisins européens, et notamment de la RFA, que des États-Unis. La singularité de sa position n'en est que plus affirmée : alors que ses voisins ont profité de l'aide américaine pour financer leur reconstruction, la France reste dépendante de l'aide extérieure après la fin de ce processus de reconstruction.

5. AMAE, PA-AP 314, note d'Olivier Wormser pour le président, 10 octobre 1955.

6. AN, F 60/2715, relevé des décisions du Conseil des ministres du 29 janvier 1958, secrétariat général du gouvernement.

7. Sur le détail des démarches et des aides accordées : Gérard Bossuat, Les aides américaines économiques et militaires à la France, 1938-1960. Une nouvelle image des rapports de puissance, Comité pour l'histoire économique et financière de la France, Paris, 2001, p. 346-350 ; L. Warlouzet, Quelle Europe économique pour la France..., op. cit., p. 248-251.

8. AMAE, PA-AP 314, carton 1, note d'Olivier Wormser du 13 janvier 1958. 
L'action énergique du gouvernement Gaillard paraît porter ses fruits dans un premier temps. La balance des paiements français s'améliore et, dès le mois de février, certains experts français envisagent un retour à la libération des échanges assez rapide, au printemps ou à l'été ${ }^{9}$, ce qui permettrait à la France de respecter ses engagements européens. Le CNPF se mobilise également de son côté.

\section{L'OFFENSIVE DU CNPF : \\ L'ASSEMBLÉE GÉNÉRALE EXTRAORDINAIRE DU 13 MAI 1958}

Le volontarisme du gouvernement Gaillard ne satisfait pas le CNPF, qui réclame des réformes plus profondes de la politique économique française, afin de l'adapter à la CEE. Le 14 janvier 1958, lors de l'assemblée générale du CNPF, Georges Villiers avait adopté un ton plus offensif qu'avant, en critiquant une politique gouvernementale trop dirigiste ${ }^{10}$. Après cette offensive, Henri Fayol $^{11}$, le président de la commission des prix du CNPF, veut aller plus loin. Il souligne l'importance des échéances européennes : la France risque « d'être prise en tutelle par l'organisation du Marché commun » si elle ne parvient pas à honorer ses engagements ${ }^{12}$. Le poids de la contrainte extérieure se perçoit dans cette remarque, écrite alors que la France négocie des crédits des Américains et des Européens. Fayol propose donc d'engager des travaux internes sur « les conditions à remplir pour que la France puisse affronter le Marché commun ». Ces travaux serviraient à « alimenter la propagande ». Pour Fayol, l'heure n'est plus aux interventions techniques mais à une campagne plus globale et offensive, dictée par les engagements européens de la France, et la nécessité de surmonter la contrainte extérieure pour préserver l'indépendance du pays.

Assez rapidement, un " groupe d'études générales » se met en place au CNPF pour prendre en charge ces travaux, avec Fayol comme animateur ${ }^{13}$. Afin d'influencer plus directement l'opinion publique, il demande la convocation d'une assemblée générale extraordinaire pour « alerter le pays et surtout les milieux patronaux sur les dangers de la situation ${ }^{14} »$. Le comité directeur du CNPF décide finalement le 15 avril 1958 de convoquer une assemblée générale

9. AMAE, POW 77, folio 297, note des Finances extérieures, André de Lattre, 15 février 1958.

10. Bulletin du CNPF, février 1958, supplément $n^{\circ} 170$, déclaration de George Villiers.

11. Henri Fayol est né en 1899, fils d'Henri Fayol, précurseur des théories du management. Son fils fit carrière dans l'industrie sidérurgique, la distribution et le textile. Président de la commission des prix du CNPF depuis 1945.

12. ACNPF, 72 AS 1382, lettre d'Henri Fayol à Emmanuel Mayolle, 22 janvier 1958.

13. ACNPF, 72 AS 1381, lettre E-RP, 25 mars 1958.

14. ACNPF, 72 AS 1381, lettre d'Henri Fayol à Georges Villiers, 22 avril 1958. 
extraordinaire pour le 13 mai $1958^{15}$. L'organisation patronale cherche à prendre l'opinion à témoin par une mobilisation spécifique, c'est en effet la première assemblée générale exceptionnelle tenue dans l'histoire du $\mathrm{CNPF}^{16}$.

La préparation de l'assemblée générale donne lieu à des réflexions très audacieuses. Dans une analyse de fond, Jean Louis demande un retour à une certaine liberté dans la fixation du cours du franc français afin de mieux tenir compte du prix du marché. Cette mesure très ambitieuse devrait impérativement être accompagnée, pour ne pas créer une spéculation destructrice contre le franc, par une politique d'austérité budgétaire et un retour progressif à la libération des échanges, sous réserve que la balance des paiements redevienne équilibrée ${ }^{17}$. Les méthodes radicales prônées par Louis font écho au triptyque du futur plan Rueff de 1958 - dévaluation-austérité-libération des échanges-le tout dans un contexte de retour à la convertibilité. Cette prise de position de Louis suscite des réticences au sein même du groupe le plus offensif du CNPF, notamment de Fayol ${ }^{18}$.

L'assemblée générale extraordinaire du CNPF du 13 mai 1958 donne lieu à une prise de position très audacieuse, sous forme d'une déclaration adoptée par les cinq cents chefs d'entreprises présents ${ }^{19}$. Pour appliquer le Marché commun et éviter la « décadence », le CNPF préconise trois réformes. D'abord et de manière classique, une politique d'austérité budgétaire est demandée. Ensuite, la « vérité des prix » doit être rétablie afin de promouvoir " une concurrence authentique et saine [...] à laquelle il faudra obligatoirement arriver dans le Marché commun ». La déclaration inscrit donc l'attaque classique contre la politique des prix - symbole du dirigisme étatique contre-productif - dans l'enjeu de l'adaptation au Marché commun. Troisième idée, la «vérité de la monnaie » doit être établie en restaurant « dans les délais les plus rapides, la libre convertibilité du franc, [par l'abolition du] contrôle des changes et [par la libération] des échanges commerciaux. Peut-être des étapes seront-elles nécessaires ; mais il est indispensable de s'engager dans cette voie... ». La note de Jean Louis semble avoir largement influencé les débats du CNPF ${ }^{20}$. Si des précautions sont prises en termes de délais, le discours est radical : la France doit rompre avec son protectionnisme commercial et monétaire.

15. Bulletin du CNPF, mai 1958, $\mathrm{n}^{\circ} 173$, éditorial de Georges Villiers.

16. Bernard Brizay, Le patronat. Histoire, structure, stratégie du CNPF, Seuil, Paris, 1975, p. 96.

17. ACNPF, 72 AS 1381, note de Jean Louis du 14 avril 1958.

18. ACNPF, 72 AS 1381, lettre d'Henri Fayol à Georges Villiers, 22 avril 1958 ; ACNPF, 72 AS 1381, lettre de Georges Matheron à Henri Fayol, 6 mai 1958. Georges Matheron est le PDG de la société Intrafor.

19. Déclaration de Georges Villiers lors de l'assemblée générale extraordinaire du 13 mai 1958 in Bulletin du CNPF, juin 1958 .

20. ACNPF, 72 AS 1381, note de Jean Louis du 14 avril 1958. 
La déclaration du CNPF s'inscrit donc dans le cadre de l'adaptation au Marché commun mais le déborde largement pour montrer la nécessité pour la France de quitter les équilibres économiques définis depuis la fin du XIX ${ }^{\mathrm{e}}$ siècle - poids de l'agriculture, des colonies et du protectionnisme - pour embrasser le monde de l'après-reconstruction, celui de la libre circulation des marchandises et des monnaies. Les trois réformes qui sont demandées inspirèrent largement les travaux du comité Rueff de 1958.

Cependant, la date même de l'assemblée générale du CNPF limite son audience. Le 13 mai 1958 en effet, un Comité de salut public prend le pouvoir à Alger. La campagne d'opinion qui aurait dû la suivre n'a donc pas pu se développer en raison des circonstances ${ }^{21}$, celles de la fin de la IV République.

\section{LA CRISE FINALE DE LA IV RÉPUBLIQUE}

La crise d'avril et de mai 1958 qui scelle le sort de la IV République est due à l'aggravation de la situation en Algérie. Le conflit s'internationalise, ce qui provoque une radicalisation des conflits politiques français, et une crise du régime en deux temps.

Le 8 février, l'armée française, dans le cadre de sa lutte contre des rebelles algériens réfugiés en Tunisie, bombarde le village tunisien de SakhietSidi-Youssef, en tuant 69 civils $^{22}$. L'affaire est portée devant l'ONU ${ }^{23}$. Devant le tollé international, la France doit accepter une mission de conciliation francotunisienne pilotée par les États-Unis et la Grande-Bretagne. Cette mission de conciliation anglo-saxonne est perçue comme une humiliation par certains parlementaires ${ }^{24}$. L'internationalisation du conflit algérien provoque ainsi une radicalisation du débat politique interne. Finalement le 15 avril 1958, le gouvernement Gaillard tombe en raison de sa modération dans ce dossier.

Après la chute de Gaillard, Pierre Pflimlin est pressenti. Il s'est montré partisan de la négociation avec les nationalistes algériens ${ }^{25}$. Il forme un gouvernement et tente d'obtenir la confiance de l'Assemblée nationale le 13 mai 1958. Ce même jour, un Comité de salut public prend le pouvoir à Alger, à la suite d'une manifestation de pieds-noirs. Finalement, dans une atmosphère troublée, Pflimlin

21. ACNPF, 72 AS 1381, note de synthèse de 18 p., juillet 1958.

22. Benjamin Stora, Histoire de la guerre d'Algérie (1954-1962), La Découverte, Paris, 1993, p. 47.

23. Martin Thomas, « France accused : French North African Policy before the UN, 1952-1962 », in Contemporary European History, 10/1, 2001, p. 109-110.

24. Année politique, 1958, PUF, Paris, 1959, p. 16.

25. B. Stora, Histoire de la guerre d'Algérie..., op. cit., p. 48. 
est investi dans l'urgence à $1 \mathrm{~h} 15$ du matin et tient un Conseil des ministres extraordinaire à 3 h $50^{26}$ ! La confiance n'est cependant pas rétablie. Dès le 14 mai, le Comité de salut public demande un retour au pouvoir du général de Gaulle. Après le passage de la Corse sous la coupe des militaires révoltés contre le pouvoir politique, le 24 mai 1958, l'Assemblée nationale investit finalement le général de Gaulle comme président du Conseil. Cette crise politique a entraîné de profondes difficultés financières et monétaires qui ont remis en cause le début de rétablissement issu des réformes mises en œuvre par Félix Gaillard. Ce contexte troublé facilite paradoxalement l'acceptation de la CEE.

\section{L'ACCEPTATION DE LA CEE}

Après la signature du traité de Rome, le 25 mars 1957, se pose le problème de sa ratification, prévue en juillet 1957, et de son application, avec la mise en place des institutions communes à partir de janvier 1958. Dans ce processus, le ralliement d'une majorité du patronat à la CEE joue un rôle important pour justifier l'intérêt économique de cet accord pour la France. De toute façon, les décideurs français se convertissent rapidement à un traité de Rome ravalé au second plan des préoccupations gouvernementales par la dramatique actualité algérienne. Cela explique, enfin, que la mise en place des institutions communautaires ne suscite pas de stratégie d'influence organisée de la part de la France.

\section{A. LE RALLIEMENT D’UNE MAJORITÉ DU PATRONAT À LA CEE}

La perspective du débat de ratification du traité de Rome par l'Assemblée nationale au début du mois de juillet 1957 suscite une profonde interrogation au sein du patronat sur la manière dont la France peut s'adapter à ce traité. D'un côté, le secteur cotonnier est l'un des derniers opposants actifs. D'un autre côté, une majorité du patronat se range désormais derrière Georges Villiers et concentre ses revendications sur l'adaptation de la France au Marché commun.

\section{La dernière opposition active : le secteur cotonnier.}

Le secteur du coton, qui avait déjà manifesté son hostilité au libéralisme du Marché commun pendant la négociation du traité de Rome, renforce son opposition. Il mène une véritable campagne d'opinion pendant le débat de

26. Année politique, 1958, PUF, Paris, 1959, p. 56. 
ratification. Le Syndicat général de l'industrie cotonnière française publie une longue note de 55 pages, largement diffusée avant le débat de ratification à l'Assemblée nationale, qui critique vigoureusement le Marché commun ${ }^{27}$. Elle condamne la logique libre-échangiste qui est à la base de la CEE et demande au contraire un tarif extérieur commun élevé et une harmonisation des charges très contraignante.

Cette étude a un grand écho car elle suscite une longue réponse de la part du cabinet de Maurice Faure ${ }^{28}$. Le secteur cotonnier est en effet très actif dans son opposition au traité de Rome. Les tentatives de Marcel Boussac d'influencer le vote des parlementaires lors du débat de ratification ont débouché sur ce qui a été appelé l' « amendement Boussac ${ }^{29} »$. Il prévoyait que le gouvernement français, au lieu de ratifier le traité de Rome, devait s'engager dans des négociations internationales destinées à interrompre le processus de désarmement douanier. Cette vision protectionniste s'explique par le fait que l'industrie cotonnière veut compenser la non-compétitivité de ses produits par le maintien d'un fort protectionnisme entre la France et ses colonies ${ }^{30}$.

Ainsi, après s'être adressé aux administrations les plus hostiles au rapport Spaak pendant la négociation du traité de Rome, le syndicat cotonnier cherche maintenant à influencer, sans succès, les parlementaires. Après la ratification des traités de Rome, cette organisation change de ligne et concentre ses efforts sur l'adaptation au Marché commun ${ }^{31}$. Dans la revue Industrie cotonnière française sont publiés des articles à caractère technique, et non plus polémique, sur la CEE, en particulier sur les clauses qui intéressent le plus le secteur cotonnier comme la politique commerciale commune ou le régime des contingents ${ }^{32}$. Le syndicat cotonnier suit en fait le chemin emprunté par d'autres organismes sectoriels autrefois hostiles au Marché commun comme la FIMTM. Cette dernière avait dès le mois de juin 1957 fait connaître une position certes critique envers le traité de CEE, mais insistant surtout sur

27. Analyse du traité de Marché commun, SGICF, second trimestre 1957, citée in J. SzokoloczySyllaba, Les organisations professionnelles..., op. cit., p. 40 et 57. Le syndicat est animé par Pierre de Calan.

28. AHUE, EN 379, « Le Marché commun, objections et réponses », manuscrit : « juin 1957. Cabinet Maurice Faure ».

29. J. Szokoloczy-Syllaba, Les organisations professionnelles..., op. cit., p. 57. C'est Pierre-Henri Teitgen qui est à l'origine de l'expression « amendement Boussac » : Journal Officiel, Débats parlementaires, Assemblée nationale, session 1956-1957, p. 3410.

30. René Girault, «La France entre l'Europe et l'Afrique », p. 352, in Enrico Serra (dir.), La relance européenne..., op. cit., p. 362. Jacques Marseille, Empire colonial et capitalisme français. Histoire d'un divorce, Albin Michel, Paris, 1984, p. 188-197.

31. J. Szokoloczy-Syllaba, Les organisations professionnelles..., op. cit., p. 58.

32. J. Szokoloczy-Syllaba, Les organisations professionnelles..., op. cit., p. 60. 
la nécessité de réformer la politique économique nationale pour s'adapter à ce nouveau défi, désormais incontournable ${ }^{33}$. Profitant de cette évolution des mentalités, Georges Villiers entreprend de rassembler le patronat autour d'une ligne favorable à la $\mathrm{CEE}$.

\section{L'action de rassemblement du CNPF en faveur de la CEE.}

L'assemblée générale du CNPF est particulièrement importante car elle a lieu le $1^{\text {er }}$ juillet 1957, quelques jours avant le débat de ratification des traités de Rome à l'Assemblée nationale. Georges Villiers, le président du CNPF, parvient à rassembler la majorité des milieux économiques autour d'une ligne tolérante envers la CEE par un discours en trois temps ${ }^{34}$.

Tout d'abord, il affirme que la voix du monde patronal a été entendue par les négociateurs français, qui se sont efforcés de relayer les intérêts des milieux économiques. Cette revendication est évidemment difficilement vérifiable dans les archives car les fonctionnaires se vantent rarement d'avoir été influencés par les milieux économiques. Elle est cependant confirmée par une note interne au $\mathrm{CNPF}^{35}$.

Ensuite, Georges Villiers détourne les éventuelles critiques adressées au Marché commun en mettant l'accent sur les difficultés françaises propres. Pour lui, le problème n'est pas le traité CEE mais l'inadaptation de la politique économique française. Villiers demande également aux entreprises de faire un effort, en multipliant les études et les ententes afin de s'adapter à l'ouverture des marchés européens ${ }^{36}$. Il met ainsi dos à dos les «malthusiens » publics et privés et plaide pour une approche contractuelle, associant libéralisme économique et accords entre les entreprises.

Enfin, Villiers souligne une nouvelle fois que la construction européenne peut être utilisée comme un levier de réforme des politiques publiques françaises. La cible principale est la politique des prix car elle est très coûteuse pour les finances publiques (par les subventions) et elle fausse le fonctionnement du marché. Les industriels se plaignent que les prix soient bloqués à un niveau artificiel, qui donne des rentes de situation aux secteurs et aux entreprises les moins efficaces. Le blocage empêche les entreprises à forte productivité de

33. ARAM, 52 J 116, « La situation économique française et le traité de CEE », FIMTM, 21 juin 1957 ; cette évolution se poursuit avec d'autres notes envoyées à l'administration française : ASGCI, 1991.0004, article 2, lettre de Jean Lecomte, secrétaire général de la FIMTM, 19 décembre 1957.

34. ACNPF, 72 AS 847, compte rendu de l'assemblée générale du CNPF du $1^{\text {er }}$ juillet 1957.

35. ACNPF 72 AS 1505, note E-RL de Raymond Lartisien du 9 avril 1957.

36. ACNPF, 72 AS 847, compte rendu de l'assemblée générale du CNPF du $1^{\text {er }}$ juillet 1957. 
gagner des parts de marché en baissant leurs prix, ou aux producteurs de biens très demandés d'augmenter leurs prix pour financer leurs investissements.

Pour défendre cette réforme de la politique des prix, le CNPF mobilise le patronat européen. À une table ronde des représentants des Six tenue le 4 octobre 1957, le CNPF cherche à favoriser une action commune dans ce domaine ${ }^{37}$. Chaque fédération patronale des Six doit donc envoyer une note sur la politique des prix de son pays au représentant français qui en fera une synthèse. Ce document permettra d'envisager une action d'harmonisation en vertu de l'article 100 CEE. Le CNPF utilise donc le relais européen pour promouvoir un objectif national. C'est la manifestation concrète de son ambition d'encadrer l'action d'un gouvernement national perturbateur par l'activité régulatrice européenne.

De même, dans le domaine de l'harmonisation sociale, le patronat cherche également à progresser par une voie contractuelle, pour combler une éventuelle inefficacité des États membres. Au CNPF, François Ceyrac, spécialiste des questions sociales, est chargé d'études sur la formation professionnelle mais aussi de l'amélioration des relations entre syndicats patronaux et ouvriers afin d'adapter la structure industrielle au Marché commun ${ }^{38}$. Une note de Renault ${ }^{39}$ et un document public de la FIMTM ${ }^{40}$ évoquent également la possibilité de développer des conventions collectives européennes. La question de l'harmonisation sociale est donc étudiée par le patronat dans la mesure où elle permettrait de s'attaquer à ce qui est perçu comme un handicap français par une démarche européenne non gouvernementale.

Ainsi, Georges Villiers mène une action de rassemblement d'un patronat dont la position évolue envers la CEE comme le montre la position de la FIMTM, ou même du syndicat cotonnier. Il parvient à surmonter l'opposition de certains milieux patronaux au Marché commun en évitant de défendre frontalement le traité de Rome, et en mettant l'accent sur l'impératif de l'adaptation de la politique économique à une libéralisation des échanges inéluctable. La CEE fait figure d'obligation salutaire, de levier de réforme du dirigisme interne, surtout si elle est mise en œuvre suivant l'approche contractuelle patronale. Cet engagement du CNPF joue certainement un rôle dans l'adaptation rapide des décideurs publics à ce nouveau cadre de coopération économique européenne.

37. 72 AS 1316, table ronde des représentants des industries des Six pays, 4 octobre 1957.

38. ACNPF, 72 AS 1505, note du 19 avril 1957, réunion avec Aubert, Ceyrac, Hommey, Lartisien et Imbert.

39. ASGCI, 1991.0004, article 1, note de Renault, "Création de la Communauté économique européenne et problèmes posés à l'industrie française », note de 21 p., mai 1957.

40. ARAM, 52 J 116, «La situation économique française et le traité de CEE », FIMTM, 21 juin 1957. 


\section{B. L'ADAPTATION RAPIDE DES DÉCIDEURS PUBLICS}

Les graves problèmes financiers, institutionnels et algériens auxquels doit faire la France ont tendance à estomper les affaires européennes. Contrairement aux discussions sur la CED en 1954, ou à ceux portant sur l'Algérie en ce même mois de juillet 1957, les débats à l'Assemblée nationale sur la ratification du traité de CEE, tenus du 3 au 10 juillet 1957, manquent de passion ${ }^{41}$. Malgré un nouveau discours hostile au Marché commun de Pierre Mendès France, les traités de Rome sont ratifiés à une très large majorité, par 342 voix contre $239^{42}$. Le processus de ratification du traité de Rome est beaucoup plus rapide que celui qui avait été mis en œuvre pour la CED. À la rentrée de septembre, moins de six mois après la signature du traité, la ratification était déjà acquise dans les trois grands pays ${ }^{43}$. Le processus se conclut le 4 décembre aux Pays-Bas.

En fait, le problème de fond, la capacité de la France à respecter le traité de Rome et à en profiter, a été ignoré. Confronté à de graves problèmes à court terme de finances publiques et d'ordre en Algérie, le pouvoir politique repousse l'examen d'un projet de loi-cadre pour l'adaptation de l'économie française au Marché commun ${ }^{44}$. Prenant acte de cette ratification rapide, l'administration accepte rapidement le cadre de la CEE.

\section{L'évolution des fonctionnaires spécialisés dans les affaires européennes.}

Une conception plus positive de la CEE commence à émerger chez certains fonctionnaires chargés plus particulièrement des affaires européennes, au-delà des cercles européistes traditionnels, comme en témoigne la série de conférences sur le Marché commun donnée au Quai d'Orsay du 2 au 7 décembre $1957^{45}$. Les 12 intervenants appartiennent tous à des services gérant les rapports entre la France et la CEE, que ce soit au ministère des Affaires étrangères (Jean-Pierre Brunet, Jean François-Poncet, Jean Mille, Alain Peyrefitte, François Valéry) ou au ministère des Finances (Jean-François Deniau, Renaud de la Genière, Alain Prate).

41. Année politique, 1957, PUF, Paris, 1958, p. 72.

42. Année politique, 1957, PUF, Paris, 1958, p. 72-73.

43. Hormis le Sénat italien, qui ratifia le 9 octobre 1957.

44. ASGCI, 1991.004, article 2, proposition de résolution des sénateurs Armengaud et Edgar Pisani, annexe $\mathrm{n}^{\circ} 711$ au PV de la séance du Conseil de la République du 18 juin 1957.

45. AMINEFI, 3 A 68 , cycle de conférences données au ministère des Affaires étrangères, documents du service des archives et de la documentation, 172 pages, 12 interventions. 
Trois idées consensuelles en émergent. Tout d'abord, Jean François-Poncet rappelle que le traité CEE est largement inespéré car " personne jusqu'à un stade [de la négociation] très avancé n'a cru à son succès ${ }^{46} \ldots$.. . Pour lui, c'est la France qui a obtenu le plus de concessions justement en raison de ses difficultés.

Ensuite, de nombreux intervenants soulignent que le Marché commun n'est pas qu'une union douanière mais une véritable union économique, avec des processus d'harmonisation et de coordination qui complètent la dynamique de libéralisation ${ }^{47}$. Dans des notes diffusées quelques mois plus tôt, Jean-François Deniau, chargé de mission au SGCI, s'était déjà efforcé de défendre le traité de Rome, qui représente pour lui un cadre stable pour l'ouverture progressive à l'extérieur et la modernisation du pays ${ }^{48}$. L'enjeu n'est donc plus de modifier ou d'infirmer un traité de Rome finalement satisfaisant, mais de profiter de ce cadre pour mener les réformes nécessaires en interne.

Enfin, la lacune monétaire du traité de Rome est soulignée par une petite moitié des intervenants ${ }^{49}$. Ces derniers ne réclament pas l'établissement d'une union monétaire mais se posent la question de savoir comment l'union commerciale, puis économique, se traduira sur le plan monétaire. Cette interrogation témoigne de la prise de conscience du caractère cumulatif du phénomène d'intégration européenne.

Au-delà de ces trois idées, un conflit à distance se noue entre Valéry, favorable à la ZLE, et son adjoint Brunet, qui utilise des arguments du CNPF pour nourrir son opposition à la $\mathrm{ZLE}^{50}$. De même, Deniau se montre très favorable au modèle d'intégration économique de la CEE, et s'oppose par conséquent au projet de $\mathrm{ZLE}^{51}$. De son côté, Peyrefitte la critique pour des raisons plus politiques, en soulignant notamment que le cadre des Six renforce la France ${ }^{52}$.

46. AMINEFI, 3 A 68, op. cit., « Historique des négociations de Bruxelles » par Jean FrançoisPoncet.

47. AMINEFI, 3 A 68, op. cit., «Les raisons et le contenu du Marché commun » par Jean Mille ; «Les problèmes douaniers et commerciaux du Marché commun » par Alain Prate.

48. ASCGI, 1991.0004, article 1, note de Jean-François Deniau du 14 juin 1957.

49. AMINEFI, 3 A 68, op. cit., interventions de Jean Mille et d'Alain Prate ; « La politique économique et sociale de la Communauté » par Jean-François Deniau ; « Aspects monétaires du Marché commun » par Renaud de La Genière ; "Conséquences de la création du Marché commun dans les relations politiques internationales » par Alain Peyrefitte.

50. AMINEFI, 3 A 68, op. cit., « Le Marché commun et la zone de libre-échange » par François Valéry ; "Les problèmes posés par le Marché commun dans les relations internationales »par Jean-Pierre Brunet.

51. AMINEFI, 3 A 68, op. cit., « La politique économique et sociale de la Communauté » par Jean-François Deniau.

52. AMINEFI, 3 A 68, op. cit., « Conséquences de la création du Marché commun dans les relations politiques internationales » par Alain Peyrefitte. 
Ces fonctionnaires « européens » de par leur fonction, mais pas nécessairement européistes, développent donc des arguments favorables au Marché commun. La très grande majorité des intervenants est jeune ${ }^{53}$. S'ils n'occupent pas de fonction de premier plan, ils ont tous été membres de la délégation française de négociation des traités de Rome ou ont assisté des membres titulaires ${ }^{54}$. Les négociations du Marché commun ont été considérées comme des questions relativement secondaires par les fonctionnaires en poste, qui y ont affecté de jeunes éléments prometteurs ${ }^{55}$. Ce constat permet également d'expliquer l'absence de contre-proposition crédible de l'administration française à l'été 1956 lorsque le rapport Spaak est présenté, car les hauts fonctionnaires les plus importants n'avaient pas pris conscience de l'enjeu du Marché commun. Un an plus tard, ce sont les jeunes fonctionnaires qui s'étaient spécialisés dans ce dossier qui occupent un rôle de premier plan dans l'adaptation de la France à la CEE. La plupart occupèrent par la suite des postes à responsabilité dans le traitement des dossiers, soit dans l'administration française (Brunet, Mille), soit dans l'administration communautaire (Deniau, Prate), signe de la permanence de leur spécialisation déjà visible à la fin de $1957^{56}$. Cette spécialisation européenne ne signifie pas une conversion à l'idéal européen mais à l'impératif du Marché commun, à la nécessité de penser la modernisation de la France dans le cadre de la CEE.

\section{L'adaptation de l'organisation administrative.}

Avec la naissance des institutions communautaires en 1958, il est nécessaire de régler les questions des liens entre l'administration française et la future administration communautaire, ainsi que de fixer le mode de désignation du représentant permanent de la France auprès des Communautés européennes.

53. Sur les huit intervenants cités, quatre ont entre 30 et 40 ans et trois ont moins de trente ans. Les dates de naissance sont : 1916 (François Valéry), 1918 (Jean Mille), 1920 (Jean-Pierre Brunet), 1925 (Renaud de la Genière, Alain Peyrefitte), 1928 (Jean-François Deniau, Jean François-Poncet, Alain Prate).

54. Alain Prate estime que la seule personne qui s'intéressait vraiment à la négociation du traité de Rome au ministère des Finances était Renaud de la Genière, que l'on retrouve à ces conférences. $\mathrm{AO} /$ Comité pour l'histoire économique et financière de la France, interview d'Alain Prate par Anne de Castelnau, 1997, minidisque 3.

55. Témoignages d'Alain Prate et de Jean-Maxime Lévêque cités in : Michel Mangenot, « La revendication d'une paternité : Les hauts fonctionnaires français et le "style" administratif de la Commission européenne (1958-1988) », in Pôle Sud, 2001-1, p. 33-46.

56. Jean-Pierre Brunet devient représentant permanent adjoint auprès des Communautés européennes (1961-1964) puis directeur de la DAEF (1966-1975) ; Jean Mille est le premier représentant permanent adjoint (1958) ; Jean-François Deniau et Alain Prate partent dans l'administration communautaire dès 1963 (Deniau jusqu'en 1963 et Prate jusqu'en 1967). 
Ce dernier participe au COREPER qui prépare les décisions du Conseil. Le gouvernement français décide de répondre à ces deux questions par une organisation bicéphale définie en avril $1958^{57}$.

À Paris, le SGCI, un service interministériel créé en 1948 pour gérer les rapports avec l'OECE, coordonne les positions des différentes administrations dans la définition de la position française. C'est un organisme léger chargé de coordonner l'action des diverses administrations françaises entre elles et avec les objectifs plus généraux de politique européenne de la France. Comme son nom l'indique, il assure le secrétariat des réunions du comité interministériel sur les questions européennes. Dès le 10 avril 1958, un premier comité technique interministériel se réunit sous la direction du ministre des Finances Pflimlin et comprend des représentants de très nombreux ministères ${ }^{58}$.

Le SGCI transmet ces instructions au représentant permanent de la France auprès de la CEE, installé à Bruxelles. C'est un diplomate. Il a le monopole des relations avec les institutions de la CEE. Il applique les instructions du SGCI à Bruxelles et coordonne l'activité des fonctionnaires français des diverses administrations envoyés à Bruxelles.

Ce système permet une très forte coordination en empêchant l'établissement de liens directs entre l'administration française et l'administration communautaire grâce au double contrôle du SGCI, lié au président du Conseil, et de la représentation permanente, confiée au Quai d'Orsay. Le ministère des Affaires étrangères se voit reconnaître un rôle important car le représentant permanent et son adjoint sont issus de ses rangs, alors que d'autres pays européens nomment des membres du ministère des Affaires économiques ${ }^{59}$. Le premier titulaire du poste, Éric de Carbonnel, est d'ailleurs un diplomate au profil plutôt politique, sans spécialisation dans les affaires de coopération européenne. Le poids du Quai d'Orsay peut s'expliquer par le fait que la CEE est susceptible d'entraîner des délégations de souveraineté qui doivent être surveillées.

Il ne faut cependant pas considérer cette décision uniquement comme un arbitrage dans une querelle fonctionnelle entre deux services. L'organisation tend plutôt à renforcer l'habitude de travail étroite que le SGCI et le Quai d'Orsay, en

57. A. de Castelnau, « Le rôle du SGCI... », op. cit., p. 218.

58. ASGCI, 1991.0004, article 1, note SGCI du 25 avril 1958, compte rendu du premier comité technique interministériel du 10 avril 1958. Une deuxième séance a lieu début mai : ASGCI, 1991.0004, article 1, note SGCI du 7 mai 1958, compte rendu du comité technique interministériel du 2 mai 1958.

59. Pierre Gerbet, «L'élaboration des politiques communautaires au niveau national français », in Joël Rideau, Pierre Gerbet, Maurice Torrelli et al. (dir.), La France et les Communautés européennes, LGDJ, Paris, 1975, p. 385-386. 
particulier la DAEF, ont commencé à développer. C'est dans ces deux services que se trouve la tête de ce nouveau groupe des " Européens fonctionnels », Jacques Donnedieu de Vabres et Olivier Wormser. Les rapports entre ces deux derniers sont bons selon les archives ${ }^{60}$. Jean-Pierre Brunet, l'un des proches collaborateurs de Wormser à la DAEF, conseille d'ailleurs de « rechercher une coopération amiable avec le SGCI plutôt qu'essayer de diminuer les prérogatives et les responsabilités de cet organisme efficace ${ }^{61} »$. Une division naturelle du travail peut s'esquisser, selon Brunet, entre la partie politique gérée par la DAEF et l'expertise technique apportée par le SGCI.

Une organisation combinant un double contrôle politique, du président du Conseil à travers le SGCI et du ministre des Affaires étrangères, et une gestion administrative technique efficace, se met donc en place. Elle manifeste bien la prise de conscience de la spécificité de la CEE, organisation de coopération économique dont la dynamique peut engendrer des délégations de souveraineté qui doivent être contrôlées. Après les controverses suscitées par la négociation du traité de Rome au sein des responsables politiques et administratifs français, la conversion rapide de la majorité des décideurs français peut s'expliquer par une analyse réaliste. La CEE s'impose non comme un projet séduisant mais comme un accord inévitable, traduisant la force d'une dynamique libreéchangiste inéluctable. Elle est donc acceptée sans enthousiasme, comme un choix de raison, en l'absence d'autres alternatives. Le ralliement d'une majorité du patronat à ce projet et la concentration de ses critiques sur la politique économique française montrent que les controverses se déplacent des négociations à Six vers l'adaptation à la CEE.

\section{L'ABSENCE DE STRATÉGIE D'INFLUENCE \\ DES JEUNES INSTITUTIONS COMMUNAUTAIRES}

À partir de janvier 1958, un nouvel acteur émerge avec la naissance de la Commission européenne. Elle prend la suite du Comité intérimaire, un organisme intergouvernemental créé le 15 avril 1957 pour appliquer le traité de Rome en attendant la mise en place des institutions communautaires en janvier $1958^{62}$.

60. Leurs liens personnels apparaissent très rarement dans les archives administratives mais sont cependant confirmés par un document : ASGCI 1977.1471, article 60, lettre d'introduction d'Olivier Wormser à Jacques Donnedieu de Vabres au projet de mémorandum français sur la ZLE, 9 août 1957.

61. AMAE, DECE 628, folio 181, note de Jean-Pierre Brunet pour François Valéry, 16 octobre 1957.

62. AHUE, annexe du procès-verbal normal de la séance du 15 janvier 1958 de la Commission européenne, rapport du président du Comité intérimaire. 
Deux nouvelles sources de pouvoirs émergent : les commissaires européens et l'administration communautaire qui leur est adossée. L'influence des autorités françaises à travers les nominations est visible et en même temps limitée.

\section{Les commissaires européens français.}

C'est à la conférence des ministres des Affaires étrangères des 6 et 7 janvier 1958 que le choix des neuf membres de la future autorité supranationale est effectué $^{63}$. Les deux commissaires européens sont Robert Marjolin et Robert Lemaignen.

Robert Marjolin est vice-président de la Commission européenne, chargé du portefeuille des affaires économiques et financières. Trois raisons peuvent expliquer ce choix. D'abord, c'est un des acteurs majeurs de la négociation du Marché commun en France, où il a joué un rôle d'intermédiaire entre le trio gouvernemental proeuropéen et une administration plus réticente. De plus, il représenta la France au Comité intérimaire. Ensuite, c'est un expert des affaires économiques grâce à ses fonctions antérieures de professeur d'université puis de directeur de la DREE (1945-1946) et de commissaire adjoint au Plan (19461948). Enfin et surtout, il bénéficie de réseaux européens et américains très étendus de par son expérience pendant la négociation qui a abouti à l'OECE ${ }^{64}$, puis comme secrétaire général de cette organisation (1948-1955). Marjolin reçoit le portefeuille stratégique des affaires économiques et financières.

Le second commissaire français, Robert Lemaignen, a un profil très différent. Issu du patronat colonial, il est nommé commissaire grâce à ses relations avec Félix Houphouët-Boigny ${ }^{65}$. Pinay avait été pressenti pour ce poste mais l'avait refusé en raison de la crise financière française ${ }^{66}$. Très impliqué dans les activités associatives patronales, Robert Lemaignen a été vice-président de la CCI de 1942 à 1958, vice-président de la commission économique du CNPF de 1950 à 1958 et coprésident, avec Jean Louis, de la commission des affaires européennes montée par Georges Villiers. Il fait partie au sein du patronat colonial du groupe proeuropéen qui a participé au congrès de La Haye en $1948^{67}$. Sa nomination à la Commission européenne l'année de ses 65 ans constitue le

63. ASGCI, 1990.0568, article 385, projet de procès-verbal de la conférence des ministres des Affaires étrangères des 6 et 7 janvier 1958, 10 janvier 1958.

64. Gérard Bossuat, La France, l'aide américaine et la construction européenne, 1944-1954, Comité pour l'histoire économique et financière de la France, Paris, tome I, 1992, p. 170, 190, 193.

65. Catherine Hodeir, Stratégies d'Empire. Le grand patronat colonial face à la décolonisation, Belin, Paris, 2003, p. 270.

66. Robert Lemaignen, L'Europe au berceau. Souvenirs d'un technocrate, Plon, Paris, p. 23-25.

67. C. Hodeir, Stratégies d'Empire..., op. cit., p. 271. 
bâton de maréchal de sa carrière, alors que Marjolin n'a que 47 ans. Il reçoit naturellement le portefeuille de l'outre-mer à la Commission européenne.

Ainsi, les deux commissaires français sont dotés d'une capacité d'influence très inégale. Certes, ils restent en contact avec l'administration française, notamment pour la négociation $Z_{L} E^{68}$, mais ils n'apparaissent pas redevables au gouvernement en place, celui de Félix Gaillard. La fréquence des changements de gouvernements n'autorise pas la poursuite d'une politique d'influence cohérente sur le long terme. Le même constat prévaut pour l'administration.

\section{L'administration communautaire et la place des fonctionnaires français.}

Au sein de la nouvelle administration communautaire, la présence française est relativement importante dans les niveaux les plus élevés. Au sommet, en plus de ses deux commissaires, la France a placé Émile Noël à la fonction charnière de secrétaire exécutif de la Commission. Ancien fonctionnaire de l'Assemblée consultative du Conseil de l'Europe, il fut le chef de cabinet de Guy Mollet. Il a une approche plus politique qu'économique. Ainsi, dans une note de juillet 1958, il justifie l'opposition à la ZLE par des raisons strictement politiques ${ }^{69}$. Parmi les hauts fonctionnaires des institutions communautaires, neuf Français doivent être signalés. Ils correspondent à trois types de hauts fonctionnaires.

Le premier ensemble regroupe les fonctionnaires communautaires de carrière comme Michel Gaudet ${ }^{70}$. Membre du corps du Conseil d'État, il a participé à la négociation de la CECA. Directeur du service juridique de la Haute Autorité de la CECA de 1952 à 1958, il occupe la même fonction à partir de 1958 au sein de la Commission européenne. Son action est complétée par celle de Maurice Lagrange, un autre membre du Conseil d'État, entré dans l'équipe Monnet en 1950 pour rédiger les articles sur la Cour de justice des Communautés européennes $^{71}$. Il a joué un rôle fondamental dans la création d'un ordre juridique européen propre, inspiré du droit administratif français ${ }^{72}$. Juge à la Cour de justice de la CECA depuis 1952, il est maintenu à ce poste dans la Cour

68. Pour Lemaignen : AMAE, DECE 753, folio 37, note du 13 février 1958 sur la réunion du 12 février 1958 chez Maurice Faure ; pour Marjolin : AMAE, DECE 753, folio 137, note de François Valéry pour le cabinet de Maurice Faure, 11 avril 1958.

69. AHUE, EN 186, note du 26 juillet 1958 d'Émile Noël pour Guy Mollet.

70. Des précisions sur Michel Gaudet in : Michel Dumoulin, "L'administration », in Michel Dumoulin (dir.), La Commission européenne, 1958-1972. Histoire et mémoire d'une institution, Communautés européennes, Bruxelles, 2007, p. 234-235.

71. Jérôme Wilson, "Aux origines de l'ordre juridique communautaire... », op. cit., p. 23.

72. Jérôme Wilson, « Aux origines de l'ordre juridique communautaire... », op. cit., p. 24-28. 
de justice des Communautés en 1958. Jacques-René Rabier a quant à lui fait carrière dans l'ombre de Jean Monnet. Il est entré au Plan en 1946 avant de le suivre à la Haute Autorité de la CECA de 1953 à 1955. Il assure la direction du service d'information de la Haute Autorité de la CECA (1955-1958), puis prend ensuite la fonction équivalente de directeur du Service commun de presse et d'information des Communautés européennes.

$\mathrm{Au}$ sein du deuxième groupe, celui des jeunes hauts fonctionnaires prometteurs, on retrouve trois inspecteurs des finances passés par l'ENA. FrançoisXavier Ortoli devient directeur général de la DG III, chargé du marché intérieur. Il a appartenu à plusieurs cabinets, notamment celui de Maurice Faure, ce qui pourrait expliquer sa nomination à ce poste important à moins de trente-cinq ans. Deux inspecteurs des finances nés en 1928, donc âgés de trente ans à peine, occupent des fonctions de directeur. Le premier est Jean-François Deniau, un ancien membre de la délégation de négociation des traités de Rome, proche de Marjolin à cette époque ${ }^{73}$. Il devient directeur de l'association avec les pays tiers en 1958, un poste crucial dans la perspective de la négociation ZLE. Le dernier inspecteur des finances, Alain Prate, a un profil assez voisin dans la mesure où il a également participé à la délégation française de négociation des traités de Rome. Il devient directeur à la DG II qui dépend de Robert Marjolin.

Un dernier groupe est constitué de personnalités plus diverses, qui semblent avoir rejoint l'administration communautaire pour relancer une carrière française atone. Le premier est Louis-Georges Rabot, le directeur général chargé de l'agriculture. Sous-directeur de l'agriculture et participant actif aux négociations européennes agricoles des années 1950, notamment celles du Pool vert, sa nomination semble liée à ses qualités techniques indiscutables ${ }^{74}$ mais aussi à sa position marginale au sein de l'administration du ministère de l'Agriculture car il n'est pas membre du corps des IGREF (Ingénieurs du génie rural, des eaux et des forêts) mais simplement agronome ${ }^{75}$. Le second, Armand Saclé, souffre également de ne pas faire partie des corps dominants au sein de son ministère. Administrateur civil à la DREE, il est parti dans l'administration communautaire car ses possibilités de promotion étaient limitées dans l'administration française ${ }^{76}$. Il a d'ailleurs été nommé après qu'un inspecteur

73. ASGCI, 1991.0004, article 4, lettre de Paul Angoulvent à Jean-François Deniau du 3 avril 1957 ; Jean-François Deniau, Mémoires de 7 vies. Tome II, Croire et oser, Plon, Paris, 1997, p. 183.

74. Katja Seidel, « Making Europe through the CAP. Formation of an Esprit de Corps among DG VI High Officials », in Kiran Klaus Patel (éd.), Fertile Ground for Europe ?..., op. cit., p. 170.

75. Michel Mangenot, «La revendication d'une paternité... », op. cit., p. 39.

76. AO/AHUE, interview d'Armand Saclé par Éric Bussière, Véronika Heyde et Laurent Warlouzet 1e 28 janvier 2004. 
des finances, Jean Wahl, avait décliné son poste, et après avoir échoué à obtenir le poste de secrétaire général adjoint du $\mathrm{SGCI}^{77}$. Il devient directeur des aides à la DG Concurrence (DG IV), car il avait participé à la mise en œuvre du système français d'aide à l'exportation et de taxes à l'importation ${ }^{78}$. Il avait par ailleurs rencontré le directeur général Verloren van Themaat lors d'un voyage d'étude de la politique de la concurrence américaine organisé par l'OECE ${ }^{79}$. Enfin, Jacques Rueff est quant à lui un haut fonctionnaire et économiste français très prestigieux mais en rupture de ban après 1945. Il est d'ailleurs étonné d'être nommé à ce poste que Pierre-Henri Teitgen et René Mayer avaient refusé avant lui ${ }^{80}$. Rabot, Rueff et Saclé ont donc été nommés pour leurs compétences techniques indiscutables, mais cela pouvait également constituer pour eux un moyen de relancer leur carrière, d'accéder à des responsabilités qui se refusaient à eux en France.

La position de la France au sein de l'organigramme de l'administration de la Commission européenne semble donc tout à fait satisfaisante. Cependant, l'influence des autorités officielles françaises sur les institutions communautaires apparaît limitée pour deux raisons. Tout d'abord, l'administration communautaire ne doit pas être perçue comme le champ d'affrontement de groupes nationaux homogènes. Les commissaires et fonctionnaires européens sont en effet indépendants de leur gouvernement national. Certes, un lien fonctionnel indirect peut exister : ceux qui désirent revenir dans leur administration nationale à terme ne peuvent se permettre de passer pour des opposants aux intérêts de leur pays. Mais ceux qui ont embrassé une carrière purement communautaire n'ont aucune intention de revenir à Paris. De plus, la notion d'intérêt national est elle-même bien difficile à définir compte tenu de la valse des gouvernements. Chaque fonctionnaire l'interprète au prisme de ses idées politiques et économiques. Au sein même des européistes, les conceptions de l'Europe sont également très différentes ${ }^{81}$.

77. AO/Comité pour l'histoire économique et financière de la France, interview d'Armand Saclé par Laurence Badel, cassette 10, 12 mai 1992.

78. AO/AHUE, interview d'Armand Saclé par É. Bussière et al., p. 2.

79. Katja Seidel, «DG IV and the origins of a supranational competition policy : Establishing an economic constitution for Europe », in Wolfram Kaiser, Brigitte Leucht, Morten Rasmussen (éd.), The History of the European Union. Origins of a trans- and supranational polity, 1950-1972, Routledge, Londres, 2008, p. 134.

80. Nicole Condorelli-Braun, Commissaires et juges dans les Communautés européennes, LGDJ, Paris, 1972, p. 81.

81. Katja Seidel, « Gestalten statt Verwalten : Der Beitrag von Europabeamten zur Europaïschen Integration ", in Jürgen Elvert, Michael Salewski (éd.), Historische Mitteilungen. Band 18, Franz Steiner Verlag, Stuttgart, 2006, p. 134-149. 
Aucune stratégie d'ensemble du pouvoir politique français ne semble avoir été définie, en dehors de la nomination des deux commissaires européens, d'ailleurs peu liés au gouvernement Gaillard en poste en janvier 1958. Les principaux responsables français au sein de l'administration communautaire doivent leur poste soit à leurs connexions avec les réseaux européistes, soit parce que l'exil à Bruxelles ne suscite pas une grande compétition à cette date, car il était très risqué, les institutions de la CEE pouvant se révéler aussi décevantes que celles de la CECA ou de l'OECE. Le projet de ZLE en particulier, s'impose sur l'agenda politique et pourrait modifier en profondeur l'application de la CEE.

\section{LA PRESSION DE LA NÉGOCIATION ZLE}

Une fois le traité de Rome signé, la négociation ZLE débute véritablement car il est impossible de laisser en friche la collaboration entre les dix-sept pays de l'OECE. L'administration se mobilise rapidement pour définir une position française sur ce projet mais la prise de conscience des enjeux que représente cette négociation est très inégale. À partir de janvier 1958, c'est le gouvernement Gaillard qui se mobilise, et renforce temporairement la position française.

\section{A. LES DÉBUTS DE LA NÉGOCIATION INTERGOUVERNEMENTALE DE LA ZLE}

Après la conclusion du traité de Rome, la négociation ZLE est véritablement lancée. Les travaux d'experts sur le projet de ZLE se déroulent au sein de l'OECE. Dès le mois d'avril 1957, des projets d'articles précis sont examinés au sein des groupes d'experts ${ }^{82}$. Le secrétaire général de l'OECE estime qu'un projet de traité pourrait être préparé pour mai $1957^{83}$, soit seulement deux mois après la conclusion du traité de Rome.

Face à cette volonté de précipiter la négociation ZLE, les Six manifestent leur unité. Selon eux, il est illogique de discuter de projets d'article précis avant tout accord sur le fond. Les Six préféreraient employer la procédure de la CEE, c'est-à-dire de commencer par un accord sur les grands principes, réunis au

82. AMAE, DECE 790, folio 129, note de René de Saint-Légier du $1^{\text {er }}$ avril 1957.

83. AMAE, DECE 751, folio 101, note de René de Saint-Légier du 13 avril 1957 ; AMAE, DECE 701, folio 122, compte rendu du Comité mixte franco-britannique du 16 avril 1957. 
sein d' ' une sorte de rapport Spaak ${ }^{84}$. De plus, les Six se concentrent sur la ratification des traités de Rome, qui n'apparaît d'ailleurs pas contradictoire avec la négociation ZLE car la nécessité de cette dernière a souvent été affirmée dans les débats parlementaires, notamment en France ${ }^{85}$. Les Six retardent donc la discussion sur la ZLE mais sans manifester d'hostilité de principe à ce projet. Cependant, Londres s'impatiente.

\section{L'agressivité britannique envers la CEE.}

Face à ces retards dans la négociation ZLE, les décideurs britanniques se crispent. En juillet 1957, Selwyn Lloyd, le ministre des Affaires étrangères menace les Six, si la ZLE ne pouvait être conclue rapidement, de l'usage par la Grande-Bretagne de tous les moyens de pression possible pour détruire le Marché commun, notamment une offensive au GATT ${ }^{86}$. Or le GATT est une institution internationale appelée à prendre une importance croissante avec le retour à la libération des échanges, qui semble s'accélérer en 1957. De ce point de vue, la négociation ZLE agit pour les décideurs français comme une sorte de révélateur du caractère inéluctable de la libération des échanges, si ce n'est pour stimuler la France, du moins pour rester intégré dans les enceintes de coopération économique internationale.

Robert Marjolin souligne la radicalisation britannique et l'attribue à la pression de ses partenaires du Commonwealth ${ }^{87}$. Ces derniers souhaitent en effet que la négociation ZLE ne conduise pas à une diminution des préférences impériales agricoles. Ils profitent d'exportations privilégiées vers leur ancienne puissance coloniale. Cette interprétation est confirmée par les archives britanniques. Lors d'une réunion présidée par Macmillan le 11 juillet 1957, le gouvernement britannique s'accorde sur la nécessité de rester modéré lors des discussions au GATT sur la CEE, mais la volonté de certains pays du Commonwealth de défendre une ligne très agressive est soulignée ${ }^{88}$.

De fait, l'offensive britannique a bien lieu dans le cadre du GATT, où le traité de Rome est examiné. Les Six refusent que le GATT puisse remettre en cause

84. AMAE, DECE 622, projet de procès-verbal de la réunion des 16 au 16 avril 1957, 2 mai 1957 ; DDF, 1957-I, document n ${ }^{\circ} 322$, télégramme de Bousquet, ambassadeur de France à Bruxelles, à Christian Pineau, 18 avril 1957, p. 643.

85. Lors du débat à l'Assemblée nationale de janvier 1957 par exemple : Année politique, 1957, PUF, Paris, 1958, p. 11.

86. DDF, 1957-II, document n 34, télégramme de Chauvel, à Christian Pineau, 11 juillet 1957.

87. AMAE, DECE 620, télégramme de Raymond Bousquet, 25 juillet 1957.

88. PRO, CAB 130/123, note du 12 juillet 1957, compte rendu d'une réunion présidée par le Premier ministre le 11 juillet 1957. 
le traité de Rome ou contrôler son application, même si une étude de ses conséquences sur les échanges peut être autorisée ${ }^{89}$. Face aux Six, la Grande-Bretagne adopte une attitude très hostile. Elle publie un mémorandum qui critique le régime préférentiel liant les territoires d'outre-mer au Marché commun ${ }^{90}$.

Ainsi, la Grande-Bretagne manifeste un double langage au sein des institutions de coopération économique internationale : à l'OECE, elle joue le rôle de moteur d'une construction économique européenne qui doit s'appuyer sur la CEE pour la compléter ; au GATT, elle critique cette même CEE accusée de pratiques discriminatoires.

\section{Le comité Maudling.}

Une fois le processus de ratification bien entamé, la Grande-Bretagne relance les négociations. Le 17 octobre 1957, le Conseil de l'OECE décide finalement de créer un comité intergouvernemental de négociation qui devra aboutir à une ZLE qui devrait « pratiquement prendre effet parallèlement au traité de Rome $^{91} \gg$, c'est-à-dire en 1958-1959 car le processus de libération des échanges de la CEE doit commencer le $1^{\text {er }}$ janvier 1959.

Le Comité de l'OECE est présidé par celui qui dirige la délégation britannique, en l'occurrence Réginald Maudling. Ce dernier est un économiste libéral, attaché à une politique mondiale de la Grande-Bretagne ${ }^{92}$. Il a été choisi par Macmillan contre un autre candidat, Sir Edward Boyle, qui était lui plus favorable à une approche plus spécifiquement européenne ${ }^{93}$. Macmillan insiste sur la nécessité de fixer les limites au-delà desquelles le Royaume-Uni n'est pas prêt à aller pour la ZLE, et de le faire savoir ${ }^{94}$. Le gouvernement craint en particulier que les revendications françaises n'entraînent un dévoiement de la ZLE. Dans ce cas, la ZLE devrait être refusée et des solutions alternatives sont évoquées comme l'accroissement du commerce avec le Commonwealth ${ }^{95}$. Cela démontre que les ambitions de la Grande-Bretagne restaient mondiales, la ZLE n'étant

89. AMAE, DECE 623, projet de procès-verbal de la réunion des 27 et 28 septembre 1957, 2 octobre 1957.

90. DDF, 1957-II, document $n^{\circ} 253$, télégramme de Chauvel à Christian Pineau, 9 octobre 1957 ; AMAE, DECE 620, lettre de Raymond Bousquet du 3 octobre 1957 sur les débats au Comité intérimaire après la réunion du GATT du 21 septembre 1957.

91. AMAE, POW 39, folio 114, document de l'OECE du 17 octobre 1957.

92. A. Milward, The Rise and Fall of a National Strategy..., op. cit., p. 275.

93. A. Milward, The Rise and Fall of a National Strategy..., op. cit., p. 275.

94. PRO, CAB 130/123, note du 30 juillet 1957, compte rendu d'une réunion présidée par le Premier ministre le 29 juillet 1957.

95. PRO, CAB 130/123, note du 12 juillet 1957, compte rendu d'une réunion présidée par le Premier ministre le 11 juillet 1957. 
qu'une étape vers la construction d'un ordre international et pas un projet de construction européenne en tant que tel.

Face à cette accélération de la négociation ZLE et à cette agressivité britannique, la France repousse les débats de fond lors de la réunion de l'OECE des 16 et 17 octobre 1957 en raison de sa crise politique ${ }^{96}$. Elle peut le faire car elle a obtenu l'accord des Six juste avant cette réunion pour que leurs divergences éventuelles ne s'affichent pas à $1^{\prime} \mathrm{OECE}^{97}$. L'urgence de définir une position constructive est cependant patente.

\section{B. UNE MÉFIANCE CROISSANTE ENVERS LA ZLE}

En réaction à cette pression internationale, les décideurs français cherchent à définir une position française plus aboutie. Ils sont influencés par une orientation très favorable à la ZLE impulsée par Christian Pineau. Pourtant les hauts fonctionnaires français spécialistes de la question définissent rapidement une position très restrictive de la ZLE, suivant en cela le patronat français.

\section{Christian Pineau et l'impératif de la ZLE.}

De janvier 1956 à mai 1958, Christian Pineau reste ministre des Affaires étrangères. Favorable au Marché commun, c'est aussi un partisan convaincu du projet de ZLE, perçu comme le complément indispensable de l'Europe à Six. Il définit en avril 1957 une position provisoire de la France sur la ZLE fondée sur le parallélisme strict avec la CEE, sans hiérarchie en faveur de cette dernière ${ }^{98}$. Lors d'une réunion sur la ZLE tenue le 28 mai 1957, tandis que Donnedieu de Vabres cherche les moyens de retarder les discussions, le volontarisme de Pineau en faveur de la ZLE est réaffirmé et expliqué par des raisons politicocommerciales : il s'agit de ne pas laisser la France dans une seule enceinte européenne, la CEE, dominée par des pays à tradition libre-échangiste ${ }^{99}$. Cet argument peut constituer une des clés d'explication de l'inclination favorable de Pineau envers la ZLE : la Grande-Bretagne apparaît proche de la France en raison de son caractère de puissance coloniale à tarifs douaniers élevés. Mais cet argument méconnaît la réalité de la proposition ZLE : pour en profiter, la

96. DDF, 1957-II, document $n^{\circ} 288$, télégramme circulaire de Christian Pineau, 25 octobre 1957.

97. AMAE, DECE 623, projet de procès-verbal du 22 octobre 1957 sur la réunion du 16 octobre 1957.

98. DDF, 1957-I, document n 311, télégramme de Pineau à Chauvel, 13 avril 1957.

99. AINDUS, 1977.1520, article 49, note manuscrite sur la réunion ZLE du 28 mai 1957. 
France, en tant que puissance exportatrice agricole, devrait obtenir un démantèlement des préférences impériales que la Grande-Bretagne n'est pas prête à concéder. Au contraire, cette dernière paraît dorénavant prête à baisser ses tarifs industriels dans la mesure où elle s'est remise de la crise de Suez, à la différence de la France. Les contradictions du camp proeuropéen et anglophile commencent à émerger à la faveur du dossier ZLE.

Au sein du Quai d'Orsay, l'enthousiasme de Pineau pour la ZLE est relayé par François Valéry, l'adjoint d'Olivier Wormser à la DAEF et le représentant de la France à l'OECE. Il souligne que les problèmes techniques qui retardent la négociation ne sont pas plus importants que ceux qui se posaient aux débuts de la négociation du Marché commun ${ }^{100}$. Il critique la tentation de se concentrer sur la CEE et le risque de privilégier un axe franco-allemand inquiétant, au détriment de l'alliance britannique traditionnelle ${ }^{101}$.

La ZLE reste donc un projet politiquement incontournable, et même particulièrement souhaitable pour un groupe influent du Quai d'Orsay, attaché à l'échelle de la Grande Europe. Cependant la majorité de l'administration tend à se crisper face à une Europe perçue comme trop libérale.

\section{La définition rapide d'une position restrictive par l'administration.}

Deux jours seulement après la signature des traités de Rome, le 27 mars 1957 , le gouvernement français installe un second comité Verret consacré à la ZLE ${ }^{102}$. Un mois plus tard, une première synthèse de la position française est effectuée par Olivier Wormser, à partir de notes émanant de différentes administrations ${ }^{103}$, et à la demande de Maurice Faure lui-même semble-t-il ${ }^{104}$. Le directeur de la DAEF, écarté de la tête de la délégation française pendant la négociation du Marché commun, revient sur le devant de la scène, sans doute pour des logiques fonctionnelles (la négociation ZLE se déroule dans le cadre de l'OECE, or c'est la DAEF qui est chargée de représenter la France à cet

100. AMAE, DECE 741, folio 17 et 23, note François Valéry, 15 mai 1957 ; ASGCI, 1977.1461, article 60, note de François Valéry du 17 mai 1957.

101. DDF, 1957-II, document $n^{\circ} 4$, note de la DAEF de François Valéry, ${ }^{\text {er }}$ juillet 1957, ASGCI, 1977.1461, article 60, note de François Valéry du 8 juin 1957 ; DDF, 1958-II, document nº 271, note de la DAEF/SCE de François Valéry, 20 octobre 1958.

102. ASGCI, 1977.1471, article 60, note H. Barbier du $1^{\text {er }}$ avril 1957, réunion du 27 mars 1957.

103. AMINEFI, B 44.248, note d'Olivier Wormser à La Genière du 29 avril 1957. Elle sert de base à un projet d'instruction à la délégation française du 6 mai 1957 (AMAE, DECE 751, folio 249).

104. AMAE, POW 39, folio 71, lettre d'Olivier Wormser à Aicardi, directeur de cabinet de Félix Gaillard, 13 août 1957. 
organisme) et de négociation : le fait qu'Olivier Wormser ait été perçu comme trop dur pendant les négociations à Six n'est pas forcément un handicap au début d'une négociation qui s'annonce difficile comme celle de la ZLE. La position définie par Wormser est fondée sur trois principes.

Tout d'abord, la primauté de la CEE sur la ZLE est clairement affirmée : «C'est autour du Marché commun que doit se déployer la zone de libre-échange et non l'inverse ${ }^{105} »$. Ainsi, la libération des échanges ne devra pas être plus rapide que celle qui est prévue dans le cadre de la CEE. Le libéralisme régulé des Six devient ainsi une référence par défaut, face au contre-modèle de la ZLE. Cette évolution se perçoit par exemple au ministère de l'Industrie, très critique envers le Marché commun en 1956 pour son libéralisme ; il transfère progressivement son hostilité envers une coopération économique européenne trop libérale de la CEE vers la ZLE ${ }^{106}$.

Deuxièmement, le directeur de la DAEF demande pour la ZLE des garanties supérieures à celle obtenues pour la CEE car elle présente des risques supérieurs en raison de l'absence de tarif extérieur commun et du nombre plus important de pays concurrents. Il recommande des solutions sectorielles au problème de l'origine. Ainsi, dans le secteur de la chimie, comme l'origine des produits est parfois impossible à déterminer, une harmonisation des tarifs extérieurs devra être demandée. À défaut une clause de sauvegarde pourra être réclamée. Ainsi, la libération des échanges est acceptée si elle est régulée selon une approche sectorielle. Sur le plan institutionnel, Wormser précise dans un second mémorandum les garanties réclamées pour neutraliser les futures institutions de la ZLE : la prise de décisions à l'unanimité, le recours possible à une clause de sauvegarde unilatérale (et pas communautaire comme dans la CEE) et un rythme de libération des échanges plus lent dans la ZLE que dans la $\mathrm{CEE}^{107}$.

Enfin, la ZLE qui se dessine dans ce projet d'instruction est essentiellement axée sur la libération des échanges de produits industriels. Pour les produits agricoles, Olivier Wormser estime que Londres refusera tout accord large ; la négociation devra donc porter sur des arrangements ad hoc. Quant aux territoires d'outre-mer, leur cas n'est pas évoqué car, dans une ZLE, la France ne

105. AMINEFI, B 44.248, note d'Olivier Wormser à La Genière du 29 avril 1957.

106. AINDUS, 1977.1520, article 49, note du secrétariat d'État à l'Industrie et au Commerce au ministère des Affaires étrangères rédigée par Vavasseur, 23 avril 1957 ; projet de lettre du 6 juin 1957.

107. ASGCI, 1977.1471, article 60, et AMAEF, POW 39, folio 52, projet de mémorandum français sur la ZLE, 9 août 1957; il a été adopté lors d'une réunion tenue un mois plus tard: ASGCI, 1977.1471, article 60, note «Zele, réunion du 5 septembre $1957 »$. 
serait plus la seule puissance coloniale et ces dispositions pourraient se révéler financièrement dispendieuses ${ }^{108}$.

Par ce premier projet de mémorandum français, Olivier Wormser définit ainsi une position de négociation restrictive. La hiérarchie entre CEE et ZLE est désormais clairement établie, car c'est le modèle de la CEE qui sert à définir les éléments constitutifs d'une ZLE souhaitable. Cette dernière ne doit pas concurrencer le Marché commun mais le compléter dans le seul domaine de la libération des échanges industriels par des engagements de nature sectorielle. Cette position restrictive est adoptée par la majorité des hauts fonctionnaires français. Ceux qui étaient hostiles à la libération des échanges transfèrent leurs critiques de la CEE vers la ZLE. Ceux qui étaient favorables au Marché commun par européisme ou par adhésion à son projet économique veulent le préserver face à la menace d'un projet concurrent. Cette évolution des réflexions a pu être encouragée par la mobilisation d'une grande partie des milieux économiques contre le projet de ZLE.

\section{Une mobilisation patronale influente en France.}

La conception de l'Europe organisée en faveur de laquelle s'exprime la majorité du patronat à l'occasion des débats sur la CEE rend le projet de ZLE peu séduisant à ses yeux.

Le CNPF se mobilise dès le 17 septembre 1957, à l'occasion de la relance de la négociation ZLE par le comité Maudling, en publiant une note sur ce sujet dans le Bulletin du $C N P F^{109}$. Partant des problèmes de l'origine soulevés par l'absence de tarif extérieur commun, cette note montre que la ZLE avantagera surtout la Grande-Bretagne, et menacera la bonne application de la CEE. Le CNPF conclut sur un refus net de la ZLE, réitéré peu après dans une lettre au nouveau président du Conseil Félix Gaillard ${ }^{110}$. Cette mobilisation du CNPF suit celle de Renault. Au début du mois de septembre 1957, son PDG Pierre Dreyfus rencontre Jean Monnet et lui transmet une note très aboutie contre la ZLE ${ }^{111}$. Il demande un décalage important entre la CEE et la ZLE. En attendant, il serait possible de répondre à l'inquiétude que suscite la CEE par des accords commerciaux ad hoc entre les Six et les autres membres de l'OECE.

108. Wormser suit une note de Sadrin : AMINEFI, B 44.246, note RG, Finex, signée Sadrin, 10 avril 1957.

109. Texte du CNPF du 17 septembre 1957 adressé au ministre des Affaires étrangères, in Bulletin $d u C N P F$, octobre $1957, \mathrm{n}^{\circ} 165$.

110. Bulletin du CNPF, décembre 1957, n 167, « Position du CNPF sur la ZLE », p. 21-22.

111. AFJM, AMK C 16/4, lettre de Maurice Bosquet à Jean Monnet, 12 septembre 1957. 
Par la suite, les branches les plus menacées par la ZLE se mobilisent publiquement. La chimie ouvre le bal car ses produits sont directement concernés par la difficulté d'identifier l'origine des produits ${ }^{112}$. C'est ensuite l'électrométallurgie et l'électrochimie qui soulignent le problème posé par la concurrence de la Scandinavie, favorisée par des prix de l'électricité faibles, et de la GrandeBretagne qui bénéficie d'approvisionnements préférentiels du Commonwealth ${ }^{113}$. Le secteur automobile enfin, se mobilise au-delà du seul constructeur Renault, toujours pour critiquer la concurrence potentielle déloyale du Royaume-Uni si une ZLE était établie ${ }^{114}$. Au-delà c'est bien la concurrence américaine qui inquiète les constructeurs français mais aussi italiens comme Fiat ${ }^{115}$. Ce n'est pas la concurrence qui est refusée en tant que telle mais l'absence d'un cadre l'organisant et la canalisant, ainsi qu'une échelle de coopération moins favorable que dans la CEE.

Cette mobilisation patronale quasiment unanime a des conséquences visibles sur les responsables administratifs. En effet, l'administration cherche naturellement à s'appuyer sur l'expertise patronale pour nourrir ses réflexions sur la ZLE. En mai 1957, Donnedieu de Vabres demande des arguments pour convaincre les Six de défendre une harmonisation tarifaire dans certains secteurs industriels ${ }^{116}$. De son côté, le ministère de l'Industrie, qui souhaite étudier le problème des usines de montages américaines soulevé par le secteur automobile ${ }^{117}$, doit rapidement reconnaître les lacunes de ses sources et demande l'aide des milieux économiques pour obtenir des informations ${ }^{118}$.

De plus l'hostilité du patronat français à la ZLE - en contraste avec sa conversion rapide à la CEE, est utilisé par les négociateurs français. L'argument est utilisé par Olivier Wormser le 7 octobre face aux Britanniques, et par Maurice Faure le 16 octobre lors de sa conversation avec

112. AMAE, DECE 628, folio 73, mémorandum de l'Union des industries chimiques du 2 octobre 1957.

113. ASGCI, 1991.004, vol. 3, lettre au directeur des Mines (Industrie), de la Chambre syndicale de l'électrométallurgie et de l'électrochimie, 29 octobre 1957.

114. AMAE, DECE 756, lettre de la Chambre syndicale des constructeurs d'automobile du 3 janvier 1958, au ministre de l'Industrie ; ASGCI, 1991.0004, article 1, lettre du directeur adjoint de Simca au directeur du cabinet du ministre de l'Industrie du 14 janvier 1958 ; ASGCI, 1991.004, article 3, conférence de presse du président François Peugeot, 17 mars 1958.

115. S. Ramirez, Public Policies..., op. cit., p. 535-542.

116. AINDUS, 1977.1520, article 49, note manuscrite : réunion ZLE du 28 mai 1957.

117. AINDUS, 1977.1520, article 49, note pour les services de Bazin, 3 août 1957.

118. AINDUS, 1977.1520, article 49, note de la DIME, du 30 août 1957 ; ASGCI, 1991.0004 , article 1, lettre du directeur adjoint de Simca, L. de Rosen, à François Delhomme, directeur du cabinet du ministre de l'Industrie du 14 janvier 1958. 
Maudling ${ }^{119}$. En interne, Sadrin cite même le CNPF comme source d'une contre-proposition globale alternative à la ZLE, celle de conclure des accords tarifaires et contingentaires bilatéraux entre les Six en tant que Communauté d'une part, et les Onze pris de manière individuelle ${ }^{120}$. Cette solution se rapproche d'ailleurs de celle qui est proposée par Maurice Faure à Ludwig Erhard le 18 février $1958^{121}$. Réduire la ZLE à un ensemble d'accords commerciaux bilatéraux conclus par la Commission européenne permettrait d'affirmer la puissance commerciale de la CEE et l'unité structurelle des Six.

Enfin, le patronat apparaît parfois comme un véritable acteur de la négociation ZLE en participant au débat franco-britannique. Lors de la réunion d'une " conférence industrielle européenne », organisée en mars 1958 par la branche britannique du Mouvement européen, la délégation française a fait l'objet d'attaques très vives de la part des Britanniques. Les organisateurs britanniques de la réunion sont d'ailleurs très proches du gouvernement de Londres et défendent la même position sur la ZLE ${ }^{122}$. L'ambassadeur de France à Londres, Jean Chauvel, remarque alors : « Je crois qu'il a été utile, en face de ces obstacles, que le point de vue français fût défendu avec beaucoup de fermeté, comme s'y employa notre délégation. [...] En plaçant l'échange de vues sur un plan concret, les représentants patronaux et syndicaux français purent ainsi faire apparaître la complexité des problèmes posés par la zone, et la très grande diversité des solutions présentées par les uns et les autres ${ }^{123} \gg$. Les représentants patronaux français ont donc suivi la tactique adoptée par les Français au comité Maudling. Elle consiste à empêcher toute prise de position de principe par l'évocation des multiples problèmes concrets que pose une zone de libre-échange. Le terme « notre délégation », employé par Chauvel, comme la tactique adoptée témoignent d'une certaine analogie entre les représentants patronaux et les fonctionnaires français engagés dans la négociation.

Un deuxième indice de cette correspondance se manifeste lors de la réunion du comité Maudling de mars 1958. À cette occasion, la délégation française avait proposé, sans succès, d'établir un mémorandum sur le secteur de la pâte à papier.

119. AMAE, DECE 752, folio 135, note sur les entretiens entre Olivier Wormser et Sir Paul Gore Booth, sous-secrétaire d'État chargé des Affaires économiques au Foreign Office, 7 octobre 1957 ; DDF, 1957-II, document $n^{\circ}$ 266, note du département, « Entretien entre M. Maurice Faure et M. Maudling », 16 octobre 1957.

120. ASGCI, 1977.1471, article 60, note de Jean Sadrin, directeur des Finances extérieures, du 14 octobre 1957.

121. AMAE, DECE 753, folio 20, note du 20 février 1958 sur les entretiens Faure-Erhard du 18 février 1958.

122. PRO, FO 371/128364, note FO, D. Ormsby-Gore, 27 octobre 1957.

123. AMAE, DECE 701, folio 206, télégramme de Chauvel du 6 mars 1958. 
Cette manœuvre aurait permis de démontrer l'irréalisme d'une simple zone de libre-échange dans ce secteur où les pays scandinaves, du fait de l'abondance de leurs ressources forestières, disposent d'un avantage comparatif susceptible de briser toute concurrence au sein de la $\mathrm{ZLE}^{124}$. Or quelques semaines plus tard, un mémorandum est établi par les représentants de cette branche des Six pays de la CEE, rejoints pour l'occasion par les producteurs britanniques ${ }^{125}$. Ils reprennent ces arguments et demandent l'exclusion de la ZLE de ce secteur, ou à défaut des mesures de sauvegarde. Un jeu de va-et-vient se développe donc entre les négociateurs au comité Maudling et les milieux économiques. Il ne faut pas voir dans ce mouvement un plan concerté, géré par un acteur unique omniscient, mais l'expression d'une même inquiétude par différents acteurs. Sur le fond, les réflexions du patronat permettent de renforcer l'intérêt du libéralisme régulé de la CEE aux yeux des décideurs français, alors que la ZLE devient rapidement un contre-modèle en incarnant le libéralisme sauvage du XIX ${ }^{\mathrm{e}}$ siècle. Cependant, son action à l'échelle européenne est entravée par ses divisions.

\section{Les divisions révélatrices du patronat européen.}

De profondes oppositions divisent les patronats européens. L'exemple de la Ligue européenne de coopération économique (LECE) est le plus frappant. La LECE est une organisation patronale d'inspiration libre-échangiste qui soutient depuis l'origine tant le projet de CEE que celui de ZLE ${ }^{126}$. Cependant, les travaux techniques menés à la LECE sur la négociation ZLE débouchent dès le mois d'octobre 1957 sur le constat du très grave problème posé par le contrôle de l'origine des produits ${ }^{127}$. Le secrétaire général de la LECE, Lucien Sermon est chargé d'une étude sur ce sujet. Elle préconise finalement une harmonisation des tarifs extérieurs et, à défaut, l'adoption de taxes compensatoires, soit des solutions proches de celles étudiées au sein de l'administration française ${ }^{128}$.

124. L'inquiétude des producteurs français envers la CEE et les pays qui composent l'AELE est évoquée in : Marc de Ferrière Le Vayer, L'industrie papetière française, 1945-2000, habilitation à diriger des recherches, juillet 2002, p. 86-89.

125. AMAE, DECE 780, mémorandum commun aux industries papetières des Six et du Royaume-Uni, 9 mai 1958.

126. Michel Dumoulin, Anne-Myriam Dutrieu, La Ligue européenne de coopération économique (1946-1981). Un groupe d'étude et de pression dans la construction européenne, Berne, Peter Lang, 1993 , p. 108 et $128-129$.

127. ALECE, compte rendu du 7 octobre 1957 d'une réunion du 2 octobre 1957 étudiant un document de la délégation britannique sur la ZLE.

128. ALECE, note de Sermon du 24 octobre 1957 ; ALECE 653, lettre adressée aux membres belges de la LECE (Lamy, Charlier, de Bièvre, Polak) parY. de Wergifosse, secrétaire général adjoint, le 14 février 1958. 
Cette vision critique de la ZLE adoptée par Sermon suscite des divisions au sein de la LECE. Il lui est reproché de considérer la CEE comme la seule référence en matière de coopération économique européenne ${ }^{129}$. Or, c'est justement l'établissement du Marché commun qui constitue le problème dans la mesure où il crée une zone préférentielle susceptible de perturber les courants commerciaux intra-européens. C'est donc ici la perspective des Britanniques et de la direction de l'OECE qui est adoptée. Le secrétaire général adjoint de l'OECE, Cahan, a d'ailleurs sollicité la LECE pour qu'elle contribue à proposer des solutions pour relancer les négociations de la ZLE en février $1958^{130}$. La LECE n'arrive toutefois pas à s'accorder sur le document proposé par Sermon ${ }^{131}$. Ce dernier propose finalement, pour débloquer les négociations, de conclure de multiples accords "spécifiques », soit par pays soit par secteurs, quitte à les harmoniser ensuite dans un cadre commun ${ }^{132}$. Cette résolution suscite une vigoureuse critique de Cahan et Sergent ${ }^{133}$. En retour, Sermon se plaint de l'obstruction des membres britanniques de la LECE qui l'empêche de continuer ses travaux de manière sereine ${ }^{134}$. Le baron Boël lui-même, le président de la LECE, est obligé d'écrire au représentant britannique pour solliciter sa modération ${ }^{135}$. De fait, les liens entre les représentants britanniques à la LECE (le président du comité est Edward Beddington-Behrens) et le gouvernement de Londres sont bien attestés dans les archives britanniques ${ }^{136}$. Par la suite, la LECE est sollicitée une nouvelle fois par Sergent le 3 novembre 1958, pour tenter de débloquer les négociations ZLE ${ }^{137}$. Mais les réflexions de la LECE deviennent de plus en plus hostiles à ce projet en raison d'une attitude britannique jugée excessivement agressive ${ }^{138}$.

Ces divisions ne sont pas propres à la LECE. Le CIFE, l'organisation patronale officielle établie à l'échelle de la Grande Europe a également des

129. ALECE 654, note de R. Lamy du 19 février 1958.

130. ALECE 654, lettre de Robert de la Forteille au baron Boël, 15 février 1958.

131. ALECE 654, compte rendu du Conseil central du 27 février 1958.

132. ALECE 654, « Résolution sur le développement de la coopération économique en Europe », 7 mars 1958.

133. Respectivement secrétaire général adjoint et secrétaire général de 1'OECE : ALECE, 654, lettre de J. F. Cahan à de la Fortelle, 21 mars 1958 ; ALECE 654, lettre de René Sergent au baron Boël, 24 mars 1958.

134. ALECE 654, lettre de Sermon à Sir Edward Beddington-Behrens, 16 mai 1958.

135. ALECE 654, lettre du baron Boël à Sir Edward Beddington-Behrens, 19 mai 1958.

136. PRO, FO 371/128364, note FO, D. Ormsby-Gore, 27 octobre 1957 ; PRO, T 336/6, lettre de Edward Beddington-Behrens à Maudling, 28 février 1958.

137. ALECE 654, lettre de René Sergent au baron Boël, LECE, 3 novembre 1958.

138. ALECE 654, projet de déclaration de la LECE sur la rupture des négociations ZLE, 18 novembre 1958. 
difficultés à faire émerger une position commune, alors même que son opinion est sollicitée par René Sergent, le secrétaire général de l'OECE, dès le mois de novembre $1957^{139}$. Un débat se tient en mars 1958 et révèle les profondes divisions patronales ${ }^{140}$. Pour éviter des divisions internes, le CIFE renvoie la question à une commission ad hoc, présidée par le suédois Axel Iveroth ${ }^{141}$. Elle présente un projet de rapport assez modéré en juillet 1958 mais le CIFE abandonne rapidement toute velléité de peser sur les négociations ${ }^{142}$.

D'une manière générale, les fédérations patronales nationales sont très divisées. Le CNPF a affirmé officiellement son hostilité au principe même de ZLE. De son côté, la Confindustria a également manifesté sa réticence envers ce projet mais de manière plus diplomatique ${ }^{143}$. Au contraire, le patronat britannique, de plus en plus sceptique sur le résultat des négociations, envisage de conclure un accord sans les Six. Avant la réunion plénière du CIFE de mars 1958, les représentants patronaux des pays non-membres de la CEE s'étaient réunis pour envisager la création d'une ZLE sans les Six si les négociations venaient à échouer ${ }^{144}$. La future AELE est issue de ces réflexions entamées par les patronats européens, en particulier britanniques et suédois ${ }^{145}$.

La mobilisation patronale européenne sur le projet de ZLE est révélatrice de deux faiblesses de ce projet. D'une part, le patronat européen est sollicité directement par le secrétariat général de l'OECE, ce qui montre la grande imprécision du projet en discussion. Au contraire, la négociation intergouvernementale sur le Marché commun était bornée par le rapport Spaak, qui définissait un cadre assez précis. D'autre part, les analyses des milieux économiques mettent en valeur les défauts techniques du projet de ZLE, trop exclusivement libéral pour pouvoir générer une concurrence régulée, donc acceptable par tous. En creux, le modèle de la CEE d'un libéralisme régulé, fondé sur une intégration économique progressive, s'en trouve renforcé. Ces deux éléments expliquent les difficultés de la négociation intergouvernementale sur la ZLE.

139. ACNPF, 72 AS 803, compte rendu de la réunion CIFE du 8 novembre 1957.

140. ACNPF, 72 AS 803, compte rendu de la réunion CIFE des 17 et 18 mars 1958.

141. ACNPF, 72 AS 803, compte rendu de la réunion CIFE du 8 mai 1958.

142. ACNPF, 72 AS 812, deuxième projet de rapport Iveroth, 2 juillet 1958, confidentiel ; ACNPF, 72 AS 803, compte rendu du conseil général du CIFE du 28 juillet 1958.

143. ASCGI, 1991.0004, article 1, information CEE, 11 décembre 1957. Aussi : AMAE, DECE 634, note de François Gavoty, conseiller commercial auprès du consulat général de Milan, 26 juin 1957.

144. PRO, BT BT 205/264, Board of Trade progress report $n^{\circ} 1$, mars 1958.

145. Neil Rollings, British Business in the Formative Years of European Integration, 1945-1973, Cambridge UP, Cambridge, 2007, p. 123-124. 


\section{LA TENTATIVE DE PRISE EN MAIN \\ DE LA NÉGOCIATION PAR GAILLARD}

Le volontarisme du gouvernement Gaillard, qui s'était déjà exprimé en matière de politique intérieure, se manifeste également dans le dossier de la ZLE, laissé à l'initiative des hauts fonctionnaires pendant une longue période. En janvier 1958, Gaillard prend directement en main ce dossier et parvient à rétablir la situation de la France dans une négociation difficile, jusqu'à la crise d'avril-mai 1958.

\section{L'investissement de l'exécutif (janvier 1958).}

La négociation intergouvernementale sur la ZLE a commencé en octobre 1957 avec la création du comité Maudling. Or aucune position française officielle n'avait été adoptée à cette date, en dépit des nombreux travaux de l'administration pendant l'été. La concentration sur les problèmes financiers et algériens ainsi que la crise politique (vacance du gouvernement entre le 30 septembre et le 4 novembre 1957) ont achevé de paralyser les décideurs politiques. Les représentants français ne peuvent exprimer qu'une position provisoire, fondée sur une ZLE minimaliste pour ne pas menacer la $\mathrm{CEE}^{146}$.

La définition d'une position officielle paraît indispensable pour maintenir l'autorité de la France dans les négociations européennes car la pression internationale reste très forte. Le 4 décembre 1957, Wormser estime ainsi que la Grande-Bretagne aura un projet de traité ZLE dans moins de trois mois ${ }^{147}$. Le 9 janvier 1958, Félix Gaillard préside un comité interministériel consacré à la ZLE ${ }^{148}$. Au cours de ce dernier, deux positions s'expriment. D'un côté, le ministre des Finances Pierre Pflimlin propose une solution radicale : calquer la ZLE sur la CEE et à défaut rompre la négociation en essayant de faire porter la responsabilité sur la Grande-Bretagne. D'un autre côté, Félix Gaillard défend une position plus modérée, qui tient mieux compte des rapports de force internationaux. Il constate que la France a besoin des Six car elle aura des difficultés à appliquer la CEE en raison des engagements de libération des échanges qu'elle porte. En conséquence, la France ne peut se permettre de faire échouer la négociation ZLE car elle se retrouverait isolée au sein des Six. Gaillard plaide pour la défense d'une ZLE minimale, alors que Pflimlin est sur la ligne d'une ZLE calquée sur la CEE.

146. AMAE, DECE 620, folio 108, télégramme de Raymond Bousquet du 14 septembre 1957 ; DDF, 1957-II, document $\mathrm{n}^{\circ}$ 204, note de M. Marjolin, 16 septembre 1957.

147. AMAE, POW 39, folio 223, note d'Olivier Wormser pour le ministre, 4 décembre 1957.

148. AMAE, POW 39, folio 235, note d'Olivier Wormser du 9 janvier 1958. 
Sur le plan tactique, Gaillard considère comme indispensable l'élaboration d'un mémorandum français sur la ZLE pour que la pression passe de la France à la Grande-Bretagne. Il est alors décidé qu'un mémorandum serait réalisé par une commission présidée par un proche de Gaillard, Jean-Paul Delcourt, son directeur adjoint de cabinet. Comme Guy Mollet avec Alexandre Verret, Félix Gaillard place un de ses proches à la tête d'une mission interministérielle de suivi des négociations de coopération économique européenne.

Cette action sur la ZLE s'inscrit dans une volonté plus globale de restauration de l'autorité française à l'échelle internationale entreprise par le gouvernement Gaillard en janvier 1958. Les deux autres volets sont l'adoption de la loi-cadre, qui vise à adapter la France au retour à la libération des échanges, et l'obtention de crédits internationaux. La définition de la position française reste toutefois difficile.

\section{Lélaboration difficile du mémorandum français.}

Une fois les directives gouvernementales fixées, encore faut-il les appliquer. Or elles sont marquées par une ambiguïté fondamentale car le choix n'a pas été fait clairement entre la conception de la ZLE sur le modèle de la CEE (Pflimlin) et celui d'une ZLE minimale (Gaillard).

Un premier projet de mémorandum est établi par Jacques Donnedieu de Vabres (SGCI) le 5 février $1958^{149}$. Il est fondé sur deux éléments. D'une part, l'approche sectorielle, déjà évoquée dans le mémorandum Wormser de l'été 1957, est systématisée. D'autre part, de nombreuses garanties négatives sont demandées en matière institutionnelle. Les trois garanties négatives définies dans le mémorandum Wormser du 9 août 1957 (décisions à l'unanimité, clauses de sauvegarde unilatérales, décalage $)^{150}$ sont reprises. Deux autres garanties négatives sont ajoutées. D'une part, la France refuse de s'engager sur un « terme final », une date de fin du processus de libération interne des échanges, qui scellerait l'ouverture complète de la zone de libre-échange. D'autre part, le mémorandum plaide pour une ZLE expérimentale, dont la poursuite dépendrait d'examens périodiques du progrès parallèle entre la libération des échanges d'une part, et des clauses d'harmonisation d'autre part comme le démantèlement des préférences impériales.

Le mémorandum du 5 février 1958 insiste donc beaucoup sur la notion de ZLE minimale et expérimentale. Les clauses les plus restrictives évoquées

149. AMAE, POW 39, folio 248, projet de mémorandum français sur la ZLE, 5 février 1958. 150. ASGCI, 1977.1471, article 60, projet de mémorandum français sur la ZLE, 9 août 1957. 
en 1955-1956 contre le projet de Marché commun sont reprises et réunies en un tout cohérent pour circonscrire le processus de libération des échanges.

En dépit de sa position restrictive, ce mémorandum est contesté au sein de l'administration pour sa modération. Cela pousse Wormser à s'engager fermement pour le défendre ${ }^{151}$. Il explique clairement dans sa note qu'il n'est pas favorable à une coopération exclusive à Six mais que cette dernière doit être absolument préservée. Il défend une stratégie réaliste : la France doit faire traîner en longueur la négociation pour obtenir des concessions mais aussi pour sensibiliser les Français au caractère incontournable de la ZLE afin, en temps voulu, d'obtenir une majorité au Parlement pour ratifier cet accord ${ }^{152}$. L'ancien opposant au rapport Spaak ne s'est donc pas subitement converti à la CEE par idéalisme. Pour Wormser, la CEE comme la ZLE démontrent le caractère inéluctable d'une libéralisation des échanges. La CEE représentant un accord économiquement plus favorable à la France, elle doit être privilégiée. Mais la ZLE reste politiquement incontournable. Il est impossible pour la France de briser la négociation en raison de ses faiblesses, donc elle doit définir une position raisonnable. L'analyse du directeur de la DAEF repose avant tout sur l'analyse des rapports de force internationaux.

Le risque d'isolement de la France en Europe à cause de sa position restrictive dans la négociation ZLE est patent. Wormser estime que Londres cherche vraisemblablement, dans la négociation ZLE, à imposer à la France un traité qu'elle ne pourrait pas ratifier, provoquant ainsi son isolement en Europe ${ }^{153}$. La tactique française consistant à faire du chantage à la ratification parlementaire serait donc condamnée, car cela deviendrait un objectif britannique. Un entretien entre Maurice Faure et le ministre allemand de l'Économie, Ludwig Erhard, le 18 février démontre l'isolement de la France ${ }^{154}$. Erhard estime que l'attitude négative des Français risque de diviser l'Europe. Surtout, il souligne que la France est seule contre les Cinq, au sein de la CEE, à s'opposer si fermement à la ZLE. Certes la position d'Erhard n'est pas celle d'Adenauer mais cet entretien démontre à la fois l'isolement réel de la position française et les risques qu'elle entraîne pour l'avenir de la CEE. Ces divergences montrent une nouvelle fois la force de l'axe Wormser-Donnedieu, dont la doctrine européenne pragmatique est nourrie par la pratique concrète des négociations européennes.

151. AMAE, POW 39, folio 249, note d'Olivier Wormser pour Louis Joxe, 5 février 1958 ; voir aussi : AMAE, POW 39, folio 223, note d'Olivier Wormser, 4 décembre 1957.

152. AMAE, POW 39, folio 249, note d'Olivier Wormser pour Louis Joxe, 5 février 1958.

153. AMAE, POW 39, folio 242, note d'Olivier Wormer pour François Valéry, 20 janvier 1958.

154. DDF, 1958-I, document $n^{\circ} 121$, note du 20 février 1958, entretien entre Maurice Faure et Ludwig Erhard du 18 février 1958. 
Finalement, le risque d'isolement de la France sur la scène européenne explique sans doute l'adoption relativement rapide d'un mémorandum français, accepté le 20 février 1958 lors d'un conseil restreint présidé par Félix Gaillard ${ }^{155}$. Comme le mémorandum Donnedieu de Vabres, il insiste sur les garanties négatives (décalage de trois ans, unanimité pour les institutions, clause de sauvegarde unilatérale, pas de terme final), sur la notion de zone expérimentale et sur la systématisation de l'approche sectorielle. Dans chaque secteur devront être définies des clauses spécifiques sur la définition de l'origine, les harmonisations législatives, la politique commerciale ou les clauses de sauvegarde. La ZLE deviendrait ainsi un écheveau d'accords sectoriels en perpétuelles renégociations.

Par ailleurs, le mémorandum français s'inspire beaucoup plus largement de la $\mathrm{CEE}^{156}$. En lieu et place de l'approche commerciale de la « zone de libreéchange», il souhaite développer une véritable «Union européenne de coopération économique (UECE) » fondée sur «l'harmonisation des conditions générales de production » devant mener à l' « égalité réelle des conditions de concurrence ${ }^{157}$ ». L'influence stimulatrice de la libération des échanges, fondée justement sur les différences dans les conditions de production, est fortement critiquée.

Pierre Pflimlin, le ministre des Finances, semble avoir joué un grand rôle dans l'orientation de ce mémorandum vers le modèle de la $\mathrm{CEE}^{158}$, alors que c'est plutôt le schéma de la ZLE minimaliste qui avait été développé dans le mémorandum Donnedieu. C'est d'ailleurs lui qui est à l'origine de la nouvelle appellation d'UECE ${ }^{159}$. À une réunion préparatoire tenue chez Maurice Faure le 12 février 1958, beaucoup de responsables français estimaient que la position de la France dans la négociation ZLE restait forte, ce qui lui permettait de manifester une position ferme ${ }^{160}$. Le mémorandum français, parfois appelé mémorandum Gaillard, est donc marqué par une certaine intransigeance mais peut servir de base de négociation réaliste. En tout cas, la vision française est confortée par le mémorandum diffusé peu après par la Commission européenne.

155. ASCGI, 1977.1471, article 61, compte rendu du conseil restreint du 20 février 1958 présidé par Félix Gaillard.

156. ASCGI 1997.1471, article 61, mémorandum français du 20 février 1958.

157. ASCGI 1997.1471, article 61, mémorandum français du 20 février 1958.

158. AMAE, POW 38, folio 349, note manuscrite sur le mémorandum Gaillard, 17 février 1958, «Pflimlin, 17.2.58».

159. AMAE, POW 39, folio 249, note d'Olivier Wormser pour Louis Joxe, 5 février 1958.

160. AMAE, DECE 753, folio 37, note du 13 février 1958 sur une réunion tenue chez Maurice Faure le 12 février 1958. Aussi : Europeus (Pierre Uri), La crise de la zone de libre-échange, Plon, Paris, 1959, p. 22, cité par Miriam Camps, Britain and the European Community, 1955-1963, Princeton UP, Princeton, p. 146. 


\section{Le mémorandum de la Commission (mars 1958).}

La Commission participe aux négociations ZLE pour faciliter la coordination des positions des Six, mais pas pour les représenter ${ }^{161}$. Cependant le nouvel exécutif bruxellois n'entend pas se priver de son pouvoir de proposition. La Commission européenne définit sa position dans un mémorandum du 19 mars $1958^{162}$. Il manifeste l'expression d'une position très offensive dans la défense du modèle CEE. Elle souligne ainsi que c'est la ZLE qui doit s'adapter à la CEE et pas l'inverse. Par rapport au mémorandum français, la position de la Commission repose sur une base plus libérale. Elle ne compte pas, comme la France, sur des garanties négatives (décalage, etc.) pour assurer l'innocuité de la ZLE, mais sur un système en deux temps. D'abord, la Commission demande que des études sectorielles soient menées pour définir le degré de libération et les mesures d'harmonisation liées (taxes compensatoires ou harmonisation des tarifs). La longueur de ces études amènera de facto à un décalage entre les débuts de la ZLE et ceux du Marché commun, dont le processus de libération des échanges commence dès le premier janvier 1959. Dès lors, et c'est le deuxième aspect, la Commission propose un accord provisoire consistant à élargir les réductions tarifaires intracommunautaires prévues au premier janvier 1959 à tous les pays du GATT.

Il faut noter que l'idée d'un accord provisoire avait déjà été évoquée par le secrétaire général de l'OECE, René Sergent en novembre $1957^{163}$. Dès cette date, il estimait que le traité de ZLE ne pourrait peut-être pas être signé avant le $1^{\text {er }}$ janvier 1959. Ce problème devrait alors être circonscrit par un arrangement ad hoc du Conseil de l'OECE. Sergent envisageait d'étendre les mesures de libération des échanges prévues entre les Six au premier janvier 1959 à l'ensemble des pays de l'OECE ${ }^{164}$. Le mémorandum de la Commission reprend cette idée en l'élargissant au GATT. Ainsi la spécificité de la CEE est affirmée tandis que le cadre concurrent de l'OECE est dilué dans celui, plus vaste, du GATT. Par ailleurs, les mesures contingentaires restent réservées aux Six, ce qui permet de préserver la spécificité de l'échelle communautaire. Ce qui fut ensuite appelé la « proposition Hallstein » d'accord au premier janvier 1959 constitue en fait une communautarisation de la proposition préalable de René Sergent.

161. AMAE, POW 32, folio 70, note du secrétariat du Conseil des ministres CEE, 21 janvier 1958 ; AMAE, DECE 624, projet de procès-verbal de la réunion des représentants qualifiés (futurs représentants permanents) du 17 janvier 1958.

162. ASCGI 1977.1471, article 61, mémorandum de la Commission sur la ZLE, 19 mars 1958, document 74/58.

163. ACNPF, 72 AS 803, procès-verbal de l'assemblée générale du CIFE, 8 novembre 1957.

164. AMAE, DECE 743, folio 1, note de Jean-Pierre Brunet, 14 mars 1958. 
La position de la Commission est particulièrement novatrice. Elle permet de reformuler les propositions françaises, qui visent avant tout à préserver la CEE, d'une manière plus habile. Les clauses les plus inacceptables (notion de zone expérimentale, aspects les plus dirigistes) n'ont pas été reprises. La Commission a, par contre, adopté les idées de taxes compensatoires et d'harmonisation tarifaire qui étaient défendues par la France. Elle n'a pas insisté sur les garanties négatives et a notamment refusé le décalage. À la place, elle a adopté un système habile fondé sur les études sectorielles préalables et la « proposition Hallstein ». Le mémorandum de la Commission est donc globalement favorable à la France. Il est d'ailleurs bien perçu par Olivier Wormser, qui souligne sa proximité avec certaines thèses françaises ${ }^{165}$. Il facilite les débats à Six.

\section{Vers une position commune des Six.}

La position de la France est renforcée par son mémorandum et celui de la Commission. À l'OECE, les Six ne défendent toujours pas de position commune mais la France est moins isolée. Ainsi, l'Italie propose en mars 1958 son «plan Carli », du nom du ministre italien du Commerce extérieur. Il doit permettre de régler le problème de l'origine par une harmonisation des tarifs extérieurs et, à défaut, par des taxes de compensation ${ }^{166}$. Ces deux mécanismes sont défendus depuis longtemps par l'administration française. Même si la France n'appuie que modestement cette proposition italienne, cette dernière est une contribution importante à la critique du système de la zone de libre-échange. Elle a d'ailleurs un succès important auprès de nombreux pays européens comme les Scandinaves, preuve que la ZLE proposée par les Britanniques n'était pas un système consensuel ${ }^{167}$.

Au sein des Six, les discussions progressent. Ils prévoient même d'arriver à un accord sur une position commune pour la session du Conseil CEE du 22 avril $1958^{168}$. Les négociations se déroulent également sur le plan bilatéral. La France et la RFA s'engagent en mars 1958 dans des conversations confidentielles pour rapprocher leurs positions ${ }^{169}$. La RFA accepte le principe des

165. AMAE, DECE 615, folio 48, télégramme d'Olivier Wormser du 20 mars 1958.

166. AMAE, DECE 743, folio 1, note de Jean-Pierre Brunet, 14 mars 1958.

167. Francesca Fauri, «Italy and the Free Trade Area Negotiations, 1956-1958 », in Revue d'histoire de l'intégration européenne, 1998/2, p. 56.

168. AMAE, RPUE 29, projet de procès-verbal du Conseil CEE du 18 mars 1958, $1^{\text {er }}$ avril 1958 ; AMAE, DECE 743, folio 49, compte rendu de la sixième session du comité Maudling, 3 avril 1958.

169. AMAE, DECE 753, folio 122, télégramme au départ du 4 avril 1958. Conversations entre Faure et Erhard à Strasbourg les 18 et 19 mars 1958, entre Wormser et Müller-Armack les 2 et 3 avril 1958. 
études sectorielles, si elles ne sont pas systématiques, et d'étudier, pour régler le problème de l'origine, la possibilité de mesures d'harmonisation tarifaires ou de taxes compensatoires ${ }^{170}$. Par contre, la RFA refuse l'exigence française du décalage. Les divergences restent fortes mais le rapprochement est réel.

Le renforcement de la position française est également observable par la déception qui gagne les Britanniques. La Grande-Bretagne se crispe et perd espoir dans la négociation ZLE ${ }^{171}$. C'est le moment où des plans alternatifs de zone de libre-échange sans les Six commencent à être évoqués outre-Manche par le patronat britannique ${ }^{172}$. Enfin, sur le plan des finances extérieures, la situation française s'améliore, ce qui permet d'envisager de ne pas recourir aux clauses de sauvegarde au premier janvier $1959^{173}$. Cependant, le redressement français est temporaire et soumis aux soubresauts de la crise algérienne.

La crise ministérielle française débute avec la chute du gouvernement Gaillard le 15 avril 1958. Elle paralyse les négociations à Six pour la définition d'une position commune sur la ZLE. Le Conseil CEE du 22 avril 1958 n'aboutit finalement à aucun accord ${ }^{174}$. Or, la pression britannique reste toujours très forte car Londres entame des discussions bilatérales destinées à rapprocher les Cinq de ses positions ${ }^{175}$. Maudling accepte toutefois de repousser les négociations jusqu'au premier juillet $1958^{176}$.

La prolongation de la crise française aggrave encore la situation. Paris se rend compte de l'affaiblissement de sa position qui résulte de son incapacité probable à respecter les engagements d'ouverture des marchés pris dans le cadre de l'OECE $^{177}$ et dans le cadre de la CEE (notamment une première diminution de $10 \%$ des tarifs douaniers au premier janvier

170. AMAE, POW 39, folio 305 et 313, notes des 2 et 3 avril 1958 sur les conversations entre Wormser et Müller-Armack.

171. M. Camps, Britain and the European Community..., op. cit., p. 143 ; PRO, T 337/7, télégramme de Maudling à G. Jebb, 15 mars 1958.

172. M. Camps, Britain and the European Community..., op. cit., p. 146 ; Wolfram Kaiser, Using Europe..., op. cit., p. 89.

173. AMAE, POW 78, folio 169, note d'Olivier Wormser du 10 avril 1958.

174. AMAE, RPUE 29, aide-mémoire sur les délibérations des Six sur la ZLE à Bruxelles le 22 avril 1958,24 avril 1958.

175. M. Camps, Britain and the European Community..., op. cit., p. 151-2. DDF, 1958-I, document $\mathrm{n}^{\circ} 368$, télégramme de Couve de Murville, ambassadeur de France à Bonn, à René Pléven, ministre des Affaires étrangères, 27 mai 1968.

176. PRO, BT 205/264, Board of Trade Progress Report n 13, avril 1958.

177. Lorsque la France avait eu recours à une suspension de la libération des échanges intervenue, le 18 juin 1957, elle s'était engagée à rétablir l'ouverture de ses marchés un an plus tard, soit le 18 juin 1958. 
1959) ${ }^{178}$. Le crédit de la France est miné face aux Six comme par rapport aux Dix-sept, ce qui obère sa position tant pour l'application de la CEE que pour la négociation ZLE. Le redressement temporaire permis par le volontarisme du gouvernement Gaillard est désormais compromis.

\section{CONCLUSION : \\ UNE CONTRAINTE INTERNATIONALE CROISSANTE}

Entre la signature du traité de Rome en mars 1957 et les graves événements d'avril-mai 1958, la France est confrontée à une crise profonde qui manifeste l'ampleur de la contrainte internationale.

En interne tout d'abord, les gouvernements Bourgès-Maunoury et Gaillard sont confrontés à des difficultés croissantes. Surtout, si certaines d'entre elles pouvaient apparaître comme temporaires en 1956, elles deviennent en 19571958 structurelles. La France n'avait pas été la seule à être humiliée à Suez en novembre 1956, par contre elle est le seul des grands pays d'Europe occidentale à connaître la conjonction d'une forte instabilité gouvernementale, d'une crise récurrente de la balance des paiements et surtout d'une crise coloniale grave qui menace de dégénérer en guerre civile. Ces difficultés se manifestent en matière européenne par un processus de décision très lacunaire. Les institutions européennes se mettent en place sans qu'une stratégie d'influence globale ne soit mise en œuvre. Surtout, aucune position officielle n'est définie dans la négociation ZLE avant mars 1958. Encore le mémorandum français est-il plus restrictif que la position définie par les responsables administratifs mobilisés sur cette question depuis un an. Les décideurs restent toujours divisés entre des partisans inconditionnels de la ZLE (Pineau, Valéry) et des opposants (Pflimlin), qui reprennent les éléments de la position restrictive définie par une majorité de l'administration française contre le projet de marché commun en 19551956. Certes, un redressement temporaire est mis en œuvre sous l'énergique gouvernement Gaillard. La mobilisation des éléments les plus réalistes de l'administration française et le soutien de la Commission européenne renforcent considérablement la position française. Une position commune des Six sur la ZLE est même en vue au début du mois d'avril 1958. Mais la situation semble trop grave pour que la $I V^{\mathbb{C}}$ République puisse se réformer par elle-même.

178. DDF, 1958-I, document n ${ }^{\circ} 305$, télégramme de Maurice Faure à Gaston Palewski, ambassadeur de France à Rome, 8 mai 1958. 
En plus de ces difficultés internes, la France subit un accroissement très fort de la contrainte internationale, qui devient beaucoup plus concrète. En 1955 et au début de 1956, cette contrainte ne s'exprime que sous la forme de déclarations du Conseil de l'OECE invitant à une libéralisation accrue, et par des négociations européennes aux conséquences incertaines. En 1957-1958, la pression est beaucoup plus directe. En termes de finances extérieures, la France n'a obtenu des crédits en janvier 1958 que sous conditions. Le conflit algérien lui-même s'internationalise après Sakhiet, ce qui contribue à faire chuter le gouvernement Gaillard. Enfin, sur le plan européen, un risque d'isolement de la France existe si elle n'adopte pas une position constructive dans les négociations européennes. Si Paris n'accepte pas la ZLE, elle pourrait voir un accord se conclure sans elle, et serait ainsi ravalée au rang de puissance de second rang. Si la France n'applique pas toutes les clauses du traité de Rome, y compris en ouvrant son marché, ses partenaires de la CEE n'appliqueront pas les clauses du traité qui l'intéressent le plus. Ils pourraient même se détourner de la CEE en privilégiant la ZLE. C'est ce risque d'isolement qui pousse deux types d'acteurs à se mobiliser. D'un côté, un groupe de fonctionnaires réalistes, à la DAEF et au SGCI, cherche à définir une position constructive de la France face à la ZLE, qui préserverait la CEE en permettant de sauvegarder l'unité des Six dans les négociations européennes. D'un autre côté, le patronat français joue un rôle considérable pour faire évoluer les mentalités en se mobilisant massivement contre la ZLE. Face à la crise de la IV République, le CNPF tente même de sortir de sa réserve imposée depuis ses débuts pour peser dans le débat public avec l'assemblée générale extraordinaire du 13 mai 1958.

La ZLE agit en fait comme un double révélateur. Elle manifeste concrètement l'importance de la contrainte économique internationale et elle démontre en contrepoint l'intérêt de la formule de la CEE et ce de deux manières. Sur le fond tout d'abord, les discussions ont montré les nombreux désavantages économiques de la formule de la zone de libre-échange, qui entraîne de nombreuses distorsions de concurrence. Ces défauts ont été mis en valeur par la France mais aussi par l'Italie (plan Carli) et la Commission dans son mémorandum. Du côté patronal, si les milieux économiques français insistent sur les défauts de la ZLE, ils sont rejoints par des responsables d'autres pays, comme le montrent notamment les débats à la LECE. Sur le plan des rapports de force en Europe ensuite, la négociation ZLE est marquée par une très forte agressivité britannique. Les attaques contre la CEE au GATT, la volonté d'isoler la France et de diviser les Six sont mal vécues par les Français, mais aussi par d'autres décideurs européens. Ces deux caractéristiques de la négociation ZLE contribuent à discréditer ce projet, et à éviter l'isolement de la France. La ZLE facilite donc une conversion rapide à la $\mathrm{CEE}$ des décideurs français non pas 
par idéalisme européen, mais par simple constatation des rapports de force européens et des cadres institutionnels de coopération européenne existants. Progressivement, la CEE devient moins l'expression de la contrainte extérieure que le moyen de s'en affranchir. Cependant, la France doit appliquer le traité de Rome, c'est-à-dire ouvrir son marché au premier janvier 1959 sans recourir de manière excessive aux clauses de sauvegarde, faute de quoi ses partenaires se tourneront définitivement vers la formule de la ZLE. 



\section{CHAPITRE III}

\section{DE GAULLE ET LA RUPTURE DANS LES NÉGOCIATIONS EUROPÉENNES (MAI-DÉCEMBRE 1958)}

En pleine négociation de la ZLE, et quelques mois avant le début de la mise en place du Marché commun, la France est confrontée à une nouvelle crise de sa balance des paiements et même à un risque de guerre civile. Elle ne peut restaurer son autorité dans les négociations européennes que par des réformes profondes. Cette rupture intervient entre juin et décembre 1958, sur le plan national avec le retour du général de Gaulle au pouvoir et la fin de la IV République, sur le plan européen avec la relance puis la fin de la négociation ZLE, et sur le plan mondial, avec le plan Rueff. En parallèle et en dépit de cette affirmation d'un fort volontarisme gaullien, un nouvel acteur supranational, la Commission européenne continue à s'affirmer.

\section{LA RUPTURE POLITIQUE NATIONALE : LE RETOUR AU POUVOIR DU GÉNÉRAL DE GAULLE}

L'arrivée au pouvoir du général de Gaulle constitue une rupture tant en termes de conceptions européennes que sur le plan de la politique intérieure.

\section{A. DES CONCEPTIONS EUROPÉENNES RELATIVEMENT FAVORABLES À LA CEE EN JUIN 1958}

Les éléments principaux de la pensée du général de Gaulle en matière de politique étrangère nous sont bien connus ${ }^{1}$, et sont d'ailleurs définis par son

1. Notamment : Maurice Vaïsse, La Grandeur. Politique étrangère du général de Gaulle, 19581969, Fayard, Paris, 1998, p. 22-52 ; Georges-Henri Soutou, L'alliance incertaine. Les rapports politico-stratégiques franco-allemands, 1954-1996, Fayard, Paris, 1996, p. 123-130 ; Gérard Bossuat, Faire l'Europe sans défaire la France. 60 ans de politique d'unité européenne des gouvernements et des présidents de la République française (1943-2003), Peter Lang, Bruxelles, 2005, p. 83-84. 
auteur dès le premier paragraphe de ses mémoires où il évoque la nécessité pour la France de mener une politique de $"$ grandeur $^{2} »$.

Son analyse repose sur trois éléments. Tout d'abord, les relations internationales reposent principalement sur les rapports entre les États-nations. Cette analyse statocentrée valorise la notion de souveraineté nationale, et se retrouve donc en porte-à-faux avec les idéologies européennes fédéralistes ou supranationales, toutes deux fondées sur de larges délégations de souveraineté à un organe supérieur aux États-nations. Deuxièmement, la vision du général de Gaulle tend à valoriser le temps long dans la compréhension de la politique extérieure de ces États-nations. L'URSS est vue par le prisme de la Russie tsariste. Enfin, le général de Gaulle tend à minorer le poids des idéologies dans ses analyses. Cela renforce sa méfiance envers une dynamique européiste qu'il perçoit comme artificielle.

Cependant, le général de Gaulle ne peut être défini comme un réaliste pur, au sens de la théorie des relations internationales. Il est sensible à la nécessité de créer un « concert des États européens ${ }^{3}$ » fondé sur une coopération interétatique et « organique ${ }^{4}$ ». La régulation strictement mécanique fondée sur la realpolitik s'oppose à la régulation organique qui s'appuie sur un socle de valeurs communes et un ordre juridique international de portée régionale. De Gaulle est donc favorable au développement d'une coopération européenne poussée mais sur base intergouvernementale et pas supranationale.

Fort de ces conceptions, le général de Gaulle a développé une doctrine européenne précoce. Ses prises de position en faveur d'un regroupement de l'Europe occidentale, certes mal défini, datent de $1943^{5}$. Il s'oppose ensuite frontalement à la CED. Dès lors, en 1958, de nombreux observateurs, en France et à l'étranger $^{6}$, craignent que de Gaulle ne rejette la CEE une fois parvenu au pouvoir. Mais, si Lacouture rapporte des propos de Charles de Gaulle hostile aux traités

2. Charles de Gaulle, Mémoires de guerre. 1, L'appel : 1940-1942, Plon, Paris, 1954, p. 2 : « [...] à mon sens, la France ne peut être la France sans la grandeur ».

3. Charles de Gaulle, Mémoires d'espoir. Le renouveau, 1958-1962, Plon, Paris, 1970, p. 182.

4. Georges-Henri Soutou, Marlis Steinert, « Ordre européen et construction européenne - XIX $\mathrm{XX}^{\mathrm{e}}$ siècles 》 in Relations Internationales, ${ }^{\circ}$ 90, été 1997, p. 127-143.

5. Maurice Vaïsse, "Europe européenne ou Europe atlantique ? Les conceptions de Charles de Gaulle », in Michel Dumoulin (dir.), L'Union européenne et les États-Unis, Peter Lang, Bruxelles, p. 90.

6. James Ellison, Threatening Europe. Britain and the Creation of the European Community, 19551958, St Martin's Press, Londres, 2000, p. 198 ; Jeffrey Glen Giauque, Grand designs and visions of unity : the Atlantic powers and the reorganization of Western Europe, 1955-1963, University of North Carolina Press, Londres, 2002, p. 36 et 83. 
de Rome ${ }^{7}$, ce dernier ne s'était pas exprimé officiellement à ce propos ${ }^{8}$. Il reste silencieux sur la construction européenne de 1955 à mai $1958^{9}$.

Selon les mémoires de Michel Debré, le général de Gaulle se serait exprimé sur cette question le 31 mai 1958 lorsqu'il consultait les parlementaires. Á une question sur les traités de Rome, il n'aurait répondu que sur la CEE en soulignant qu'elle est « d'une grande utilité pour notre économie et pour les resserrements des liens entre les pays européens ». Il estime donc que l'expérience doit se poursuivre loyalement. Il mettra la France en mesure d'honorer la signature qu'elle a apposée au bas de ce « traité de commerce ${ }^{10} »$. Le général de Gaulle semble donc bien percevoir l'importance et l'aspect stimulateur du Marché commun mais il n'évoque pas l'Euratom. Son absence d'hostilité s'explique aussi par sa sous-estimation de la dynamique communautaire : la CEE est assimilée à un " traité de commerce». Le mouvement d'intégration économique progressive n'est pas compris. Enfin, le problème de l'application du Marché commun relève aussi de la crédibilité politique de la France.

Les archives et sources imprimées confirment ce témoignage de Michel Debré à la fois dans le compte rendu de la première réunion interministérielle consacrée aux questions européennes, le 10 juin $1958^{11}$, et dans la note à son conseiller diplomatique Jean-Marc Boegner d'août $1958^{12}$. Pour de Gaulle, le Marché commun est un accord favorable aux intérêts français mais secondaire par rapport à l'essentiel : l'établissement d'une coopération politique étroite en Europe. La CEE est donc utile pour affirmer un cadre des Six qui servira à lancer des projets de coopération politique et culturelle. C'est bien la CEE qui apparaît comme la base de la politique européenne de la France sans qu'elle doive constituer d'ailleurs un cadre exclusif ${ }^{13}$. Aucune décision sur la ZLE

7. Jean Lacouture, De Gaulle, tome II, p. 645 cité par Maurice Vaïsse, op. cit., p. 163.

8. William B. Cohen, « De Gaulle et l'Europe d'avant 1958 » in Institut Charles de Gaulle (éd.), De Gaulle en son siècle, tome V, L'Europe, Plon, Paris, 1992.

9. Edmond Jouve, Le général de Gaulle et la construction de l'Europe (1940-1966), LGDJ, Paris, 1967, p. 26 et $252-253$.

10. Michel Debré, Trois républiques pour une France, Mémoires, t. II, 1946-1958, Agir, Albin Michel, Paris, 1988, p. 311-12.

11. AMAE, PA-AP 314, carton 1, compte rendu de la réunion interministérielle du 10 juin 1958.

12. Note pour les Affaires étrangères du 13 août 1958, in Charles de Gaulle, Lettres, notes et carnets. Juin 1958-décembre 1960, Plon, Paris, 1985, p. 73. Le destinataire a été identifié in : G.-H. Soutou, L'alliance incertaine..., op. cit., p. 73.

13. De Gaulle précise ainsi : «Dans cet esprit, la mise en œuvre des traités du Marché commun et d'Euratom sera poursuivie. À partir de la base ainsi établie, la coopération pourra être développée dans un cadre plus vaste que celui des Six en évitant, toutefois, que l'évolution provoque des difficultés graves dans tel ou tel pays ", note du 13 août 1958 in C. de Gaulle, Lettres, notes et carnets..., op. cit., p. 73. 
n'est d'ailleurs prise par le général de Gaulle, qui repousse ce problème à une réunion ultérieure.

Cette acceptation de la CEE a pu être encouragée par trois facteurs. Tout d'abord, sur le plan conjoncturel, de Gaulle a pu être influencé par la dégradation du climat avec les Anglo-Saxons depuis Suez, en 1956, et après le bombardement de Sakhiet du début 1958. Ensuite, la CEE pouvait être un cadre de collaboration adapté pour les projets de coopération politique du général de Gaulle car la France restait la principale puissance des Six sur le plan international. Georges-Henri Soutou a souligné la cohérence de la vision stratégique duale de Charles de Gaulle : la promotion d'une coopération dans un cadre européen continental restreint doit servir de levier pour la France ${ }^{14}$. Renforcée, celle-ci pourrait alors revendiquer une place aux côtés des Américains et des Britanniques dans la gestion de l'Alliance atlantique, c'est l'idée de « directoire à trois » de l'OTAN. Enfin, les avantages économiques de la CEE ont dû influencer la vision du nouveau président du Conseil, car ils commencent à être reconnus par un nombre croissant de décideurs économiques, administratifs et politiques, alors que la ZLE suscite une réprobation unanime du patronat.

De plus, de Gaulle arrive au pouvoir en pleine crise financière et commerciale ; il sait que la puissance internationale de la France repose avant tout sur sa capacité à ne pas aller quémander des subsides aux États-Unis et, pire encore, à ses voisins européens comme en janvier 1958. La France ne peut prétendre avoir une politique extérieure autonome si elle est obligée de solliciter périodiquement ses créanciers étrangers. La contrainte extérieure-l'ouverture des marchés - doit être surmontée et utilisée comme levier de l'indépendance nationale. Dans cette optique, la CEE a un rôle important à jouer. La ZLE n'était pas rejetée d'emblée si elle peut se combiner harmonieusement avec le Marché commun, mais le redressement de la France et l'expression de sa " grandeur » devait passer par le cadre des Six. Pour surmonter une situation de crise aiguë, de Gaulle s'appuie sur une position personnelle très forte à la tête de son gouvernement.

\section{B. LA POSITION DE FORCE DU PRÉSIDENT DU CONSEIL DE GAULLE}

L'arrivée au pouvoir du général de Gaulle provoque une profonde rupture dans le processus de décision en matière de politique extérieure car le nouveau président du Conseil peut s'appuyer sur une légitimité personnelle forte, acquise pendant la deuxième guerre mondiale. À la faveur des troubles en Algérie, le

14. G.-H. Soutou, L'alliance incertaine..., op. cit., p. 123-126. 
général de Gaulle obtient ainsi les pleins pouvoirs, votés pour six mois les 2 et 3 juin 1958 par les parlementaires. Par la suite, il est renforcé par quatre victoires électorales massives en $1958^{15}$.

Fort de cette légitimité exceptionnelle, de Gaulle peut contrôler étroitement le processus de décision en matière de politique européenne. Au contraire, pendant la majeure partie de la $I V^{\mathfrak{e}}$ République, des thèses récentes ont démontré le caractère erratique du processus de décision en matière de politique extérieure, et les graves défaillances de l'arbitrage politique ${ }^{16}$. Certes, sous le gouvernement Mollet, le président du Conseil impose un choix politique clair en faveur du Marché commun à des élites majoritairement hostiles, mais sa politique économique créé des déséquilibres financiers structurels majeurs. À partir de juin 1958, la situation change : les décisions principales en matière de politique européenne sont prises par de Gaulle et appliquées par un gouvernement qui n'a pas le loisir de les contester.

Le gouvernement mis en place reflète la position prééminente du général de Gaulle et un choix clair de la CEE. Le nouveau ministre des Finances, Antoine Pinay, est connu pour sa capacité à rétablir la confiance dans les finances françaises, une tâche cardinale et complémentaire du rétablissement de la confiance politique incarnée par de Gaulle. D'autre part, le gouvernement comprend un nombre très important de hauts fonctionnaires sans expérience politique ${ }^{17}$. Le nouveau ministre des Affaires étrangères, Maurice Couve de Murville, incarne cette rupture. Inspecteur des finances passé à Alger en mars 1943, il entre au Quai d'Orsay par la grande porte en 1945, comme directeur des Affaires politiques, pour mettre en pratique la politique du président du Conseil de Gaulle et de son ministre Georges Bidault, fondée sur une grande méfiance à l'égard de l'Allemagne ${ }^{18}$. Robert Schuman l'écarte en le nommant ambassadeur au Caire (1950-1954) $)^{19}$. Après un passage par Washington (1955-1956), il est nommé ambassadeur de France à Bonn où il entretient des rapports étroits avec

15. Lors du référendum du 28 septembre 1958, des élections législatives des 23 et 30 novembre 1958 et enfin pour l'élection présidentielle du 21 décembre 1958.

16. François David, John Foster Dulles, secrétaire d'État, et la France (1953-1959). Les relations franco-américaines entre idéalisme politique et réalités militaires, thèse dir. Georges-Henri Soutou, Univ. Paris IV, 2006 ; Jenny Raflik, Les décideurs français face à l'Alliance atlantique, 1947-1954, thèse dir. Robert Frank, Université Paris I, 2006.

17. Outre le cas de Maurice Couve de Murville, parmi les autres hauts fonctionnaires devenus ministres figurent notamment le ministre de l'Intérieur (Émile Pelletier, préfet) et le ministre des Armées (Pierre Guillaumat, haut fonctionnaire).

18. M. Vaïsse, La Grandeur..., op. cit., p. 308.

19. M. Vaïsse, La Grandeur..., op. cit., p. 309. 
Adenauer $^{20}$. De Gaulle nomme un véritable expert des affaires étrangères et des relations franco-allemandes. Pendant la négociation du traité de Rome, il avait plaidé pour la modération des exigences françaises en démontrant la pertinence de certaines critiques allemandes ${ }^{21}$. En matière européenne, Couve de Murville est renforcé par l'absence de secrétaire d'État aux Affaires étrangères chargé plus spécialement de ce dossier comme Maurice Faure l'était. Dans ce dossier, il s'appuie sur l'expertise d'un proche, le directeur de la DAEF, Olivier Wormser ${ }^{22}$.

Le choix de Couve de Murville comme ministre des Affaires étrangères ne s'imposait pas. Selon Michel Debré, le général de Gaulle avait un temps pensé lui confier la charge du Quai d'Orsay avant de le nommer finalement à la Justice ${ }^{23}$. Certes, l'urgence de rédiger une nouvelle constitution légitime la nomination de Debré, par ailleurs issu du Conseil d'État, à ce poste. Mais il faut aussi considérer que l'arrivée de Michel Debré au ministère des Affaires étrangères aurait constitué un signal très négatif envers la CEE. Debré a en effet un parcours européen très contrasté. Auteur de diverses publications proeuropéennes à la fin des années quarante, il est devenu le principal contempteur de l'Europe supranationale dans les années cinquante ${ }^{24}$. Il s'oppose vertement à l'Euratom. Il est moins hostile à la CEE mais la nomination de Debré au Quai d'Orsay aurait pu infléchir la politique européenne de la France dans un sens plus hostile à la coopération à Six. Le garde des Sceaux n'a toutefois pas l'occasion de manifester ses préférences européennes pendant cette période car il se concentre sur son travail constitutionnel ${ }^{25}$.

Le nouveau gouvernement doit s'efforcer de régler les trois dossiers qui ont provoqué la chute des gouvernements précédents : le problème algérien - et, au-delà, le dossier colonial, la réforme des institutions, la restauration financière. Ces trois éléments sont indissociables pour la restauration du crédit de la France. La question de la coopération économique européenne est au centre des trois dossiers. La CEE est à la fois la condition et le cadre d'expression de l'indépendance de la France. Le général de Gaulle ne peut se désintéresser d'un élément fondamental dans l'établissement de nouvelles bases pour la puissance française.

20. M. Vaïsse, La Grandeur..., op. cit., p. 309.

21. Voir le chapitre I.

22. Robert Marjolin, Le travail d'une vie..., op. cit., p. 258 et p. 311 ; Henri Froment-Meurice, $V u$ du Quai. Mémoires 1945-1983, Fayard, Paris, 1998, p. 303.

23. M. Debré, Trois républiques pour une France..., op. cit., p. 275-86.

24. M. Debré, Trois républiques pour une France..., op. cit., p. 19.

25. M. Debré, Trois républiques pour une France..., op. cit., p. 323. 


\section{LA RUPTURE EUROPÉENNE : LA FIN DE LA ZLE}

L'arrivée au pouvoir du général de Gaulle permet à la France de renforcer sa position dans la négociation ZLE. Face à cette remise en selle, la GrandeBretagne se crispe et ne peut éviter une rupture de la négociation ZLE.

\section{A. LE RENFORCEMENT DE LA POSITION FRANÇAISE (JUIN-OCTOBRE 1958)}

De retour au pouvoir, le général de Gaulle est confronté à de multiples dossiers lourds et urgents, en particulier celui de l'Algérie. Dès lors, les hauts fonctionnaires les plus avancés dans la négociation ZLE se mobilisent pour attirer l'attention de l'exécutif sur le caractère fondamental de cette négociation.

\section{L'acceptation de la CEE et la nouvelle position sur la ZLE.}

Olivier Wormser, le directeur de la DAEF, fait le point sur les principaux enjeux de la politique européenne dans une note de synthèse rédigée dès le 2 juin $1958^{26}$. Elle constitue un vigoureux plaidoyer en faveur de la CEE, défendue par des arguments de realpolitik, donc susceptibles de toucher de Gaulle, et pas du tout par européisme. Il estime qu'il faut absolument éviter de " dénoncer » le traité de Rome à la fois pour des raisons politiques (risque de crise francoallemande) et pour des raisons économiques (risque de retour au protectionnisme). Sa défense du traité de Rome montre que la perspective de son rejet avait été envisagée au moment du retour du général de Gaulle au pouvoir.

Pour appliquer la CEE, d'importantes réformes intérieures sont nécessaires mais, pour Wormser, elles sont de toute façon indispensables pour restaurer le crédit extérieur du pays, indépendamment de l'enjeu européen. Il estime indispensable le retour à une politique d'austérité qui seule peut permettre d'éviter le recours humiliant à des crédits extérieurs comme en janvier 1958.

Pour Wormser, la CEE constitue un stimulant nécessaire pour insérer la France dans un cadre " semi-libéral », c'est-à-dire dans une ouverture progressive et contrôlée à la concurrence internationale. Nul européisme dans ce constat pratique, comme le prouve la référence à une « bifurcation $^{27}{ }^{\prime}$, c'est-à-dire à un moment où les intérêts de la France et de l'intégration économique par la $\mathrm{CEE}$ ne coïncideront plus, et où cet engagement européen pourra être mis

26. AMAE, POW 78, folio 217, note d'Olivier Wormser du 2 juin 1958.

27. AMAE, POW 78, folio 217, note d'Olivier Wormser du 2 juin 1958. 
entre parenthèses. L'Europe n'est pas une fin en soi. Wormser est soucieux de ne pas présenter la CEE comme un engagement définitif mais comme un outil d'assainissement de l'économie française, au bénéfice de sa crédibilité extérieure. D'ailleurs, il n'oppose pas CEE et ZLE car il estime que le problème de l'application de cette dernière se présente dans des termes voisins ${ }^{28}$.

La réunion interministérielle du 10 juin 1958 permet à de Gaulle de prendre position sur ces problèmes ${ }^{29}$. Olivier Wormser est le premier orateur sur la partie consacrée aux affaires européennes. Il insiste sur les éléments de contrainte extérieure, commerciale et financière. De Gaulle oriente immédiatement le débat sur des considérations politiques et notamment le siège des institutions européennes. Il considère que : «Si les choses doivent en rester là où elles en sont aujourd'hui, la question du siège n'a pas grande importance. En effet la CECA n'a apporté aucun changement profond. [...] En fin de compte, la CECA n'a eu d'effet que dans des domaines secondaires ». Cette déclaration du général de Gaulle est tout à fait révélatrice. Il estime que le projet fonctionnaliste semble voué à l'échec, comme en témoigne l'inertie de la CECA. De Gaulle n'attribue donc aucun crédit à la dynamique de l'intégration européenne. Après avoir minoré l'importance de l'Euratom, de Gaulle conclut : «L'essentiel, c'est le Marché commun qui, en soit, n'est pas une mauvaise chose, et surtout l'organisation politique et culturelle de l'Europe. À cet égard, rien n'a été fait ». La CEE est donc acceptée car elle est perçue comme un accord à la fois positif et inoffensif. Elle doit servir de cadre à une coopération politique future. Dans cette réunion, Couve de Murville a également défendu le cadre de coopération des Six, notamment en soulignant l'importance des crédits accordés par la RFA en janvier 1958.

Cependant, si de Gaulle accepte la CEE, rien n'a été décidé sur la ZLE. Or les négociations doivent reprendre rapidement. Olivier Wormser s'emploie à définir une position plus réaliste dans une nouvelle note ${ }^{30}$. Il commence par démontrer le caractère politiquement incontournable de la ZLE puis il conseille d'abandonner le décalage - une exigence qui avait été largement critiquée par les $\mathrm{Six}^{31}$, et d'adopter à la place la « proposition Hallstein », c'est-à-dire l'extension de la baisse de $10 \%$ de ses tarifs douanières prévue entre les Six au premier janvier 1959 à l'ensemble des pays du GATT. Cette note semble

28. AMAE, POW 78, folio 217, note d'Olivier Wormser du 2 juin 1958.

29. AMAE, PA AP 314, carton 1, compte rendu d'une réunion interministérielle du 10 juin 1958.

30. DDF, 1958-I, document $n^{\circ} 412$, note d'Olivier Wormser, 12 juin 1958.

31. DDF, 1958-I, document $n^{\circ} 152$, note du secrétaire d'État aux Affaires étrangères, cabinet, 3 mars 1958. 
influente car dès le 16 juin 1958, Maurice Couve de Murville décide de défendre la proposition Hallstein dans le cadre de la $\mathrm{CEE}^{32}$.

Mais il est impossible pour la France de circonscrire son attention sur les seules discussions à Six car Macmillan demande à rencontrer le général de Gaulle rapidement justement pour débloquer ce dossier brûlant ${ }^{33}$. Le gouvernement britannique est dans une phase de raidissement sur la ZLE. L'adoption d'une stratégie plus agressive, fondée sur la promotion d'une ZLE radicale, sans concessions sur les préférences impériales et avec une liberté tarifaire absolue, est envisagée ${ }^{34}$.

Les entretiens entre de Gaulle et Macmillan ont finalement lieu les 29 et 30 juin $1958^{35}$. De Gaulle affirme à de nombreuses reprises son accord de principe sur la ZLE, mais aussi son rejet d'un libéralisme excessif. Il préfère 1'approche sectorielle. Face à cette position dilatoire, Macmillan choisit de dramatiser. Une absence d'accord sur la ZLE aboutirait à une " division de l'Europe », à une « guerre économique », voire à « la fin de l'OTAN ». Juste après cet entretien, Macmillan relance le général de Gaulle par une lettre où il souligne la capacité de la Grande-Bretagne de constituer un groupement économique européen alternatif en cas d'échec de la ZLE ${ }^{36}$. La pression exercée par Macmillan est relayée par Maudling, qui rencontre Couve de Murville et Pinay le 3 juillet $1958^{37}$. Il obtient d'eux l'engagement par la France de définir publiquement une nouvelle position sur la ZLE pour la prochaine session du comité Maudling.

\section{La nouvelle position française sur la ZLE.}

Pour préparer ce comité Maudling du 25 juillet 1958, une réunion est organisée à la présidence du Conseil sous la présidence de Roger Goetze, conseiller du général de Gaulle, le 10 juillet $1958^{38}$. Ce dernier définit clairement l'objectif

32. AMAE, RPUE 1149, note d'Olivier Wormser du 17 juin 1958.

33. Lettre de Charles de Gaulle à Macmillan du 7 juin 1958, in Charles de Gaulle, Lettres, notes et Carnets, juin 1958-décembre 1960, Plon, Paris, 1985, p. 22.

34. PRO, CAB 130/123, Cabinet, Free Trade Area, réunion du 23 juin 1958, note du 24 juin 1958 ; voir aussi : PRO, CAB 130/123, Cabinet, Free Trade Area, réunion du 15 mai 1958, note du 16 mai 1958.

35. DDF, 1958-I, document n ${ }^{\circ}$ 459, entretiens entre Charles de Gaulle et Harold Macmillan, compte rendu de la troisième séance, 30 juin 1958.

36. DDF, 1958-II, document $\mathrm{n}^{\circ} 15$, annexe, lettre de Macmillan au général de Gaulle, 30 juin 1958.

37. DDF, 1958-II, document $\mathrm{n}^{\circ} 17$, télégramme circulaire du ministre des Affaires étrangères, 6 juillet 1958.

38. AMAE, DECE 753, folio 284, note de François Valéry du 12 juillet 1958. 
principal du gouvernement : ne pas provoquer de rupture dans la négociation ZLE. Pour cela, la réunion permet d'aboutir à la définition d'une position française minimale, fondée sur l'obtention de quatre garanties essentielles : la clause de sauvegarde unilatérale, la prise de décision à l'unanimité pour les décisions principales (notamment le passage d'étape), la mise en place d'une architecture de libération des échanges atténuée par des systèmes inspirés du plan Carli (taxes compensatoires) et de l'approche sectorielle. En échange, la France devra se résoudre à deux concessions importantes, l'abandon du décalage et l'acceptation du terme final. Le décalage était d'ailleurs fréquemment interprété par les Britanniques comme la possibilité de donner à la France un statut spécial au sein de la ZLE afin de l'isoler ${ }^{39}$. Il commençait donc à se retourner contre la France. Cette position novatrice s'inspire des notes précédentes de Wormser. La France accepte le schéma libéral de la ZLE, tempéré par des garanties négatives et l'approche sectorielle, et abandonne l'optique dirigiste du mémorandum de février 1958.

La nouvelle position française est exposée aux partenaires de la France en trois temps, révélateur de la stratégie européenne de la France. C'est d'abord dans un cadre franco-allemand, les 21 et 22 juillet 1958, que la position française est présentée, puis aux Cinq lors du Conseil CEE du 23 juillet 1958 et enfin aux Seize pays intéressés par la ZLE lors du comité Maudling des 24 et 25 juillet 1958. Face aux Allemands, Olivier Wormser commence par affirmer que «si jusqu'à présent, la position exprimée par la délégation française au comité Ockrent a été celle de l'administration, c'est cette fois la position gouvernementale française qui va être exposée à la délégation allemande ${ }^{40} »$. L'engagement du pouvoir politique est clairement mis en valeur pour marquer une rupture par rapport à la période précédente. Le gaullisme de Wormser s'affiche ainsi clairement car il minore la volonté de Gaillard de définir une position constructive dans ce dossier. La nouvelle position française suscite une réaction globalement positive de son interlocuteur allemand ${ }^{41}$. Le lendemain, les Six acceptent de soutenir une partie de la thèse française $e^{42}$. Enfin,

39. PRO, FO 371/134501, doc 611/513, note de Hugh Ellis-Rees, 14 mai 1958, entretiens avec Valéry, 13 mai 1958 ; PRO, CAB 130/123, Cabinet, Free Trade Area, réunion du 23 juin 1958, note du 24 juin 1958.

40. DDF, 1958-II, document $n^{\circ} 87$, note DAEF, conversations franco-allemandes des 21 et 22 juillet 1958, 30 juillet 1958.

41. DDF, 1958-II, document $n^{\circ} 87$, note DAEF, conversations franco-allemandes des 21 et 22 juillet 1958, 30 juillet 1958.

42. AMAE, RPUE 31, procès-verbal du Conseil CEE des 23 et 24 juillet 1958, document du 9 août 1958. 
lors du comité Maudling, les Dix-sept acceptent la mise en œuvre d'études sectorielles $^{43}$. La France a obtenu que l'approche sectorielle prévale dans le règlement des problèmes de l'origine grâce aux concessions qu'elle a consenties sur le décalage et le terme final.

D'une manière générale, Olivier Wormser estime que la position de la France s'est considérablement renforcée ${ }^{44}$. Elle a restauré sa crédibilité car elle a abandonné tout ce qui faisait douter de sa volonté de s'engager véritablement et de manière irréversible dans une ZLE, le décalage, le terme final et la conception dirigiste du mémorandum de février 1958. La France se retrouve ainsi dans une position parallèle à celle qui était la sienne en septembre 1956 dans la négociation CEE, lorsqu'elle avait choisi d'abandonner son exigence de ne s'engager que pour la première étape du Marché commun. Elle a été contrainte à ce mouvement pour ne pas se retrouver isolée dans les négociations européennes car la Grande-Bretagne semblait envisager très sérieusement une rupture des négociations ZLE depuis le printemps 1958. Deux négociations parallèles s'ouvrent alors, l'une sur les accords sectoriels, l'autre sur la forme globale de la ZLE.

\section{Les progrès des négociations sectorielles.}

Au sein de l'administration française, dès le 2 août 1958, Goetze préside une réunion qui décide du lancement d'études sectorielles par l'administration ${ }^{45}$. Wormser insiste beaucoup sur ces travaux car ils doivent permettre de renforcer la position des représentants français dans une négociation où les arguments techniques ont déjà permis d'obtenir des concessions ${ }^{46}$. Mais le directeur de la DAEF se plaint à plusieurs reprises à Couve de Murville de la réticence du ministère de l'Industrie, qui refuse d'effectuer les études sectorielles demandées sous la pression du patronat ${ }^{47}$. Le CNPF ${ }^{48}$, mais aussi Renault par l'intermédiaire

43. AMAE, DECE 743, note DAEF du 30 juillet 1958 sur le comité Maudling des 24 et 25 juillet 1958.

44. AMAE, POW 40, folio 109, note d'Olivier Wormser, 29 juillet 1958.

45. ASGCI, 1977.1471, article 61, compte rendu d'une réunion interministérielle présidée par Roger Goetze, 2 août 1958.

46. AMAE, POW 40, folio 155, note d'Olivier Wormser pour le ministre, 29 août 1958.

47. AMAE, POW 40, folio 134, note d'Olivier Wormser à Roger Goetze, 22 août 1958 ; idem, folio 162, note d'Olivier Wormser au ministre, 11 septembre 1958 ; idem, folio 239, note d'Olivier Wormser, 20 octobre 1958.

48. ASGCI, 1977.1471, article 69, lettre de Georges Villiers à Maurice Couve de Murville, 15 octobre 1958 ; « Marché commun et zone de libre-échange, la position du CNPF », communiqué diffusé le 27 octobre 1958, in Bulletin du CNPF, novembre 1958, $\mathrm{n}^{\circ}$ 178, p. 17-18. 
d'un article influent de Pierre Dreyfus ${ }^{49}$, continuent en effet de proclamer leur hostilité à la ZLE.

Pendant ce temps, les négociations sectorielles à Six se déroulent de manière assez satisfaisante pour la France. Les instructions aux experts soulignent la nécessité pour eux d'être « constructif» et d'avoir un « souci de coopération ${ }^{50}$ ». Elles leur donnent une grande liberté car ils peuvent proposer des solutions originales « sans se préoccuper outre mesure de la structure générale de la zone ». On retrouve encore le souci stratégique de retarder la négociation globale sur les principes de la ZLE. À la mi-novembre, les discussions semblent se dérouler de manière satisfaisante. La France n'est plus isolée car l'Italie la soutient très souvent, l'Allemagne jouant un rôle d'arbitre ${ }^{51}$.

La stratégie française est claire. Il s'agit moins d'accepter ou de refuser la ZLE que de maintenir l'unité des Six et l'intégrité de la CEE. Une ZLE acceptable pour la France devrait en sortir naturellement après de longues discussions sectorielles. Entre-temps la France aura démontré à ses partenaires de la CEE que les problèmes précis de distorsions de concurrence dont elle se plaignait sont une réalité. Cela permet de condamner l'économie générale du système ZLE, et de valoriser celui de la CEE.

\section{Vers une position commune des Six.}

Ces progrès dans le cadre des négociations sectorielles sont parallèles à ceux effectués sur la conception globale de la zone au sein des Six. Deux étapes peuvent être distinguées : les discussions franco-allemandes puis les négociations à Six.

Une première rencontre entre le général de Gaulle et le chancelier Adenauer est prévue le 14 septembre 1958 à Colombey-les-deux-Églises. Dans le domaine de la coopération économique européenne, elle est préparée par une note d'Olivier Wormser ${ }^{52}$. Le directeur de la DAEF met l'accent sur la nécessité

49. La large diffusion est attestée par sa présence dans de nombreux fonds d'archives : ALECE, 654, compte rendu du $1^{\text {er }}$ octobre 1958 de la conférence du 29 septembre 1958; AMAE, DECE 756, folio 184, déclaration de Pierre Dreyfus à la revue Occident, 29 septembre 1958; ASGCI, 1977.1471, article 69, lettre de Maurice Bosquet à Jacques Donnedieu de Vabres, 2 octobre 1958; AHUE, BAC 61/1982, volume 7, lettre de Maurice Bosquet à Jean-François Deniau, 9 octobre 1958. Voir aussi : S. Ramirez, Public Policies... op. cit., p. 547-548.

50. AMAE, DECE 754, folio 157, note de Maurice Ulrich du 3 novembre 1958 ; ASGCI, 1977.1471, article 63, compte rendu de la réunion du 30 octobre 1958.

51. AMAE, DECE 785, folio 145, lettre du représentant permanent de la France à Bruxelles, 10 novembre 1958.

52. AMAE, POW 31, folio 308, note d'Olivier Wormser pour le ministre, 12 septembre 1958. 
d'appliquer pleinement la CEE sans recourir outre mesure aux clauses de sauvegarde au premier janvier 1959 (début du processus de libération des échanges entre les Six), car c'est de cela que dépendra le soutien des Cinq à la France dans la négociation ZLE.

Cette première rencontre franco-allemande au sommet est un succès. Si elle n'aboutit pas à des décisions particulières tant pour la CEE que pour la ZLE ${ }^{53}$, elle manifeste une entente franco-allemande qui était loin d'être évidente avant cette réunion ${ }^{54}$. De Gaulle affirme qu'il appliquera le traité de Rome « de toute bonne foi ». La France aura vraisemblablement recours en partie aux clauses de sauvegarde, mais se placera dans le cadre communautaire. Cet engagement résolu et inconditionnel en faveur de la CEE a sans doute représenté un élément très positif aux yeux du chancelier Adenauer. La convergence franco-allemande ne doit pas être surestimée - en particulier sur les questions stratégiques ${ }^{55}$ - mais elle est réelle en matière de coopération économique européenne.

Peu après cette rencontre franco-allemande fructueuse, les Six sont réunis à Venise du 18 au 20 septembre 1958 pour définir une position commune sur la ZLE. Ils parviennent à un certain nombre d'accords ${ }^{56}$. Tout d'abord, la conception française du règlement des problèmes de l'origine par les études sectorielles, exposée par Wormser, est acceptée, ce qui abouti à la création des groupes d'experts sectoriels à Six. Ensuite, sur le plan institutionnel, grâce au soutien de la Commission ${ }^{57}$, les conceptions françaises progressent. Les Six acceptent deux de ses exigences, les clauses de sauvegarde unilatérales et le passage d'étape à l'unanimité.

À la conférence de Bruxelles du 8 octobre 1958, la France obtient en plus la prise de décision à l'unanimité, au moins pour la période initiale ${ }^{58}$. Les Six conviennent de rédiger un mémorandum commun après l'avoir expurgé des sujets les plus controversés ${ }^{59}$. Dénommée "Association économique

53. DDF 1958-II, document $\mathrm{n}^{\circ} 155$, procès-verbal de l'entretien du général de Gaulle et du chancelier Adenauer le 14 septembre 1958.

54. La rencontre avait été annoncée dès juin puis retardée car la presse allemande avait été très méfiante envers le général de Gaulle : Année politique, 1958, PUF, Paris, 1959, p. 432.

55. G.-H. Soutou, L'alliance incertaine..., op . cit., p. 137-146.

56. AMAE, RPUE 31, procès-verbal du Conseil CEE des 18 au 20 septembre 1958; AMAE, DECE 744, folio 79, note DAEF, 24 septembre 1958.

57. AMAE, DECE 744, folio 12, mémorandum de la Commission en vue de la conférence de Venise, 5 septembre 1958.

58. AMAE, RPUE 32, procès-verbal du Conseil CEE des 6 et 7 octobre 1958 ; AMAE, DECE 754, folio 57, note DAEF, 14 octobre 1958.

59. AMAE, POW 40, folio 96, mémorandum Ockrent du 17/10/58. 
européenne », la future ZLE devrait contenir de nombreuses prescriptions d'harmonisations contenues dans le traité de Rome (harmonisation sociale, etc.).

La note de la DAEF sur ces discussions à Six est plutôt optimiste. Elle anticipe la signature d'un traité sur la ZLE assez largement compatible avec les exigences françaises dans « le courant de l'année 1959, si possible dès le premier semestre $^{60} \gg$. La DAEF constate donc que la position française de juillet 1958 ayant été acceptée par les Six dans ses grandes lignes, la France est dorénavant placée devant ses responsabilités et devra s'habituer à l'idée de la ZLE.

En ce début du mois d'octobre 1958, la ZLE est donc encore très probable. Sa forme définitive reste très floue et prendra peut-être la forme d'une simple amélioration sectorielle des procédures OECE. Dans tous les cas, elle ne semble plus pouvoir menacer sérieusement la CEE. Paris n'est plus isolé au sein des Six. Les Français peuvent compter sur une convergence avec l'Italie dans le domaine économique, sur un très fort soutien de la Commission pour les questions institutionnelles et sur l'appui politique de la RFA. Cependant, c'est justement à partir de ce même mois d'octobre 1958 que la négociation ZLE paraît sérieusement menacée.

\section{B. LA RUPTURE DE LA NÉGOCIATION ZLE (OCTOBRE-DÉCEMBRE 1958)}

En dépit des progrès des travaux techniques, notamment au sein des Six, la négociation ZLE reste toujours difficile. Dès lors, la stratégie de la rupture commence à être développée dès le début d'octobre 1958, alors que l'interruption officielle intervient finalement le 14 novembre 1958, à un moment où presque plus personne ne voulait encore d'une ZLE à court terme. Cela explique que la France ait réussi à communautariser cette rupture en l'inscrivant dans le cadre de l'action de la CEE.

\section{La stratégie de la rupture (octobre-début novembre 1958).}

Au sein des « réalistes » de l'administration française, ceux qui défendent une position constructive dans la négociation ZLE, l'idée de la rupture commence à être envisagée à partir d'octobre 1958. C'est Olivier Wormser qui est encore l'acteur majeur de cette révision de la position française, à travers deux notes des 4 et 6 octobre $1958^{61}$. Deux éléments font évoluer la réflexion du directeur

60. ASCGI, 1977.1471, article 63, note de la DAEF du 14 octobre 1958.

61. AMAE, POW 40, folio 189, télégramme d'Olivier Wormser à l'ambassade de France à Londres, 4 octobre 1958 ; DDF, 1958-II, document n 225, note DAEF d'Olivier Wormser, 6 octobre 1958. 
de la DAEF. Tout d'abord, la stratégie française reposant sur la définition d'une position commune à Six connaît des limites car les Six ne sont pas toujours unis en dépit des accords conclus à Venise. Par ailleurs, le directeur de la DAEF remarque que la Grande-Bretagne semble moins intéressée par la ZLE dans la mesure où elle réfléchit à des formes de coopération économique à dimension plus mondiale, s'appuyant en particulier sur le rôle mondial de la livre et sa relation privilégiée avec les États-Unis ${ }^{62}$. C'est d'ailleurs en octobre 1958 que les Américains proposent de lancer un round de négociations au GATT pour obtenir une libéralisation des échanges dans un cadre mondial ${ }^{63}$. Les autorités américaines, confrontées à des tensions croissantes en matière de balance commerciale, se montrent beaucoup plus intéressées par cette perspective que par celle de la ZLE, alors même que la CEE continue d'être fortement soutenue pour des raisons politiques ${ }^{64}$. Pour Washington aussi, les deux échelles des Six et du monde occidental semblent s'imposer progressivement.

Dès lors, Oliver Wormser propose d'exposer à la Grande-Bretagne une doctrine plus offensive, en demandant aux Britanniques un engagement explicite de défendre la préférence commerciale européenne. À défaut, il faudrait « laisser entendre que le gouvernement français pourrait rompre ouvertement sur cette question la négociation de la zone... ${ }^{65}$. Olivier Wormser envisage donc de poser la question de la finalité de la coopération économique européenne : s'agit-il de préparer une coopération économique mondiale - la ZLE constituant une antichambre du GATT - ou de promouvoir en tant que telle la coopération européenne - donc en acceptant une discrimination commerciale face à l'extérieur? Cette question permet de mettre la Grande-Bretagne au pied du mur. Le directeur de la DAEF n'est pourtant pas un défenseur enthousiaste de la CEE, dont il reconnaît les « exagérations » du point de vue britannique ${ }^{66}$, mais c'est le meilleur cadre de coopération européenne disponible pour la France.

Les archives britanniques confirment cette impression de Wormser. Depuis le printemps 1958, des schémas alternatifs à la ZLE étaient étudiés en GrandeBretagne. En juin 1958, le cabinet semble envisager de plus en plus sérieusement la rupture de la négociation ZLE si cette dernière ne satisfait pas les intérêts

62. AMAE, POW 40, folio 189, télégramme d'Olivier Wormser à l'ambassade de France à Londres, 4 octobre 1958 .

63. Pascaline Winand, Eisenhower, Kennedy and the United States of Europe, St. Martin's Press, New York, 1993, p. 127-128.

64. Jeffrey Glen Giauque, Grand designs and visions of unity..., op. cit., p. 65.

65. DDF, 1958-II, document $\mathrm{n}^{\circ} 225$, note DAEF d'Olivier Wormser, 6 octobre 1958.

66. AMAE, POW 40, folio 262, note d'Olivier Wormser, 5 novembre 1958. 
britanniques ${ }^{67}$. Ces réflexions se radicalisent encore à partir d'août 1958 lorsque David Eccles, le président du Board of Trade, estime que la priorité britannique devrait être de favoriser un mouvement mondial de libération des échanges avec l'appui américain ${ }^{68}$. Face à lui, Reginald Maudling défend toujours la ZLE car elle reste le projet le plus favorable à la Grande-Bretagne ${ }^{69}$. Londres hésite en effet entre une stratégie européenne et une stratégie mondiale.

La situation se tend plus encore après l'exposé par Wormser à Londres, le 14 octobre 1958, de la nouvelle position française ${ }^{70}$. Cet entretien a un impact majeur sur les Britanniques. Dès le lendemain, Macmillan demande explicitement quelles sont les mesures de représailles que Londres peut envisager contre Paris en cas de rupture de la négociation ZLE ${ }^{71}$. Il propose plusieurs pistes de réflexions à son administration :

Can we take action on the economic plan, in GATT by a tariff war, or by some other forms of discrimination to counter their discrimination against us? By political action. I hardly think we could justify remaining in NATO and keeping four divisions of our troops at considerable expense to defend militarily a group of countries who were carrying an economic war against $u s^{72}$.

Cette note démontre bien la confusion des objectifs économiques et politiques entretenue par le Premier ministre Britannique, et la radicalité de ses réflexions. Pour lui, le dossier de la ZLE est intrinsèquement lié à celui de la réforme de l'OTAN, relancé par de Gaulle avec son mémorandum du 17 septembre 1958. Cependant, son administration lui déconseille fortement de recourir à ces mesures de représailles ${ }^{73}$.

En France, les réflexions du général de Gaulle sur l'OTAN ne semblent pas interférer avec la coopération économique européenne, mais appartenir à deux échelles complémentaires ${ }^{74}$. Dans la première, la France cherche à entamer un dialogue avec les États-Unis et la Grande-Bretagne, dans la seconde, elle

67. PRO, CAB 130/123, Cabinet, Free Trade Area, réunion du 23 juin 1958, note du 24 juin 1958.

68. PRO, T 337/49, note de David Eccles, Board of Trade, pour le Premier ministre, 14 juillet 1958.

69. PRO, T 337/49, note de Reginald Maudling pour le Premier ministre, 5 août 1958.

70. AMAE, RPUE 30, télégramme du représentant permanent au ministre des Affaires étrangères, 20 octobre 1958, réunion du COREPER du 17 octobre 1958.

71. PRO, T 234/378, Harold Macmillan au chancelier de l'Échiquier, 15 octobre 1958.

72. PRO, T 234/378, Harold Macmillan au chancelier de l'Échiquier, 15 octobre 1958.

73. PRO, T 234/378, note RWB Clarke, service du ministère des Finances, 16 octobre 1958 ; note du Foreign Office transmise par S. Lloyd le 31 octobre 1958.

74. Georges-Henri Soutou, L'alliance incertaine, op. cit., p. 123-124. 
doit privilégier l'échelle de coopération des Six et la base franco-allemande, sans se couper des autres pays. Fort de ce cadre stratégique cohérent, Wormser poursuit ses réflexions. Il produit le 20 octobre 1958 une longue note justifiant sa stratégie de rupture ${ }^{75}$. Selon le directeur de la DAEF, Londres veut briser le processus de construction européenne pour imposer une approche mondiale fondée notamment sur le retour prochain à la convertibilité de la livre. Il faut en profiter pour briser la négociation, en comptant sur le soutien que la RFA devrait apporter à la France pour des raisons politiques. Pour ne pas se couper de la Grande-Bretagne, la France devra présenter une contre-proposition à destination de Londres qui préserve ses intérêts commerciaux. Le directeur de la DAEF affirme clairement, une nouvelle fois, que le gouvernement français devra alors s'engager pleinement pour l'application de cette ZLE devenue inoffensive, y compris en l'imposant au patronat ${ }^{76}$. Wormser reste dans le schéma d'une ZLE politiquement incontournable.

En octobre 1958, la négociation se tend car les objectifs français et britanniques sont contradictoires. Pour de Gaulle et Wormser, c'est la CEE qui peut établir les bases d'une restauration de la puissance française. La réflexion inverse est menée par Macmillan : seule une ZLE qui briserait la dynamique de la CEE pourrait rétablir la prépondérance financière, commerciale et économique britannique. C'est cette opposition de fond qui conditionne un durcissement puis la rupture des négociations ZLE.

\section{La rupture des négociations (14 novembre 1958).}

Les réunions internationales de la fin octobre 1958 permettent au directeur de la DAEF d'appliquer sa stratégie offensive, démontrant ainsi qu'il a obtenu l'aval du gouvernement. Lors du Conseil CEE du 23 octobre 1958 face aux Cinq $^{77}$, puis lors du comité Maudling du 24 octobre 1958 face aux Seize ${ }^{78}$, il pose de front le problème de la liberté tarifaire. Faisant explicitement référence au discours de David Eccles (président du Board of Trade) au GATT plaidant pour un mouvement mondial de libération des échanges, il se demande si la Grande-Bretagne entend véritablement respecter le principe de la préférence européenne.

75. AMAE, RPUE 1150, note d'Olivier Wormser, 20 octobre 1958 ; POW 40, folio 239, note d'Olivier Wormser pour le ministre, 20 octobre 1958.

76. AMAE, POW 40, folio 262, note d'Olivier Wormser, 5 novembre 1958.

77. AMAE, RPUE 32, projet de procès-verbal du Conseil CEE du 20 novembre 1958, session du 23 octobre 1958.

78. AMAE, DECE 789, folio 197, déclarations du délégué français à la conférence intergouvernementale du 24 octobre 1958, document OECE. 
Les délégués des autres pays européens participant à la négociation ont été « frappés » par ce discours offensif ${ }^{79}$. Au sein des décideurs britanniques, seul Maudling veut encore poursuivre des négociations que le Treasury veut mettre entre parenthèses ${ }^{80}$. D'une manière générale, après les réunions intergouvernementales de la fin octobre, de nombreux responsables britanniques considèrent que la négociation ZLE est condamnée et devrait être interrompue, en attendant une relance ultérieure sur de nouvelles bases ${ }^{81}$.

En Allemagne, le secrétaire d'État Alfred Müller-Armack envisage de déplacer les négociations du cadre du comité Maudling vers des réunions tripartites franco-britannico-allemandes ${ }^{82}$. De son côté, le chancelier Adenauer et son ministre des Affaires étrangères von Brentano envisagent une négociation entre les Six, représentés par Hallstein, le président de la Commission (et par ailleurs ancien collaborateur d'Adenauer), et la Grande-Bretagne ${ }^{83}$. À la Commission européenne, Robert Marjolin, dans un entretien avec des fonctionnaires français du 5 novembre 1958, se place également dans un autre cadre que le comité Maudling ${ }^{84}$. Il envisage de déplacer la discussion tarifaire vers le GATT.

Ainsi, au début du mois de novembre 1958, il apparaît clairement que de nombreux protagonistes de la négociation ZLE ne croient plus à son succès, en tout cas à court terme et sous la forme du comité Maudling. Cependant, personne ne veut prendre la responsabilité de briser la négociation.

La rupture intervient finalement lors de la réunion du comité Maudling du 14 novembre 1958, alors que Reginald Maudling prend prétexte d'une déclaration du ministre français de l'Information Jacques Soustelle, pour suspendre les négociations ${ }^{85}$. Un débat existe pour savoir si la responsabilité de la rupture incombe à la France - en raison de l'intervention de Soustelle - ou à la Grande-Bretagne-Maudling réagissant de manière excessive à une déclaration secondaire.

79. AMAE, DECE 754, folio 94, note pour Olivier Wormser, 25 octobre 1958.

80. PRO, T 337/49, note de Clarke, 4 novembre 1958.

81. PRO, CAB 130/123, Cabinet, Free Trade Area, réunion du 31 octobre 1958, note du 3 novembre 1958.

82. AMAE, DECE 754, folio 96, note sur les entretiens entre Olivier Wormser et Alfred MüllerArmack du 25 octobre 1958, 25 octobre 1958 ; AMAE, DECE 785, folio 143, note de Maurice Ulrich, 6 novembre 1958.

83. DDF, 1958-II, document n 296, télégramme de François Seydoux, ambassadeur de France à Bonn, à Maurice Couve de Murville, 28 octobre 1958.

84. ASCGI 1977.1471, article 63, entretien avec Robert Marjolin, 5 novembre 1958.

85. DDF, 1958-II, document $\mathrm{n}^{\circ}$ 344, télégramme circulaire de Maurice Couve de Murville aux représentants diplomatiques de la France à l'étranger, 20 novembre 1958. 
L'historien britannique Alan Milward estime que les déclarations de Soustelle ne constituent qu'une répétition, certes de manière moins diplomatique, de la position affirmée par Couve de Murville à Londres ${ }^{86}$, ce qui est confirmé par les sources contemporaines ${ }^{87}$. Frances Lynch va plus loin et considère que Maudling est tombé dans le piège français car les Français ne voulaient de toute façon pas d'une ZLE ${ }^{88}$. De fait, une note de la DAEF du 6 novembre 1958 envisageait très sérieusement de rompre la négociation à la réunion du comité Maudling du 13 novembre ${ }^{89}$. Surtout, les archives britanniques montrent un Maudling soucieux de justifier ce geste à ses compatriotes, ce qui montre son embarras ${ }^{90}$. En interne, face à ses collègues britanniques, Maudling reconnaît que les déclarations de Soustelle ne changent rien à la position française mais il se défend alors d'avoir rompu les négociations et parle d'une simple annulation de réunion ${ }^{91}$.

Le gouvernement français profite de cette maladresse et impute la rupture de la négociation ZLE au seul Réginald Maudling, la France n'ayant pas changé de position ${ }^{92}$. Dès le 15 novembre 1958, le général de Gaulle en personne écrit à Macmillan pour confirmer cette interprétation. Selon lui, la négociation ZLE dans le cadre du comité Maudling est terminée ${ }^{93}$.

Finalement, il apparaît que la rupture est issue de la nervosité de Maudling, déçu par la tournure prise par une négociation en laquelle de moins en moins de décideurs européens croyaient. Les Français ont profité de ce geste excessif pour imposer un arrêt complet des négociations ZLE, et pas une simple suspension. Il faut désormais, dans l'esprit des décideurs français, communautariser la rupture.

\section{La communautarisation de la rupture (novembre-décembre 1958).}

Une fois la rupture de la négociation ZLE acquise, le gouvernement français cherche à la confirmer en adaptant sa stratégie interne et externe.

86. Alan S. Milward, The Rise and Fall of a National Strategy, op. cit., p. 290-91.

87. Voir les déclarations de Soustelle in L'Année politique, 1958, PUF, Paris, 1959, p. 482.

88. Frances Lynch, "The Rueff Plan and the Free Trade Area », in Contemporary European History, vol. 9, 2000/1, p. 131.

89. AMAE, PA AP 314, carton 1, note DAEF, 6 novembre 1958.

90. PRO, T 337/7, note J. E. Coulson, 17 novembre 1958.

91. PRO, T 337/7, note J. E. Coulson, 17 novembre 1958.

92. DDF, 1958-II, document $\mathrm{n}^{\circ}$ 344, télégramme circulaire de Maurice Couve de Murville aux représentants diplomatiques de la France à l'étranger, 20 novembre 1958.

93. DDF, 1958-II, document n ${ }^{\circ} 34$, lettre du général de Gaulle à Harold Macmillan, 15 novembre 1958. 
La première étape consiste à définir la position française sur les mesures à prendre au premier janvier 1959. Le comité interministériel du 18 novembre 1958 prend trois mesures complémentaires ${ }^{94}$ :

- Face aux Six, les obligations CEE devront être respectées. Cela signifie que la France accepte les mesures de libération contingentaires et tarifaires prévues au premier janvier 1959 sans recourir aux clauses de sauvegarde (article 108 CEE). Cependant, comme son commerce extérieur est entièrement contingenté, un engagement de réduire de $10 \%$ ses tarifs extérieurs n'engage à rien. La véritable négociation portera donc sur le taux de libération des échanges auquel la France voudra revenir. Un taux de $40 \%$ est envisagé, ce qui reste modeste par rapport aux $82 \%$ atteints en juin 1957. Sur le plan politique, le symbole est important car la France renonce à recourir aux clauses de sauvegarde, comme cela avait été envisagé depuis la naissance de la CEE.

- Face aux dix-sept de l'OECE, des mesures contingentaires devront être prises sauf les contingents faibles et nuls. Ces derniers doivent être portés à $3 \%$ de la production nationale au premier janvier 1959 dans le cadre des Six. Cette mesure ne sera pas élargie et restera propre à la CEE, afin de maintenir une spécificité du cadre des Six.

- Enfin, la baisse de $10 \%$ des tarifs douaniers prévue dans le cadre des Six sera étendue à l'ensemble des pays du GATT. Il est également décidé d'accepter l'ouverture des négociations au GATT proposée par Dillon, alors que cette proposition avait été considérée initialement avec un grand scepticisme ${ }^{95}$. Là aussi, tout dépendra du taux de libération des échanges que la France acceptera mais le geste politique est fort. Ainsi, la stratégie adoptée consiste donc à effectuer une relance dans deux cadres, la CEE et le GATT, afin de mettre entre parenthèses le cadre de l'OECE. Elle prévoit des mesures libérales, qui ne peuvent être mises en œuvre qu'après un rétablissement financier.

Dans un second temps, un accord franco-allemand est recherché. Les entretiens du président du Conseil français et du chancelier Adenauer à Bad Kreuznach le 26 novembre 1958 aboutissent à une large base d'accord ${ }^{96}$. Le général de Gaulle commence par affirmer son plein soutien au Marché commun car il

94. ASGCI, 1977.1471, article 63, note d'Olivier Wormser du 18 novembre 1958 ; pour la réunion préalable présidée par Goetze : ASGCI, 1977.1471, article 63, compte rendu de la réunion du 15 novembre 1958.

95. AMAE, POW 40, folio 257, télégramme pour Washington, « lu Brunet », sans doute d'Olivier Wormser, $1^{\text {er }}$ novembre 1958.

96. DDF, 1958-II, document $n^{\circ} 370$, comptes rendus des entretiens franco-allemands du 26 novembre 1958 ; AMAE, POW 40, folio 170, compte rendu manuscrit de ces mêmes entretiens, sans doute par Olivier Wormser. 
a « provoqué un éveil économique en France, facteur d'importance considérable ». Fort des décisions prises lors du comité interministériel du 18 novembre 1958, de Gaulle peut aller plus loin qu'à Colombey et affirmer que la France n'aura pas recours aux clauses de sauvegarde au premier janvier 1959. Le général de Gaulle annonce aussi l'acceptation par la France de la proposition Dillon, c'est-à-dire de l'offre américaine de négocier une baisse des tarifs dans le cadre du GATT.

Adenauer salue ces décisions qui traduisent la volonté française de respecter ses engagements internationaux de libération des échanges. Sur les mesures au premier janvier 1959, la RFA se range à la position française. À propos de l'avenir de la négociation ZLE, un accord est rapidement conclu sur la nécessité de donner mandat à la Commission de rédiger un rapport sur ce sujet; idée déjà évoquée par les Allemands auparavant ${ }^{97}$. Cette décision, même si elle n'est pas issue de Paris, renforce la France car la Commission a pris dans la négociation ZLE des positions proches des conceptions françaises.

Enfin, le reste de l'entretien est très largement consacré à la crise de Berlin, issue de l'ultimatum de Khrouchtchev du 10 novembre 1958. Sur ce problème, la France soutient une position face à l'URSS beaucoup plus ferme que les Américains et surtout les Britanniques, ce qui a pu constituer un facteur important dans le rapprochement stratégique entre Adenauer et de Gaulle ${ }^{98}$. Le rapprochement franco-allemand est donc complet.

Une fois l'accord obtenu à deux, le dossier est étudié par les Six à la session suivante du Conseil CEE du 3 décembre 1958. Là aussi, 1'accord se fait autour des mesures préconisées par la France ${ }^{99}$. Sur le plan tarifaire, la réduction de $10 \%$ prévue au sein des Six est étendue à tous les pays du GATT sans réciprocité. Sur le plan contingentaire, les dispositions CEE sont étendues aux membres de l'OECE, sauf les mesures concernant les contingents faibles et nuls, réservées aux Six. Enfin, la Commission fera un rapport pour le $1^{\text {er }}$ mars 1959 sur les rapports entre les Six et les Onze. La France a donc réussi à communautariser la rupture car elle a démontré sa bonne foi dans la construction de l'Europe, contrairement à la Grande-Bretagne. De nombreux responsables économiques

97. AMAE, POW 40, folio 412, document de travail remis par Van Scherpenberg à Olivier Wormser le 19 novembre 1958. Miriam Camps estime qu'il s'agit d'une concession de la France à la RFA : Miriam Camps, Britain..., op. cit., p. 175-176.

98. Georges-Henri Soutou, La Guerre de Cinquante ans. Les relations Est-Ouest, Fayard, Paris, 2001, p. 375.

99. DDF, 1958-II, document $n^{\circ} 389$, télégramme de Maurice Couve de Murville aux représentants diplomatiques de France à l'étranger, 4 décembre 1958 ; AMAE, RPUE 32, projet de procès-verbal du Conseil du 3 décembre 1958, 30 décembre 1958. 
et politiques au sein des Six n'étaient pas convaincus par le projet de ZLE mais l'ont soutenu pour des raisons politiques. Comme le montre Francesca Fauri pour le cas italien, l'échec de la ZLE les a largement soulagés ${ }^{100}$. Ces décisions à Six doivent maintenant être présentées dans le cadre des Dix-Sept.

\section{L'indécision britannique et la rupture finale du 15 décembre 1958.}

Face au renforcement de la situation française, Londres a du mal à définir une stratégie de contre-offensive. L'administration ne parvient pas à fixer sa position sur les mesures à prendre au premier janvier 1959 et convient d'attendre les propositions des $\mathrm{Six}^{101}$. La même hésitation est perceptible au sein du gouvernement. Dans les discussions au sein du cabinet, de nombreuses perspectives à moyen terme sont évoquées : libération dans le cadre du GATT, zone de libre-échange alternative en Europe sans les Six mais peut-être avec le Canada, reprise de la négociation ZLE en juin 1959 avec une position spéciale pour la France. Les réunions se multiplient en novembre et décembre 1958 sans que des choix clairs ne soient définis ${ }^{102}$. Macmillan reste sur une tactique offensive et envisage de menacer de remettre en cause les liens militaires en Europe ${ }^{103}$.

Cette agressivité se manifeste lors de la réunion de l'OECE du 15 décembre 1958, consacrée à l'examen des mesures que la CEE compte prendre au premier janvier 1958. Dans ce cadre, la solidarité communautaire s'effrite. La RFA, la Belgique et les Pays-Bas remettent en cause les décisions prises lors du Conseil CEE du 3 décembre $1958^{104}$. Ces trois délégations acceptent en effet de discuter de l'extension à l'OECE des clauses sur les contingents faibles et nuls, proposée par le délégué britannique, David Eccles. Les deux délégués allemands, Erhard et Van Scherpenberg, ont, cependant, des positions divergentes sur ce problème ${ }^{105}$, traduisant la permanence de l'opposition entre la ligne pro-ZLE d'Erhard et la ligne d'Adenauer. La France parvient de toute

100. Francesca Fauri, «Italy and the Free Trade Area Negotiations, 1956-1958 », in Revue d'histoire de l'intégration européenne, 1998-2, p. 65-66.

101. PRO, T 234/379, Cabinet, Economic Steering Committee, 20 novembre 1958.

102. PRO, CAB 130/123, comptes rendus des réunions présidées par le Premier ministre des 17 novembre 1958, 27 novembre 1958, 4 décembre 1958 et 12 décembre 1958.

103. PRO, CAB 130/123, compte rendu de la réunion présidée par le Premier ministre du 12 décembre 1958.

104. DDF, 1958-II, document $n^{\circ} 426$, télégramme circulaire de Maurice Couve de Murville, 17 décembre 1958.

105. PRO, T 234/379, télégramme de la délégation britannique à l'OECE au Foreign Office, 16 décembre 1958. 
façon à faire écarter cette proposition ${ }^{106}$. David Eccles propose alors que les mesures des Six soient étudiées en vue de la prochaine réunion de l'OECE prévue le 15 janvier 1959, faute de quoi des mesures de rétorsion seront prises, en particulier envers la France. Après avoir affirmé que la France ne négocierait pas sous la menace, Couve de Murville stigmatise cette mesure qui soumet les décisions des Six à un examen extérieur. Il faut observer que la proposition de David Eccles était ingénieuse dans la mesure où elle ne coûtait rien aux Six sur le plan commercial : la taille des contingents accordés par les Six restait la même mais ils étaient ouverts à dix-sept pays au lieu de six. Le véritable débat portait sur un principe politique, celui du maintien d'une discrimination entre les Six et ceux qui ont choisi de ne pas entrer dans la CEE, cadre contraignant qui donne des droits et des obligations.

La ZLE est condamnée. À l'initiative des organisations patronales suédoises et britanniques, l'étude d'une zone de libre-échange limitée à sept pays de l'OECE non-membres de la CEE (Grande-Bretagne, Suède, Norvège, Danemark, Autriche, Suisse, Portugal) est rapidement lancée ${ }^{107}$. Après une rapide négociation intergouvernementale, elle débouche sur l'EFTA (European Free Trade Association), une organisation strictement commerciale qui manifeste la permanence du modèle de la Grande Europe du libéralisme pur et non régulé.

Le succès français dans la négociation ZLE est indéniable. En juin 1958 par exemple, les cinq pays membres de la CEE (et certains Français favorables à la ZLE comme François Valéry ${ }^{108}$ ) s'orientaient vers des mesures au premier janvier 1959 réservées aux pays de l'OECE et incluant des éléments permettant de préfigurer la ZLE ${ }^{109}$. Au contraire, la France a réussi à promouvoir des mesures au premier janvier 1959 renforçant sa stratégie de double échelle de coopération, à Six sur le plan européen, et par le GATT à l'échelle mondiale, court-circuitant l'échelle devenue dangereuse de l'OECE. Aucun élément annonçant une future ZLE n'a été accepté en dehors du rapport à venir de la Commission européenne, qui elle-même s'est montrée très méfiante envers la ZLE. La France parvient donc, au prix d'une nouvelle crise avec la Grande-Bretagne, à préserver non sans mal l'unité des Six, et à briser la négociation ZLE.

106. DDF, 1958-II, document $n^{\circ} 426$, télégramme circulaire de Maurice Couve de Murville, 17 décembre 1958.

107. Neil Rollings, British Business..., op. cit., p. 124-126.

108. AMAE, DECE 743, folio 79, note de François Valéry du 28 avril 1958.

109. AMAE, POW 40, folio 61, note DAEF, 21 juin 1958, réunion du comité Ockrent des 16 et 17 juin 1958. 


\section{Conclusion : l'échec de la ZLE en 1958.}

Sous le gouvernement de Gaulle, la négociation ZLE est à la fois relancée et brisée. Plusieurs incertitudes pèsent sur l'interprétation de ces mouvements : la France du général de Gaulle était-elle prête à une ZLE ? Qui est à l'origine de la rupture ? Quelles sont les conséquences de cette rupture?

Selon certains historiens, le général de Gaulle ne voulait absolument pas d'une $Z_{L E}{ }^{110}$. L'étude des archives ne permet pas de confirmer cette thèse. De Gaulle a soutenu une mobilisation de l'administration destinée à élaborer une position constructive sur la ZLE afin de restaurer le crédit de la France en Europe. Il ne s'agissait pas de conclure une ZLE rapidement mais d'éviter tout isolement français en assurant l'unité des Six, et de faire progresser les thèses françaises pour une éventuelle ZLE à long terme. Le succès des négociations sectorielles a d'ailleurs permis à la France de montrer que ses critiques techniques de la formule de la zone de libre-échange étaient fondées. De Gaulle a donc permis à la France de disposer d'une position réaliste, alors que le mémorandum Gaillard de février 1958 restait trop intransigeant. Il semble que jusqu'à la mi-octobre 1958, une ZLE semblait envisageable pour les négociateurs français les plus engagés comme Olivier Wormser. Elle devait évidemment prendre une forme très lâche et intervenir le plus tard possible, deux conditions indispensables pour sauvegarder l'essentiel, la CEE. Ainsi il n'y a pas de contradiction entre la position officielle très volontariste de juillet 1958 sur la ZLE et l'acceptation d'une rupture progressive dès le mois d'octobre 1958. C'est le renforcement de juillet 1958 qui permet d'envisager en octobre 1958 une rupture dans des conditions acceptables, ce qui aurait été impensable auparavant.

L'origine de la rupture est à chercher dans ce climat délétère. L'étude des archives montre que dès le début du mois de novembre 1958, de nombreux décideurs à Paris, Bonn, Bruxelles ou Londres ne croient plus au succès du comité Maudling, donc à la conclusion proche d'une ZLE. Cette rupture s'explique par une divergence croissante entre la France et la Grande-Bretagne sur le leadership en Europe. D'un côté, la France a défini une voie de modernisation qui passe par l'intégration économique communautaire, seule solution pour s'engager dans une libération des échanges incontournable. Au contraire, la Grande-Bretagne hésite entre une approche mondiale et une approche européenne. Elle n'a jamais été pleinement convaincue par la ZLE et souffre d'un soutien américain prioritairement dirigé vers la CEE.

110. Alan Milward, The Rise and Fall..., op. cit., p. 266. 
Cette opposition franco-britannique a été longtemps éclipsée par la méthode de négociation maladroite du comité Maudling, qui ne s'appuyait pas sur un document de base commun comme le rapport Spaak, mais a entamé immédiatement des discussions techniques de détail. À partir de juillet 1958, deux facteurs permettent à cette divergence fondamentale d'apparaître plus clairement. D'une part la France entre de plain-pied dans la négociation en développant pour la première fois une position cohérente et réaliste. D'autre part, la Grande-Bretagne, déçue par les mémorandums Gaillard et de la Commission du printemps 1958, commence à perdre espoir dans la négociation ZLE. Elle s'engage à partir de l'été dans une stratégie plus mondiale. Macmillan semble marqué personnellement par cet échec et envisage des représailles très sévères envers la France, mêlant aspects économiques, monétaires, politiques et militaires. La rupture de la négociation ZLE le 14 novembre 1958 intervient donc à un moment ou plus personne ne voulait sérieusement d'une négociation ZLE dans le cadre du comité Maudling.

Les conséquences de cette rupture pouvaient être potentiellement très graves pour la France et aboutir à son isolement au sein des Six ou à une crise profonde dans les relations franco-britanniques. Pourtant la France a réussi à éviter ces deux écueils. Elle est parvenue à communautariser la rupture en faisant endosser par les Six ses propositions de mesures au premier janvier 1959. Deux cadres sont mis en valeur : la CEE et le GATT. En fait, le travail de la France a consisté à mettre le doigt sur l'incompatibilité des stratégies mondiales et européennes de la Grande-Bretagne, en soulevant le problème de la préférence européenne.

Une fois l'échec de la négociation ZLE obtenue, il reste à effectuer un redressement économique et financier interne pour mener la politique commerciale libérale que Paris avait annoncé. C'est la fonction du plan Rueff.

\section{LA RUPTURE EUROPÉENNE ET MONDIALE : LE PLAN RUEFF}

Pour assurer le succès de sa stratégie de coopération économique internationale à double échelle - CEE et GATT, la France doit montrer qu'elle peut s'insérer dans le mouvement international de libération des échanges et des paiements. Il lui faut dépasser le monde de la reconstruction, celui des dérogations accordées par l'OECE et des crédits consentis par l'UEP et le FMI.

Le plan Rueff entend répondre à cet enjeu et doit ainsi être lu à une échelle triple, nationale, européenne et mondiale, comme ont déjà tenté de le faire Paul 
Pitman $^{111}$, Sylvia Schwaag ${ }^{112}$ et surtout Frances Lynch ${ }^{113}$ et Olivier Feiertag ${ }^{114}$ dans des études éclairantes mais qu'il est possible de préciser en établissant un lien précis avec les échéances européennes - négociation ZLE et mesures au premier janvier 1959. Il est nécessaire de croiser les archives avec la bibliographie internationale consacrée au retour à la convertibilité ${ }^{115}$ et avec celle, plus franco-française, du plan Rueff ${ }^{16}$.

Pour étudier le plan Rueff, il est nécessaire de surmonter de nombreux écueils. Tout d'abord, les témoignages des principaux acteurs sont parfois contradictoires, notamment celui de Rueff lui-même. Il affirme ainsi que le plan qui lui est associé a été très largement décidé lors d'une réunion tenue le 18 novembre

111. Paul Pitman, « Le retour à la convertibilité monétaire en Europe occidentale et le redressement financier français », in Maurice Lévy-Leboyer, Alain Plessis, Michel Aglietta, Christian de Boissieu (dir.), Du franc Poincaré à l'écu, Comité pour l'histoire économique et financière de la France, Paris, 1993, p. 449-470. L'étude croise les archives françaises et britanniques mais les négociations européennes (CEE et ZLE) manquent.

112. Sylvia Schwaag, "Currency convertibility and European Integration : France, Germany and Britain », in Anne Deighton, Alan Milward (éd.), Widening, deepening and acceleration : The European Economic Community, 1957-1963, Bruylant, Bruxelles, 1999, p. 89-106. Contrairement au titre, son article se concentre principalement sur le point de vue britannique, qui est expliqué de manière très éclairante.

113. Frances Lynch, « De Gaulle's First Veto. France, the Rueff Plan and the Free Trade Area », in Contemporary European History, 9, 1, 2000, p. 111-135. L'étude de Frances Lynch est la plus aboutie car elle croise la négociation ZLE et celle du plan Rueff. Elle n'intègre cependant pas les archives françaises en dehors du ministère des Affaires étrangères, ni les archives CEE.

114. Olivier Feiertag, Wilfrid Baumgartner. Un grand commis des Finances à la croisée des pouvoirs (1902-1978), Comité pour l'histoire économique et financière de la France, Paris, 2006. Cette étude dépasse la simple biographie au sens étroit pour insérer le plan Rueff dans une histoire financière de la France qui prend en compte la dimension internationale.

115. En plus des ouvrages cités précédemment : Jacob Kaplan, Günther Schleiminger, The European Payments Union. Financial Diplomacy in the 1950s, Clarendon Press, Oxford, 1989, p. 273-320 ; John Fforde, The Bank of England and Public Policy, 1941-1958, Cambridge UP, Cambridge, 1992, p. 595-605 ; Gérard Bossuat, « La Banque de France dans les relations monétaires internationales de la France, 1945-1960 », in Olivier Feiertag et Michel Margairaz (dir.), Politiques et pratiques des banques d'émission en Europe (XVII'-XX siècle), Albin Michel, Paris, 2003, p. 748-751.

116. Les ouvrages de référence sont ceux de 1'Institut Charles de Gaulle : 1958 : la faillite ou le miracle économique. Le plan de Gaulle-Rueff, Economica, Paris, 1986 et De Gaulle en son siècle. Volume 3 : Moderniser la France, Plon, Paris, 1992. Voir aussi : Michel-Pierre Chelini, « Le Plan de stabilisation Pinay-Rueff, $1958 »$ in Revue d'histoire moderne et contemporaine, 48-4, octobredécembre 2001, p. 102-123. Pour les mémoires et témoignages : Charles de Gaulle, Mémoires d'espoir. Le renouveau, 1958-1962, Paris, Plon, 1970, p. 146-154 ; Nathalie Carré de Malberg (texte établi, présenté et annoté par), Entretiens avec Roger Goetze, haut fonctionnaire des finances. Rivoli-AlgerRivoli, 1937-1958, Comité pour l'histoire économique et financière de la France, Paris, 1997, p. 343360 ; Jacques Rueff, Cuvres complètes. Politique économique, tome III, volume 2, Plon, Paris, 1980, p. 368-415 ; Jacques Rueff, Combats pour l'ordre financier, Plon, Paris, p. 244-247. Sur Pinay : Sylvie Guillaume, Antoine Pinay ou la confiance en politique, FNSP, Paris, 1984, p. 158-177. 
$1958^{117}$. Par ailleurs, Rueff établit une continuité directe entre sa note de juin 1958 demandant des réformes et le plan de décembre $1958^{118}$. Sur ces deux points l'étude des archives et de la correspondance entre la genèse du plan Rueff et les négociations européennes permettra de remettre en cause ce témoignage de l'économiste français. Deuxième difficulté, le processus d'élaboration de ce plan est entouré d'un certain secret car le comité Rueff s'est réuni en « semiclandestinité $^{119}$ ». Ses délibérations restent donc inconnues. Le processus de décision ayant abouti à la dévaluation et au retour à la convertibilité est lui aussi très discret, comme il est d'usage dans ce type d'opération. Enfin, les décideurs qui géraient les questions européennes, CEE et ZLE, et ceux qui s'occupaient des questions monétaires paraissent évoluer dans des mondes différents et cloisonnés, tant en France qu'en Grande-Bretagne.

Il est donc nécessaire de savoir quand et par qui le plan Rueff a été défini. Le but de cette étude est de montrer le lien avec la chronologie des négociations ZLE : première rupture du 14 novembre 1958, accord franco-allemand de Bad Kreuznach le 26 novembre 1958, accord à Six les 3 et 4 décembre 1958, seconde rupture le 15 décembre 1958. Les liens entre la définition du plan Rueff et la ZLE sont en effet très nets, et ce dès le lancement de l'opération Unicorn par Londres.

\section{A. UNE NOUVELLE INITIATIVE BRITANNIQUE : L'OPÉRATION UNICORN}

À partir de l'été 1958, les Britanniques commencent à envisager un retour à la convertibilité de la livre sous le nom d'opération Unicorn (Licorne). Cet objectif ancien avait été retardé depuis 1955 par une conjoncture défavorable. Il est relancé par le chancelier de l'Échiquier, Derrick Heathcoat-Amory, par un mémorandum diffusé le 8 septembre $1958^{120}$. Amory utilise l'argument classique du renforcement du rôle international de la livre et y ajoute des considérations liées à des échéances du FMI. Ainsi, des facilités de crédit du FMI à la Grande-Bretagne doivent être renouvelées à la fin de l'année 1958 et un retour à la convertibilité améliorerait la position britannique dans ces négociations. Le mémorandum envisage ce mouvement pour la fin de l'année 1958.

117. Jacques Rueff, Combats..., op. cit., p. 249-250.

118. Décalage relevé in O. Feiertag, Wilfrid Baumgartner..., op. cit., p. 562.

119. N. Carré de Malberg, Entretiens avec Roger Goetze..., op. cit., p. 344. 1958.

120. PRO, PREM 11/2671, 180-182, mémorandum du chancelier de l'Échiquier du 8 septembre 
À l'encontre du retour à la convertibilité, il soulève plusieurs arguments, le principal portant sur le choix de politique économique intérieure, avec le lancinant débat entre ceux qui privilégient la croissance et ceux qui insistent sur l'équilibre financier. Ainsi, il apparaît que le retour à la convertibilité de la livre est envisagé principalement dans un double contexte national et international, car les négociations européennes sont à peine évoquées. De même, lors de la réunion interministérielle du 11 septembre 1958 suivant ce mémorandum, la ZLE n'est évoquée que de manière très secondaire ${ }^{121}$.

Les représentants britanniques sondent ensuite leurs partenaires sur un éventuel retour à la convertibilité de la livre. Ce sont les Européens rencontrés par les Britanniques lors de l'assemblée générale du FMI à New Delhi du 6 au 10 octobre 1958, qui replacent cette opération dans le cadre européen ${ }^{122}$. Ils soulignent en effet l'impérieuse nécessité de tenir compte de la France, qui pourrait se sentir attaquée par un mouvement général de retour à la convertibilité des monnaies auquel elle ne semble pas en mesure de participer.

Le 28 octobre 1958, une nouvelle réunion présidée par Macmillan témoigne de l'évolution des esprits à Londres ${ }^{123}$. Le problème spécifique de la France est désormais pris en compte, et a fait l'objet d'une note spécifique dont les conclusions sont reprises par un mémorandum du chancelier de l'Echiquier ${ }^{124}$. Elle conclut que la France devrait vraisemblablement se résoudre à revenir elle aussi à la convertibilité du franc français pour des raisons de prestige. La GrandeBretagne devrait l'aider par des soutiens dans d'éventuelles demandes de crédit. Mais lors de la réunion du 28 octobre 1958, le Premier ministre Macmillan a une toute autre interprétation des problèmes européens ${ }^{125}$. Selon lui, le retour à la convertibilité pourrait constituer un prétexte pour la France pour rompre les négociations ZLE, ce qui devrait entraîner de la part de la Grande-Bretagne des mesures de rétorsions envers le Marché commun.

La Grande-Bretagne hésite sur l'attitude à tenir face à la France. Le principal intéressé de la négociation ZLE, Reginald Maudling, veut repousser Unicorn en

121. PRO, PREM 11/2671, 169-172, compte rendu de la réunion présidée par le Premier ministre du 11 septembre 1958.

122. PRO, PREM 11/2671, 153-155, mémorandum du chancelier de l'Échiquier en vue de la réunion du 28 octobre 1958 ; J. Kaplan, G. Schleiminger, The European Payments Union..., op. cit., p. 306.

123. PRO, PREM 11/2671, 133-36, compte rendu d'une réunion présidée par le Premier ministre, 28 octobre 1958 .

124. PREM 11/2671, 118-124, note Treasury établie en liaison avec la Banque d'Angleterre, «Unicorn/France », 27 octobre 1958.

125. PRO, PREM 11/2671, 133-36, compte rendu de la réunion présidée par le Premier ministre le 28 octobre 1958 . 
attendant une amélioration des discussions franco-britanniques sur la ZLE ${ }^{126}$. À la réunion présidée par le Premier ministre du 6 novembre 1958, il est d'ailleurs décidé de repousser l'opération pour éviter que la France en profite pour briser les négociations $\mathrm{ZLE}^{127}$. La première rupture de la négociation ZLE, le 14 novembre 1958, ne clarifie pas la situation. Lors de la réunion du 27 novembre 1958, le gouvernement britannique estime qu'il faut attendre les contrepropositions des Six pour décider de sa stratégie ${ }^{128}$.

La situation en Grande-Bretagne est donc relativement confuse. Le chancelier de l'Échiquier et la Banque d'Angleterre soutiennent très fortement le retour à la convertibilité pour des raisons mondiales. Macmillan, de son côté, reste sur une position agressive. Il paraît concentré sur la négociation ZLE et même paralysé par elle. Au fur et à mesure que le calendrier avance, la capacité d'initiative de Londres se réduit, tant sur le plan mondial, comme le chancelier a donné des indices sur le retour prochain à la convertibilité, que sur le plan européen dans la négociation ZLE. En fait, Londres souffre d'une contradiction entre sa stratégie mondiale, qui repose sur la coopération monétaire et commerciale, et sa stratégie européenne, qui se crispe sur un affrontement politique.

Le projet de retour à la libre convertibilité de la livre constitue en tout cas une pression supplémentaire sur les décideurs français pour deux raisons. D'une part, le retour à la convertibilité de la livre entraînerait très rapidement celui des autres monnaies européennes. La France serait vraisemblablement le seul grand pays d'Europe occidentale à ne pas pouvoir suivre ce mouvement, en raison de la faiblesse de sa balance des paiements. L'isolement de la France serait ainsi patent. D'autre part, le retour à la convertibilité devrait entraîner la fin de l'UEP et son remplacement par l'AME (Accord monétaire européen). Pour dissoudre l'UEP, l'accord des pays représentant cinquante pour cent au mois des quotas est nécessaire, or si d'autres pays européens importants comme la RFA suivent la Grande-Bretagne, ce niveau sera atteint. La France pourrait donc se voir imposer la fin de l'UEP, même contre son gré. Les clauses concernant l'attribution de crédit dans l'AME sont beaucoup plus strictes que dans l'UEP, ce qui affaiblit la situation des pays débiteurs, comme la France.

126. J. Fforde, The Bank of England..., op. cit., p. 597 ; J. Kaplan, G. Schleiminger, The European Payments Union..., op. cit., p. 310.

127. PRO, PREM 11/2671, 98-105, compte rendu de la réunion présidée par le Premier ministre, 6 novembre 1958.

128. PRO, PREM 11/2671, 96-97, compte rendu de la réunion présidée par le Premier ministre, 27 novembre 1958. 


\section{B. LA RÉACTION FRANÇAISE : \\ LE COMITÉ RUEFF ET LES DÉCISIONS DU 18 NOVEMBRE 1958}

Face à cette pression internationale, le gouvernement français doit réagir s'il veut jouer un rôle dans la réorganisation des institutions de coopération économiques et monétaires internationales qui s'annonce. Les incertitudes britanniques lui donnent une marge de manœuvre et la première rupture de la négociation ZLE, le 14 novembre 1958, l'oblige à prendre une décision.

La réaction française passe par le redressement interne. Les manœuvres tactiques et les discussions d'experts dans la négociation ZLE, le recours aux clauses de sauvegarde au sein de la CEE, de l'OECE ou de l'UEP ne sont que des expédients à court terme. Pour regagner une crédibilité internationale, la France doit redresser sa balance commerciale et diminuer son déficit budgétaire afin de ne plus dépendre de l'aide internationale.

Trois solutions sont possibles. La première est d'imposer une sévère cure d'austérité budgétaire, qui réduira le déficit budgétaire mais aussi le déficit commercial par une pression sur la demande donc sur les importations. Elle suppose néanmoins une volonté politique forte. La seconde est de recourir à une dévaluation pour accroître la compétitivité des exportations françaises. L'échec de la dévaluation en deux temps d'août 1957 montre cependant qu'une dévaluation ne peut être isolée et doit s'intégrer dans un vaste mouvement de réformes destinées à empêcher que le manque de confiance dans la monnaie et l'inflation n'annulent rapidement les effets positifs de la dévaluation. La troisième solution consiste à améliorer la compétitivité des exportations françaises de manière structurelle en accroissant la pression concurrentielle. En interne, cela consiste à supprimer les rentes de situation, et à surveiller les ententes et concentrations. En externe, cela passe par l'ouverture à la concurrence internationale.

Dans un premier temps, le général de Gaulle a paré au plus pressé avec l'emprunt Pinay de juin $1958^{129}$. Mais les faiblesses structurelles demeurent. Des réformes plus profondes fondées sur la combinaison de ces trois mesures doivent donc être appliquées. Le 30 septembre 1958, une nouvelle étape est franchie. Le président du Conseil décide de former un comité d'experts indépendants présidé par l'économiste Jacques Rueff pour trouver les moyens de restaurer l'équilibre financier de la France de façon pérenne. L'initiative n'est sans doute pas liée à l'opération Unicorn, qui n'est pas encore bien connue, mais

129. Description précise de l'emprunt et de ses résultats in : M.-P. Chelini, « Le Plan de stabilisation Pinay-Rueff... », op. cit., p. 104-105. 
reflète la nécessité impérative d'adapter l'économie française aux contraintes internationales.

Jacques Rueff est une personnalité prestigieuse et aux facettes multiples ${ }^{130}$. C'est d'abord un ancien haut fonctionnaire français au profil classique : inspecteur des finances et ancien directeur du mouvement général des fonds. Il y ajoute une orientation internationale marquée, comme membre de la section financière de la SDN (1927-1930) ou juge à la Cour de justice des Communautés européennes (1952-1962). Il a l'expérience de l'action politique de crise car il a fait partie du cabinet de Poincaré au moment de l'opération de stabilisation de 1926, puis du ministre des Finances Paul Reynaud en 1938-1939 ${ }^{131}$. Jacques Rueff est un des représentants des ingénieurs économistes, l'un de ces polytechniciens qui, à l'instar de Maurice Allais, jouent un rôle de premier plan dans les débats académiques français en économie ${ }^{132}$. Il est d'ailleurs membre de l'Institut.

En termes de doctrine économique, le choix de Jacques Rueff est clairement celui de la rupture. Il est en effet le meilleur représentant français d'un néolibéralisme proche du libéralisme classique ${ }^{133}$. Membre fondateur de la section française de la société du Mont-Pèlerin, c'est un admirateur des ordolibéraux allemands et de leur politique économique incarné par Ludwig Erhard ${ }^{134}$. Comme opposant au keynésianisme dominant de l'après-guerre, il est assez isolé, d'où sa position administrative quelque peu périphérique à la Cour de justice des Communautés.

Sur le plan européen, Jacques Rueff a déjà exprimé son point de vue sur le Marché commun dans un article paru au début de $1958^{135}$. Il se montre très favorable à la construction d'un « marché institutionnel », celui d'un libéralisme fort mais régulé, qui s'oppose au libéralisme brut et primaire du XIX ${ }^{\mathrm{e}}$. La CEE est donc une occasion de faire triompher sa vision néolibérale.

Sur le plan de la procédure, c'est le général de Gaulle qui choisit de créer un comité d'expert indépendant présidé par une personnalité influente et réformatrice pour bousculer les pesanteurs administratives, en dépit des réticences de

130. D'autres éléments biographiques in : O Feiertag, Wilfrid Baumgartner..., op. cit., p. 141-144 et $567-568$.

131. M. Debré, Trois républiques..., tome I, op. cit., p. 147.

132. O. Dard, «Économie et économistes... », op. cit., p. 182-183.

133. François Denord, Néo-libéralisme version française..., op. cit., p. 120.

134. François Denord, Néo-libéralisme, version française..., op . cit., p. 232-233 et 248.

135. Jacques Rueff, « Une mutation dans les structures politiques : le marché institutionnel des Communautés européennes. » in Revue d'économie politique, $\mathrm{n}^{\circ}$ 1, 1958. p. 1-10. 
Pinay ${ }^{136}$. Auparavant, Rueff avait de lui-même envoyé au ministre des Finances une note préconisant une réforme profonde du système financier français ${ }^{137}$. Le comité Rueff réunit un nombre restreint de personnalités éminentes et représentatives de la diversité de la haute fonction publique et du secteur privé.

Une première mouture du rapport Rueff est terminée le 8 novembre 1958. Pinay reçoit Rueff à ce propos le 12 novembre 1958 et paraît surpris par l'ampleur des mesures proposées ${ }^{138}$. Le rapport semble déjà préconiser des mesures radicales comme la dévaluation du franc ${ }^{139}$, une mesure à laquelle Pinay est hostile ${ }^{140}$. Finalement, c'est lors du comité interministériel du 18 novembre 1958 que les décisions sont prises ${ }^{141}$. Baumgartner, le gouverneur de la Banque de France, y propose le taux de dévaluation final de $17,4 \%{ }^{142}$ et la direction des Prix met à l'étude divers scénarios de dévaluation ${ }^{143}$. Le processus de décision semble donc s'accélérer entre le 8 et le 18 novembre.

Cette radicalisation semble s'expliquer par la négociation ZLE et les rumeurs autour de l'opération Unicorn. Il faut aussi mentionner le second projet Marjolin de renforcement de la coopération monétaire dans le cadre de la CEE, qui date du 7 novembre $1958^{144}$. La date du 18 novembre 1958 correspond d'ailleurs à celle des décisions sanctionnant la première rupture des discussions à dix-sept, le 14 novembre 1958. C'est bien le 18 novembre que les décideurs français choisissent la voie de mesures libérales à prendre au premier janvier 1959, avec la mise en valeur du cadre de la CEE et du GATT. Cependant, la réalité de la conversion de la France à l'ouverture des marchés dépend du taux de libération des échanges qu'elle accepte. Fixé pour lors à $40 \%$, il reste modeste, en dessous des prescriptions de l'OECE. La France devait en effet revenir à $82,3 \%$ de libération au 18 décembre 1958, et rejoindre ensuite les $90 \%$ et plus pratiqués par tous ses principaux partenaires. Mais pour appliquer ces mesures d'ouverture sans risque et pour aller plus loin, de profondes réformes intérieures sont nécessaires, d'où les décisions liées au plan Rueff. Une lettre

136. S. Guillaume, Antoine Pinay..., op. cit., p. 171 ; Charles de Gaulle, Mémoires d'espoir. Le renouveau..., op. cit., p. 149-150.

137. Jacques Rueff, Euvres complètes..., op. cit., p. 365 ; O. Feiertag, Wilfrid Baumgartner..., op. cit., p. 556-561.

138. S. Guillaume, Antoine Pinay..., op. cit., p. 173.

139. O. Feiertag, Wilfrid Baumgartner..., op. cit., p. 588.

140. S. Guillaume, Antoine Pinay..., op. cit., p. 174-175.

141. DDF, 1958 -II, document n ${ }^{\circ} 343$, note d'Olivier Wormser pour le ministre, 18 novembre 1958 ; ASGCI, 1977.1471, article 63, note d'Olivier Wormser du 18 novembre 1958.

142. O. Feiertag, Wilfrid Baumgartner..., op. cit., p. 588.

143. AMINEFI, B 57629, note de Louis Franck du 18 novembre 1958 ; AMINEFI, B 55896, note de la DG Prix sur les « projets financiers » du 29 novembre 1958.

144. Voir ci-après. 
de Charles de Gaulle à Antoine Pinay du 20 octobre 1958 confirme d'ailleurs le lien entre la négociation sur la ZLE et les mesures économiques et financières ${ }^{145}$. Dans cette lettre, le président du Conseil demande, en vue de la reprise des négociations ZLE au comité Maudling, une communication au gouvernement sur l'application possible par la France des clauses du traité de Rome. Le redressement financier français s'inscrit dans les échéances européennes de la CEE et de la ZLE.

Ainsi, les pressions française (prérapport Rueff), communautaire $\left(2^{\mathrm{e}}\right.$ plan Marjolin), européenne (rupture de la négociation ZLE) et mondiale (retour à la convertibilité de la livre et projets de libéralisation commerciale dans le cadre du GATT) se conjuguent pour forcer le gouvernement français à un changement de paradigme, et à accepter rapidement le retour à la libération des échanges. Le mouvement français paraît certes modeste - on ne parle pas explicitement de retour à la convertibilité et le taux de libération reste à $40 \%$ - mais il ne s'agit que d'une première étape. Les négociations ZLE peuvent encore rebondir et le retour à la convertibilité de la livre n'est toujours pas fixé de manière précise.

\section{LE DÉBAT SUR LE PLAN RUEFF ET LA CONVERTIBILITÉ}

Après ces décisions majeures du 18 novembre 1958, la pression retombe un peu sur la France. Dans le cadre de la ZLE, Paris parvient à obtenir l'appui de Bonn le 26 novembre puis des Six le 3 décembre 1958. Deux éléments relancent les réflexions sur les mesures à prendre : la présentation du rapport Rueff et le retour imminent à la convertibilité de la livre.

Le rapport Rueff est présenté le 8 décembre 1958 au général de Gaulle ${ }^{146}$. Il présente quatre volets complémentaires ${ }^{147}$ :

- Un volet budgétaire classique fondé sur une politique d'austérité.

- Un volet de libéralisation interne de l'économie par la « réduction des interventions économiques » comme les subventions au commerce extérieur.

- Un volet de libéralisation externe de l'économie. Le rapport préconise, sans donner de chiffres précis, d'aller au-delà des mesures que l'OECE demande à la France (soit au-delà de 82,3\%). Le rapport Rueff se montre bien plus libéral que l'administration française qui a plaidé pour le taux de $40 \%$ de libération accepté le 18 novembre 1958.

145. Lettre de Charles de Gaulle à Antoine Pinay du 20 octobre 1958, in Charles de Gaulle, Lettres, notes et Carnets, juin 1958-décembre 1960, Plon, Paris, 1985, p. 117.

146. C. de Gaulle, Mémoires d'espoir. Le renouveau..., op. cit., p. 150.

147. J. Rueff, Euvres complètes..., op. cit., p. 402-413. 
- Un volet financier et monétaire qui est simplement esquissé dans le rapport proprement dit. Il se contente d'appeler à une plus grande libéralisation des mouvements de capitaux avec l'étranger et souligne que : «l'application des recommandations contenues dans le présent chapitre constituera une étape importante sur le chemin de la convertibilité ${ }^{148}$ ». Il faut attendre une lettre secrète de Jacques Rueff au ministre des Finances du 15 décembre 1958 pour que la dévaluation soit explicitement demandée, et associée à la création d'un franc lourd ${ }^{149}$. Le retour à la libre convertibilité n'est donc pas explicitement demandé.

Le caractère radical de ce plan est particulièrement frappant. Rueff a lui-même beaucoup évolué ${ }^{150}$. Sa note de juin 1958 était concentrée sur la critique du système financier français et en particulier de la généreuse politique d'escompte menée par la Banque de France ${ }^{151}$. Au contraire le rapport de décembre 1958 évite ce sujet de la réforme du système financier français, sans doute en raison de l'opposition du gouverneur de la Banque de France Wilfrid Baumgartner, dont les rapports inamicaux avec Rueff sont bien connus ${ }^{152}$.

Cette évolution peut s'expliquer par plusieurs éléments. L'élément conjoncturel a pu jouer un rôle, le déficit de la balance des paiements français s'aggrave une nouvelle fois de manière forte en novembre 1958 après quelques mois de répit ${ }^{153}$. Par ailleurs, Roger Goetze, le conseiller économique du président du Conseil de Gaulle, joue un rôle crucial dans les réflexions du comité Rueff ${ }^{154}$. Sur le plan économique, Goetze semble être un libéral, comme en témoigne sa note soutenant le rapport Spaak ${ }^{155}$. Il y défendait le Marché commun moins par européisme que par attachement au retour aux mécanismes du marché. Plus généralement, les décideurs français semblent se convertir à la libéralisation du commerce et des paiements du fait de la pression internationale. C'est particulièrement le cas des dirigeants du CNPF, comme le montrent les exhortations de Georges Villiers à l'assemblée générale extraordinaire du 13 mai 1958 mais aussi la note interne de Jean Louis d'avril 1958 qui demandait de laisser flotter

148. J. Rueff, Euvres complètes..., op. cit., p. 410.

149. Lettre de Jacques Rueff à Antoine Pinay, 15 décembre 1958, in J. Rueff, Combats..., op. cit., p. $247-8$.

150. O. Feiertag, Wilfrid Baumgartner..., op. cit., p. 561.

151. J. Rueff, Oeuvres complètes..., op. cit., p. 365.

152. O. Feiertag, Wilfrid Baumgartner..., op. cit., p. 564-565.

153. AMAE, POW 78, folio 250, statistiques OECE sur la France, 9 décembre 1958.

154. M. Debré, Trois républiques..., op. cit., p. 327 ; AMINEFI, B 57629, lettre de Louis Franck à Arasse, chef de cabinet d'Antoine Pinay, 22 août 1958 ; note de Louis Franck pour Le Portz, 10 décembre 1958 ; note de Louis Franck pour George Pompidou, 10 décembre 1958.

155. ARAM, 52 J 114, note de Roger Goetze du 7 mai 1956. 
le franc ${ }^{156}$. Cette note a dû être connue de l'administration car de Lattre y fait référence ${ }^{157}$.

Par ailleurs, cette pression internationale se manifestait de manière très concrète à chaque fois que la France demandait l'aide à ses partenaires. Ainsi, par exemple, lorsque l'UEP accorda de très larges facilités financières à la France en janvier 1958, elle divisa son aide en deux et soumit l'attribution de la seconde tranche à l'étude des mesures prises par le gouvernement français $^{158}$. La négociation avec le FMI en janvier 1958 a donné lieu à la remise d'un mémorandum prévoyant une diminution importante du nombre d'hommes appelés sous les drapeaux, ce qui menace directement la politique algérienne de la France ${ }^{159}$. Olivier Feiertag tisse un lien entre les analyses de Per Jacobsson (FMI) sur la situation française en décembre 1957 et certains des éléments du plan Rueff ${ }^{160}$. La Commission européenne, à la fin de sa procédure d'examen de la crise française de mai 1958, avait également fait une recommandation implicite de dévaluer ${ }^{161}$. Enfin, les événements de l'automne 1958 manifestent le retour rapide à une libération mondiale des échanges et des paiements. Tous ces faits manifestent concrètement les conséquences politiques de la faillite financière française. Ils ne pouvaient être ignorés du général de Gaulle. Il paraît impossible de mener une politique de «grandeur » si la France risque de passer sous la tutelle des institutions internationales. Il semble donc qu'un débat majeur agite l'exécutif français autour du 10 décembre 1958. Les questions du taux de libération des échanges, de la dévaluation du franc ou du retour à la convertibilité restent en suspens ${ }^{162}$.

\section{LES DÉCISIONS FRANÇAISES : DU 10 AU 31 DÉCEMBRE 1958}

La pression sur la France s'intensifie en deux temps. Une première rupture se produit le 10 décembre 1958. Ce jour-là, Wilfrid Baumgartner téléphone à la Banque d'Angleterre et annonce que la France devrait, selon toute

156. ACNPF, 72 AS 1381, note de Jean Louis pour son exposé devant la Commission d'Henri Fayol le 14 avril 1958.

157. AMAE, POW 77, folio 308, note d'André de Lattre, Finances extérieures, 3 juillet 1958.

158. J. Kaplan, G. Schleiminger, The European Payments Union..., op. cit., p. 281.

159. AMAE, POW 78, note d'Olivier Wormser pour Louis Joxe, 15 janvier 1958.

160. O. Feiertag, Wilfrid Baumgartner..., op. cit., p. 541.

161. AHUE, annexe au procès-verbal spécial des 22-24 et 26 juillet 1958, document COM (58) 165 rév.

162. J. Kaplan, G. Schleiminger, The European Payments Union..., op. cit., p. 311-312. 
vraisemblance, revenir à la libre convertibilité du franc français ${ }^{163}$. Cette annonce paraît surprenante car aucune décision n'est encore prise en France. Il est possible, comme le pensent les Britanniques à l'époque et comme l'envisage son biographe, Olivier Feiertag, que Baumgartner tente de convaincre en interne les autorités françaises de dévaluer et de revenir à la convertibilité, et utilise pour cela la pression de ses partenaires internationaux. Erhard assura d'ailleurs de Gaulle cinq jours plus tard que des discussions se tenaient entre les banquiers centraux sur le retour à la convertibilité ${ }^{164}$. Il semble que le plan Rueff, présenté officiellement à de Gaulle le 8 décembre, fasse l'objet d'âpres discussions en interne, d'où l'intervention de Baumgartner.

De leur côté, les Britanniques sont paralysés car ils ont peur d'une manœuvre française. Soit Paris compte revenir à la convertibilité avant Londres, ce qui ruinerait le prestige britannique dans cette opération, soit Paris veut revenir à la convertibilité après Londres mais pourrait alors accuser la perfide Albion de l'avoir acculé à ce mouvement ${ }^{165}$. La poursuite d'un semblant de négociation ZLE gêne la mise en œuvre de l'opération Unicorn, en obérant la collaboration internationale dont la Grande-Bretagne a besoin. L'accord de la RFA est nécessaire pour mettre fin à l'UEP. Or la RFA est liée à la France sur le plan politique.

Face aux hésitations de Paris et de Londres, Bonn prend les devants. La pression allemande s'exprime par exemple par des déclarations sans ambiguité d'Erhard sur un retour à la convertibilité imminent des monnaies européennes ${ }^{166}$. Ces déclarations ne sont pas anodines car elles émanent du principal créancier européen de la France. Dans un entretien avec son homologue britannique, le chancelier de l'Échiquier Amory le 14 décembre 1958, Erhard affirme que la RFA est prête à aider la France si elle revient à la convertibilité ${ }^{167}$. Il encourage Amory à abandonner la posture attentiste britannique et à en discuter directement avec les Français. La situation se débloque finalement le 15 décembre 1958 avec la crise au Conseil de l'OECE sur la ZLE.

163. PRO, PREM 11/2671, note Treasury pour le Premier ministre, 10 décembre 1958 ; PRO, PREM 11/2671, réunion présidée par le Premier ministre, 12 décembre 1958 ; O. Feiertag, Wilfrid Baumgartner..., op. cit., p. 589.

164. AMAE, PA-AP 314, carton 1, compte rendu d'un entretien entre de Gaulle et Erhard du 15 décembre 1958.

165. PRO, PREM 11/2671, folio 72-74, réunion présidée par le Premier ministre, 12 décembre 1958.

166. DDF, 1958-II, document $\mathrm{n}^{\circ}$ 402, télégramme de François Seydoux à Maurice Couve de Murville, 10 décembre 1958.

167. PRO, T 236.4822, folio 28, record of a conversation Erhard-Chancellor of the Exchequer, 14 décembre 1958. 
La rupture du 15 décembre 1958 permet de crever l'abcès de la ZLE et de repartir sur des bases saines. En France, c'est de ce jour que date la lettre secrète de Jacques Rueff au ministre des Finances demandant explicitement une dévaluation ${ }^{168}$. Surtout, c'est également le 15 décembre 1958 qu'Erhard évoque directement avec de Gaulle la perspective du retour prochain à la convertibilité de la livre et des monnaies européennes ${ }^{169}$. Ce à quoi de Gaulle répond : « En ce qui concerne la convertibilité, je pense que la livre est liée au deutschmark et au franc français. Nos intentions ne sont pas encore publiées. Elles ne le seront pas avant la fin de l'année, mais elles vont dans le sens que vous indiquez... ». De Gaulle ne révèle donc pas toute l'ampleur du futur plan Rueff même s'il indique, implicitement, que des mesures fortes sont envisagées. Il donne explicitement son accord à un mouvement concerté sur les monnaies des trois pays.

La date du 15 décembre 1958 est décisive car deux jours plus tard, le 17 décembre 1958, des discussions entre les trois ministres des Finances français (Pinay), allemand (Etzel) et britannique (Amory) lancent concrètement le processus concerté de retour à la convertibilité des principales monnaies européennes ${ }^{170}$. Le lendemain, le 18 décembre 1958, Macmillan autorise le lancement d'Unicorn ${ }^{171}$, tandis que le 19 décembre 1958, la France annonce officiellement son intention de rétablir la convertibilité du franc français si le mouvement est général en Europe ${ }^{172}$.

Un nouveau coup d'accélérateur est donné juste après Noël, car l'élection présidentielle est passée ( 21 décembre) et la période est propice aux annonces monétaires : le 26 décembre a lieu le Conseil restreint décisif où le plan Rueff est décidé. Il est avalisé le lendemain par le Conseil des ministres, et annoncé à la radio par le général de Gaulle le 28 décembre 1958. Il repose sur les trois piliers déjà évoqués, la libéralisation interne étant repoussée à plus tard (ce sera l'objet du comité Rueff-Armand de 1960) : un pilier budgétaire (économie budgétaire et augmentations d'impôts), la libéralisation externe (retour à la libération des échanges) et l'opération monétaire (dévaluation et retour à la convertibilité).

168. Lettre de Jacques Rueff à Antoine Pinay, 15 décembre 1958, in Jacques Rueff, Combats..., op. cit., p. 247-248.

169. AMAE, PA-AP 314, carton 1, compte rendu d'un entretien entre de Gaulle et Erhard du 15 décembre 1958.

170. PRO, PREM 11/2671, folio 59, note sur une conversation entre Pinay, Etzel et Amory, 17 décembre 1958.

171. Paul Pitman, « Le retour à la convertibilité monétaire... », op. cit., p. 465.

172. AMAE, DECE 681, réunion du Comité monétaire du 19 décembre 1958. 
Sur le plan monétaire, l'annonce officielle du retour à la libre convertibilité de la livre sterling et des monnaies des Six est faite à l'UEP le 27 décembre $1958^{173}$. L'UEP est remplacée automatiquement par l'AME. La collaboration internationale en matière monétaire a donc bien fonctionné. La France a d'ailleurs obtenu de larges possibilités de crédits à court terme des banques centrales britanniques, allemandes, belges et hollandaises pour surmonter d'éventuelles difficultés résultant du retour à la libre convertibilité ${ }^{174}$. Il semble que le principe de ces accords de crédit ait été obtenu dès la mi-décembre ce qui tend à confirmer l'hypothèse du caractère décisif de la seconde rupture de la négociation ZLE le 15 décembre $1958^{175}$. La France n'utilisa finalement pas ces facilités en raison du rétablissement de sa situation financière.

Les mesures monétaires sont directement complémentaires des mesures commerciales. Or, dans ce domaine, les projets français restent modestes avec l'annonce d'un retour à $40 \%$ de libération des échanges. Le 26 décembre encore, une note pour de Gaulle indiquait clairement que ni le taux de libération ni le taux de change du franc n'étaient définis ${ }^{176}$. C'est finalement le 29 décembre 1958 seulement que le taux de libération de $90 \%$ envers les pays de l'OECE est rendu public ${ }^{177}$. Ce taux a pu être choisi suite à la pression qui s'est exercée sur la France lors de la réunion OECE du 15 décembre 1958. La Grande-Bretagne avait en effet décidé de concentrer ses attaques sur le non-respect par la France des engagements OECE - notamment les $90 \%$ de libération ${ }^{178}$. Passer de 40 à $90 \%$ permettait de se soustraire à toute situation dérogatoire à l'OECE.

Face à la zone dollar, la France annonce le 31 décembre 1958 une libération à un taux de $50 \%$, alors qu'un taux de $7 \%$ avait été envisagé auparavant ${ }^{179}$. Cette concession paraît indispensable car les États-Unis avaient demandé la fin des discriminations pratiquées par les pays de l'OECE envers la zone dollar ${ }^{180}$. La vocation de l'OECE en tant que zone de préférence européenne est donc

173. J. Kaplan, G. Schleiminger, The European Payments Union..., op. cit., p. 317.

174. O. Feiertag, Wilfrid Baumgartner..., op. cit., p. 593 ; Monika Dickhaus, « Facing the Common Market : the German Central Bank and the Establishment of the EEC, 1955-1958 », in Revue d'histoire de l'intégration européenne, 1996-2, p. 106.

175. Source cité in O. Feiertag, Wilfrid Baumgartner..., op. cit., p. 593 : Monika Dickhaus, Die Bundesbank im Westeuropaïschen Wiederaufbau, die internationale Währungspolitik der Bundesrepublik Deutschland 1948 bis 1958, Oldenbourg, Munich, 1996, p. 246.

176. AN, F 60/2725, note du cabinet pour le président du Conseil, 26 décembre 1958.

177. AN, F 60/2725, communiqué de presse du 29 décembre 1958.

178. PRO, CAB 130/123, Free Trade Area, réunion présidée par le Premier ministre, 12 décembre 1958, note du 12 décembre 1958.

179. DDF, 1958-II, document $\mathrm{n}^{\circ} 343$, note de la DAEF d'Olivier Wormser pour le ministre, 18 novembre 1958 ; ASGCI, 1977.1471, article 63, note d'Olivier Wormser du 18 novembre 1958.

180. J. Kaplan, G. Schleiminger, The European Payments Union..., op. cit., p. 318. 
condamnée par le retour à la convertibilité. Le remplacement de l'UEP par l'AME constitue également une rupture plus qu'une continuité car ni la France ni la Grande-Bretagne ne veulent donner à cet organisme de pouvoirs impor$\operatorname{tants}^{181}$. La fin de l'UEP représente donc la fin d'une coopération monétaire étroite organisée à l'échelle de la Grande Europe.

Le retour à la convertibilité et une très large libération des échanges - au plan européen comme au plan mondial - sont les deux éléments majeurs du plan Rueff. Or ces deux mesures étaient absentes de la note Rueff de juin 1958 et n'avaient été évoquées que de manière diffuse dans le rapport Rueff. Elles ont certainement été prises sous la pression des négociations internationales, celles des Six et des dix-sept dans le contexte des débats sur les mesures à prendre au premier janvier 1959 et sur le retour à la convertibilité. Ces mesures permettent de briser le cadre de solidarité de l'OECE et de l'UEP, qui s'était révélé dangereux avec la négociation ZLE. Ne subsistent donc désormais plus, comme aires de coopération dominantes, que la CEE d'un côté, et le couple GATT-FMI de l'autre.

Il faut donc considérer le plan Rueff non pas seulement comme un plan d'assainissement interne, mais comme une mise en conformité de la France avec une dynamique internationale de retour à la libération des échanges et des paiements, que Paris réussit à infléchir en préservant une échelle protectrice intermédiaire, celle des Six. C'est la double pression britannique, au retour à la convertibilité et à un règlement satisfaisant de l'échéance du premier janvier 1959, qui a donné toute sa mesure à un plan Rueff surtout concentré sur les réformes internes initialement. Les dimensions intérieures et extérieures du redressement sont inséparables. Le caractère radical de ce qui fut appelé le «plan Rueff » impose de s'interroger sur le processus de décision qui a présidé à sa définition.

\section{E. LE PROCESSUS DE DÉCISION DU PLAN RUEFF}

Les débats qui ont abouti au plan Rueff apparaissent particulièrement liés à la pression internationale. Chronologiquement, la séquence de décision paraît être la suivante : vers le 10 novembre 1958, les principales idées du plan Rueff sont présentées et discutées. Elles suscitent des réticences mais la première rupture de la négociation ZLE, le 15 novembre 1958, précipite une première série de

181. John Fforde, The Bank of England..., op. cit., p. 600 ; Sylvia Schwaag, " Currency convertibility... », op. cit., p. 96 et 104 ; J. Kaplan, G. Schleiminger, The European Payments Union..., op. cit., p. 320. 
mesures de libéralisation lors du Conseil restreint du 18 novembre 1958. Dans un second temps, après la présentation officielle du rapport Rueff au début du mois de décembre 1958, c'est une nouvelle fois la négociation ZLE, avec la seconde rupture du 15 décembre 1958 et la perspective d'un retour imminent d'un retour à la libre convertibilité en Europe, qui joue le rôle de déclencheur de mesures prises dans la quinzaine suivante : l'annonce du retour à la convertibilité du franc si le mouvement est général en Europe intervient le 19 décembre. Pour faire passer l'ensemble des mesures, connues sous le nom de «plan Rueff », et destinées à préparer et accompagner ce retour à la convertibilité, un nouveau conseil restreint est nécessaire le 26 décembre 1958. Les décisions s'enchaînent ensuite : annonce officielle du retour à la convertibilité des monnaies des Six le 27 décembre, de la libération à $90 \%$ envers la zone OECE le 29 décembre et de $50 \%$ envers la zone dollar le 31 décembre 1958. Les principales décisions sont prises au cours de conseils restreints, les 18 novembre et 26 décembre, qui suivent les deux ruptures de la négociation ZLE.

Ce processus de décision rapide a permis d'élaborer un plan très volontariste et audacieux. De nombreux observateurs s'opposent en effet à la libération des échanges et à la dévaluation. Elles risqueraient d'entraîner une brusque envolée du prix des importations et une relance de l'inflation, qui annulerait rapidement le gain de compétitivité issu de cette même dévaluation. Se profile une spéculation massive contre le franc qui obligerait la France à revenir tant sur la libération des échanges que sur la libre convertibilité du franc. Ce scénario noir est tout à fait probable si l'on se réfère à l'expérience récente : la suspension de libération des échanges de juin 1957, la dévaluation cachée et manquée de l'été 1957, les difficultés financières extrêmes de la fin 1957 et les crises spéculatives de mai et de décembre 1958. Une voie intermédiaire aurait pu être de libérer modérément les échanges, sans revenir à la libre convertibilité. Mais l'audace et le ressort du plan Rueff résident dans sa radicalité : c'est le retour à $90 \%$ de libération qui va imposer le caractère incontournable de l'ouverture extérieur, c'est le retour à la libre convertibilité du franc français en même temps que les autres monnaies européennes qui va rétablir la confiance dans la monnaie. Plus que tout, c'est la combinaison des deux mesures qui va insérer la France dans la libération mondiale des échanges et des paiements. Le plan Rueff marque donc tout autant une rupture interne qu'externe pour la France. Pour le général de Gaulle, selon une expression célèbre, c'est « le miracle ou la faillite ${ }^{182} \gg$ : soit la France reprend sa place en Europe et dans le monde, soit

182. « En somme, l'alternative, c'est le miracle ou la faillite », in Charles de Gaulle, Mémoires d'espoir. Le renouveau, 1958-1962, Plon, Paris, 1970, p. 146. 
elle revient à l'étape de janvier 1958, c'est-à-dire à la tournée des créanciers internationaux et à la mise sous tutelle.

Ce plan aussi radical a suscité de nombreuses réticences à toutes les étapes de son élaboration et de la part d'observateurs multiples. Au sein du comité Rueff tout d'abord, Roger Goetze rappelle dans un témoignage l'hostilité générale des hauts fonctionnaires entendus par le comité Rueff et les divisions profondes des membres du comité ${ }^{183}$. D'une manière générale, les hauts fonctionnaires semblent être extrêmement réservés envers le plan Rueff. En octobre 1958 ainsi, les Finances envisagent une libération des échanges très modeste, de l'ordre de 35 à $40 \%{ }^{184}$. Le ministère de l'Industrie reste dans le schéma ancien du rétablissement des aides à l'exportation sur le modèle de ce qui existait avant la suspension de la libération des échanges de $1957^{185}$. À la DREE, le 10 décembre 1958, Alexandre Kojève estimait impossible toute dévaluation ${ }^{186}$. Louis Franck craint une véritable récession assortie d'une relance de l'inflation ${ }^{187}$. Aux Finances extérieures, l'europhile Jean Sadrin s'opposait le 12 décembre 1958 encore au principe d'une dévaluation «à froid », c'est-à-dire sans qu'une crise de la balance des paiements ne l'y oblige ${ }^{188}$. À la Banque de France, les sousgouverneurs Saltes et Calvet sont également très sceptiques envers cette dévaluation et le taux choisi ${ }^{189}$. Olivier Wormser lui-même, pourtant ardent partisan d'un vigoureux effort de redressement financier national depuis le début de 1957 et proche du nouveau pouvoir gaulliste, se montre anxieux envers le plan Rueff. Le 30 décembre 1958, il envoie une lettre personnelle à Wilfrid Baumgartner où il estime que «nous venons de faire un pari très risqué ${ }^{190} »$. Il craint « que la libération des échanges ne se termine par une nouvelle invocation par la France

183. Témoignage de Roger Goetze in 1958 : la faillite ou le miracle économique..., op. cit., p. $51-52$.

184. Pour la position de Renaud de la Genière (cabinet d'Antoine Pinay) : AMAE, POW 31, folio 310, note d'Olivier Wormser pour François Valéry, 2 octobre 1958 ; pour la position de la DREE : AMAE, DECE 754, folio 63, note d'Olivier Wormser du 14 octobre 1958.

185. AINDUS, 1977.1386, article 53, projet de lettre au ministre des Finances du 31 octobre 1958.

186. AMAE, POW 41, folio 148, note d'Alexandre Kojève, DREE, 10 décembre 1958.

187. AMINEFI, B 57629, note secrète du $1^{\text {er }}$ décembre 1958 ; AMINEFI, B 55908, procès-verbal de la séance du comité des Prix du 29 décembre 1958.

188. Note de J. Sadrin du 12 décembre 1958 citée par O. Feiertag, Wilfried Baumgartner..., op. cit., p. 579.

189. Note de J. Saltes du 8 décembre 1958 et note de P. Calvet du 4 décembre 1958 citées par O. Feiertag, Wilfrid Baumgartner..., op. cit., p. 577 et p. 579-581 ; Sur Calvet, voir aussi : PRO, PREM 11/2671, folio 67, télégramme de la délégation britannique à l'OECE au Foreign Office, 12 décembre 1958 .

190. AMAE, POW 41, folio 42, folio 115, lettre d'Olivier Wormser à Wilfried Baumgartner, 30 décembre 1958. 
des clauses échappatoires de l'OECE et du Marché commun » car il se montre sceptique tant sur la capacité de l'industrie française à profiter de la dévaluation pour exporter, que sur le rétablissement de la confiance dans le franc. Les réticences sont donc quasi générales chez les hauts fonctionnaires.

Ces réactions de crainte sont évidemment partagées par de nombreux ministres. C'est d'abord le ministre des Finances lui-même, Antoine Pinay, qui ne se reconnaît pas dans l'augmentation des impôts et dans la dévaluation et offre sa démis$\operatorname{sion}^{191}$. Le général de Gaulle finit par le convaincre de défendre le plan Rueff. Par la suite, ce sont les trois ministres socialistes qui veulent démissionner car ils refusent la dévaluation ${ }^{192}$. Ils restent finalement en poste jusqu'au 8 janvier 1959. Le général de Gaulle a surmonté toutes ces oppositions. Comme le dit Roger Goetze, c'est donc autant un « plan de Gaulle » qu'un « plan Rueff ${ }^{193}$ ». Jacques Rueff a eu l'idée du plan. Sa radicalité a été renforcée par d'autres acteurs comme Goetze ou Baumgartner mais c'est bien le général de Gaulle qui lui a donné cette ampleur et a permis son application. Le Conseil des ministres du 27 décembre 1958 se contente d'entériner ces décisions.

\section{F. LA RUPTURE DU PLAN RUEFF ET LA ZLE}

Le plan Rueff ne peut donc se comprendre sans prendre en compte le contexte international et en particulier les discussions européennes. Les principales décisions sont prises après les deux ruptures de la négociation ZLE des 14 novembre et 15 décembre 1958. La ZLE semble avoir largement accru l'ampleur du plan Rueff à la fois sur le plan conjoncturel, en précipitant des décisions, et de manière plus profonde en préparant les esprits au caractère inéluctable du retour à la libération des échanges.

Plus largement, le plan Rueff marque bien un changement d'époque, à trois échelles. Tout d'abord, en interne, le processus de décision annonce d'ores et déjà bien des éléments en vigueur sous l'administration gaulliste de la $V^{e}$ République : importance du secret (il est vrai traditionnel dans toutes les décisions de dévaluation), rôle cardinal des conseils restreints, administrations soumises et parfois bousculées. L'administration est cependant régulièrement consultée mais les idées viennent de personnages qui sont à la marge, comme Rueff et Goetze, et enfin Baumgartner dans la mesure où il traduit les

191. N. Carré de Malberg..., Entretiens avec Roger Goetze..., op. cit., p. 348 ; Charles de Gaulle, Mémoires d'espoir. Le renouveau, 1958-1962, Plon, Paris, 1970, p. 153.

192. Année Politique, 1958, PUF, Paris, 1959, p. 160.

193. N. Carré de Malberg..., Entretiens avec Roger Goetze..., op. cit., p. 352. 
pressions émanant de la communauté internationale des banquiers centraux. Paradoxalement le plan Rueff émane moins de Rueff, comme en témoigne le décalage avec sa note de juin 1958, que de la contrainte internationale et de la volonté du général de Gaulle de la surmonter.

Ensuite, sur le plan européen, le plan Rueff permet de véritablement appliquer le traité de Rome conclu le 25 mars 1957, et donc de rejeter la formule de la ZLE. La ZLE a démontré l'intérêt économique de la CEE, perçue dorénavant comme une contrainte nécessaire, la meilleure voie pour faire passer la France du monde de la reconstruction à celui du libre-échange international. À partir du plan Rueff, le libre-échange n'est plus repoussé mais accepté s'il est contrôlé. C'est un stimulant indispensable. Ce changement de paradigme se perçoit aussi dans les mesures au premier janvier 1959. Alors que l'approche du troc bilatéral contingentaire continuait d'imprégner de nombreux esprits, c'est une approche multilatérale, universelle et très largement fondée sur une démobilisation tarifaire qui s'impose. L'ère du primat de l'OECE et de ses négociations contingentaires semble terminée.

Sur un plan international, le plan Rueff permet le renforcement de l'échelle de la CEE et du GATT, et l'affaiblissement de celle de l'OECE. La libération générale des échanges et des paiements rend l'OECE et l'UEP-AME moins utiles. Par contre, la CEE sort renforcée de l'échec de la négociation ZLE. Elle a démontré sa cohésion malgré les difficultés et surtout la pertinence de son modèle d'intégration économique. C'est le couronnement de la stratégie française qui reposait sur la promotion de deux échelles complémentaires, la CEE et le GATT.

Cela explique le soutien de la RFA, qui joue un rôle considérable à la fin 1958 en raison de la faiblesse financière de la France et politique de la Grande-Bretagne. La promotion de ces deux échelles permet de satisfaire les deux tendances du gouvernement allemand, l'approche libérale et internationale d'Erhard et la tendance plus favorable à la France et à la CEE d'Adenauer. Au contraire la Grande-Bretagne n'a pas réussi à développer une stratégie cohérente combinant les deux projets qu'elle a lancés, la ZLE et Unicorn. Londres estimait que le retour à la convertibilité allait gêner une France fragile qui aurait une nouvelle fois recours à des crédits internationaux en janvier 1959 . La Grande-Bretagne pourrait alors reprendre l'initiative en relançant la ZLE. Le plan Rueff condamne tous ces espoirs britanniques.

Le plan Rueff ne peut donc se comprendre sans référence à sa dimension internationale. Il marque un changement d'époque brutal pour les décideurs français, qui doivent également s'adapter à l'affirmation de la Commission européenne. 


\section{L'AFFIRMATION DE LA COMMISSION EUROPÉENNE EN 1958}

Si la France souffre de difficultés persistantes tout au long de l'année 1958, elle bénéficie de l'action d'un nouvel allié, la Commission européenne. L'institution bruxelloise s'affirme rapidement comme une gardienne exigeante de la dynamique du traité de Rome, tant dans les négociations ZLE que par ses projets de renforcement de l'union économique et monétaire.

\section{A. LA DÉFENSE DE L'INTÉGRITÉ DE LA CEE DANS LES NÉGOCIATIONS ZLE}

La négociation ZLE constitue un enjeu important, qui risque de remettre en cause la dynamique de la CEE pour de nombreux décideurs français mais aussi pour la Commission européenne, qui se met en place en 1958. Elle s'affirme bientôt pour défendre l'intégrité de la dynamique communautaire ${ }^{194}$.

\section{L'enjeu de la négociation ZLE pour la jeune Commission européenne.}

Au moment de sa naissance, en janvier 1958, la Commission européenne est une institution dont l'avenir est très incertain. Elle souffre de trois grandes faiblesses. Tout d'abord, les commissaires européens n'ont pas été choisis par le président de la Commission mais par les États membres. L'équipe est donc très hétérogène. Ensuite c'est une institution jeune, très occupée au cours de l'année 1958 par le recrutement d'une équipe multinationale et l'élaboration de méthodes de travail. Enfin, le rôle que la Commission européenne est appelée à jouer dans l'organisation de la coopération économique européenne est encore très indécis au début de 1958. Si la France n'applique pas les clauses de libération des échanges de la CEE et qu'une ZLE est rapidement conclue, cette dernière devrait rapidement prendre l'ascendant sur la CEE. Dès lors, en janvier 1958, de nombreux observateurs français, au gouvernement ou au CNPF par exemple, estiment que la Commission européenne aura beaucoup de mal à s'affirmer ${ }^{195}$.

194. Pour plus de détails sur cette partie : Laurent Warlouzet, «La Commission européenne face au défi de la "Grande Europe" : la négociation de la zone de libre-échange en 1958 », in Gérard Bossuat, Anne Deighton (éd.), Les Communautés européennes, acteurs de la sécurité mondiale ? Bilan de 50 ans de relations extérieures, Soleb, Paris, p. 364-381 ; L. Warlouzet, Quelle Europe économique..., op. cit., p. 407-422.

195. AMAE, POW 39, folio 235, DECE 753, folio 4, note d'Olivier Wormser du 9 janvier 1958 ; ACNPF, 72 AS 1315, exposé de Jean Louis du 20 janvier 1958. 
La ZLE est une négociation cruciale pour la Commission car de son résultat dépendra en grande partie son rôle dans l'organisation économique de l'Europe. Ce sujet a pourtant été négligé par l'historiographie car les débats au sein de la Commission sont rarement mis en valeur, en particulier sur le dossier de la ZLE. Les nombreuses études menées sur le président de la Commission, Walter Hallstein, se concentrent sur les années soixante et ignorent son rôle dans la ZLE ${ }^{196}$. C'est pourtant un acteur essentiel en 1958. Proche d'Adenauer, ancien secrétaire d'État aux Affaires étrangères, il a dirigé la délégation allemande tant pour les négociations de la CECA que pour celles de la CEE.

Deux études livrent cependant des pistes. D'une part, William Wallace a souligné la proximité entre les positions de Hallstein et celles de la France pendant la négociation ZLE, mais il s'est limité à l'étude de la doctrine, sans étudier l'insertion concrète de l'acteur institutionnel communautaire dans la négociation $\mathrm{ZLE}^{197}$. D'autre part, Miriam Camps, dans son étude de référence de 1964, a souligné le rôle de la Commission dans la négociation sans toutefois l'étudier précisément car ce n'était pas le sujet de son étude ${ }^{198}$. Or avec l'ouverture des archives, il est désormais possible de montrer comment la Commission a réussi à s'imposer dans la négociation ZLE pour défendre le modèle communautaire de la CEE.

\section{L'affirmation rapide de la Commission Hallstein.}

La Commission européenne naît en janvier 1958 alors que la négociation ZLE est déjà bien entamée. Elle occupe donc une place modeste. Elle doit participer au comité Maudling pour coordonner les positions des Six et pour représenter la $\mathrm{CEE}$, mais sans pouvoir de décision propre ${ }^{199}$.

196. Wilfrid Loth, «Walter Hallstein : un Européen déterminé », in M. Dumoulin (dir.), La Commission européenne, 1958-1972..., op. cit., p. 83-94 ; Gerhard Th. Mollin., « La "Commission Hallstein" 1958-1967 : aux frontières d'un "gouvernement supranational" », in Wilfried Loth (dir.), La gouvernance supranationale dans la construction européenne, Bruylant, Bruxelles, 2005, p. 86 ; Matthias Schönwald, «Walter Hallstein et les institutions des Communautés européennes », in MarieThérèse Bitsch (dir.), Le couple France-Allemagne et les institutions européennes. Une postérité pour le Plan Schuman, Bruylant, Bruxelles, 2001, p. 151-168 ; d'autres contributions associent réalisations politiques et économiques sans évoquer précisément la ZLE : Hans von der Groeben, « Walter Hallstein als Präsident der Kommission » et Karl-Heinz Narjes, « Walter Hallstein in der Frühphase der EWG », in Wilfried Loth, William Wallace, Wolfgang Wessels (dir.), Walter Hallstein. Der vergessene Europäer?, Europa Union Verlag, Bonn, 1995, p. 121-138 et p. 139-164.

197. William Wallace, «Walter Hallstein - Aus britischer Sicht», in W. Loth et alii (dir.), Walter Hallstein..., op. cit., p. 236-238.

198. Miriam Camps, Britain..., op. cit., p. 147-150.

199. AHUE, procès-verbal normal, $1^{\text {re }}$ session de la Commission CEE, 15 janvier 1958, annexe III au doc. $\mathrm{CEE} / \mathrm{C} / 10 / 58$. 
Toutefois le président Hallstein s'investit rapidement dans la négociation en rencontrant dès février 1958 l'Anglais Maudling et le Français Faure ${ }^{200}$. Son activisme n'est pas consensuel au sein du collège des commissaires car le principe même de la participation de la Commission à la discussion de fond à Six est discuté $^{201}$. Hallstein choisit de faire rédiger un mémorandum exprimant la position de la Commission mais, là aussi, les débats sont très vifs ${ }^{202}$. Si Marjolin joue un rôle certain pour donner un ton offensif au mémorandum de la Commission, le président Hallstein s'engage pleinement dans cette entreprise $\mathrm{e}^{203}$.

Le mémorandum de la Commission du 19 mars 1958 affirme ainsi de manière très offensive la légitimité et la spécificité du modèle de la $\mathrm{CEE}^{204}$. Il est à l'origine de la solution de l'accord provisoire consistant à élargir les réductions tarifaires intracommunautaires prévues au premier janvier 1959 à tous les pays du GATT, connue sous le nom de « proposition Hallstein ». Elle permet de repousser en douceur la conclusion d'une ZLE. Pratiquement, l'effet serait le même que le " décalage » promu par les Français. Il devrait permettre de laisser à la CEE le temps de se mettre en place et de se renforcer. Le mémorandum de la Commission reprend des éléments de la position française sans cautionner ce qu'elle avait d'excessif. Il permet de réintroduire la France dans la négociation sur des bases satisfaisantes, et d'envisager un accord à six sur ce sujet en avril $1958^{205}$. Par ce mémorandum, Hallstein déçoit d'ailleurs tant les ministres allemands les plus favorables à la ZLE comme Erhard ${ }^{206}$, que les Britanniques comme Maudling, qui anticipaient un soutien du président de la Commission à leurs thèses ${ }^{207}$.

Grâce à ce mémorandum, la Commission devient un acteur à part entière des discussions. Alors que le président du Comité intérimaire jouait essentiellement le rôle d'arbitre et de coordinateur, en fait de primus inter pares, la Commission européenne s'est imposée comme une force de proposition crédible. Par la

200. AHUE, procès-verbal normal, $5^{\mathrm{e}}$ session de la Commission CEE du 19 février 1958.

201. AHUE, procès-verbal normal, $7^{\mathrm{e}}$ session de la Commission CEE des 5-6 mars 1958, « compte rendu confidentiel ».

202. AHUE, procès-verbal normal, $9^{\mathrm{e}}$ session de la Commission CEE du 17 mars 1958.

203. AHUE, procès-verbal normal, $9^{\mathrm{e}}$ session de la Commission CEE du 17 mars 1958 ; PRO, FO 134501, Doc 611/513, note de Hugh Ellis-Rees, 14 mai 1958, entretiens avec Valéry, 13 mai 1958.

204. AHUE, procès-verbal normal, $10^{\mathrm{e}}$ session de la Commission CEE du 20 mars 1958.

205. AMAE, RPUE 29, projet de procès-verbal du Conseil CEE du 18 mars 1958, $1^{\text {er }}$ avril 1958.

206. William Wallace, op. cit., p. 237.

207. PRO, T 337/7, note sur une rencontre entre Erhard et Maudling, en présence d'Hallstein, 17 février 1958 ; PRO, T 337/7, note de F.M. Bennett pour Sir John Coulson, entretien avec Hallstein, 6 mars 1958. 
suite, l'institution bruxelloise cherche à renforcer plus encore son emprise sur la négociation, mais elle doit se contenter d'un rôle de coordination actif.

\section{Au service d'une approche communautaire de la ZLE.}

Avec le renforcement considérable de la France en juillet 1958, la Commission se concentre sur la définition d'une position commune aux Six. L'institution bruxelloise multiplie les études afin de définir des mécanismes assurant l'innocuité de la ZLE. Le Français Jean-François Deniau rédige des notes à l'intention de son commissaire chargé des relations extérieures, Jean Rey, sur la question institutionnelle ${ }^{208}$. Lors de la conférence de Venise, la Commission parvient à faire accepter le principe d'une procédure assurant une attitude commune des Six au sein de la ZLE ${ }^{209}$. La dynamique propre de la CEE est ainsi préservée. La Commission parvient à obtenir un début de position commune avec le mémorandum Ockrent d'octobre $1958^{210}$.

Par la suite, alors que les négociations se tendent, le commissaire belge Rey et le directeur général français Ortoli critiquent, au sein de l'institution bruxelloise, la thèse britannique du refus de la préférence européenne ${ }^{211}$. Un groupe d'étude sur la ZLE est monté, sous la présidence d'Ortoli, pour étudier des solutions à moyen terme, au cas où la Commission européenne serait chargée d'une étude sur ce problème. La Commission européenne anticipe donc déjà la rupture prochaine des négociations ZLE, comme la plupart des acteurs impliqués.

Juste après la rupture de la négociation ZLE le 14 novembre 1958, le président Hallstein entreprend une tournée des Six pour faciliter la définition d'une position commune ${ }^{212}$. Elle est finalement définie lors du Conseil CEE des 3 et 4 décembre 1958, qui demande à la Commission un rapport pour mars $1959^{213}$. La relance des négociations ZLE devrait donc se faire non plus sur la base des propositions britanniques, mais sur un document de la CEE. Hallstein décide de s'occuper personnellement de ce mémorandum avec un petit groupe de

208. AHUE, BAC 61/1982, volume 1, folio 136, note de Jean-François Deniau pour Jean Rey, $1^{\text {er }}$ septembre 1958.

209. AHUE, procès-verbal, $30^{\mathrm{e}}$ session de la Commission CEE, séance du 24 septembre 1958.

210. AMAE, POW 40, folio 96, mémorandum Ockrent du 17 octobre 1958.

211. AHUE, BAC 61/1982, volume 3, folio 625, note du 4 novembre 1958 ; AHUE, BAC 61/1982, volume 3, folio 618 , compte rendu de la réunion du groupe de travail sur la ZLE, note du 7 novembre 1958.

212. Gérard Bossuat, L'Europe des Français..., op. cit., p. 393.

213. DDF, 1958 -II, document $n^{\circ} 389$, télégramme circulaire de Couve de Murville, 4 décembre 1958 ; AMAE, RPUE 32, projet de procès-verbal du Conseil du 3 décembre 1958, 30 décembre 1958. 
commissaires ${ }^{214}$. Le rapport de mars 1959 définit finalement une conception très restrictive de la ZLE qui suscite la déception des partisans du projet britannique comme les ordolibéraux allemands ${ }^{215}$. Enfin, dernier signe de l'importance de la Commission européenne, les mesures au premier janvier 1959 adoptées par les Six sont largement inspirées de la «proposition Hallstein ».

\section{La convergence apparente entre la France et la Commission.}

Dans la négociation ZLE, la Commission s'est imposée comme un acteur majeur. Elle a rempli des fonctions d'expertise mais aussi de proposition, que ce soit sur l'architecture générale de la ZLE (mémorandum du 19 mars 1958) ou sur la " proposition Hallstein ». Elle est même parvenue à infléchir l'opinion dominante des Six dans le sens de ses thèses, très protectrices envers la CEE, et donc à éviter l'isolement de la France. La Commission a progressivement endossé l'habit de gardienne des traités. Elle a empêché que la jeune communauté des Six ne se disloque en raison de l'intransigeance française d'une part, et de l'attirance d'autres membres de la CEE pour le modèle de la ZLE d'autre part. Son rôle annonce finalement celui de gardienne de l'acquis communautaire qu'elle joue en 1961-1963 pendant la première candidature britannique ${ }^{216}$.

La convergence entre la France et la Commission est réelle en 1958 dans le dossier de la ZLE. Elle repose sur l'engagement fort du président Hallstein mais aussi sur l'action des Français présents au sein de la Commission européenne (Marjolin, Ortoli, Deniau). Cela ne signifie pas qu'ils sont aux ordres de Paris mais qu'ils font passer à la Commission une approche française de la ZLE, qui repose sur la défense de la dynamique communautaire de la CEE.

Cependant, la convergence entre la France et la Commission européenne reste limitée sur le fond. Ainsi, si le gaulliste Wormser défend les prérogatives de la Commission européenne devant un proche d'Erhard, Müller-Armack, qui les conteste ${ }^{217}$, il ne se prive pas de critiquer les ambitions d'Hallstein en interne ${ }^{218}$. De même, l'administration française se préoccupe très tôt des

214. AHUE, procès-verbal, $2^{\mathrm{e}}$ partie, $41^{\mathrm{e}}$ séance de la Commission CEE, décembre 1958.

215. AMAE, POW 43, folio 174, note d'Olivier Wormser, 19 mars 1959. Sur les débats de 1959 : Gérard Bossuat, L'Europe des Français..., op. cit., p. 397-398.

216. Piers Ludlow, Dealing with Britain. The Six and the first UK application to the EEC, Cambridge UP, Cambridge, 1997, p. 240.

217. AMAE, POW 40, folio 252, entretiens d'Oliver Wormser et d'Alfred Müller-Armack, 25 octobre 1958.

218. AMAE, PA-AP 314, papiers privés d'Olivier Wormser, carton 1, note du 26 décembre 1958. 
conceptions extensives qu'Hallstein a des prérogatives de la Commission en matière de relations extérieures ${ }^{219}$.

Enfin, l'influence de la Commission européenne sur la négociation ZLE ne doit pas être surestimée. Ce n'est pas elle qui a fixé le timing des négociations ZLE mais la France, par son mémorandum de février 1958, sa nouvelle position de juillet 1958, puis les deux ruptures des 14 novembre et 15 décembre 1958 . L'Allemagne d'Adenauer a également joué un rôle essentiel en s'accordant avec Paris pour définir des compromis acceptables à six. La Commission a donc essentiellement réagi aux événements plus qu'elle ne les a précédés. Sans être un décideur, la Commission joue un rôle d'arbitre, de conseiller et de promoteur d'une vision exigeante de l'intégration européenne, qui rejoint celle de la France dans ce dossier. Elle a facilité la préservation de l'unité des Six et de l'intégrité de la CEE. Dans un autre domaine, celui de l'union monétaire, la Commission européenne tente également de profiter de circonstances difficiles pour renforcer l'intégration européenne.

\section{B. RENFORCER L'EUROPE MONÉTAIRE PAR LA CRISE FRANÇAISE}

Le lien entre Marché commun et union monétaire paraît évident pour de nombreux observateurs. En 1958, cette relation est renforcée par les pressions britanniques et allemandes à des réformes profondes de la coopération monétaire européenne. Cela encourage le commissaire français Robert Marjolin à lancer une action communautaire dans ce domaine, d'abord lorsque la Commission intervient dans la crise française de mai 1958 au titre de l'article 108, ensuite par deux projets d'union économique et monétaire, en mai 1958 et novembre 1958.

\section{Marché commun et union monétaire : un lien évident en 1956-1958.}

Dans les années cinquante, le lien entre libération des échanges commerciaux et des paiements paraît naturel. Le contre-exemple des années 1930 joue à plein : le protectionnisme et les dévaluations monétaires s'entretenaient mutuellement. De plus, la libre convertibilité des monnaies n'étant pas assurée en 1958, il est difficile d'établir des accords de libre-échange sans clauses monétaires assurant les règlements des échanges commerciaux, et l'assistance à des pays en

219. ASGCI, 1990.0638, article 23, note du Conseil CEE, 13 août 1958, transmise par C. Calmes à Couve de Murville le 2 septembre 1958 ; AMAE, RPUE 245, télégramme du représentant permanent au ministre des Affaires étrangères, 31 octobre 1958. 
difficulté. C'est le rôle de l'UEP qui permet à l'OECE de mener avec succès sa libération commerciale.

À partir de 1958, la perspective du retour à la libération des échanges et des paiements annonce le remplacement de l'UEP par l'AME. Or l'octroi d'aides est plus difficile dans le cadre de l'AME alors que, en parallèle, la France continue de souffrir de crises régulières de sa balance des paiements. Il faut donc envisager un nouveau système de coopération monétaire européenne. Les réflexions se multiplient. L'une des contributions les plus célèbres est celle de l'économiste belge Robert Triffin, professeur à Yale, qui propose, dans son livre Europe and the Money Muddle sorti en 1957, un projet d'unification monétaire de l'Europe combiné au retour à la convertibilitééc

Les réflexions se sont également multipliées chez les décideurs français. Une semaine seulement après le rapport Spaak, Jean Sadrin, le directeur des Finances extérieures, propose de compléter le Marché commun par une coopération en matière monétaire se traduisant par des aides en devises ${ }^{221}$. Ce principe est formulé de manière plus concrète en octobre 1956, avec un mémorandum de la direction des Finances extérieures demandant l'instauration d'un Comité monétaire $^{222}$. Cette institution consultative distincte de la Commission européenne devrait à la fois préserver l'indépendance des politiques monétaires nationales tout en assurant leur coordination. Elle devrait également intervenir dans la procédure de concours mutuel. Le Comité monétaire finalement prévu dans le traité de Rome est assez modeste mais manifeste la pertinence de l'échelle des Six en matière de coopération monétaire. Après la conclusion du traité, le lien entre le Marché commun et le renforcement de la coopération monétaire à six apparaît à de nombreuses reprises dans les analyses des fonctionnaires français $^{223}$, ou même au sein du patronat européen ${ }^{224}$. Le débat rebondit en 1958 avec des contributions des gouvernements allemands et britanniques.

\footnotetext{
220. Robert Triffin, Europe and the Money Muddle, Oxford UP, Oxford, 1962 [1957], p. 288292.

221. ARAM, 52 J 114, note de Jean Sadrin, directeur des Finances extérieures, pour Ramadier, 28 avril 1956 ; voir aussi sur Sadrin : ARAM, 52 J 115, note du directeur Finex 16 janvier 1957 ; elle influence une note de Ramadier à Pineau sur ce sujet : AFJM, ARM 15/4, lettre de Paul Ramadier à Christian Pineau, 21 janvier 1957.

222. AN, F60, 3112, projet de mémorandum français sur le Comité monétaire, manuscrit : « Remis par M. Lévêque [Finex] le 13 octobre 1956 ».

223. AMINEFI, 3 A 68, cycle de conférences données au ministère des Affaires étrangères, interventions de Jean Mille, Renaud de La Genière, Alain Prate, Alain Peyrefitte, Jean-François Deniau ; voir le chapitre II.
}

224. ALECE, 653, note de Lucien Sermon du 24 octobre 1957. 


\section{Le débat au début de 1958 : visions allemandes et britanniques.}

$\mathrm{Au}$ sein des décideurs allemands, la nécessité de renforcer la coopération monétaire dans la CEE a été évoquée tant par les parlementaires ${ }^{225}$ que par le patronat allemand ${ }^{226}$. De son côté, le gouvernement allemand exprime une doctrine fondée sur l'équilibre entre coopération monétaire et coordination des politiques économiques. Elle est particulièrement visible dans un document de travail de juin $1957^{227}$. Il insiste sur la nécessité de fonder toute coopération monétaire sur une convergence des politiques économiques vers une gestion rigoureuse, garantie par des clauses contractuelles qui s'imposeraient au pouvoir politique. L'ordolibéralisme influence largement ce document : l'action de l'État doit se cantonner à créer un cadre au marché et ses interventions doivent être strictement limitées par des règles de droit intangibles, destinées à permettre le libre exercice des libertés politiques et économiques.

Ces propositions allemandes convergent partiellement avec certaines propositions britanniques du premier semestre 1958 sur une nouvelle architecture de la coopération monétaire européenne autour de la ZLE. Discutées en février 1958 dans le cadre de l'UEP, elles visent à soumettre les clauses de sauvegarde UEP à un accord préalable des futures institutions de la ZLE ${ }^{228}$. Elles pourraient même autoriser des « mesures de rétorsion à l'encontre de ceux d'entre eux qui ne satisferaient pas à leurs obligations commerciales » et « rendre ces pays inéligibles au titre des crédits que l'Organisation serait habilitée à consentir ${ }^{22} \gg$. La France apparaît clairement visée. Elle ne pourrait plus obtenir comme en janvier 1958 des crédits de l'UEP et des dérogations à la libération des échanges aussi facilement. Au contraire, elle serait même exclue du bénéfice de ces facilités financières si elle ne respecte pas les clauses libre-échangistes de la ZLE. On retrouve ici la volonté britannique d'isoler la France dans une future ZLE si elle se refuse à jouer le jeu de l'ouverture des marchés.

225. En particulier au moment du débat de ratification des traités de Rome le 5 juillet 1957 : DDF, 1957-II, document n 19 , télégramme de Maurice Couve de Murville à Christian Pineau, ministre des Affaires étrangères, 6 juillet 1957.

226. AMAE, DECE 629, folio 191, télégramme de François Leduc, chargé d'affaire à l'ambassade de France à Bonn, 10 mars 1958.

227. ASGCI, 1991.004, article 3, comité intérimaire, observations de la délégation allemande « sur la nécessité et l'étendue de la coordination des politiques monétaires dans la zone de libre-échange », 28 juin 1957 ; cette vision a été exprimée également par Müller-Armack : AMAE, POW 39, folio 305, note d'Olivier Wormser, 2 avril 1958.

228. PRO, T 337/38, annexe de la note de Sir Denis Rickett, « Payments Arrangements in the Free Trade Area », 12 février 1958.

229. AMINEFI, 3 A 68, rapport du sous-gouverneur de la Banque de France Calvet, vice-président du comité de direction de l'UEP, 19 mars 1958 ; PRO T 337/38, document « Economic Policy in the Free Trade Area ». 
Mais la convergence entre les visions britanniques et allemandes est limitée $^{230}$. En fait, la situation financière de la Grande-Bretagne est trop fragile pour qu'elle puisse renoncer à des clauses de sauvegarde UEP assez souples. Par ailleurs, des divisions au sein de l'UEP provoquent finalement un échec de ce projet en mai $1958^{231}$. À cette date, la France connaît des difficultés financières importantes dont la Commission européenne tente de profiter.

\section{La communautarisation de la crise française de mai 1958.}

À la différence des précédentes, la nouvelle crise française de la balance des paiements d'avril-mai 1958 intervient alors que la Commission existe. Elle joue donc un rôle essentiel dans sa gestion.

La crise politique de mai 1958 se traduit par une crise de confiance dans le franc. La France risque ainsi de dépenser en quelques mois les crédits obtenus en janvier $1958^{232}$. Elle avertit les Six, lors du Conseil CEE du 20 mai 1958, qu'elle devra recourir à de nouvelles mesures de restrictions des échanges ${ }^{233}$. La réaction de la Commission européenne est très rapide. Elle proteste officiellement auprès de la représentation permanente car elle n'a pas été informée au préalable ${ }^{234}$. Pour répondre à la demande de la Commission, la France lui transmet un aide-mémoire détaillant les mesures prévues et demandant le recours à l'article $108^{235}$. L'article 108 est l'un des rares articles concernant la solidarité monétaire. Il permet à la Commission, après étude de la situation d'un État membre connaissant de graves difficultés de balance des paiements, de recommander des mesures, puis, si elles s'avèrent insuffisantes, de proposer un concours mutuel au Conseil (sous forme de crédits ou de facilités commerciales par exemple). Si le concours mutuel n'est pas adopté, la Commission peut accorder des mesures de sauvegarde, dont elle surveille étroitement l'application. Le processus est donc pleinement communautarisé.

Une première réponse de la Commission est transmise à titre officieux par Hallstein ${ }^{236}$. Elle estime que la France n'a pas respecté la procédure de

230. PRO, T 337/38, note de Sir Denis Rickett, 12 février 1958 ; PRO, T 337/7, record of a conversation between $\mathrm{M}^{\mathrm{r}}$ Maudling and $\mathrm{M}^{\mathrm{r}}$ Erhard, 17 février 1958.

231. AMINEFI, 3 A 68, rapport du sous-gouverneur de la Banque de France Calvet, 7 mai 1958.

232. A. de Lattre, La politique économique française..., op. cit., p. 133.

233. AMAE, POW 78, folio 181; DECE 615, folio 58, note d'Olivier Wormser, 19 mai 1958.

234. DDF, 1958-I, document $n^{\circ} 347$, télégramme du représentant permanent de la France, de Carbonnel, à René Pléven, ministre des Affaires étrangères, 21 mai 1958.

235. AMAE, DECE 753, folio 159, mémorandum français du 28 mai 1958.

236. DDF, 1958-I, document $n^{\circ} 393$, télégramme de Carbonnel à Couve de Murville, 4 juin 1958. 
l'article 108 car elle aurait dû attendre des recommandations de la Commission, un éventuel concours mutuel du Conseil puis, enfin, en cas de rejet de ce dernier, des mesures dérogatoires. Hallstein effectue cette démarche pour que la France tempère ses demandes, afin d'éviter un refus officiel de la Commission. La Commission demande au gouvernement français de retirer son aide-mémoire du 28 mai 1958, et de faire de même pour l'aide-mémoire envoyé à l'OECE ${ }^{237}$.

Répondant aux demandes de la Commission, la France, dorénavant gérée par le gouvernement du général de Gaulle, décide de retirer ses aide-mémoire à la $\mathrm{CEE}$ et à $\mathrm{l}^{\prime} \mathrm{OECE} \mathrm{E}^{238}$. À la réunion du 10 juin 1958 chez le nouveau président du Conseil, il est précisé clairement que c'est l'opposition de la Commission européenne qui a poussé le ministre des Finances Antoine Pinay à renoncer à ses projets de réduction des importations françaises ${ }^{239}$.

Sur le fond, le dossier français est instruit par la DG II Affaires économiques et financières, placée sous la tutelle du commissaire français Robert Marjolin. Elle auditionne des hauts fonctionnaires français ${ }^{240}$. Marjolin rencontre notamment son ami Wormser pour le convaincre de laisser la procédure communautaire suivre son cours, en dépit du rétablissement de la confiance permis par le retour au pouvoir du général de Gaulle, car la France pourrait de nouveau avoir besoin de la solidarité communautaire dans l'avenir ${ }^{241}$. Par réalisme, le gaulliste Wormser plaide alors pour se conformer aux demandes de la Commission, tout en lui demandant d'agir discrètement ${ }^{242}$.

La DG II recommande de pratiquer une politique d'austérité budgétaire, de restrictions de crédit, et également d'accepter une dévaluation, même si ce terme n'est pas employé explicitement ${ }^{243}$. Elle reconnaît les efforts du gouvernement Gaillard et la stabilité apportée par le gouvernement de Gaulle. La Commission décide alors d'étudier le cas français avec une certaine bienveillance. Elle consulte au préalable Paris avant de rendre ses recommandations, tout en précisant bien que cela ne doit pas constituer un précédent pour la procédure de mise en œuvre de l'article $108^{244}$.

237. AHUE, procès-verbal de la réunion de la Commission des 3 et 4 juin 1958 .

238. AHUE, procès-verbal de la réunion de la Commission du 11 juin 1958.

239. AMAE, PA-AP 314, carton 1, compte rendu de la réunion du 10 juin 1958 ; voir aussi : AHUE, EN 349, entretien d'Hallstein avec de Carbonnel du 10 juin 1958, doc Com 435/58 du 11 juin 1958.

240. AHUE, procès-verbal de la réunion de la Commission des 3 et 4 juin 1958.

241. AMAE, PA-AP 314, carton 1, lettre d'Olivier Wormser du 17 juin 1958.

242. AMAE, PA-AP 314, carton 1, lettre d'Olivier Wormser du 17 juin 1958.

243. AHUE, EN 349, note de la Commission, DG Ecofin, 3 juin 1958, annexe au document 381/58.

244. AHUE, procès-verbal de la réunion de la Commission du 11 juin 1958. 
Cependant, le ministre des Finances Antoine Pinay reste très critique envers un premier projet de la Commission, qu'il estime trop sévère ${ }^{245}$. Son cabinet avait d'ailleurs fermement souligné l'inopportunité de cette ingérence de la Commission dans les affaires françaises ${ }^{246}$. Les recommandations de la Commission interviennent finalement le 22 juillet $1958^{247}$, alors que la crise française a été résorbée par l'action énergique du nouveau gouvernement. Elles consistent principalement à recommander de suivre une politique budgétaire d'austérité, de restreindre le crédit et de libérer progressivement les importations $^{248}$. Elles sont accompagnées d'une lettre secrète qui manifeste l'inquiétude de la Commission sur le niveau général des prix français. Le procès-verbal de la réunion précise : « certains membres de la Commission expriment l'opinion qu'il y aurait intérêt à rédiger cette lettre de manière plus explicite encore ${ }^{249} »$, ce qui signifie demander clairement une dévaluation.

Si cet épisode de la crise française n'a finalement pas donné lieu à de grandes manifestations de solidarité communautaire, il a en tout cas permis d'affirmer un peu plus l'autorité de la Commission. L'exécutif bruxellois a rejeté un premier aide-mémoire et obligé la France à retirer également son aide-mémoire présenté à l'OECE. L'action de la CEE a donc eu une influence directe sur l'OECE, qui était auparavant l'institution de référence pour la gestion des crises des balances des paiements. Par la suite, la Commission a étudié le cas français en obligeant un pays souverain à justifier ses choix. Elle a même conseillé implicitement une dévaluation. Enfin, malgré les réticences de Pinay, la France n'a pas réussi à interrompre la procédure de l'article 108 en dépit de ses concessions. Ces trois victoires institutionnelles de la Commission se sont déroulées alors que la France n'a obtenu aucune aide financière de la CEE. Cela démontre l'importance des procédures communautaires, qui enserrent les Étatsmembres demandeurs d'aide dans une surveillance beaucoup plus étroite que celle pratiquées par l'UEP. La Commission européenne aurait pu aller encore plus loin si la France n'avait finalement rétabli son équilibre seule, grâce au retour du général de Gaulle. Le commissaire européen Robert Marjolin avait

245. DDF, 1958-I, document $n^{\circ}$ 446, télégramme de Couve de Murville à de Carbonnel, 25 juin 1958.

246. AMAE, PA-AP 314, carton 1, lettre d'Olivier Wormser du 17 juin 1958.

247. AMINEFI, B. 62.128, recommandations de la Commission à la France au titre de l'article 108, 22 juillet 1958.

248. AHUE, procès-verbal spécial de la session de la Commission des 22-24 et 26 juillet 1958 , réunion du 22 juillet 1958.

249. AHUE, annexe au procès-verbal spécial de la réunion de la Commission des 22-24 et 26 juillet 1958, document COM (58) 165 rév. ; AHUE, EN 349, note de la Commission, 3 juin 1958, annexe au document $381 / 58$. 
en effet profité de cette crise financière pour lancer un premier projet d'union économique et monétaire.

\section{Le premier projet d'union économique et monétaire.}

Le commissaire à l'économie et aux finances Robert Marjolin est à la fois un ancien professeur d'économie et l'ancien secrétaire général de l'OECE, l'organisation qui chapeaute l'UEP. Il a donc une grande expérience théorique et pratique de la coopération monétaire européenne. Dès la fin de 1957, alors qu'il est encore membre du cabinet du ministre français des Affaires étrangères, Christian Pineau, Marjolin fait connaître ses réflexions sur ce thème ${ }^{250}$. Dans le cadre de la définition d'une contre-offensive dans la négociation ZLE, il conseille de relancer les efforts d'intégration européenne en renforçant la coordination des politiques économiques et monétaires.

Marjolin participe également au groupe qui, avec Uri et Monnet réfléchit particulièrement à ces questions depuis la fin $1957^{251}$. En mars 1958, Monnet a d'ailleurs lancé un projet de fonds européen de réserve (FER) ${ }^{252}$. Il serait financé par les réserves des banques centrales, qui fourniraient des crédits en unité de compte européenne. Ce schéma semble s'inspirer de l'idée de créer une sorte d'UEP au sein des Six. Ce FER devrait servir de cadre à l'application de l'article 108. Des accords liant tous les pays de l'OECE pourraient compléter ce FER. Enfin des réunions entre les organes de direction du fonds, les ministres des Finances et des gouverneurs des banques centrales devraient assurer une coordination minimale des politiques monétaires nationales. Ce projet de Monnet est fondé en particulier sur des réflexions de Pierre Uri et surtout de Robert Triffin ${ }^{253}$. Triffin est également proche de Marjolin ${ }^{254}$.

250. AFJM, ARM 13/5/26, note de Robert Marjolin du 5 novembre 1957.

251. François Duchêne, Jean Monnet..., op. cit., p. 312 ; Jean Monnet, Mémoires..., op. cit., p. 639.

252. AHUE, PU 81, note de Pierre Uri du 12 mars 1958 ; AHUE, PU 112, note du 25 février 1958 ; cités in : Frances Lynch, «De Gaulle's First Veto. France, the Rueff Plan and the FTA » in Contemporary European History, 9, 1, 2000, p. 117. Voir enfin : «Le projet de fonds européen de réserve » de novembre et décembre 1957, annexes IV et V in Catherine Ferrant et Jean Sloover (éd.), Robert Triffin. Conseiller des Princes, Témoignages et Documents, Ciaco, Bruxelles, 1990, p. 99-107.

253. AHUE, PU 80, mémorandum sur la création d'un fonds européen de réserve, 21 décembre 1957, RT, envoyé à Pierre Uri ; voir aussi le témoignage de Robert Triffin : C. Ferrant et J. Sloover, Robert Triffin..., op . cit., p. 95.

254. De plus à la fin des années 1940, les deux hommes se fréquentaient lorsque Marjolin était à l'OECE tandis que Triffin était à la tête du bureau Europe du FMI. Voir : C. Ferrant et J. Sloover, Robert Triffin..., op. cit, p. 30. 
Robert Marjolin s'inspire de ces réflexions et cherche à définir un projet politiquement acceptable. En mai 1958, il s'entretient avec des responsables allemands pour évoquer ces idées ${ }^{255}$. Après ces consultations, Robert Marjolin lance finalement un premier projet d'union économique et monétaire le 31 mai $1958^{256}$. Le contexte est favorable car la France subit une nouvelle crise de sa balance des paiements alors même qu'elle avait obtenu de très larges facilités financières internationales en janvier 1958. Par ailleurs, la Grande-Bretagne a abandonné son offensive à l'UEP. Il est temps pour la Commission européenne de reprendre la main et de repenser la solidarité monétaire européenne devant ces crises à répétition.

Marjolin justifie ses propositions par une réflexion néofonctionnaliste : l'unification commerciale des marchés doit être complétée par une coordination forte des politiques économiques, financières et monétaires des Six pour ne pas créer de nouvelles divisions au sein de cet espace (point 2 du mémorandum). Or le traité de Rome doit impérativement être complété dans ce domaine, en particulier car la procédure de concours mutuel au sein de la CEE (article 108) est moins bien définie que celle de 1'UEP (point 6). Il faut donc conclure un nouveau traité qui permettra de communautariser des domaines aussi essentiels que « le volume des dépenses budgétaires, le surplus ou le déficit des recettes par rapport aux dépenses, la politique de crédit, le montant des investissements publics, le taux de change » (point 5). Il s'agit ainsi de passer à une véritable union économique, ou tous les principaux leviers de pouvoirs de l'État, même ceux les plus sensibles politiquement, devront être gérés en commun. Cette union sera également monétaire car, à la fin du processus : "Il sera alors indifférent aux nations des différents pays de détenir leurs avoirs en l'une ou l'autre des monnaies de la Communauté » (point 14). Le projet est politique, car il s'agit de créer une véritable union européenne dans tous les domaines sensibles de la souveraineté économique des États.

Par ailleurs, Marjolin souligne que cette évolution est dans l'intérêt même des États-membres, des débiteurs comme des créditeurs. Pour les premiers, il s'agit de sécuriser une source de crédit en cas de difficulté. Pour les seconds, il s'agit de s'assurer que les plus fragiles « suivent une politique économique et financière raisonnable » (point 7). Le commissaire français semble viser ici clairement la France et répondre aux craintes allemandes. Il faut rappeler les critiques de Marjolin, qui faisait partie du cabinet de Léon Blum en 1936, à

255. AHUE, procès-verbal de la réunion de la Commission du 7 mai 1958, $16^{\mathrm{e}}$ session ; AFJM, ARM 25/1, notes manuscrites sur un entretien avec Erhard le 19 mai 1958.

256. AFJM, ARM 32/1, mémorandum Marjolin du 31 mai 1958, « confidentiel ». 
l'égard de sa gestion économique et financière ${ }^{257}$. Le seul moyen pour Marjolin d'éviter à la France de retomber périodiquement dans de tels errements semble être de l'intégrer dans une solidarité européenne étroite et contraignante.

Pour mettre en œuvre ce projet ambitieux, Marjolin pense à une procédure en deux temps. Dans une première étape, la Commission proposerait des recommandations à un État membre en difficulté financière (point 8). Le Conseil en discuterait puis, sur la proposition de la Commission, une recommandation serait envoyée à l'État en difficulté. Ce dernier ne serait pas tenu de suivre ces recommandations, sauf s'il veut bénéficier de la solidarité financière des Six, c'est-à-dire de crédits. Dans une deuxième étape, les recommandations deviendraient des décisions obligatoires prises à la majorité qualifiée (point 10). Des pouvoirs accrus seraient donnés à un Conseil des gouverneurs des banques centrales à créer. Cette dernière institution n'aurait qu'un pouvoir consultatif dans un premier temps puis serait chargée de créer un « système des banques centrales européennes analogue au Federal Reserve System américain ». Lors de la deuxième étape, il prendrait ses décisions à la majorité et « recevrait des pouvoirs étendus en ce qui concerne la politique de crédit, notamment les avances des banques centrales aux gouvernements, les taux d'intérêts à court terme, le crédit à moyen terme, etc. » (point 16). La Commission aurait également des compétences accrues, tout comme le Comité monétaire. Enfin, Marjolin rejette l'idée de créer un Fonds européen de réserves (point 13). Il préfère établir une collaboration entre banques centrales plus étroite et plus décentralisée afin de gagner en souplesse et de se coordonner plus efficacement avec l'UEP.

La solution proposée par Marjolin doit permettre de résoudre les crises françaises pour éviter que le Marché commun n'implose. Pour cela, un équilibre est établi entre les obligations des pays créditeurs, et celles des pays débiteurs qui doivent se conformer à une discipline stricte. Sur le plan institutionnel, le choix est clairement supranational avec un accroissement des pouvoirs de la Commission, l'utilisation accrue du vote à la majorité qualifiée. Ce sont les technocrates communautaires mais aussi nationaux - hauts fonctionnaires participant au Comité monétaire, gouverneurs des banques centrales - qui sont renforcés face aux autorités politiques nationales.

Marjolin utilise cependant une méthode progressive et néofonctionnaliste pour promouvoir son plan, avec un système d'étapes, où les États membres conservent de nombreuses prérogatives dans un premier temps.

257. Robert Marjolin, Le travail d'une vie..., op. cit., p. 69. 
Le plan de Marjolin est donc clairement néofonctionnaliste, progressif, et fondé sur deux piliers consubstantiels, le rapprochement des politiques économiques et celui des politiques monétaires. Il diffère profondément du système proposé par Monnet en mars 1958, qui s'intéressait surtout au versant monétaire, et même plus précisément aux crédits. Il s'apparente à la réflexion de Triffin par certains aspects, comme la mise en place d'un système décentralisé de banques centrales, mais pas par d'autres, car Triffin estimait qu'une convergence forte des politiques économiques n'était pas un préalable indispensable au rapprochement des politiques monétaires. Finalement, le plan de Marjolin se rapproche beaucoup plus des préoccupations allemandes, qui visent à obliger la France à mener une politique intérieure plus raisonnable, afin de ne pas menacer la dynamique de construction européenne. Marjolin communautarise cette exigence. Cependant, le retour au pouvoir du général de Gaulle condamne ce projet. L'idée est cependant reprise six mois plus tard.

\section{Le second projet d'union économique et monétaire.}

$\mathrm{Au}$ second semestre 1958, le contexte international change alors que le retour à la convertibilité de la livre se précise. L'UEP devrait être prochainement remplacée par l'AME. Devant cette réorganisation des instances de coopération monétaire qui n'est pas à l'avantage de la France, Wormser estime en octobre 1958 que « la question des idées de M. Marjolin sur un accord monétaire entre les Six » reste posée ${ }^{258}$. Cela ne signifie pas que Wormser est favorable au projet de Marjolin dans toute son ampleur, mais que ce dernier répond à un besoin réel, celui d'établir l'après-UEP.

À la Commission européenne, Marjolin continue son travail. Il s'entoure de deux conseillers spécialistes de ce domaine, Pierre Uri et Robert Triffin ${ }^{259}$. Le 7 novembre 1958, Marjolin présente une deuxième version de son mémorandum destiné à promouvoir une union économique et monétaire ${ }^{260}$. Il repose sur un mécanisme différent, fondé sur l'institution d'un Fonds européen de réserve (FER) qui s'apparente à une UEP à Six. Ce FER serait constitué par les contributions des États membres. Il accorderait des crédits. Certains seraient automatiques, les plus importants seraient soumis à l'accord du Conseil des ministres, sur proposition de la Commission.

258. AMAE, POW 31, folio 310, note d'Olivier Wormser pour François Valéry, 2 octobre 1958.

259. AHUE, procès-verbal des réunions de la Commission du 18 juin 1958 et du 19 novembre $1958,21^{\circ}$ et $38^{\circ}$ session.

260. AFJM, ARM 32/1/2, note DG II Com (58) 249, « Coopération économique, financière et monétaire dans la Communauté économique européenne (présenté par M. Marjolin) », 7 novembre 1958. 
Par rapport au mémorandum du 31 mai 1958, trois différences notables apparaissent. Tout d'abord, l'instauration d'un FER entend parer à une menace perçue comme imminente - le premier point comporte l'expression « le plus rapidement possible »-d'un remplacement de l'UEP par un AME. Chronologiquement, ce mémorandum intervient en effet juste après les conférences internationales où le retour prochain à la convertibilité de la livre a fait l'objet d'indiscrétions. Ce deuxième mémorandum de Marjolin est aussi une réponse aux incertitudes résultant de la crise latente de la négociation ZLE. Il veut préparer l'après OECE-UEP et se place dans le cadre d'une coopération entre les Six - le FER - et le monde - le FMI -, tout comme, dans le domaine commercial, la proposition Hallstein cherchait à imposer le cadre de la CEE et celui du GATT.

Deuxièmement, ce mémorandum apparaît beaucoup plus agressif dans la défense du modèle communautaire. La ZLE est explicitement citée dans ce document et opposée à la CEE (point 6). Au contraire, une coopération accrue en matière économique, financière et monétaire est défendue pour permettre aux nombreuses politiques communes de fonctionner. En novembre 1958, la situation a évolué par rapport à mai 1958. La conférence de Stresa de juillet 1958 par exemple a permis de lancer le processus de définition de la future PAC.

Troisièmement, pour promouvoir ses idées, Robert Marjolin use cette fois-ci d'une modération beaucoup plus grande. Son mémorandum est beaucoup moins néofonctionnaliste. Dans le projet de novembre 1958, la Commission n'a essentiellement qu'une fonction de proposition. Le Comité des gouverneurs de banques centrales, appelé dans le premier mémorandum à devenir une sorte d'autorité administrative indépendante avant la lettre, disparaît. Le comité de direction du FER n'a qu'un pouvoir consultatif. Beaucoup de passages du mémorandum restent flous et sont laissés à des négociations ultérieures, en particulier sur l'obligation des États de se conformer à des normes précises en matière de politique économique et financière. Enfin, Marjolin ne parle pas de conclure un nouveau traité mais de " préciser » les dispositions du traité de Rome. Ce projet est donc moins ambitieux que le premier, en dépit de la présence d'un fonds de réserve.

Le collège des commissaires adopte ce second mémorandum de Marjolin le 19 novembre 1958, en réservant toutefois la question de la procédure à suivre pour le soumettre aux États membres ${ }^{261}$. Très rapidement cependant, le contexte change avec la première rupture de la négociation ZLE et le retour imminent à la convertibilité des monnaies combiné à de profondes réformes intérieures

261. AHUE, procès-verbal de la 38e session de la Commission du 19 novembre 1958. 
en France. Par ailleurs, les divergences entre Marjolin et de Gaulle ne tardent pas à se révéler. Le 18 décembre 1958, Robert Marjolin et Charles de Gaulle se rencontrent. Dans ses notes manuscrites, Marjolin inscrit : "Accueil : poli mais froid, pas un instant cordial $^{262} »$. De Gaulle manifeste particulièrement son hostilité à la supranationalité. Marjolin proteste « Ce n'est pas pour la supranationalité que j'ai fait le traité ». De Gaulle lui répond : «Peut-être pas vous, mais vous êtes fonctionnaire $»$. On ne sait si ce qualificatif s'applique au Marjolin conseiller de Pineau lors de la négociation du traité de Rome ou au commissaire européen, car le présent de l'indicatif est utilisé. Cela démontre en tout cas le peu de considération que de Gaulle manifeste envers Marjolin. Après cet entretien décevant, l'amertume de Marjolin transparaît dans cette réflexion : "pas un mot sur les services que je rends ${ }^{263}$ ». Intimement persuadé de l'intérêt d'un processus d'intégration économique européenne pour la France, Marjolin a tenté de faire comprendre le point de vue français en l'intégrant dans une vision communautaire. Il ne peut qu'être déçu des rapports établis avec le nouvel homme fort de Paris.

\section{CONCLUSION : UNE AFFIRMATION RÉUSSIE DE LA COMMISSION EUROPÉENNE}

Ainsi les commissaires européens Walter Hallstein et Robert Marjolin ont tenté de profiter du contexte difficile de la négociation ZLE et du risque d'isolement de la France en Europe pour accroître les prérogatives de la Commission.

Dans la négociation ZLE, la Commission a défendu avec succès le modèle de la CEE et s'est imposée dans le concert international comme une force de proposition majeure. Le président Hallstein a affirmé son autorité en s'appuyant notamment sur le vice-président français Robert Marjolin. Ce dernier a tenté de profiter du contexte particulier de 1958, crises financières françaises et incertitudes sur l'architecture future de la coopération monétaire, pour lancer deux projets d'union économiques et monétaires. Ils traduisent la spécificité de la réflexion de Marjolin, fondée sur une démarche ambitieuse, et finalement très proche de certaines réflexions allemandes. Elle a finalement échoué pour de multiples raisons, en particulier le retour au pouvoir du général de Gaulle.

262. AFJM, ARM 25/1, entrevue avec Charles de Gaulle, 18 décembre 1958, notes manuscrites.

263. AFJM, ARM 25/1, entrevue avec Charles de Gaulle, 18 décembre 1958, notes manuscrites. 


\section{CHARLES DE GAULLE ET LES NOUVEAUX ÉQUILIBRES EN FRANCE ET EN EUROPE}

Avec l'arrivée au pouvoir du général de Gaulle, la France peut régler les dossiers que les gouvernements précédents n'avaient pas pu surmonter. La situation économique et financière française a été durablement assainie par le plan Rueff, qui a permis d'appliquer pleinement la CEE et de rejeter la ZLE sans que l'unité des Six ne soit remise en cause. La chronologie de la période laisse entrevoir quatre temps qui ont entraîné trois ruptures majeures, aux échelles nationale, européenne et mondiale.

Le premier temps, en juin 1958, a été consacré à la définition d'une nouvelle politique européenne dans un contexte de forte dépendance extérieure. La Commission européenne exerçait une tutelle certes bienveillante mais réelle au titre de l'article 108. Marjolin lance d'ailleurs son premier projet d'union économique et monétaire. La nouvelle politique française repose avant tout sur la défense impérative de la CEE, qui passe par la définition d'une position crédible sur la ZLE.

Dans un second temps, en juillet 1958, cette stratégie offensive est appliquée avec succès. La France n'est plus isolée dans la négociation ZLE. Cependant il reste à convaincre des acteurs intérieurs réticents (ministère de l'Industrie, patronat). Par ailleurs, la Grande-Bretagne commence à se désintéresser de cette négociation et se laisse séduire par l'opération Unicorn.

Par la suite, ces deux incertitudes pèsent sur la négociation ZLE. La méthode de négociation au sein du comité Maudling apparaît condamnée dès la fin du mois d'octobre 1958 car les principaux acteurs à Paris, Londres, Bonn et Bruxelles perdent espoir dans une conclusion rapide. Marjolin craint même des représailles britanniques dans le domaine monétaire et lance son second plan d'union économique et monétaire en urgence. La rupture du 14 novembre 1958 est donc à la fois une surprise dans son déclenchement et un aboutissement logique. Elle ne permet pas de conclure rétrospectivement que la France ne voulait pas de la ZLE. La priorité reste de conserver l'unité des Six ; or cette dernière semble pouvoir être préservée sans une ZLE à court terme en novembre 1958, d'où la rupture des négociations au comité Maudling.

Dans une quatrième et dernière étape, la France parvient à communautariser la rupture des discussions au comité Maudling puis, après la seconde rupture du 15 décembre 1958, à la mondialiser par le plan Rueff et le retour concerté à la convertibilité des monnaies européennes.

Ces multiples offensives françaises n'ont été possibles que par de profondes mutations à toutes les échelles permises par l'arrivé au pouvoir du général de Gaulle. 
Sur le plan national, le gouvernement de Gaulle impose des évolutions profondes au processus de décision. Certaines personnalités proches du pouvoir voient naturellement leurs fonctions s'accroître : c'est le cas d'Olivier Wormser en matière de politique économique européenne et de Roger Goetze pour la politique économique et financière nationale. Le pouvoir central n'hésite pas à bousculer l'administration, à l'été 1958 avec la nouvelle position officielle sur la ZLE, puis à la fin 1958 avec le plan Rueff.

En matière européenne ensuite, la rupture est tout aussi nette avec les gouvernements précédents. Mollet acceptait tant la CEE que la ZLE pour des raisons essentiellement politiques. Gaillard avait une vision plus économique mais a manqué d'autorité politique. De Gaulle clarifie la position française. Il est prêt à accepter la conclusion d'une ZLE, si elle ne menace pas la CEE. Il était plus habile d'accepter une ZLE retardée et minimale, et de mettre en œuvre avec succès la CEE dans l'intervalle, que de passer de nouveau pour un obstacle à la construction d'une Europe unie. Cette position a également permis de rompre la négociation ZLE sans douleur car la position constructive de juillet 1958 a permis d'engager des discussions sectorielles qui ont démontré la justesse de certaines critiques techniques de ce projet.

Sur le plan européen, la France gaulliste profite d'une alliance paradoxale avec une Commission européenne ambitieuse, qui profite des difficultés françaises pour s'affirmer. Le choix de la CEE par les décideurs gaullistes ne résulte cependant pas d'une conversion européiste mais d'une analyse réaliste, qui peut être rétrospectivement qualifiée de milwardienne : la CEE est le meilleur levier de modernisation de l'Etat-nation français, de son adaptation au monde de la libération internationale des échanges et des paiements.

Cet engagement externe doit cependant se combiner avec une réforme interne, permise par le plan Rueff. Le plan Rueff constitue bien une rupture nationale, européenne et mondiale dans la mesure où il est coordonné avec le retour à la convertibilité des monnaies européennes. Sans cette dimension internationale, le plan Rueff aurait d'ailleurs certainement été très différent comme le montre la note initiale de Rueff en juin 1958. La chronologie montre clairement l'influence de la négociation ZLE sur cette internationalisation du plan.

Le plan Rueff a permis à la France de mettre en application sa double stratégie européenne et mondiale. Elle reposait, en matière économique, sur la promotion de deux échelles de coopération, la CEE et le GATT, négligeant ainsi l'OECE. De même, dans le domaine politique, de Gaulle développe une vision organisée et cohérente différenciant la « Petite Europe » de la sphère de coopération atlantique et mondiale (d'où le mémorandum de réforme 
de l'OTAN). C'est cette incapacité de la Grande-Bretagne à concilier ses stratégies européennes et mondiales qui a permis à la France de rompre la négociation.

Enfin, le plan Rueff a une dimension novatrice. Ce n'est pas un plan d'austérité des années cinquante mais un plan de libéralisation qui préfigure les années soixante. L'intervention de l'État n'est pas refusée mais elle doit être plus régulatrice que dirigiste. Il manifeste aussi la fin définitive de l'utopie du développement par l'empire colonial. À la fin de 1958, la décolonisation est d'ailleurs entamée partout sauf en Algérie, où l'arrivée au pouvoir de Charles de Gaulle provoque cependant, rétrospectivement, une rupture. La France change de dimension avec le plan Rueff et peut embrasser sans complexe l'intégration économique européenne par la CEE. 



\section{CONCLUSION DE LA PREMIÈRE PARTIE}

\section{LA FRANCE FACE À LA RÉORGANISATION DE LA COOPÉRATION ÉCONOMIQUE EUROPÉENNE (1955-1958)}

La période 1955-1958 est marquée par la profondeur de la crise française. Celle-ci permet paradoxalement à la France de se convertir à la CEE. Enfin, cette période voit le triomphe du modèle de la CEE sur les autres formes de coopération économique européenne.

\section{LA CRISE FRANÇAISE}

Les deux ruptures majeures de la période 1955-1958 correspondent au rapport Spaak d'avril 1956, et au plan Rueff de décembre 1958. Elles encadrent des ruptures secondaires en termes de politique européenne de la France, qui s'inscrivent pleinement dans la crise profonde de la $I V^{\mathbb{N}}$ République confrontée à la guerre d'Algérie.

\section{A. LES DEUX RUPTURES PRINCIPALES : LE RAPPORT SPAAK ET LE PLAN RUEFF}

Ce n'est pas le traité de Rome du 25 mars 1957 ni même sa ratification à l'été 1957 qui constituent les ruptures majeures car c'est le rapport Spaak qui a préfiguré les grandes lignes du traité de Rome. Il a défini sa spécificité, sa logique d'intégration économique. Son acceptation par la France traduit son engagement dans un processus irréversible de libération des échanges et d'intégration économique à six. Auparavant, la résolution de Messine laissait la porte ouverte à différentes voies d'intégration économique, y compris en termes d'échelles de coopération. La signature du traité de Rome sanctionne cette conversion.

Mais l'incertitude pèse sur les capacités de la France à honorer sa signature et donc à orienter la construction européenne en fonction de ses intérêts. Cette hypothèque n'est levée qu'avec le plan Rueff. C'est cette réforme majeure qui 
permet à la fois d'appliquer le traité CEE dans toute son ampleur, et de rejeter la ZLE dans tout ce qu'elle a de plus dangereux pour la dynamique d'intégration économique à six. Il permet d'insérer la CEE dans un mouvement mondial de libéralisation des échanges et des paiements lié à la fin de la reconstruction. Deux échelles sont maintenant mises en valeur : celle de la Petite Europe de la CEE d'une part, celle du monde libre avec le GATT et le FMI d'autre part.

Ces deux événements sont étroitement liés. Mollet et son équipe avaient réussi à imposer le traité de Rome à un gouvernement et à une administration en grande partie réticents. De Gaulle fait de même avec le plan Rueff. Les deux moments représentent les deux faces d'un même changement de paradigme. La France avait accepté théoriquement de s'intégrer dans le mouvement de libération des échanges dans le cadre de l'intégration européenne à six lors de l'acceptation du rapport Spaak en mai 1956. Elle applique concrètement cet engagement en décembre 1958. Mollet pensait avoir obtenu avec le traité de Rome un engagement de libération maximal et conditionnel, la ZLE a démontré à de Gaulle qu'il était en fait minimal et obligatoire. Dans les deux cas, les décideurs politiques à la source de ces deux ruptures ne sont pas des européistes fondamentalement enthousiasmés par le traité de Rome. Guy Mollet et Christian Pineau restent toujours séduits par la Grande Europe franco-britannique. Charles de Gaulle quant à lui n'est certes pas plus suspect d'européisme mais il considère la CEE comme un accord utile. La CEE est perçue comme une contrainte nécessaire, la meilleure voie pour faire passer la France du monde de la reconstruction à celui des années soixante.

\section{B. LES TEMPS DES NÉGOCIATIONS EUROPÉENNES} ET DE LA CRISE FRANÇAISE

En termes de politique européenne de la France face à l'intégration économique industrielle, cinq ruptures secondaires émergent de la période 1955-1958.

En septembre 1956, Mollet fait accepter sa position constructive sur le Marché commun industriel à son gouvernement et à son administration, avant de la faire triompher au sein des Six après l'échec de Suez, en novembre 1956. Les équilibres de la CEE ont donc été définis, pour le cœur de l'intégration économique, bien avant la signature du traité de Rome, retardé en raison des dossiers agricoles, institutionnels et coloniaux.

La deuxième rupture date d'octobre 1957. La négociation ZLE est véritablement lancée à l'échelle gouvernementale alors que, dans le même temps, la France s'enfonce dans la crise politique et financière. Les décideurs politiques français ne peuvent se décider sur la ZLE tandis que le CNPF manifeste 
publiquement une position originale fondée sur une franche opposition. Cette situation difficile persiste jusqu'au début de 1958, avec le rétablissement permis par Gaillard. Mais cette restauration, fondée sur l'obtention d'importants crédits internationaux, a permis de mesurer la dépendance française àl'égard del'extérieur, non plus seulement des États-Unis mais aussi de ses partenaires européens.

En mars 1958, l'entrée en jeu de la Commission européenne permet de reformuler plus habilement les propositions françaises - le décalage devient la proposition Hallstein - et donc de rompre l'isolement de la France. Il atténue le caractère trop radical du mémorandum français de février 1958. Cet événement marque l'émergence politique sur la scène internationale d'un nouvel acteur, la Commission européenne, après sa naissance institutionnelle en janvier 1958.

La crise de mai 1958 paraît constituer une prise de conscience radicale pour la France à la fois de la profondeur de ses difficultés et de sa dépendance récente à l'égard de la Commission européenne, qui manifeste son autorité dans la procédure de l'article 108 et dans le plan Marjolin d'union économique et monétaire. Cette crise est l'élément déterminant pour permettre les ruptures de la période de Gaulle.

En juillet 1958, la France restaure son autorité dans la négociation ZLE en présentant une nouvelle position, plus constructive que celle du mémorandum Gaillard. Cet événement a souvent été minoré car il intervient peu de temps avant la rupture de la négociation ZLE. Mais il est déterminant car c'est lui qui permet à la France d'affirmer son autorité en matière européenne et de reconstituer l'unité des Six. Sans le succès de juillet 1958, la rupture sans crise européenne - à la fois au sein des Six et des dix-sept - de la négociation ZLE n'aurait pas été possible. De Gaulle n'avait pas exclu la possibilité de conclure une ZLE après un long processus de dilution du projet dans les négociations sectorielles.

La chronologie des négociations européennes n'épouse donc pas la chronologie institutionnelle (signature, ratification et mise en œuvre du traité de Rome), mais est plus proche de la chronologie politique française, car les crises financières et politiques imposent des prises de conscience successives pour les décideurs français. L'ombre de la guerre d'Algérie pèse sur la période. En aggravant la crise financière, elle impose une réforme radicale du modèle français.

\section{CRISE ET RÉFORME DU MODÈLE FRANÇAIS PAR LA CEE}

L'aggravation du conflit en Algérie a été, paradoxalement, un facteur positif pour l'affirmation de la CEE. Pendant la négociation du traité de Rome, le début 
des « événements » d'Algérie a détourné l'opinion d'une discussion technique et a sans doute contribué à apaiser le débat parlementaire. Pendant la négociation de la ZLE, la faiblesse financière française récurrente, aggravée par ce conflit, a démobilisé les nombreux décideurs français qui auraient été naturellement favorables à une coopération européenne poussée avec la Grande-Bretagne, tout en décourageant les décideurs britanniques à partir du printemps 1958. Enfin, la guerre d'Algérie a montré les limites des politiques économiques fondées sur le protectionnisme colonial et sur la priorité à la demande interne sur les équilibres financiers externes.

Sans l'aggravation du conflit algérien, le gouvernement Mollet aurait peutêtre pu s'engager rapidement dans une ZLE et le gouvernement Gaillard aurait vraisemblablement pu restaurer la situation intérieure et européenne. Mais l'Algérie impose finalement une rupture majeure dans de nombreux domaines. La France abandonne à la fin de 1958 les sources de sa prospérité issue de la III ${ }^{\mathrm{e}}$ République : le régime parlementaire est fortement corrigé par la $\mathrm{V}^{\mathbb{R}}$ République, le protectionnisme est condamné dans son essence tout comme l'orientation de l'économie sur l'empire colonial.

La profondeur de cette crise impose une réforme du modèle français qui passe par la CEE. À partir de 1956 pour les plus fervents partisans du Marché commun comme Marjolin, et à partir du plan Rueff pour la majorité des décideurs français, modernisation et libéralisation économique vont de pair grâce à la dynamique d'intégration européenne par la CEE. Elle seule permet de concilier la création d'un ordre mondial libre-échangiste et le développement de l'État providence français, par les garanties qu'elle offre. La construction européenne est donc un moyen de réformer le consensus national de 1945, en l'adaptant à l'ordre mondial libre-échangiste de l'après-reconstruction. Cela ne veut pas dire que la CEE est la seule source de modernisation. D'autres voies de réformes avaient été imaginées : les « fonctionnaires modernisateurs 》 pensent à la planification indicative, tandis que Rueff défendait une voie libérale classique, reposant notamment sur une réforme du système financier français. Toutes ces pistes de modernisation sont reportées à l'après 1958 car c'est l'intégration européenne par la CEE qui s'impose comme l'urgence incontournable dans le domaine économique.

\section{LA CONVERSION DE LA FRANCE À LA CEE}

La conversion rapide de la France à la CEE peut constituer une source d'étonnement. Il s'agit de savoir comment un pays plutôt protectionniste et en proie à de graves difficultés financières a finalement accepté la CEE - un accord 
libre-échangiste - comme une voie de modernisation incontournable. Cette conversion est issue d'une réflexion de fond sur les limites de la puissance française en 1956-1958. Elle a concerné des groupes d'acteurs très divers, ce qui pose le problème de sa profondeur.

\section{A. LA CEE, DERNIER LEVIER \\ D'INFLUENCE INTERNATIONALE POUR LA FRANCE}

L'intensité de la crise française remet en cause les bases de la puissance nationale de manière radicale. Trois temps peuvent être identifiés pour expliquer cette mutation.

Dans une première étape, la crise française constitue, paradoxalement, un levier de puissance. Les difficultés commerciales françaises sont un moyen pour elle d'obtenir des concessions dans le cadre des négociations du traité de Rome, puis de retarder la négociation de la ZLE. Le spectre d'un nouveau 30 août 1954 est fréquemment utilisé pour convaincre les partenaires de la France de tenir compte de sa situation exceptionnelle. La France reste un partenaire politique et économique incontournable à l'échelle de l'Europe.

Cette stratégie française trouve ses limites en 1958. Dans le cadre des Six, elle signifie que la France risque de se retrouver sous la tutelle d'une Commission européenne certes bienveillante pour l'instant, mais ambitieuse et sourcilleuse comme le prouve l'exercice de la procédure de l'article 108 en juin-juillet 1958. De plus, les dérogations et crédits dont bénéficie la France, notamment en janvier 1958, se traduisent par des limitations de souveraineté concrètes et sensibles. Enfin, dans la négociation ZLE, l'exigence française de tenir compte de sa situation exceptionnelle risque d'être contre-productive : Londres pense au printemps 1958 à une ZLE avec un statut dérogatoire pour la France qui permettrait de l'isoler.

Dès lors, la France doit retrouver des vecteurs plus traditionnels d'influence, donc de puissance. Le gouvernement de Gaulle rétablit l'autorité politique de la France en juin 1958, puis sa solidité monétaire avec le plan Rueff. C'est la fin des mesures dérogatoires françaises et de la stratégie de l'influence par la faiblesse.

Le rétablissement de la puissance française passe aussi par une bonne gestion des rapports de forces internationaux. D'une part, la France bénéficie du soutien décisif des Cinq, et en particulier de la RFA, ainsi que de la neutralité bienveillante - en matière européenne, des États-Unis. D'autre part, la France profite des erreurs britanniques. La Grande-Bretagne n'a pas réussi à définir une stratégie cohérente qui associerait échelle européenne et échelle mondiale. Au 
contraire, ces deux dimensions tendent à se contrarier à de multiples moments en 1956-1958. Au second semestre 1956, c'est l'attachement au Commonwealth qui empêche le cabinet Eden d'adopter rapidement la ZLE et de la lancer avant que les Six ne s'engagent de manière inéluctable dans la négociation CEE. À l'été 1957, c'est l'agressivité de certains pays du Commonwealth qui tend la situation au GATT. Au second semestre 1958, Unicorn semble paralyser Londres sur la ZLE. Enfin, un facteur personnel peut également être mis en valeur : Harold Macmillan mélange fréquemment considérations économiques et politiques ce qui le conduit à réfléchir très souvent en termes de représailles envers la France, et l'empêche de considérer des propositions plus rationnelles. De Gaulle paraît a contrario à la fois plus pragmatique et plus cohérent sur le plan doctrinal. À l'étonnement général, il accepte la CEE comme voie de modernisation économique de la France, car elle ne contredit pas ses plans de coopération politique à deux niveaux (Petite Europe et espace atlantique voire mondial).

Ces erreurs britanniques pèsent lourd dans l'appréciation des décideurs français des efforts du gouvernement Macmillan pour participer au mouvement d'intégration européenne, que ce soit en 1956-1958 avec la ZLE ou en 19611963 avec la première candidature britannique. Elles facilitent leur conversion à la CEE.

\section{B. LES VECTEURS INTERNES DE LA CONVERSION}

La conversion de la France à la CEE a été permise par l'engagement inconditionnel de trois groupes de décideurs français.

Le sommet de l'exécutif, tout d'abord, se mobilise rapidement, en particulier les présidents du Conseil Guy Mollet, Félix Gaillard et Charles de Gaulle, assistés, au Quai d'Orsay, de Christian Pineau, Maurice Faure et Maurice Couve de Murville. C'est bien le pouvoir officiel qui impulse la conversion à la CEE et pas des personnalités en marge des institutions : Jean Monnet et Pierre Uri sont des voix écoutées mais n'ont pas de prise directe sur le processus de décision. La IV République tant décriée pour sa faiblesse gouvernementale semble avoir trouvé, dans ce domaine précis, des leaders efficaces entre 1956 et 1958.

Ce groupe placé à la tête de l'exécutif s'appuie sur une très forte centralisation, encore accrue en 1956-1958. Elle repose sur des relais ponctuels comme Robert Marjolin, intermédiaire entre le trio gouvernemental, les milieux administratifs et le patronat pour les questions économiques. Des institutions ad hoc sont montées et dirigées par des proches des présidents du Conseil successifs (Verret puis Delcourt) pour superviser l'ensemble de l'administration. Avec 
l'institutionnalisation de la CEE, un système bicéphale se met en place, fondé sur une collaboration étroite entre le SGCI et le Quai d'Orsay, et le développement d'une approche européenne réaliste par Donnedieu de Vabres et Wormser. Face à ces relais puissants de l'exécutif se dresse une administration très largement réticente envers le Marché commun en 1956, puis envers la ZLE en 1958, mais qui doit se plier aux directives de l'exécutif.

Un troisième groupe de promotion de la conversion à la CEE joue alors un rôle indispensable pour alimenter la réflexion sur le fond. Il s'agit du patronat pro CEE et notamment de Georges Villiers à la tête du CNPF, ainsi que du groupe dirigeant de Renault (Dreyfus). Ces milieux économiques donnent des arguments essentiels pour faire accepter la CEE, refuser la ZLE et promouvoir des réformes intérieures drastiques. L'opposition rapide et totale du CNPF à la ZLE marque les décideurs français car la confédération patronale s'était montrée plutôt favorable au projet de marché commun. Au-delà, l'assemblée générale extraordinaire du 13 mai 1958 s'inscrit dans une dynamique de lobbying offensif, largement éclipsée par le retour au pouvoir du général de Gaulle. Mais ce dernier ne contredit pas la dynamique patronale sur le fond : le plan Rueff offre de nombreuses similitudes avec les réflexions du groupe offensif du CNPF. Le patronat ne doit pas être vu comme un manipulateur du pouvoir politique mais comme une source d'expertise indispensable, et parfois comme l'initiateur de projets plus ambitieux, comme en témoignent ses contre-propositions dans la négociation ZLE.

Ces trois groupes interagissent et n'interviennent pas de manière juxtaposée. Les partisans du Marché commun et ses contempteurs se recrutent à la fois dans les milieux politiques, administratifs et économiques. Progressivement la prise de conscience paraît généralisée. Cependant, si la conversion à la CEE devient assez rapidement majoritaire, sa profondeur doit être nuancée.

\section{DE LA PROFONDEUR DE LA CONVERSION}

La conversion à la $\mathrm{CEE}$ signifie-t-elle que ses promoteurs avaient bien compris le modèle de la CEE ? Cette question appelle des réponses très contrastées.

Le groupe à la tête de l'exécutif qui est à l'origine du succès de la CEE semble, paradoxalement, ne pas en avoir compris toutes les implications. Mollet et Pineau paraissaient tout autant préoccupés de réussir l'Europe francoanglaise que le Marché commun. Ils ne semblent pas avoir compris la spécificité du modèle économique de la CEE. De Gaulle non plus n'a pas anticipé la force de la dynamique d'intégration et continue d'assimiler la CEE à un traité uniquement commercial. 
Par contre, un autre groupe de décideurs a pleinement pris conscience de la nouveauté de l'intégration économique entraînée par la CEE. Mais ils quittent rapidement le devant de la scène française. Marjolin, Deniau ou Uri partent ainsi à Bruxelles.

Pour la plupart des décideurs français, la conversion à la CEE reste partielle. Pour les Européens « fonctionnels » par exemple, la CEE est le seul moyen pour la France de retrouver une influence internationale, car il permet de l'insérer en douceur dans le mouvement international de libération des échanges. Particulièrement sensibles à l'écheveau de contraintes européennes et internationales dans lequel se débat la France, la CEE représente pour eux le choix de la raison et de la restauration progressive de la puissance française. Pour la plupart, la conversion se fait par défaut, faute d'alternative. Les négociations de 1955-1958 ne se déroulent pas ex nihilo mais s'inscrivent dans un certain nombre de dynamiques institutionnelles antérieures (des « path-dependencies ») qui limitent la marge de manœuvre des décideurs. Ainsi, c'est l'échec des voies alternatives, par l'empire français ou par l'Europe franco-britannique, qui rend la CEE incontournable. C'est 1'héritage de la CECA et des divers projets avortés des années 1950 qui oriente la rédaction du rapport Spaak et du traité de Rome.

La conversion à la CEE de la France a donc été remarquable par sa rapidité, mais pas par sa profondeur. La CEE s'est imposée par défaut. Elle paraît incontournable mais séduit surtout par sa flexibilité.

\section{LE SUCCÈS DU MODÈLE FLEXIBLE DE LA CEE}

La flexibilité du modèle de la CEE est à la source de son succès et constitue en même temps sa principale faiblesse. La CEE fait l'objet d'interprétations très diverses par les responsables français. Son modèle a été renforcé par la négociation ZLE, qui a également facilité la mise en place réussie de la CEE en 1958.

\section{A. Des INTERPRÉTATIONS MULTIPLES DE LA CEE}

La CEE repose sur un traité-cadre à l'application progressive, qui s'appuie sur un double équilibre, politique entre supranationalisme et intergouvernementalisme, et économique entre libre-échange et harmonisation volontariste des structures. Plusieurs interprétations de la CEE peuvent donc être développées. Trois groupes peuvent être distingués. 
Un premier ensemble associe les décideurs réticents car attachés au modèle de la Grande Europe. Certains sont aussi des promoteurs de la CEE comme Mollet ou Pineau. La plupart sont très réticents envers la CEE soit par libéralisme économique, comme Valéry, soit au contraire par un attachement au dirigisme comme Mendès France ou Ramadier.

D'autres décideurs français sont favorables à la CEE car elle conforte une ambition plus générale. Les libéraux Goetze et Rueff la perçoivent comme un élément important dans un programme de rétablissement des lois du marché. Les décideurs attachés à la notion de puissance nationale, comme de Gaulle, Couve de Murville, Peyrefitte ou Wormser, estiment que la voie de la "Grandeur » passe par le Marché commun.

L'attachement à la dynamique d'intégration économique n'est finalement que le fait d'une minorité. Marjolin met également l'accent sur la dimension macroéconomique et le rôle des experts dans ce processus. Sa vision néofonctionnaliste et technocratique s'exprime particulièrement avec son premier projet d'union monétaire de mai 1958. Les milieux économiques, au contraire, s'attachent à promouvoir une intégration économique reposant sur des schémas d'Europe contractuelle renouvelés.

D'une manière générale, la CEE apparait, pour les européistes, comme une première étape vers une unification économique et politique de l'Europe. Pour les décideurs français les plus attachés à la souveraineté nationale comme de Gaulle ou Wormser, la CEE symbolise au contraire cette dynamique de « rescue of the nation-state » décrite par Alan Milward ${ }^{1}$ : elle constitue un cadre de coopération indispensable pour l'adaptation du modèle économique, social et politique français aux nouvelles exigences de la coopération internationale (libération des échanges et des paiements).

La flexibilité du modèle de la CEE a donc facilité son acceptation, encouragée par le contre-exemple de la ZLE.

\section{B. L'INFLUENCE POSITIVE DE LA ZLE SUR LA CEE}

La négociation de la ZLE a eu une triple influence positive sur la CEE. Tout d'abord, elle a démontré a posteriori tout l'intérêt de la méthode de négociation du Marché commun. Le rapport Spaak a permis de circonscrire le cadre d'une discussion par nature difficile. À défaut d'un tel document de synthèse endossé par les responsables politiques, les négociations ZLE se sont enlisées dans des

1. Alan Milward, The European Rescue of the Nation-State..., op. cit., p. 3-10. 
controverses à la fois générales et techniques car aucun cadre commun n'avait été défini. Cela permet à la France de reprendre la même tactique d'obstruction que pendant la négociation du Marché commun mais avec plus de succès. La France a donc pu utiliser les mêmes formules - décalage, première étape conditionnelle, etc. - sans scrupule, jusqu'au risque d'être isolé de manière irréversible. À cet égard, les arguments de juin 1958, lorsque le décalage semble se transformer en statut spécial pour la France dans la ZLE, se rapprochent de ceux de septembre 1956, lorsque Maurice Faure agitait la menace d'un « droit de sécession » offert à la France, pour convaincre de la nécessité de définir une position réaliste sur la CEE.

Ensuite, la ZLE a facilité l'acceptation de la CEE par les décideurs français. Elle a montré le caractère inéluctable de la libération des échanges mais aussi l'ampleur des concessions que la France avait obtenues dans le cadre du Marché commun, et sur lesquels certains des Cinq paraissaient prêts à revenir grâce à la ZLE.

Enfin, la ZLE a démontré aux Cinq tout l'intérêt de l'intégration économique européenne par la CEE. Les critiques techniques du projet de ZLE dépassent les décideurs français et sont également le fait du gouvernement italien ou du patronat européen. À l'automne 1958, l'offensive française sur la question de la préférence européenne permet de souligner clairement que le projet britannique a une finalité universelle et pas européenne. La France cherche alors à poursuivre cette logique jusqu'à son terme en acceptant le transfert de prérogatives gérées à l'échelle de la Grande Europe (OECE, UEP) à l'échelle mondiale (GATT, FMI). La ZLE a permis de faire ressortir la spécificité du modèle de la CEE et de discréditer l'échelle de coopération de la Grande Europe pour un temps. Elle a également facilité la mise en place rapide de la CEE.

\section{LA MISE EN PLACE RÉUSSIE DE LA CEE}

Paradoxalement, le défi que constitue la ZLE a obligé la Commission européenne à affirmer rapidement son autorité. Hallstein a fait jouer à la Commission un rôle important dans la négociation ZLE, même si le dernier mot reste toujours aux mains des États. Marjolin a proposé une interprétation très ambitieuse de la CEE, fondée sur le développement d'une véritable union économique et monétaire. Ce projet n'a pas réussi à s'imposer car il reposait sur l'exploitation d'une crise française qui s'est finalement résolue par une voie nationale. L'administration communautaire s'est mise en place et de nombreux Français y occupent des postes importants.

Cependant l'affectation à Bruxelles semble peu prestigieuse pour les Français en 1958. Cela s'explique par le manque de considération, voire de 
compréhension, des décideurs français pour les institutions communautaires. Aucune stratégie d'influence cohérente n'est définie en 1958. À Paris, la plupart des décideurs français sont surpris par la capacité d'initiative de la Commission européenne.

Cette mise en place réussie de la CEE est à la source de nombreux malentendus entre les décideurs français et les institutions européennes au cours des années 1960. 



\section{DEUXIÈME PARTIE}

LES EUROPE ÉCONOMIQUES EN DÉBAT : LES DÉCIDEURS FRANÇAIS ET LA CEE

(1959-1969) 

À partir de 1959, le rejet de la ZLE assure le succès du modèle de la CEE. Les débats de 1956-1958 sur l'organisation générale de la coopération économique en Europe sont désormais tranchés. L’enjeu réside dorénavant dans l'application du traité de Rome, qui peut supporter plusieurs interprétations en matière d'intégration économique européenne.

Pendant les onze premières années d'application du traité de Rome, de 1958 à 1969, la politique de la France est marquée par une doctrine européenne gaulliste qui limite les initiatives de Paris en matière d'intégration économique européenne (chapitre IV). La Commission fait preuve d'une très grande liberté d'action au début. En son sein, un groupe dominé par les Allemands cherche à promouvoir une Europe ordolibérale, fondée sur une conception très ambitieuse de la politique de la concurrence (chapitre V). Cette dynamique s'oppose frontalement aux projets d'Europe organisée du commissaire français Robert Marjolin, qui donnent un rôle plus important à l'intervention des autorités publiques dans l'économie (chapitre VI). À partir de 1965, le gouvernement français et son administration deviennent plus actifs dans le domaine de l'intégration économique européenne. En lien avec certains réseaux français et transnationaux de Bruxelles, il tente de promouvoir une politique industrielle européenne sous différentes formes (chapitre VII). 



\section{CHAPITRE IV}

\section{LES BASES DE LA POLITIQUE EUROPÉENNE DE LA FRANCE GAULLISTE (1959-1969)}

La politique européenne de la France des années 1959 à 1969 est dominée par la figure du général de Gaulle, qui imprime sa marque à la politique étrangère tout en reprenant certaines de ses orientations antérieures. Les conceptions européennes du général de Gaulle ont fait l'objet d'une littérature extensive'. Pourtant, les sources traduisant directement la pensée du président français sont rares, à la différence des très nombreuses mémoires hagiographiques émanant de ses proches. Il est donc nécessaire de se concentrer sur les ouvrages de référence récents ${ }^{2}$, et de revenir aux sources primaires. Les discours et les mémoires (inachevées ${ }^{3}$ ) livrent des informations intéressantes mais biaisées par le fait que ces écrits sont publics, destinés à entretenir la stature du personnage, et, pour le cas des mémoires, écrites quelques années après les événements. Les écrits d'époque du général de Gaulle sont disponibles grâce aux Lettres, notes et carnets ${ }^{4}$, qui rassemblent des documents authentiques choisis par son fils, Philippe de Gaulle, et publiés dans les années 1980. Si le choix des textes reflète les préoccupations de l'amiral de Gaulle ${ }^{5}$, ces textes sont très intéressants et se

1. L'institut Charles de Gaulle a même publié des bibliographies pour se retrouver dans l'œuvre abondante consacrée au chef de l'État français : Bibliographie internationale sur Charles de Gaulle, 1940-1981, Plon, Paris, 1981 ; Nouvelle bibliographie internationale sur Charles de Gaulle, 19801990, Plon, Paris, 1990.

2. Voir notamment : Georges-Henri Soutou, La Guerre de Cinquante ans. Le conflit Est-Ouest, 1943-1990, Fayard, Paris, 2001 ; Georges-Henri Soutou, L'alliance incertaine. Les rapports politicostratégiques franco-allemands, 1954-1996, Fayard, Paris, 1996 ; Maurice Vaïsse, La Grandeur. Politique étrangère du général de Gaulle, 1958-1969, Fayard, Paris, 1998. En termes de biographies, voir un ouvrage récent fondé sur des archives variées : Éric Roussel, Charles de Gaulle, NRF Gallimard, Paris, 2002.

3. Charles de Gaulle, Mémoires d'espoir. Le renouveau, 1958-1962, Plon, Paris, 1970 ; Charles de Gaulle, Mémoires d'espoir. L'effort, 1962-..., Plon, Paris, 1970.

4. Charles de Gaulle, Lettres, notes et Carnets, Plon, Paris, 1985-1987 (tomes VIII à XI).

5. Lui-même officier de marine, Philippe de Gaulle insère dans ces recueils une abondante correspondance de son père avec les militaires, en particulier dans la marine (et notamment avec lui-même). 
retrouvent d'ailleurs dans les fonds d'archives ouverts ${ }^{6}$. Ces archives justement sont assez paradoxales. D'un côté, de larges parties d'entre elles demeurent fermées au public mais, de l'autre, les archives nationales accessibles (fond 5 AG 1) et les archives privées des proches collaborateurs (principalement les fonds Couve de Murville et Debré) donnent finalement accès à des notes assez variées. Enfin, la dernière source qui peut être considérée comme primaire sous réserve - est celle constituée par les trois volumes du C'était de Gaulle d'Alain Peyrefitte $^{7}$. Ce dernier affirme en introduction qu'il ne s'agit pas de mémoires mais d'un recueil de paroles du général de Gaulle, composées à partir de notes qu'il a prises à l'époque après ses entretiens en tête-à-tête avec le chef de l'État et surtout lors des Conseils des ministres. Ministre de l'Information de 1962 à 1966, il est le seul (avec le Premier ministre) autorisé à prendre des notes pendant les Conseils ${ }^{8}$. Si les citations de Peyrefitte doivent être manipulées avec précaution, elles ne contredisent pas les sources précédentes pour ce qui concerne la CEE et semblent authentiques. Cette source est particulièrement précieuse car les comptes rendus des Conseils sont absents des archives, sauf à de très rares exceptions ${ }^{9}$. La principale lacune des sources porte donc moins sur la vision du général du Gaulle, qui peut être reconstituée, que sur le processus de décision au sommet, plus opaque.

La conception de la CEE du général de Gaulle est marquée par une compréhension très partielle de la dynamique juridique et économique de l'intégration européenne, une caractéristique commune à de nombreux décideurs des années soixante. Ses objectifs proprement économiques sont très ciblés, voire limités, alors que ses ambitions politiques sont fortes, mais s'expriment par une stratégie institutionnelle manquant de réalisme.

\section{DES OBJECTIFS ÉCONOMIQUES CIBLÉS, VOIRE LIMITÉS}

Les conceptions économiques de l'intégration européenne par la CEE du général de Gaulle sont limitées car la CEE n'est qu'un « traité de commerce » pour lui, utile pour promouvoir une libération des échanges dorénavant bien acceptée si elle est régulée. Même sur le plan de la politique agricole, les

6. À titre d'exemple, la « Note sur l'organisation politique des Six » du 6 octobre 1960 figure dans le volume 8 à la page 401 mais aussi dans les fonds Couve de Murville (CM 7) et Debré (2 DE 29).

7. Alain Peyrefitte, C'était de Gaulle, Fayard, Paris 1994 (tomes I et II) et 2001 (tome III).

8. A. Peyrefitte, C'était de Gaulle, tome I..., op. cit., p. 139.

9. AN, 5 AG 1, volume 29, Conseil restreint du 16 octobre 1967 ; pour les autres Conseils, on dispose parfois de maigres relevés de décisions. 
ambitions proprement économiques et financières sont restreintes car la PAC est avant tout issue de considérations sociopolitiques.

\section{A. LE MARCHÉ COMMUN : UN « TRAITÉ DE COMMERCE »}

Si l'économie n'était pas la priorité du général de Gaulle, il ne pouvait pas ignorer ces dossiers. L'intérêt du général de Gaule pour les questions économiques et financières est confirmé par ses proches collaborateurs comme Roger Goetze (conseiller économique en 1958) ou Alain Prate (conseiller économique du général de Gaulle de 1967 à 1969) ${ }^{10}$. L'image d'un de Gaulle négligeant " l'intendance », selon une phrase qui lui est attribuée sans que son caractère authentique ou apocryphe ne soit confirmé, ne tient de toute façon pas devant la réalité des problèmes que la France devait régler. Son retour au pouvoir en juin 1958 coïncide d'ailleurs avec une grande période de crise financière qui mine le crédit international de la France. La puissance française dépend de sa solidité financière et économique.

Les conceptions économiques du général de Gaulle sont fondées sur une base libérale et sur un fort volontarisme économique. D'un côté, le président français s'inscrit dans les fondements de l'économie de marché néoclassique. Les lois du marché doivent donc être encouragées car elles sont à la base d'une économie prospère. Le protectionnisme de la $I V^{\circledR}$ République a clairement montré ses limites avec la crise financière de 1957-1958. D'un autre côté, estimant les milieux économiques et sociaux incapables de progresser seuls dans la voie de la modernisation, le général de Gaulle considère que l'État doit avoir un rôle fort pour guider l'économie. Les milieux économiques se plaignent souvent des rapports difficiles qu'ils pouvaient avoir avec un chef de l'État qui les a souvent dévalorisés ${ }^{11}$.

Cette inclination se manifeste sous la forme de " plans » qui peuvent être généraux (il a créé le commissariat au Plan en 1946 et l'a relancé lorsqu'il était président de la République), ponctuels (plan Rueff) ou sectoriels (plan Calcul). On retrouve également cette ambition d'orienter les grands équilibres de l'économie et de la société dans les projets de politique des revenus, puis de participation, qui revenaient à organiser la redistribution des richesses par l'État.

10. Alain Prate, Les batailles économiques du général de Gaulle, Plon, Paris, 1978, p. 18 ; N. Carré de Malberg (textes établis, présentés et annotés par), Entretiens avec Roger Goetze..., op. cit., p. 348352.

11. AO, Fondation Charles de Gaulle, entretiens de François Ceyrac avec Daniel Desmarquest le 3 décembre 1996. 
Ces conceptions économiques volontaristes ne peuvent toutefois pas s'adapter à l'échelle européenne pour des raisons institutionnelles, car cela supposerait la création d'un super-État européen pour la prendre en charge. Dès lors, le général de Gaulle n'attend de la CEE qu'une action sur la partie libérale de sa doctrine. Pour lui, la CEE est avant tout un « traité de commerce ».

Dès le mois de juin 1958, les archives confirment que de Gaulle accepte la CEE car il l'assimile à un " traité de commerce ${ }^{12}$ ", expression qui revient à de nombreuses reprises au début des années $1960^{13}$. Cette formule traduit tout à la fois l'intérêt que représente la CEE pour lui - stimuler les milieux économiques français qui cèdent trop facilement aux sirènes du protectionnisme mais aussi le caractère très limité qu'il lui attribue. Alors que le traité de Rome contient de très nombreux articles sur le processus d'harmonisation législative ou le développement de politiques communes, le général de Gaulle néglige ces développements car il se fonde sur son interprétation du développement de la CECA, qui illustre selon lui le décalage entre un traité supranational ambitieux et des réalisations limitées ${ }^{14}$. Ce préjugé reste tenace tout au long de la période. Ainsi, peu de temps avant son départ de la présidence, lors du célèbre entretien qu'il a accordé à l'ambassadeur de Grande-Bretagne en France, Christopher Soames, le 4 février 1969, de Gaulle reste dans le même cadre mental. Selon son propre compte rendu de l'entretien, il envisage des conversations bilatérales entre Paris et Londres non pas pour remettre en cause le Marché commun, mais pour « faire connaître ses vues sur ce que pourrait être une entente économique européenne (avec ses facilités d'échange et ses engagements d'importation pour certaines catégories de produits provenant des pays membres) pour le cas où, dans l'avenir, le Marché commun lui-même s'effacerait pour faire place à un autre régime ${ }^{15} \gg$. Les éléments saillants de la pensée du général de Gaulle restent présents : la CEE est avant tout un « traité de commerce » agrémentée d'accords agricoles (« engagements d'importation »), et qui a un caractère provisoire. Comme l'OECE ou la CECA, la CEE représente donc un accord multilatéral

12. AMAE, PA-AP 314, volume 1, compte rendu d'une réunion du 10 juin 1958 chez de Gaulle sur les questions internationales; voir le chapitre III.

13. Charles de Gaulle, Lettres, notes et carnets, tome IX, Plon, Paris, 1986, p 48-49 : « apostille sur une note du Premier ministre à propos de la politique européenne », 27 février 1961; A. Peyrefitte, C'était de Gaulle, tome II..., op. cit., p. 335, entretien du 20 novembre 1963 entre Peyrefitte et de Gaulle.

14. AMAE, PA-AP 314, volume 1, compte rendu d'une réunion du 10 juin 1958 chez de Gaulle sur les questions internationales.

15. AFNSP, CM 9, compte rendu d'un entretien avec Christopher Soames, ambassadeur de France en Grande-Bretagne, 4 février 1969. 
de nature essentiellement commerciale et dont la dynamique pourrait n'être que transitoire, son déclin pouvant survenir à court ou moyen terme.

Pourtant, cela ne signifie pas que la CEE occupe une place secondaire dans la politique économique. Arrivé au pouvoir en pleine crise financière déclenchée justement par des problèmes de déficit de la balance commerciale (et par le coût de la guerre d'Algérie), de Gaulle estime que l'adaptation de l'économie française à la concurrence internationale est indispensable. Dans ses mémoires, il la place au premier plan dans les objectifs du plan Rueff ${ }^{16}$. Mais la dimension la plus volontariste de la politique économique, en particulier la politique industrielle, ne peut être mise en œuvre que par les États membres, seuls ou à plusieurs, mais pas dans un cadre communautaire. Ainsi par exemple, dans un entretien avec le chancelier Erhard en février 1965, de Gaulle reconnaît que la CEE représente un cadre commercial intéressant mais il estime que la coopération industrielle européenne ne peut être organisée que par les États, en particulier par la coopération franco-allemande ${ }^{17}$.

La CEE est donc une base, un préalable, mais pas le cadre unique de la coopération économique européenne. La conception gaulliste n'est d'ailleurs pas particulièrement originale dans la France de la fin des années 1950 car un large consensus existe au sein des décideurs français sur la nécessité de pratiquer, dans le cadre de la CEE, une politique économique de libéralisation régulée.

\section{B. L’ENCOURAGEMENT À LA LIBÉRATION DES ÉCHANGES}

Le principal levier de modernisation de l'économie française par la CEE pour de Gaulle est avant tout la libération des échanges, qui doit être beaucoup plus prononcée que pendant les années 1950, aussi bien à l'intérieur de la CEE qu'envers l'extérieur.

À l'intérieur du Marché commun, une fois le redressement de la compétitivité française acquis par le plan Rueff, le gouvernement français se montre très favorable à la libération des échanges. Dès le mois d'avril 1959, le ministre des Finances Antoine Pinay pense à une accélération du rythme de diminution 151.

16. Charles de Gaulle, Mémoires d'espoir. Le renouveau, 1958-1962, Plon, Paris, 1970 , p. 150-

17. AAPD, 1965-I, doc $n^{\circ} 26$, Gespräch des Bundeskanzlers Erhard mit Staatspräsident de Gaulle im Rambouillet, 20 janvier 1965, p. 149 ; Laurent Warlouzet, « La dimension industrielle du couple franco-allemand : les tentatives de créer une coopération bilatérale institutionnalisée entre 1965 et 1969 », in Jean-François Eck, Stefan Martens, Sylvain Schirmann (dir.), L'économie, l'argent et les hommes. Les relations franco-allemandes de 1871 à nos jours, Comité pour l'histoire économique et financière de la France, Paris, 2009, p. 287-307. 
des droits de douane prévu par le traité de Rome afin de faire pression sur l'inflation $^{18}$. En octobre 1959 il écrit même à Couve de Murville pour évoquer la possibilité de mesures de libération des échanges unilatérales de la part de la France ${ }^{19}$. Une première accélération du rythme de libération des échanges au sein du Marché commun est d'ailleurs acceptée par le Conseil CEE le 12 mai 1960 et une seconde le 15 mai 1962. Par la suite, les conseillers du général de Gaulle continuent de défendre périodiquement le recours à une libération accrue des échanges soit pour limiter l'inflation, soit pour diminuer le prix des biens importés et donc accroître la compétitivité des industries françaises ${ }^{20}$. Ce soutien français au mouvement de libération des échanges intracommunautaires permet d'achever la période transitoire le premier juillet 1968, après neuf ans et demi de période transitoire, au lieu des douze à quatorze années prévues initialement dans le traité, et alors que de nombreux décideurs français estimaient en 1956 que ce délai serait impossible à tenir. La France avait même paru un temps accepter la date du premier juillet 1967 avant qu'un événement de nature politique - la crise de la chaise vide - ne l'amène à renoncer à cette concession ${ }^{21}$.

Face à l'extérieur également, le gouvernement français se montre relativement libéral. Ainsi, il accepte pendant la négociation sur l'accélération de la mise en place du Marché commun une diminution du TEC de vingt pour cent de manière unilatérale afin d'encourager le mouvement de libération des échanges européen et mondial ${ }^{22}$. De même, dans son étude du Kennedy Round (1964-1967), Lucia Coppolaro a montré que la France, comme l'Italie, avait une position un peu moins libérale que la RFA et le Benelux, mais que tous acceptaient le principe d'une diminution générale des droits de douane pour stimuler la croissance économique mondiale, tout en tenant des positions protectionnistes sur certains secteurs précis ${ }^{23}$. Pour Paris, les principaux problèmes dans cette négociation concernent les produits agricoles (pour préserver la PAC) et les aspects politiques (refus du projet Kennedy de zone atlantique) ${ }^{24}$, et pas la libération des échanges des produits industriels. Le gouvernement français estime que ses

18. AMINEFI, B 55.909, compte rendu du comité des Prix du 21 avril 1959.

19. AMINEFI, B 17.680, lettre d'Antoine Pinay, ministre des Finances et des Affaires économiques, à Maurice Couve de Murville, ministre des Affaires étrangères, 30 octobre 1959.

20. AN, 5 AG1, volume 49, note du secrétariat général de la présidence de la République, 30 janvier 1963 ; note pour de Gaulle du 8 octobre 1963 ; note de Jean-Maxime Lévêque du 14 octobre 1963 ; AN, 5 AG1, volume 31, note de J. Chabrun du 20 décembre 1966.

21. AN, 5 AG1, volume 48, note de Jean Dromer du 8 mai 1967.

22. AMAE, DECE 616, folio 39, note de Maurice Ulrich (DAEF), du 12 avril 1960.

23. Lucia Coppolaro, Trade and Politic across the Atlantic : the European Economic Community (EEC) and the United States of America in the GATT Negotiations of the Kennedy Round (1962-1967), thèse dir. Alan Milward, Institut universitaire européen de Florence, 2006, p. 13, 302, 420.

24. L. Coppolaro, Trade and Politics across the Atlantic..., op. cit., p. 91-93. 
industries étaient compétitives. Ainsi, dans le compte rendu d'une discussion entre fonctionnaires français et allemands en 1963, les Français estiment que les positions de fond sur les tarifs industriels sont proches mais que la grande divergence est politique, les Allemands se montrant beaucoup trop tendres avec les Américains ${ }^{25}$. Piers Ludlow estime que Paris a eu parfois tendance à surestimer publiquement sa réticence envers les négociations du GATT afin d'obtenir des concessions dans d'autres dossiers ${ }^{26}$.

L'attitude de la France face à la libération des échanges est donc radicalement différente de celle des années 1950. Alors que la France réclamait toujours des exceptions, elle accepte maintenant pleinement un mouvement général qu'elle n'hésite pas à encourager dans des cas spécifiques. Le contraste est très fort avec les craintes exprimées lors de la négociation et de la signature du traité de Rome, en 1956-1957, alors que de nombreux responsables français estimaient que leur pays serait incapable de supporter la mise en place d'un marché commun. Cette conversion de la France s'explique par la dévaluation de 1958, mais aussi par le fait que la libération des échanges est utile pour remplir des objectifs conjoncturels (lutte contre l'inflation) et structurels (modernisation de l'industrie française). Certes la France est toujours moins libre-échangiste que certains de ses voisins (RFA, pays du Benelux) mais elle accepte pleinement cette dynamique car la CEE offre un cadre de régulation adapté.

\section{LE CONSENSUS FRANÇAIS AUTOUR D'UNE LIBÉRALISATION RÉGULÉE}

La nécessité d'obtenir une régulation de la libération des échanges par l'action des institutions communautaires est inscrite au cœur de la doctrine de l'équilibre entre libération des échanges et harmonisation des conditions de concurrence définie depuis 1956 tant par le CNPF que par les négociateurs français du traité de Rome. Il est à la base des équilibres définis dans ce traité : le processus de libération y est précisément défini mais il est compensé - à la différence de la ZLE - par des éléments autorisant une suppression des distorsions de concurrence les plus flagrantes.

Concrètement, la régulation se matérialise par plusieurs éléments. Tout d'abord, la gestion des échanges extérieurs est mise en commun pour éviter les problèmes de détournements de trafics présents dans une zone de libre-échange

25. AMAE, POW 2, folio 99, note GL (DAEF/SCE) du 27 juin 1963 ; AMAE, POW 2, folio 241, note de Maurice Ulrich (DAEF) du 16 novembre 1963.

26. P. Ludlow, The European Community and the Crises of the 1960s..., op. cit., p. 127. 
(tarifs élevés contournés par l'importation par un pays à tarif faible). Le TEC est défini rapidement et dès le Kennedy Round (1964-1967), une politique commerciale commune est mise en œuvre ${ }^{27}$. La Commission négocie au nom des Six. La procédure n'est pas supranationale mais communautaire : l'institution bruxelloise a un mandat impératif et doit respecter scrupuleusement la position définie par les États membres. Elle permet néanmoins aux Six de négocier en étant beaucoup plus puissants que s'ils avaient été divisés.

Au-delà, la régulation communautaire concerne aussi la libération interne des échanges, y compris les clauses de sauvegarde. Pendant la négociation du traité de Rome, la France a beaucoup insisté sur ces revendications, en demandant des garanties très larges (possibilité de retarder le rythme de mise en place du Marché commun, protocole sur les taxes à l'importation et les aides à l'exportation, etc.), ce qui pouvait instiller un doute sur sa volonté de respecter la libéralisation des échanges. Après le plan Rueff, la France accepte pleinement l'ouverture des marchés et ne compte plus, comme ses partenaires, que sur des garanties spécifiques et gérées de manière communautaire. En effet, la CEE peut concéder des exceptions au principe de base de libéralisation des échanges en accordant des contingents tarifaires, des tarifs spéciaux (liste G) ou même des protections temporaires. Ainsi, en 1962, la France a eu recours à la protection de l'article 226 - clause de sauvegarde en cas de difficultés sectorielles ou régionales, contre des importations massives de réfrigérateurs italiens, pour permettre une restructuration du secteur concerné ${ }^{28}$.

Plus généralement, la régulation porte sur l'harmonisation des distorsions de concurrence les plus flagrantes. Une fois l'harmonisation des tarifs extérieurs acquise (TEC), et après la disparition assez rapide d'une revendication d'harmonisation sociale jugée de plus en plus inutile (en raison des progrès de l'État providence dans l'ensemble des Six ${ }^{29}$, la France met l'accent sur l'harmonisation fiscale. Elle est en effet désavantagée par son système de TVA, alors que les Cinq ont des systèmes de taxe en cascade qui leur donnent le droit de lever des taxes compensatoires à un niveau mal défini ${ }^{30}$. À la demande expresse

27. C'est l'objet de la thèse de Lucia Coppolaro: L. Coppolaro, Trade and Politics across the Atlantic..., op. cit.

28. Jacques et Colette Nême, Économie européenne, PUF, Paris, 1970, p. 71.

29. Lise Rye, "The Rise and Fall of the French Demand for Social Harmonization in the EEC, 1955-1966 », in Katrin Rücker, Laurent Warlouzet (éd.), Quelle(s) Europe(s) ? Nouvelles approches en histoire de l'intégration européenne, Peter Lang, Bruxelles, 2006, p. 155-168.

30. Les taxes de compensations sont nécessairement imprécises car elles doivent correspondre à des taxes en cascades prélevées, comme leur nom l'indique, à chaque étape de la transformation d'un produit. Au contraire la TVA est beaucoup plus simple à prélever à l'importation et à exonérer à l'exportation car elle est prélevée en une seule fois au stade du consommateur final. 
du CNPF, la France avait déjà obtenu l'article 97 qui donne à la Commission le pouvoir de surveiller ces taxes compensatoires ${ }^{31}$. Paris estime que certains pays fixent ces taxes à des niveaux trop élevés. Elles constituent alors de véritables barrières protectionnistes et sont donc assimilables à des aides à l'exportation et à des taxes à l'importation. En 1961, le ministre de l'Industrie Jeanneney se montre particulièrement agressif envers l'Italie car il est sollicité par le CNPF et parce qu'il estime que le secrétaire d'État aux Finances Giscard d'Estaing est trop souple sur ce dossier ${ }^{32}$. À son instigation, et faute de décisions communautaires suffisamment rapides, la France envoie un aide-mémoire à l'Italie ${ }^{33}$. Le règlement des conflits par les institutions communautaires parait en effet très imparfait car la France se plaint ensuite, en 1963, de manipulations fiscales émanant cette fois de RFA ${ }^{34}$ et provoque un débat au Conseil ${ }^{35}$. Le problème n'est réglé qu'à la fin de la période transitoire. Suite à la pression exercée par le nouveau ministre des Finances Michel Debré lors du Conseil du 20 décembre 1966, la Commission propose le 28 juin 1967 une directive d'harmonisation du calcul des taxes de compensations qui est adoptée par le Conseil le 25 mars $1968^{36}$.

La récurrence de ce problème de manipulations fiscales conduit la France à envisager dès 1960 une solution plus radicale, celle de l'extension du système de la TVA aux Six ${ }^{37}$. La France se fonde sur l'article 99 qui donne le pouvoir à la Commission d'harmoniser les taxes sur le chiffre d'affaires. La Commission soutient bien évidemment cette doléance française dans la mesure où elle peut accroître ses prérogatives. Le dossier est cependant bloqué entre 1962 et 1965 par une opposition franco-allemande ${ }^{38}$. Le commissaire allemand von der

31. Voir le chapitre I; ACNPF 72 AS 1590, note de Hommey pour Villiers, 27 mars 1957 ; ASCGI, 1991.004, art. 2, lettre de Faure à Villiers du 4 juin 1957.

32. AINDUS, 1977.1386, volume 54, projet de lettre du ministre de l'Industrie aux ministres des Affaires étrangères et des Finances, ainsi qu'au secrétaire d'État aux Finances, du 10 avril 1961 ; ACNPF, 72 AS 1315, note de Georges Villiers (CNPF) à J. Violet, 27 janvier 1961.

33. AINDUS, 1977.1386, volume 54, note de Claude Beaurepaire, IG, à Raymond Barre, directeur de cabinet de Jeanneney, ministre de l'Industrie, du 3 janvier 1962.

34. AINDUS, 1977.1386, volume 54, projet de lettre du ministre de l'Industrie au secrétaire d'État aux Finances, 15 mai 1961.

35. AMAE, RPUE 49, procès-verbal de la $103^{\mathrm{e}}$ session du Conseil des 30 et 31 mai 1963, point 15 ; RPUE 50, procès-verbal de la $105^{\mathrm{e}}$ session du Conseil du 18 juin 1963, point 17.

36. AN, 540 AP, volume 15, note du SGCI du $1^{\mathrm{er}}$ mars 1968 ; J. et C. Nême, Économie européenne..., op. cit., p. 90.

37. Sur ce dossier de la TVA : Éric Bussière, «La concurrence », in M. Dumoulin (dir.), La Commission européenne, 1958-1972..., op. cit., p. 323-326 ; Frédéric Tristram, Une fiscalité pour la croissance. La direction générale des Impôts et la politique fiscale en France de 1948 à la fin des années 1960, Comité pour l'histoire économique et financière de la France, Paris, 2005, p. 563-576.

38. F. Tristram, Une fiscalité pour la croissance..., op. cit., p. 564-567. 
Groeben et la RFA veulent en effet profiter de l'harmonisation des taxes sur le chiffre d'affaire pour supprimer les frontières fiscales et imposer un taux unique de TVA. Au contraire, la France plaide pour une harmonisation qui préserverait des taux différents. La réticence française s'explique par des raisons politiques - ne pas s'engager dans la voie d'une harmonisation fiscale trop poussée - et surtout pour des raisons budgétaires. En effet les impôts indirects, en particulier la TVA, ont un poids plus fort en France que dans les autres pays de la Communauté ${ }^{39}$.

Les positions restent les mêmes jusqu'en 1966. À partir de cette date, le nouveau ministre des Finances Michel Debré adopte une position de fond conforme à la doctrine française antérieure ${ }^{40}$, mais y ajoute un volontarisme plus fort. Debré s'implique personnellement dans ce dossier ${ }^{41}$, qui n'a jamais été véritablement traité à l'échelle politique selon le $\mathrm{SGCI}^{42}$. Il prononce un discours lors du Conseil des ministres du 20 décembre 1966 où il propose un véritable programme d'action pour le premier juillet 1968, fondé sur la définition de quelques chantiers prioritaires dont celui de la TVA ${ }^{43}$. Finalement, la situation se débloque rapidement. Le 11 avril $1967^{44}$, les ministres des Six s'accordent sur les textes de deux directives d'harmonisation des taxes sur le chiffre d'affaires qui prévoient l'extension aux Cinq du système français de TVA pour le $1^{\mathrm{er}}$ janvier 1970. Pour décourager toutes les manipulations fiscales, Debré a cherché à imposer que les exceptions à la règle d'harmonisation ne puissent être prises qu'après une approbation du Conseil à l'unanimité ${ }^{45}$. Debré a ainsi imposé une solution à la fois européenne - le dossier de la TVA est dorénavant traité au niveau européen - et relativement intergouvernementale - le Conseil décide à l'unanimité, même si le dossier est bien traité selon une procédure communautaire dorénavant. Les États membres perdent leur liberté d'action unilatérale dans ce domaine.

Le dossier de l'harmonisation fiscale démontre combien la France est prête à consentir des délégations de souveraineté dans des domaines précis si la CEE semble remplir une mission indispensable à la régulation de l'ouverture des

39. AMAE, RPUE 635, note de R. Mermoux, conseiller financier à la représentation permanente, 27 mars 1964 ; F. Tristram, Une fiscalité pour la croissance... op. cit., p. 564-567.

40. AFNSP, 4 DE 12, note de Debré pour Laxan (DG des Impôts), 18 avril 1966.

41. AN, 86 AJ, volume 84, note de Jean-René Bernard du 15 décembre 1966.

42. AMAE, DECE 1117, 1961-1966, folio 36, note du SCGI du 12 octobre 1965.

43. ASGCI, 1990.0646, volume 8, discours de Michel Debré lors du Conseil CEE du 20 décembre 1966.

44. Le 11 avril 1967 est la date de l'accord au Conseil. Les ministres des Finances sont parvenus à un accord le 9 février 1967.

45. AMAE, DECE 729, télex de Boegner du 10 février 1967. 
marchés. Le cas de la TVA est, dans cette perspective, analogue à celui du TEC, autre prérogative communautaire pleinement acceptée par la France. Au-delà, les décideurs français sont même prêts à envisager que la Commission européenne devienne un véritable arbitre des interventions des États membres.

\section{L'ACCEPTATION D'UNE EUROPE-ARBITRE}

L'ambition d'utiliser la CEE pour promouvoir une régulation du libéralisme se voit dans la volonté de donner aux institutions communautaires - la Commission mais aussi le Conseil - une véritable fonction d'arbitre économique, y compris en direction des États. C'est particulièrement évident dans le domaine du contrôle des aides d'État. Dès janvier 1959, la Commission européenne plaide pour la création d'une procédure de notification à la Commission des projets d'aides d'États ${ }^{46}$. Les Etats membres devraient donc attendre l'accord de l'institution supranationale pour mettre en œuvre ce qui est une prérogative essentielle de la politique économique des gouvernements européens.

Face à ces ambitions de la Commission, la France définit assez rapidement, en 1959-1960, une position de principe double ${ }^{47}$. D'un côté, sur le plan institutionnel, la France est hostile à des délégations de souveraineté trop importantes et donc au système des notifications s'il est trop contraignant. Un État membre ne devrait pas attendre l'autorisation de la Commission pour appliquer l'aide notifiée. Mais, d'un autre côté, sur le plan économique, la France est favorable au développement d'une véritable politique communautaire des aides afin d'éviter les distorsions de concurrence excessives. Ainsi, la France est favorable à un large développement de l'information de la Commission sur les aides d'État existantes.

Cependant, la France subit l'activisme de la Commission dans ce domaine dès juin 1959. À cette date, le commissaire von der Groeben demande à la France de modifier une aide reposant sur une déduction fiscale aux investissements instaurée par un arrêté du 28 mai $1959^{48}$. Le commissaire européen demande de supprimer une clause territoriale considérée comme discriminatoire. En effet, l'aide française n'est accordée qu'aux investissements portant sur des biens

46. AMAE, DECE 675, lettre de Verloren van Themaat au représentant permanent français, 23 décembre 1958 ; AMAEF, DECE 675, note SGCI du 3 février 1959.

47. AMAE, DECE 675, note SGCI du 24 avril 1959 sur la réunion du 17 avril 1959 des experts nationaux sur les aides; AMINEFI, B 16678, note SGCI (JS) du 31 mars 1960 sur la visite en France de von der Groeben.

48. AHUE, BAC 1/1971, volume 79, folio 206, rapport de von der Groeben du 19 juin 1959, doc COM (59)84. 
d'équipement fabriqués en France. Von der Groeben reconnaît qu'il n'a pas le pouvoir de supprimer cette aide car l'interprétation du traité de Rome sur ce point n'est pas déterminée ${ }^{49}$, mais il peut compter sur le soutien de milieux économiques et politiques européen $\mathrm{s}^{50}$ qui se sont plaints de cette aide, notamment une plainte du gouvernement belge $\mathrm{e}^{51}$. Face à cette menace de la Commission européenne, le Premier ministre Michel Debré reste intransigeant ${ }^{52}$. Au contraire, les diplomates de la DAEF conseillent la modération car ils reconnaissent l'incompatibilité flagrante de l'aide française avec le traité de Rome ${ }^{53}$.

La Commission organise alors une réunion des experts des Six pour étudier l'aide française. Elle aboutit à une condamnation unanime de cette dernière ${ }^{54}$. Donnedieu de Vabres intervient alors directement auprès du Premier ministre pour conseiller la modération ${ }^{55}$. L'ambassade de Belgique elle-même intervient auprès du Quai d'Orsay pour hâter la décision ${ }^{56}$. Finalement Debré accepte l'abrogation des dispositions attaquées par la Commission, sous la pression des diplomates et du ministre des Finances Pinay ${ }^{57}$. La prime spéciale d'équipement, qui remplace en 1960 cette aide aux investissements, est elle aussi placée immédiatement sous la surveillance de la Commission ${ }^{58}$. Ainsi la France subit dès 1959 l'autorité de la Commission européenne dans ce domaine alors même qu'aucun règlement d'application du traité n'a été accepté. La pression des États membres partenaires a sans doute joué un rôle aussi important que la contrainte juridique, issue directement du traité de Rome.

Par contre, la DG IV ne parvient pas à mettre en place un système communautaire de surveillance systématique des aides nationales en raison des réticences françaises mais aussi belges et allemandes ${ }^{59}$. Elle continue toutefois

49. AHUE, BAC 1/1971, volume 79, folio 206, rapport de von der Groeben du 19 juin 1959, doc COM (59)84. 1959.

50. AMAE, DECE 675, folio 45, lettre de von der Groeben aux représentants permanents, 15 juillet

51. AMAE, DECE 662, folio 41, lettre de l'ambassade de Belgique en France au ministre, 18 juin 1959.

52. AMAE, DECE 675, folio 61, note de Maurice Ulrich (DAEF) du 5 octobre 1959.

53. AMAE, DECE 675, folio 61, note de Maurice Ulrich (DAEF) du 5 octobre 1959.

54. AMAE, DECE 675, folio 70, télégramme de la REP, Mille, 21 octobre 1959.

55. AMAE, DECE 675, folio 72, note de Maurice Ulrich (DAEF), 29 octobre 1959.

56. AMAE, DECE 675, folio 88, lettre de l'ambassade de Belgique à Paris à Quioc (DAEF), 18 novembre 1959.

57. AMAE, DECE 675, folio 94, note de Maurice Ulrich (DAEF), 26 novembre 1959.

58. AHUE, BAC 1/1971, volume 80, folio 157, doc IV/COM(60)54, communication de von der Groeben au collège des commissaires du 31 mars 1960.

59. AMAE, RPUE 619, télex du 2 février 1961 sur la réunion des experts gouvernementaux sur les aides d'État du 24 janvier 1961 : AMINEFI, B 17.722, télex du 24 janvier 1961 sur la réunion des experts gouvernementaux sur les aides d'État du 24 janvier 1961. 
d'entretenir des ambitions importantes en la matière. Elle diffuse à la fin du mois d'octobre 1964 un mémorandum qui préconise un examen a priori des projets d'aides nationaux ${ }^{60}$. Les États devraient notifier les décisions individuelles prises en application de ces aides.

Face à ce projet, le ministère français de l'Industrie se montre assez favorable aux grandes lignes du mémorandum de la Commission car il défend «l'harmonisation progressive mais indispensable des régimes d'aides, dès lors que les protections douanières auront été supprimées dans la Communauté ${ }^{61} \gg$. Il fonde sa position sur la conviction que les aides françaises ne sont pas plus importantes que celles qui ont cours à l'étranger, mais qu'elles sont plus visibles. Pour éviter que l'industrie française ne soit désavantagée, il demande donc des garanties en terme d'information (communication de statistiques annuelles par secteurs) et la possibilité de recours d'un État membre contre une aide précise. La note du ministère de l'Industrie est écrite dans le contexte des aides à Ford-Belgique qui font l'objet d'une procédure devant la Commission ${ }^{62}$. Elle manifeste donc clairement la volonté de la France d'utiliser les institutions communautaires pour faire pression sur ses partenaires européens en la matière.

La réunion tenue au SGCI se conclut sur une position assez proche ${ }^{63}$. La position officielle reste favorable aux grandes orientations retenues par la Commission, mais la France demande des garanties sur les informations concernant les régimes étrangers d'aide et leur application. Sur le plan institutionnel enfin, elle refuse d'accorder trop de délégation de pouvoirs à la Commission : les décisions individuelles ne sauraient lui être transmises, les critères de surveillance devraient être définis en coopération avec les Etats membres, etc. Finalement, la négociation n'avance pas en 1964 et 1965 en raison des réticences des six États membres.

Le dossier des aides d'État paraît particulièrement révélateur des conceptions de certains décideurs français, même s'il n'aboutit pas à des décisions marquantes. Malgré la condamnation de son régime d'aide aux investissements, la France semble accepter la contrainte communautaire dans ce domaine dans la mesure où elle s'exprime dans un cadre à dominante intergouvernemental et où elle pense avoir beaucoup à gagner du démantèlement des régimes d'aides de ses voisins. La thématique des aides étrangères cachées, par opposition à des aides françaises beaucoup plus visibles, est importante dans la psychologie

60. AMAE, DECE 1267, projet de lettre du SGCI au REP du 27 octobre 1964.

61. AMAE, DECE 1267, note de Robert Gardellini, dir. de cab. du ministre de l'Industrie, 30 novembre 1964.

62. S. Ramirez, Public Policies..., op. cit., p. 689-692.

63. AMAE, DECE 1267, note de synthèse SGCI (HB) du 9 décembre 1964. 
économique française. Au-delà du seul dossier des aides, elle explique le soutien à une harmonisation assez poussée dans de nombreux domaines comme la régulation de la libération interne des échanges ou l'harmonisation fiscale.

Par ailleurs, sur le plan des acteurs, le pragmatisme du couple DAEF-SGCI dans le domaine des aides, l'évolution de Michel Debré - intransigeant en 1959 face à la condamnation de l'aide française puis soutien de poids à l'harmonisation fiscale entre 1966 et 1968, témoigne de l'acculturation progressive des professionnels des affaires européennes à la contrainte communautaire. La promotion de la régulation du libéralisme par la CEE paraît donc très largement répandue parmi les décideurs français. Elle est à la base de leur interprétation économique du traité de Rome, surtout dans la mesure où la PAC apparaît comme un dossier essentiellement sociopolitique.

\section{E. LA PAC : UNE PRIORITÉ POLITIQUE MAL MAÎTRISÉE}

En dehors de l'acceptation d'une libération des échanges régulée, la politique économique européenne de la France repose sur la priorité accordée à l'agriculture. La connaissance de la PAC a progressé grâce aux travaux menés par Ann-Christina Knudsen ${ }^{64}$, Gilbert Noël ${ }^{65}$, Piers Ludlow ${ }^{66}$ et Kiran Patel ${ }^{67}$. Ils doivent être croisés avec les études sur la politique agricole gaulliste ${ }^{68}$ ainsi que les sources déjà évoquées sur la pensée du président français. Leur étude

64. Ann-Christina Knudsen, Farmers on Welfare. The Making of Europe's Common Agricultural Policy, Cornell UP, Ithaca, 2009.

65. Gilbert Noël, « Politique agricole commune : l'approche commerciale de la France », in Le rôle des ministères des Finances et de l'Économie dans la construction européenne (1957-1978), Comité pour l'histoire économique et financière de la France, Paris, 2002, p. 393-410 ; Gilbert Noël, «Les finalités de la politique agricole commune (1958-1972). Marché et cohésion économique et sociale », in Antonio Varsori (éd.), Inside the European Community. Actors and Policies in the European Integration, 1957-1972, Bruylant, Bruxelles, 2006, p. 283-300.

66. Piers Ludlow, «The Green Heart of Europe? The Rise and Fall of the CAP as the Community's Central Policy, 1958-1985 », in Kiran Patel (éd.), Fertile Ground for Europe ? The History of European Integration and the Common Agricultural Policy since 1945, Nomos, Baden-Baden, 2009, p. 79-96 ; Piers Ludlow, «The Making of the CAP : Towards a historical analysis of the EU's first major policy », in Contemporary European History, 24 (2005), p. 347-371.

67. Kiran Patel, « Europeanisation à contre cœur. West Germany and agricultural Integration, 1950-1975 », in Kiran Patel (éd.), Fertile Ground for Europe?..., op. cit., p. 139-160 ; Kiran Patel, Europäisierung wider Willen : Die Bundesrepublik Deutschland in der Agrarintegration der EWG, 1955-1975, Oldenbourg, Münich, 2009.

68. Bernard Bruneteau, Les paysans dans l'État: le gaullisme et le syndicalisme agricole sous la Cinquième République, L'harmattan, Paris, 1994 ; Pierre Muller, Le technocrate et le paysan : essai sur la politique française de modernisation de l'agriculture, de 1945 à nos jours, Les éditions ouvrières, Paris, 1984. 
permet de dégager trois traits saillants. Tout d'abord, la PAC est avant tout une politique de " welfare state ", surtout dans le cas français. Ensuite, elle s'est imposée comme la priorité de la politique européenne de la France du fait du général de Gaulle. Cependant, ce dernier, comme les autres acteurs de la négociation, n'a pas réussi à maîtriser un processus de décision communautaire marqué par une forte inertie.

Tout d'abord, depuis la thèse de la chercheuse danoise Ann-Christina Knudsen ${ }^{69}$, il est désormais bien établi que la PAC est avant tout une politique de « welfare state » (d'État providence). Elle n'est pas issue d'un calcul économique rationnel mais d'une motivation sociopolitique : il s'agit de soutenir le revenu agricole pour assurer la paix sociale dans les campagnes, soumises à la très forte pression de l'exode rural qui détruit ses structures. La PAC prend la suite des politiques très interventionnistes mises en place dans presque tous les pays occidentaux au moins depuis la crise de 1929. L'agriculture n'est en effet pas un secteur soumis de manière directe aux lois du marché, mais fait l'objet d'une très forte régulation publique. En ce sens, la PAC représente un " European Rescue of the agricultural welfare state » selon Knudsen ${ }^{70}$ qui reprend ici la formule d'Alan Milward : elle a servi à renforcer la légitimité des États-nations démocratiques, mise à mal entre 1929 et 1945 , en assurant l'adhésion d'un groupe social potentiellement frondeur, les agriculteurs.

Cette thèse, très largement acceptée par les études les plus récentes ${ }^{71}$, se vérifie particulièrement dans le cas français. Les agriculteurs se sentaient particulièrement vulnérables face à la dynamique soutenue d'industrialisation et d'urbanisation des années cinquante, après des années quarante marquées par la pénurie alimentaire, où leur rôle social était donc valorisé ${ }^{72}$. Représentant encore $20 \%$ de la population active, ils pèsent bien plus encore sur le plan culturel, avec leurs valeurs de travail, d'individualisme et de mobilisation politique qui restent au cœur du consensus républicain ${ }^{73}$. Ce décalage entre une représentation ancienne de centralité au sein de la société française, et une marginalisation

69. La thèse a été soutenue en 2001 : Ann-Christina Knudsen, Defining the Common Agricultural Policy, A Historical Study, thèse dir. Alan Milward, Institut universitaire européen de Florence, 2001 ; et publiée en 2009 : A.-C. Knudsen, Farmers on Welfare..., op. cit.

70. A.-C. Knudsen, Farmers on Welfare..., op. cit., p. 315.

71. Kiran Patel, « Introduction », in Kiran Patel (éd.), Fertile Ground for Europe..., op. cit., p. 18 ; Piers Ludlow, «The Green Heart of Europe ?... », op. cit., p. 83.

72. Jean Meynaud, La révolte paysanne, Payot, Paris, 1963, p. 17, 31, 45.

73. Edgard Pisani, Le Général indivis, Albin Michel, Paris, 1974, p. 75-76 ; Bernard Bruneteau, «Les usages de la référence paysanne dans la construction du consensus républicain en France », in Histoire et politique, Mélanges offerts au Doyen Monange, Association des amis du Doyen Monange, Brest, 1994, p. 284. 
croissante dans les Trente Glorieuses s'est cristallisé après 1958. Lorsque de Gaulle revient au pouvoir, il impose une politique macroéconomique austère, marquée par la lutte contre l'inflation, notamment par la suppression de l'indexation des prix agricoles. L'agriculture n'est en effet pas une priorité au début du mandat du nouveau président ${ }^{74}$. Cette politique entraîne de nombreuses manifestations entre 1959 et 1961, qui sont parfois violentes (occupation d'une souspréfecture en Bretagne en 1961) $)^{75}$. Leurs conséquences politiques sont importantes. Les agriculteurs restent très influents dans de nombreuses circonscriptions et obtiennent en 1960 qu'un nombre suffisant de parlementaires se mobilise pour obtenir la convocation d'une session spéciale sur cette question, mais le président de l'Assemblée nationale, le gaulliste Jacques Chaban-Delmas bloque cette initiative $^{76}$. Surtout dans un contexte de guerre civile larvée, avec notamment la tentative de coup d'État militaire à Alger en avril 1961, de Gaulle ne peut pas se permettre de laisser se développer une agitation paysanne aussi forte. Deux lois d'orientation agricoles importantes sont donc votées en 1960 et 1962 pour encourager la modernisation du secteur et un nouveau ministre de l'Agriculture plus dynamique, Edgard Pisani, est nommé en $1961^{77}$. Il continue les réformes structurelles internes, et il voit dans la PAC leur complément naturel : la pacification rurale passe par des transferts financiers que la CEE peut fournir par l'intermédiaire de cette nouvelle politique commune.

Pour de Gaulle, l'agriculture est moins un atout économique qu'une charge lourde, tant sur le plan financier que sur le plan des troubles politiques si l'on se fie à ses mémoires et à ses propos rapportés par Peyrefitte ${ }^{78}$. D'ailleurs, les agriculteurs ont rapidement compris l'intérêt de cette nouvelle politique européenne pour eux et se sont mobilisés contre de Gaulle lors des élections présidentielles de décembre 1965, pour protester contre la politique de la chaise vide qui peut remettre en cause la $\mathrm{PAC}^{79}$.

Cette protestation est paradoxale car, et c'est le deuxième aspect, l'agriculture n'est devenue une priorité dans la politique européenne de la France que du fait

74. Édouard Lynch, « Le "moment Debré" et la genèse d'une nouvelle politique agricole », in Serge Berstein, Pierre Milza and Jean-François Sirinelli (éd.), Michel Debré. Premier ministre, PUF, Paris, 2005, p. 223.

75. É. Lynch, «Le "moment Debré"... », op. cit., p. 226-231; Gordon Wright, Rural Revolution in France. The Peasantry in the Twentieth Century, Stanford UP, Stanford, 1964, p. 167-168.

76. J. Meynaud, La révolte paysanne..., op. cit., p. 61.

77. John T.S. Keeler, The Politics of Neocorporatism in France. Farmers, the State, and Agricultural Policy-making in the Fifth Republic, Oxford UP, Oxford, 1987, p. 63-67.

78. Charles de Gaulle, Mémoires d'espoir. Le renouveau, 1958-1962, Plon, Paris, 1970, p. 167 ; Alain Peyrefitte, C'était de Gaulle, tome II, Fayard, Paris, 1994, p. 364, 401, 489, 492, 499-501 et 508.

79. B. Bruneteau, Les Paysans dans l'État..., op. cit., p. 120-121. 
du général de Gaulle. Pendant la négociation du traité de Rome, les problèmes agricoles ont fait l'objet d'un traitement superficiel car les négociateurs gardaient en mémoire l'échec du pool vert ${ }^{80}$. Du côté français, l'étude des moments clés de la définition de la position française (mémorandum d'octobre 1955, intervention de Pineau à la conférence de Venise en mai 1956, comité interministériel de septembre 1956, accord franco-allemand de novembre 1956) démontre que le dossier agricole était important, mais secondaire par rapport à la libération des échanges et à la question politico-institutionnelle ${ }^{81}$. Le même constat peut être fait pour la négociation ZLE ${ }^{82}$. De plus, l'étude de la création de la PAC par Knudsen a clairement démontré que la négociation a été dominée par la Commission européenne, qui a réussi à faire passer ses propositions en 1962 et 1964 grâce au dynamisme de Sicco Mansholt mais aussi à la faible implication des Etats membres ${ }^{83}$. La France a commencé à se mobiliser à partir de la nomination de Pisani, à la mi-1961 soit seulement quelques mois avant la négociation décisive, mais reste globalement plus réactive que proactive ${ }^{84}$. Les études sur archives ont également démontré que l'État le plus inflexible sur la PAC n'était pas la France mais la RFA, qui s'est souvent retrouvée isolée entre 1960 et 1964 dans une position d'opposition, devenant ainsi un « Veto Player $n^{\circ} 1^{85}$ ». De son côté, la France n'a pas réussi à influencer de manière décisive une négociation où ce sont les propositions de compromis de la Commission qui s'imposent, ainsi sur la fixation des prix des céréales en 1964 ou des prix plus élevés que ceux préconisés par la France ont été adoptés. Au contraire, le général de Gaulle a affirmé dans de nombreux documents son exigence d'une modération de la progression des prix agricoles français tant pour limiter l'inflation que pour affirmer l'autorité de l'État face aux revendications des syndicats agricoles ${ }^{86}$.

80. K. Patel, «Europénisation à contrecœur...», op. cit., p. 142-3; A.-C. Knudsen, Farmers on Welfare..., op. cit., p. 59-60, A. Milward, The European Rescue of the Nation-State..., op. cit., p. 309-315.

81. Voir le chapitre I.

82. Voir les chapitres I à III.

83. A.-C. Knudsen, Farmers on Welfare..., op. cit., p. 139-141, 310-311.

84. A.-C. Knudsen, Farmers on Welfare..., op . cit., p. 191, 261-262.

85. Kiran Patel, «Veto Player $n^{\circ} 1$ ? Germany and the Creation of the EEC's Common Agricultural Policy, 1957-1964 », in Michael Gehler (éd.), From Common Market to European Union Building. 50 Years of the Rome Treaties, 1957-2007, Böhlau, Cologne, 2009, p. 349-370 ; A.-C. Knudsen, Farmers on Welfare..., op. cit., p. 71-76, 173, 237-244.

86. AN, 5 AG1, volume 49, note de la présidence de la République du 30 janvier 1963 ; in Charles de Gaulle, Lettres, notes et carnets, op. cit. : note à Pompidou du 6 avril 1963 (tome IX, p. 327), note pour Pompidou du 7 février 1964 (tome X, p. 33), note pour Pompidou du 19 septembre 1964 (tome X, p. 89), lettre à Pompidou du 19 février 1968 (tome XI, p. 197-198), lettre à Couve de Murville, 19 août 1968 (tome XI, p. 235). 
Aucun acteur n'a d'ailleurs réussi à maîtriser une négociation qui avait une grande force d'inertie. Le premier accord de 1962 ne concernait que la structure générale, fondé sur un soutien aux prix agricoles. Il fallait donc définir les prix, ce qui fit l'objet d'une nouvelle négociation marathon en 1964. Enfin, le financement de ces dépenses (soutien aux prix) devait être trouvé, d'où les négociations de 1965-1966, interrompues par une crise de la chaise vide dont le casus belli était justement le règlement financier de la PAC. La négociation paraît ainsi particulièrement irrationnelle car les dépenses (accord de 1964 sur les prix) ont été décidées avant les recettes (accord de 1966). De plus, de très nombreux effets négatifs de la PAC (surproduction, inflation des prix alimentaires, concentration des aides sur les agriculteurs les plus riches, coûts financiers, paralysie du système décisionnel communautaire) se sont développés dès la seconde moitié des années soixante. Ils n'ont généralement pas été anticipés car la négociation sur la PAC a été fondée moins sur des études objectives que sur des représentations ${ }^{87}$. Du côté français par exemple, la PAC a certes apporté des avantages indéniables car elle s'insérait dans une stratégie de modernisation du secteur agricole par l'accroissement des exportations développée depuis la $\mathrm{IV}^{\mathrm{e}}$ République $^{88}$. Mais la rationalité économique de la priorité donnée à la PAC dans la politique européenne reste limitée : la France reste importatrice nette de produits agricoles jusqu'en 1968, la part des exportations agricoles dans le total des exportations reste faible ${ }^{89}$ et, surtout, il paraît particulièrement étrange pour un dirigeant attaché à l'influence internationale de son pays de fonder son développement sur l'agriculture à l'heure des Trente Glorieuses. Les défauts de la PAC ont d'ailleurs été visibles très tôt et critiqués par des proches du général de Gaulle dès $1965^{90}$.

Ainsi, la PAC apparaît bien plus comme un choix politique et social qu'économique fait par le général de Gaulle vers 1961, en rupture avec une politique antérieure. C'est bien de Gaulle qui fait de la PAC une priorité de la politique européenne de la France, même s'il n'a pas réussi à maîtriser le processus de décision, comme d'ailleurs l'ensemble des autres acteurs du système communautaire. Si la PAC a apporté des avantages financiers et économiques indéniables

87. A.-C. Knudsen, Farmers on Welfare..., op. cit., p. 305-306.

88. G. Bossuat, L'Europe des Français..., op. cit., p. 318 ; Frances Lynch, France..., op. cit., p. $165-166$.

89. Laurent Warlouzet, «The Deadlock : The choice of the CAP by de Gaulle and its impact on French EEC policy (1958-1969) », in Kiran Patel (éd.), Fertile Ground for Europe ?..., op. cit., p. 103.

90. Voir ci après le chapitre VII pour les critiques de Michel Debré et des hauts fonctionnaires favorables à la politique industrielle. Plus généralement, voir : Laurent Warlouzet, «The Deadlock... », op. cit., p. 99-118. 
à la France, elle est issue essentiellement de motivations sociopolitiques. La vision de la CEE comme d'un échange entre des exportations agricoles françaises contre les exportations industrielles allemandes est donc un mythe sans rapport avec la réalité des négociations ${ }^{91}$. Cette explication commerciale simpliste $^{92}$ néglige le poids considérable des autres acteurs de la négociation (Commission et Pays-Bas principalement) et des déterminants sociaux, politiques et culturels. Pourtant, cette idée reste profondément ancrée chez certains témoins. Elle apparaît d'ailleurs dans les archives mais assez tardivement, en Allemagne à partir de $1962-1964^{93}$ et en France surtout dans des interventions publiques du général de Gaulle à partir de la crise de la chaise vide ${ }^{94}$. Elle est sans doute liée à une volonté de rationalisation ex post d'une politique aux conséquences négatives, tant économiques que politiques, largement sous-estimées. Le succès de la PAC entre après 1962 dans un discours officiel laudateur partagé, de manière paradoxale, à la fois par la Commission européenne et par la France gaullienne. Critiquer la PAC revient ainsi à remettre en cause la construction européenne (ou la politique du général de Gaulle d'un point de vue français). La PAC devient ainsi une « vache sacrée », extrêmement difficile à réformer jusqu'à ce qu'elle perde son statut de réussite exemplaire de la CEE dans les années $1980^{95}$.

Les conceptions économiques du général de Gaulle dépendent donc peu de la PAC, qui apparaît avant tout comme un choix certes crucial mais fondé sur des arguments de nature sociopolitique. Une rationalisation économique ex post a toutefois été largement diffusée, avec le mythe d'une négociation reposant sur l'échange des exportations agricoles françaises contre des exportations industrielles allemandes. Cette simplification commerciale a caché les débats essentiels sur le plan économique. De Gaulle a soutenu la CEE pour imposer une conversion de la France en faveur d'une libération des échanges internationaux perçue comme stimulante mais uniquement si elle est régulée d'où l'intérêt du cadre de la CEE. Cette conception inspire toute la politique économique européenne des décideurs français, bien au-delà du général de Gaulle. Certains sont mêmes prêts à favoriser le développement d'une Europe-arbitre, où les autorités communautaires auraient des pouvoirs de régulation étendus.

91. K. Patel, «Européanisation... », op. cit., p. 17-18 ; A.-C. Knudsen, Farmers on Welfare..., op. cit., p. 6 ; L. Coppolaro, Trade and Politic..., op. cit., p. 420-421.

92. Encore influente malgré tout : A. Moravcsik, The Choice for Europe..., op. cit., p. 177-180.

93. K. Patel, « Européanisation...», op. cit., p. 152.

94. Conférence de presse de Charles de Gaulle du 9 septembre 1965, disponible sur le site www. ena.lu.

95. P. Ludlow, «The Green Heart of Europe ?... », op. cit., p. 89-95. 
Cependant, pour le président français, la CEE reste avant tout un « traité de commerce» amélioré. Il s'inscrit dans une vision assez répandue au sein des décideurs français, qui sous-estime la dynamique d'intégration économique et institutionnelle portée par le traité de Rome. Le manque de maîtrise du processus de décision communautaire, visible notamment dans la négociation sur la PAC, traduit une vision gaulliste des institutions de la CEE largement décalée par rapport à la réalité.

\section{UNE AMBITION POLITIQUE ET INSTITUTIONNELLE IRRÉALISTE}

La politique extérieure du général de Gaulle est issue de conceptions rigides très handicapantes pour comprendre le processus d'intégration européenne. Elle conduit en particulier à mettre en œuvre une politique révisionniste agressive, qui révèle ses limites lors de la crise de la chaise vide ${ }^{96}$, combinée avec une volonté de contrôler les institutions communautaires au quotidien. Elle est d'autant plus dommageable qu'elle n'est contrebalancée par aucune ligne concurrente au sommet de l'exécutif.

\section{A. LES HANDICAPS DE LA VISION GAULLISTE POUR LA POLITIQUE EUROPÉENNE}

La politique extérieure du général de Gaulle est fondée sur deux convictions profondes : une conception statocentrée des relations internationales et la nécessité pour la France de jouer un rôle directeur, de mener une politique de «Grandeur ». Cette conception porte trois faiblesses majeures dans la définition de la politique de la France envers la CEE.

Tout d'abord, sur le plan des rapports de force, la France n'est qu'une puissance moyenne depuis 1940 , et ne peut jouer un rôle à la hauteur des objectifs du général de Gaulle. Ce dernier adopte donc une politique essentiellement " déclaratoire » et un style cassant (lors des deux rejets de la Grande-Bretagne, de la chaise vide, etc.) qui heurte ses partenaires européens, mais aussi ses propres diplomates ${ }^{97}$. Certes, la «magie du verbe » a été à la base de la légitimité du général de Gaulle, car c'est elle seule qui lui a permis de défendre

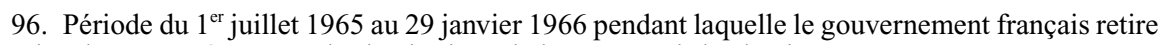
certains de ses représentants des institutions de la CEE; voir le chapitre V.

97. M. Vaïsse, La Grandeur..., op. cit., p. 677 pour la référence à la politique « déclaratoire »; pour la dernière idée : p. 294 (retrait de l'OTAN en 1966), p. 309 (Québec libre en 1967), p. 329 (en général). 
sa légitimité en 1940, alors qu'il est largement isolé et inconnu. Mais dans un univers de droit comme la CEE, le style percutant est contre-productif. Bien plus, sa conception fondée sur une inégalité entre les États européens, la France devant montrer la voie aux autres pays, va à l'encontre du présupposé de l'égalité entre les nations qui est à la base de la coopération européenne ${ }^{98}$. Elle crispe ses partenaires européens.

Plus généralement, ce décalage conditionne une très forte oppositionà la GrandeBretagne, concurrente naturelle de la France dans l'organisation de l'Europe. Si la Grande-Bretagne est rejetée en 1958, 1963 et 1967, c'est pour des raisons économiques - essentiellement la préservation de la dynamique d'intégration de la CEE, mais aussi parce qu'elle menace l'influence française en Europe continentale, qui se mesure notamment à sa capacité d'orienter la CEE en fonction de ses objectifs. Or ces rejets dévoilent une contradiction croissante au sein même de la politique gaulliste qui se contredit en cherchant à la fois à promouvoir une Europe intergouvernementale et à écarter le principal soutien de ce type de construction européenne. La tension est également issue du style cassant du leader français : de Gaulle rejette ainsi brutalement la candidature britannique par une conférence de presse unilatérale le 14 janvier 1963, alors même que de nombreux acteurs de la négociation hors de France avaient exprimé de nombreuses réticences face aux demandes britanniques ${ }^{99}$. Il aurait peut-être été possible d'obtenir un échec moins dommageable pour le crédit français par une opposition plus progressive, comme à la fin de 1958 avec la ZLE. Enfin, ce même projet de ZLE de 1956-1958 a montré que la France n'a pas d'alternative au Marché commun si elle veut tenter de constituer une zone d'influence en Europe.

Deuxième faiblesse, la vision statocentrée conduit le général de Gaulle à minimiser le poids des idéologies. L'URSS est ainsi analysée à travers le prisme de la Russie éternelle, ce qui entretient l'illusion gaulliste de réhabiliter l'axe franco-russe de la fin du XIX ${ }^{\mathrm{e}}$ siècle, particulièrement prégnante dans les années 1966-1967 ${ }^{100}$. De Gaulle tend à sous-estimer la logique binaire de la guerre froide. Cela contribue à tendre les relations entre la France et ses

98. Alfred Grosser, « Pour l'admiration critique, contre l'adulation mystifiante », in Institut Charles de Gaulle, De Gaulle en son siècle, vol. 1 : Dans la mémoire des hommes et des peuples, Plon, Paris, 1991, p. 504.

99. Piers Ludlow mentionne notamment les Allemands, les Italiens et la Commission européenne : Piers Ludlow, Dealing with Britain. The Six and the first UK application to the EEC, Cambridge UP, Cambridge, 1997, p. 236-241 ; Wolfram Kaiser évoque aussi la méfiance des chrétiens-démocrates face à cette remise en question de la " core Europe » : Wolfram Kaiser, Christian Democracy..., op. cit., p. 308-312.

100. AFNSP, CM 8 et Charles de Gaulle, Lettres, notes et carnets, tome XI : juillet 1966-Avril 1969, Plon, Paris 1987, p. 18, note de Charles de Gaulle du 10 août 1966. 
partenaires de la CEE car ces derniers sont fortement attachés à l'unité du camp occidental dans la guerre froide. La RFA notamment ne peut qu'être perplexe devant ces tentatives de renouer avec la logique des alliances de revers.

Enfin, si de Gaulle minore le poids des idéologies, il sous-estime également le rôle du droit et des institutions internationales, et en particulier la dynamique des institutions communautaires. Il semble ainsi considérer à plusieurs reprises que le Marché commun est provisoire ${ }^{101}$. Les contraintes juridiques du traité de Rome sont minorées alors que dès 1958 ce dernier fait sentir ses effets. De Gaulle n'est toutefois pas le seul responsable français à découvrir après coup ces contraintes. Ainsi, à l'occasion de la crise financière de mai 1958, beaucoup de décideurs français découvrent qu'ils ne peuvent plus rétablir de système d'aide à l'exportation et de taxes à l'importation sans autorisation communautaire ${ }^{102}$. La crise de la chaise vide traduit l'aboutissement logique de cette conception : de Gaulle décide de retirer les représentants français de la plupart des institutions communautaires car, pour lui, seul le rapport de force politique compte, les décisions de droit international n'ayant aucune portée sans le volontarisme des États. Il néglige la dépendance de la France envers la CEE au quotidien, que ce soit sur le plan juridique, avec l'émergence d'un droit communautaire propre, ou sur le plan de la mise en œuvre des politiques économiques, étroitement dépendante des relations avec l'administration communautaire dans un nombre croissant de sujets. Il confond donc le rejet du supranationalisme comme idée et le refus des conséquences institutionnelles de la dynamique supranationale, qui constituent une réalité concrète. De Gaulle semble pris dans une situation de dépendance envers des accords institutionnels antérieurs dont il n'a pas maîtrisé les conséquences, suivant la logique de path-dependency décrite par Paul Pierson ${ }^{103}$. Ce constat s'applique d'ailleurs à de très nombreux responsables politiques, dépassés par les effets juridiques et institutionnels de décisions prises au moment de la négociation et de la signature du traité de Rome. Pour tenter de remédier à cette situation, de Gaulle adopte une politique institutionnelle de nature révisionniste.

\section{B. UNE POLITIQUE RÉVISIONNISTE AGRESSIVE}

Pour de Gaulle, la CEE est un « traité de commerce » utile mais doté de virtualités politiques à la fois méprisées et craintes. Il défend donc une politique

101. Alain Peyrefitte, C'était de Gaulle..., op. cit., tome I, p. 465 (Conseil des ministres du 9 janvier 1963 ) et tome III, p. 266-267 (Conseil des ministres du $1^{\text {er }}$ février 1967) ; M. Vaïsse, La Grandeur..., op. cit., p. 543.

102. AMAE, DECE 628, folio 216, note du service juridique du 23 mai 1958.

103. Paul Pierson, «The Path to European Integration... », op. cit., p. 123-163. 
institutionnelle révisionniste, qui vise à imposer une interprétation intergouvernementale du traité de Rome. La Commission européenne a certes démontré son utilité depuis 1958, par exemple dans la négociation ZLE, celle de la PAC ou de la première candidature britannique ; elle ne doit pas être supprimée mais être réduite à un rôle d'expert et d'arbitre, de facilitateur des négociations des six États membres.

L'offensive pour promouvoir une révision du traité de Rome, de sa lettre sinon de son esprit, commence très tôt. L'organisation politique de l'Europe a été évoquée par de Gaulle dès son arrivée au pouvoir en juin $1958^{104}$, puis dans une note assez générale du 13 août $1958^{105}$. Le dossier est relancé en septembre 1959 par Michel Debré, qui souhaite développer une offensive contre les institutions communautaires ${ }^{106}$. Le représentant permanent adjoint à Bruxelles, Jean Mille, relève fréquemment les excès de pouvoirs auxquels se livre la Commission ${ }^{107}$. Il pose d'autre part le problème de l'amélioration du fonctionnement de la branche intergouvernementale des institutions communautaires, le Conseil et le COREPER ${ }^{108}$. Face à un Conseil souvent engorgé, il propose d'accroître le rôle du COREPER en lui adjoignant des groupes d'experts ${ }^{109}$. Cette proposition va directement à l'encontre des objectifs de la Commission européenne, qui souhaite de son côté réduire l'importance du COREPER, dont elle refuse l'institutionnalisation ${ }^{110}$, car c'est une institution qui n'est pas mentionnée dans le traité de Rome et qui constitue un relais majeur du pouvoir des États membres ${ }^{111}$.

104. AMAE, PA AP 314, carton 1, compte rendu d'une réunion interministérielle du 10 juin 1958.

105. « Note pour les Affaires étrangères » du 13 août 1958, in : Charles de Gaulle, Lettres, notes et carnets, tome VIII : juin 1958-décembre 1960, Plon, Paris, 1985, p. 73.

106. AFNSP, 2 DE 12, note de Michel Debré du 26 septembre 1959; sur le rôle de Michel Debré dans le lancement du plan Fouchet : Georges-Henri Soutou, « Michel Debré, une vision mondiale pour la France », in Michel Debré, Premier ministre, PUF, Paris, 2005, p. 407.

107. AMAE, RPUE 123, note de Jean Mille au cabinet du ministre des Affaires étrangères, 9 septembre 1959 ; AMAE, RPUE 118, lettre de Jean Mille au cabinet du ministre des Affaires étrangères, 16 septembre 1959 .

108. AMAE, RPUE 121, télex de la REP au cabinet du ministre des Affaires étrangères, 24 mars 1960.

109. AMAE, RPUE 123, note de Jean Mille (REP) à Calmes (secrétariat général du Conseil), 22 octobre 1960.

110. AMAE, RPUE 118, lettre de Calmes (secrétariat général du Conseil) à Gorse (REP), 19 février 1960.

111. Sur le rôle du COREPER : Piers Ludlow, « Mieux que six ambassadeurs. L'émergence du CORPER durant les premières années de la CEE » in Laurence Badel et al. (dir.), Les administrations nationales... op. cit., p. 337-356. 
Ces réflexions conduisent de Gaulle à lancer l'offensive en matière d'Europe politique en 1959-1960. Elle vise non seulement à organiser une coopération interétatique sous la forme d'un « concert politique des $\mathrm{Six}^{112}$ » qui rappelle le concert européen ${ }^{113}$, mais aussi à utiliser ces nouvelles institutions pour contrôler la CEE.

En août 1960, une note d'Alain Peyrefitte, député gaulliste spécialiste des affaires communautaires ${ }^{114}$, consulté par de Gaulle sur l'Europe politique, définit de manière plus précise ce qui devint la doctrine gaulliste en matière d'institutions européennes ${ }^{115}$. Peyrefitte estime que la France, dans les négociations sur l'Europe politique, doit rester prudente et ne doit surtout pas s'attaquer de front aux institutions communautaires. Cela braquerait les Cinq contre la France et, de plus, ces communautés sont négligeables pour Peyrefitte : "Pourquoi, du reste, s'attaquer aux institutions existantes? Ne leur donnons pas une importance qu'elles n'ont pas. Depuis huit ans que la Haute Autorité, deux ans et demi que les commissions de Bruxelles essaient d'affermir leur pouvoir, elles n'en détiennent toujours pas l'ombre. La supranationalité n'existe pas [...]. Si les traités pouvaient être interprétés, à l'origine, comme tendant à faire des « exécutifs » l'embryon d'un gouvernement, cette possibilité est maintenant morte : il est donc inutile de la tuer. [...] Sans le prolongement politique, il [le traité de Rome] ne serait plus qu'un traité de commerce ${ }^{116} »$. Cette note est particulièrement instructive et s'inscrit tout à fait dans les réflexions du général de Gaulle. Lors de la réunion du 10 juin 1958, de Gaulle avait en effet souligné l'échec des institutions de la CECA, qui n'avaient pas réussi à créer une dynamique supranationale en dépit des prérogatives qui leur étaient attribuées par le traité de Paris ${ }^{117}$. Peyrefitte reprend cette idée et l'associe à la $\mathrm{CEE}$, qui elle aussi sera condamnée à voir ses ambitions politiques végéter et devra se contenter d'être un « traité de commerce ». Comme Michel Debré, Peyrefitte défend ensuite la nécessité d'encadrer l'action de la CEE par une organisation politique de l'Europe qui servira d' « instance d'appel» et prendra

112. AFNSP, 2 DE 69 et CM 7, note de Charles de Gaulle du 6 octobre 1960.

113. Georges-Henri Soutou, Marlis Steinert, «Ordre européen et construction européenne - XIX $\mathrm{XX}^{\mathrm{e}}$ siècles » in Relations Internationales, ${ }^{\circ}$ 90, été 1997, p. 127-143.

114. Ancien diplomate, membre de la sous-direction des organisations européennes, Alain Peyrefitte a fait partie de la délégation française chargée de la négociation du traité de Rome. Voir les chapitres I et III.

115. AFNSP, 2 DE 69, note de Peyreffitte, 29 août 1960, «La négociation européenne : les conditions de son succès $»$.

116. AFNSP, 2 DE 69, note de Peyreffitte, 29 août 1960, « La négociation européenne : les conditions de son succès $»$.

117. AMAE, PA AP 314, carton 1, compte rendu d'une réunion interministérielle du 10 juin 1958. 
progressivement l'ascendant sur elle. Michel Debré puis de Gaulle donnent leur accord à cette stratégie ${ }^{118}$.

Cette position gaulliste donne une vision paradoxale des institutions communautaires. D'un côté, leur dynamique propre est niée car elles sont considérées comme incapables de se transformer en une véritable autorité indépendante, un pouvoir politique autonome. D'un autre côté, de Gaulle, Debré et Peyrefitte veulent encadrer ces institutions par une organisation intergouvernementale supérieure, ce qui montre les craintes qu'ils nourrissent à leur égard. Après l'échec des plans Fouchet en 1962, cette politique révisionniste est relancée en 1965 et connaît son apogée à l'occasion de la crise de la chaise vide.

\section{LES LIMITES DE LA POLITIQUE RÉVISIONNISTE FRANÇAISE : LA CRISE DE LA CHAISE VIDE}

Le révisionnisme gaulliste rebondit en 1965 à la faveur de la crise de la négociation agricole. Piers Ludlow a montré que la crise de la chaise vide n'avait pas été préméditée par de Gaulle mais que ce dernier avait profité de circonstances qu'il ne pouvait pas prévoir, l'impasse de la négociation agricole et le niveau très élevé des tensions entre des États membres dont certains étaient autrefois plus conciliants (Italie, RFA), pour mettre en avant des revendications anciennes ${ }^{119}$. L'étude des archives et des sources sur de Gaulle confirme cette interprétation : si la stratégie de révision institutionnelle est ancienne, sa mise en œuvre sur le plan tactique au moment de la chaise vide est largement improvisée. La chaise vide montre cependant aux décideurs français l'état de dépendance de leur pays à l'égard de la CEE, ce qui explique le caractère décevant du compromis de Luxembourg pour la France.

La stratégie révisionniste gaulliste, tout d'abord, est ancienne. La principale source est donnée par le témoignage d'Alain Peyrefitte. Selon lui, la stratégie conduite par la France pendant la crise de la chaise vide a été déterminée par sa note déjà citée du 29 août 1960 et un entretien préalable qu'il a eu avec

118. AFNSP, 2 DE 69, annotation manuscrite de Michel Debré sur la note de Peyrefitte du 29 août 1960 ; AFNSP, 2 DE 30, note de Charles de Gaulle, annotations manuscrites sur une note de Michel Debré du 27 février 1961 ; Georges-Henri Soutou, « Michel Debré... », op. cit., p. 410.

119. Piers Ludlow, « De-Commissioning the Empty Chair Crisis : the Community Institutions and the Crisis of 1965-1966 », in Jean-Marie Palayret, Helen Wallace, Pascaline Winand (éd.), Visions, Votes and Vetoes. The Empty Chair Crisis and the Luxembourg Compromise. Forty Years On, Peter Lang, Bruxelles, 2006, p. 79-88 ; Piers Ludlow, The European Community and the Crises of the 1960 s..., op. cit., p. 70 et p. 74. 
le général de Gaulle le 13 juillet $1960^{120}$. Cet entretien s'avère en effet particulièrement prémonitoire. De Gaulle a convoqué en Peyrefitte l'expert du traité de Rome pour connaître les moyens de « se prémunir contre le risque de perte de l'indépendance nationale que comporterait ce traité si l'on n'y prenait garde ». Peyrefitte lui répond qu'il n'est pas nécessaire de s'attaquer de manière frontale au Marché commun car : « d'ici à la fin de la deuxième étape, nous pouvons opposer notre veto à toute décision. Mais surtout, nous pouvons, au dernier moment, opposer notre veto à la décision de passer à la troisième étape, à partir de laquelle les décisions seraient prises à la majorité. On resterait définitivement dans la deuxième étape. Ou, de préférence, nous pouvons poser comme condition, avant d'accepter le pas, que soit préservé notre veto pour les questions que nous considérons comme essentielles ${ }^{121} »$. Si ce témoignage est rigoureusement exact, il faut reconnaître qu'Alain Peyrefitte commet des approximations juridiques. Le traité de Rome prévoit en effet que des décisions à la majorité peuvent être prises dans de nombreux domaines, parfois très importants comme l'adoption du budget ${ }^{122}$, dès la première étape et que, lors de la troisième, de nombreuses décisions fondamentales restent prises à l'unanimité ${ }^{123}$. Par ailleurs le passage à la troisième étape ne peut pas être indéfiniment retardé selon le traité sauf à l'unanimité des Six (article 8). Peyrefitte est pourtant un spécialiste du traité de Rome. Il privilégie en fait les rapports de force politiques plus que l'analyse juridique. Le volontarisme politique doit pouvoir renverser ces contraintes institutionnelles, la France doit pouvoir imposer son interprétation du traité de Rome au besoin en ignorant certaines de ses prescriptions.

Cette stratégie révisionniste est confirmée dans les années 1963-1965. Le contexte des négociations communautaires est difficile pendant ces deux années en raison de discussions agricoles continuelles et d'une dégradation de la relation franco-allemande après le remplacement d'Adenauer par Erhard. Les représentants français menacent à plusieurs reprises d'interrompre le Marché commun s'ils n'obtiennent pas satisfaction en matière agricole ${ }^{124}$.

Pourtant les hésitations du début du mois de juillet 1965 montrent que la crise n'a pas été préméditée. Certes dès le $1^{\text {er }}$ juillet 1965, après une réunion en

120. Alain Peyrefitte, C'était de Gaulle, tome II..., op. cit.,p. 91.

121. Alain Peyrefitte, C'était de Gaulle, tome II..., op. cit., p. 89.

122. Article 203. On peut citer également les dispositions relatives aux règles de concurrence qui sont prises à la majorité qualifiée trois années après l'entrée en vigueur du traité : voir le chapitre V.

123. Par exemple sur l'extension du champ du traité (article 235), la conclusion des accords d'association (article 237) ou d'adhésion (article 238).

124. Piers Ludlow, The European Community and the Crises of the 1960s..., op. cit., p. 51. 
urgence du Conseil des ministres, le porte-parole du gouvernement, Peyrefitte, annonce que la France ne participera pas à d'autres réunions du Conseil en juillet $1965^{125}$. Le lendemain, Boegner siège au COREPER comme d'habitude et ne peut rien annoncer de plus à ses collègues ${ }^{126}$. Il faut attendre le 5 juillet 1965 pour qu'une instruction officielle du Quai d'Orsay fixe l'attitude française : la France ne participera plus au Conseil, au COREPER ou aux comités d'experts consacrés à des études ou projets ${ }^{127}$. Par contre l'attitude n'est pas déterminée pour les réunions concernant des politiques déjà appliquées comme la politique douanière ou la PAC. Finalement la France adopte une position pragmatique : les représentants français continuent de participer aux réunions de mise en œuvre des politiques déjà appliquées et Maurice Ulrich, le représentant permanent adjoint, reste à Bruxelles pour assurer la liaison avec les Cinq et avec la Commission, alors que Boegner est rappelé à Paris ${ }^{128}$. Ces hésitations montrent que la crise de la chaise vide n'avait pas été préméditée. Paris a au contraire profité de l'impasse de la négociation agricole pour relancer sa stratégie révisionniste. Cela apparaît dès le 6 juillet 1965 dans un télégramme circulaire du Quai d'Orsay fixant la position officielle pour tous les représentants français à l'étranger ${ }^{129}$. Après un long développement sur la PAC - le casus belli, le télégramme termine par deux considérations institutionnelles : d'une part la Commission n'a pas joué son rôle habituel de modérateur car elle s'est arcboutée sur des propositions largement rejetées par les États membres, d'autre part ces derniers n'ont pas respecté les accords politiques antérieurs. Ces deux constats préparent naturellement les deux demandes de révisions du traité qui ont été portées par la France à partir de la conférence de presse du 9 septembre 1965 : réduire les pouvoirs de la Commission et ne pas appliquer le vote à la majorité dans certains cas.

La fixation de l'attitude française est issue d'un débat au sein de l'administration. D’un côté, le SCGI souligne dès le 3 juillet 1965 la nécessité de « ne pas compromettre des intérêts français importants par une abstention inutile ou dangereuse $»{ }^{130}$. Le SGCI conseille dans cette note de continuer à participer au

125. Piers Ludlow, The European Community and the Crises of the 1960s..., op. cit., p. 72.

126. ASGCI 1990.0638, volume 25, télex de Boegner du 3 juillet 1965.

127. ASGCI, 1990.0638, volume 25, télégramme au départ de Beaumarchais, DAEF/SCE, pour REP, 5 juillet 1965 ; devient le télégramme circulaire de Couve de Murville à Boegner du 5 juillet 1965 in DDF, 1965-II, doc n 16.

128. ASGCI, 1990.0638, volume 25, note pour Brunet (DAEF) du 13 juillet 1965.

129. AMAE, DECE 1111, folio 206, télégramme d'information du ministre aux postes diplomatiques, 6 juillet 1965.

130. ASCGI, 1990.0638, volume 25, note du SGCI du 3 juillet 1965, « Les conditions de participation françaises aux travaux des Communautés européennes ». 
Conseil et au COREPER mais avec une délégation et un ordre du jour réduit. Le secrétaire général adjoint Jean Dromer est plus direct : « Si la France s'abstenait de fournir certaines informations aux services bruxellois, de participer à quelques réunions d'experts, de concourir sous certaines conditions à la formation de décisions communautaires, elle pourrait se mettre rapidement «hors du traité ${ }^{131} \gg$. Dès lors les Cinq pourraient prendre des décisions sans la France. Or pour Dromer, une collaboration minimale de la France est indispensable pour ne pas remettre en cause les acquis de la CEE qui l'intéressent le plus comme l'union douanière ou la politique agricole commune. Il conseille donc de continuer à participer à un certain nombre de groupes d'experts, d'informer la Commission et de recourir à la procédure écrite (elle permet à la France de donner son accord à des décisions prises par le Conseil sans y être présent).

Au contraire, même s'il part de prémisses identiques, le conseiller juridique du Quai d'Orsay aboutit à une conclusion totalement différente. Dans une note du 13 juillet 1965, il affirme que la politique de la chaise vide ne va pas assez loin car « si la France ne se place pas délibérément et clairement hors du système juridique communautaire, ses partenaires de la CEE peuvent trouver dans celui-ci les moyens, au moment qu'ils choisiraient, de la conduire à la rupture $^{132} »$. En effet, les Cinq peuvent toujours prendre des décisions à la majorité qualifiée dans certains domaines. La note du ministère des Affaires étrangères conclut : « Ces réflexions font apparaître que si la France veut bloquer définitivement le mécanisme communautaire sur son territoire, elle devra à un moment quelconque proclamer son retrait de l'organisation de Bruxelles afin de consacrer la rupture entre l'ordre juridique national et l'ordre juridique de la $\mathrm{CEE}^{133}$ ». Le conseiller juridique du Quai d'Orsay découvre en fait, à l'occasion de la crise de la chaise vide, le principe de l'effet direct et de la suprématie du droit communautaire sur le droit national, affirmés dans deux arrêts de la CJCE de 1963 et $1964^{134}$. Le dynamisme de la Cour européenne dans la création d'un ordre juridique communautaire est d'ailleurs, paradoxalement, entretenu par un ancien ministre du général de Gaulle, Robert Lecourt, qui y siège depuis 1962 après avoir démissionné du gouvernement français (en 1961)

131. ASGCI, 1990.0638, volume 25, projet de note de Jean Dromer, secrétaire général adjoint du SGCI, 17 septembre 1965, «Les échéances et les décisions à prendre dans les communautés européennes avant la fin de l'année 1965 ».

132. ASCGI, 1990.0638, volume 25, note du conseiller juridique du ministère des Affaires étrangères, 13 juillet 1965 .

133. ASCGI, 1990.0638, volume 25, note du conseiller juridique du ministère des Affaires étrangères, 13 juillet 1965 .

134. Les arrêts Van Gend \& Loos (5 février 1963) et Costa/Enel (15 juillet 1964) qui établirent respectivement l'effet direct du droit communautaire et sa suprématie sur le droit national. 
pour protester contre l'orientation trop intergouvernementale de sa politique ${ }^{135}$. C'est cet activisme d'un groupe transnational de juristes communautaires ${ }^{136}$ que le Quai d'Orsay veut briser.

À la demande de Couve de Murville, une autre note est rédigée par ses services le 28 juillet $1965^{137}$. Elle liste les dérives de l'interprétation du traité de Rome qui ont été permises par la Commission européenne. Le ministre refuse donc la solution radicale de la rupture mais demande à ses services les modifications juridiques et institutionnelles que la France devra exiger. Il semble que certains observateurs du Quai d'Orsay se rendent compte de l'ampleur des délégations de souveraineté accordées par la France et souhaitent revenir dessus, suivant une hypothèse déjà avancée par Joseph Weiler ${ }^{138}$.

En tout cas la « chaise vide » ne signifie en aucune manière la rupture des liens avec Bruxelles. Dès la fin du mois de juillet, de nombreuses procédures écrites sont acceptées pour des mesures de gestion courante comme des nominations ou l'octroi de contingents tarifaires ${ }^{139}$. La Commission européenne continue de prendre des décisions qui s'appliquent toujours à la France et à ses entreprises, par exemple en matière de politique de la concurrence ${ }^{140}$. Dans ce domaine, une décision de la Cour d'appel de Paris du 7 juillet 1965 confirme la pleine compétence de la Commission et de la CJCE en la matière ${ }^{141}$. Cette décision

135. C'est l'hypothèse de Pierre Pescatore, devenu juge peu après Robert Lecourt : témoignage de Pierre Pescatore in Commission européenne (dir.), 40 ans des traités de Rome ou la capacité des traités d'assumer les avancées de la construction européenne. Colloque universitaire organisé à la mémoire d'Émile Noël, Bruylant, Bruxelles, 1999, p. 73. Pour une mise au point historique : Morten Rasmussen, "The Origins of a Legal Revolution. The Early History of the European Court of Justice », in Revue d'histoire de l'intégration européenne, 2008/2, p. 91-86.

136. Ce groupe de juristes communautaires fait l'objet d'un programme de recherche dont les contours et publications sont évoqués in : Antoine Vauchez, «Une élite d'intermédiaires. Genèse d'un capital juridique européen, 1950-1970 », in Actes de la recherche en sciences sociales, $\mathrm{n}^{\circ}$ 166-167, février 2007, p. 3-13.

137. ASCGI, 1990.0638, volume 25, note du conseiller juridique du ministère des Affaires étrangères, 28 juillet 1965.

138. Weiler n'a toutefois pas une vision mécanique : «I do not suggest that, as a direct result of the decisions of the Court, in say, Van Gend \& Loos (in 1963) or Costa v. ENEL (in 1964) the French governement decided (in 1965) to precipitate the crisis that led to the Luxembourg Accord. I suggest that $[\ldots]$ because Community norms in terms of substance were important, and because they were by then situated in a context that did not allow selective application, control of the creation of the norm itself was the only possible solution for individual states " : Joseph Weiler, "The transformation of Europe ", in The Yale Law Journal, vol 100, p. 2427. Ludlow discute brièvement Weiler in : Piers Ludlow, The European Community and the Crises of the 1960s..., op. cit., p. 78.

139. ASGCI, 1990.0638, volume 25, message de Jean Dromer à Maurice Ulrich.

140. Décision « DRU-Blondel » $n^{\circ} 65 / 366 /$ CEE du 8 juillet 1965.

141. Arrêt de la Cour d'appel de Paris, $1^{\text {re }}$ chambre, du 7 juillet 1965, Affaire société anonyme La Technique Minière, L.T.M. c/Société Maschinenbau Ulm. 
concerne une affaire en cours impliquant une entreprise française et est donc complètement indépendante des circonstances politiques de la crise de la chaise vide. Toujours en matière de concurrence, le directeur général des Prix Huet se demande si le retrait des fonctionnaires français du fonctionnement des institutions communautaires touche aussi ceux qui accompagnent les fonctionnaires communautaires dans les entreprises françaises au titre des enquêtes menées en application du règlement $17 / 62^{142}$. Dans ce cas, un retrait de la participation française augmenterait clairement le pouvoir de la Commission alors même que la collaboration entre les deux administrations dans ces affaires est généralement bonne et appréciée par la tierce partie, l'entreprise contrôlée.

Par ailleurs avec l'allongement de la crise, deux dossiers de gestion courante mais d'une importance politique certaine, se posent : l'adoption du budget de 1966 et l'échéance tarifaire du premier janvier 1966 (un nouvel abaissement des droits de douane intracommunautaires est prévu). Significativement, le SGCI conseille la modération sur ces deux points et le recours par la France à la procédure écrite pour donner son accord ${ }^{143}$. Lors du Conseil restreint du 23 décembre 1965, il est finalement décidé de ne pas adopter le budget mais de respecter l'échéance tarifaire ${ }^{144}$. Dans un autre domaine, Lucia Coppolaro souligne que les Français demandent à être tenus informés des poursuites des négociations du Kennedy Round pendant la chaise vide ${ }^{145}$. C'est en effet la Commission européenne qui représente les Six au GATT. Ces exemples montrent que les décideurs français ne souhaitent pas briser la CEE, qui constitue toujours un cadre de libéralisation régulée irremplaçable.

Enfin, le compromis de Luxembourg du 30 janvier 1966 sanctionne également l'échec des prétentions révisionnistes françaises les plus ambitieuses. Paris doit reconnaître qu'il est impossible d'imposer de manière unilatérale son interprétation du traité de Rome. La France attendait en effet trois concessions de ses partenaires ${ }^{146}$. Tout d'abord, elle souhaitait obtenir le départ d'Hallstein, or ce dernier est confirmé à son poste même s'il est discrédité. Son affaiblissement est d'ailleurs tout autant le fait de la crise en tant que telle que de ses

142. ASGCI, 1988.0516, volume 1, lettre de Huet, DG Prix, au SGCI, 12 juillet 1965. Le règlement 17/62 concerne la surveillance des ententes entre les entreprises par la Commission européenne : voir le chapitre V.

143. AN, 5 AG1, volume 28, notes SGCI des 16 et 17 décembre 1965 en vue du Conseil restreint du 23 décembre 1965.

144. AN, 5 AG1, volume 28, note du secrétariat général de la présidence de la République, 24 décembre 1965.

145. Lucia Coppolaro, Trade and Politic across the Atlantic..., op. cit., p. 263.

146. AN, 5 AG1, volume 28 , note du secrétariat général de la présidence de la République, 24 décembre 1965. 
audacieuses propositions de mars 1965, qui n'ont été soutenues par aucun des États membres, et de son obstination à les défendre au lieu de rechercher un compromis, et ce jusqu'au 30 juin $1965^{147}$. Hallstein s'est discrédité par luimême, en obligeant les Cinq à reconnaître le décalage qu'il y avait entre leurs discours fédéralistes, et la réalité de leur politique européenne nationale, plus classiquement intergouvernementale.

Ensuite, la France souhaitait obtenir une diminution de l'indépendance politique de la Commission. Paris avait diffusé un programme en dix points, ou « décalogue » qui contenait certaines modifications institutionnelles importantes comme la nécessité pour la Commission de ne pas outrepasser les délégations de pouvoirs que lui accorde le Conseil ${ }^{148}$. Or tous les points contraignants disparaissent de l'Heptalogue sur lequel les Six s'accordent, et qui constitue essentiellement un code de bonne conduite consensuel.

Enfin, la France voulait obtenir le retour à l'usage de l'unanimité en lieu et place du vote à la majorité qualifiée. Or elle n'a obtenu qu'une déclaration très vague et nullement contraignante des Cinq, à laquelle elle a adjoint une déclaration unilatérale précisant ses vues, ce qui démontre bien qu'elle n'a pas réussi à les imposer ${ }^{149}$. De plus, cette déclaration intéressait tout autant la France que la RFA, qui a manifesté à plusieurs occasions sa volonté de continuer à utiliser son droit de veto dans certains dossiers sensibles, comme la fixation des prix agricoles ${ }^{150}$. Ainsi, le vote à la majorité a été utilisé avant la crise de la chaise vide, pour des sujets aussi importants que le vote du budget par exemple, et continue d'être utilisé après. Certes, le Conseil tend à rechercher un consensus dans certains dossiers sensibles, même lorsque le vote à la majorité pourrait

147. Voir le chapitre V. D.

148. AMAE, DECE 1115 , folio 158 , aide-mémoire français en dix points, point $n^{\circ} 3$; AN, 5 AG1, volume 24, note du secrétariat général de la présidence de la République, Conseil des affaires européennes du 14 janvier 1966.

149. Les deux premiers points de l'" Arrangement intervenu au sujet du vote majoritaire » sont les suivants :

1. «Lorsque, dans le cas d'une décision susceptible d'être prise à la majorité sur proposition de la Commission, des intérêts très importants d'un ou de plusieurs partenaires sont en jeu, les membres du Conseil s'efforceront dans un délai raisonnable d'arriver à des solutions qui pourront être adoptées par tous les membres du Conseil dans le respect de leurs intérêts mutuels et de ceux de la Communauté, conformément à l'art. 2 du traité. »

2. «En ce qui concerne le paragraphe précédent, la délégation française estime que, lorsqu'il s'agit d'intérêts très importants, la discussion devra se poursuivre jusqu'à ce que l'on soit parvenu à un accord unanime $»$.

150. Piers Ludlow, The European Community and the Crises of the 1960s... op. cit., p. 101 ; Kiran Patel, « Veto Player n 1 ? », op. cit., p. 349-370; Ann-Christina Knudsen, Defining the Common Agricultural Policy..., op. cit., p. 314 et 367 ; Lucia Coppolaro, Trade and Politic across the Atlantic..., op. cit., p. 14 et 53 . 
être appliqué, mais les périodes ultérieures ont montré que la France n'était pas l'État le plus intéressé par cette possibilité ${ }^{151}$. Ainsi, on peut se demander si le vote à la majorité se serait véritablement appliqué à la lettre sans la crise de la chaise vide, alors que la RFA par exemple tenait fermement à son droit de veto. La tension croissante des négociations entre 1963 et 1965 ainsi que l'effet d'apprentissage des États membres, qui laissaient beaucoup moins d'initiatives à la Commission dans cette période qu'en $1958-1962^{152}$, peuvent permettre d'imaginer qu'une diminution de la capacité d'initiative de la Commission serait intervenue tôt ou tard. Le compromis de Luxembourg marque moins une victoire de l'interprétation gaulliste de la CEE que l'affirmation d'un constat partagé par chacun des Six États membres sur la nécessité d'éviter les écueils du fédéralisme comme de l'intergouvernementalisme ${ }^{153}$.

Finalement, comme le remarque Piers Ludlow, la crise a montré à chacun des États membres combien il avait intérêt à une CEE qui fonctionne, au-delà des discours théoriques sur l'indépendance nationale (France) ou sur le soutien à une Europe fédérale (les Cinq) ${ }^{154}$. C'est particulièrement vrai pour la France, dont les responsables ont dû ravaler leurs ambitions révisionnistes et accepter une « chaise vide » très partielle, où les contacts avec les services de Bruxelles sont maintenus dans de nombreux dossiers. La chaise vide a finalement manifesté moins la marge de manœuvre de la France gaulliste que les limites de sa capacité d'action autonome, en raison d'une intégration économique et juridique déjà bien avancée. Dès lors, la politique révisionniste de la France devient moins brutale après 1965. Paris cherche plus à orienter la CEE de l'intérieur en mettant l'accent sur la stratégie d'influence administrative menée depuis 1958.

\section{CONTRÔLER ET INFLUENCER L'ADMINISTRATION COMMUNAUTAIRE}

Dès 1958, la préoccupation du général de Gaulle d'appliquer le traité de Rome tout en évitant une interprétation trop supranationale conduit à envisager un contrôle étroit de l'administration communautaire par l'administration française. Cela passe d'abord par la centralisation des contacts quotidiens grâce

151. Voir : Fiona Hayes-Renshaw, Helen Wallace, « Changing the Course of European Integration - or Not? ", in Jean-Marie Palayret et al. (éd.), Visions, Votes and Vetoes..., op. cit., 2006, p. 301320. Elles citent plusieurs invocations du compromis de Luxembourg dans les années 1980-1990 principalement par la Grèce, le Danemark et surtout la Grande-Bretagne, pays du « Luxembourg compromise Club » (p. 312).

152. Sur cette évolution, voir les exemples donnés dans les chapitres ultérieurs.

153. Cette crise est moins une rupture que « part of an evolutionary process » selon Fiona HayesRenshaw, Helen Wallace, « Chaging the Course... », op. cit., p. 318.

154. Piers Ludlow, The European Community and the Crises of the 1960s..., op. cit., p. 101. 
au couple SGCI-représentation permanente mis en place en avril 1958. Son efficacité au service de la centralisation politique satisfait le pouvoir gaulliste. Ainsi, dès le 12 juin 1958, quelques jours après le retour au pouvoir du général de Gaulle, Donnedieu de Vabres a été chargé de rappeler la centralité de ce couple SGCI-REP ${ }^{155}$. Dans cette note, il insiste sur la nécessité de limiter le nombre de groupes d'experts auxquels pourraient être conviés les fonctionnaires français et d'assurer un contrôle étroit de ces groupes par la représentation permanente. Il s'agit de coordonner le travail de consultation d'experts de la Commission avec le travail de rapprochement des positions nationales mené par le COREPER. Soucieux d'éviter les rapports directs entre fonctionnaires de Bruxelles et de Paris, sans contrôle politique, le gouvernement a constamment rappelé, tout au long des années soixante, la nécessité de passer obligatoirement par ce couple SGCI-REP ${ }^{156}$.

Progressivement cependant, les décideurs français comprennent la nécessité de passer du contrôle de la correspondance avec l'administration communautaire à son influence, en agissant sur son recrutement. Les spécialistes des affaires communautaires les plus sensibles aux problèmes institutionnels, comme le représentant permanent adjoint Jean Mille, défendent dès 1959 le principe du « va-et-vient » entre l'administration française et l'administration communautaire ${ }^{157}$. Les Français nommés à Bruxelles ne devraient y passer qu'un temps limité, avant de revenir dans l'administration française. Ils y apporteraient ainsi des compétences utiles pour comprendre le fonctionnement de la Commission et l'influencer. De même, s'ils sont en poste pour peu de temps à Bruxelles, ils conserveraient un attachement à leur pays et à sa position officielle plus fort que s'ils y passent toute leur carrière. Pour cela, la représentation permanente souligne qu'il faut garantir une bonne réintégration aux fonctionnaires partis à Bruxelles depuis $1958^{158}$. Or cela ne semble pas évident si l'on considère que parmi les fonctionnaires français de premier plan affectés à Bruxelles en 1958, la plupart étaient partis car ils n'avaient pas de perspectives de carrière nationale aussi intéressantes ${ }^{159}$.

Avec la crise de la chaise vide, cette problématique de l'influence française au sein de l'administration communautaire rebondit. Les contacts à Bruxelles

155. AMAE, RPUE 245, note de Jacques Donnedieu de Vabres pour la représentation permanente, 12 juin 1958.

156. AMAE, RPUE 617, télégramme de la REP $(\mathrm{PhC})$ à la DG Concurrence de la Commission européenne, 18 mars 1964 ; ASGCI, 1990.0638, volume 23, note du Premier ministre du 17 février 1965 ; ASGCI, 1990.0638, volume 24, télex Boegner du 26 janvier 1968.

157. AMINEFI, B 17678, note de Jean Millet (REP) du 17 octobre 1959.

158. AMAE, RPUE 197, note de la REP, 19 novembre 1960.

159. Voir le chapitre II. 
entre Maurice Ulrich, à la représentation permanente, et le cabinet de Marjolin, qui centralise une grande partie des offres d'emploi ouvertes aux Français dans les services de la Commission, restent maintenus ${ }^{160}$. Se pose notamment le problème du remplacement d'un chef de division français pour lequel aucun candidat ne se profile ${ }^{161}$, ce qui témoigne du manque d'organisation de ce « vaet-vient » encore largement dépendant des initiatives individuelles. Alors que la crise de la chaise vide a démontré les limites des moyens d'influence classique de la diplomatie traditionnelle (comme le boycott), le secrétaire général du SGCI, Jean Dromer, critique en avril 1966, 1'absence de « politique du personnel pour les institutions communautaires ${ }^{162} \gg$. Les pierres d'achoppement sont toujours les mêmes : décalage du niveau de salaires, prise en compte de l'ancienneté lors de la réintégration, progression de carrière lors des mouvements entre Paris et Bruxelles. L'expérience européenne est rarement valorisée lors du retour à Paris - à défaut d'appuis politiques comme dans le cas d'Ortoli ou de Deniau -, comme l'illustre par exemple le témoignage d'Armand Saclé ${ }^{163}$. La création de la Commission unique en 1967 offre une nouvelle occasion pour le SGCI et la représentation permanente de présenter les mêmes doléances ${ }^{164}$. Debré lui-même évoque peu après le problème dans les mêmes termes en citant en exemple la pratique britannique de « va-et-vient » pratiquée pour leur fonction publique internationale ${ }^{165}$, mais aucune décision n'est prise.

Au-delà de l'aspect structurel d'une bonne organisation de la rotation entre Paris et Bruxelles à long terme, le problème de l'influence des commissaires français est crucial. Ces derniers ont toujours été considérés, selon la doxa gaulliste, comme des fonctionnaires internationaux, dépendant en dernier ressort de leur gouvernement national, et pas comme des personnalités politiques indépendantes, porteuse d'une légitimité propre. Les traces d'influence

160. ASGCI 1990.0641, volume 13, télex de la représentation permanente du 19 novembre 1965.

161. ASGCI 1990.0641, volume 13, télex de la représentation permanente du 19 novembre 1965. C'est Touzelet, chef de la division « législation douanière » de la DG du Marché intérieur, qui part de Bruxelles.

162. AMAE, DECE 1135, note de Jean Dromer, SGCI, 20 avril 1966.

163. Malgré les nombreuses relations qu'il a pu tisser de part son importante fonction à Bruxelles (directeur des aides à la DG IV), Saclé a du mal à trouver un poste et devient directeur du récent Institut national de la consommation (1969) où il a du mal à s'épanouir. AO/Comité pour l'histoire économique et financière de la France, cassette 13, interview d'Armand Saclé avec Laurence Badel le 26 mai 1992.

164. AMAE, DECE 1117, note du SGCI du 10 octobre 1966 ; ASGCI, 1990.0638, volume 55, note SGCI, FM, 19 juin 1967 ; AN, 5 AG1, volume 32, note Dromer pour de Gaulle, 28 juillet 1967 ; ASGCI, 1990.0638, volume 55, télex de Boegner (REP) du 21 septembre 1967.

165. AFNSP, 4 DE 10, lettre de Debré à Michelet, 18 avril 1968. 
des décideurs politiques français de Paris sur les commissaires européens français à Bruxelles sont toutefois rares car ce type de rapport de subordination est explicitement interdit par le traité (article 157-2). Deux indices laissés par les archives témoignent de la considération limitée dont bénéficient les commissaires européens aux yeux du pouvoir gaulliste.

Tout d'abord, les noms des successeurs évoqués pour les commissaires français sont bien souvent plus des fonctionnaires que des personnalités politiques importantes. Ainsi lorsque, en 1961, le problème du remplacement de Robert Lemaignen se pose, ce sont des noms de hauts fonctionnaires qui sont évoqués : Louis Franck (directeur des Prix), Yves Guéna (ancien directeur de cabinet de Michel Debré), et Pierre Châtenet qui est certes ministre de l'Intérieur mais qui quitte la carrière politique pour celle de haut fonctionnaire en $1961^{166}$. De Gaulle avait également pensé à Wilfrid Baumgartner pour la présidence de la Commission européenne ${ }^{167}$. Ministre des Finances, Baumgartner est certes un personnage politique important en apparence mais il exerce sa charge sans prendre d'initiative, en haut fonctionnaire plus qu'en homme politique réformateur ${ }^{168}$. Les noms des remplaçants que le gouvernement français propose pour Robert Marjolin (Pierre Châtenet, le directeur du Trésor Maurice Pérouse, etc.) sont également éclairants ${ }^{169}$. C'est d'ailleurs un professeur d'économie qui n'a jamais eu de mandat politique, Raymond Barre, qui prend sa succession.

Par ailleurs, les archives témoignent, certes très rarement, de formes d'influence plus directes, notamment sur Pierre-Olivier Lapie, membre de la Haute Autorité de la CECA de 1959 à 1967. C'est le dossier de la reconcentration de l'industrie allemande de l'acier qui pousse Lapie à solliciter le ministre de l'Industrie Jeanneney en $1960^{170}$ puis le Premier ministre Debré en 1961 pour leur souligner l'évolution dangereuse de ce dossier pour la France ${ }^{171}$. Lapie

166. AMAE, POW 35, note d'Olivier Wormser (DAEF) pour le ministre du 7 septembre 1961. Pierre Châtenet devient président de l'Euratom (1962-1967) puis président de la toute nouvelle COB, la Commission des opérations de bourse.

167. Lettre de Charles de Gaulle à Michel Debré, $1^{\mathrm{er}}$ août 1961, in Charles de Gaulle, Lettres, notes et Carnets, tome IX : janvier 1961-décembre 1963, Plon, Paris, 1986, p. 118-119.

168. O. Feiertag, Wilfrid Baumgartner..., op. cit, p. 629-635 ; C'est surtout Michel Debré qui critique Baumgartner sur ce point : AFNSP, 2 DE 14, note de Michel Debré du 27 juillet 1961 et lettre de Michel Debré à Charles de Gaulle du 21 août 1961 ; de Gaulle le reconnaît lui-même à mots couverts : lettre de Charles de Gaulle à Michel Debré, $1^{\text {er }}$ août 1961, in Charles de Gaulle, Lettres, notes et carnets, tome IX, Janvier 1961-décembre 1963, Paris, 1986, p. 118-119.

169. Voir le chapitre VI.

170. AMINEFI, B 17730, lettre de P.-O. Lapie à J.-M. Jeanneney, 11 septembre 1960.

171. AFNSP, 2 DE 70, lettre P.-O. Lapie, 20 juillet 1961, à Michel Debré. 
souligne à Debré que « dans cette affaire, comme dans toutes les affaires de quelque importance, $\mathrm{j}$ 'ai veillé à ce qu'une liaison constante soit maintenue entre mon cabinet et les services du Quai d'Orsay et du ministre de l'Industrie $^{172} \gg$. Lapie se comporte donc en fonctionnaire respectueux des procédures et d'une hiérarchie implicite qui le subordonne toujours au gouvernement français. Ensuite, en 1967, Lapie envoie à de Gaulle une lettre qui résume l'esprit qui l'a animé à Luxembourg : " Au-delà de la mission particulière de défense des intérêts français, la mission générale que vous m'avez confiée, en me faisant l'honneur de me nommer à la CECA, consistait à dégager cette institution de l'excès de supranationalité dans laquelle, en 1950, ses fondateurs l'avaient enserrée ${ }^{173} \gg$. Cette attitude semble liée à l'isolement politique de Lapie. Député SFIO, il n'est pas réélu en 1958 et se trouve en disgrâce au sein de son parti. Il entame donc une campagne intense auprès du général de Gaulle et de Michel Debré pour être nommé à la Haute Autorité, afin de voir sa carrière rebondir. Il obtient donc ce poste au début de 1959 grâce aux réseaux gaullistes ${ }^{174}$.

Cette interprétation éminemment gaulliste que Lapie fait de sa fonction est particulièrement remarquable. Elle a pu encourager les gouvernants français à vouloir assurer le même lien avec les commissaires européens français, après les déconvenues enregistrées avec Robert Marjolin. Nommé par les socialistes, le commissaire français s'est plaint dès un entretien de décembre 1958 de rapports personnels froids avec le général de Gaulle ${ }^{175}$. Ces rapports dégénèrent en franche hostilité après la candidature avortée de Marjolin aux législatives de 1962 sous les couleurs socialistes ${ }^{176}$. Or la perspective de son départ en 1967 relance les espoirs du gouvernement français de pouvoir influencer plus directement la Commission à travers l'un de ses vice-présidents. Jean Dromer au SGCI estime que l'action du futur commissaire français devra être étroitement coordonnée avec celle du gouvernement et de l'administration ${ }^{177}$.

Barre n'emprunte toutefois pas le même chemin que Lapie. Ses initiatives en matière de coordination des politiques conjoncturelles irritent fortement le

172. AFNSP, 2 DE 70, Lettre P.-O. Lapie, 20 juillet 1961, à Michel Debré.

173. AN, 5 AG1, volume 48, lettre de P.-O. Lapie à Charles de Gaulle, 19 avril 1967.

174. Sur cet épisode : Mauve Carbonnell, Des hommes à l'origine de l'Europe. Biographies des membres de la Haute Autorité de la CECA, Publications de l'Université de Provence, Aix-en-Provence, 2008, p. 131.

175. AFJM, ARM 25/1, entrevue avec Charles de Gaulle, 18 décembre 1958, notes manuscrites.

176. Note de Charles de Gaulle pour Georges Pompidou et Maurice Couve de Murville du 2 décembre 1962 demandant à ce que tous les contacts soient coupés avec Marjolin, qui n'est pas nommé (il est désigné de manière pudique par un sobre « $\mathrm{M}$. X ») : Charles de Gaulle, Lettres, notes et carnets..., op. cit., p. 280.

177. ASGCI, 1990.0638, volume 55, note de Jean Dromer du 20 juin 1967. 
ministre des Finances Michel Debré qui le fait savoir à Barre ${ }^{178}$. Les tentatives d'influencer les commissaires français ont donc été sans doute très nombreuses, beaucoup plus que ne le laissent supposer les quelques traces retrouvées dans les archives, mais elles n'ont pas débouché sur une véritable coordination entre Paris et Bruxelles. Même un gaulliste sans expérience politique importante comme Raymond Barre a commencé à développer à Bruxelles une politique indépendante en raison de ses compétences propres, de sa personnalité, mais aussi de sa logique de fonction, même si celle-ci a ses limites comme le montre l'exemple de Pierre-Olivier Lapie.

Cette politique agressive envers les institutions européennes est permise par une domination sans partage du général de Gaulle sur la politique européenne de la France.

\section{E. L'AUTORITÉ INCONTESTÉE DU GÉNÉRAL DE GAULLE EN MATIÈRE DE POLITIQUE EUROPÉENNE}

Les conceptions du général de Gaulle en matière de construction européenne ont pu s'imposer de 1958 à 1969 grâce à sa domination incontestée sur ce secteur. Sur le plan fonctionnel et institutionnel, les prérogatives dévolues au président de la République sous la $V^{\circledR}$ République ont certainement participé de cette dynamique qui doit surtout beaucoup à la personnalité propre du général. L'ampleur, la profondeur et l'originalité de sa vision en politique étrangère, ainsi que sa légitimité exceptionnelle depuis 1940, ont conduit à faire de la politique étrangère un domaine largement soumis à l'influence du président de la République. Il est difficile de parler de "domaine réservé » au sens strict, surtout en matière européenne où les décisions sont quasi quotidiennes et souvent techniques, car les principaux ministres intéressés (Premier ministre, ministre des Affaires étrangères, ministre de l'Économie et des Finances) ont tous disposé d'une marge de manœuvre véritable. Toutefois, celle-ci s'exerçait dans les limites des conceptions gaullistes générales de la politique extérieure de la France qui n'ont été contestées par personne comme le montre l'étude de ses principaux collaborateurs.

Le personnage principal dans l'application de la politique étrangère de la France du général de Gaulle a été Maurice Couve de Murville. Ministre des Affaires étrangères de juin 1958 à mai 1968 puis Premier ministre du général de Gaulle, Couve de Murville bénéficiait, comme le montre sa carrière politique (il est nommé Premier ministre peu après mai 1968), d'une très grande confiance du

178. AFNSP, 4 DE 6, lettre de Michel Debré à Raymond Barre, 2 octobre 1967. 
chef de l'État. En matière de conception européenne, il est considéré comme si proche du général de Gaulle qu'il ne semble pas avoir de réflexion propre. C'est le reproche qui lui est fréquemment adressé par Michel Debré notamment ${ }^{179}$. Les études historiques semblent confirmer cette observation. Ainsi, Maurice Vaïsse constate « une certaine «ankylose» de la réflexion diplomatique dans la mesure où l'impulsion vient de l'Élysée et où toute pensée dissidente est écartée $^{180} \gg$. De fait, Couve de Murville semble avoir professé des idées d'une orthodoxie gaulliste parfaite.

L'inamovible ministre des Affaires étrangères s'appuie sur un réseau gaulliste très actif au sein de son département. Il profite notamment de ses liens avec le directeur de la DAEF, Olivier Wormser ${ }^{181}$. Comme son ministre, Olivier Wormser est un diplomate au profil atypique. Trois caractéristiques de leur biographie les rapprochent : ce ne sont pas des diplomates de carrière, rentrés par la voie royale du concours ; ils sont très sensibles aux problèmes économiques et financiers ${ }^{182}$, et ils ont tous deux été écartés par le pouvoir politique dans les années 1950 pour un manque d'enthousiasme européiste ${ }^{183}$. Dès le début du mois de juin 1958, Couve de Murville, devenu ministre, fait d'Olivier Wormser son principal collaborateur pour les affaires européennes, occupant de facto la position occupée autrefois par Maurice Faure car il n'y a plus de secrétaire d'État aux Affaires étrangères dans le nouveau gouvernement ${ }^{184}$. Miriam Camps, observatrice attentive de la négociation ZLE, relève que, au comité Maudling, même si Wormser était l'un des seuls à ne pas avoir le rang de ministre : "[he] had as much power as most ministers in the de Gaulle government ${ }^{185} \gg$. Enfin, lorsque Couve de Murville accède à la tête du gouvernement en juillet 1968, il propose à son ami Wormser de devenir son ministre des Finances ${ }^{186}$. Devant son refus, il le nomme au poste très convoité de gouverneur de la Banque de la France. Wormser reste directeur de la DAEF jusqu'en 1966.

179. Entretien entre Michel Debré et Charles de Gaulle des 9 janvier 1962 et 8 juillet 1968, in Michel Debré, Entretiens avec le général de Gaulle, 1961-1969, Albin Michel, Paris, 1993, p. 56 et p. 138-142.

180. Maurice Vaïsse, La Grandeur..., op. cit., p. 312.

181. Robert Marjolin, Le travail d'une vie..., op. cit., p. 258 ; Henri Froment-Meurice, Vu du Quai. Mémoires 1945-1983, Fayard, Paris, 1998, p. 303.

182. Couve de Murville est inspecteur des finances et Wormser a rédigé une thèse d'économie.

183. Sur Olivier Wormser : voir chapitre I. A ; sur Maurice Couve de Murville : voir chapitre III. A.

184. AMAE, POW 78, folio 223, lettre de Maurice Couve de Murville à Antoine Pinay, 6 juin 1958.

185. Miriam Camps, Britain and the European Community, 1955-1963, Princeton UP, Princeton, 1964, p. 163.

186. André de Lattre, Servir aux Finances..., op. cit., p. 225. 
Son successeur, Jean-Pierre Brunet, perpétue ses conceptions en matière de construction européenne.

La doctrine européenne de la DAEF repose tout d'abord sur l'hostilité à la Grande-Bretagne et la défense de la CEE en réaction à la menace d'isolement de la France que représentait pour eux la ZLE en 1956-1958 ${ }^{187}$. Le caractère fondateur de l'épisode de la ZLE pour la mentalité de ces diplomates gaullistes est particulièrement important : Wormser a été lancé dans la carrière diplomatique par Massigli ${ }^{188}$, dont il suivait l'inclination pour une Grande Europe lâche, fondée sur le couple franco-britannique, et la méfiance envers la Petite Europe supranationale. Toujours méfiant envers l'Allemagne, il se convertit à la CEE non par idéalisme européen mais du fait de la menace que représente la ZLE pour la puissance française. Dans ce cadre, l'hostilité à la GrandeBretagne, concurrente de la France dans la lutte à la prééminence en Europe, est une constante à la DAEF, mais aussi chez de Gaulle, en rupture complète avec certains de ses prédécesseurs de la $\mathrm{IV}^{\mathbb{E}}$ République comme Guy Mollet par exemple. Le souvenir de la ZLE est d'ailleurs utilisé par Wormser pour critiquer la Grande-Bretagne lors de la première candidature britannique ${ }^{189}$. Les partisans de la Grande-Bretagne, comme François Valéry qui a défendu la ZLE de manière énergique en 1956-1958, sont mis de côté. Alors qu'il avait un rang supérieur à Jean-Pierre Brunet en 1956-1958, c'est ce dernier qui succède à Wormser en 1966, sans doute parce qu'il a suivi la ligne hostile à la ZLE. Brunet suit la carrière prestigieuse de Wormser, lui succédant à la direction de la DAEF puis comme ambassadeur de France à Bonn et accédant à la dignité d'ambassadeur de France ${ }^{190}$. Le Quai d'Orsay a dû être divisé sur la politique européenne de la France mais les lignes divergentes n'ont pas eu le loisir de s'exprimer, tant le groupe gaulliste de la DAEF est proche du pouvoir.

187. Laurent Warlouzet, « Le Quai d'Orsay face au traité de Rome. La direction des Affaires économiques et financières (DAEF) de 1957 à $1975 »$, in Laurence Badel et al. (dir.), Les administrations nationales..., op. cit., p. 144-165 ; Matthieu Osmont, «Europe politique versus Europe économique? Rivalités et répartition des rôles dans les dossiers européens entre la direction des Affaires politiques et la direction des Affaires économiques et financières au Quai d'Orsay (1955-1974) », in Michele Affinito, Guia Migani, Christian Wenkel (dir.), Les deux Europes, actes du III colloque international RICHIE, Peter Lang, Bruxelles, 2009, surtout p. 201-206.

188. AMAE, Papiers Massigli, volume 91, folio 17, lettre de Massigli à Alphand du 17 mars 1945 ; volume 94, folio 49, lettre de Massigli à Chauvel du 16 mars 1945 ; Raphaële Ulrich-Pier, René Massigli (1888-1988)..., op. cit., p. 1012-1013.

189. Piers Ludlow, " Diplomacy with different rules : learning to negociate in the EEC », in Marie-Thérèse Bitsch, Raymond Poidevin, Wilfried Loth (dir.), Institutions européennes et identités européennes, Bruylant, Bruxelles, 1998, p. 246.

190. Olivier Wormser est ambassadeur à Bonn à partir de 1974, avant que Jean-Pierre Brunet ne lui succède en 1977-1981. Le premier accède à la dignité d'ambassadeur de France en 1968, le second en 1980. 
Couve de Murville suit naturellement cette ligne. S'il est heurté par la brutalité de la conférence de presse du 14 janvier $1963^{191}$, il reste fidèle à la doctrine d'exclusion de la Grande-Bretagne sur le fond. Ainsi, dans un conseil restreint sur la seconde candidature britannique dont les verbatim ont été conservés, Couve de Murville apparaît plus radical encore que de Gaulle dans le rejet de la Grande-Bretagne ${ }^{192}$. Alors que le général de Gaulle envisage de repousser la discussion sur l'entrée de la Grande-Bretagne à 1970, si Londres entame les réformes nécessaires, Couve estime que fixer une date serait encore trop conciliant.

Ce groupe gaulliste du Quai d'Orsay professait également une grande méfiance envers les prétentions supranationales de la Commission européenne. Dans sa note de juin 1958, Wormser cherche ainsi à convaincre le général de Gaulle d'adopter la CEE car elle correspond aux intérêts de la France pour le moment, mais il évoque une " bifurcation » ${ }^{193}$, c'est-à-dire un moment où les intérêts de la France et de l'intégration économique par la CEE ne coïncideront plus, et où le traité de Rome pourra être mis entre parenthèses. Une note de 1961 évoque d'ailleurs la « méfiance presque maladive » d'Hallstein envers Wormser ${ }^{194}$. Sur les problèmes institutionnels, Couve de Murville semble encore être le gaulliste le plus radical. En avril 1968, dans un comité interministériel, il s'interroge sur les risques de crise prochaine du Marché commun et conclut sur la nécessité de poursuivre la CEE afin d'éviter le retour de l'économie française à ses habitudes protectionnistes ${ }^{195}$. Cette conclusion est typiquement dans la logique gaulliste : le Marché commun est avant tout un utile « traité de commerce » qui n'a pas vocation à être permanent, d'où les interrogations périodiques sur sa remise en cause éventuelle.

L'autre grand gaulliste orthodoxe est Michel Debré. Premier ministre de 1959 à 1962 puis ministre de l'Économie et des Finances de 1966 à 1968 et enfin ministre des Affaires étrangères de 1968 à 1969, il a joué un rôle considérable en matière de construction européenne car ce dossier l'intéresse depuis longtemps. Debré défend depuis l'immédiat après-guerre la construction d'une Europe très organisée, mais intergouvernementale, en particulier dans une publication

191. Piers Ludlow, Dealing with Britain..., op. cit., p. 210. Couve de Murville pensait que les Britanniques allaient faire échouer la négociation seuls.

192. AN, 5 AG1, volume 29, verbatim des entretiens lors du Conseil restreint du 16 octobre 1967.

193. AMAE, POW 78, folio 217, note d'Olivier Wormser du 2 juin 1958.

194. AMINEFI, B 17.678, note du SDECE du 8 mars 1961 ; Sur l'hostilité aux prétentions institutionnelles de la Commission, voir aussi : note de la DAEF du 25 mai 1965, in DDF, 1965-II, doc. $\mathrm{n}^{\circ} 241$.

195. AN, 5 AG1, volume 35, note de Prate du 4 avril 1968. 
de $1948^{196}$. Il développe donc des idées personnelles dans ce dossier, indépendamment du général de Gaulle, même si leurs réflexions se rejoignent sur le fait que la construction européenne doit être fondée exclusivement sur les États. Deux différences peuvent être identifiées par rapport au général de Gaulle.

D'une part, Debré avait une vision moins hostile à la Grande-Bretagne que le général de Gaulle. Cela se perçoit particulièrement lorsqu'il était Premier ministre en 1959-1962 ${ }^{197}$. Debré prend en effet bien soin de toujours inclure la Grande-Bretagne dans ses projets d'Europe politique. Ainsi dans une note du 26 septembre 1959, Debré souligne l'impérieuse nécessité de s'entendre avec la Grande-Bretagne et de l'inclure dans les projets d'Europe politique, ce que les commentaires manuscrits du général de Gaulle sur la note refusent catégoriquement ${ }^{198}$. De même lors du Conseil restreint sur la seconde candidature britannique du 16 octobre 1967, si Debré ne défend pas l'entrée de la Grande-Bretagne dans la CEE, il oriente le débat sur les moyens de l'aider à sortir de ses difficultés ${ }^{199}$. Il est plus modéré que Couve de Murville sur ce sujet. Enfin à partir de novembre 1968, face à l'arrogance monétaire allemande, il cherche à convaincre de Gaulle de se rapprocher de la Grande-Bretagne ${ }^{200}$. Cependant, Debré ne conteste pas les trois rejets de la Grande-Bretagne, de 1958, de 1963 et de 1967, et désapprouve le comportement de Londres dans l'affaire Soames.

D'autre part, Debré se montre beaucoup plus attentif aux évolutions institutionnelles que le général de Gaulle. Sa formation de conseiller d'État doit jouer dans cette inclination. Ainsi, Debré se préoccupe très rapidement des liens que la Commission européenne entend développer avec les anciennes colonies françaises dans le cadre de la politique de développement ${ }^{201}$. Par ailleurs, il se méfie des ambitions de la Commission en matière de relations extérieures et

196. Publication intitulée Projet d'union des États européens (Nagel, 1948) ; Michel Debré, Trois républiques pour une France, Mémoires, $t$. II : 1946-1958, Agir, Albin Michel, Paris, 1988, p. 19 et p. 195.

197. G.-H. Soutou, « Michel Debré... », op. cit., p. 413.

198. AFNSP, 2 DE 29, lettre de Debré à de Gaulle avec des annotations manuscrites de ce dernier, 26 septembre 1959.

199. AN, 5 AG1, volume 29, verbatim des entretiens lors du Conseil restreint du 16 octobre 1967 ; voir aussi : A. Peyrefitte, C'était de Gaulle, tome III, Fayard, Paris, 2001, p. 268-269.

200. Hélène Plisson, La mésentente cordiale franco-britannique : la deuxième tentative d'adhésion britannique au Marché commun à l'épreuve du veto français (octobre 1964-avril 1969), thèse dir. Jean-Paul Bled, Université Paris IV, 2004, p. 691-692 et 698.

201. Guia Migani, «The commissioner Robert Lemaignen and the African States : the Origins of the European Develoment Policy (1958-1961)», in Jürgen Elvert, Michael Salewski (éd.), Historische Mitteilungen, Band 18, Franz Steiner, Stuttgart 2005, p. 156. 
notamment du droit de légation extérieur, et ce dès $1960^{202}$. Enfin, en matière d'Europe politique, Debré détaille au général de Gaulle précisément tous les excès de pouvoir dont la Commission se rend coupable selon lui ${ }^{203}$, alors que ce dernier estime au contraire que le Marché commun « demeurera au niveau d'un traité de commerce facilitant les échanges et obligeant notre industrie à se moderniser ${ }^{204} \gg$. Cependant, cela n'empêche pas Debré d'avoir une action limitée sur l'ampleur des délégations de souveraineté que la France doit concéder. Le problème algérien a dû en fait mobiliser la majeure partie de l'énergie du Premier ministre entre 1959 et 1962, et il était trop tard pour infléchir la pratique institutionnelle ensuite.

Debré est donc bien un « hypergaulliste ${ }^{205}$ ». Contrairement à Couve de Murville, il affirme beaucoup plus fortement ses idées personnelles mais elles semblent largement compatibles avec celles du général de Gaulle en matière de politique européenne. D'autres responsables politiques importants ont pu manifester des conceptions sensiblement divergentes mais ils n'eurent pas véritablement l'occasion de les exprimer en matière européenne.

Le successeur de Michel Debré au poste de Premier ministre, Georges Pompidou, a un profil différent. C'est un homme politique débutant, qui n'a occupé aucun mandat électoral. La faiblesse des sources d'archives le concernant pour la période où il résidait à Matignon, alors que Couve de Murville et Debré ont chacun déposé des fonds personnels importants, tend à renforcer cette impression d'un effacement du Premier ministre. Pourtant, des indices témoignent d'un intérêt précoce, dès 1962, de Georges Pompidou pour les questions économiques européennes, en particulier sous l'angle industriel ${ }^{206}$. D'autre part, comme Michel Debré, Georges Pompidou exprime une position plus modérée que celle de Maurice Couve de Murville et de Charles de Gaulle envers la Grande-Bretagne lors du Conseil restreint d'octobre 1967 dont on possède les verbatim ${ }^{207}$. Par ailleurs, le Premier ministre avait la tutelle directe du SGCI et il a nommé des proches à ce poste comme François-Xavier Ortoli

202. AFNSP, 2 DE 12, note de Debré pour Amanrich (cabinet) du 10 février 1960 ; AFNSP, 2 DE 69, lettre de Debré à Couve de Murville, 13 février 1960 ; AFNSP, 2 DE 29, Lettre de Debré à de Gaulle, 19 mars 1960.

203. AFNSP, 2 DE 29, note de Debré à de Gaulle des 26 et 28 juillet 1960.

204. AFNSP, CM7, annotations manuscrites de Charles de Gaulle sur une note de Michel Debré du 27 février 1961.

205. Georges-Henri Soutou, « Michel Debré... », op. cit., p. 405.

206. Voir le chapitre VII.

207. AN, 5 AG1, volume 29, verbatim des entretiens lors du Conseil restreint du 16 octobre 1967. 
(de 1962 à 1966) puis Jean-René Bernard (nommé en 1967), qu'il a réussi à imposer face à la candidature d'Alain Prate, envisagée par Barre, Debré et Couve de Murville ${ }^{208}$. Georges Pompidou a donc dû exercer une influence non négligeable sur certains dossiers économiques européens, où il a pu profiter de son expérience antérieure chez Rothschild, mais la domination de la politique étrangère par le tandem de Gaulle-Couve de Murville et l'activisme de son ministre des Finances Michel Debré en la matière ont limité sa marge de manœuvre.

Les autres ministres importants du gouvernement en matière européenne n'ont pas non plus réussi à peser sur le processus de décision dans un sens contraire à celui du général de Gaulle. C'est notamment le cas des trois ministres des Finances qui ont précédé Debré. Antoine Pinay tout d'abord a des sentiments plus favorables à l'Europe supranationale que de Gaulle mais en conflit avec ce dernier, il quitte le gouvernement dès 1960. Wilfrid Baumgartner ne semble pas avoir eu de doctrine spécifique ou en tout cas pas de volonté de la promouvoir ${ }^{209}$. Quant à Valéry Giscard d'Estaing, son action dans le domaine des investissements américains ${ }^{210}$ ou du $\mathrm{SMI}^{211}$ semble démontrer qu'il souhaite avant tout afficher sa fidélité aux idées du général de Gaulle. De même en matière financière, il diffère des réformes de libéralisation préparées par ses services pour se concentrer sur la politique conjoncturelle ${ }^{212}$. Étudiant les réformes financières de 1966-1967, Laure Quenouëlle s'est demandé pourquoi elles ont été décidées en quelques mois par Debré et pas par son prédécesseur Giscard d'Estaing alors que certaines étaient prêtes depuis un certain temps. Elle conclut que la clé réside dans la conjoncture, qui n'est pas favorable (plan de stabilisation) mais aussi dans la personnalité du ministre, plus libéral dans ses doctrines et ses discours que dans ses $"$ pratiques $^{213} »$. Cette observation est confirmée par une note de Dromer de 1965, qui se plaint auprès du général de Gaulle car le ministre des Finances n'a toujours pas mis en œuvre les mesures de libéralisation des prix envisagées ${ }^{214}$. Les idées spécifiques de Valéry

208. AN, 5 AG1, volume 32, note de Dromer du 18 septembre 1967.

209. Olivier Feiertag, Wilfrid Baumgartner... op. cit., p. 649-678, notamment p. 678.

210. Voir le chapitre VII. A.

211. Il prononce un discours assez agressif en 1965, dans la continuité des déclarations du général de Gaulle du 4 février 1965 : Robert Solomon, Le Système monétaire international, Économica, Paris, 1979 [1976], p. 52.

212. Voir le chapitre VII.

213. Laure Quenouëlle-Corre, La direction du Trésor 1947-1967. L'Etat-banquier et la croissance, Comité pour l'histoire économique et financière de la France, Paris, 2000, p. 504.

214. AFNSP, note du 21 janvier 1965 de Dromer, « Les orientations et les réformes souhaitables à bref délai dans le domaine économique et financier », note de 30 pages. 
Giscard d'Estaing en matière d'intégration économique européenne sont donc difficiles à percevoir et camouflées sous une orthodoxie gaulliste garante de son influence politique.

\section{CONCLUSION : FORCES ET FAIBLESSES DE LA FRANCE GAULLISTE}

De Gaulle domine véritablement la politique européenne de la France. Il n'a pas de concurrent au sein de l'exécutif français, alors même que d'autres pays européens sont beaucoup plus divisés sur la politique à mener face à la CEE. Couve de Murville, à la tête d'un groupe gaulliste du Quai d'Orsay, est d'une fidélité à toute épreuve, le remuant Debré est « hypergaulliste », quant à Pompidou ou Giscard d'Estaing, ils n'ont pas le loisir d'exprimer d'éventuelles divergences. Légitimé par son rôle durant la seconde guerre mondiale, les multiples élections et référendums gagnés entre 1958 et 1968, de Gaulle peut imposer ses conceptions en matière de politique européenne avec une force et une constance sans égale, en particulier par rapport aux gouvernements de la $\mathrm{IV}^{\mathrm{e}}$ République. De plus, ses choix en matière de politique étrangère recueillent un assentiment très large, bien au-delà de la droite, car ils ont servi à redonner une fierté aux Français après la défaite de 1940, autour d'une nouvelle identité post-impériale. C'est notamment l'interprétation de Maurice Agulhon qui dresse le parallèle entre de Gaulle s'opposant aux Américains et Astérix résistant aux Romains $^{215}$. Ce consensus autour de la politique extérieure gaulliste rend parfois difficile, en France, la critique d'un personnage qui n'était pas infaillible, ne pouvait décider de tout ${ }^{216}$, ni embrasser l'exceptionnelle diversité et la très grande technicité des dossiers traités à l'échelle communautaire.

Cette stature exceptionnelle du personnage du général de Gaulle est aussi une faiblesse pour la France. Certes de Gaulle attend beaucoup de la construction européenne. Mais ses conceptions souffrent de deux handicaps. D'une part sa priorité systématique aux objectifs politiques sur les logiques économiques le conduit à négliger certains dossiers considérés comme mineurs. Elle le conduit à accepter avec la PAC une politique aux justifications sociopolitiques évidentes, mais qui a de nombreuses conséquences néfastes sur le processus de décision communautaire, comme sur le plan économique et financier.

215. Maurice Agulhon, De Gaulle. Histoire, symbole, mythe, Plon, Paris, 2000, p. 128-130.

216. De Gaulle reconnaît volontiers dans ses mémoires qu'il se contentait souvent de définir les grandes orientations : Charles de Gaulle, Mémoires d'espoir. Le renouveau, 1958-1962, Plon, Paris, 1970, p. 139-142. 
Surtout de Gaulle, et avec lui la majorité des décideurs français, sousestime la dynamique des institutions communautaires. Il minore la dépendance progressive qui s'instaure entre la France et la CEE sur les plans économiques et juridiques, et qui éclate lors de la crise de la chaise vide. De Gaulle avait bien compris que le traité de Rome contenait des virtualités supranationales mais il estimait que les moyens de la diplomatie multilatérale traditionnelle (négociation interétatique avec le plan Fouchet, boycott avec la crise de la chaise vide) suffiraient pour lui retirer ses développements les plus dangereux. Focalisé sur les rapports de force politiques, il a ignoré la dynamique juridique et économique de l'intégration européenne, qui conduit la France à s'insérer dans un réseau de solidarité communautaire qui ne peut être brisé sans dégâts. En fait, avec sa conception statocentrée et son exigence du messianisme français, de Gaulle manifeste avec l'éclat la difficile compatibilité de l'exception bonapartiste française avec la construction européenne.

Si la personnalité exceptionnelle du général de Gaulle renforce l'autorité de la France en Europe, elle ne lui permet pas de peser de manière optimale dans le débat sur l'orientation économique de l'Europe. Les décideurs français adoptent très largement le modèle du libéralisme régulé de la CEE tout en se concentrant sur la PAC, dont les justifications et les dynamiques sont beaucoup plus sociopolitiques qu'économiques. L'adoption de la vision de la CEE comme d'un échange entre des exportations agricoles françaises et des exportations industrielles allemandes résulte d'une rationalisation ex post et d'une absence de vision stratégique de l'intégration économique par le traité de Rome chez les décideurs français. Le gouvernement français est donc en retard dans les discussions sur les formes d'intégration économique européenne qui débutent dès 1958 autour du dossier crucial de la politique de la concurrence. 



\section{CHAPITRE V}

\section{L'EUROPE ORDOLIBÉRALE : LA POLITIQUE DE LA CONCURRENCE \\ (1958-1965)}

La première expression d'une interprétation volontariste du processus d'intégration économique européenne provient d'un groupe au sein de l'administration communautaire, animé par le commissaire à la concurrence, l'allemand Hans von der Groeben. Ces acteurs ont cherché à promouvoir une union économique ordolibérale à partir du socle de compétence que leur donnait le traité en terme de politique de la concurrence, et plus précisément dans la lutte contre les ententes. Domaine encore très récent lors des débuts de la CEE, il est rapidement pris en charge par le commissaire von der Groeben qui parvient à faire accepter un règlement 17/62 qui lui est très favorable. Mais la difficulté d'appliquer ce règlement sanctionne l'échec de cette Europe ordolibérale en 1964-1965.

\section{UNE NOUVELLE POLITIQUE PUBLIQUE À L'ÉCHELLE DU MARCHÉ COMMUN}

La politique de la concurrence est un domaine d'intervention largement nouveau dans l'Europe des Six en 1957. Le patronat européen se mobilise pourtant assez rapidement en tentant de définir une position commune sur l'application des règles de concurrence du traité de Rome. En parallèle, la Commission met en place un réseau d'acteurs autour d'elle.

\section{A. LES ENJEUX DE LA POLITIQUE DE LA CONCURRENCE EN 1957}

La politique de la concurrence désigne la régulation par une autorité publique des rapports entre les acteurs économiques sur un marché donné, afin d'organiser la compétition la plus juste possible. Dans le domaine de l'intégration européenne, la politique de la concurrence se justifie plus particulièrement. Sans elle, le désarmement douanier et contingentaire qui est à la base de la 
CEE pourrait en effet être contourné par des ententes restrictives interdisant l'accès à des concurrents extérieurs. Les marchés resteraient donc cloisonnés. La politique de la concurrence apparaît comme le complément naturel et indispensable de la libération des échanges. C'est une politique publique neuve, car les années précédentes étaient marquées par une tolérance assez forte envers les ententes (dénommées généralement « cartels ») en Europe, considérées comme des formes de rationalisation de la production. Leur rôle était particulièrement fort à l'échelle internationale. La création du cartel de l'acier en 1926, ou la renaissance du cartel de l'aluminium la même année ${ }^{1}$ témoignent de cette approche ${ }^{2}$. Au contraire, après 1945, le bloc occidental est reconstruit selon une logique libérale qui vise à éviter les replis protectionnistes des années 1930.

La politique de la concurrence s'attaque à toutes les pratiques dites « restrictives », c'est-à-dire entravant la libre concurrence. Elles peuvent provenir des acteurs privés, par des ententes (accords entre des entreprises gardant leur autonomie juridique) ou des fusions (appelées aussi « concentrations »), comme des acteurs publics, par les aides d'États. La politique de la concurrence n'interdit pas ces pratiques mais les surveille. Ainsi, une entente peut être tout à fait bénéfique pour le marché, par exemple si deux entreprises s'associent pour développer un nouveau produit ou pour le commercialiser. Elle devient néfaste si l'objet de l'accord est de restreindre la concurrence, par exemple en se partageant secrètement les marchés. Mais il est souvent difficile de porter un jugement définitif sur une entente. Ainsi, un accord de distribution exclusive réduit nécessairement la concurrence entre les distributeurs, mais peut faciliter la vente d'un produit complexe, qui a besoin d'un service après-vente. Bien plus, un même accord peut avoir des effets négatifs sur la concurrence à court terme, mais positif à long terme, comme les accords de brevets par exemple. Dans le domaine de la coopération européenne, la situation est d'autant plus compliquée que les ententes ont souvent été vues comme un moyen d'intégrer les marchés. La collaboration entre les entreprises est vue comme le complément naturel de l'ouverture des marchés, en évitant une mise en concurrence trop brutale et destructrice. Après

1. Florence Hachez-Leroy, L'aluminium français : l'invention d'un marché, 1911-1983, CNRS éditions, Paris, 1999, p. 161.

2. Sur les cartels dans les années 1930 : Dominique Barjot (dir.), International Cartels Revisited. Vues nouvelles sur les cartels internationaux (1880-1980), éditions du Lys, Caen, 1994 ; Françoise Berger, «Les milieux économiques et les États face aux tentatives d'organisation des marchés européens dans les années 1930 », in Éric Bussière, Michel Dumoulin, Sylvain Schirmann (dir.), Europe organisée, Europe du libre-échange? Fin XIXe siècle-Années 1960, Peter Lang, Bruxelles, 2006, p. 71-106. 
1945, cette doctrine de l' « Europe contractuelle ${ }^{3} »$ continue d'imprégner le patronat européen. L'application de la politique de la concurrence est donc particulièrement délicate.

\section{Des pratiques nationales diverses.}

En 1957, la plupart des pays de la CEE ne disposent pas d'une telle législation (Belgique, Luxembourg, Italie). Trois exemples principaux influencent les débats européens de par les options contradictoires qu'ils ont adoptées : les États-Unis, la France et la RFA ${ }^{4}$.

La législation américaine est la plus ancienne car elle naît avec le célèbre Sherman Act de 1890 qui interdit le délit de «coalition ». Cette loi a surtout des justifications politiques : protéger les plus faibles contre les trusts et unifier l'espace américain sur le plan de la législation économique. Dans la politique américaine, l'instruction est assurée par les autorités publiques mais ce sont les tribunaux qui prononcent les décisions.

La politique allemande de la concurrence est la plus récente car la loi finale date du 27 juillet 1957. Elle repose sur le principe dit de l'« interdiction » : toutes les ententes sont interdites sauf si elles sont explicitement autorisées par une autorité indépendante, le Bundeskartellamt (BKA). Les entreprises doivent donc enregistrer leurs accords auprès du BKA, et attendre son autorisation. De nombreuses exceptions sont prévues tant sur le type d'ententes (les ententes d'exportations sont autorisées notamment) que sur le secteur' ${ }^{5}$.

L'approche allemande est issue de la doctrine ordolibérale, très influente en RFA $^{6}$. La politique de la concurrence faisait partie du projet de reconstruction d'une Allemagne démocratique développée par l'École de Fribourg. Elle influença des hommes politiques allemands importants comme Alfred Müller-

3. Éric Bussière, "Les milieux économiques face à l'Europe au $\mathrm{XX}^{\mathrm{e}}$ " in Revue d'histoire de l'intégration européenne, 1997-2, p. 5-23.

4. La politique britannique est également ancienne (1948 et 1956) mais, selon Stephen Wilks, elle est marquée par une certaine confusion dans sa définition : Stephen Wilks, «The prolonged Reform of United Kingdom Competition Policy », in G. Bruce Doern et Stephen Wilks (éd.), Comparative Competition Policy. National Institutions in a Global Market, Clarendon Press, Oxford, 1996, p. 142145.

5. Arved Deringer, "La législation allemande », in Revue du Marché commun, supplément au numéro de juillet 1959 sur les journées d'études de Caen, « La libre concurrence dans les pays du Marché commun », 8-10 mai 1959, p. 7-8.

6. David Gerber, Law and competition in $X X^{\text {th }}$ Century Europe. Protecting Prometheus, Clarendon Press, Oxford, 1998; François Denord, «Néolibéralisme et «économie sociale de marché »: les origines intellectuelles de la politique européenne de la concurrence (1930-1950) », in Histoire, économie et sociétés, mars 2008, p. 23-31. 
Armack - l'inventeur de l'expression « économie sociale de marché » et Ludwig Erhard ${ }^{7}$. La doctrine ordolibérale reposait sur un lien étroit entre libéralisme politique et libéralisme économique. Si l'individu devait être protégé des interventions liberticides de l'État, il devait l'être tout autant des comportements répréhensibles des entreprises. Toute concentration de pouvoir doit être évitée. Le rôle du droit est fondamental : seule la loi peut permettre au marché de bien fonctionner. Une véritable « constitution économique » doit être adoptée pour assurer la libre concurrence et la répartition équitable des bénéfices, tout en minimisant les interventions gouvernementales. L'ordre juridique devait traduire cette " constitution économique », qui encadrerait la politique gouvernementale. C'est l'Ordnungspolitik: la politique gouvernementale ne peut être discrétionnaire et doit suivre ces lois. Elle doit se limiter à établir un cadre pour l'activité économique. En terme pratique, cette approche se manifeste par la préférence pour une autorité judiciaire indépendante et forte, et une méfiance envers une procédure administrative sur laquelle pèsent des soupçons d'arbitraire. La politique de la concurrence allemande s'est rapidement imposée comme un modèle car le BKA est très rapidement monté en puissance. En quatre années, de 1958 à 1961, le BKA a ainsi traité plus de mille notifications d'ententes de toute sorte ${ }^{8}$.

$\mathrm{Au}$ contraire, la politique de la concurrence française est plus souple et plus ancienne. Elle date en effet de l'immédiat après-guerre et est fondée sur deux textes, l'ordonnance du 30 juin 1945 sur la réglementation des prix et le décret du 9 août $1953^{9}$. La législation française est en effet issue de la surveillance des prix ${ }^{10}:$ le but n'est pas tant de lutter contre les acteurs les plus puissants (comme aux États-Unis) ou de limiter l'intervention de l'État au strict nécessaire (comme en RFA), mais de lutter contre l'inflation en fluidifiant le fonctionnement des marchés par l'intervention de l'État dans l'économie. Pourtant, un projet de loi proposant de créer un véritable droit « antitrust » à la française, avec une procédure judiciaire inspirée des États-Unis, avait été déposé en 1952 par la députée Germaine Poinso-Chapuis (MRP), de retour d'une mission

7. David Gerber, Law and Competition..., op. cit., p. 236-237 ; Patricia Commun, « La contribution d'Alfred Müller-Armack à l'initiation d'un ordre écolibéral en Europe de 1958 à 1963 », in Marie-Thérèse Bitsch (dir.), Le Couple France-Allemagne et les institutions européennes, Bruxelles, Bruylant, 2001, p. 171-190.

8. Louis Franck, La libre concurrence, PUF, Paris, 1967, p. 88.

9. Dominique Brault, L'État et la concurrence en France, Économica, Paris, 1987, p. 37 ; Alain Chatriot, «Les ententes : débats juridiques et dispositifs législatifs (1923-1953). La genèse de la politique de la concurrence en France », in Histoire, économie et sociétés, mars 2008, p. 7-22.

10. Sur la politique des prix : Michel-Pierre Chelini, Inflation, État et opinion en France de 1944 à 1952, Comité pour l'histoire économique et financière de la France, Paris, 1998. 
outre-Atlantique $^{11}$. Au contraire, le décret de 1953 s'inscrit dans la continuité de l'interventionnisme étatique français et établit un système administratif : c'est la direction générale des Prix du ministère des Affaires économiques qui instruit le dossier et prend la décision, même si une commission indépendante, la Commission technique des ententes (CTE) doit donner un avis consultatif.

L'application de cette politique est assez souple. La doctrine française est celle de l'«abus » et pas de l'interdiction : les ententes sont autorisées sauf si elles ont des conséquences néfastes. La CTE - qui comprend d'ailleurs des représentants des milieux économiques - applique cette approche de manière très tolérante, en admettant de nombreuses justifications aux ententes et en demandant des modifications des accords fautifs plutôt que des condamnations ${ }^{12}$. Le patronat français lui-même se montre satisfait du travail de cette CTE, saluée pour son pragmatisme ${ }^{13}$. Il semble que les ententes bénéficient d'un préjugé relativement positif car la taille moyenne des entreprises françaises restant relativement faible - du moins dans la perception des décideurs des années cinquante, les accords entre les acteurs économiques sont perçus comme un vecteur de rationalisation.

La direction des Prix se concentre en fait sur la surveillance des prix et des pratiques commerciales, notamment en luttant contre le refus de vente. Le souvenir des pénuries et du marché noir nourrit beaucoup plus cette politique que le modèle américain de l'antitrust. La politique de la concurrence française repose donc sur une approche pragmatique et économique plus que juridique. Son application est administrative plus que juridique.

Ainsi, trois modèles coexistent au moment où le traité de Rome est signé. La politique américaine est la plus ancienne mais l'approche ordolibérale allemande gagne rapidement en prestige, tandis que la pratique française reste assez marginale, dans la mesure où elle n'est qu'un embryon de la politique des prix.

\section{Les dispositions du traité de Rome.}

Lors de la négociation du traité de Rome, entre 1955 et 1957, le dossier de la concurrence apparaît comme secondaire mais pas négligeable car le précédent de la CECA était dans tous les esprits. Dans le traité de Paris en effet, les dispositions sur la politique de la concurrence étaient particulièrement importantes pour des raisons politiques, éviter une reconcentration de l'industrie

11. M.-P. Chelini, Inflation, État et opinion..., op. cit., p. 567.

12. L. Franck, La libre concurrence..., op. cit., p. 99.

13. ACNPF, 72 AS 1388, compte rendu de la réunion CIFE du 27 mai 1957. 
allemande $^{14}$, mais aussi économiques. Matthias Kipping a mis en valeur le rôle d'un petit groupe mobilisé autour de Jean Monnet et de certains milieux patronaux consommateurs d'acier comme Pierre Lefaucheux, PDG de Renault, pour la défense d'une politique de la concurrence forte, garante de prix bas ${ }^{15}$. Un réseau transatlantique influencé par l'exemple américain, les réflexions ordolibérales allemands et l'exigence modernisatrice des planificateurs français s'est mis en place à l'occasion de la négociation du traité de Paris ${ }^{16}$.

Le traité de Paris donne donc à la Haute Autorité de larges prérogatives en matière de politique de la concurrence. Cependant, l'institution supranationale n'a pas réussi à s'imposer dans ce domaine face aux puissantes entreprises du charbon et de l'acier, notamment le cartel charbonnier de la Ruhr ${ }^{17}$. Le rapport Spaak tient compte de ce bilan en demi-teinte. Il prévoit de donner à la Commission des compétences sur de très nombreuses infractions à la concurrence (ententes, concentrations, aides d'État, etc.) mais inclut un contrôle des États membres par l'intermédiaire du Conseil des ministres ou d'organes consultatifs $^{18}$.

Pendant la négociation du traité de Rome, la principale opposition est francoallemande. La position française est fondée sur une politique de la concurrence à la fois effective mais pas trop supranationale : la Commission devra mener l'instruction en liaison avec les États membres, le Conseil devrait avoir un pouvoir de décision à la majorité qualifiée si un État membre n'agit pas ${ }^{19}$. Sensibles au libéralisme régulé, les Français veulent s'assurer que tous les États membres respecteront la politique de la concurrence alors que la RFA s'est souvent opposée aux ambitions de la CECA en la matière. Au contraire, le représentant allemand, Müller-Armack, plaide pour des provisions plus générale ${ }^{20}$. Il opère

14. Raymond Poidevin et Dirk Spierenburg, Histoire de la Haute Autorité de la CECA, Bruylant, Bruxelles, 1993, p. 223.

15. M. Kipping, La France et les origines de l'Union européenne..., op. cit., p. 355-356.

16. Brigitte Leucht, «Transatlantic policy networks in the creation of the first European antitrust law : Mediating between American antitrust and German ordoliberalism », in Wolfram Kaiser, Brigitte Leucht, Morten Rasmusen (éd.), The History of the European Union. Origins of a trans- and supranational polity, 1950-1972, Routledge, Londres, 2008, p. 56-73.

17. Jacques Houssiaux, Concurrence et Marché commun, éditions Génin, Paris, 1960, p. 86 ; voir aussi une thèse récente : Tobias Witschke, Gefahr für den Wettbewerb ? Die Fusionskontrolle der Europäischen Gemeinschaft für Kohle und Stahl und die «Rekonzentration» der Ruhrstahlindustrie 1950-1963, Akademie, Berlin, 2009.

18. Rapport Spaak, titre II, chapitre I, sections I et II.

19. AHUE, CM3/NEGO/236, projets d'articles sur les règles de concurrence, doc MAE 175/56 du 17 juillet 1956.

20. AHUE, CM3/NEGO/236, mémento interne du Secrétariat, débats des 3-5 septembre 1956, du 7 septembre 1956 et du 13 septembre 1956, projet remis par M. Thiesing, 10 septembre 1956. 
cependant une distinction entre les concentrations, moins gênantes selon lui, et les ententes, qui devront être soumises à un traitement sévère et notamment à une procédure d'enregistrement obligatoire. On retrouve donc une ligne de fracture classique. D'un côté, les ordolibéraux allemands - dont Müller-Armack est l'un des représentants emblématiques - sont avant tout concentrés sur la lutte contre les ententes. Ils sont également influencés par le débat en cours en RFA sur l'établissement de la loi sur la concurrence - finalement votée en 1957. Erhard tient particulièrement à ce que les dispositions du traité de Rome soient assez sévères envers les ententes afin de faire pression sur le débat national ${ }^{21}$. $\mathrm{Au}$ contraire, les Français semblent plus préoccupés par l'action des grandes entreprises. Ils semblent craindre une possible reconcentration de l'industrie allemande mais aussi une domination de firmes américaines s'établissant en Europe, notamment via la Grande-Bretagne ou la RFA. C'est particulièrement la crainte du secteur automobile, alors que Ford et General Motors sont fortement implantés en Allemagne ${ }^{22}$.

Finalement les Six parviennent à un compromis qui annonce dans ses grandes lignes le traité de Rome ${ }^{23}$. Müller-Armack estime qu'une grande partie des revendications allemandes a été reprise ${ }^{24}$. Le traitement des ententes et des positions dominantes (notion proche mais différente de celle des concentrations) est différencié, une sévérité accrue étant prévue à l'encontre des premières (futur article 85). C'est donc l'approche allemande qui s'impose même si la France obtient la reconnaissance d'un traitement spécial pour les entreprises publiques (article 90). En terme d'application institutionnelle, la Commission joue un rôle central car elle devra proposer un règlement d'application qui sera adopté par le Conseil à l'unanimité pendant les trois premières années puis à la majorité qualifiée ensuite (futur article 87).

D'une manière générale, les articles sont suffisamment généraux pour faire l'objet d'interprétations très différentes, tant sur le plan économique

21. Heike Schweitzer, Parallels and Differences in the Attitudes towards Single-Firm Conduct: What are the Reasons? The History, Interpretation and Underlying Principles of Sec. 2 Sherman Act and Art 82 EC, EUI Working Paper LAW n ${ }^{\circ}$ 2007/32, p. 13.

22. Sigfrido Ramirez, «Antitrust ou anti US ? L'industrie automobile européenne et les origines de la politique de la concurrence de la CEE », in Éric Bussière, Michel Dumoulin, Sylvain Schirmann (dir.), Europe organisée, Europe du libre-échange? Fin XIX

23. AHUE, CM3/NEGO/236, document du secrétariat de la conférence intergouvernementale pour le Marché commun, 20 novembre 1956. Sur cette négociation, voir de nombreux documents publiés in : Reiner Schulze, Thomas Hoeren (éd.), Dokumente zum Europaïschen Recht, Band 3 : Kartellrecht (bis 1957), Springer, Berlin, 2000, p. 156-308.

24. Selon son témoignage : Alfred Müller-Armack, Auf dem Weg nach Europa. Erinnerungen und Ausblicke, Poeschel, Stuttgart, 1971, p. 114. 
qu'institutionnel. L'enjeu reste principalement de définir le contenu du règlement d'application de l'article 87, qui doit transcrire en une politique effective les articles 85 (ententes) et 86 (positions dominantes). Trois éléments doivent être définis : la doctrine suivie (abus ou interdiction), la procédure (judiciaire ou administrative, enregistrement des ententes ou pas) et l'équilibre des pouvoirs entre les institutions intergouvernementales et supranationales. Ces incertitudes traduisent les ambiguïtés fondamentales du dossier général de la politique de la concurrence en 1957 : c'est un domaine nouveau en Europe, en plein renouvellement en 1956-1958 ${ }^{25}$, très technique et marqué par l'insuccès de la CECA. Cela n'empêche pas le patronat européen de se mobiliser rapidement dans ce dossier.

\section{B. UNE MOBILISATION PATRONALE PRÉCOCE (1956-1957)}

Cibles de la politique de la concurrence, inquiétés une première fois par les prescriptions du traité de Paris, les milieux économiques se mobilisent dès la négociation du traité de Rome pour tenter de limiter l'impact de la future politique de la concurrence de la CEE. Le mouvement provient tout d'abord du syndicat patronal allemand. Les débats au sein du patronat européen ne permettent toutefois pas de surmonter de profondes divisions.

\section{L'inquiétude du BDI.}

C'est l'équivalent du CNPF, le BDI (Bundesverband der Deutschen Industrie), qui est à l'origine de contacts à la fin de 1956 avec le patronat français sur cette question car le parlement allemand débattait de l'adoption d'une loi nationale sur la politique de la concurrence ${ }^{26}$. Le but, fixé le 30 mars 1957, est de définir une position commune « afin d'éviter que les services officiels ne dégagent à eux seuls, dans un sens dirigiste ou suivant des conceptions divergentes, l'usage qui pourra être fait de l'article 85 sur le plan européen ${ }^{27} \gg$. Ainsi, moins d'une semaine après la signature du traité de Rome, le patronat européen cherche à s'accorder pour influencer l'application de ce traité. Au sein de l'UNICE, l'organisation patronale des Six remise en activité le 25 avril 1957, une réunion sur la politique de la concurrence se tient dès le 27 avril $1957^{28}$. L'intérêt du

25. Des lois nouvelles sont votées aux Pays-Bas et en Grande-Bretagne en 1956, en RFA en 1957, en France en 1958 (il s'agit d'une réactualisation du décret de 1953, annulé pour des raisons législatives).

26. ACNPF, 72 AS 1388, note de Lartisien, 30 mars 1957.

27. ACNPF, 72 AS 1388, note de Lartisien, 30 mars 1957.

28. ACNPF, 72 AS 803, réunion évoquée dans une réunion du CIFE du 2 juillet 1957. 
patronat européen n'est pas surprenant. Déjà, lors du débat sur la CECA, le CIFE avait concentré ses critiques sur les pouvoirs excessifs donnés à la Haute Autorité en matière de politique de la concurrence ${ }^{29}$. D'autre part, sur le plan national, le CNPF et le BDI se sont largement impliqués dans les débats nationaux sur ce dossier tout au long des années $1950^{30}$. Le patronat est favorable à une organisation de l'intégration européenne par des ententes, qui permettent d'atténuer le choc de la libération internationale des échanges.

Cependant le BDI semble plus inquiet que le CNPF. La loi allemande du 27 juillet 1957 paraît très sévère. Au contraire le CNPF est satisfait de l'évolution de la politique nationale. Cette position transparaît clairement lors des premières réunions du patronat européen, qui commencent par l'exposé des législations nationales. Le représentant français, Fabre, y réaffirme la grande tolérance dont font preuve les autorités françaises envers les ententes ${ }^{31}$. La position du CNPF est de favoriser une transposition à l'échelle de la CEE du modèle français. Ce dernier devrait s'imposer naturellement dans la mesure où les prescriptions du traité de Rome en matière de politique de la concurrence ressemblent à la loi française ${ }^{32}$. Il ne s'agit pas forcément de créer une Commission technique des ententes européenne car le CNPF craint l'émergence d'une bureaucratie supranationale dirigiste. Des structures plus légères, issues notamment du Comité économique et social, sont évoquées ${ }^{33}$. Ce décalage entre le CNPF et le BDI se perçoit rapidement dans les débats européens.

\section{Les divisions internes au patronat européen.}

Les réunions du CIFE donnent lieu à l'expression de divergences sur l'action que doit mener le patronat européen. Les Français et les Belges conseillent de se limiter à des contacts avec les autorités nationales, estimant l'action

29. Matthias Kipping, Neil Rollings, « Networks of Peak Industrial Federations. The Council of Directors of European Industrial Federations and the Council of European Industrial Federations », in Michel Dumoulin (dir.), Réseaux économiques et construction européenne, Peter Lang, Bruxelles, 2004, p. 290.

30. Pour le CNPF : Matthias Kipping, « Concurrence et compétitivité. Les origines de la législation antitrust française après $1945 »$ in Etudes et Documents, IV, Comité pour l'histoire économique et financière de la France, Paris, 1994, p. 438, 440, 443 ; pour le BDI : D. Gerber, Law and competition..., op. cit., p. 273-6. Voir aussi : Marine Moguen, L'ouverture des frontières européennes dans les années 1950. Fruit d'une concertation avec les industriels?, Peter Lang, Bruxelles, 2002, p. 85-105.

31. ACNPF, 72 AS 1388, compte rendu de la réunion CIFE du 27 mai 1957.

32. ACNPF, 72 AS 1505, note du 19 avril 1957.

33. ACNPF, 72 AS 1358, document de Fabre pour Lartisien, 11 février 1958, réponse au questionnaire de la LECE. 
européenne inutile, alors que les Néerlandais et les Allemands sont plus offensifs $^{34}$. Le Belge Sermon se demande «s'il est de l'intérêt de l'industrie de demander des précisions. Ne risque-t-elle pas de provoquer des interprétations qui seraient peu favorables à la cause qu'elle entend défendre ${ }^{35}$ ? ». Il a donc peur qu'un lobbying patronal trop visible dans le domaine des ententes amène les gouvernements à se préoccuper par trop de ce domaine sensible, et à placer finalement le patronat dans une position d'accusé. Le représentant français partage ses craintes. Il affirme d'ailleurs que les autorités françaises lui ont confirmé que le traité de Rome n'apportait rien de nouveau à la réglementation française.

$\mathrm{Au}$ sein de la CIFE, le débat est clairement posé lors de la réunion de mars 1958 comme l'illustre un échange, au sein de l'organisation patronale, entre le représentant patronal néerlandais (Rom Colthoff) et le baron Snoy et d'Oppuers, haut fonctionnaire belge ayant participé aux travaux de la CEE et de la ZLE :

« Rom Colthoff remarque que les difficultés d'application de l'Union du Benelux qu'a signalées le baron Snoy, ont souvent trouvé leur solution dans des ententes entre les industries des deux pays, ententes agissant sous le contrôle et avec la collaboration des deux gouvernements. Ne peut-on pas penser que bien des difficultés que soulèvera l'ouverture du marché pourront être également résolues par les ententes industrielles ? À cet égard, les articles 85 et suivants du traité de Rome ont provoqué de vives appréhensions et l'on espère que la question trouvera une solution plus libérale dans la ZLE. »

«Le baron Snoy confirme que les ententes ont permis de trouver de précieuses solutions aux difficultés du Benelux. La méthode demeure ouverte en dépit des articles 85 et 86 puisque la Commission européenne pourra estimer utiles et autoriser certaines ententes ${ }^{36} »$.

Le modèle de l'Europe organisée reste donc la norme. Si certaines ententes défensives doivent être écartées, de nombreux accords ont au contraire des effets utiles, car ils servent à faciliter l'interpénétration des marchés par la coopération des entreprises. Cette conviction est partagée par une majorité de décideurs économiques, mais aussi par de nombreux décideurs politiques comme le prouve la réaction du baron Snoy, pourtant connu pour ses opinions

34. ACNPF, 72 AS 1388, compte rendu de la réunion CIFE du 27 mai 1957 ; ACNPF, 72 AS 1388, compte rendu de la réunion du 4 juillet 1957.

35. ACNPF, 72 AS 1388, compte rendu de la réunion du 4 juillet 1957.

36. ACNPF, 72 AS 803, réunion des présidents des fédérations de la CIFE des 17 au 18 mars 1958. 
libérales ${ }^{37}$. Par contre, cet échange montre l'ampleur des divergences sur la tactique à suivre : Rom Colthoff veut utiliser la ZLE pour infléchir la CEE. Il s'agit donc d'une reprise, à l'échelle patronale, d'une stratégie dangereuse pour la France, celle qui consiste à vider le traité de Marché commun de ses éléments les plus intégrationnistes, par la ZLE. Or le CNPF est très opposé à la ZLE. Face à ce risque de débordement, les experts du CNPF prônent un changement de stratégie. Robert Fabre, l'expert du CNPF pour la politique de la concurrence, et Lartisien, secrétaire général de la commission économique du CNPF, demandent une action offensive ${ }^{38}$. Elle doit porter tant sur la doctrine que sur l'établissement de contacts avec l'administration de la Commission européenne. Il s'agit de surveiller l'élaboration du règlement d'application des articles 85 et 86 pour ne pas être surpris.

\section{L'UNICE mobilisée mais sans doctrine.}

À la réunion du 14 avril 1958 des représentants patronaux des Six, à l'UNICE, la stratégie d'influence se précise ${ }^{39}$. Le texte du 4 juillet 1957 sur la nécessité de cantonner les règles du traité de Rome à de simples « principes» en attendant le règlement d'application est accepté. Le débat porte maintenant sur la manière de promouvoir cette idée et de l'appliquer juridiquement. Il est décidé que chaque fédération patronale devra intervenir officieusement auprès du commissaire de son pays pour s'assurer des intentions de la Commission sur ce problème de la période transitoire. Le compte rendu de la réunion souligne la nécessité impérieuse de contacter Robert Marjolin car « il faut en effet devancer une action éventuelle des services de M. Erhard ${ }^{40} \gg$. Le très ordolibéral ministre allemand de l'Économie passait en effet pour défendre une politique de la concurrence forte. Marjolin est choisi comme relais de préférence à Lemaignen car seul le premier participe au groupe « concurrence » à la Commission.

37. Vincent Dujardin, « Jean-Charles Snoy et d'Oppuers : du Benelux aux traités de Rome », in Geneviève Duchenne, Vincent Dujardin, Michel Dumoulin (dir.), Rey, Snoy, Spaak. Fondateurs belges de l'Europe, Bruylant, Bruxelles, 2007, p. 113-144; Michel Dumoulin, « Les travaux du Comité intérimaire pour le Marché commun et Euratom (avril 1957-janvier 1958) », in Antonio Varsori (éd.), Inside the European Community. Actors and Policies in the European Integration 1957-1972, Bruylant, Bruxelles, 2006, p. 32.

38. ACNPF, 72 AS 1388, lettre de Fabre à Lartisien, 28 mars 1958 ; note de Lartisien à Hommey, $1^{\text {er }}$ avril 1958.

39. ACNPF, 72 AS 1388, réunion de l'UNICE sur la politique de la concurrence du 14 avril 1958.

40. ACNPF, 72 AS 1388, réunion de l'UNICE sur la politique de la concurrence du 14 avril 1958. 
La mobilisation de l'UNICE est cependant bien tardive. À la réunion du 14 avril 1958 est d'ailleurs évoqué également le problème récurrent de la concurrence interne entre les organisations patronales, mais cette fois au niveau européen. La Chambre de commerce internationale (CCI) prévoit en effet de prendre position sur le règlement d'application de l'article $87^{41}$. La CCI avait déjà pris une résolution le 11 décembre 1957 sur la période transitoire, appelant les gouvernements des Six à déclarer que les prescriptions du traité de Rome ne sont que des principes, non applicables directement ${ }^{42}$. Le 7 mai 1958, la CCI publie une nouvelle résolution fondée sur la défense du principe de l'abus et la consultation du patronat avant toute réglementation ${ }^{43}$. Certes ces positions sont consensuelles dans le monde patronal, mais elles posent un problème en termes de représentation des décideurs économiques auprès des instances communautaires. L'UNICE, lors de sa réunion du 10 mai 1958, affirme alors la nécessité d'une coordination étroite entre les deux organisations, et même la primauté de l'UNICE dans cette question ${ }^{44}$. La coordination avec la CCI doit être assurée par la présence de représentants au sein des commissions étudiant la politique de la concurrence tant de l'UNICE que de la CCI, comme le Belge Lucien Sermon, rapporteur de la Commission sur les ententes de la CCI. Il rédige le rapport qui servit de base à la résolution de mai 1958 de la $\mathrm{CCI}^{45}$. Également secrétaire général de la LECE, c'est un homme central pour les réseaux patronaux européens.

La stratégie de communication avec la Commission européenne est définie lors de la réunion de la commission concurrence de l'UNICE du 10 mai $1958^{46}$. Une note doit être transmise à titre officieux à la Commission. Le patronat souhaite donc affirmer sa doctrine tout en restant discret pour ne pas braquer des tierces personnes contre sa position, qui pourrait être jugée malthusienne. La Commission n'est pas considérée comme hostile a priori.

Le Français Fabre lance de son côté le débat sur le rôle des institutions dans la future politique de la concurrence communautaire qui sera issue de l'article 87. Pour lui : «Il apparaît que les autorités nationales ne peuvent être laissées

41. ACNPF, 72 AS 1388, réunion de l'UNICE sur la politique de la concurrence du 14 avril 1958.

42. AHUE, BAC 1/1971, volume 79, folio 42, résolution adoptée par le conseil de la CCI lors de la session des 6 et 7 mai 1958 qui reprend le texte de la résolution du 11 décembre 1957.

43. AHUE, BAC 1/1971, volume 79, folio 42, résolution adoptée par le conseil de la CCI lors de la session des 6 et 7 mai 1958 .

44. ACNPF, 72 AS 1388, compte rendu de la réunion de la commission concurrence de l'UNICE du 10 mai 1958.

45. Sigfrido Ramirez, «Antitrust ou anti US...», op. cit., p. 220.

46. ACNPF, 72 AS 1388, compte rendu de la réunion de la commission concurrence de l'UNICE du 10 mai 1958. 
en dehors du circuit ${ }^{47} \gg$. Fabre veut leur assurer une place importante car il a confiance dans l'action mesurée des autorités françaises dans ce domaine. Le délégué français pense qu'un organe spécifique devrait être créé pour appliquer la politique de la concurrence communautaire, et se demande donc comment associer les milieux professionnels à son activité. Il s'agit de transposer à l'échelle des Six le modèle de la CTE, c'est-à-dire celui d'une institution spécialisée non politique. D'une manière générale, les discussions tenues au CNPF en 1958 laissent transparaître l'impression que la future politique de la concurrence sera fortement influencée par l'exemple français ${ }^{48}$. La note française destinée à nourrir les débats de l'organisation patronale européenne est donc minimaliste ${ }^{49}$. Elle se contente de considérer les articles du traité de Rome comme des principes non applicables immédiatement, et à plaider pour un rapprochement progressif des législations nationales.

Ainsi, le patronat européen se mobilise rapidement sur le dossier de la politique de la concurrence, qui est fondamental pour les entreprises européennes. Il reste cependant divisé tant sur la stratégie que sur la doctrine. Cela laisse le champ libre à la Commission européenne.

\section{LA CONSTITUTION D'UN RÉSEAU AUTOUR DE LA COMMISSION (1958-1959)}

À partir de 1958, un groupe chargé de la politique de la concurrence se constitue à la Commission européenne autour d'un réseau ordolibéral allemand et développe une approche prudente. L'institution communautaire parvient finalement à tisser un réseau autour d'elle incluant le patronat européen, les États membres, mais aussi une communauté d'experts académiques.

\section{Le groupe ordolibéral de la Commission.}

Le groupe chargé d'élaborer la politique de la concurrence au sein de la Commission européenne est constitué d'experts liés au réseau ordolibéral alle$\operatorname{mand}^{50}$. Le commissaire responsable tout d'abord, Hans von der Groeben, a

47. ACNPF, 72 AS 1388, compte rendu de la réunion de la commission concurrence de l'UNICE du 10 mai 1958.

48. ACNPF, 72 AS 1460, compte rendu de la réunion du 9 juin 1958.

49. ACNPF, 72 AS 1388, note de Lartisien du 13 juin 1958.

50. Katja Seidel, «DG IV and the origins of a supranational competition policy : Establishing an economic constitution for Europe », in Wolfram Kaiser, Brigitte Leucht, Morten Rasmusen (éd.), The History of the European Union. Origins of a trans- and supranational polity, 1950-1972, Routledge, Londres, 2008, p. 128-147. 
travaillé pendant de nombreuses années au ministère de l'Économie de Ludwig Erhard. C'est aussi un spécialiste des dossiers européens car il a dirigé la section charbon-acier de ce ministère, gérant ainsi les rapports avec la CECA. Il joua un rôle considérable dans les négociations du traité de Rome : il fut l'un des principaux rédacteurs du rapport Spaak avec Pierre Uri puis fut le président du groupe du Marché commun. En 1957, il avait rédigé le rapport de synthèse du comité intérimaire sur les problèmes posés par la ZLE pour la CEE en insistant particulièrement sur la politique de la concurrence ${ }^{51}$. Comme son compatriote Hallstein, il est attaché aux réseaux démocrates-chrétiens allemands favorables à l'intégration politique de l'Europe ${ }^{52}$. Proche des ordolibéraux allemands comme Erhard, il est donc plus attaché à la dynamique communautaire que ce dernier ${ }^{53}$.

Le chef de cabinet de von der Groeben ensuite, Ernst Albrecht, est aussi un chrétien-démocrate allemand ${ }^{54}$. Comme son commissaire, c'est un spécialiste des affaires européennes. Il a travaillé pour le secrétariat du Conseil des ministres de la CECA puis fut le secrétaire du groupe « Marché commun » dirigé par von der Groeben pendant la négociation du traité de Rome. Il a rédigé une thèse sous la direction de Fritz W. Meyer, un néolibéral allemand ${ }^{55}$.

Le directeur général de la Direction générale chargée de la politique de la concurrence, la DG IV, n'appartient pas aux mêmes réseaux. Pieter Verloren van Themaat est en effet un socialiste néerlandais. C'est néanmoins un spécialiste des questions de concurrence aux Pays-Bas et à l'échelle européenne, car il a participé comme expert pour les cartels aux négociations du Benelux et de la $Z_{L E}^{56}$. Afin de contrebalancer l'influence du socialiste Verloren van Themaat, le président Hallstein écrit à Erhard pour lui demander de nommer un directeur chargé des ententes allemand ${ }^{57}$. Hallstein avait même pensé à y nommer Eberhard Günther, le directeur du BKA. Mais cette nomination n'aurait pas été une promotion pour lui. C'est donc Hermann Schumacher qui fut nommé à la tête de la direction A « ententes et monopoles ». Schumacher était le fils d'un économiste proche de Walter Eucken, un économiste ordolibéral ${ }^{58}$.

51. AMAE, DECE 620, folio 76, télégramme de Raymond Bousquet, ambassadeur à Bruxelles, du 25 juillet 1957 ; AMAE, DECE 741, folio 150, débats au comité intérimaire du 25 juillet 1957.

52. G. Th. Mollin, « La commission Hallstein... », op. cit., p. 69.

53. H.-J. Küsters, Fondements de la CEE..., op. cit., p. 36.

54. Il devint même ministre président de Basse-Saxe de 1976 à 1990 sous les couleurs de la CDU.

55. Katja Seidel, « DG IV... », op. cit., p. 135.

56. Katja Seidel, «DG IV... », p. 133-134.

57. Lettre du 11 avril 1958 citée in : Katja Seidel, « DG IV ... », p. 134.

58. Katja Seidel, « DG IV... », p. 134. 
Pour développer son action, la Commission développe un réseau plus institutionnalisé autour d'elle en organisant des conférences d'experts nationaux. Le 20 octobre 1958, Walter Hallstein envoie aux États membres une convocation pour une première réunion d'experts en matière de politique de la concurrence présidée par la Commission ${ }^{59}$. Des réunions d'experts sont ensuite organisées régulièrement, la première se tenant en novembre $1958^{60}$. Tout en consultant les États membres, la DG IV cherche naturellement à prendre contact avec le patronat.

La réunion entre la Commission et 1'UNICE est organisée dès le 15 juillet 1958 entre le directeur général Verloren van Themaat et des délégués patronau $^{61}$. Ces derniers stigmatisent l'incertitude juridique qui règne. Ils demandent une coordination forte entre la Commission européenne et les autorités nationales et une non-application directe des articles du traité de Rome. Face à eux, Verloren van Themaat reste sur une ligne très modérée même s'il affirme la nécessité de respecter dès à présent les prescriptions du traité de Rome. Le délégué patronal belge Del Marmol synthétise de manière optimiste la réunion « qui lui a laissé une impression réconfortante de mutuelle confiance ${ }^{62}$ ». La première rencontre entre la Commission et le patronat se conclut sur une note d'autant plus consensuelle qu' aucun débat de fond sur la future politique de la concurrence n'a eu lieu. Pour se prononcer sur cette question délicate, l'UNICE tente de se mobiliser en dépit de ses divisions persistantes.

\section{Les divisions persistantes de l'UNICE.}

L'UNICE veut profiter de la bonne volonté affichée par la Commission. En juillet 1958, le Français Fabre ${ }^{63}$ et le Belge Del Marmol ${ }^{64}$ estiment nécessaire d'engager des travaux concrets afin de montrer, à partir d'exemples précis, l'intérêt des ententes pour le Marché commun. L'UNICE convoque une vaste réunion consacrée à la politique de la concurrence à Rome, entre le 9 et le 13 septembre 1958. La réunion est ouverte par l'un des principaux responsables du dossier de la politique de la concurrence à l'UNICE, l'Italien Franco Mattei,

59. ASGCI, 1979.0791, article 261, lettre de W. Hallstein du 20 octobre 1958.

60. ASGCI, 1979.0791, article 261, compte rendu de la première conférence des experts des 18 et 19 novembre 1958. Les deuxième et troisième conférences des experts, se tiennent les 15 et 16 janvier 1959 , et les 14 et 15 avril 1959 .

61. ACNPF, 72 AS 1388, compte rendu de la réunion du 15 juillet 1958 établi par Robert Fabre.

62. ACNPF, 72 AS 1388, compte rendu de la réunion du 15 juillet 1958 établi par Robert Fabre.

63. ACNPF, 72 AS 1388, lettre de Fabre à Claessens, UNICE, 22 juillet 1958.

64. ACNPF, 72 AS 1358, compte rendu de la réunion du $1^{\mathrm{er}}$ juillet 1958. 
vice-secrétaire de la Confindustria et partisan de l'« intégration par la cartellisation » selon Francesco Petrini ${ }^{65}$. Elle a pour but de définir une position unique de l'UNICE mais les controverses se multiplient.

Sur la stratégie de communication à adopter, le délégué néerlandais, soutenu en général par son collègue allemand, souhaite une action volontariste face à la Commission. Il plaide pour la définition d'un document défendant les ententes. Il justifie cette action par un mouvement de cartellisation qu'il croit général. Il explique que : « les Pays-Bas étant une jeune nation industrielle, la concentration y est nécessaire au développement de l'industrie ${ }^{66} »$. De même, le délégué allemand déplore le faible rôle joué par le patronat européen pendant les négociations du traité de Rome. Les Allemands sont particulièrement irrités des premières initiatives de la Commission en la matière. Sa publication sur la signification des articles 85 et suivant a eu une influence négative sur la politique allemande ${ }^{67}$. Le Bundeskartellamt (BKA), l'autorité de la concurrence allemande, a en effet décidé d'inclure les ententes à l'exportation dans son champ d'action lorsqu'il applique le traité de Rome, alors même qu'elles ne sont pas concernées par la législation allemande. Les Allemands et les Néerlandais défendent donc le principe d'une attitude plus offensive envers la Commission.

Au contraire d'autres délégués patronaux, dont le Français Lartisien, estiment qu'il est particulièrement maladroit de défendre les ententes par principe : «Il fut un temps où l'on a lutté pour la défense des droits de l'homme. Ces principes ont fait du chemin. M. Lartisien n'est pas sûr que le droit aux ententes progresse de la même façon ${ }^{68} \gg$. Ces divisions se retrouvent sur un deuxième point de friction, les grandes lignes de la future politique de la concurrence communautaire. Les Français défendent l'enregistrement facultatif car c'est le système qu'ils ont défendu à l'échelle nationale (dans le cadre des débats sur la réforme du décret français de 1953$)^{69}$. À la réunion suivante, en novembre 1958, ils parviennent progressivement à faire prévaloir la défense du principe de l'abus, plus souple par rapport à celui de l'interdiction ${ }^{70}$. Au contraire, lorsqu'ils veulent définir la doctrine de l'UNICE, les Hollandais affirment que les « travaux devront se

65. Sur ce personnage (à ne pas confondre avec Enrico Mattei, le dirigeant de l'ENI) : Francesco Petrini, «Les milieux industriels italiens et la création du Marché commun », in Revue d'histoire de l'intégration européenne, 2003-1, p. 21.

66. ACNPF, 72 AS 1388, compte rendu de la réunion de Rome, séance du 10 septembre 1958.

67. AHUE, BAC 1/1971, volume 79, folio 94, note DG IV pour la Commission, 8 octobre 1958 , doc (58)217 rév.

68. ACNPF, 72 AS 1388, compte rendu de la réunion de Rome, séance du 10 septembre 1958.

69. ACNPF, 72 AS 1388, compte rendu de la réunion de Rome, séance du 10 septembre 1958.

70. ACNPF, 72 AS 1388, compte rendu de la réunion du 7 novembre 1958. 
baser sur la réalité et en particulier sur les expériences faites aux Pays-Bas, en Allemagne et aux États-Unis ${ }^{71} »$. L'absence de référence française, alors même que la politique de la concurrence française est plus ancienne que celle pratiquée outre-Rhin, est particulièrement révélatrice du poids intellectuel de la référence allemande.

La réunion des présidents des fédérations membres de l'UNICE le 26 novembre 1958 ne permet pas de débloquer ce dossier ${ }^{72}$. Aucun accord sur la stratégie à mener n'est trouvé. Le président Léon Bekaert souligne en conclusion que les méthodes de travail de l'UNICE sur ce dossier ne sont pas satisfaisantes. Ces divergences au sein du patronat européen traduisent une opposition entre deux visions de l'Europe organisée patronale.

\section{Les deux Europe organisées du patronat.}

Deux visions de l'Europe contractuelle émergent de ces discussions, au-delà d'un consensus autour de l'idée d'une « Europe organisée », fondée sur un équilibre entre l'ouverture des marchés et les ententes. D'un côté, la vision française semble être celle d'un pays d'entreprises moyennes, habituées à multiplier les accords pour acquérir une taille critique tout en conservant leur autonomie. Cette image d'Épinal de la France est peut-être fausse ${ }^{73}$ mais ce qui compte est la représentation de la structure industrielle nationale des délégués français à l'UNICE, plus que la réalité statistique. Les Français sont marqués par une représentation de leur structure industrielle fondée sur un poids plus important des entreprises de taille moyenne, peu habituées à la concurrence internationale, qu'il faut impérativement pousser à s'entendre pour s'adapter aux défis du Marché commun. L'aspect psychologique de la politique de la concurrence - ne pas décourager les entreprises, traditionnellement individualistes, à s'associercompte beaucoup dans les réflexions françaises ${ }^{74}$, ce qui démontre la force des représentations économiques et sociales.

Face à eux se dressent les industries allemande et néerlandaise, beaucoup plus concentrées. Deux notes préparatoires à la réunion du 7 novembre 1958 soulignent ce prisme de lecture ${ }^{75}$. Elles insistent sur la réalité du phénomène

71. ACNPF, 72 AS 1388, compte rendu de la réunion du 7 novembre 1958.

72. ACNPF, $72 \mathrm{AS} 450$, compte rendu de la réunion des présidents de fédération du 26 novembre 1958.

73. Elle est cependant confirmée par les études générales : Wolfgang Neumann, Henrik Uterwedde, Industriepolitik : ein deutsch-französischer Vergleich, Leske Verlag, Leverkusen, 1986, p. 41.

74. ACNPF, 72 AS 1460, lettre de B. de Termont à Lartisien, 21 novembre 1958.

75. ACNPF, 72 AS 1388, note néerlandaise du 30 novembre 1958 ; note allemande en vue de la réunion UNICE du 7 novembre 1958. 
de la concentration industrielle, qui tend à s'accentuer. Face à cette tendance structurelle, la politique de la concurrence doit se limiter à réprimer les abus et à l'orienter dans une direction favorable. La principale crainte est que la Commission de la CEE ne reprenne à son compte les croisades entamées par les autorités antitrust américaines ou par la Haute Autorité de la CECA contre les plus grandes entreprises. Les Allemands et les Hollandais développent une réflexion centrée sur la défense des concentrations plus que sur celle des ententes. Ils se placent dans l'optique de la création d'un grand marché analogue aux États-Unis qui devra être couvert par des entreprises de taille européenne. Ce sont donc deux visions de la future structure industrielle européenne.

Une autre divergence porte sur les rapports entre l'État et les entreprises. Les Français paraissent plus confiants que les Allemands dans leur capacité d'influencer leur administration. Les premiers profitent de l'exemple de la CTE qui fonde son action sur des critères économiques, tandis que les seconds ont peur du juridisme du BKA. Cela ne signifie pas que les délégués patronaux français défendent tous les aspects de leur modèle économique national. Ils distinguent les aspects strictement dirigistes et contre-productifs, comme une politique des prix autoritaire et contraire aux lois du marché, des aspects plus contractuels des relations entre les États et les entreprises. L'intervention de l'État est tolérée si elle est souple et s'effectue en concertation avec les entreprises.

En 1958, le patronat européen reste divisé tant sur la stratégie de communication à mener que sur la doctrine à défendre. Des divergences profondes existent entre deux modèles d'Europe contractuelle, l'approche française qui privilégie les ententes entre entreprises de taille moyenne, et les Allemands qui mettent l'accent sur la concentration. Ces divisions patronales laissent le champ libre à la Commission pour dominer le débat intellectuel.

\section{Le débat intellectuel.}

La politique de la concurrence étant un domaine neuf, l'action de promotion intellectuelle de cette nouvelle politique publique est particulièrement importante. Katja Seidel a souligné que le commissaire von der Groeben est particulièrement attentif à l'association d'experts académiques à son action ${ }^{76}$. Il recrute notamment Ernst-Joachim Mestmäcker, un élève de Böhm, lié au groupe ordolibéral de l'école de Freiburg, et spécialiste des cartels. Il devient conseiller de la DG IV officiellement en 1962 mais conseille von der Groeben de manière informelle auparavant ${ }^{77}$.

76. Katja Seidel, « DG IV... », op. cit., p. 129-147.

77. Katja Seidel, « DG IV... », op. cit., p. 135-139. 
L'intérêt porté au débat intellectuel se perçoit également dans l'organisation de colloque comme celui de Caen en 1959, l'un des premiers consacrés à la future politique de la concurrence de la $\mathrm{CEE}^{78}$. Ouvert par Jean-Marcel Jeanneney, lui-même professeur d'économie et surtout ministre de l'Industrie et du Commerce, il accueille de très nombreux experts internationaux de premier plan comme le $\mathrm{D}^{\mathrm{r}}$ Günther, président du Bundeskartellamt, Arved Deringer, député européen et avocat allemand spécialiste de la question, de nombreux spécialistes français ${ }^{79}$, ainsi que de nombreux fonctionnaires nationaux et représentants patronaux ${ }^{80}$ issus des six pays de la CEE. L'administration de la Commission européenne est très largement représentée avec notamment Verloren van Themaat et Schumacher, mais aussi de nombreux représentants du Service commun de presse et d'information des Communautés européennes, et notamment le directeur Rabier en personne. La présence de ce dernier n'est pas anodine : le colloque a été organisé par un collectif associant l'Université de Caen, les chambres de commerce locales mais aussi le Service d'information des Communautés européennes. Ce colloque est donc moins une manifestation d'érudits universitaires se disputant l'exégèse d'un problème juridique théorique qu'un jalon dans une politique de communication de la Commission visant à sensibiliser les élites des États membres à la nécessité de développer une action dans ce domaine.

Le colloque ne donne pas lieu à l'expression d'une doctrine car les thèmes et les intervenants sont trop divers. Ainsi le professeur André Marchal, dans son rapport introductif, défend les ententes positives car elles permettent de moderniser les structures mais aussi de faciliter l'interpénétration des marchés ${ }^{81}$. C'est l'intégration des marchés « par le bas », complémentaire de l'intégration «par le haut» qui est le fait des gouvernements et des législations. Au contraire Arved Deringer, dans son rapport sur les ententes, adopte une perspective très juridique et marquée par l'expérience ordolibérale allemande ${ }^{82}$. Aucune doctrine n'émerge donc de cette réunion mais elle a permis de poser dans le détail

78. «La libre concurrence dans les pays du Marché commun », Revue du Marché commun, supplément au $\mathrm{n}^{\circ} 16$ de juillet 1959 .

79. Les professeurs d'économie André Marchal et Jacques Houssiaux (encore chargé de cours), 1'avocat Jacques Lassier.

80. On relève notamment la présence de nombreux spécialistes des ententes qui participent aux réunions de 1'UNICE ou de la LECE sur cette question : les Belges Sermon, Del Marmol et van Reepinghen (ce dernier est un conseiller juridique à la FIB); les Français Fabre (CNPF), Joly (FIMTM) et Simon (Syndicat général de la construction électrique) ; les Néerlandais Visser, Delfos et Wertheimer.

81. Revue du Marché commun, supplément au n 16 de juillet 1959, p. 6.

82. Revue du Marché commun, supplément au n 16 de juillet 1959, p. 33. 
tous les problèmes que devront résoudre les futurs règlements d'application des articles 85 et 86 du traité de Rome. Par son action, notamment au colloque de Caen, la Commission a réussi à créer un réseau intellectuel qui a démontré tous les enjeux de cette politique, mais aussi toute sa complexité.

Ainsi, en 1958 et 1959, la politique de la concurrence communautaire reste très floue, mais la Commission en tant qu'institution a réussi son départ dans ce domaine. Elle tisse de larges réseaux d'acteurs, patronaux, administratifs et intellectuels. Elle profite de l'absence de mobilisation d'autres acteurs car le patronat européen est divisé entre deux modèles d'Europe contractuelle, l'un fondé sur la défense des ententes et un autre centré sur les concentrations. Cette faiblesse pèse lourdement dans le succès de la Commission lors de la négociation du règlement 17/62.

\section{UNE MOBILISATION FRANÇAISE INEFFICACE FACE À LA COMMISSION}

Après l'établissement d'un réseau de consultation, la Commission se mobilise en 1959-1960 pour mettre en place une politique lui assurant de larges prérogatives. Face à elle, ni le gouvernement français ni le patronat européen ne parviennent à se mobiliser efficacement.

\section{A. JUIN 1959-JUIN 1960 : \\ IMPATIENCE ET MOBILISATION DE LA COMMISSION}

Face aux résultats décevants des procédures de consultation des États membres, von der Groeben et la DG IV s'engagent dans une stratégie plus offensive.

\section{La nécessité d'un changement de stratégie.}

À partir de la fin de l'année 1959, la Commission perçoit les limites de la méthode des conférences d'experts. Les six États membres et la Commission se sont mis d'accord pour que les autorités nationales chargées de l'application de la politique de la concurrence puissent consulter la Commission avant toute décision, afin de coordonner les diverses pratiques nationales ${ }^{83}$. Mais la DG IV

83. ASGCI, 1979.0791, article 261, compte rendu de la sixième conférence d'experts, 15 et 16 décembre 1959. 
a beaucoup de mal à obtenir des informations des administrations nationales ${ }^{84}$. Von der Groeben choisit alors de dépasser les enceintes techniques comme la conférence des experts gouvernementaux pour s'adresser directement aux instances politiques. Il exprime donc devant le Conseil des ministres, au début de 1960, la doctrine de la commission en matière de concurrence afin d'obtenir un soutien clair des États membres ${ }^{85}$. Le commissaire européen insiste sur certains principes et notamment celui de la «cohérence » : la politique de la concurrence doit s'inscrire dans les autres actions communautaires. Comme le désarmement douanier et contingentaire progresse rapidement, la politique de lutte contre les ententes apparaît logiquement comme une priorité pour la Commission, qui souligne que de nombreuses ententes néfastes se sont créées pour dresser de nouvelles barrières internes au Marché commun. Von der Groeben affirme ensuite le principe d' « homogénéité », c'est-à-dire d'une application uniforme de la politique de la concurrence dans chacun des Six pays de la CEE. Le commissaire européen se montre donc particulièrement ambitieux même s'il tient à affirmer une autre ligne directrice, l' « empirisme ». La doctrine d'intervention en matière de politique de la concurrence devrait se développer de manière progressive, par la jurisprudence et sans a priori.

Le discours de von der Groeben provoque des réactions mesurées au Conseil, où les Six ne paraissent pas avoir de position bien définie. Le Conseil adopte finalement ces principes généraux de la politique de la concurrence ${ }^{86}$. Cela encourage von der Groeben qui entame, à la suite de cette session du Conseil, une tournée des responsables politiques et administratifs des six pays ${ }^{87}$. Il cherche ensuite à faire endosser par la Commission un programme d'action. Dans une communication du 15 février 1960 à destination de ses collègues, il affirme sa nouvelle stratégie ${ }^{88}$. Après avoir reconnu que la coopération des administrations nationales s'avère décevante, il conclut que la Commission devra s'efforcer de se constituer une documentation propre afin de lancer des instructions de manière autonome. Il affirme ainsi clairement qu'il entend obtenir des prérogatives importantes pour l'autorité supranationale dans le futur règlement d'application de l'article 87 , tant en matière d'information - l'idée

84. AMAEF, RPUE 613, lettre de Hans von der Groeben à Maurice Couve de Murville, 16 février 1960.

85. AHUE, BAC 1/1971, volume 80, folio 78, note du Conseil CEE, doc R/68/60 du 21 janvier 1960.

86. ASGCI, 1979.0791, volume 262, compte rendu de la septième conférence d'experts, 16-17 mars 1960.

87. AMAEF, RPUE 608, télex de la REP, 10 février 1960.

88. ACNPF, 72 AS 1388, communication de von der Groeben à destination du collège des commissaires, doc. IV/COM (60) 17 du 15 février 1960. 
d'enregistrement des ententes est évoquée - que d'investigation - il évoque notamment la possibilité pour la Commission d'entrer en relation directement avec les entreprises. Mais aucune piste précise n'est définie.

À l'extérieur de la Commission, la DG IV reste très prudente sur les contours du futur règlement d'application de l'article 87. Ainsi, l'idée d'enregistrement obligatoire des ententes est reprise peu après par Verloren van Themaat dans une conférence d'experts gouvernementaux, mais elle est présentée comme une piste parmi d'autres ${ }^{89}$. De même, le directeur général évoque plusieurs schémas institutionnels possibles sans se prononcer sur une voie particulière ${ }^{90}$. En interne cependant, la DG IV précise ses vues et élabore une proposition de règlement.

\section{Une proposition de règlement ambitieuse.}

Après les succès de février 1960, les travaux au sein de la DG IV progressent lentement, obligeant von der Groeben à s'excuser auprès de ses collègues ${ }^{91}$. Un projet de proposition de règlement est présenté en septembre $1960^{92}$. Son ambition est limitée au seul article 85 et laisse de côté un certain nombre de points de procédure. Un deuxième règlement devrait donc rapidement suivre le premier.

Ce règlement prévoit d'instaurer un système fondé sur une forte centralisation de la procédure sur la Commission. Les ententes devraient être obligatoirement enregistrées auprès de l'institution communautaire qui seule pourrait les autoriser et les sanctionner, sous réserve d'un contrôle de la CJCE. La Commission profiterait donc d'un monopole au niveau de l'information comme de la décision. L'instruction serait menée conjointement avec les États membres. À défaut d'une autorisation de la Commission, les ententes seraient interdites. C'est donc le principe de l'interdiction et pas celui de l'abus qui est retenu.

Cette proposition va bien au-delà de ce qui avait été envisagé auparavant. Elle tire les leçons des difficultés rencontrées par la Commission dans les conférences d'experts gouvernementaux tant sur le plan de l'information - pour obtenir de la documentation - que de la décision - car les États membres n'ont pas manifesté

89. ASGCI, 1979.0791, volume 262, compte rendu de la septième conférence d'experts, 16-17 mars 1960.

90. ASGCI, 1979.0791, volume 262, compte rendu de la septième conférence d'experts, 16-17 mars 1960 ; ACNPF, 72 AS 1388, discours de Francfort de Verloren van Themaat du 15 juin 1960.

91. AHUE, EN 721, notes manuscrites d'Émile Noël sur la réunion du 27 juillet 1960 de la Commission.

92. AHUE, BAC 71/1988, volume 107, folio 56, document IV.5176/60 du 23 septembre 1960. 
de véritable volonté d'appliquer les articles 85 et $86^{93}$. La DG IV justifie aussi l'enregistrement par une nécessité technique : même si les autorités nationales lui transmettent des informations, ces dernières sont marquées par des préoccupations issues du cadre législatif national et ne sont donc pas forcément les plus pertinentes pour une action européenne ${ }^{94}$. Cette argumentation est proprement fonctionnaliste : le transfert de pouvoir à l'échelle européenne s'impose naturellement pour des raisons d'efficacité technique. Enfin, le monopole du pouvoir de décision à la Commission est justifié par la nécessité de mener une politique cohérente et unitaire au sein du Marché commun.

Après une série de consultations d'experts gouvernementaux et patronaux ${ }^{95}$, la proposition de règlement d'application de l'article 87 de la Commission au Conseil est modifiée. Lors de la réunion de la Commission du 26 octobre 1960, la DG IV présente la proposition définitive ${ }^{96}$. Une place plus importante est donnée aux États membres. Lors de la discussion au collège des commissaires, il est décidé que la création d'un "Comité consultatif » associant des représentants des États membres sera mentionnée dans l'exposé des motifs. L'équilibre général du projet, qui repose sur le monopole de la Commission en matière d'information et de décision, reste le même.

D'une manière générale, cette proposition de règlement d'application de l'article 87 semble assez proche de la loi allemande ${ }^{97}$, comme en témoigne le choix du principe de l'interdiction par opposition à celui de l'abus. Par contre la proposition de règlement abandonne l'idée de créer une autorité indépendante chargée de la décision, analogue au BKA allemand, sans doute pour renforcer la centralisation sur la Commission. L'idée avait pourtant été évoquée de manière récurrente par de nombreux acteurs comme la $\mathrm{CCI}^{98}$ ou les commissaires Robert Marjolin ${ }^{99}$ et Walter Hallstein ${ }^{100}$. Il semble que von der Groeben veuille centraliser au maximum les pouvoirs sur sa DG. D'une manière générale, le

93. C'est également l'opinion de Charley Del Marmol, président de la commission des règles de concurrence à l'UNICE : ACNPF, 72 AS 1388, document de travail du 6 juillet 1960.

94. ASGCI, 1979.0791, volume 262, note CEE sur les études sectorielles, 31 mai 1961.

95. AHUE, BAC 71/1988, volume 107 , folio 230 , extrait du procès-verbal de la réunion de la Commission du 26 octobre 1960.

96. Voir notamment in : "Annexe : premier règlement d'application des articles 85 et 86 du traité (proposition de la Commission au Conseil) », in Revue du Marché commun, janvier 1961, p. 16.

97. Robert Plaisant, « La CEE et les projets de règlements relatifs aux règles de concurrence », in Revue du Marché commun, novembre 1960, p. 370.

98. AMAEF, RPUE 614, avis de la CCI sur la création d'un comité consultatif, 22 février 1961.

99. AHUE, procès-verbal de la séance de la Commission des 15 et 16 juillet 1958 , $25^{\mathrm{e}}$ session.

100. AMAEF, RPUE 245, lettre de Walter Hallstein au président du Conseil CEE, 27 mai 1960. 
commissaire allemand profite de l'apathie des deux acteurs qui pouvaient être le plus opposés à ce texte : le gouvernement français et le patronat européen.

\section{B. LE DÉCALAGE DES DÉCIDEURS FRANÇAIS (1958-1960)}

Les décideurs administratifs et économiques ont du mal à se mobiliser dans le dossier de la politique de la concurrence communautaire car leur attention est appelée par d'autres enjeux que les ententes.

\section{Une réflexion minimaliste et concentrée sur la circulaire Fontanet (1958-1960).}

Jusqu'au milieu de l'année 1960, les réflexions françaises en matière de définition de la politique de la concurrence communautaire sont minimalistes. Les décideurs administratifs chargés de ce dossier, au ministère de l'Industrie et à la direction des Prix, estiment tout naturellement que la Commission n'aura que très peu de pouvoirs dans ce domaine ${ }^{101}$. Ils ont développé en juin 1959 une position minimale sur la question reposant sur deux exigences contradictoires : limiter les pouvoirs de la Commission et assurer une coordination efficace des politiques nationales, pour être sûr que la même sévérité prévale dans chacun des Six pays ${ }^{102}$. La France craint la tolérance de ses voisins envers des pratiques anticoncurrentielles qui désavantageraient ses entreprises. Cependant, lorsque von der Groeben se prépare à faire son discours sur les grands principes directeurs de son action, le SGCI souligne l'absence de véritable position française sur la question ${ }^{103}$. D'ailleurs aucun expert administratif français ne participe au colloque de Caen de 1959, alors que des experts allemands, belges et néerlandais sont présents ${ }^{104}$.

Si la réflexion française sur la question reste minimale jusqu'en 1960, c'est en partie à cause de la concentration sur les problèmes internes. Depuis 1958, la réforme de la politique de la concurrence française est en débat. Le second comité Rueff, dit comité « Rueff-Armand », de 1960 plaide pour un renforcement de la politique de la concurrence française par la création d'une procédure

101. ACNPF, 72 AS 1503, lettre interne au CNPF, Fabre à Lartisien, 28 novembre 1959 ; ASGCI, 1990.0452, volume 23, lettre du 27 juin 1960 de la DG Prix pour le secrétaire d'État.

102. AMAEF, RPUE 613, note de la DG Prix transmise à Cabouat (REP), juin 1959.

103. ASGCI 1988.0516, volume 1, note SGCI du 28 janvier 1960.

104. Liste des participants in Revue du Marché commun, supplément au n 16 de juillet 1959 , p. 3-4. 
plus judiciaire qu'administrative ${ }^{105}$, et pense même, au grand dam du CNPF, à adapter le système de la déclaration obligatoire en France ${ }^{106}$. Ces réflexions ne débouchent pas sur des réformes importantes mais l'ampleur du débat - la CTE ne siège pas pendant toute une partie de l'année 1959 à cause de sa réforme - ne doit pas aider les pouvoirs publics français à définir une doctrine cohérente.

De toute façon, le gouvernement préfère emprunter la voie plus traditionnelle de la politique des prix. La célèbre circulaire Fontanet, du nom du secrétaire d'État au Commerce intérieur Joseph Fontanet, est ainsi adoptée le 31 mai 1960. Elle renforce notamment l'interdiction du refus de vente, des prix imposés et de certains accords d'exclusivité. Cette législation a été encouragée par de nouveaux distributeurs comme Leclerc, qui se plaignent auprès des autorités françaises du refus de vente de certains grossistes ${ }^{107}$. Le Premier ministre Michel Debré lui répond personnellement pour l'assurer de son soutien car son action contribue à faire diminuer le coût de la distribution ${ }^{108}$.

Face à ces acteurs soucieux de s'appuyer sur une politique de la concurrence forte à l'échelle nationale afin d'assainir les structures de distribution, se dressent la majorité des milieux économiques, opposés à une circulaire Fontanet perçue comme dirigiste. Au cours de l'année, de nombreuses réunions entre le patronat et l'administration ont lieu sur la définition et l'application de cette circulaire, tandis que Villiers multiplie les démarches de protestation auprès du gouvernement ${ }^{109}$.

En parallèle, le CNPF cherche à développer une action européenne sur la circulaire Fontanet et pas sur la politique envers les ententes, qui lui paraît secondaire et inoffensive. Lartisien rédige ainsi un projet de questionnaire destiné à permettre une comparaison des politiques des prix nationales ${ }^{110}$, base d'une action future destinée à demander une harmonisation européenne afin de

105. ASGCI, 1990.0452, volume 23, lettre du 27 juin 1960 de la DG Prix pour le secrétaire d'État.

106. AFNSP, 2 DE 12, lettre de Jacques Rueff à Charles de Gaulle, 20 août 1959.

107. AFNSP, 2 DE 12, lettre de Leclerc au ministre de la Justice, et réponse de Michel Debré à Leclerc du 22 octobre 1959. Sur les liens entre l'action de Leclerc et le soutien apporté par la politique de la concurrence française : William James Adams, Restructuring the French Economy. Governement and the Rise of Market Competition since World War II, The Brookings Institution, Washington, 1989, p. 223-234.

108. AFNSP, 2 DE 12, lettre de Leclerc au ministre de la Justice, et réponse de Michel Debré à Leclerc du 22 octobre 1959.

109. ACNPF, 72 AS 1460, lettre de Georges Villiers à Joseph Fontanet, 30 mars 1960 ; ACNPF 72 AS 1389, note du 22 juin 1960, observations sur la circulaire Fontanet.

110. ACNPF, 72 AS 1460, lettre de Lartisien à Arnaud, 25 mai 1960. 
limiter le dirigisme français. Il soulève le problème à une réunion de l'UNICE dès le mois de juin $1960^{111}$.

Paradoxalement, c'est la même voie de l'harmonisation européenne qu'emprunte le gouvernement français. L'objectif est le même que celui du patronat : éviter que les milieux économiques ne soient désavantagés par une législation trop sévère. Mais pour atteindre cet objectif de non-discrimination, l'administration française propose une harmonisation sur la législation la plus stricte, en généralisant les prescriptions de la circulaire Fontanet. C'est le sens de la lettre du 3 octobre 1960 de Fontanet à Verloren van Themaat qui demande cette harmonisation pour éviter que les producteurs français ne soient désavantagés ${ }^{112}$. Le directeur général de la DG IV donne son accord dès le 28 octobre 1960 pour que l'un des articles de l'exposé des motifs du règlement prévoie un second règlement, dans un délai d'un an, pour régler ces problèmes de prix imposés et de contrats d'exclusivité ${ }^{113}$.

Ainsi la réflexion française sur la politique de la concurrence semble paralysée par l'importance prise par la circulaire Fontanet. L'action européenne de tous ces acteurs est fondée sur l'harmonisation européenne sur la base ou contre cette circulaire. Dès lors, le dossier des ententes, qui est au cœur de la réflexion des autorités européennes, est ignoré. Ce tropisme est renforcé par une focalisation excessive sur le problème de la concentration de l'industrie allemande.

\section{L'obsession française de la concentration de l'industrie allemande.}

La France avait accepté le développement d'une politique de la concurrence communautaire forte dans le traité CECA car elle devait être une garantie contre toutes velléités de reconcentration de l'industrie allemande. Or ces craintes anciennes sont ravivées en septembre 1959, avec une lettre de Ludwig Erhard, ministre allemand de l'Économie, demandant au ministre français de l'Industrie Jean-Marcel Jeanneney, de soutenir une demande, déposée auprès de la Haute Autorité de la CECA, d'une concentration entre deux entreprises sidérurgiques allemandes ${ }^{114}$. L'opération est présentée comme une simplification car les deux entreprises ont les mêmes actionnaires majoritaires. Or cette demande intervient peu après deux autres demandes de concentration de la sidérurgie allemande.

111. ACNPF, 72 AS 1388, compte rendu de la réunion UNICE, 30 juin 1960.

112. ASGCI, 1979.0791, volume 264, lettre signée d'Antoine Veil, directeur de cabinet de Fontanet, pour transmission à Verloren van Themaat.

113. ASCGI, 1979.0791, volume 264, lettre de Verloren van Themaat au secrétaire d'État au Commerce intérieur, 28 octobre 1960.

114. AFNSP, 2 DE 70, note du cabinet de Michel Debré, 23 septembre 1959. 
Prévenu de cette situation par Pierre-Olivier Lapie, membre français de la Haute Autorité de la CECA, le Premier ministre Michel Debré mobilise alors l'administration pour définir une contre-offensive ${ }^{115}$. Le ministère des Affaires étrangères s'inquiète du « problème des reconcentrations excessives dans la Ruhr ${ }^{116}$. Debré convoque un Conseil ministériel sur cette affaire le 9 décembre $1959^{117}$. Finalement, grâce à une action combinée de l'ambassade de France en Allemagne et de Pierre-Olivier Lapie ${ }^{118}$, la Haute Autorité rend une décision qui préserve les intérêts des deux parties, en autorisant une fusion sous condition ${ }^{119}$. Le Quai d'Orsay demande alors qu'en contrepartie, satisfaction soit donnée à la RFA sur un autre dossier de concentration ${ }^{120}$.

Cette affaire permet de mettre en valeur à la fois l'extrême sensibilité de la France à l'égard du dossier de la concentration industrielle en Allemagne, mais aussi la manière dont le gouvernement considère la politique communautaire. La Haute Autorité paraît être une simple arène d'un marchandage intergouvernemental et ses membres de simples relais des intérêts nationaux.

Fort logiquement, ce double tropisme marque la vision française des débats sur la politique de la concurrence CEE. D'une part, sur le plan institutionnel, les Français estiment impensable d'attribuer à la Commission des pouvoirs propres importants. D'autre part, ils ont tendance à privilégier l'article 86 sur l'article 85 dans les débats sur la politique de la concurrence CEE. L'article 86 concerne les positions dominantes et pourrait, selon la vision française, être plus facilement utilisé contre les grandes entreprises allemandes que l'article 85, qui concerne les ententes. En octobre 1959 par exemple, l'expert français de la direction des Prix, Marcille, demande la collaboration des experts patronaux dans les travaux communautaires concernant l'article $86^{121}$.

Enfin, il faut noter que ces craintes d'une concentration excessive de l'industrie allemande sont largement répandues en France encore à cette époque. Dans un article de 1960 intitulé « Non à l'Europe des cartels », Guy Mollet stigmatise l'insuffisante sévérité de la politique de la concurrence CECA face à la reconcentration de l'industrie allemande ${ }^{122}$. À la même époque paraît dans

115. AFNSP, 2 DE 12, note de Michel Debré pour Amanrich du 14 septembre 1959.

116. AFNSP, 2 DE 70, télégramme au départ de la DAEF pour Bonn, 28 janvier 1959.

117. AFNSP, 2 DE 70, lettres de Debré à Jeanneney et à Couve de Murville, 30 novembre 1959 ; AFNSP, 2 DE 70, note du 7 janvier 1961 de C. Contamine à Jacques-Bernard Dupont.

118. AFNSP, 2 DE 70, lettre de Pierre-Olivier Lapie à Michel Debré du 20 juillet 1961.

119. AFNSP, 2 DE 70, note du ministère des Affaires étrangères du 20 octobre 1961.

120. AFNSP, 2 DE 70, note du ministère des Affaires étrangères du 20 octobre 1961.

121. ACNPF, 72 AS 1503, lettre interne au CNPF, Fabre à Lartisien, 19 octobre 1959.

122. AHUE, EN 185, article de Guy Mollet, document du 29 avril 1960. 
la Revue du Marché commun un article d'un professeur enseignant en Belgique qui rappelle comme un fait établi les craintes que de nombreux voisins de l'Allemagne éprouvent face à une concentration industrielle excessive en RFA $^{123}$.

Les acteurs politiques, administratifs et économiques français sont avant tout préoccupés par les questions de législation des prix et des conditions de vente, ainsi que par la concentration de l'industrie allemande. Ils ne sont pas hostiles en principe à une action communautaire dans le domaine de la concurrence mais le domaine des ententes reste pour eux secondaire. Ils ne réagissent donc que très tardivement aux initiatives de la Commission. Le même aveuglement prévaut au sein du patronat européen.

\section{L'IMPOSSIBLE LOBBYING EUROPÉEN DU PATRONAT (1959-1960)}

Le patronat européen souffre toujours de faiblesses structurelles fortes. Malgré plusieurs tentatives de mobilisation, il a du mal à mener une action cohérente face aux ambitions de von der Groeben.

\section{La faiblesse structurelle de l'UNICE dans les débats initiaux.}

La période comprise entre le traité de Rome et la proposition de règlement de von der Groeben, à l'automne 1960, est marquée par une grande fébrilité de l'UNICE, à la fois très intéressée par ce dossier de la politique de la concurrence, et incapable de surmonter trois faiblesses : les divisions internes à l'UNICE, le manque de coordination avec la CCI, et l'incertitude maintenue par la Commission.

Les clivages au sein de l'UNICE restent profonds. Les Français sont favorables à une action de l'UNICE auprès de la Commission tendant à soutenir la théorie de l'abus ${ }^{124}$. Mais le représentant allemand souligne que les industriels allemands souffriraient alors d'une discrimination car ils devraient supporter à l'échelle nationale une législation plus sévère, fondée sur le principe de l'interdiction. Ils sont donc tentés de "réclamer une législation d'interdiction c'est-à-dire le même fléau pour l'ensemble des pays de la Communauté » ${ }^{125}$. À la réunion suivante, en mai 1960, le nouveau président de la commission

123. Jacques Trempont, « Réflexions sur les concentrations industrielles en Allemagne fédérale », in Revue du Marché commun, mars 1960, p. 108-113.

124. ACNPF, 72 AS 450, note de Fabre préparant la réunion de la commission des règles de concurrence UNICE du 6 juillet 1959.

125. ACNPF, 72 AS 450, compte rendu de la réunion du 12 juin 1959 des présidents UNICE. 
des règles de concurrence, le Belge Del Marmol souligne que si l'UNICE veut véritablement s'imposer comme un acteur de poids dans le débat européen, cela implique un travail interne important d'analyse et de proposition ${ }^{126}$. Les problèmes de fond n'ont toujours pas été résolus, que ce soit sur l'opportunité de lancer une action de propagande - par l'organisation de colloques et la publication d'articles - ou sur les solutions de fond à promouvoir - la déclaration facultative des ententes fait d'ailleurs l'objet d'un débat ${ }^{127}$.

La seconde faiblesse de l'UNICE est la division institutionnelle des organisations patronales européennes. Lors de la rencontre entre l'UNICE et Verloren van Themaat en novembre 1959, le directeur général n'hésite pas à affirmer que la discrétion de l'UNICE au cours de l'année 1959 a poussé d'autres organisations nationales à prendre directement contact avec la Commission ${ }^{128}$. Par ailleurs, au début de 1960, les délégués de l'UNICE s'inquiètent de l'activisme de la $\mathrm{CCI}^{129}$. Pour le CNPF, ses prises de position posent des problèmes de coordination car sa réflexion est biaisée par la présence de membres extérieurs aux Six, d'où l'impératif de préserver la primauté de $1^{\prime} U N I C E^{130}$. Ainsi, le 14 mars 1960 se tient une commission des pratiques restrictives du CNPF qui entend René Arnaud ${ }^{131}$. Il y présente un prérapport de la CCI sur ce thème, que Lartisien et Simon trouvent trop complaisant envers la Commission ${ }^{132}$. Il est probable que l'influence du CNPF sur les réflexions de la CCI a dû se faire sentir car le rapport final de la CCI, daté du 30 mars 1960, est plus prudent ${ }^{133}$.

La CCI reste très active. Consultée en mai 1960 par Verloren van Themaat pour l'élaboration du projet de règlement, elle élabore un questionnaire sur les différents problèmes à résoudre ${ }^{134}$. La commission des règles de concurrence

126. ACNPF, 72 AS 1388, compte rendu de la réunion de la commission des règles de concurrence de l'UNICE des 11 et 12 mai 1960 .

127. ACNPF, 72 AS 1388, lettre de Del Marmol à Lartisien sur la préparation de la réunion du 29 mars 1960 de la commission des règles de concurrence de l'UNICE.

128. ACNPF, 72 AS 1503, compte rendu de la réunion de la commission des règles de concurrence de l'UNICE du 30 novembre 1959.

129. ACNPF, 72 AS 450, compte rendu du conseil des présidents UNICE du 28 janvier 1960.

130. ACNPF, 72 AS 1388, note du CNPF du 28 janvier 1960.

131. ACNPF, 72 AS 1388, réunion du CNPF de la commission française des pratiques restrictives affectant la concurrence, 14 mars 1960.

132. Raymond Lartisien est le secrétaire général de la commission économique générale du CNPF ; J.-P. Simon est le représentant d'Henri Davezac, vice-président délégué du syndicat général de la construction électrique.

133. AHUE, BAC89/1983, volume 11, rapport de la commission des pratiques restrictives affectant la concurrence du 30 mars 1960.

134. ACNPF, 72 AS 1388, document de la CCI du 16 mai 1960. 
de l'UNICE se réunit le 7 juin 1960 pour y répondre, ce qui démontre que c'est bien la CCI qui mène le débat en la matière ${ }^{135}$. Les débats au sein de l'UNICE comme de la CCI tournent d'ailleurs autour des mêmes propositions, comme celles du hollandais Wertheimer sur l'enregistrement ${ }^{136}$. Ce dernier affirme d'ailleurs à l'UNICE qu'il cherche à retarder les travaux de la CCI dans ce domaine ${ }^{137}$, pour qu'elle ne prenne pas l'ascendant sur l'UNICE.

La présence fréquente des mêmes personnalités dans les différentes organisations patronales, surtout pour des sujets aussi techniques, n'empêche pas une véritable concurrence institutionnelle de se développer entre les organisations patronales. Celle-ci apparaît particulièrement stérile car elle aboutit à retarder les travaux plus qu'à les accélérer. La Commission européenne en profite pour rester au centre du jeu européen.

La dernière faiblesse de l'action patronale européenne réside d'ailleurs dans l'attitude de la Commission européenne, très prudente et sibylline sur ses intentions véritables. Le 18 décembre 1959, Verloren van Themaat affirme aux représentants patronaux que la Commission n'a aucun projet de règlement ${ }^{138}$. Il demande même aux experts patronaux de lui fournir des suggestions de solutions pratiques sur l'interprétation de l'article 87. En février 1960, l'expert français considère toujours que la Commission n'a pas de véritable doctrine ${ }^{139}$. En juillet 1960 encore, dans des rencontres successives avec les représentants du patronat européen, von der Groeben comme Verloren van Themaat restent très évasifs et imprécis ${ }^{140}$. Or von der Groeben avait fixé le cap de ses réflexions dès le mois de février 1960 : obtenir un système centralisé sur la Commission pour remédier aux défauts de la période transitoire ${ }^{141}$.

Ainsi le patronat européen paraît divisé à la fois en termes de doctrine, de stratégie et d'organisation institutionnelle. L'imprécision des intentions de la Commission européenne encourage cet attentisme. La définition d'une

135. ACNPF, 72 AS 1388, compte rendu de la réunion du 7 juin 1960 de la commission des règles de concurrence UNICE.

136. ACNPF, 72 AS 1388, compte rendu de la réunion du 7 juin 1960 de la commission des règles de concurrence UNICE; compte rendu de la réunion des 13 au 14 juin 1960 du groupe de travail «Les pratiques restrictives et l'intégration européenne » de la CCI.

137. ACNPF, 72 AS 1388, compte rendu de la réunion des $1^{\text {er }}$ et 2 juillet 1960 de la commission des règles de concurrence UNICE.

138. ACNPF, 72 AS 1503, compte rendu de la réunion du 18 décembre 1959 de la commission des règles de concurrence UNICE.

139. ACNPF, 72 AS 1388, lettre de Fabre (CNPF) à $\mathrm{M}^{\text {lle }}$ Claessens (UNICE), $1^{\text {er }}$ février 1960.

140. ACNPF, 72 AS 1388, note sur la réunion des présidents UNICE du 18 juillet 1960 ; ACNPF, 72 AS 1504, compte rendu de la réunion de l'UNICE avec Verloren van Themaat le 27 juillet 1960.

141. ACNPF, 72 AS 1388, communication de von der Groeben à destination du collège des commissaires, document IV/COM (60) 17 du 15 février 1960, confidentiel. 
proposition de règlement d'application de l'article 87 oblige le patronat européen à réagir. L'initiative provient alors non pas des Français mais des Belges.

\section{L'offensive belge de l'été 1960.}

À l'été 1960, un nouveau soubresaut offensif, sous l'impulsion des Belges, agite l'UNICE. À l'origine se trouvent les réflexions du président de la commission des règles de concurrence, le Belge Charley Del Marmol face aux déclarations de von der Groeben à un congrès tenu à Francfort où il plaidait en faveur du principe de la déclaration obligatoire ${ }^{142}$. Del Marmol est très opposé à cette procédure qui témoigne d'une volonté de contrôle sévère des ententes ${ }^{143}$. Par ailleurs, il souligne que cela introduit une discrimination envers les petites entreprises au profit des grandes. Les premières doivent en effet recourir aux ententes, qui risquent d'être fortement réprimées par l'article 85 , tandis que les secondes en ont moins besoin et relèveraient plutôt de l'article 86 dont se désintéresse la Commission. Del Marmol souligne la nécessité de mener une véritable action de publicité destinée à contrebalancer les effets négatifs de ce congrès de Francfort qualifié d' " antitrust ». L'enjeu est de taille : «En laissant aux hommes politiques, aux juristes américains et aux fonctionnaires antitrust l'exclusivité des initiatives en ce domaine, l'industrie européenne risque un jour d'être privée des structures nécessaires pour lutter efficacement contre ses grands concurrents : les États socialistes des pays de l'Est et les puissants complexes industriels des USA ${ }^{144} \gg$. Cette réflexion montre bien l'urgence de la mobilisation patronale mais aussi sa dimension offensive : il ne s'agit pas de préserver des rentes de situation passées mais de s'adapter au monde des superpuissances et de leurs grandes unités de production.

Del Marmol est soutenu dans sa volonté offensive par l'expert français Lartisien qui demande lui aussi un effort de « propagande » après le congrès de Francfort ${ }^{145}$. Les Belges demandent l'appui des Français dans une campagne auprès des gouvernements destinée à faire prendre conscience des dangers de la déclaration obligatoire ${ }^{146}$. Celle-ci pourrait aboutir, si elle donne lieu à la publication des renseignements notifiés, à des poursuites menées par des

142. ACNPF, 72 AS 1504, réunion des présidents UNICE du 18 juillet 1960, exposé de C. Del Marmol.

143. ACNPF, 72 AS 1388, document de travail du 6 juillet 1960 signé Charley Del Marmol.

144. ACNPF, 72 AS 1388, document de travail du 6 juillet 1960 signé Charley Del Marmol

145. ACNPF, 72 AS 1504, lettre de Lartisien pour Colombier, réponse à la note Del Marmol établie en prévision de la réunion du conseil des présidents du 18 juillet 1960.

146. ACNPF, 72 AS 1388, lettre de de Staercke au ministre belge des Affaires économiques, J. van der Schueren, 15 juillet 1960, envoyée par Del Marmol à Lartisien le 19 juillet 1960. 
autorités antitrust étrangères contre des entreprises européennes. Les Belges semblent donc craindre particulièrement l'activisme des autorités américaines de la concurrence. Le syndicat belge, la FIB, partage de toute façon la même inclination que le CNPF vers une politique de la concurrence souple fondée sur l'abus ${ }^{147}$.

En juillet 1960, Del Marmol semble bien au courant des réflexions de la DG IV car il estime que la Commission va demander un fort accroissement de ses prérogatives en réaction à la faible coopération des administrations nationales ${ }^{148}$. Dès lors, Del Marmol défend à l'UNICE le principe d'une offensive fondé sur un effort de propagande et la défense de la déclaration facultative comme solution de repli éventuelle ${ }^{149}$. Il est soutenu par le Belge de Staercke ${ }^{150}$, qui représente la FIB. La position de principe de Del Marmol est finalement approuvée ${ }^{151}$.

Les milieux patronaux belges continuent à se mobiliser activement après cette réunion car les projets de règlement de la Commission commencent à être connus. Une lettre est écrite au chef de cabinet du ministre belge des Affaires économiques (le libéral Jacques van der Schueren, très lié aux milieux économiques par sa famille ${ }^{152}$ ) dès le 18 août 1960 , avant que la lettre officielle de la FIB au gouvernement belge ne soit envoyée le 5 octobre $1960^{153}$. Les deux lettres insistent sur trois éléments principaux. La première critique porte sur le système de la déclaration obligatoire. Les notes rappellent qu'il avait été écarté de la récente loi belge instaurant une législation nationale de la concurrence. Ce système est perçu comme psychologiquement néfaste car il introduit une suspicion généralisée envers les ententes, et juridiquement inefficace car il n’apporte aucune sécurité juridique aux entreprises qui doivent attendre la

147. Nicole Loeb, Le patronal industriel belge et la CEE, Centre national d'étude des problèmes de sociologie et d'économie européenne/ULB, Bruxelles, 1995, p. 95.

148. ACNPF, 72 AS 1388, document du 6 juillet 1960 signé Charley Del Marmol en vue de la réunion UNICE du 18 juillet 1960.

149. ACNPF, 72 AS 1504, compte rendu du conseil des présidents UNICE du 18 juillet 1960.

150. Roger de Staercke, dirigeant de diverses associations professionnelles textiles depuis les années trente, administrateur-délégué de la FIB de 1953 à 1962. Il devint ensuite président de la FIB (1962-1970). Voir : Ginette Van-Hentenryk, Serge Jaumain, Valérie Montens (éd.), Dictionnaire des patrons en Belgique : les hommes, les entreprises, les réseaux, De Boeck, Bruxelles, 1996, p. $227-$ 228.

151. ACNPF, 72 AS 1504, compte rendu du conseil des présidents UNICE du 18 juillet 1960.

152. Son frère Roger Van der Schueren est administrateur de brasseries et de sociétés de presse. Il devint président de la FEB (fédération des entreprises belges, successeur de la FIB) de 1975 à 1978. Voir : G. Van-Hentenryk et al. (éd.), Dictionnaire des patrons en Belgique..., op. cit., p. 610-611.

153. ACNPF, 72 AS 1504, lettre à Raymond Pulinckx, chef de cabinet du ministre des Affaires économiques, 18 août 1960 ; ACNPF, 72 AS 1504, lettre de la FIB au gouvernement belge, 5 octobre 1960. 
décision de la Commission européenne avant de voir leur accord confirmé. Le second reproche concerne la priorité donnée à l'application de l'article 85 sur les articles 86 (positions dominantes) et 90 (entreprises publiques). Selon les milieux économiques belges, cette différenciation introduit une discrimination en faveur des pays possédant des grandes entreprises publiques ou privées, au détriment de la Belgique.

Dernier élément, les deux notes critiquent fortement la centralisation excessive des pouvoirs sur la Commission européenne. La première note en particulier insiste fortement sur cet élément politique : « Je considère que l'art 87.1 [...] contient en germe un danger d'abdication pour les autorités économiques belges. Il est donc très important que le ministre se rende bien compte qu'à l'occasion de la discussion qui interviendra sur les premiers projets de règlement, c'est tout le problème des pouvoirs d'intervention de la Commission dans la politique des prix, de la production, de la croissance économique, qui va être posé... ${ }^{154}$.

Les milieux économiques belges mènent donc une campagne très vigoureuse contre le projet de règlement de von der Groeben, qui est considéré comme juridiquement imparfait et économiquement dangereux. Ils n'hésitent pas à recourir à des arguments politiques en soulignant le risque d'une délégation de souveraineté irréversible et inquiétante. Ils développent à la fois des arguments proches de ceux du CNPF (peur d'une politique trop sévère envers les ententes et d'une concentration excessive de pouvoirs sur la Commission) et des idées plus spécifiques, liées à la grande ouverture internationale du pays (crainte de l'action des autorités antitrust américaines et de la concurrence des grands groupes internationaux) ou à sa petite taille (méfiance envers les grandes entreprises publiques françaises et italiennes). Par ailleurs, le débat sur la politique de la concurrence en Belgique est récent - la loi date du 27 mai 1960. Ce problème complexe est donc resté frais dans les mémoires lorsque von der Groeben présente officieusement son projet de règlement quelques mois plus tard.

\section{Le patronat face aux propositions de von der Groeben.}

Le commissaire à la concurrence von der Groeben diffuse officieusement un premier projet de proposition de règlement le 23 septembre $1960^{155}$. Sa proposition définitive est présentée au Conseil des ministres CEE le 31 octobre

154. ACNPF, 72 AS 1504, lettre à Raymond Pulinckx, chef de cabinet du ministre des Affaires économiques, 18 août 1960 .

155. ACNPF, 72 AS 1504, envoi par Verloren van Themaat à l'UNICE du document IV/5176/60 du 23 septembre 1960, projet de règlement de l'art 87. 
$1960^{156}$. Entre les deux, l'UNICE rencontre von der Groeben et Verloren van Themaat, mais cette réunion ne donne lieu qu'à des interventions très modérées des délégués de l'UNICE ${ }^{157}$. Les divisions des patronats semblent avoir eu raison des velléités offensives belges. La réaction du délégué français, Robert Fabre, est à cet égard caractéristique : il estime que l'UNICE a été beaucoup trop souple face à une Commission européenne décidée et ferme ${ }^{158}$. L'action doit désormais passer par le lobbying auprès du Conseil, car la plupart des délégués des gouvernements paraissent également très critiques envers les propositions de la Commission ${ }^{159}$. Il est d'ailleurs symptomatique de remarquer la faible représentation française : un seul délégué français, Fabre, est présent à la réunion du 7 octobre contre quatre Allemands et quatre Belges. Fabre a également été le seul à assister à la réunion préparatoire du 6 octobre mais il a manqué celle du 5 octobre. Aucun Français ne participait donc à la première réunion de l'UNICE sur les propositions de von der Groeben. Le cadre d'action privilégié du CNPF reste l'échelle nationale et son prolongement européen - le Conseil-, et l'UNICE doit surtout servir à coordonner ces actions nationales.

À Paris, les débats du CNPF face au projet de la Commission portent moins sur le fond que sur les personnalités nationales devant faire l'objet d'une démarche. Fabre estime indispensable d'agir au niveau du Conseil des ministres mais il se demande quel sera le ministre responsable ${ }^{160}$. Cela manifeste bien le poids négligeable de ces questions de concurrence sur la scène politique française. L'idée de faire intervenir des Français de la Commission comme Ortoli est évoquée. Mais cette chimère est vite écartée par les experts patronaux qui connaissent le mieux les institutions communautaires : la proposition présentée est celle de la Commission dans son ensemble et plus celle d'un service en particulier ${ }^{161}$. À la réunion du 14 octobre 1960, l'organisation patronale européenne arrive à obtenir un consensus sur un texte minimal, même si la délégation allemande semblait se satisfaire du texte de la Commission pourvu qu'il prévoie un régime

156. AMAE, DECE 674, lettre d'Hallstein à Luns, président du Conseil CEE, 31 octobre 1960, transmission du projet de règlement (doc COM (60) 158 final).

157. ACNPF, 72 1504, compte rendu de la réunion du 7 octobre 1960, note UNICE du 22 novembre 1960.

158. ACNPF, 72 AS 1504, note personnelle de Robert Fabre à $M^{\text {lle }}$ Claessens, UNICE, 7 octobre 1960.

159. ACNPF, 72 AS 1504, note personnelle de Robert Fabre à $\mathrm{M}^{\text {lle }}$ Claessens, UNICE, 7 octobre 1960.

160. ACNPF, 72 AS 1389, compte rendu de la réunion CNPF présidée par Jean Louis du 19 septembre 1960 .

161. ACNPF, 72 AS 1389, compte rendu de la réunion CNPF présidée par Fabre du 3 octobre 1960. 
d'exemption $^{162}$. Le 19 octobre 1960, le commentaire officiel de l'UNICE sur le premier projet de règlement d'application de l'article 87 est envoyé à la Commission ${ }^{163}$. Il reprend les trois critiques des notes belges, sur le régime de la déclaration obligatoire, sur le déséquilibre entre l'application sévère de l'article 85 et l'ignorance de l'article 86 (qui avantage les grandes entreprises) et sur la centralisation excessive des pouvoirs sur la Commission. Une quatrième idée, inspirée de la législation française, est ajoutée : la nécessité de créer une commission consultative des ententes qui se prononce sur la décision d'autorisation en fonction de critères économiques (notamment la notion de «bilan économique ») et pas juridiques. On retrouve ici des analogies avec la Commission technique des ententes (CTE) française.

La CCI a adopté une stratégie différente. Le délégué français s'est retrouvé isolé dans son opposition frontale au projet de la Commission européenne ${ }^{164}$. Le délégué américain a souligné toutefois que l'expérience américaine permettait d'affirmer que la déclaration obligatoire serait non seulement paralysante pour la Commission - en raison de la masse des documents à traiter - et inefficace - car les ententes les plus néfastes ne se déclareront pas. L'avis de la CCI du 21 septembre 1960 est donc plus modéré que le commentaire de l'UNICE du 19 octobre 1960. Si la CCI critique la déclaration obligatoire, elle propose comme solution de compromis la déclaration facultative. Surtout, elle accepte le principe de la centralisation des pouvoirs par la Commission, gage de l'unité de la politique de la concurrence communautaire, alors qu'il est sévèrement critiqué dans la note de $1^{\prime} \mathrm{UNICE}^{165}$. Contrairement à ce dernier document, l'avis de la CCI est publié et fait l'objet de nombreux commentaires ${ }^{166}$. La proposition de règlement finale de Hans von der Groeben du 31 octobre 1960 retient certains éléments des critiques patronales ${ }^{167}$. Sur le plan juridique par exemple, la Commission accepte de considérer comme provisoirement licites les ententes qui se sont déclarées même si elle ne s'est pas encore prononcée dessus. Mais

162. ACNPF, 72 AS 450, compte rendu du conseil des présidents UNICE du 14 octobre 1960.

163. AHUE, BAC 1/1971, volume 81, folio 66, note du secrétariat exécutif pour les membres de la Commission, 24 octobre 1960. Voir aussi : N. Loeb, Le patronal industriel belge..., op. cit., p. $98-99$.

164. ACNPF, 72 AS 1504, compte rendu de la réunion de la commision des pratiques restrictives affectant la concurrence du 21 septembre 1960.

165. AHUE, BAC 89/1983, volume 11 , folio 279 , avis de la CCI sur la déclaration des ententes, 21 septembre 1960 .

166. Il est cité notamment par Robert Plaisant : Robert Plaisant, « La CEE et le projet de règlement relatif aux règles de concurrence », in Revue du Marché commun, 1961-1, p. 15.

167. AMAE, DECE 674, lettre d'Hallstein à Luns, président du Conseil CEE, 31 octobre 1960, transmission du projet de règlement (doc COM (60) 158 final). 
l'économie générale du projet, et notamment sa très forte centralisation sur la Commission, reste identique.

Le patronat européen n'a donc pas réussi à infléchir véritablement le projet de la Commission mais il est particulièrement divisé, tant sur le plan de la doctrine que de la stratégie d'influence. L'UNICE et les organisations nationales qui la composent préfèrent miser sur un lobbying national plus que communautaire. Elles critiquent fortement la centralisation des pouvoirs par la Commission qui est au contraire louée par la CCI. Cette dernière publie sa position, ce qui est également en contradiction avec la prudence traditionnelle de l'UNICE. Face à ces divisions des acteurs patronaux européens, la Commission a toute latitude pour élaborer une proposition de règlement qui l'avantage. Reste à convaincre les États membres réunis au sein du Conseil de l'accepter.

\section{LE RÈGLEMENT 17/62 : SUCCÈS ET ÉCHECS DE L'EUROPE ORDOLIBÉRALE}

La Commission parvient à profiter d'une véritable dynamique communautaire de la négociation sur le futur règlement 17/62. Elle impose ses priorités et obtient un règlement proche de ses objectifs. Mais son application pose de très nombreux problèmes.

\section{A. LA DYNAMIQUE COMMUNAUTAIRE \\ DE LA NÉGOCIATION (FIN 1960-MI-1961)}

La proposition de règlement de von der Groeben est ambitieuse. Elle subit donc de vigoureuses critiques, en particulier de la part de la France.

\section{La réaction française à la proposition de la Commission.}

Lorsque von der Groeben présente son projet de proposition de règlement le 23 septembre 1960, les États membres sont surpris et ne peuvent réagir sur le fond, comme en témoigne le compte rendu de la conférence des experts gouvernementaux qui suit cette présentation ${ }^{168}$. La France fait porter ses critiques sur l'aspect institutionnel de la question : le commissaire à la concurrence aurait

168. ASGCI, 1979.0791, volume 262, compte rendu de la huitième conférence d'experts des 27-29 septembre 1960 . 
dû consulter les États membres sur ce projet ${ }^{169}$. Von der Groeben en convient mais veut associer à cette phase de consultation les milieux économiques, l'Assemblée parlementaire européenne (APE) et le Comité économique et social $(\mathrm{CES})^{170}$. Le délégué français s'y oppose mais il est isolé parmi les Six. Von der Groeben diffuse alors largement son projet, y compris à la presse ${ }^{171}$. Avant même l'étude des questions de fond, von der Groeben réussit donc à imposer sa proposition comme le document de base des discussions en le diffusant largement.

Sur le fond l'administration française met très rapidement au point une réponse très hostile au projet de proposition de règlement ${ }^{172}$. Elle reprend trois arguments déjà présents dans les notes patronales : l'inefficacité du système de l'enregistrement obligatoire, la focalisation sur l'article 85 au détriment de l'article 86, la concentration excessive des pouvoirs par la Commission européenne. Cette dernière devrait partager son pouvoir d'instruction et de décision. Elle ne devrait pas pouvoir s'adresser directement aux entreprises. Le seul cas où le recours à la Commission est reconnu est celui de carence : si un État n'agit pas suffisamment contre une entrave à la concurrence, la Commission doit pouvoir intervenir après une procédure d'arbitrage.

Lors de la réunion du 7 octobre 1960 avec les représentants de la Commission européenne, le délégué français fait connaître cette position avec une certaine vigueur $^{173}$. Cette posture est remarquée par les patronats français et belge qui cherchent à en profiter pour organiser une action d'influence commune auprès de leurs deux gouvernements. Il est prévu que le patronat belge incite le ministre belge des Affaires économiques à prendre contact avec le secrétaire d'État français Valéry Giscard d'Estaing afin qu'ils se concertent avant la session du Conseil des ministres $\mathrm{CEE}^{174}$. Vers le 20 octobre, Lartisien envoie aux ministres français responsables et au commissaire Robert Lemaignen une longue note (12 pages) reprenant toutes les critiques adressées à la proposition de la Commission ${ }^{175}$. Elle comprend une contre-proposition relativement précise :

169. ASCGI, 1979.0791, volume 264, télex du SGCI (FM) à la REP (Gorse), le 22 septembre 1960.

170. AMAE, RPUE 613, télex de la REP du 23 septembre 1960.

171. ACNPF, 72 AS 1504, note de Lartisien pour Jean Louis, 9 novembre 1960.

172. ASGCI, 1979.0791, volume 264, télex du SGCI (FM) à la REP (Gorse), 5 octobre 1960 : instructions pour les réunions des 6 et 7 octobre 1960 issues de la réunion tenue le 4 octobre 1960 .

173. ACNPF, 72 AS 1504, compte rendu de la réunion du 7 octobre 1960, note UNICE du 22 novembre 1960.

174. ACNPF, 72 AS 1504, lettre de C. Del Marmol à Lartisien, 17 octobre 1960 ; lettre de Lartisien pour Jean Louis, 9 novembre 1960.

175. ACNPF, 72 AS 1504, lettre de Lartisien à C. Del Marmol, 22 octobre 1960 ; lettre de Lartisien à Lemaignen, 18 octobre 1960. Les notes sont envoyées à Wilfried Baumgartner, ministre de l'Économie et des Finances, Jean-Marcel Jeanneney, ministre de l'Industrie, et Valéry Giscard d'Estaing, secrétaire d'État aux Finances. 
le règlement devrait se contenter de définir la procédure des actions engagées sur plainte. L'instruction serait menée par les administrations nationales avec un représentant de la Commission. Une commission consultative sur le modèle de la CTE formulerait un avis sur la décision, qui serait prise de manière conjointe par les autorités nationales et communautaires. Par ailleurs, en dehors de cette procédure judiciaire, les entreprises pourraient obtenir de la Commission des avis sur leurs pratiques, au lieu d'organiser une déclaration obligatoire répressive. Le système est donc fondé sur une coopération intergouvernementale rationalisée, avec une dimension corporatiste, la voix des entreprises devant être largement entendue tant par les autorités nationales que par la commission consultative. L'approche du CNPF est plus économique et pédagogique, que juridique et répressive. Le schéma d'ensemble ressemble au modèle français. Lartisien insiste sur cette contre-proposition car il a le sentiment que les officiels français se concentrent trop sur l'aspect institutionnel - l'excessive délégation de pouvoirs à la Commission - et pas assez sur la doctrine économique et juridique ${ }^{176}$.

La prise de conscience du gouvernement est cependant très lente sur ce problème. L'incertitude règne quant au ministre qui représentera la France au Conseil CEE devant traiter de ce problème, le ministre Baumgartner ou le secrétaire d'État Giscard d'Estaing ${ }^{177}$, alors que les premiers signes de mobilisation du gouvernement sur cette question proviennent de Jeanneney, qui a envoyé une lettre à son ami Michel Debré pour souligner le caractère inacceptable de ce projet ${ }^{178}$. Selon les termes d'une note résumant les griefs du ministre, le projet aboutirait à une étroite surveillance de l'économie française alors que l'économie allemande, « où les ententes au sens classique du terme sont moins nombreuses, serait en fait à l'écart de tout contrôle ${ }^{179} \gg$. La thématique classique du danger de l'industrie allemande plus concentrée que son homologue française ressurgit dans cette remarque. Jeanneney demande peu après une courte note de synthèse sur ce problème complexe directement à Lartisien ${ }^{180}$. Cependant, ce n'est pas Jeanneney qui est en charge du dossier mais Joseph Fontanet, le secrétaire d'État au Commerce intérieur. La note du CNPF ne lui parvient que le 9 novembre 1960, trois semaines après le premier envoi ${ }^{181}$. Le même retard est observable avec la représentation permanente de la France à Bruxelles. C'est

176. ACNPF, 72 AS 1504, lettre de Lartisien à Fabre, 22 octobre 1960.

177. ACNPF, 72 AS 1389, lettre de Lartisien à Villiers et Louis, 27 octobre 1960.

178. ACNPF, 72 AS 1389, lettre de Lartisien à Villiers et Louis, 27 octobre 1960.

179. AFNSP, 2 DE 29, note pour Michel Debré du 25 octobre 1960.

180. ACNPF, 72 AS 1504, lettre de Lartisien à Jeanneney, 25 novembre 1960.

181. ACNPF, 72 AS 1504, lettre de Lartisien à Fontanet, 9 novembre 1960. 
le représentant permanent adjoint, Jean Mille, qui doit demander lui-même la position du CNPF à l'un de ses correspondants au sein de l'organisation patronale $^{182}$. Il ne la reçoit que le 7 novembre $1960^{183}$.

Ainsi, le gouvernement français apparaît à la fois très hostile au texte de la Commission mais aussi mal organisé pour y répondre et mal informé, d'où son recours à la source d'expertise du CNPF. Cette faiblesse a aussi pour origine une grande confiance dans les rapports de force au sein des institutions communautaires. La réunion organisée par le SGCI le 19 novembre 1960 se conclut de manière rassurante : " il s'agit d'infléchir les lignes générales du projet et les conceptions de la Commission, et non pas de prendre position sur le détail du texte ${ }^{184} »$. La même attitude se perçoit dans un projet de lettre du Premier ministre du 22 décembre 1960. Elle demande une définition de la position française sur le fond en posant des questions très générales comme par exemple : " Convient-il d'introduire, par règlement du Conseil, des dispositions conférant à la Commission européenne des pouvoirs analogues à ceux dont dispose la Haute Autorité de la CECA ? ${ }^{185}$. Or le projet de règlement du 23 septembre 1960 est justement une première réponse à cette question. Il semble que les décideurs français estiment qu'ils ont encore du temps avant de se mobiliser dans le détail sur un dossier aussi complexe. Ainsi, en décembre 1960, trois mois après le premier projet de von der Groeben et deux mois après le contre-projet proposé par le CNPF, aucune position précise n'est défendue par les autorités françaises. Cela permet à la Commission de faire progresser son texte en dépit des oppositions.

\section{La proposition passe l'étape du Conseil des ministres.}

Après avoir diffusé au cours de simples consultations le premier projet de proposition de règlement du 23 septembre 1960, von der Groeben présente officiellement son projet de règlement d'application de l'article 87 le 31 octobre 1960 , sous une forme quasiment identique à celle du 23 septembre ${ }^{186}$. Reste à lui

182. ACNPF, 72 AS 1504, note de J. Servot, service d'études législatives du CNPF, à M. Aubert, 7 novembre 1960 .

183. AMAE, RPUE 613, lettre de Servot (CNPF) à Mille (REP) du 7 novembre 1960.

184. AMAE, DECE 674, conclusion de la réunion SGCI du 19 novembre 1960, document du 21 novembre 1960.

185. ASGCI, 1988.0516, article 1, projet de lettre du Premier ministre aux ministres des Finances et de l'Industrie, 22 décembre 1960, projet de lettre remis à Pérouse.

186. AMAE, DECE 674, lettre d'Hallstein à Luns, président du Conseil CEE, 31 octobre 1960, transmission du projet de règlement (doc COM (60) 158 final). 
faire passer l'étape initiale, celle du Conseil des ministres, malgré l'opposition française. Le commissaire européen mène une action en deux temps.

Dans un premier temps, la proposition de la Commission est étudiée lors de la session du Conseil des ministres des 14 et 15 novembre $1960^{187}$. Von der Groeben demande que sa proposition soit soumise à l'APE et au CES. Il s'oppose au ministre belge pour qui le projet doit être soumis à un échange de vue préalable entre les gouvernements et la Commission. Von der Groeben réplique mollement mais c'est bien le délégué néerlandais qui porte le coup de grâce à la proposition belge par une démonstration juridique implacable. Il rappelle que toute proposition de la Commission ne peut être modifiée qu'à l'unanimité par le Conseil. Ce n'est donc pas une suggestion mais une décision, sur laquelle l'Assemblée est appelée à se prononcer en tant que telle. La procédure proposée par le ministre belge n'est pas prévue dans le traité.

En fait, cette controverse porte sur l'article 149 qui stipule : « Lorsque en vertu du présent traité, un acte du Conseil est pris sur proposition de la Commission, le Conseil ne peut prendre un acte constituant amendement de la proposition que statuant à l'unanimité. Tant que le Conseil n'a pas statué, la Commission peut modifier sa proposition initiale, notamment dans le cas où l'Assemblée a été consultée sur cette proposition ». Le délégué néerlandais insiste sur la première partie de l'article et le délégué belge sur la seconde.

Quoi qu'il en soit, grâce à ce vigoureux appui supranationaliste néerlandais, un compromis est scellé : une session spéciale du Conseil constituée des ministres compétents sera réunie le 29 novembre 1960. Elle devra proposer des solutions pour le Conseil des 6 et 7 décembre 1960 qui décidera d'une éventuelle transmission de la proposition à l'APE et au CES.

La session des ministres compétents réunis à Luxembourg le 29 novembre 1960 donne lieu à de très longs débats, réunis dans un procès-verbal de 39 pages rien que pour les exposés initiaux ${ }^{188}$. Deux positions se dégagent de ces exposés. D'un côté, deux délégations (Pays-Bas et RFA) soutiennent le projet de la Commission. Le délégué allemand, Müller-Armack, l'un des théoriciens de l'ordolibéralisme, soutient énergiquement la doctrine de l'interdiction et le principe de la déclaration obligatoire, en vigueur en Allemagne.

187. ASGCI 1979.0791, volume 264, procès-verbal du Conseil CEE des 14 et 15 novembre 1960.

188. AHUE, BAC 1/1971, volume 81, folio 212, projet de procès-verbal de la session ministérielle tenue à Luxembourg le 29 novembre 1960 ; ASGCI, 1979.0791, volume 264, note de synthèse sur la session du Conseil CEE du 29 novembre 1960. 
D'un autre côté, trois délégations (France, Belgique, Luxembourg) s'opposent catégoriquement au projet de la Commission pour des raisons d'efficacité économique et lui demandent explicitement de revoir sa proposition avant toute transmission à l'Assemblée ${ }^{189}$. Le système de la déclaration obligatoire est jugé lourd et inefficace. Cependant ce camp est divisé car le délégué luxembourgeois soutient le principe de la centralisation des pouvoirs par la Commission au nom de l'unité de la politique communautaire. Le représentant français, Joseph Fontanet, n'évite pas les contradictions : il lui arrive de reconnaître que l'article 85 est fondé sur le principe d'interdiction ${ }^{190}$, alors même qu'il défend le principe de l'abus dont se prévaut la loi française. L'exposé belge est plus incisif. Le ministre belge des Affaires économiques Van der Schueren reprend de nombreuses idées de la note de la FIB envoyée à son chef de cabinet le 18 août $1960^{191}$.

Von der Groeben répond ensuite longuement sur chacun des points, en faisant preuve d'une certaine virtuosité juridique. De plus, aucune contre-proposition cohérente et surtout consensuelle n'est effectuée. La Belgique se concentre sur le problème de la déclaration obligatoire tandis que la France axe sa critique sur la centralisation excessive des pouvoirs sur la Commission, et introduit le problème supplémentaire des accords d'exclusivité (réprimés plus sévèrement en France que dans les autres pays). Dans le débat, von der Groeben peut compter sur l'appui de Müller-Armack qui replace aisément le débat sur la controverse juridique doctrinale abus/interdiction, en plaidant vigoureusement en faveur de cette dernière. Cela provoque la lassitude de Fontanet qui propose de tenir une nouvelle réunion. Habilement, von der Groeben constate qu'il parait difficile de rapprocher les positions des États et qu'il vaudrait mieux transmettre le texte en l'état à l'Assemblée, ce que les ministres acceptent de guerre lasse ${ }^{192}$.

Pourtant, la note du SGCI dressant le bilan de ces discussions est relativement optimiste. Elle constate que certaines positions de fond de la France - opposition à la déclaration obligatoire, nécessité d'un équilibre entre les articles 85 et 86 - sont majoritaires ${ }^{193}$. Par contre, l'isolement de la France sur la nécessité de rompre le monopole du pouvoir de décision de la Commission apparaît dès ce moment-là. D'une manière générale, cette note ignore que la coalition

189. L'Italie est isolée car elle s'oppose au projet de règlement pour des raisons purement juridiques.

190. AHUE, BAC 1/1971, volume 81, folio 231, projet de procès-verbal de la session ministérielle tenue à Luxembourg le 29 novembre 1960, p. 20.

191. ACNPF, 72 AS 1504, lettre à Raymond Pulinckx, chef de cabinet du ministre des Affaires économiques, 18 août 1960 .

192. ASGCI, 1979.0791, volume 264, décision du COREPER du $1^{\text {er }}$ décembre 1960.

193. ASGCI, 1979.0791, volume 264, décision du COREPER du $1^{\text {er }}$ décembre 1960. 
des mécontents ne suffit pas à créer une contre-proposition cohérente comme le stipule d'ailleurs clairement l'article 149 : l'unanimité des États membres $\mathrm{du}$ Conseil est requise pour modifier une proposition de la Commission. Par ailleurs, le traité prévoit que ce domaine ne soit plus soumis à l'unanimité mais au vote à la majorité qualifiée à partir du premier janvier 1961, ce qui peut encore accentuer l'isolement de la France. L'administration française et son gouvernement restent pourtant persuadés qu'il sera toujours possible de renverser la vapeur lors du retour du projet devant le Conseil.

Von der Groeben participe à cet apaisement par un patient travail de consultation, dirigé contre ceux qu'il perçoit comme les plus farouches adversaires de son projet. Il choisit en particulier de se rapprocher du patronat français, qui a pris la tête du mouvement de contestation patronale. Une rencontre a lieu, à la demande de von der Groeben, avec Lartisien ${ }^{194}$. Le commissaire allemand maintient sa position mais se montre conciliant sur la forme, insistant sur la volonté de la Commission de ne pas mener de politique répressive. Lartisien conclut : «M. von der Groeben a incontestablement le souci de ne pas "braquer" les milieux industriels à l'égard de la Commission ${ }^{195} »$. Le 12 janvier 1961, von der Groeben continue son travail de consultation en rencontrant, toujours à sa demande, Joseph Fontanet, le ministre responsable, et Georges Villiers, le président du $\mathrm{CNPF}^{196}$. L'entretien n'aboutit à aucune inflexion de la position de la Commission.

Ainsi après les débats de Luxembourg, von der Groeben a réussi à faire passer sa proposition à l'Assemblée sans que le Conseil ne lui apporte des modifications. Il souligne l'importance de ce succès dans ses mémoires ${ }^{197}$. Deux facteurs ont permis ce passage. D'une part, von der Groeben a cherché à imposer très largement sa proposition dans l'opinion en la diffusant largement sous prétexte de consultations - dont il n'a d'ailleurs presque pas tenu compte. D'autre part, les opposants au projet de la Commission sont trop divisés dans leurs critiques et n'ont pas formulé de contre-proposition commune. Au contraire, les partisans du règlement - von der Groeben et Müller-Armack en tête, sont particulièrement affûtés dans ce dossier très technique.

194. ACNPF, 72 AS 1504, compte rendu de l'entretien de Lartisien avec Hans von der Groeben, 3 novembre 1960 .

195. ACNPF, 72 AS 1504, compte rendu de l'entretien de Lartisien avec Hans von der Groeben, 3 novembre 1960 .

196. ACNPF, 72 AS 1504, compte rendu de l'entretien entre Georges Villiers et Hans von der Groeben du 12 janvier 1961.

197. Hans von der Groeben, Combat pour l'Europe. La construction de la Communauté Européenne de 1958 à 1966, Office des publications officielles des Communautés européennes, Bruxelles, 1985, p. 121. 


\section{La contre-offensive du CNPF par l'UNICE.}

Face à ce premier succès de von der Groeben, le CNPF poursuit son offensive et cherche maintenant à agir par l'UNICE. À la fin de novembre 1960, Lartisien devient vice-président de la commission des règles de concurrence et assure la présidence de facto en remplacement de Del Marmol, malade ${ }^{198}$. Il est confiant dans sa capacité d'influencer le gouvernement et l'administration française car il estime l'expertise patronale supérieure à celle de l'administration française dans ce domaine ${ }^{199}$. Il compte sur une action coordonnée des patronats français, belges et luxembourgeois auprès de leurs gouvernements pour créer un front hostile au projet de la Commission ${ }^{200}$. Cependant, la contreproposition de l'UNICE n'existe pas encore. Le CNPF définit sa propre contreproposition au début de 1961 et l'expose à l'UNICE ${ }^{201}$. Elle repose sur les deux éléments consensuels, l'opposition à la déclaration obligatoire et l'exigence d'un traitement parallèle des ententes (article 85) et des positions dominantes (article 86), ainsi que l'idée de partage des pouvoirs de la Commission. Les étapes de l'instruction et de la définition de la sanction devraient être menées en coopération avec les États membres, la décision sur l'entente devrait être prise en liaison avec un comité consultatif où les milieux économiques pourraient être représentés ${ }^{202}$.

L'UNICE parvient finalement à se mettre d'accord sur une contreproposition seulement le 15 septembre $1961^{203}$. Elle repose assez largement sur les réflexions du CNPF. En termes de stratégie, l'UNICE reste dans une démarche prudente. Chaque pays doit être couvert par un délégué qui doit faire un travail d'influence auprès des acteurs nationaux. Cet accord sur la définition d'une position commune est très tardif. Il intervient seulement un mois avant que l'APE ne rende son avis et bien après les prises de position de la CCI.

La CCI définit de son côté une position sensiblement différente de celle du CNPF. Elle plaide pour la création d'un véritable « tribunal des ententes » formé de magistrats professionnels spécialisés, indépendants des États membres

198. ACNPF, 72 AS 1388, réunion du 26 novembre 1960 de la commission des règles de concurrence UNICE ; ACNPF, 72 AS 1504, lettre de C. Del Marmol à Lartisien, 28 novembre 1960.

199. ACNPF, 72 AS 1388, note de Lartisien (CNPF) à Fabre (CNPF).

200. ACNPF, 72 AS 1504, lettre de Lartisien (CNPF) à Del Marmol (FIB), 6 décembre 1960.

201. ACNPF, 72 AS 1504, compte rendu de la réunion des présidents UNICE du 20 février 1961 ; rapport de la commission des relations économiques internationales du CNPF pour 1960, assemblée générale du CNPF du 17 janvier 1961, in Patronat français, nº spécial, 1961, p. 61-62.

202. ACNPF, 72 AS 1388, notes du CNPF du 20 juin 1960 et du 2 mai 1960 pour l'UNICE.

203. ACNPF, 72 AS 450, compte rendu de la réunion des présidents UNICE du 15 septembre 1961. 
comme de la Commission ${ }^{204}$. En attendant la création de ce tribunal qui nécessiterait une modification des traités, le comité consultatif à créer devrait être constitué exclusivement de magistrats professionnels spécialisés, et pas de fonctionnaires ou de représentants des milieux économiques. Ils devraient être choisis par la Commission. La DG IV jouerait le rôle de procureur et les milieux économiques de défenseur dans une procédure contradictoire supervisée par le Comité consultatif. Selon Sigfrido Ramirez, le projet de « tribunal des ententes » développé par la CCI est une duplication du modèle américain de Federal Trade Commission $^{205}$. Il a été développé par Minoli206 ${ }^{206}$ l'avocat de Fiat, pour assurer le développement d'une politique de la concurrence complètement indépendante du pouvoir politique. La discussion du 13 mars 1961 entre les experts de la CCI et les représentants de la DG IV est très instructive sur les motivations des membres de la CCI responsables de ce projet ${ }^{207}$. Les principaux intervenants à cette discussion sont des représentants de très grandes entreprises : Minoli, lié à Fiat, et le comte Raoul de Vitry d'Avaucourt, président de Péchiney. Leur principal objectif est d'assurer une unité parfaite de la politique de la concurrence communautaire en diminuant au maximum les interventions perturbatrices des autorités nationales. Tous les pouvoirs devraient être concentrés dans la Commission et le Comité consultatif. La réunion est donc le théâtre d'une discussion étonnante où von der Groeben et Verloren van Themaat sont obligés de défendre les prérogatives des États membres et notamment la nécessité de les associer à la procédure. Dans ses prises de positions ultérieures, la CCI continue sur cette ligne d'une défense intransigeante de la centralisation maximale des pouvoirs par la Commission européenne pour éviter tout « droit de veto » des États membres qui briserait l'unité du Marché commun industriel ${ }^{208}$.

Cette attitude paraît symptomatique de la conception de l'intégration européenne que pouvaient avoir de grandes entreprises habituées à dépasser l'échelle nationale et très indépendantes des autorités administratives et politiques nationales. La création du Marché commun est pour elles l'occasion de dépasser une échelle nationale de régulation perçue comme inutilement bureaucratique et mal adaptée aux réalités économiques contemporaines. L'échelle communautaire

204. AMAE, RPUE 614, avis de la CCI sur la création d'un comité consultatif, 22 février 1961.

205. S. Ramirez, «Antitrust ou anti-US ?...», op. cit., p. 225-226.

206. Eugenio Minoli, avocat, doyen de la faculté de droit de Modène : AHUE, BAC 89/1983, volume 11, document CEE IV/2301-61 du 28 mars 1961.

207. AHUE, BAC 89/1983, volume 11, document CEE IV/2301-61 du 28 mars 1961. Voir aussi :

S. Ramirez, Public Policies..., op. cit., p. 630-632.

208. ACNPF, 72 AS 1504, doc 225/79, 3 septembre 1961. 
doit permettre d'instaurer une régulation plus neutre, fondée sur un pouvoir judiciaire et pas politique et administratif.

Certes le contraste ne doit pas être trop exagéré. Ainsi de Vitry reprend l'argument classique du CNPF sur la nécessité de ne pas adopter une attitude trop répressive envers les ententes pour ne pas décourager celles qui aboutissent à une rationalisation des structures ${ }^{209}$. Par ailleurs la CCI reste opposée au système de déclaration obligatoire prévu par le projet de von der Groeben ${ }^{210}$. Enfin, un minimum de coordination est assurée par la participation de Lartisien à certaines réunions du comité français de la $\mathrm{CCI}^{211}$. Mais les divergences de fond et de stratégie restent fortes entre l'UNICE et la CCI, ce qui renforce l'hétérogénéité des milieux patronaux européens. L'action du CNPF par l'UNICE étant très imparfaite, le syndicat patronal français cherche également à agir au niveau national.

\section{L'action des acteurs patronaux et administratifs français.}

La faible mobilisation des autorités françaises en matière de politique de la concurrence facilite l'action d'influence nationale du CNPF. Au début de 1961, la position française reste en effet la même : la Commission et les États membres devraient se partager le pouvoir de décision, avec le recours à un système d'arbitrage complexe en cas de désaccord ${ }^{212}$. La procédure d'enquête ne serait pas déclenchée suite à une déclaration obligatoire mais à la suite d'une plainte, par l'auto-saisine de la Commission ou à la suite de la demande d'une entreprise souhaitant obtenir une validation de son entente (système voisin de la déclaration facultative $)^{213}$. La France ne fait donc aucun effort pour définir un système reprenant des éléments du projet de von der Groeben. Elle pense que ce dernier va être rejeté et se place donc dans un cadre complètement différent.

Or, la proposition de la Commission semble de plus en plus incontournable. Le 7 mars 1961, lors du Conseil CEE, von der Groeben demande un nouvel échange de vue sur les positions des États membres ${ }^{214}$. Habilement, il place

209. AHUE, BAC 89/1983, volume 11, compte rendu succinct de la réunion du 13 mars 1961.

210. ACNPF, 72 AS 1504, compte rendu de la réunion de la commission des pratiques restrictives affectant la concurrence du comité français de la CCI, 19 septembre 1961.

211. ACNPF, 72 AS 1504, compte rendu de la réunion de la commission des pratiques restrictives affectant la concurrence du comité français de la CCI, 19 septembre 1961.

212. AMAE, DECE 1258, note de la DG Prix du $1^{\text {er }}$ mars 1961 ; ASGCI, 1979.0791, volume 264, note de Gulphe à Morin, 28 février 1961.

213. AMAE, RPUE 614, note FM (SGCI), du 11 avril 1961.

214. AHUE, SCGI 1979.0791, volume 264, projet de procès-verbal du Conseil CEE restreint du 7 mars 1961. 
le débat sur le problème du choix entre l'abus et l'interdiction. La discussion s'engage alors sur des controverses juridiques théoriques qui démontrent les profondes divisions entre États membres. Cela pousse le ministre belge des Affaires économiques Van der Schueren, qui préside la réunion, a tenté de trouver un compromis. Il suggère que les débats se concentrent sur les aspects économiques plus que juridiques, en prenant comme base de discussion le projet de la Commission mais tout en tenant compte du fait que d'autres solutions sont possibles. Von der Groeben rebondit immédiatement : il accepte l'étude article par article de son projet, ce qui l'impose comme base de discussion. De plus, il rappelle l'urgence d'arriver à un accord, sinon l'interprétation des articles 85 et 86 reviendrait à la $\mathrm{CJCE}$, à défaut de l'adoption d'un règlement d'application de l'article 87. Ce dernier argument traduit la vigueur de la dynamique institutionnelle de la CEE.

Le débat revient donc aux experts gouvernementaux, qui sont chargés d'établir une liste de questions à approfondir dans l'étude de la proposition de von der Groeben ${ }^{215}$. La France est isolée sur deux points ${ }^{216}$. D'une part, elle est la seule à considérer que la déclaration obligatoire est inutile. En effet même la délégation belge reconnaît maintenant l'utilité de la déclaration obligatoire, au moins pour certains secteurs. L'arrivée au pouvoir d'un gouvernement socialiste en Belgique en mars 1961, après les grèves très dures de l'hiver 1960-1961 ${ }^{217}$, a sans doute fait évoluer les positions. D'autre part, la France est de nouveau la seule à réclamer un partage des pouvoirs entre la Commission et les États membres au stade de la décision ${ }^{218}$.

Ce double isolement de la France n'empêche pas l'administration française de dresser un bilan satisfaisant de cette réunion ${ }^{219}$. Le cabinet de Fontanet a dû cependant constater l'évolution défavorable des rapports de force sur l'enregistrement obligatoire car il demande à Lartisien, au CNPF, d'imaginer une solution de compromis sur ce problème ${ }^{220}$. Lartisien joue un rôle d'expert quasi officiel auprès de Fontanet. Mais leur coopération est limitée par leurs divergences sur l'appréciation de la situation. Les experts du CNPF deviennent de plus en plus pessimistes, alors que les fonctionnaires sont plus optimistes.

215. ASGCI, 1979.0791, volume 264, télégramme de la Commission au REP (Gorse), 12 avril 1961.

216. AMAE, RPUE 614, projet de compte rendu de la réunion du 17 mai 1961.

217. Marie-Thérèse Bitsch, Histoire de la Belgique de l'Antiquité à nos jours, Complexe, Bruxelles, 2004, p. 200-204.

218. AMAE, RPUE 614, projet de compte rendu de la réunion du 17 mai 1961.

219. ASGCI, 1979.0791, volume 264, télex Gorse au SGCI, 19 mai 1961 sur réunion 17 mai 1961.

220. ACNPF, 72 AS 1504, note du 14 juin 1961 de Lartisien (CNPF) pour Gulphe. 
Cela se perçoit par exemple dans les commentaires portant sur les travaux d'Arved Deringer, le député européen allemand chargé du rapport de l'APE sur le projet de règlement. Lartisien, dans une note qu'il envoie au SGCI, souligne que l'avocat allemand a une approche essentiellement juridique, qui prend la législation allemande comme référence et accepte la centralisation des pouvoirs par la Commission ${ }^{221}$. Au contraire les fonctionnaires français chargés du dossier considèrent que les études de Deringer contribuent à mettre en valeur les défauts internes du projet de la Commission, et donc à renforcer la contreproposition française ${ }^{222}$. Cette attitude se répercute au sommet de l'État. Le 9 juin 1961, le Premier ministre écrit au président de la République à propos de l'évolution du dossier de la politique de la concurrence : «Un récent conseil interministériel a montré qu'en ce qui concerne le troisième point [la politique de la concurrence] l'Allemagne peut se trouver relativement isolée et que nous pouvons, le cas échéant, écarter cette menace ${ }^{223} \gg$. Le constat d'isolement de la RFA fait par Michel Debré n'a qu'un lointain rapport avec la réalité même s'il peut être cohérent avec le compte rendu optimiste des discussions du 17 mai 1961. À la mi-1961, les autorités françaises pensent encore que le projet de von der Groeben sera vraisemblablement transformé de fond en comble.

\section{B. LA DERNIÈRE ÉTAPE DES NÉGOCIATIONS ET LE RÈGLEMENT 17/62 (JUIN 1961-DÉCEMBRE 1961)}

Alors que la France espère encore en juin 1961 que le projet de von der Groeben sera majoritairement rejeté, les rapports de force s'inversent clairement en quelques mois. Les divisions de l'administration française et le soutien de l'APE permettent à von der Groeben de revenir devant le Conseil en position de force. La France pense cependant encore pouvoir l'emporter. Mais, en dépit d'une dernière offensive du CNPF, elle est finalement obligée de céder.

\section{Les divisions de l'administration française face aux ambitions de la Commission.}

L'approche française reste marquée par la volonté de mettre en place une politique de la concurrence efficace à l'échelle européenne, car elle correspond

221. ASGCI, 1979.0791, volume 264, note Lartisien (CNPF) sur l'avant-projet de rapport de Deringer au SGCI, 3 février 1961.

222. ASGCI, 1979.0791, volume 264, notes de Gulphe au SGCI des 23 février 1961 et 28 avril 1961.

223. AFNSP, 2 DE 30, lettre de Michel Debré à Charles de Gaulle, 9 juin 1961. 
à l'objectif d'une libéralisation régulée. Cela pousse parfois certains experts français à soutenir la Commission plus que ne le supposerait la position officielle du gouvernement. Ainsi, la France transmet aux institutions communautaires les rapports d'activités de la CTE en juin 1961 mais elle est la seule à le faire car la RFA et les Pays-Bas, les deux pays qui disposent de ce type de document, ne diffusent pas ce type d'information ${ }^{224}$. Dans le domaine des marchés publics également, la Commission cherche à profiter de la bonne volonté des experts administratifs français. Lors de la conférence d'experts de juin 1961, les experts français relèvent benoîtement que « lors des passations des marchés d'État et des grandes entreprises publiques, les autorités françaises avaient constaté que, en général, seules les entreprises nationales y participaient ; dans les cas, très rares où des entreprises étrangères étaient aussi soumissionnaires, leurs conditions de prix étaient égales, ou très souvent, plus élevées que celles des entreprises françaises. Cela faisait penser qu'un accord plus ou moins tacite pourrait exister pour éviter, dans le cadre des marchés publics passés dans un pays, une concurrence aux entreprises ressortissantes de ce pays ${ }^{225} \gg$. Verloren van Themaat propose alors d'élaborer une circulaire d'information pour les administrations sur les articles 85 et 86 et de convoquer une réunion avec les responsables des services publics les plus importants. Les deux propositions sont acceptées.

Ces décisions provoquent l'ire de Claude Beaurepaire, l'inspecteur général chargé des affaires extérieures au ministère de l'Industrie. Dans une lettre au SGCI du 29 août 1961 se référant directement à cette conférence d'experts, il se plaint de l'attitude des experts français ${ }^{226}$. Elle expose la France à devoir ouvrir ses marchés sans contrepartie : «Il y a d'ailleurs lieu de remarquer que M. Verloren van Themaat ayant bien entendu accueilli avec faveur la suggestion française, et ayant demandé aux autres délégations si elles s'y ralliaient, ces dernières ont formulé des réponses très évasives [...]. On peut présumer que si M. Verloren van Themaat s'engage effectivement dans cette voie, il obtiendra de l'administration française un certain nombre de dénonciations plus ou moins justifiées, mais pas grand-chose des administrations allemandes, italiennes, etc. ${ }^{227} \gg$. Beaurepaire rapproche cette maladresse d'une autre commise un peu plus tôt : la suggestion française d'utiliser les rapports

224. ASGCI 1979.0791, volume 262, compte rendu de la $9^{\text {e }}$ conférence d'experts du 30 juin 1961.

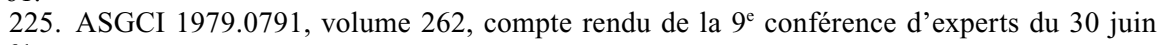
1961.

226. ASGCI 1979.0791, volume 262, lettre de Beaurepaire au SGCI, FM, 29 août 1961.

227. ASGCI 1979.0791, volume 262, lettre de Beaurepaire au SGCI, FM, 29 août 1961. 
des autorités nationales pour déceler les ententes nationales a abouti à une proposition de Verloren van Themaat d'ouvrir des enquêtes sectorielles pouvant gêner les industriels français. Beaurepaire conclut sur la nécessité d'une forte coordination des positions françaises par le SGCI. Il demande enfin à participer à la prochaine réunion évoquant ce problème des marchés publics. Il semble avoir obtenu satisfaction car il prend part à la conférence d'experts suivante, où un exposé initial de la délégation française ferme la porte à toute collaboration dans le domaine des marchés publics ${ }^{228}$.

Au-delà du problème de la coordination administrative, nécessairement délicate alors que les réunions à Bruxelles se multiplient, cet incident démontre surtout l'opposition entre deux conceptions de la politique de la concurrence communautaire. Ainsi, il semble bien que le volontarisme français manifesté en matière de coopération européenne dans le domaine des marchés publics réponde moins à une maladresse française devant le machiavélisme de la DG IV, qu'à une orientation doctrinale plus profonde. La direction des Prix a en effet demandé l'étude de la possibilité d'ouvrir aux fournisseurs des Six les marchés publics, sans doute dans une optique de pression sur les prix $^{229}$. Une politique de la concurrence communautaire sévère n'est donc pas rejetée a priori si elle peut faciliter la lutte contre l'inflation. Au contraire, Beaurepaire s'oppose à cette tendance car il demande avant tout une réciprocité effective en matière d'ouverture des marchés. Si ce projet était néanmoins accepté, un contrôle communautaire de la non-discrimination en matière de marchés publics efficace devrait alors s'imposer à tous les pays membres de la CEE, " à moins bien entendu que ces déséquilibres ne soient explicables par des différences notoires de compétitivité des industries nationales intéressées ${ }^{230} \gg$. Cette dernière précision est intéressante car elle montre le chemin parcouru par Beaurepaire depuis 1956, lorsqu'il s'opposait vigoureusement au rapport Spaak. Les différences de compétitivité sont désormais prises en compte alors qu'une approche compensatrice plus statique était en vigueur en 1956.

Les décideurs français restent dans le schéma d'une CEE vecteur d'un libéralisme régulée, mais ils divergent sur ses modalités d'application. Ils ne parviennent pas à contrer la Commission qui bénéficie par ailleurs du soutien de l'Assemblée parlementaire européenne.

228. ASGCI, 1979.0791, volume 262, compte rendu de la $10^{\mathrm{e}}$ conférence d'experts du 14 septembre 1961.

229. AINDUS, 1977.1386, article 54, projet de lettre du ministre de l'Industrie, transmis par Beaurepaire, au SGCI, 25 octobre 1961.

230. AINDUS, 1977.1386 , article 54, projet de lettre du ministre de l'Industrie, transmis par Beaurepaire, au SGCI, 25 octobre 1961. 


\section{Le soutien de l'Assemblée (septembre-octobre 1961).}

À l'Assemblée parlementaire européenne, le rapport du député chrétiendémocrate allemand Arved Deringer est déposé en septembre 1961. Il reprend l'essentiel du dispositif prévu par la Commission : principe d'interdiction, déclaration obligatoire et centralisation du pouvoir de décision à la Commission européenne. Les débats à l'Assemblée s'orientent de manière favorable aux thèses du commissaire allemand. Le 25 octobre 1961 a lieu le vote sur l'avis définitif de l'APE sur le projet de règlement de la Commission. Les socialistes ont massivement voté en faveur du projet de la Commission ${ }^{231}$. L'opposition au projet de la Commission était principalement issue des libéraux français et de quelques démocrates-chrétiens italiens, qui reflétaient en cela les positions de leur gouvernement ${ }^{232}$. Le sénateur français André Armengaud, inscrit au groupe des libéraux, a été particulièrement actif pendant les débats comme il le fut tout au long de l'étude du projet de la Commission par l'Assemblée ${ }^{233}$. Au contraire Fontanet pensait pouvoir influencer l'APE en agissant sur Maurice Faure, dont il est proche ${ }^{234}$. Mais sur un dossier technique comme la politique de la concurrence, seul un spécialiste comme Armengaud peut avoir une influence. De plus, les députés UNR (gaullistes) sont absents lors du vote. Il apparaît clairement qu'aucune stratégie d'influence française par l'APE n'a été conçue au niveau gouvernemental.

Pour la France, le vote de l'APE ne change pas fondamentalement la configuration des débats : l'Assemblée à un rôle simplement consultatif et, comme au Conseil trois pays (France, Italie, Luxembourg) sont opposés à son règlement, von der Groeben sait qu'il ne pourra pas le faire passer, même avec la majorité qualifiée. Le gouvernement français, suite à une réunion tenue le 2 novembre 1961 chez le secrétaire d’État Missoffe - qui a remplacé Fontanet - définit alors une position offensive en vue du Conseil des ministres CEE du 6 novembre $1961^{235}$. Le commissaire sera obligé de soumettre son projet à la discussion de manière inchangée en raison du vote de l'APE. Il devrait être rejeté rapidement, ce qui permettra à la France de faire une contre-proposition de compromis qui

231. ASGCI, 1979.0791, volume 265, document du groupe des libéraux de l'APE, 25 octobre 1961.

232. AHUE, BAC 28/1980, volume 39, folio 106, document S/O 5499/61 du secrétariat de la Commission, 21 octobre 1961.

233. Sybille Hamblocht, « Die Entstehung der Verordnung 17 von 1962 im Rhamen der EWGWettbewerbspolitik », in Europarecht, novembre 2002, p. 890 ; ASGCI, 1979.0791, volume 264, note de Gulphe au SGCI (FM), 28 avril 1961.

234. ACNPF, 72 AS 1504, lettre du 13 mai 1961 d'un expert du CNPF (sans doute Lartisien) : « Communication avec M. Gulphe le 12 mai 1961 ». Gulphe appartient au cabinet de Fontanet.

235. AMAE, RPUE 614, note pour l'ambassadeur, 6 novembre 1961. 
devrait s'imposer naturellement. Les délégués patronaux qui ont participé à cette réunion du 2 novembre 1961 sont plus prudents car si le vote du projet de la Commission ne nécessite que la majorité qualifiée, l'élaboration d'un contreprojet par les représentants des États membres requiert l'unanimité236.

Le déroulement du Conseil CEE du 6 novembre 1961 donne satisfaction aux observateurs français ${ }^{237}$. Il manifeste les profondes divergences entre deux camps constitués chacun de trois pays : la RFA, les Pays-Bas et la Belgique (qui a changé de position depuis le retour des socialistes au pouvoir) étant favorables au projet de la Commission sous réserve de modifications de détails ; la France, 1'Italie et le Luxembourg s'y opposant catégoriquement ${ }^{238}$.

Pourtant l'examen du compte rendu du Conseil montre que la position de la France est moins forte qu'il n'y paraît. D'abord, la France est isolée dans son attaque des futures prérogatives de la Commission européenne ${ }^{239}$. Ensuite, l'Italie ne s'oppose pas au projet de la Commission pour les mêmes raisons que la France. Son argumentation est essentiellement juridique et pas économique ${ }^{240}$. D'autre part, le télex de Boegner reconnaît lui-même que : " Le représentant allemand a rappelé que, pour son pays, l'adoption d'un règlement relatif à la concurrence était indispensable pour permettre le passage à la deuxième étape ». Le passage à la deuxième étape de la période transitoire du traité de Rome doit se faire le premier janvier 1962. Il demande l'unanimité. Même si des clauses sont prévues pour retarder ce passage d'étape, il paraît illogique de le repousser alors que le rythme de mise en place de l'union douanière a été accéléré. À l'occasion de ce passage d'étape, chaque État fait monter la pression en définissant un ensemble de dossiers prioritaires sur lesquels l'intégration européenne devrait absolument avoir avancé faute de quoi le passage d'étape ne sera pas possible. Pour la France, la PAC est devenue à cette date le dossier prioritaire. Si la RFA demande en échange un accord sur la politique de la concurrence, la France pourra difficilement lui refuser.

Même s'il a profité du revirement du gouvernement belge et de l'avis favorable de l'APE, le projet de von der Groeben reste toujours âprement discuté au Conseil. Le CNPF cherche à profiter de ces débats pour lancer une offensive décisive.

236. ACNPF, 72 AS 1504, note pour Villiers du 2 novembre 1961.

237. ASGCI, 1979.0791, volume 265, télex de Boegner au SGCI du 8 novembre 1961.

238. AHUE, BAC 28/1980, volume 39, doc Conseil R/475/61 (RC 21) du 10 novembre 1961.

239. ASGCI, 1979.0791, volume 265, note CEE du 7 septembre 1961.

240. ASGCI 1979.0791, volume 265, procès-verbal de la réunion du Conseil du 6 novembre 1961. 


\section{Le dernier effort du CNPF.}

Lors de la réunion des 21 et 22 novembre 1961, les rapports de force évoluent de manière défavorable car l'Italie rejoint maintenant le camp des défenseurs de la déclaration obligatoire ${ }^{241}$. De plus, les représentants de la Commission font preuve d'une « très grande vivacité, en même temps que de la volonté de ramener constamment à leur projet initial [ce qui] a constitué une entrave très sérieuse aux tentatives de transactions qui auraient pu se réaliser entre les experts $»^{242}$. La Commission rappelle donc constamment son monopole du pouvoir de proposition.

Cela ne décourage pas Lartisien qui envisage une action d'influence à la fois européenne, par l'UNICE, et nationale. Sur le plan européen, il demande une action des milieux économiques pour pousser à la création d'un front de quatre pays qui devraient soutenir une contre-proposition patronale : France, Luxembourg, Italie et Pays-Bas. Lartisien a déjà contacté l'expert néerlandais, qui s'était montré assez favorable aux thèses patronales, pour qu'il se coordonne avec Marcille, l'expert français. À l'échelle nationale, il estime que Villiers devrait s'assurer que le nouveau secrétaire d'État, Missoffe, a bien pris conscience de la gravité de ce problème technique et prendra position dessus.

À la réunion suivante des représentants des six gouvernements, celles des 28 et 29 novembre 1961, tous ces espoirs s'évanouissent. La France est à nouveau isolée avec le Luxembourg car l'expert néerlandais prend finalement une position beaucoup plus proche de celle de la Commission que ce qu'il avait déclaré à l'UNICE ${ }^{243}$. Lartisien dresse un constat d'échec de l'action de la commission des règles de la concurrence. Selon lui, les patronats allemand et même belge (depuis le changement de gouvernement) n'ont aucune influence sur leur gouvernement dans ce domaine. La Confindustria elle-même est obligée de rester prudente dans une « question qui risque d'avoir des prolongements qu'elle redoute sur le plan national », car le débat sur la création d'une politique de la concurrence nationale agite aussi l'Italie. Enfin les délégués néerlandais ont défendu avec leurs experts gouvernementaux une solution de compromis qu'ils ont ensuite abandonnée face à la Commission, alors que les experts français sur les conseils des délégués du CNPF - la soutenaient. Face à ce sentiment de trahison, les représentants du CNPF ont demandé l'annulation de la réunion de décembre 1961 de la commission des règles de concurrence UNICE ${ }^{244}$.

241. ACNPF, 72 AS 1504, note Lartisien pour Villiers sur la réunion des 21-22 novembre 1961. 242. ACNPF, 72 AS 1504, note Lartisien pour Villiers sur la réunion des 21-22 novembre 1961. 243. ACNPF, 72 AS 1504, note Lartisien pour Villiers sur la réunion des 28-29 novembre 1961. 244. ACNPF, 72 AS 1504, note Lartisien pour Villiers sur la réunion des 28-29 novembre 1961. 
L'activisme de l'UNICE sous l'impulsion du CNPF, qui avait été remarqué par l'administration française ${ }^{245}$, se conclut sur un échec : les tentatives de coordination des actions nationales n'ont pas permis de dépasser les divergences gouvernementales. Le gouvernement français est de plus en plus isolé dans son opposition.

\section{Le revirement du gouvernement français.}

Les réunions d'experts de novembre 1961 se sont soldées par un échec pour la France. Au Conseil des ministres spécialisés du 2 décembre 1961, la France tente une nouvelle fois de lancer une contre-proposition mais ne reçoit que le soutien du Luxembourg ${ }^{246}$. Or ces deux pays n'ont pas assez de voix pour s'opposer aux quatre autres pays dans le cas d'un vote à la majorité. La position française évolue sous la pression d'un enjeu plus large, le passage à la deuxième étape. De fait, c'est le Premier ministre Michel Debré qui prend les arbitrages. Dans une note du 6 décembre 1961 au général de Gaulle, Debré évoque comme urgente cette question du « régime des cartels et des ententes » car elle doit être résolue avant la fin de la première étape ${ }^{247}$. L'évolution est nette par rapport aux notes précédentes du 24 octobre 1961 et du 20 novembre 1961 sur le passage d'étape qui ne parlaient pas de la politique de la concurrence ${ }^{248}$. Debré évoque un Conseil des ministres français tenu le 7 décembre 1961 qui doit trancher cette question. Le compte rendu est absent des archives mais il semble bien qu'une position conciliante y ait été définie.

En effet lors de la réunion des experts gouvernementaux des 12 et 13 décembre 1961 , un compromis est trouvé ${ }^{49}$, qui est ensuite adopté par le Conseil ${ }^{250}$. Il reprend l'essentiel du projet de la Commission mais inclut des concessions demandées par la France dans trois domaines. Tout d'abord, les procédures de plainte et de requêtes des entreprises (attestation négative) sont acceptées. Ensuite, la France obtient que les accords d'exclusivité ne soient pas dispensés de notification. Dans ce domaine, la législation française est plus sévère que

245. ASGCI, 1979.0791, article 265, note du SGCI (FM) du 27 novembre 1961.

246. ASGCI, 1979.0791, article 265, télex de Boegner du 4 décembre 1961.

247. AFNSP, 2 DE 30, note de Michel Debré pour Charles de Gaulle, 6 décembre 1961.

248. AFNSP, 2 DE 13, note du 24 octobre 1961 de Michel Debré pour Amanrich et Dupont-Fauville ; note du 20 novembre 1961 de Michel Debré.

249. AHUE, BAC 28/1980, volume 39, note du Conseil R/529/61 du 16 décembre 1961 ; AMAEF, RPUE 608, télex Boegner du 14 décembre 1961; ASGCI, 1979.0791, volume 265, note du SGCI, 16 décembre 1961 ; ASGCI, 1979.0791, volume 265, conseil du 19 décembre 1961, compte rendu de Boegner (REP), 21 décembre 1961.

250. ASGCI, 1979.0791, volume 265, conseil du 19 décembre 1961 : compte rendu de Boegner, 21 décembre 1961. 
celle de ses voisins, ce qui pouvait faire craindre une distorsion de concurrence au bénéfice des distributeurs étrangers. Enfin, la France a réussi à faire progresser l'application de l'article 86. Elle a obtenu, en dépit de l'opposition allemande mais avec le soutien de la Commission, que cette dernière puisse lancer des enquêtes sectorielles destinées à évaluer la présence éventuelle de positions dominantes. La Commission pourra demander des renseignements aux entreprises dans ce cadre.

Ainsi les concessions accordées à la France donnent encore plus de pouvoirs à la Commission, dont l'action pourrait désormais englober les accords d'exclusivité et les positions dominantes. Les six États membres n'arrivent pas à s'entendre pour limiter les prérogatives de la Commission, qui obtient avec le règlement 17/62 de très fortes délégations de souveraineté théoriques.

\section{Le règlement 17/62 : une victoire pour la Commission.}

Le règlement a été adopté en français et en allemand lors de la session du Conseil du 16 décembre 1961, avant que les experts traducteurs ne se réunissent en janvier ${ }^{251}$, pour permettre au Conseil d'adopter la version définitive du règlement lors de sa session du 6 février 1962, sous le nom de « règlement $17 / 62 »$.

Il se fonde très largement sur la conception allemande de la politique de la concurrence. L'article 1 impose sans ambiguïté la doctrine de l'interdiction : toutes les ententes sont interdites jusqu'à la publication d'une décision d'autorisation.

La Commission reçoit de très nombreuses prérogatives. Les articles 4 et 5 organisent le système de la déclaration obligatoire. L'article 9 donne compétence exclusive à la Commission pour appliquer l'article 85 , sous réserve de la consultation d'un comité consultatif (article 10). La Commission a le pouvoir d'exiger des renseignements des entreprises, de procéder à des vérifications, d'adresser des recommandations aux entreprises, de leur imposer des décisions, des amendes et des astreintes (articles 11, 13, 14, 15, 16).

La Commission n'est cependant pas toute puissante. D'une part, un recours à la CJCE est possible. D'autre part, les États sont associés à l'instruction à la fois par une information obligatoire de la Commission et parce que ce sont les administrations nationales qui assurent les vérifications en collaboration avec l'administration communautaire (articles 10, 13 et 14 notamment). Surtout, un comité consultatif en matière d'ententes et de positions dominantes est

251. AHUE, BAC 28/1980, volume 39, note du Conseil, doc 69/62 du 23 janvier 1962. 
constitué (article 10-3). Composé d'un fonctionnaire par État membre, il doit être consulté obligatoirement avant toute décision de la Commission en matière d'autorisation.

Par rapport au projet initial, la Commission a dû à la fois diminuer ses ambitions - en acceptant la création du Comité consultatif - mais a également largement élargi ses prérogatives grâce au marchandage interétatique. Elle a ainsi obtenu, grâce à la France, des procédures supplémentaires de saisine (notamment l'attestation négative), la possibilité de mener des enquêtes sectorielles au titre de l'article 86 et l'inclusion des accords d'exclusivité dans le champ du règlement. L'équilibre initial de la proposition de von der Groeben : partage du pouvoir avec les administrations nationales pour l'instruction, centralisation sur la Commission pour l'information et la décision, est respecté car le Comité consultatif n'a pas, comme son nom l'indique, de pouvoir de décision propre et il est trop petit (un fonctionnaire par pays) pour pouvoir contrôler efficacement un domaine aussi vaste.

Le règlement 17/62 est une large victoire de la Commission, et est interprété comme tel par les observateurs contemporains comme le député européen allemand Arved Deringer ${ }^{252}$. Il note toutefois la lourdeur de la procédure. De même, un professeur de droit italien estime que le règlement 17/62 est «particulièrement compliqué » et aboutira " probablement» à un « engorgement dans le travail de la Commission ${ }^{253} »$. Il souligne néanmoins le succès que représente ce règlement dans la définition d'un droit commun de la concurrence.

Les opposants au règlement sont les plus inquiets. Assez rapidement, l'UNICE dresse un bilan très sombre du règlement 17/62 et de sa capacité d'influence dans la négociation du règlement $17 / 62^{254}$. De son côté, la FIB critique une « réglementation théorique méconnaissant les réalités de la vie économique [qui] ne peut que freiner le développement économique, l'accroissement des échanges, la pénétration des marchés, la rationalisation et la spécialisation ${ }^{255} \gg$.

Les experts français comme le représentant permanent Boegner ou le député André Armengaud soulignent la lourdeur de la solution de l'enregistrement

252. Arved Deringer, «Les règles concernant la concurrence dans le cadre du Marché commun entrent en vigueur », in Revue du Marché commun, 1962-2, p. 83.

253. R. Fracheschelli, «Le premier règlement d'application des articles 85 et 86 du traité de Rome », in Revue du Marché commun, 1962-9, p. 350-351.

254. ACNPF, 72 AS 1544, lettre de Lartisien à Claessens (UNICE), 4 avril 1963 ; ANCPF, 72 AS 450, lettre de la secrétaire générale sur la réunion des présidents UNICE du 15 avril 1963.

255. Fédération des industries belges, L'industrie belge dans la Communauté économique européenne. Une enquête de la FIB sur la situation des secteurs industriels et leurs perspectives d'avenir après quatre ans de Marché commun, 1962, p. 34. 
obligatoire et les difficultés probables que la Commission connaîtra dans son application $^{256}$.

Avec le règlement 17/62, la Commission acquiert un pouvoir formidable de surveillance des structures industrielles européennes qu'aucune autorité nationale ne possédait sur son territoire national car le règlement combine les prérogatives du BKA (déclaration obligatoire et monopole de décision) et de certaines dispositions les plus sévères de la loi française (accords d'exclusivité). Elle va maintenant devoir l'appliquer.

\section{L'IMPOSSIBLE APPLICATION DU RÈGLEMENT 17/62}

L'ampleur même du règlement 17/62 oblige la DG IV à régler deux séries de problèmes. D'une part, elle doit assurer, sur le plan administratif, une mise en œuvre satisfaisante de la procédure de notification et statuer sur ces dernières. D'autre part, elle doit définir une doctrine à la fois juridique et économique sur le type d'entente admissible. Très rapidement, la DG IV est confrontée à des difficultés majeures en raison d'un afflux massif de notifications. Elle subit une véritable crise de confiance en 1963 et 1964, avant de redresser partiellement la situation à partir de la fin 1964.

\section{Le problème de masse : l'afflux des notifications (1962-1964).}

Les notifications des ententes sont au cœur de la centralisation des pouvoirs sur la Commission permise par le règlement 17/62. Dans un premier temps, la DG IV est déçue du nombre trop faible d'accords qui lui parviennent. Elle ne reçoit que 800 notifications au premier novembre 1962, date limite pour les accords regroupant plus de deux entreprises. Ce chiffre est considéré par certains observateurs comme " ridiculement faible » et traduit une volonté des milieux économiques de dissimuler leurs accords, d'autant plus que dans certains secteurs économiques importants (textile, chimie organique, appareils électroménagers) aucune notification n'est parvenue ${ }^{257}$.

La Commission adopte donc dès l'été 1962 un report du délai de notification $^{258}$. Par ailleurs, la DG IV cherche à élargir le champ d'application du règlement 17/62 en particulier envers les accords d'exclusivité, ceux-là même que

256. ASGCI, 1979.0791, volume 265, conseil du 19 décembre 1961 : compte rendu de Boegner, 21 décembre 1961 ; André Armengaud, "La thèse française en matière d'entente ", in Revue du Marché commun, 1962-2, p. 84.

257. AMAE, RPUE 614, note de synthèse de Jean-Marc Boegner (REP), 5 juin 1963.

258. ACNPF, 72 AS 812, note CNPF de Colombier, 12 octobre 1962. 
la France a réussi à inclure dans le règlement ${ }^{259}$. En novembre, la Commission publie des communications sur les accords d'exclusivité et de licence ${ }^{260}$. En décembre 1962, un nouveau règlement est adopté pour offrir aux entreprises ayant conclu des accords d'exclusivité une procédure de notification simplifiée ${ }^{261}$. Ces deux décisions conduisent à un élargissement considérable du champ d'action du règlement 17/62 dans la mesure où les accords d'exclusivité sont très nombreux et étaient dispensés de notification obligatoire dans le règlement $17 / 62^{262}$. Ils n'étaient soumis qu'à une notification facultative.

Dès lors, le risque inverse, celui d'un afflux massif de notifications, pèse sur la Commission. Pour régler ce problème potentiel, le commissaire von der Groeben envisage deux solutions. Tout d'abord, il demande aux États membres des postes supplémentaires ${ }^{263}$. Cependant ces derniers se montrent réticents car la DG IV a déjà obtenu des personnels supplémentaires dans le budget de 1962 mais elle ne les a pas affectés à l'application du règlement $17 / 62^{264}$. Von der Groeben doit finalement renoncer à une partie de ses demandes devant l'opposition du Consei ${ }^{265}$. L'autre solution envisagée par le commissaire allemand est juridique. Il s'agit de permettre à la Commission européenne d'élaborer des exemptions par catégories ${ }^{266}$. Elle déciderait ainsi que certains types d'accords théoriquement soumis à la notification par le règlement 17/62, en seraient finalement exclus car ils seraient considérés comme inoffensifs ou non-prioritaires pour la Commission. La DG IV disposerait alors d'un outil de gestion du flux des notifications très souple. Elle pourrait adapter le stock de notification à ses capacités de traitement. Or les États membres, en particulier la France et la RFA, considèrent que le pouvoir de déclarer des exemptions par catégories relève de leurs prérogatives et pas de celles de la Commission ${ }^{267}$. Cette dernière a reçu par le règlement 17/62 une délégation d'application de l'article 85 de la

259. AMAE, DECE 1260, note MC du 15 janvier 1963.

260. JOCE du 9 novembre 1962.

261. Règlement $\mathrm{n}^{\circ} 153 / 62$ publié au JOCE du 24 décembre 1962.

262. Règlement 17/62, article 4, ACNPF, 72 AS 812, compte rendu du groupe de travail du CIFE, 3-4 janvier 1963.

263. ASCGI, 1979.0791, volume 262, compte rendu de la $12^{\mathrm{e}}$ conférence des experts, 5 et 6 juillet 1962 ; AMINEFI, B 17.679, lettre de Hans von der Groeben à Valéry Giscard d'Estaing, 21 décembre 1962.

264. AMAE, RPUE 189, télex de la REP, 31 mars 1962.

265. AMAE, RPUE 49, compte rendu de la session du Conseil des 30 et 31 mai 1963.

266. ACNPF, 72 AS 1544, note du 15 jullet 1962 sur une rencontre entre des représentants de l'UNICE et Hans von der Groeben.

267. ASGCI, 1979.0791, article 262, compte rendu de la $13^{\mathrm{e}}$ conférence des experts, 22 et 23 novembre 1962. 
part du Conseil qui concerne tous les types d'accords, entre lesquels la DG IV n'est pas autorisée à choisir.

Les délégués français ne sont pas hostiles par principe à la solution des exemptions par catégories mais ils estiment que la Commission doit d'abord dégager des éléments de jurisprudence avant de décider quels sont les accords concernés par ces exemptions ${ }^{268}$. D'autre part sur le plan institutionnel, la Commission ne doit pas recevoir une délégation générale lui permettant de décider seule des exemptions de catégories. Ce travail doit se faire en concertation avec le Conseil ${ }^{269}$. Pour les Français, la Commission a reçu suffisamment de pouvoir avec le règlement 17/62 et elle ne saurait se prévaloir de prérogatives supplémentaires avant d'avoir fait la preuve de son efficacité.

De toute façon, face à un dossier neuf et complexe, la DG IV a du mal à définir une position précise. Le Conseil n'est saisi d'une proposition de règlement autorisant la Commission à décider d'exemptions par catégories qu'en mars $1964^{270}$. Elle est examinée au sein du groupe des questions économiques du COREPER en juin 1964 et donne lieu à une opposition de cinq pays, qui estiment que cette proposition donne encore trop de pouvoirs à la Commission ${ }^{271}$. La situation paraît bloquée pour la DG IV en 1963 et 1964.

\section{La crise de confiance de la DG IV (1963-1964).}

À peine un an après l'adoption du règlement 17/62, la Commission reconnaît officiellement le 15 mars 1963 des retards dans son application en raison de l'affluence de notifications ${ }^{272}$. Alors que von der Groeben avait évalué les notifications à quelques centaines pour $1962^{273}$, la DG IV s'est finalement trouvée au début de 1963 à devoir traiter plus de 36000 notifications ${ }^{274}$. Cela paralyse la Commission qui s'avère incapable de prendre une décision d'application du règlement 17/62 jusqu'en septembre 1964.

268. AMAE, RPUE 609, télex de la REP du 12 novembre 1962.

269. AMAE, RPUE 615, télex de la REP du 27 février 1964 ; note SGCI du 5 mai 1964.

270. AMAE, DECE 1259, proposition de règlement du Conseil transmise par la Commission le 28 février 1964, 2 mars 1964.

271. ASGCI, 1988.0516, article 4, télex de la REP du 10 juin 1964. Seuls les Pays-Bas sont favorables au projet de la Commission.

272. AMAE, REPU 609, lettre de Hallstein au président du Conseil CEE (Schaus), 15 mars 1963.

273. AMAE, RPUE 609, télex de la REP du 19 février 1962. ASGCI, 1990.0641, volume 16, télex de la REP (Boegner) du 3 mars 1962.

274. ASCGI, 1979.0791, volume 262, compte rendu de la $15^{\mathrm{e}}$ conférence d'experts gouvernementaux ; AMAE, RPUE 614, note de synthèse de la REP, 5 juin 1963. 
Cet échec majeur entraîne un discrédit croissant et généralisé de la DG IV auprès de nombreux acteurs. Le patronat européen critique la paralysie de la Commission dès l'été $1963^{275}$. Les entreprises sont doublement désavantagées. D'une part, les accords entre les entreprises existants sont menacés par un contexte juridique très incertain. D'autre part, les ententes futures sont découragées par ces aléas. Les milieux économiques préfèrent donc que le règlement 17/62, auquel ils n'étaient pas favorables, s'applique de manière claire plutôt que de rester dans une incertitude paralysante.

Les gouvernements européens expriment leur insatisfaction également en juin 1963 dans le cadre de la conférence d'experts sur la politique de la concurrence $^{276}$. Même la délégation allemande se montre critique. Elle demande à la Commission de prendre rapidement quelques décisions exemplaires qui feront jurisprudence et permettront de régler un grand nombre de cas.

C'est également en juin 1963 qu'est rédigée la première de quatre notes de synthèse émanant de la représentation permanente et critiquant l'action de la Commission dans ce domaine ${ }^{277}$. Submergée par une masse énorme de notifications, l'administration communautaire n'a pas réussi à les classer et à déterminer des priorités. De plus, les accords les plus dangereux pour l'exercice de la libre concurrence ne se sont pas déclarés. Cela se vérifie dans les archives : l'une des principales entreprises françaises, la CGE (Compagnie générale d'électricité) décide ainsi de ne notifier qu'une petite partie de ses ententes ${ }^{278}$. En dehors de France, Neil Rollings cite également l'exemple de Babcock and Wilcox, qui choisit de ne pas notifier ses ententes de par l'incertitude qui règne sur la réglementation ${ }^{279}$.

La deuxième critique de ces notes françaises porte sur l'organisation des institutions communautaires. Elle s'accentue fortement entre la première série de notes, en juin et août 1963, et la seconde, en février 1964. La critique porte sur tous les échelons : « Le directeur Schumacher est universellement critiqué. Le directeur général Verloren van Themaat ne fait pas confiance à son directeur,

275. ACNPF, compte rendu du comité de l'intégration du CIFE, 24 juin 1963 ; ACNPF, 72 AS 1544, compte rendu de la réunion de l'UNICE, 9 juillet 1963.

276. ASGCI, 1979.0791, volume 262, compte rendu de la $14^{\text {e }}$ conférence d'experts, 11 et 12 juin 1963.

277. AMAE, RPUE 614, note de synthèse de Jean-Marc Boegner (REP) au ministre Couve de Murville, 5 juin 1963, note rédigée par Philippe Cuvillier; ASCGI, 1990.0452, volume 23, note de la REP du 20 août 1963 ; AMAE, RPUE 615, note du diplomate Philippe Cuvillier (REP) du 11 février 1964 ; ASCGI 1988.0516, article 1, note de Jean-Pierre Brunet (REP) du 25 février 1964.

278. Yves Bouvier, La Compagnie générale d'électricité : un grand groupe industriel et l'État. Technologies, hommes et marchés. 1898-1992, thèse, dir. Pascal Griset, Université Paris IV, 2005, p. 514.

279. Neil Rollings, British Business..., op. cit., p. 211-212. 
ne donne aucune impulsion, et est fréquemment court-circuité. [...] Le cabinet de von der Groeben ne fait pas confiance aux services et donne des conseils contradictoires aux commissaires. M. von der Groeben ne fait confiance à personne et semble préférer ne rien faire plutôt que de faire des bêtises. Il redoute, paraît-il, de soumettre des cas à la Commission qui lui poserait des questions indiscrètes sur sa politique générale en matière d'ententes ${ }^{280} »$. S'il est difficile d'évaluer ces jugements lapidaires, les archives laissent entrevoir de nombreuses traces de la gêne éprouvée par von der Groeben au sein du collège des commissaires, car il est fréquemment obligé de s'excuser du retard des travaux. Le point 37 de la réunion du 8 avril 1964 concerne par exemple les « problèmes liés à l'application du règlement $n^{\circ} 17^{281}$ ». Von der Groeben propose trois cas d'application du règlement 17 mais le collège des commissaires lui demande au préalable un exposé général sur la politique qu'il compte suivre en matière $d$ 'application de ce règlement. C'est donc une nouvelle fois sa carence en termes de doctrine économique qui est mise en cause. Trois semaines plus tard, von der Groeben se résout à annoncer qu'il assurera cet exposé en juin ${ }^{282}$. Il est prononcé finalement à la séance du 22 juillet $1964^{283}$. Selon le témoignage de l'un de ses collaborateurs, von der Groeben semble hésiter à prendre des décisions d'application et c'est poussé par son cabinet qu'il prend position sur une première affaire, le cas Grundig-Consten ${ }^{284}$. Il faut noter que l'état de santé de von der Groeben, qui a raté de nombreuses séances de la Commission en 1964 et 1965, n'a pas contribué à faciliter sa tâche ${ }^{285}$. Les problèmes de relations entre la DG IV et les autres services de la Commission sont également confirmés par les documents internes à la CEE, en particulier au secrétariat général ${ }^{286}$.

De plus, la cohésion du groupe des chrétiens-démocrates allemands autour d'une doctrine ordolibérale précise, ambitieuse et dont la pertinence semble être prouvée par le « miracle économique » allemand, a pu entraîner une certaine hybris. Katja Seidel a ainsi trouvé un document interne à la Commission de 1963 qui critique vigoureusement le manque de transparence du processus

280. AMAE, RPUE 615, note du diplomate Philippe Cuvillier (REP) du 11 février 1964.

281. AHUE, procès-verbal spécial de la $268^{\mathrm{e}}$ réunion de la Commission du 8 avril 1964.

282. AHUE, 1964, procès-verbal spécial de la $271^{\mathrm{e}}$ réunion de la Commission du 29 avril 1964.

283. AHUE, procès-verbal de la $282^{\mathrm{e}}$ réunion de la Commission, 22 juillet 1964.

284. Éric Bussière, «La concurrence », in M. Dumoulin (dir.), La Commission européenne, 19581972..., op. cit., p. 318-319, citant le témoignage de Manfred Casparti.

285. AHUE, procès-verbal spécial de la $262^{\mathrm{e}}$ réunion de la Commission, 19 février 1964 ; AHUE, procès-verbal spécial de la $307^{\mathrm{C}}$ réunion de la Commission, 24 février 1965.

286. AHUE, papiers Émile Noël 2409, note H. Étienne pour Émile Noël 14 janvier 1965. 
de décision au sein de la DG IV, et le mépris pour la consultation des experts nationaux et patronaux ${ }^{287}$. Les Français ont déjà critiqué l'organisation interne de la DG IV en y dénonçant le poids trop fort des Allemands aux postes à responsabilité ${ }^{288}$. Par ailleurs, une étude interne à l'administration communautaire datant de la fin des années 1960 souligne le problème de la surreprésentation des Allemands et de l'absence de véritable doctrine économique concrète et pragmatique à la $\mathrm{DG} \mathrm{IV}^{289}$.

Enfin, ces quatre notes de synthèse de la représentation permanente soulignent l'importance de la politique de la concurrence communautaire pour la France. Le diplomate souligne que : « la carence de la Commission gêne notre politique des ententes sur le plan national : en effet, il est rare que les ententes nationales dont nous avons à connaître n'aient pas de prolongement sur le plan international et l'incertitude sur la jurisprudence qui sera retenue pèse sur les décisions de notre Commission technique des ententes. À un moment où le gouvernement favorise le renforcement de la concurrence pour peser sur les prix, nous pouvons avoir intérêt à combattre les accords ou les pratiques qui limitent cette concurrence ${ }^{290} \gg$. La paralysie de la politique de la concurrence communautaire gêne donc le renforcement de la politique de la concurrence française, elle-même guidée moins par la doctrine ordolibérale que par l'objectif macroéconomique de lutte contre l'inflation. Ainsi, le nouveau directeur des Prix souligne en mai 1962 que l'effet positif de l'ouverture extérieure sur les prix est finalement assez limité en raison de la multiplication des ententes internationales qui limitent la concurrence effective ${ }^{291}$. De même, certains services du ministère des Finances plaident toujours pour l'accélération des travaux communautaires sur l'ouverture des marchés publics nationaux aux Six dans le but de diminuer les prix, suscitant l'irritation du ministère de l'Industrie, qui campait sur une position plus restrictive (la demande d'une réciprocité effective $)^{292}$. La France ne se réjouit donc pas de l'échec de l'application d'un règlement qu'elle avait combattu.

287. Katja Seidel, « DG IV... », op. cit., p. 139-141.

288. AMAE, RPUE 246, note sur l'organisation de la DG IV du 29 mars 1963 ; AMAEF, RPUE 609, questions d'André Armengaud, député de l'APE du groupe des libéraux, 4 mars 1964.

289. Jean-Pierre Dubois, Les mécanismes de l'autorité à l'intérieur de la DG de la Concurrence de la Commission des Communautés européennes, mémoire de DES dirigé par Paul Reuter, 1970.

290. AMAE, RPUE 615, note du diplomate Philippe Cuvillier (REP) du 11 février 1964.

291. AN, 540 AP, note de Philippe Huet, directeur général des Prix, 18 mai 1962.

292. La volonté de libéralisation émane de la direction générale des Prix et de la commission centrale des marchés de l'État : AINDUS, 1977.1386, article 54, projet de lettre du ministre (de l'Industrie) au SGCI du 25 octobre 1961 ; projet de lettre au ministre des Finances et des Affaires économiques du 12 septembre 1963. 
Cet échec de la Commission européenne dans un domaine où elle a obtenu de très larges délégations de souveraineté a durablement marqué la France. Ainsi, dans le « décalogue » de janvier 1966, la politique de la concurrence est l'un des domaines explicitement cités dans les notes du Quai d'Orsay où l'institution bruxelloise outrepasse ses prérogatives ${ }^{293}$.

En 1963 et 1964, l'efficacité de la DG IV et du commissaire von der Groeben est donc remise en cause par le patronat, les gouvernements nationaux mais aussi à l'intérieur de la Commission européenne. Universellement critiqués à partir de juin 1963 et au début de 1964, la DG IV et von der Groeben sortent de l'abîme à l'automne 1964 avec le déblocage de dossiers en souffrance.

\section{La sortie de crise (1964-1965).}

À partir de l'automne 1964, deux problèmes récurrents commencent à être réglés progressivement pour l'application de la politique de la concurrence : la première condamnation d'une entente au titre du règlement 17/62 est décidée tandis que la négociation sur les exemptions par catégories se débloque.

Le 23 septembre 1964, la Commission approuve la proposition de von der Groeben d'appliquer pour la première fois le règlement 17/62 dans un sens répressif à une entente ${ }^{294}$. Il s'agit de la célèbre décision "Grundig-Consten » qui condamne le contrat d'exclusivité passé entre le fabriquant Grundig et le distributeur français Consten, considéré comme trop restrictif dans la protection territoriale qu'il accorde ${ }^{295}$. Les commissaires européens mais aussi les experts gouvernementaux félicitent la DG IV pour cette décision ${ }^{296}$. Les milieux économiques sont évidemment moins enthousiastes : Lartisien à l'UNICE conteste le bien-fondé juridique et les justifications économiques de cette décision ${ }^{297}$.

Cette décision est fondamentale car elle fixe la jurisprudence de la Commission européenne pour les accords d'exclusivité qui constituent les $2 / 3$ des dossiers en souffrance. Elle contribue à définir l'étendue des clauses d'exclusivité et à signaler celles qui ne sont pas acceptables par la Commission. Elle fait partie des dossiers les plus urgents car il s'agissait d'une procédure engagée par la Cour d'appel de Paris, qui avait décidé en janvier 1963 de surseoir à statuer sur

293. AMAE, DECE 1115, folio 78, note EC, 14 janvier 1966.

294. AHUE, procès-verbal de la $286^{\mathrm{e}}$ réunion de la Commission, 23 septembre 1964.

295. JOCE du 20 octobre 1964, décision de la Commission du 23 septembre 1964, 64/566/ CEE.

296. AMAE, RPUE 615 , compte rendu de la $16^{\circ}$ conférence des experts gouvernementaux du 10 novembre 1964.

297. ACNPF, 72 AS 1544, exposé de Lartisien à la réunion UNICE du 18 novembre 1964. 
cette question jusqu'au jugement de la Commission. Celui-ci intervient donc près de 18 mois après que la procédure nationale a été interrompue. Après la décision " Grundig-Consten », tout n'est d'ailleurs pas réglé pour la DG IV. Dans les années qui suivent, les sentences restent encore très rares. Seules quatre décisions sont prises entre « Grundig-Consten » et la fin de la période transitoire du Marché commun industriel, le premier juillet $1968^{298}$.

Par ailleurs, un mois après la décision « Grundig-Consten », la négociation sur les exemptions par catégories se débloque. Certes la Commission campe sur sa position initiale mais, au COREPER, les États membres parviennent à se mettre d'accord sur un contre-projet grâce à des concessions françaises et au recours à la majorité qualifiée qui permet d'isoler le représentant italien ${ }^{299}$. Le contre-projet des États membres réduit les prérogatives de la Commission en obligeant celle-ci à revenir devant le Conseil à chaque fois qu'elle souhaite obtenir une exemption pour une catégorie précise d'entente ${ }^{300}$. Le règlement ne lui donnerait donc qu'une faculté théorique d'exemption, à charge pour elle de l'appliquer au cas par cas en demandant l'accord du Conseil.

La Commission accepte finalement la contre-proposition des cinq États membres, qui revient au Conseil le 2 février $1965^{301}$. Elle devient le règlement 19/65, qui reconnaît d'ailleurs explicitement le problème de masse induit par les notifications ${ }^{302}$. Ce règlement accorde à la Commission le pouvoir d'établir des règlements d'exemptions par catégories qu'elle doit proposer au Conseil. Le travail n'est donc pas terminé pour la DG IV. En février 1966 par exemple, la France s'oppose au projet de règlement d'exemptions de la Commission car la jurisprudence est encore insuffisante ${ }^{303}$. Le règlement exemptant certains types d'accords d'exclusivité est finalement voté par le Conseil le 22 mars $1967^{304}$, soit près de cinq années après avoir été imaginé par von der Groeben en 1962.

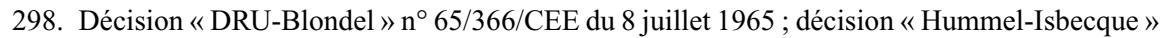
$\mathrm{n}^{\circ}$ 65/426/CEE du 17 septembre 1965 ; décision « Maison Jallate-Hans Voss » $n^{\circ} 66 / 5 /$ CEE du 17 décembre 1965 ; décision «Transocean Marine Paint Aossciation »n ${ }^{\circ}$ 67/454/CEE du 27 juin 1967.

299. AMAE, RPUE 615, télex de Boegner du 30 octobre 1964.

300. AMAE, DECE 1260, note du Conseil CEE du 7 décembre 1964.

301. ASGCI 1988.0516, volume 4, note sur le Conseil CEE du 2 février 1965.

302. Règlement 19/65 du 2 mars 1965, JOCE du 6 mars 1965, $3^{\mathrm{e}}$ considérant.

303. AMAE, RPUE 615, télex Dromer (SGCI) du 9 février 1966; ASGCI, 1979.0791, volume 266, procès-verbal de la $9^{\circ}$ réunion du Comité consultatif créé en application du règlement 17/62, 10 et 11 novembre 1966.

304. Règlement $n^{\circ}$ 67/67 du 22 mars 1967. 
D'autres solutions de réformes plus radicales encore avaient été évoquées. Ainsi le gouvernement allemand avait envisagé de donner à la DG IV une autonomie administrative par rapport à la Commission ${ }^{305}$. Elle pourrait ainsi décider sur les cas les moins problématiques, laissant à l'appréciation du collège des commissaires les seules affaires sensibles. Cette vision se rapproche des réflexions du président Hallstein sur la « décentralisation » de certains services de la Commission pour décharger le collège des commissaires des décisions les moins importantes ${ }^{306}$. Ces réflexions sont menées dans le contexte de la négociation du traité de fusion des exécutifs de 1965. Elles n'aboutissent pas mais traduisent la force du modèle ordolibéral allemand, où le BKA est indépendant du gouvernement. En effet le ministère de l'économie allemand dispose d'une capacité d'intervention car il peut autoriser des accords interdits et donner des instructions à caractère général au BKA mais cette prérogative n'a été que très rarement utilisée ${ }^{307}$. Sur le long terme, cette inclination ordolibérale allemande persiste car elle se retrouve dans le débat sur la réforme du contrôle communautaire des fusions menée dans les années 1990, lors duquel le gouvernement allemand a plaidé de nouveau pour la création d'un office indépendant de la Commission ${ }^{308}$. Les débats des années 1960 influencent donc les préférences de long terme des acteurs communautaires.

Les premières décisions de la Commission européenne ainsi que l'adoption de règlements d'exemptions par catégories ont permis à la DG IV de sortir de la phase aiguë de la crise mais n'ont pas réglé le problème de fond : aucune doctrine économique pragmatique guidant la politique de la concurrence communautaire n'existe encore.

\section{CONCLUSION : SUCCÈS ET LIMITES DU PROJET D'EUROPE ORDOLIBÉRALE}

Le succès remporté par la Commission européenne dans la négociation du règlement 17/62 s'explique par la division de ses opposants et son habileté

305. ASGCI, 1990.0638, volume 50, note MAE du 13 février 1964 ; AMAE, POW 3, folio 184, note d'Olivier Wormser, 27 mai 1964.

306. AHUE, EN 313, note PB/64/25, 27 janvier 1964.

307. David Gerber, Law and Competition..., op. cit., p. 278 ; Jean François-Poncet, La politique économique de l'Allemagne occidentale, Sirey, Paris, 1970, p. 169.

308. Michelle Cini, Lee Mc Gowan, Competition Policy in the European Union, Macmillan Press, Londres, 1998, p. 132. 
tactique, qui lui permettent de mettre en œuvre une politique à la fois ordolibérale et néofonctionnaliste. Son échec ne doit pas masquer le retard des réflexions françaises ni la dynamique communautaire du système institutionnel de la CEE révélé par ces négociations.

\section{A. LA DIVISION DES OPPOSANTS}

L'une des principales explications du succès de la Commission dans la négociation du règlement 17/62 est la division de ses opposants.

Les milieux économiques, tout d'abord, ont pâti du manque de coordination entre l'UNICE et la CCI, en dépit du fait que de nombreux experts étaient communs aux deux organisations. Un décalage profond s'est manifesté entre une UNICE prudente voire inaudible et une CCI plus volontaire et moins hostile aux projets de la Commission, peut-être en raison de la présence de représentants extérieurs aux Six ou de l'influence de grandes entreprises qui étaient avant tout attachés à une régulation commune à l'échelle de la CEE. Par ailleurs, plusieurs modèles d'Europe organisée s'expriment, eux-mêmes révélateurs de structures institutionnelles et mentales nationales. Les Français défendent les ententes tandis que les Allemands se préoccupent surtout des concentrations.

La dernière source de division tient aux rapports avec les pouvoirs politiques. Les capacités d'influence sont très variables. La FIB dispose de bons relais dans le gouvernement belge mais le retour des socialistes au pouvoir mine sa capacité d'influence. Le CNPF semble avoir une certaine facilité à approcher les responsables nationaux et Lartisien s'impose même comme l'un des principaux conseillers de Fontanet. Mais les deux acteurs sont parfois en opposition comme sur la politique des prix : le CNPF veut se servir de la CEE pour l'atténuer, le gouvernement français pour diffuser son modèle.

Les États membres sont également divisés dans leur opposition. Sur le plan institutionnel, la France est le seul État à s'attaquer aussi frontalement à la volonté de la Commission de centraliser le pouvoir de décision. La Belgique et le Luxembourg concentrent leurs critiques sur le système de la déclaration obligatoire. L'Italie développe une argumentation exclusivement juridique qui l'isole dans les réunions.

Au contraire la Commission a pu compter sur le soutien indéfectible, construit et argumenté des autorités allemandes, soutenues la plupart du temps par les Hollandais. Müller-Armack a constamment supporté les ambitions communautaires, ce qui correspond à son engagement pour l'ordolibéralisme. Cette division des opposants a permis à la Commission européenne de faire jouer le système institutionnel communautaire en sa faveur. 


\section{B. LA COMMISSION EUROPÉENNE \\ AU CEEUR DU SYSTÈME INSTITUTIONNEL COMMUNAUTAIRE}

Lors de la négociation du règlement 17/62, von der Groeben a réussi à imposer les priorités de la Commission en utilisant une stratégie en trois temps. Tout d'abord, il endort et divise les experts nationaux et patronaux avec des réunions multiples de 1958 à l'été 1960, associées à des opérations de promotion comme le colloque de Caen de 1959. Puis, il impose son projet de proposition de règlement à l'automne 1960 de manière très audacieuse. Il utilise pour cela des arguments politiques, en lançant des consultations sur la base de son projet avec de multiples acteurs, et des arguments institutionnels : la consultation de l'APE est nécessaire avant toute poursuite de la discussion. Ayant ensuite obtenu le soutien de l'APE et du CES, il revient devant le Conseil en 1961 en position de force, malgré les illusions françaises. La proposition de la Commission conserve un rôle central et bénéficie même de surenchères de dernière minute pour obtenir l'assentiment français.

Les milieux patronaux ont échoué dans leur volonté d'influencer la négociation en raison de leur division mais aussi parce qu'ils ont adopté une stratégie d'influence essentiellement nationale. Leur principale cible reste les gouvernements nationaux, donc le Conseil des ministres. Or c'est bien la DG IV qui a élaboré la proposition et le collège des commissaires qui l'a accepté. Elle a, d'autre part, reçu le soutien décisif de l'APE qui n'a fait l'objet d'aucune tentative d'influence véritablement coordonnée de la part des milieux patronaux ou administratifs français.

Finalement, von der Groeben a véritablement profité d'un système de négociation communautaire qui repose sur trois éléments : la Commission bénéfice du monopole du pouvoir de proposition, sauf contre-proposition des États membres à l'unanimité ; l'avis de l'APE a un poids politique important même s'il n'est que consultatif; le vote au Conseil se fait à la majorité qualifiée ce qui interdit tout veto. Les Français, aussi bien au CNPF que dans l'administration, n'ont pas compris que le travail d'influence se fait avant le vote définitif au Conseil et pas à ce dernier moment. Ils restent dans la logique du package deal intergouvernemental. Or cette dynamique a certes joué son rôle dans le règlement 17/62 - avec la négociation sur le passage à la deuxième étape-, mais uniquement à l'extrême fin, alors que les rapports de force étaient déjà fixés. Si la France ne s'était pas ralliée au projet de la Commission, son opposition aurait été circonscrite par le vote à la majorité.

Après 1962, les difficultés de la Commission provoquent un rééquilibrage de l'autorité politique au sein du système communautaire vers le Conseil. La 
négociation sur les exemptions par catégories s'est traduite par l'adoption du compromis déterminé par les États-nations selon une procédure communautaire, car ils ont voté à la majorité en isolant l'Italie. On ne peut donc pas parler d'une revanche des États membres de manière individuelle mais d'un retour en force des États membres collectivement, à travers leurs institutions communautaires, Conseil et COREPER.

Enfin, le développement d'une politique commune aussi complexe et technique que la politique de la concurrence a légitimé la montée en puissance d'institutions perçues au départ comme secondaires mais qui se sont affirmées comme des lieux de rencontre irremplaçables entre l'expertise technique et l'intérêt politique. Le COREPER a joué ce rôle auprès du Conseil et l'APE a réussi à s'imposer dans la négociation du règlement 17/62 grâce à la compétence de certains de ses membres comme l'Allemand Deringer.

La politique de la concurrence a permis à un système institutionnel véritablement communautaire - mais pas entièrement supranational car les intérêts nationaux y sont très présents - de s'exprimer. Elle a démontré la capacité d'entraînement de la Commission autour d'un projet ordolibéral et néofonctionnaliste très ambitieux.

\section{AMBITION ET ÉCHEC \\ D’UN PROJET ORDOLIBÉRAL NÉOFONCTIONNALISTE}

Si von der Groeben a fait preuve d'une grande habilité tactique dans la négociation, il a aussi pu s'appuyer sur une équipe soudée autour d'une doctrine précise, l'ordolibéralisme, ce qui est un atout majeur dans un domaine neuf comme la politique de la concurrence.

Le règlement 17/62 impose une approche très juridique qui suppose une neutralité des pouvoirs publics face aux acteurs économiques. L'ordolibéralisme se perçoit aussi dans la procédure de la déclaration obligatoire.

La politique de la concurrence s'impose finalement comme l'un des domaines d'intervention de la Commission les plus supranationaux. En effet, pour la PAC la Commission doit s'accommoder de négociations périodiques tendues entre les États membres tant pour la fixation des prix que pour le budget, mais aussi de leur présence au sein des comités de gestion ${ }^{309}$. Quant à la politique commerciale extérieure, si la Commission exprime la position commune des Six, cette

309. Ann-Christina Knudsen, Farmers on Welfare..., op. cit., p. 191. 
dernière est définie suivant une logique intergouvernementale et l'institution bruxelloise reste sous la surveillance constante du comité de l'article $111^{310}$.

$\mathrm{Au}$ contraire, la Commission a le monopole de l'information et du pouvoir de décision en matière de concurrence. L'enregistrement obligatoire permet d'obtenir des informations que les autorités nationales n'avaient pas ou ne souhaitaient pas fournir. Le monopole de la décision assure une application homogène dans tous les pays de la CEE. C'est donc au nom d'arguments techniques que la délégation de souveraineté a été justifiée et acceptée, suivant exactement le principe de la logique néofonctionnaliste. De plus, le transfert de souveraineté a été obtenu par une méthode progressive, la négociation du règlement 17/62 et ses multiples consultations, et pas par un accord politique majeur - du type traité - qui témoignerait d'une logique plus fédéraliste, ni par un compromis entre les États membres, qui s'apparenterait à une méthode intergouvernementale. Comme il est impossible d'appliquer la doctrine ordolibérale à la lettre, en créant une autorité administrative indépendante (comme le BKA allemand) qui risquerait d'être dépourvue de toute autorité, la centralisation sur la Commission est le gage de l'efficacité institutionnelle. Elle est d'ailleurs soutenue par une partie des milieux économiques, en conformité avec la dynamique du shift of loyalty (le transfert de légitimité des milieux économiques des autorités nationales aux autorités supranationales) décrite par les néofonctionnalistes.

Les difficultés dans l'application du règlement 17/62 témoignent du caractère trop théorique de cette double ambition ordolibérale et néofonctionnaliste dans le contexte de la période 1958-1965. Sur le plan doctrinal, l'ordolibéralisme n'avait pas fait ses preuves car la politique de la concurrence n'était appliquée que depuis 1958 en RFA. La situation à l'échelle européenne étant particulièrement complexe, en raison d'expériences nationales en la matière à la fois embryonnaires et contrastées, il a été extrêmement difficile de transcrire la doctrine théorique en critères d'application concrets.

Par ailleurs le système institutionnel communautaire lui-même était peut-être trop faible pour supporter le système du règlement 17/62. De plus, comme le règlement 17/62 devait prendre en compte les souhaits de nombreux pays, son domaine de compétence s'est étendu bien au-delà de ce que l'administration communautaire pouvait traiter. C'est tout le paradoxe des accords de distribution exclusive, inclus dans le règlement pour satisfaire un de ses opposants, la France, et qui contribuent à en paralyser l'application. Si von der Groben et la DG IV ont profité d'un système communautaire décentralisé pendant la négociation du

310. Lucia Coppolaro, Trade and Politic across the Atlantic..., op. cit., p. 423-424. 
règlement 17/62, par le recours à des réunions d'experts, à l'APE et au CES, ils n'ont pas su s'adapter aux exigences du système supranational centralisé qu'ils ont fondé. Dès lors le shift of loyalty décrit par les néofonctionnalistes ne s'est pas poursuivi en raison de l'inefficacité de la Commission. La négociation du règlement 17/62 a montré que les milieux économiques réagissent encore essentiellement selon des logiques nationales, sauf peut-être quelques grandes entreprises multinationales qui s'expriment à la CCI selon des modalités voisines de celles reprises dans les années 1980 autour de l'European Round Table (ERT).

L'Europe ordolibérale représente donc clairement l'échec d'un projet néofonctionnaliste. La vigueur de ce projet européen met toutefois en valeur, en creux, la vision française de la politique de la concurrence.

\section{LA DÉFINITION TARDIVE D’UNE APPROCHE FRANÇAISE DE LA POLITIQUE DE LA CONCURRENCE}

La France n'avait manifestement pas prévu l'émergence de cette Europe ordolibérale. Après avoir constaté l'activisme de la Commission en 1958 grâce au dossier de la ZLE, Paris estimait certainement que la Commission allait rentrer dans le rang avec la restauration de la puissance française permise par le plan Rueff. La réaction des autorités françaises montre que le gouvernement n'avait pas véritablement défini de projet d'intégration économique européenne au-delà de son soutien à une libéralisation progressive et régulée de son économie. Les doctrines ordolibérales restaient très largement inconnues et le système institutionnel communautaire n'a pas été bien utilisé. Le poids des États membres a été survalorisé par rapport à celui du Conseil pris collectivement, de la Commission ou encore de l'APE. La définition et la coordination des positions au sein des réunions d'experts laissaient à désirer. Aucun ministre ne s'est sérieusement impliqué sauf Jeanneney, qui n'était pas chargé directement du dossier.

De plus, les décideurs français sont divisés. D’un côté, ils souhaitent une politique de la concurrence communautaire forte, pour lutter contre l'inflation, pour ne pas voir ses industriels discriminés par une législation des prix trop sévère, et pour surveiller les entreprises des pays étrangers. D'un autre côté, ils s'opposent à la doctrine économique et institutionnelle de la Commission. Pour les Français, la CEE doit servir à harmoniser les politiques publiques nationales pour éviter les distorsions de concurrence les plus flagrantes, comme des aides massives ou des ententes restreignant les échanges. Dans ce cadre, c'est une action communautaire reposant sur la concertation des États membres mais avec l'arbitrage et l'expertise indispensable de la Commission qui a la faveur de la 
France. Il s'agit d'un projet à la fois intergouvernemental et communautaire, qui reconnaît à la Commission européenne une fonction d'arbitre et aux institutions communautaires - Commission et Conseil - la possibilité d'imposer une décision à un État récalcitrant. Cette Europe-arbitre doit assurer une régulation forte et communautaire - mais pas supranationale - de l'ouverture des marchés.

Cette approche française de l'intégration économique européenne se manifeste de manière plus ambitieuse avec les projets d'Europe organisée défendus par le commissaire français Robert Marjolin. 


\section{CHAPITRE VI}

\section{L'EUROPE « ORGANISÉE » DE MARJOLIN}

Pour compléter le développement de l'Europe-arbitre, celle de la libération régulée des échanges et de la politique de la concurrence, le commissaire français Robert Marjolin développe des projets d'Europe organisée plus volontariste. Pour assurer une véritable fusion des économies des Six, il est nécessaire selon lui de coordonner l'action des principaux acteurs économiques, et en premier lieu les interventions publiques, qu'elles soient nationales ou communautaires. Son action est fondée sur deux piliers, la coordination des politiques économiques à moyen terme - qui se rapproche de la planification indicative, et la coordination des politiques conjoncturelles et monétaires. Ces deux projets ont été développés en parallèle, principalement entre 1962 et 1965. Leur promotion suscite un conflit au sein de la Commission, d'abord entre deux conceptions de l'Europe économique, puis entre deux projets politiques, juste avant la crise de la chaise vide. Raymond Barre, le successeur de Marjolin, poursuit cette ambition principalement dans sa seconde dimension au début de son mandat à la Commission européenne.

\section{LA COORDINATION DES POLITIQUES ÉCONOMIQUES À MOYEN TERME}

Nommé à la Commission européenne en 1958, le vice-président français s'appuie sur une expérience et une autorité importante dans les dossiers économiques européens. Cela lui permet de lancer un ambitieux projet d'adaptation à l'échelle européenne des méthodes de la planification indicative française en deux temps : d'abord en constituant progressivement un réseau de planificateurs européens, ensuite en développant de manière institutionnelle la " politique économique à moyen terme ».

\section{A. LA DOCTRINE ÉCONOMIQUE ET EUROPÉENNE DU COMMISSAIRE ROBERT MARJOLIN}

Professeur d'économie, ancien haut fonctionnaire français et européen, le commissaire français Robert Marjolin se caractérise par sa séduction pour les 
idées planificatrices, sa souplesse doctrinale en matière économique et son engagement européen.

Dès les années trente, le futur commissaire européen a appartenu à des groupes planistes ${ }^{1}$, en particulier Révolution constructive ${ }^{2}$. En 1935, il défend le principe des grands travaux et de la nécessité de mobiliser l'épargne au profit de l'investissement productif ${ }^{3}$. Dès 1937, il lit la Théorie générale de Keynes, sortie en anglais en $1936^{4}$. Dans sa thèse, soutenue en 1940, il se livre à « un examen - globalement très favorable - des théories de Keynes » selon Pierre Rosanvallon qui en fait un « pionnier du keynésianisme ${ }^{5}$ ». En 1944, Marjolin devient directeur de la DREE puis il fait partie de la première équipe du commissariat au Plan, celle qui définit la planification indicative française, comme commissaire au plan adjoint (1946-1948) ${ }^{6}$.

Cependant, Marjolin n'a rien du planificateur doctrinaire. Dans les années trente, s'il participe au groupe Révolution constructive, il devient également le secrétaire de Charles Rist, un économiste néoclassique, et participe au colloque Walter Lippmann de 1938 qui est à l'origine du courant néolibéral ${ }^{7}$. De même, lors de ses expériences en cabinet ministériel auprès de Léon Blum en 1936 et de Christian Pineau en 1956, il n'hésite pas à critiquer les aspects trop dispendieux des politiques socialistes. En 1936 par exemple, il met en cause le protectionnisme $^{8}$, puis la loi des 40 heures et la surévaluation du franc ${ }^{9}$.

Refusant tout engagement doctrinal exclusif, Marjolin paraît séduit par le pragmatisme des Anglo-Saxons. Il effectue un séjour à Yale au début des années 1930 et en revient avec un livre sur le syndicalisme américain ${ }^{10}$. Il est en

1. Philippe Mioche, Le plan Monnet, genèse et élaboration, 1941-1947, PUPS, Paris, 1987, p. 172.

2. Stéphane Clouet, De la rénovation à l'utopie socialiste. Révolution constructive, un groupe d'intellectuels socialistes des années 1930, Presses universitaires de Nancy, Nancy, 1991, p. 29-30; Miguel Karm, L'Europe à l'économie du politique. Les contributions des premiers néolibéraux aux projets de gouvernance économique de l'Europe, thèse Paris II, dir. P. Raynaud, 2005, p. 810-826.

3. Michel Margairaz, L'État, les finances et l'économie. Histoire d'une conversion, 1932-1952, Comité pour l'histoire économique et financière de la France, Paris, p. 187.

4. Pierre Rosanvallon, «Histoire des idées keynésiennes en France », in Revue française d'économie, vol. $2, \mathrm{n}^{\circ} 2,1987$, p. 30 .

5. P. Rosanvallon, « Histoire des idées keynésiennes... », op. cit., p. 30 ; Richard Arena, « Les économistes français en $1950 »$, in Revue économique, 2000, vol. 51, n 5, p. 996-997.

6. P. Mioche, Le plan Monnet..., op. cit., p. 88 et 97.

7. F. Denord, Néolibéralisme version française..., op. cit., p. 118-119.

8. M. Margairaz, L'État, les finances et l'économie..., op. cit., p. 199.

9. Robert Marjolin, Le travail d'une vie..., op. cit., p. 69 ; partiellement confirmé in M. Margairaz, L'État, les finances et l'économie..., op. cit., p. 224.

10. Robert Marjolin, L'évolution du syndicalisme aux États-Unis : de Washington à Roosevelt, F. Alcan, Paris, 1936. 
contact avec les économistes anglo-saxons dès l'avant-guerre, pour les besoins de sa thèse, et approfondit ses relations pendant la guerre ${ }^{11}$. Son engagement socialiste et planiste apparaît compatible avec un grand pragmatisme. Marjolin s'avoue d'ailleurs moins convaincu par Marx que par les socialistes français prémarxistes comme Proudhon ${ }^{12}$.

Enfin, Robert Marjolin est guidé par un puissant engagement européen. Il est séduit par le modèle américain de grand marché et son expérience de la guerre l'amène naturellement à défendre la construction européenne. Dès 1948, lors des discussions sur la création de la future OECE, Robert Marjolin avait parlé de « supranationalité ${ }^{13}$ ». Après avoir participé aux négociations de l'OECE, il en devient le premier secrétaire général (1948-1955). Il y a défendu un projet de coordination étroite des politiques économiques sans succès ${ }^{14}$. Il est déçu par sa fonction à l'OECE à partir de 1952-1953 car les Britanniques refusaient de donner plus de prérogatives économiques à cette institution ${ }^{15}$. La CEE peut représenter l'aboutissement de ce qu'il avait toujours appelé de ses vœux, c'està-dire une organisation européenne dotée de pouvoirs véritables, pouvant mettre en œuvre une intégration en profondeur des économies européennes. Marjolin n'est cependant pas un fédéraliste militant et radical. Lorsqu'il devient commissaire européen, en 1958, il loue d'ailleurs l'expérience de l'OECE, qui a permis, malgré des institutions intergouvernementales, d'importantes réalisations au début de son existence grâce à l'existence d'un fort consensus politique, alors même que la Haute Autorité de la CECA n'a pas réussi à exploiter tout le potentiel supranational du traité de Paris ${ }^{16}$.

Robert Marjolin a eu un parcours assez proche de celui de Jean Monnet. Comme lui, c'est un personnage atypique qui est devenu haut fonctionnaire sans être passé par les grands corps. Leurs parcours initiaux sont cependant contrastés : fils d'un producteur de Cognac, Monnet parcourt le monde dès l'adolescence et se forme en autodidacte. Au contraire Marjolin est d'origine modeste et commence à travailler à 14 ans. Il reprend ses études sur le tard, sans avoir passé le baccalauréat, et finit par devenir un véritable intellectuel,

11. R. Marjolin, Le travail d'une vie..., op. cit., p. 52 et p. 118.

12. R. Marjolin, Le travail d'une vie..., op. cit., p. 36 et p. 54-56.

13. G. Bossuat, La France, l'aide américaine... op. cit., p. 191.

14. G. Bossuat, La France, l'aide américaine... op. cit., p. 643.

15. R. Marjolin, Le travail d'une vie..., op. cit., p. 245-246; Wendy Asbeek Bruce, Tariffs, trade and European integration, 1947-1957 : from study group to Common Market, St Martin Press, New York, 1997, p. 107.

16. Robert Marjolin, «Coopération intergouvernementale et autorités supranationales », in Revue économique, 1958, vol 9, $\mathrm{n}^{\circ} 2$, p. 267-271. 
se liant avec les philosophes Raymond Aron et Alexandre Kojève ${ }^{17}$ et obtenant l'agrégation d'économie. Les parcours de Marjolin et de Monnet se sont croisés à plusieurs reprises. Le premier a été l'adjoint du second, d'ailleurs plus âgé de 23 ans, lors de plusieurs missions menées pendant la guerre puis au commissariat au Plan. Dans le leadership pour l'application de l'intégration européenne, un véritable chassé-croisé se produit entre les deux hommes : Marjolin prend l'ascendant en exerçant un magistère actif au poste de secrétaire général de l'OECE. Monnet accède ensuite à la présidence de la Haute Autorité de la CECA en 1952. Quand il quitte la Haute Autorité en 1955, il ne parvient pas à retrouver de poste officiel alors que Marjolin pénètre bientôt au cœur de l'appareil d'État au cabinet de Christian Pineau à partir de 1956. Jean Monnet est alors âgé de 70 ans et se concentre, au sein du Comité d'action pour les États-Unis d'Europe (CAEUE), essentiellement sur des dossiers politiques comme l'Euratom ou le plan Fouchet. Il n'a qu'une influence limitée sur l'évolution de la CEE alors que Marjolin devient vice-président de la Commission européenne. Lorsqu'il cède la place à la fin des années soixante, Monnet retrouve paradoxalement une certaine influence dans la construction européenne vers 1969-1974 (dans les dossiers de l'Union monétaire puis du Conseil européen), alors que Marjolin n'occupe plus de fonction de premier plan.

Lorsqu'il arrive à la Commission européenne en 1958, Robert Marjolin profite d'une expérience qui lui assure compétence, autorité et réseaux de relations nécessaires pour développer des projets volontaristes de coordination des politiques économiques.

\section{B. LA CONSTITUTION D'UN RÉSEAU DE PROMOTION DE LA PROGRAMMATION EUROPÉENNE}

Afin d'instaurer une coordination des politiques économiques efficace et volontariste, Marjolin reprend certains éléments de la planification indicative française, relancée à l'époque, pour promouvoir un projet de " programmation européenne ». Il se constitue progressivement un réseau de planificateur européens, sur lequel il s'appuie pour promouvoir plus largement ses idées.

\section{Un contexte favorable : la relance de la planification indicative.}

La planification indicative française repose sur l'élaboration d'un document unique qui définit les grandes orientations de l'évolution économique du pays

17. R. Marjolin, Le travail d'une vie..., op. cit., p. 56-57. 
sur cinq années, et ce d'une manière indicative et non impérative comme la planification soviétique. Elle est mise en œuvre par le commissariat au Plan, créé en 1946 comme une administration de mission, peu nombreuse, et dirigée par un personnage atypique, Jean Monnet. La planification indicative s'inscrit à la fois dans des logiques de long terme (la tradition interventionniste de l'État français), de moyen terme (l'influence de l'idée de planification depuis la crise de 1929, y compris sous Vichy) et de court terme (les nécessités de la reconstruction $)^{18}$. Le premier plan de 1947-1953 est particulièrement important car il doit répartir des ressources rares entre des secteurs prioritaires peu nombreux dans un pays en pleine reconstruction. Avec la normalisation de la situation économique française, la planification perd en importance avant d'être relancée, en 1961, par le général de Gaulle et Michel Debré ${ }^{19}$. Le quatrième plan (1962-1965) est ainsi beaucoup plus ambitieux. Sur le plan social et sous l'influence notamment de Jacques Delors ${ }^{20}$, il entend limiter la progression de la consommation privée au profit des investissements collectifs (santé, éducation, urbanisme). De plus, la thématique de la «planification démocratique » se développe ${ }^{21}$. Afin de dépasser le caractère technocratique du Plan, son processus d'élaboration doit s'ouvrir et acquérir un caractère public pour qu'une véritable démocratie sociale soit créée. Le Plan est d'ailleurs un document politique car il est adopté par le gouvernement après consultation de l'Assemblée et du Sénat. Enfin le IV $V^{\mathbb{C}}$ plan inclut des objectifs de promotion de la politique des revenus, qui s'est particulièrement développée après la grève des mineurs de 1963. La politique des revenus avait des objectifs sociaux (meilleure redistribution des revenus, tendre vers l'égalité dans leur progression) et économiques (adapter les hausses de salaires aux gains de productivité).

Relancée au début des années 1960, la planification indicative française est à son apogée entre 1961 et 1965, lorsque Pierre Massé en est le commissaire général (1959-1965). L'intérêt du Plan réside pour Massé dans son processus de

18. Jean Bouvier, « Sur la politique économique en 1944-1946 », in La libération de la France, Éditions du CNRS, Paris, 1976, p. 853 ; P. Mioche, Le plan Monnet..., op. cit., p. 277 ; Henry Rousso, «Introduction : pour une histoire du Plan », in Henry Rousso (dir.), De Monnet à Massé. Enjeux politiques et objectifs économiques dans le cadre des quatre premiers Plans (1946-1965), CNRS Éditions, Paris, 1986, p. 9.

19. Gérard Pogorel, «Le Plan dans le débat politique français, (1946-1965) », in H. Rousso (dir.), De Monnet à Massé..., op. cit., p. 186-187.

20. Né en 1925, après une carrière à la Banque de France, il devient chef du service des affaires sociales au commissariat général au Plan de 1962 à 1969.

21. Philippe Mioche, "Syndicats et CNPF dans le plan : l'amorce d'un consensus », in Henry Rousso (dir.), La planification en crise (1965-1985), CNRS Éditions, Paris, 1987, p. 89-91 ; Sylvain Schirmann, «CFDT et organisation des marchés européens au cours des années 1960 », in É. Bussière et al. (dir.), Europe organisée, Europe du libre-échange..., op. cit., p. 243. 
concertation $^{22}$. Le Plan est en effet issu de consultations politiques, mais aussi du travail de six commissions de modernisation horizontales et de vingt-six commissions de modernisation sectorielles qui associent fonctionnaires, représentants patronaux et syndicaux. Pour Massé, ce sont ces consultations qui font du Plan un instrument utile, accepté par tous y compris par les entreprises pour lesquelles il constitue une référence qui permet de faciliter leurs choix d'investissements sur le long terme ${ }^{23}$. Il ne s'oppose pas à la libre entreprise mais éclaire les choix des acteurs économiques. Le Plan est à la fois une administration (le commissariat général au Plan), un document et une procédure. Processus non contraignant, il constitue cependant une référence dans de nombreux documents de l'époque car c'est un « mythe mobilisateur ${ }^{24} »$.

Le Plan apparaît pour ses défenseurs, dans la première moitié des années soixante, comme l'instrument majeur de la modernisation économique et sociale de la France, la synthèse parfaite entre capitalisme et dirigisme d'une part, et entre technocratie et démocratie d'autre part. Il intéresse énormément les hauts fonctionnaires français ${ }^{25}$. Il illustre l'emprise du keynésianisme et, au-delà, de l'illusion scientiste qui motive une partie des « fonctionnaires modernisateurs » les plus ambitieux, ceux qui souhaitent transformer l'expérience d'un interventionnisme étatique fort et positif des années de reconstruction en donnée permanente. Cet apogée de la planification française, entre 1961 et 1965, s’inscrit dans un contexte international favorable à la thématique de la planification indicative. Dans un livre paru en 1965 et devenu une référence, Andrew Shonfield estime que les économies occidentales sont marquées par une intervention croissante des autorités publiques dans l'économie et un attrait marqué pour les prévisions de long terme chez tous les acteurs, qu'ils soient publics ou privés ${ }^{26}$. Il fait de la planification indicative française l'un des modèles les plus représentatifs de cette tendance. En plus de la France, il identifie d'ailleurs sept autres pays européens qui recourent à cette technique ${ }^{27}$, y compris la Grande-Bretagne travailliste qui

22. Pierre Massé, « préface », in John Mc Arthur, Bruce Scott, L'industrie française face aux plans, Harvard ausculte la France, Les éditions d'organisation, Paris 1970, p. XIV-XIV.

23. Pierre Massé, «Le métier de Commissaire au Plan : en feuilletant l'introduction au IV Plan », in H. Rousso (dir.), De Monnet à Massé..., op. cit., p. 197-208.

24. Gérard Pogorel, « Le Plan...», op. cit., p. 183.

25. Par exemple François Bloch-Lainé et le Club Jean Moulin : Florence Descamps, « François Bloch-Lainé et la réforme de l'État : de l'action au magistère moral, 1946-1996 », in M. Margairaz (dir.), François Bloch-Lainé..., op. cit, p. 196-199.

26. Andrew Shonfield, Modern Capitalism. The changing Balance of Public and Private Power, Oxford UP, 1965, p. 65-67.

27. A. Shonfield, Modern Capitalism..., op. cit., p. 122 : outre la France et la Grande-Bretagne, 1'Italie, la Belgique, les Pays-Bas, l'Autriche, la Suède et la Norvège ont des systèmes de planification indicative. 
lance une planification très ambitieuse en $1964^{28}$. Le débat sur la planification gagne même les États-Unis. Business Week se demande si « l'économie américaine n'aurait pas, elle aussi, besoin d'un $\operatorname{plan}^{29} »$, tandis que l'université Harvard entame un programme d'étude de la planification indicative française pour comprendre les sources de la croissance économique hexagonale ${ }^{30}$.

Il paraît donc naturel que ce thème central dans les débats économiques européens soit traité à l'échelle communautaire. Pourtant, même si Jean Monnet est l'un des initiateurs principaux de la planification indicative et de la construction européenne, le lien entre les deux sujets est rarement effectué dans l'abondante bibliographie sur la planification française. Le plan est ainsi assimilé à une spécificité française, une marque de son colbertisme qui la rend inclassable. À l'époque, le lien paraît pourtant évident pour certains économistes comme Jean Meynaud ou André Marchal ${ }^{31}$, qui suggèrent d'adapter à l'échelle de la CEE les méthodes de la planification indicative. Enfin, il faut rappeler que le projet français de contre-rapport Spaak de mai 1956 prévoyait une coordination des politiques économiques inspirées de la planification ${ }^{32}$. Au début des années soixante, Robert Marjolin associe ces deux dynamiques en constituant un réseau planificateur européen.

\section{Le développement d'un réseau planificateur européen.}

Pour asseoir l'autorité de la Commission européenne dans la coordination des politiques économiques des États membres, il est indispensable de renforcer sa capacité d'expertise. Pour cela, Marjolin s'appuie sur sa direction générale où il recrute quelques fonctionnaires sensibles aux thématiques planificatrices comme Pierre Millet, le directeur de la conjoncture puis des structures et du développement économique (1960-1961) à la DG II. C'est un ancien du Service des études économiques et financières (SEEF), le service qui fournit l'expertise économique à long terme du ministère des Finances français ${ }^{33}$. C'est également

28. Geoffrey Denton, Murray Forsyth, Malcolm Maclennan, Economic Planning and Policies in Britain, France and Germany, George Allen, Londres, 1968, p. 108-132.

29. ACNPF, 72 AS 1412, Business Week du 25 mai 1963.

30. J. Mc Arthur et B. Scott, L'industrie française face aux plans..., op. cit., 1970.

31. Jean Meynaud, Le Marché commun : essai de présentation générale, EPHE, Paris, mars 1957, p. 25 ; André Marchal, "Concentrations et ententes dans le Marché commun... », op. cit., in Revue du Marché commun, supplément au n ${ }^{\circ} 16$ de juillet 1959, p. 6.

32. AN, F60, 3112, "projet de document de travail sur l'établissement d'un marché présenté par la délégation française », date manuscrite : « mai $1956 »$.

33. Sur le SEEF : Aude Terray, Des francs-tireurs aux experts. L'organisation de la prévision économique au ministère des Finances. 1948-1968, Comité pour l'histoire économique et financière de la France, Paris, 2002. 
le cas du remplaçant de Millet, Alain Prate, le directeur de la structure et du développement économique de la DG II de 1961 à 1965.

Pour développer l'expertise économique de la DG II, Marjolin a recours à des économistes professionnels extérieurs à la DG II comme Pierre Uri. Il est chargé de la direction d'un groupe de travail pour les problèmes de structures et de développement à long terme. Il comprend de nombreux planificateurs européens comme le Français Claude Gruson, directeur général de l'INSEE, le Néerlandais Pieter de Wolff, directeur du bureau central du Plan de La Haye, et le Belge Albert Kervin de Lettenhove, secrétaire général du bureau de programmation économique à Bruxelles. Ces travaux aboutissent à un rapport d'ensemble sur les «perspectives de développement économique dans la CEE de 1960 à $1970 »$ terminé en juillet $1962^{34}$. Pour Marjolin, ce rapport vise clairement à établir des projections économiques, terme préféré à celui de « prévisions ${ }^{35}$ ». Marjolin reste donc prudent. Le groupe Uri continue ses travaux par la suite en publiant un rapport sur les aspects structurels des perspectives de développement économiques dans la $\mathrm{CEE}^{36}$. Le travail du groupe semble très indépendant des autorités nationales car, en France, le SGCI se plaint de ne pas être informé de ses activités par le représentant français, Claude Gruson ${ }^{37}$.

Marjolin approfondit son travail de mobilisation des réseaux planificateurs et de promotion intellectuelle par l'organisation d'un grand colloque à la fin 1962. Tenu à Rome grâce au soutien de la Commission européenne, ce colloque porte sur : «La programmation économique européenne et la programmation économique nationale dans les pays de la CEE $»^{38}$. La programmation économique désigne les diverses expériences de planification indicative, le terme de " planification » n'ayant pas été repris car il a une connotation totalitaire dans la mesure où il rappelle le régime soviétique.

Le rapport général est présenté par Robert Marjolin qui peut ainsi exposer sa vision de la «programmation européenne ». Il est soutenu par des rapports nationaux qui sont assurés par des personnalités issues en général des réseaux

34. AHUE, BAC 62/1980, volume 7, rapport du groupe de travail pour les problèmes de structures et de développement à long terme, perspectives de développement économiques dans la CEE de 1960 à 1970,1962 .

35. AHUE, BAC 62/1980, volume 3, folio 236, note du secrétariat pour les membres de la Commission, 28 juin 1962.

36. AHUE, BAC 62/1980, volume 7, doc. II/10680/63-F, rapport sur les perspectives de développement économiques dans la CEE de 1960 à 1970, aspects structurels, 1963.

37. ASGCI, 1979.0791, volume 100, commentaires sur le document CEE II/5455/61 du 31 juillet 1961.

38. La programmation économique européenne et la programmation économique nationale dans les pays de la CEE, Vallechi, Rome, 1963. 
planificateurs. Ainsi, c'est Pierre Massé en personne, le commissaire général au Plan français, qui prononce le rapport français. Le rapport belge est assuré par Kervin de Lettenhove et le rapport néerlandais par de Wolff, qui ont déjà travaillé indirectement avec Marjolin par leur participation au groupe Uri. L'audience est très large et comprend des hauts fonctionnaires de tous les pays de la CEE ainsi que des économistes et des représentants des milieux économiques.

Ainsi, grâce aux études menées au sein de la DG II et par le groupe Uri, la Commission européenne acquiert un début d'expertise. Marjolin mobilise le réseau des planificateurs français (Massé, Gruson) et européens pour faire émerger la prise de conscience de la nécessité d'une forte coordination des politiques économiques sur le long terme sous la forme du projet de « programmation européenne ». Se développe ainsi une « epistemic community ${ }^{39} »$, un réseau d'experts et de technocrates consultés pour la définition d'une politique publique, et pouvant assurer sa mise en œuvre une fois qu'elle aura été définie. Elle permet donc d'assurer au projet de programmation une légitimité scientifique et politique.

\section{La promotion de l'idée de programmation.}

En dehors des réseaux planificateurs, la promotion de l'idée de programmation européenne commence très tôt, que ce soit au sein des institutions communautaires ou dans les milieux patronaux.

Marjolin exprime ses ambitions de manière plus officielle mais encore assez vague dans le « programme d'action pour la Communauté pendant la deuxième étape » (deuxième étape de la période transitoire du Marché commun) du 24 octobre $1962^{40}$. Il annonce que la Commission fera des propositions en 1963 sur la « programmation communautaire », comportant de nombreuses indications sur le " cours désirable et possible de l'activité économique ». Le vocabulaire reste donc relativement prudent même si l'ambition de Marjolin est clairement affirmée.

Ces projets produisent une certaine effervescence dans les milieux économiques européens et un grand intérêt de la part du patronat français. Le groupe

39. Peter M. Haas, «Introduction : Epistemic Communities and International Policy Cooridnation », in International Organization, 1992, p. 3 : « An epistemic community is a network of professionals with recognized expertise and competence in a particular domain and an authoritative claim to policyrelevant knowledge within that domain or issue-area ».

40. «Le mémorandum de la Commission sur le programme d'action de la Communauté pendant la deuxième étape », in Bulletin de la CEE, décembre 1962, $\mathrm{n}^{\circ} 12,5^{\mathrm{e}}$ année, p. 9. 
français du Comité européen pour le progrès économique et social (CEPES) ${ }^{41}$ organise ainsi un colloque les 4 et 5 juin 1962 pour expliquer le système de planification français. Le rapport issu de cette manifestation est très favorable à la mise en place d'une coordination des politiques économiques des Six à l'échelle européenne ${ }^{42}$. Lors de cette manifestation, les patrons français présents comme Paul Huvelin ont globalement défendu leur planification indicative nationale avec des nuances. De même, à l'UNICE, Raymond Lartisien souligne que « les confrontations entre les milieux d'affaires, l'administration et le monde du travail auxquelles donnent lieu la préparation et la mise en œuvre du Plan sont très utiles et augmentent la qualité des jugements respectifs et des décisions ${ }^{43}$ ». De son côté, Emmanuel Mayolle, l'un des principaux dirigeants du CNPF, défend à l'étranger le modèle de la planification française qui est à la fois " volontariste » et " non dirigiste » car elle constitue une « étude de marché » très utile ${ }^{44}$. Il reprend ainsi l'expression de Pierre Massé qui fait du plan une « étude de marché » à l'échelle de la nation ${ }^{45}$.

Le colloque de Rome de la fin 1962 permetà Marjolin de présenter officiellement son projet. Il justifie tout d'abord la programmation européenne par l'adoption par un nombre croissant de pays d'une «planification indicative » ou d'une «programmation souple... ». Il défend une programmation neutre sur le plan doctrinal en affirmant qu'il veut « éviter une polémique entre libéraux et dirigistes [...]. Pour moi, le problème de la programmation n'est pas une affaire de théories économiques ou d'idéologies politiques, c'est une question technique ${ }^{46} \gg$. Pour lui, la programmation ne traduit pas un choix politique car elle ne sert qu'à donner de la cohérence et de la rationalité aux décisions des acteurs économiques.

Après avoir justifié la programmation, Marjolin dévoile quelques éléments de mise en œuvre. La première étape sera constituée par la confrontation des programmes et des prévisions nationales, puis leur homogénéisation dans un cadre global. C'est en vue de ce premier travail que la DG II et le groupe Uri ont commencé leurs études. À partir des prévisions budgétaires pluriannuelles nationales et d'études sectorielles, une coordination des interventions publiques devra être menée. Marjolin reste flou sur de nombreux aspects pour

41. Anne-Myriam Dutrieue, « Le CEPES, un mouvement patronal européen ? (1952-1967)», in Michel Dumoulin, René Girault, Gilbert Trausch (éd.), L'Europe du patronat, Peter Lang, Bruxelles, p. 213-230.

42. ACNPF, 72 AS 1412, rapport du CEPES, Planification et stratégie des investissements, colloque des 4 et 5 juin 1962 à Paris.

43. ACNPF, 72 AS 1412, exposé de Lartisien du 18 décembre 1962, document du 23 janvier 1963.

44. ANCPF, 72 AS 1412, exposé d'Emmanuel Mayolle, 24 mai 1963.

45. La programmation économique européenne..., op. cit., p. 45.

46. Ibid., p. 88 . 
rester consensuel. Ainsi, sur le plan de la coordination des investissements, il semble viser surtout les investissements publics mais évoque aussi, dans son introduction, les problèmes de l'imparfaite allocation des investissements privés $^{47}$.

Les ambiguités sur le rapport entre la programmation et les forces du marché ne manquent pas d'être relevées par les défenseurs du libre marché. Les Allemands sont particulièrement sceptiques tout comme l'économiste néolibéral Jacques Rueff. La majorité des interventions tendent cependant à soutenir l'intérêt de la programmation comme par exemple l'influent patron français Marcel Demonque (Ciments Lafarge) ${ }^{48}$. Louis Camu et Alexandre Lamfallussy, de la Banque de Bruxelles, sont plus mesurés mais ne contestent pas l'intérêt de la programmation ${ }^{49}$. Le colloque est un succès pour Marjolin qui a obtenu, selon les mots du journaliste Paul Fabra, un véritable « consensus » sur son projet $^{50}$. Dans son compte rendu du colloque de Rome à la commission des relations internationales du CNPF, Marcel Demonque estime que « le débat a été entièrement dominé par M. Marjolin ${ }^{51} »$. Reste maintenant à profiter de ce consensus intellectuel pour développer une proposition institutionnelle.

\section{L'ADOPTION DE LA « POLITIQUE ÉCONOMIQUE À MOYEN TERME »}

Après avoir assuré la promotion de ses idées dans un vaste réseau de responsables administratifs et économiques, Robert Marjolin entreprend de concrétiser son projet. Il lance tout d'abord une première proposition officielle en juillet 1963. Elle donne lieu, après négociation au sein du Conseil (1963-1964), à la mise en place de la politique économique à moyen terme en 1964-1965.

\section{La proposition de la Commission du 25 juillet 1963.}

Marjolin présente ses idées dans une communication officielle de la Commission au Conseil le 25 juillet $1963^{52}$. Dans cette communication, il

47. Ibid., p. 21.

48. Ibid., p. 141-144.

49. Ibid., p. 216-219 et p. 223-227.

50. Paul Fabra, «Une bonne base d'accord existe déjà entre les Six sur la "programmation européenne" », in Le Monde, 5 décembre 1962.

51. ACNPF, 72 AS 1412, compte rendu du colloque de Rome à la commission des relations internationales du CNPF, 10 décembre 1962.

52. AHUE, procès-verbal normal de la $237^{\mathrm{e}}$ session de la Commission européenne, séance du 25 juillet 1963, doc. II/COM(63)271 final du 25 juillet 1963, recommandation de la Commission au Conseil, « Politique économique à moyen terme de la Communauté ». 
propose deux actions complémentaires : charger un comité d'experts d'élaborer des projections économiques à cinq ans d'une part, créer un comité de politique économique à moyen terme (CPEMT) constitué de représentants des États et de la Commission d'autre part. Ce dernier devrait, à partir de ces projections, établir des « programmes » de politiques économiques pour les Six et la CEE à cinq ans. L'inspiration du modèle français de la planification indicative est claire.

Plus précisément, le mécanisme de base de la programmation européenne est l'établissement par un comité d'expert de «perspectives quantitatives » (point 9 de l'exposé des motifs de la communication ${ }^{53}$ ) sur les investissements publics et privés, la consommation ou le solde extérieur. Il ne s'agit pas de définir des objectifs contraignants mais de donner des éléments de références pour les acteurs économiques (points 13, 23 et 26).

Ensuite, le CPEMT devrait établir un programme qui doit constituer un « cadre d'ensemble de politique économique à moyen terme [5 ans] dans lequel s'insérerait l'action des gouvernements et des institutions européennes » (point 9). Le point 26 précise que « l'objet essentiel des projections à moyen terme est de provoquer une discussion continue des objectifs et des mesures de politique économique. Il importe donc que les responsables gouvernementaux et les institutions européennes décident en commun, sur la base de ces perspectives, quelles sont les politiques qui doivent être suivies ». Le projet de décision détaille les trois tâches du comité de politique économique à moyen terme : préparer un programme à cinq ans « exposant les grandes lignes des politiques économiques que les États membres et les institutions européennes entendent suivre [...] et assurer la coordination de ces politiques », suivre la politique économique des États membres pour évaluer leur compatibilité avec le programme, émettre des avis à la demande de la Commission ou de sa propre initiative. En fonction de l'interprétation de ce projet de décision, le Comité pourrait donc disposer d'un pouvoir considérable de coordination des politiques économiques suivies par les États membres et les différentes branches de la Commission européenne. Il pourrait en effet obliger un État membre dont la politique s'écarte du programme à venir se justifier devant ses partenaires des Six et devant la Commission européenne. Une inconnue majeure réside donc dans l'interprétation qui sera donnée à ces dispositions.

53. Après cette première référence, seule sera indiquée dans le texte la mention «point $X$ ». Elle correspond à l'exposé des motifs du document déjà cité : AHUE, procès-verbal normal de la $237^{\mathrm{e}}$ session de la Commission européenne, séance du 25 juillet 1963, doc. II/COM(63)271 final du 25 juillet 1963, recommandation de la Commission au Conseil, « Politique économique à moyen terme de la Communauté ». 
Par ailleurs, le point 11 affirme que les « perspectives quantitatives » sont à la base de la programmation car il s'agit de profiter des « progrès réalisés par la comptabilité nationale et l'analyse économique ». Toute l'ambition scientiste permise par les progrès de l'économie et de l'informatique transparaît dans cette affirmation d'une possibilité de maîtriser les mécanismes de l'économie et donc de la croissance. La croissance, le niveau d'investissement, voire même les revenus ou la consommation sont de moins en moins perçus comme des résultats et de plus en plus comme des objectifs à atteindre grâce à des outils appropriés, dont dispose le gestionnaire moderne.

Ce volontarisme technocratique se manifeste aussi dans une méfiance envers le libre jeu du marché. Certes, la communication de Marjolin reste prudente. On ne parle pas de «planification » mais de «programme » et de " politique économique à moyen terme $»$. Bien plus, Marjolin affirme que la programmation n'aboutira pas à une augmentation des interventions publiques mais pourrait au contraire se traduire, grâce à leur rationalisation, par leur diminution (points 4 et 25). Le « libre jeu du marché » est à la base de l'économie, tout au moins « dans les secteurs où la concurrence joue suffisamment» (point 2). Cette dernière précision laisse aux autorités publiques un champ considérable d'action dans de très nombreux secteurs qui seront au centre de la programmation telle que l'envisage Marjolin : politique budgétaire générale y compris l'action dans le domaine de l'éducation, de la santé et des transports, politique régionale, agriculture, énergie, logement et bien sûr politique des revenus (points 28 à 37). Par ailleurs la communication de la Commission évoque même la possibilité pour le programme de servir de document d' "orientation au secteur privé » (point 7). Enfin, elle affirme la nécessité de s'attacher au problème de l'équilibre entre consommation individuelle et investissements collectifs (point 30). Dans une perspective à la fois sociale et austère, il souhaite éviter un développement excessif d'un consumérisme matérialiste pour privilégier les besoins collectifs (éducation, santé, etc.). Ainsi, la communication de la Commission défend la conception d'un État technocratique éclairé qui prend en charge la modernisation de nombreux pans de l'économie et de la société.

Reste le problème épineux de la méthode de mise en œuvre de ce programme ambitieux. Le CPEMT devra réunir des hauts fonctionnaires en charge de la planification et de la prévision pour qu'ils coordonnent leurs travaux. Cette institution paraît donc bien modeste mais Marjolin ne pouvait pas proposer un changement institutionnel majeur car il n'avait pas l'appui politique nécessaire au sein de la Commission et des États membres. Il développe une méthode prudente et inspirée de la planification française. Elle est fondée sur la mise en place d'une véritable gouvernance, c'est-à-dire d'un système de gestion plus horizontal que vertical et hiérarchique. Marjolin espère que la confrontation 
régulière des points de vue des membres du CPEMT les amènera à européaniser progressivement leurs réflexions. Le processus est le même que pour celui du plan français : le commissariat au Plan n'a pas de pouvoirs coercitifs mais il obtient l'adhésion de tous à ses objectifs grâce à un processus de consultation et d'élaboration en commun d'un document unique qui sert de « mythe mobilisateur ».

La communication de la Commission sur la politique économique à moyen terme du 25 juillet 1963 propose donc clairement un système de coordination des politiques économiques technocratique, volontariste et inspiré des doctrines de la planification indicative française. Assez prudent dans la forme, il est très ambitieux sur le fond car Marjolin présente un véritable projet de société sous couvert d'une coordination des politiques économiques. Deux inconnues majeures pèsent sur ce projet s'il est accepté, d'abord en termes de doctrine économique et sociale du futur CPEMT, ensuite en termes de pouvoirs institutionnels. Dans un premier temps toutefois, c'est aux États membres de se prononcer sur le projet.

\section{La négociation au Conseil (juillet 1963-avril 1964).}

Avant la négociation au Conseil, ce sont d'abord les milieux économiques et sociaux qui se mobilisent face aux ambitions de Marjolin. La CISL (Confédération internationale des syndicats libres) se prononce clairement en faveur de la constitution d'un « commissariat général au Plan européen » avec la création d'un « comité consultatif » constitué des représentants des travailleurs et des employeurs ${ }^{54}$. L'UNICE est plus prudente mais son avis officiel est favorable au projet de la Commission européenne, pourvu qu'elle respecte le libre jeu du marché et qu'elle ne concerne que les acteurs publics ${ }^{55}$.

$\mathrm{Au}$ Conseil, la situation est moins favorable. D'un côté, le gouvernement allemand manifeste de manière prévisible sa réticence, en particulier chez le chancelier Erhard ${ }^{56}$. D'un autre côté, les représentants français apparaissent favorables au principe de la programmation européenne, qu'ils assimilent à une adaptation à l'échelle européenne des méthodes française de la planification

54. AMINEFI, B 17.685, position de la CISL sur « la programmation européenne », 23 janvier 1964, transmise par le Conseil le 5 février 1964.

55. AHUE-archives du Conseil, CM2, avis de l'UNICE, 14 février 1964 ; ACNFP, 72 AS 1544, compte rendu de la réunion UNICE du 14 février 1964.

56. AMINEFI, B 17.685, note de Poniatowski, directeur de cabinet du ministre des Finances, pour le directeur Finex, 28 août 1962. 
indicative, tout en restant très prudents sur le plan institutionnel ${ }^{57}$. Face aux réticences prévisibles des Allemands, les Français adoptent une stratégie pragmatique, consistant à soutenir la Commission sans adopter de posture maximaliste.

Le débat institutionnel entre les États membres suit trois étapes. De septembre 1963 à février 1964, c'est une section spécialisée du COREPER, le groupe des questions économiques, qui étudie la proposition de la Commission et rend son avis le 27 février $1964^{58}$. Les représentants permanents se saisissent ensuite du dossier et transmettent leurs conclusions au Conseil CEE le 9 avril $1964^{59}$. Comme la Commission européenne, représentée par Marjolin, accepte rapidement les demandes de modifications du Conseil, ce dernier adopte le texte dès le 15 avril $1964^{60}$. Les discussions intergouvernementales se sont donc déroulées principalement non pas entre les ministres mais entre les représentants permanents et leurs adjoints.

Dans un premier temps, les débats sont assez vifs car les Allemands posent de nombreux problèmes de principes ${ }^{61}$. Les positions se rapprochent toutefois car les États décident de ne pas se prononcer sur l'exposé des motifs en 48 points, qui relève de la seule responsabilité de la Commission, et décident de se concentrer sur le projet de décision, beaucoup plus court ${ }^{62}$. Les Allemands et les Hollandais obtiennent des modifications visant à restreindre les pouvoirs de la Commission européenne ${ }^{63}$. Ainsi, le CPEMT ne doit plus être institué « auprès de la Commission » et son règlement intérieur devra être approuvé par le Conseil. De même, il ne devra plus élaborer un projet de programme à moyen terme, soumis ensuite à la Commission, mais un avant-projet soumis à la Commission, qui deviendra enfin un projet soumis au Conseil. Enfin, les références précises aux politiques publiques nationales et communautaires devant plus particulièrement faire l'objet d'une coordination sont supprimées.

57. AMAE, DECE 1296, note pour Ulrich de Calbiac, 28 octobre 1963 ; ASGCI, 1979.0791, 68, note SGCI du 14 novembre 1963.

58. AHUE-archives du Conseil, procès-verbal de la $269^{\mathrm{e}}$ session du COREPER des 17-18-19 et 23 septembre 1963 ; AHUE-archives du Conseil, doc. R/209/64 (AG 82) du Conseil du 27 février 1964.

59. AMAE, RPUE 693, avis du COREPER du 9 avril 1964, doc. R/357/64 (AG 201) (ECO 21).

60. AHUE, BAC 62/1980, volume 7, décision du Conseil du 15 avril 1964 créant un comité de politique économique à moyen terme, 16 avril 1964, doc. du Conseil CEE $n^{\circ}$ 554/64.

61. ASCGI, 1979.0791, volume 68, télex du conseiller fin de la REP, 9 décembre 1963.

62. AHUE-archives du Conseil, CM2/1964, aide-mémoire du 20 décembre 1963 de la réunion du groupe des questions économiques du 22 novembre 1963.

63. AHUE-archives du Conseil, avis du groupe des questions économiques du COREPER, doc. R/209/64 (AG 82) du Conseil du 27 février 1964 ; AMAEF, RPUE 693, avis du COREPER du 9 avril 1964, doc. R/357/64 (AG 201) (ECO 21). 
Toutes ces modifications sont finalement acceptées par Marjolin ce qui permet d'obtenir le vote du Conseil ${ }^{64}$.

Les discussions à Six sur le projet de CPEMT se sont traduites par un contrôle de tout le processus de négociation par les États membres, contrairement à la négociation du règlement 17/62. Ce sont les représentants permanents qui ont mené le processus de bout en bout, la Commission devant se plier à leurs demandes. Marjolin ayant réussi à créer un climat intellectuel favorable à ses propositions avant leur discussion, il parvient à sauvegarder l'essentiel de son projet. Un décalage clair s'établit entre un exposé des motifs ambitieux mais que les États n'ont pas validé, et des décisions novatrices mais dont la mise en œuvre reste incertaine.

\section{La mise en ouvre de la PEMT (1964-1965).}

La constitution du comité de politique économique à moyen terme (CPEMT) s'effectue en six mois, ce qui est assez rapide compte tenu de l'intermède estival. Il tient sa première séance le 11 décembre $1964^{65}$. Il est présidé par l'allemand Langer, qui s'était manifesté lors du colloque de Rome par son scepticisme envers le projet de programmation. Selon l'expert patronal Lartisien, il s'agit d'une stratégie de Marjolin consistant à contourner l'opposition allemande en donnant la présidence du CPEMT à un Allemand ${ }^{66}$. Il est, de toute façon, étroitement encadré par les réseaux planificateurs européens : Pierre Massé, le commissaire au plan français, est vice-président du comité et le Belge Kervin de Lettenhove préside le groupe d'étude des perspectives économiques associé au CPEMT ${ }^{67}$.

Cette première réunion est marquée par un très grand volontarisme. Le comité décide de soumettre à la Commission un avant-projet de premier programme pour le mois de septembre 1965 et de lancer en parallèle une série de travaux sectoriels. Les premiers concernent notamment la politique sociale et la politique agricole, les deux commissaires concernés (respectivement Levi Sandri et Mansholt) acceptant rapidement de collaborer avec le CPEMT ${ }^{68}$.

64. AHUE, BAC 62/1980, volume 7, décision du Conseil du 15 avril 1964, doc. du Conseil CEE $\mathrm{n}^{\circ} 554 / 64$.

65. AHUE, BAC 27/1985, volume 1, compte rendu de la première réunion du CPEMT du 11 décembre 1964.

66. ACNFP, 72 AS 1412, une note de Lartisien du 17 décembre 1964.

67. AHUE, BAC 27/1985, volume 1, compte rendu de la première réunion du CPEMT du 11 décembre 1964.

68. AHUE, EN 242, « communication de M. Marjolin sur la première réunion du comité pour la politique économique à moyen terme ", séance de la Commission du 21 décembre 1965 ; AHUE, BAC 27/1985, volume 1, compte rendu de la première réunion du CPEMT du 11 décembre 1964. 
Les travaux progressent de manière satisfaisante au début de 1965 dans deux directions. D'une part des études macroéconomiques générales sont entamées pour dégager les grandes tendances de l'évolution à moyen terme des économies des Six et de la CEE dans son ensemble ${ }^{69}$. Le groupe d'étude des perspectives économiques à moyen terme rend de son côté un premier rapport intérimaire très macroéconomique dès mars $1965^{70}$. D'autre part, le CPEMT s'engage dans des études sectorielles plus précises dans des secteurs nouveaux, où il n'y a pas encore de politique européenne et peu de politiques nationales. Des groupes de travail sont ainsi créés pour étudier la politique des revenus, la politique régionale et la politique des structures sectorielles, afin de comparer les modes d'interventions nationales ou les réflexions en cours dans ces trois domaines ${ }^{71}$. De plus, à la suite d'une requête française, un groupe de travail sur la politique de la recherche scientifique et technique est mis en place $^{72}$. Le 9 avril 1965, le CPEMT peut émettre un communiqué de presse assez optimiste. L'avant-projet de programme est toujours prévu pour la fin de l'année $1965^{73}$. La mise en place du CPEMT semble réussie à la veille de la crise de la chaise vide.

\section{CONCLUSION : LA COHÉRENCE DU PROJET DE MARJOLIN}

Le projet de coordination des politiques économiques à moyen terme de Marjolin est marqué par une grande ambition, qui correspond à la période d'apogée du prestige international de la planification indicative. À moyen terme, elle s'inscrit également dans un projet personnel de Marjolin qu'il avait déjà tenté de développer à l'OECE. Sur le plus long terme enfin, ce projet s'inscrit pleinement dans la logique de l'Europe organisée qui a commencé à s'exprimer dans les années 1920. Il s'agit toujours d'accompagner l'ouverture des marchés par une coordination des principaux acteurs économiques.

La méthode du commissaire français est prudente. Elle s'inspire de sa propre expérience à l'OECE, où il a constaté que même avec des institutions très

69. AHUE, BAC 27/1985, volume 2, compte rendu de la $2^{\mathrm{e}}$ réunion du CPEMT du 29 janvier 1965.

70. AHUE, BAC 27/1985, volume 4, rapport intérimaire à la Commission sur les perspectives de développement économique dans la CEE jusqu'en 1970, mars 1965.

71. AHUE, BAC 27/1985, volume 2, compte rendu de la $2^{\mathrm{e}}$ réunion du CPEMT du 29 janvier 1965.

72. AHUE, BAC 27/1985, volume 3, compte rendu de la $3^{\mathrm{e}}$ réunion du CPEMT du 5 mars 1965 ; AHUEB, BAC 27/1985, volume 6, compte rendu de la 4 e réunion du CPEMT des 2 et 9 avril 1965.

73. AMAE, RPUE 693 et AHUE, BAC 27/1985, CPEMT, communiqué de presse du 9 avril 1965. 
intergouvernementales, il est possible de prendre des décisions importantes si un consensus idéologique émerge, jouant alors le rôle de « moralité sans sanc$\operatorname{tion}^{74} \gg$. Ses deux échecs dans la promotion d'une Europe monétaire en 1958 et les difficultés dans l'application du règlement 17/62 renforcent sa conviction et le conduisent naturellement à adopter une stratégie indirecte. Il s'appuie sur de véritables « epistemic communities » pour assurer la promotion intellectuelle de son projet. Il compte ensuite sur l'européanisation progressive des hauts fonctionnaires réunis au sein du CPEMT. Il suit une logique néofonctionnaliste technocratique qui s'inspire du processus de concertation et de mobilisation du Plan français.

Cette prudence débouche en 1964 sur la création du CPEMT qui démarre à la fin 1964 ses travaux avec de grandes ambitions. Pour compléter cette coordination des politiques économiques à moyen terme, le commissaire français a développé en parallèle des efforts en matière de coordination des politiques conjoncturelles et monétaires.

\section{LA COORDINATION DES POLITIQUES CONJONCTURELLES ET MONÉTAIRES}

En dépit de la base étroite donnée par le traité de Rome en matière de coordination des politiques monétaires, Marjolin avait développé deux projets en 1958. Au début des années 1960, le contexte est moins favorable qu'en 1958 mais Marjolin cherche à profiter des circonstances (suites de la négociation ZLE, problèmes du SMI) pour relancer ses efforts en la matière, en suivant la même méthode que pour la coordination des politiques économiques à moyen terme, et en parvenant également à obtenir des décisions importantes en 1964.

\section{A. LE BESOIN DE COOPÉRATION MONÉTAIRE}

Le débat sur le renforcement de la coopération monétaire européenne s'est d'abord cristallisé dans le cadre de la négociation ZLE, puis dans celui du SMI. Cela a conduit Marjolin à approfondir ses réflexions, en relation avec Monnet, Uri et Triffin.

74. Robert Marjolin, «Coopération intergouvernementale et autorités supranationales », in Revue économique, 1958, vol 9, $\mathrm{n}^{\circ} 2$, p. 271. 


\section{Le dernier avatar de la négociation ZLE : le comité de politique conjoncturelle.}

La première tentative de renforcer les coordinations des politiques économiques et monétaires en Europe provient des ordolibéraux du gouvernement allemand et se place dans la droite ligne de la négociation ZLE. Le secrétaire d'État allemand à l'Économie, Alfred Müller-Armack, avait proposé en 1958 de renforcer la coordination des politiques monétaires et conjoncturelles dans le cadre de l'OECE ${ }^{75}$. Il présente un projet de « bureau européen de conjoncture » le 11 mai $1959^{76}$. Enceinte de consultation composée de représentants des pays européens, il serait chargé d'édicter un code de comportement en matière de politique conjoncturelle qui servirait pour l'attribution de fonds aux pays en difficulté de balance des paiements. Les compétences du bureau seraient très larges et toucheraient aussi bien la politique du crédit que la politique budgétaire, y compris pour accélérer ou retarder des programmes d'investissements nationaux en fonction de la conjoncture. L'objectif est clairement d'établir un système de régulation conjoncturelle contraignant empêchant les États les moins disciplinés de mettre en danger le système monétaire et financier européen. $\mathrm{Ce}$ projet est vraisemblablement issu des craintes nées de la crise de la balance des paiements française de 1956-1958 et s'inscrit bien dans la volonté ordolibérale de créer un ordre juridique contraignant, y compris pour les États.

Cette proposition ne vise pas à renforcer le cadre des Six car l'échelle de coopération (OECE ou CEE), n'est pas précisée ${ }^{77}$. De plus, il suit un projet de 1958 qui s'inscrivait clairement dans le cadre de l'OECE et de la négociation $\mathrm{ZLE}^{78}$. Cette ambition échoue très rapidement car les Britanniques refusent de s'engager dans un cadre institutionnel aussi contraignant ${ }^{79}$.

Marjolin reprend alors la proposition de Müller-Armack en la communautarisant. Il propose de créer un comité de politique conjoncturelle dans le cadre des Six, constitué de représentants des États membres, chargé de missions de consultation et de l'établissement d'un code de bonne conduite ${ }^{80}$. La Commission européenne prévoit la possibilité d'obtenir d'un gouvernement

75. AMAE, POW 39, folio 305, note d'Olivier Wormser, 2 avril 1958; AMAE, DECE 680, folio 25, note JD de mai 1959.

76. AMAE, DECE 680, folio 87, note sur un projet de bureau européen de conjoncture, 11 mai 1959.

77. AMAE, DECE 680, folio 87, note sur un projet de bureau européen de conjoncture, 11 mai 1959.

78. AMAE, DECE 680, folio 82, note de Jean-Pierre Brunet (entre le 13 et le 17 mai 1959).

79. AMAE, DECE 680, folio 122, lettre du ministre des Finances au Premier ministre du 13 juin 1959.

80. AMAE, DECE 680, folio 133, note de la Commission, DG II, 27 juillet 1959. 
de différer une mesure si ses partenaires en font la demande au Comité de politique conjoncturelle.

Hostiles à de telles délégations de souveraineté, les fonctionnaires français sont cependant favorables à ce projet car il renforce la CEE tout en développant la coordination des politiques économiques, pendant naturel de la libération des échanges dans la conception française de l'intégration économique européenne $^{81}$. Finalement le Conseil des 9 et 10 mars 1960 accepte la création d'un comité de politique conjoncturelle strictement consultatif ${ }^{82}$. Composé de hauts fonctionnaires représentants des États membres, il a pour but d'organiser des échanges systématiques sur la politique conjoncturelle des Six sans avoir de pouvoirs contraignants. Il sert de source d'information pour la Commission. Marjolin parvient ainsi à récupérer habilement l'initiative ordolibérale allemande pour renforcer le dispositif institutionnel communautaire existant grâce à la création d'un organisme certes modeste, mais qui traduit le besoin d'un renforcement de la coordination dans ce domaine. Après la négociation ZLE, c'est d'une autre sollicitation extérieure, le besoin de réforme du SMI, que provient une incitation à approfondir la coopération monétaire à Six.

\section{La coopération des Six et le SMI.}

Le système monétaire international a radicalement changé entre les débuts de la négociation du traité de Rome, en 1955-1956, et son application en $1959^{83}$. En termes de balance des paiements, les Six ont renforcé leur position, aidés en cela par le redressement français après le plan Rueff. Au contraire, des signes de fragilité apparaissent dans les balances des paiements des deux pivots du SMI, le Royaume-Uni et les États-Unis. La livre et le dollar font l'objet d'attaques spéculatives en particulier à l'automne 1960 pour le dollar et au printemps 1961 pour la livre.

Marjolin tente alors de profiter de cette nouvelle position de force des Six. Ce domaine lui tient particulièrement à cœur comme l'ont montré ses deux plans d'union économique et monétaire de 1958. Il profite par ailleurs des prérogatives de la DG II, qui assure le secrétariat du Comité monétaire mais aussi des réunions des ministres des Finances des Six qui se développent à partir de 1959.

81. AMAE, DECE 680, folio 85, lettre manuscrite de R. de la Genière du 17 mai 1959 ; DECE 680, folio 122, lettre du ministre des Finances au Premier ministre du 13 juin 1959.

82. AMAE, DECE 680, folio 221, compte rendu de la $31^{\mathrm{e}}$ session du Conseil des 9-10 mars 1960 ; AMINEFI, B 62.158, note pour le Ministre pour le Conseil des 9-10 mars 1960.

83. Sur l'histoire du SMI, voir notamment : Robert Solomon, Le SMI, Économica, Paris, 1979 [1976] ; Michel Lelart, Le SMI, La découverte, Paris, 2003. 
Or, comme ces réunions sont officieuses, dans la mesure où elles n'ont pas été prévues par le traité de Rome, la DG II est la seule destinataire des documents qui y sont discutés et de leurs délibérations. En 1961, elle refuse d'ailleurs de les diffuser aux autres services de la Commission ${ }^{84}$, ce qui traduit bien l'importance qu'elle accorde à ce levier d'influence.

Le cœur des négociations sur l'avenir du SMI réside dans les moyens d'aider les pays aux monnaies fragiles à bénéficier de larges crédits. Elles aboutissent en décembre 1961 avec la conclusion des Accords généraux d'emprunts (AGE) entre dix pays de l'OCDE - le « groupe des Dix », dont les Six, les États-Unis et la Grande-Bretagne, pour accorder des lignes de crédit supplémentaires au FMI en cas de besoin. Olivier Feiertag a montré que les discussions des Six au sein du Comité monétaire en 1960 et 1961 ont permis de faire émerger à la fois une position commune sur la réforme du FMI et une doctrine monétaire rigoureuse, fondée sur deux éléments, la peur de l'inflation et donc de crédits accordés de manière trop libérale à l'échelle internationale, et la nécessité d'accorder une place importante aux banques centrales - et pas au seul FMI dans la régulation du SMI ${ }^{85}$.

Marjolin cherche à encourager ce mouvement en appelant, lors des réunions des ministres des finances des Six, à une coordination des interventions des États membres de la $\mathrm{CEE}^{86}$. Mais la logique des discussions reste bien intergouvernementale. Ainsi la réévaluation du deutschmark et du florin en mars $1961^{87}$ n'a pas été précédée de consultations ni même d'une information de la Commission ${ }^{88}$ alors que l'article 107 prévoit que « chaque État membre traite sa politique en matière de taux de change comme un problème d'intérêt commun ». Les discussions lors de la réunion des ministres des Finances qui suit ces réévaluations montrent le trouble de Marjolin ${ }^{89}$. Le commissaire français, après avoir rappelé l'accord de la Commission européenne avec les mesures prises, suggère néanmoins de lancer une discussion sur l'amélioration

84. AHEU, BAC 26/1969, volume 746, folio 54, note de Bobba au DG relex, 26 avril 1961.

85. O. Feiertag, Wilfried Baumgartner..., op. cit., p. 662-669.

86. AMINEFI, B 17.738, compte rendu de la $4^{\mathrm{e}}$ réunion des ministres des Finances, 11-12 juillet 1960, doc. CEE DG II du 16 août 1960 ; AHUE, BAC 26/1969, volume 744, compte rendu de la réunion des ministres des Finances des Six des 24 et 25 octobre 1960 ; AHUE, BAC 26/1969, volume 745, compte rendu de la réunion des ministres des Finances des Six des 13 et 14 janvier 1961.

87. Monika Dickhaus, «La politique extérieure de la Banque centrale allemande après 1958 », in O. Feiertag et M. Margairaz (dir.), Politiques et pratiques des banques d'émission en Europe..., op. cit., p. 770.

88. AHUE, BAC 3/1978, volume 990, folio 17, document CEE du 7 mars 1961.

89. AHUE, BAC 26/1969, volume 745, folios 62-64, compte rendu de la réunion des ministres des Finances des Six des 20 et 21 mars 1961, document II/2487/61 du 6 avril 1961. 
des procédures de consultations préalables. Face à lui, le ministre des Finances allemand Etzel, pourtant proche des réseaux proeuropéen allemands, souligne la nécessité de maintenir le secret indispensable à ce type d'opération. Marjolin pense au contraire « qu'il n'était pas impossible d'annoncer les réévaluations du Mark et du Florin dans un seul communiqué, accompagné d'une déclaration des autres gouvernements ${ }^{90} »$. La discussion se clôt par la réponse sèche d'Etzel qui « pense que des consultations ne pourraient demeurer secrètes et qu'il n'y a pas lieu d'étudier de nouvelles procédures de consultations ».

Les institutions communautaires restent un simple cadre de discussions, une enceinte de l'intergouvernementalisme rationalisé. L'enjeu pour Marjolin est dorénavant de profiter de cette convergence des réflexions monétaires des Six, de ces habitudes de discussions dans le cadre de la CEE, pour promouvoir des projets plus ambitieux.

\section{Les réflexions de Marjolin, de Triffin et de Jean Monnet (1959-1961).}

Comme en 1958, Triffin reste attaché à son projet de fonds de réserve (FER). Proche de Marjolin, il est devenu son conseiller spécial à la Commission européenne toute en restant professeur à Yale ${ }^{91}$. Il présente un nouveau projet en septembre 1959 fondé sur la mise en commun d'au moins $20 \%$ des réserves nationales au sein d'un $\mathrm{FER}^{92}$. Ce dernier aurait deux fonctions. En interne, il servirait à la mise en œuvre de l'article 108. On retrouve ici la principale motivation du renforcement de la solidarité monétaire en 1958 : assurer une solidarité intracommunautaire effective envers un pays qui aurait des difficultés de balance des paiements. En externe, le FER permettrait d'assurer un prêt commun des Six aux organismes internationaux comme le FMI. Cette seconde fonction est plus directement liée au contexte de 1959, celui d'un rôle accru des Six dans une réforme du SMI qui s'annonce comme de plus en plus urgente. Ce projet de Triffin envoyé à Monnet débouche sur une résolution du CAEUE du 20 novembre 1959 demandant la création d'un fonds européen commun aux $\operatorname{Six}^{93}$.

90. AHUE, BAC 26/1969, volume 745, folios 62-64, compte rendu de la réunion des ministres des Finances des Six des 20 et 21 mars 1961, document II/2487/61 du 6 avril 1961.

91. AHUE, procès-verbal spécial de $283^{\mathrm{e}}$ séance de la Commission, 28 juillet 1964, point 3.

92. AFJM, AMK 62/2, note Triffin, "Fonds de réserve européen », 10 septembre 1959, « confidentiel».

93. Gérard Bossuat, «Jean Monnet et l'identité monétaire europénne », in Gérard Bossuat, Andreas Wilkens (dir.), Jean Monnet, l'Europe et les chemins de la paix, Publications de la Sorbonne, Paris, 1999, p. 372-373. 
Marjolin de son côté termine le 30 août 1960 un mémorandum secret prévoyant une « harmonisation des politiques monétaires nationales des pays de la Communauté ${ }^{94} \gg$. Ce document constitue une synthèse entre les réflexions du commissaire français et celles de l'économiste belge. D'un côté, on retrouve dans ce document une préoccupation très forte, affirmée dès le début du texte, de la nécessité de rester très strict avec les déficits des balances des paiements et la lutte contre l'inflation, ce qui est caractéristique des préoccupations de Marjolin. D'un autre côté, le document souligne la fragilité du SMI issue de la faiblesse du dollar et de la livre, et l'insuffisance des liquidités internationales, ce qui rejoint le constat de Triffin.

L'harmonisation des politiques monétaires est justifiée, comme dans le document Triffin de 1959, pour des raisons internes (mettre en œuvre l'article 108) et externe (coordonner l'action des Six dans le cadre du FMI). En termes de doctrine un compromis entre la vision «monétariste » de Triffin et l'approche plus « économiste » de Marjolin est également trouvé : si le document ne vise que l'harmonisation des politiques " monétaires » et pas « économiques », il désigne cependant clairement la politique du crédit comme une des compétences devant faire l'objet d'une coordination étroite, justement par l'influence directe qu'elle peut avoir sur le rythme de l'activité économique.

En terme institutionnel, le pragmatisme l'emporte, sans doute en raison de l'expérience personnelle de Marjolin - l'échec des deux projets d'UEM et le cours intergouvernemental des discussions sur le FMI. Il est donc prévu de renforcer le Comité monétaire en créant un sous-comité des gouverneurs des banques centrales en son sein, et en augmentant ses prérogatives. Le mémorandum prévoit ainsi qu'un nombre croissant de décision devrait recevoir un examen a priori obligatoire du Comité monétaire. À terme, un vote contraignant à la majorité pourrait être envisagé et le Comité monétaire devrait réfléchir à des réformes institutionnelles visant à doter la $\mathrm{CEE}$ des instruments d'une « véritable politique commune en matière monétaire ». Le mécanisme est donc à la fois progressif et ambitieux. Il repose non pas sur une logique fédérale mais sur la communautarisation de la logique intergouvernementale par l' « intercompénétration grandissante des administrations nationales compétentes seules capables de mettre en œuvre et d'appliquer en pratique les décisions communes ${ }^{95} \gg$. Le processus de transfert de souveraineté à l'échelle de la CEE ne se fait pas par une attribution de compétence des États membres à la Commission mais par

94. AFJM, ARM 32/1/4, mémorandum du 30 août 1960, secret, « harmonisation des politiques monétaires nationales des pays de la Communauté ».

95. Ibid., p. 18. 
le processus d'européanisation des esprits, et par l'utilisation d'une procédure de coordination ex ante et plus ex post, associée à une utilisation croissante du vote majoritaire. Cette méthode annonce celle qui sera adoptée un peu plus tard dans le cadre de la politique économique à moyen terme avec le CPEMT.

Le projet Marjolin du 30 août 1960 est un document fondamental car il témoigne d'une convergence des réflexions du commissaire français et de l'économiste belge autour d'une ambition commune de réforme du SMI et de promotion prudente d'une Europe monétaire, mais aussi de l'expression d'une méthode pragmatique fondée sur la communautarisation des négociations intergouvernementales. L'aboutissement de ce projet fait apparaître la résolution du CAEUE de 1961 demandant la création d'une union européenne de réserve comme une proposition vague et terne ${ }^{96}$. Rien n'est précisé sur sa mise en œuvre et son fonctionnement. La note du ministère des Finances français qui analyse la proposition du comité d'action ne s'y trompe pas car elle souligne qu'elle a déjà été formulée à de nombreuses reprises et qu'elle s'inspire du projet Marjolin du 30 août $1960^{97}$.

La demande britannique d'adhésion à la CEE formulée en août 1961 ajoute une nouvelle dimension au dossier. Marjolin cherche à en profiter comme en témoignent des notes manuscrites schématiques sur une déclaration qu'il comptait faire à de Gaulle : « Les Anglais sont en train de défaire l'Europe. Si impossible de résister complètement sur le terrain où ils se sont placés, renforcement de l'Europe dans une autre direction : politique et monétaire ${ }^{98}$. »>. L'idée est de renforcer la CEE pour éviter que l'adhésion britannique ne menace son unité, mais aussi de se préparer à un éventuel recours de la Grande-Bretagne à une assistance monétaire extérieure, une hypothèse examinée très sérieusement dans les cercles internationaux à l'automne $1961^{99}$. Dans ce cadre, et c'est l'argument défendu notamment par Esteva au Finex, le projet de FER pourrait être perçu comme un moyen non pas de renforcer mais de limiter les exigences de solidarité intracommunautaires, car seules les réserves déposées au sein du FER pourraient être sollicitées ${ }^{100}$. Cette note d'Esteva justifie dans de nombreux passages le renforcement de la coordination des politiques monétaires européennes en reprenant des arguments favorables à l'intégration européenne.

96. AMINEFI, B 17712, déclaration commune du CAEUE, $9^{\mathrm{e}}$ session des 10-11 juillet 1961.

97. AMINEFI, B 17712, note Finex du 21 août 1961 ; AMINEFI, note Finex, JC, pas de date, étude de la proposition du comité d'action de Jean Monnet de juillet 1961.

98. AFJM, ARM 25/1, projet de conversation avec Charles de Gaulle, notes manuscrites, pas de date mais sans doute 1960 .

99. AMINEFI, B 44248, 34 ${ }^{\mathrm{e}}$ session des 3,4 octobre 1961 de l'AME.

100. AMINEFI, papiers privés de Lattre, carton 2, liasse 10, chemise 10, note de Pierre Esteva pour André de Lattre du 28 juin 1962. 
Ces passages tout comme celui qui défend la solution du FER sont d'ailleurs barrés par le relecteur, certainement André de Lattre, le directeur de cabinet de Baumgartner ${ }^{101}$. Le problème de la livre et de la coopération monétaire à Six joue finalement un rôle mineur dans la première négociation d'adhésion de la Grande-Bretagne mais il suscite déjà des études au sein de l'administration française et communautaire ${ }^{102}$.

À la fin de 1961, le contexte est donc favorable pour la relance des projets de renforcement de la coopération monétaire européenne. À l'argument initial, développé en 1958, de favoriser la solidarité intracommunautaire par la mise en œuvre de l'article 108, se sont ajoutés des arguments internes - compléter l'accélération de l'union douanière et bientôt la mise en place de la PAC, et surtout externes avec les problèmes de la réforme du SMI et de l'adhésion britannique. Marjolin développe en 1960 un projet assez original, fondé sur une méthode pragmatique et une doctrine consensuelle, qui peuvent se rapprocher du consensus minimal que les Six ont défini progressivement en matière monétaire en 1961 avec la négociation sur les AGE. L'accent mis sur la lutte contre l'inflation et le rôle donné aux banques centrales sont en effet tout à fait compatibles avec les réflexions de Marjolin de 1960 et sont au cœur de son nouveau projet d'union économique et monétaire défini à la fin de 1962.

\section{B. LE PROJET D'UNION ÉCONOMIQUE ET MONÉTAIRE DE MARJOLIN}

Selon une chronologie parallèle à celle de la promotion de la programmation européenne, Marjolin lance ses idées à la fin de 1962, les expose dans une communication de juillet 1963 et obtient des premiers succès en 1964-1965.

\section{La définition du projet (fin 1962-début 1963).}

Le « programme d'action de la Communauté pour la deuxième étape » est un premier pas dans la concrétisation des projets de Marjolin. Il évoque la possibilité d'aboutir à « des taux de change fixes pour les monnaies des États membres, sous réserve de variation dans des limites très étroites » à moyen terme ${ }^{103}$. Concrètement, le programme d'action propose d'instaurer un mécanisme de

101. AMINEFI, papiers privés de Lattre, carton 2, liasse 10, chemise 10, note de Pierre Esteva pour André de Lattre du 28 juin 1962.

102. Céline Paillette, Candidatures britanniques à la CEE et stratégies monétaires françaises, 1961-1967, maîtrise dir. Robert Frank, Paris I, septembre 2001.

103. "Le mémorandum de la Commission sur le programme d'action de la Communauté pendant la deuxième étape », in Bulletin de la CEE, décembre 1962, $\mathrm{n}^{\circ} 12,5^{ }$année, p. 9. 
consultations préalables entre les Six sur un grand nombre de sujets de politique monétaire comme les taux d'intérêts ou les taux de change. D'autre part, il estime nécessaire de créer une institution réunissant les gouverneurs des banques centrales ${ }^{104}$. Ces deux propositions se trouvaient déjà dans le mémorandum Marjolin du 30 août 1960. Le FER en est absent car cette idée est plutôt proche des réflexions de Triffin que de celles de Marjolin. De plus, il serait inutile si la méthode d'européanisation des responsables de la politique économique et monétaire est suivie.

Ces deux propositions de Marjolin suscitent des réactions assez mitigées. L'administration française y est favorable en principe - car elles s'inscrivent dans la doctrine française traditionnelle de l'équilibre entre libération et harmonisation, mais elle les juge largement « illusoires » en raison de la prégnance des intérêts nationaux sur ces questions monétaires ${ }^{105}$. De plus, certains représentants des banques centrales sont sceptiques comme en témoigne un article d'Otto Emminger (membre du directoire de la Bundesbank) ${ }^{106}$. Les banquiers centraux jouent un rôle fondamental dans la régulation du SMI à l'échelle européenne car l'UEP leur a donné l'habitude de se consulter et de développer une vision commune, en particulier à l'occasion de l'examen des pays en difficulté ${ }^{107}$. Cependant, ces banquiers centraux n'ont pas développé de vision spécifique de l'intégration européenne et ont plutôt tendance à situer leurs modalités d'intervention à l'échelle du SMI depuis 1959, comme en témoignent la faiblesse de l'AME et le développement d'instances de réflexions sur le SMI à l'échelle de l'espace atlantique (Groupe des Dix, « Groupe de Bellagio ») ${ }^{108}$. L'UEP est en effet une structure provisoire, l'échelle européenne n'étant adoptée qu'à défaut de l'échelle mondiale, le temps de la reconstruction.

Il s'agit donc de convaincre les banquiers centraux de l'utilité d'une échelle intermédiaire entre l'État et le SMI, au niveau de l'Europe des Six. Marjolin

104. Ibid., p. 10.

105. ABDF, 1489.2002.05, volume 46, réunion SGCI du 9 novembre 1962, compte rendu du 16 novembre 1962 ; AMINEFI, B 17.682, compte rendu d'une réunion «Lapautre, 1963 »; AMINEFI, B 62.158, note LB pour Esteva du 7 mars 1963.

106. AMINEFI, B 62128, note transmise par Bernard Rivain le 14 février 1963. L'article est paru le $1^{\text {er }}$ janvier 1963 dans le Zeitschrift für das Gesamte Kreditwesen.

107. Olivier Feiertag, «Banques centrales et relations internationales au XX ${ }^{\mathrm{e}}$ siècle : le problème historique de la coopération monétaire internationale », in Relations internationales, 1999, p. 372-374.

108. André de Lattre, «La coopération monétaire internationale, comités et réseaux », in Le rôle des ministères des Finances et de l'Économie dans la construction européenne (1957-1978), Comité pour l'histoire économique et financière de la France, Paris, 2002, p. 203 ; Jérôme Wilson, « Le groupe de Bellagio : origines et premiers pas (1960-1964) », in Michel Dumoulin (dir.), Réseaux économiques..., op. cit., p. 391-410. 
rencontre les gouverneurs des Six à Bâle le 2 décembre $1962^{109}$. Il défend l'instauration d'un comité des gouverneurs des banques centrales. Il veut obtenir une communautarisation des politiques économiques et monétaires non pas par une centralisation sur la Commission mais par la création d'un cadre où les contraintes seraient exercées par une multitude d'acteurs, supranationaux (Commission européenne), gouvernementaux et paragouvernementaux (gouverneurs de banques centrales, plus ou moins indépendants des gouvernements en fonction des pays). Marjolin réussit à obtenir le soutien des banquiers centraux à son projet de comité des gouverneurs ${ }^{110}$. Ces derniers soulignent toutefois qu'il devrait se réunir juste après la réunion de la BRI, ce qui montre la permanence de l'intérêt porté à une échelle de coopération plus large que celle de la CEE. Par ailleurs, les gouverneurs émettent des doutes sur les possibilités de mettre en place une réelle politique de consultation préalable. Enfin, pour reprendre les termes du débat sur l'union monétaire tels qu'ils se développent dans les années 1970 , ils se rallient à la conception «économique ${ }^{111} »:$ : l'union monétaire doit couronner l'union économique, dès lors la coordination des politiques monétaires doit s'étendre à la coordination des politiques budgétaires. Cet accord de principe suffit à Marjolin pour lancer sa véritable proposition de coopération monétaire et financière au sein de la CEE en 1963.

\section{Le lancement du projet : la communication du 19 juin 1963.}

Le 19 juin 1963, le collège des commissaires adopte la communication de la Commission au Conseil préparée par le vice-président Marjolin sur « La coopération monétaire et financière au sein de la Communauté économique européenne $^{112} \gg$. Elle s'inscrit dans la droite ligne du programme d'action de 1962 et surtout du mémorandum Marjolin du 30 août 1960. Elle est adoptée quelques jours avant la communication du 25 juillet 1963 sur la politique économique à moyen terme car les deux projets sont liés.

Marjolin propose de créer deux comités consultatifs, un Comité des gouverneurs des banques centrales de la CEE, et un Comité de politique budgétaire. Constitués des fonctionnaires nationaux compétents, ces deux organes

109. AFJM, ARM 32/1, notes manuscrites sur des conversations avec les gouverneurs à Bâle le 2 décembre 1962.

110. AFJM, ARM 32/1, avis des gouverneurs des banques centrales, 4 décembre 1962.

111. Selon la conception des «économistes», la convergence des politiques économiques doit précéder l'union monétaire. Selon les « monétaristes » (à ne pas confondre avec les disciples de Milton Friedman), la solidarité monétaire peut être organisée avant la convergence effective des politiques économiques.

112. AHUE, BAC, 3/1978, volume 990, folio 21, doc. II/COM(63) 216 final du 19 juin 1963, « La coopération monétaire et financière au sein de la Communauté économique européenne ». 
serviraient de forum pour confronter les politiques nationales. Par ailleurs, il souhaite renforcer les prérogatives du Comité monétaire par l'organisation de consultations préalables obligatoires tant sur les grandes questions monétaires internationales (fonctionnement du SMI, recours d'un État membre aux prêts du FMI ou participation à ses actions de soutien) que sur les modifications de taux de change. Une procédure très lâche est prévue : le Comité monétaire doit étudier la question et formuler un avis que la Commission devra utiliser pour faire une proposition au Conseil.

Sur le plan institutionnel, Marjolin a abandonné les ambitions de son mémorandum du 31 mai 1958 qui envisageait de conclure un nouveau traité. Suivant la méthode définie dans son mémorandum du 30 août 1960, il veut parvenir à une union monétaire par une intégration progressive des administrations nationales. Il compte sur la logique d'européanisation des esprits par la multiplication des comités de hauts fonctionnaires. Ils représentent une institution à base intergouvernementale, mais dont le fonctionnement est appelé à devenir de plus en plus communautaire, par le passage progressif des échanges de vues non contraignants à des consultations préalables obligatoires, et - même si ce n'est pas évoqué - de recommandations décidées à l'unanimité à des prescriptions coercitives votées à la majorité. Pour l'instant, Marjolin ne prévoit de consultations préalables obligatoires que dans le domaine du changement de parité, selon une procédure qui devra être définie.

Cette méthode prudente explique certainement l'abandon des projets de FER défendus par Monnet et Triffin. Mais ce choix peut aussi être justifié par l'évolution du SMI. Son instabilité croissante explique que la préoccupation de Marjolin soit plus la gestion de l'instabilité des changes que la mise en œuvre de l'article 108 - elle-même à la source de la création du FER. Le commissaire français s'appuie sur une doctrine intermédiaire entre les conceptions « monétaristes » et « économistes » qui repose sur une coordination en parallèle des politiques monétaires et des politiques économiques à court terme (par le biais de la politique budgétaire). Cette approche prudente paraît sage car les réactions des Etats membres sont assez réticentes.

\section{Le débat à Six et les décisions des 13-15 avril 1964 .}

Les États membres font preuve d'une grande méfiance institutionnelle devant les projets du commissaire français. Ils commandent une étude juridique au secrétariat général du Conseil sur ses propositions. Ce dernier répond à la fin de 1963 en la critiquant sur de nombreux points ${ }^{113}$. Elle estime que les

113. AMAE, RPUE 693, lettre de Calmes, SG Conseil, au COREPER, 4 octobre 1963. 
propositions de Marjolin accentuent une tendance ancienne qui prive le Conseil de ses prérogatives. En effet, de multiples institutions ont prospéré en contestant le monopole théorique du Conseil : réunions des ministres des finances qui créent des groupes de travail indépendants, Comité monétaire, comité de politique conjoncturelle. Cette note s'attaque donc de manière très claire à la méthode Marjolin. Cette dernière consiste non pas à s'attaquer de front aux prérogatives des États membres en demandant leur transfert à la Commission européenne, mais à diviser le pôle intergouvernemental en une multitude d'acteurs politiques (ministres des Affaires étrangères au Conseil, ministres des Finances au sein des réunions régulières) et administratifs (comités). Ceux-ci ont donc naturellement plus de mal à se coordonner face à une communautarisation progressive de leurs prérogatives. Au contraire, la Commission peut assurer un suivi plus cohérent de tous ces organismes car c'est un même service, la DG II, qui en assure bien souvent le secrétariat et qui rédige les documents exploratoires et de synthèse.

La Commission doit accepter de voir ses ambitions revues à la baisse. Elle présente donc un nouveau projet qui est accepté par le Conseil lors de sa session des 14 et 15 avril $1964^{114}$. La Commission obtient la création du Comité de politique budgétaire, du Comité des gouverneurs des banques centrales, et également du Comité de politique économique à moyen terme. Elle réussit également à élargir le mandat du Comité monétaire et à permettre que les Six se concertent en son sein sur les relations monétaires internationales. Par contre, la Commission n'a pas obtenu l'adoption de principes contraignants en matière de changement de parité des monnaies. Dans ce domaine, les Etats n'ont adopté qu'une déclaration secrète, émanant non pas du Conseil en tant qu'institution mais des représentants des Etats membres réunis au sein du Conseil. Ils acceptent une consultation préalable au sein du Comité monétaire, selon des procédures non contraignantes à définir ${ }^{115}$.

Marjolin obtient également le 14 avril 1964 que le Conseil accepte une recommandation de politique conjoncturelle aux six États membres ${ }^{16}$. Elle contient tout d'abord des prescriptions à caractère général comme la priorité à la stabilité monétaire (point 1). Pour cela, les États doivent adopter une politique budgétaire plus stricte et limiter « autant que possible » la croissance des « sorties du Trésor » à $5 \%$ (point 4). Un objectif chiffré clair est donc inscrit dans la recommandation. Les États devront aussi augmenter temporairement

114. AMINEFI, B 17.687, télex Boegner du 15 avril 1964.

115. AFJM, ARM 23/3, avis du Comité monétaire du 14 décembre 1964, transmis le 22 janvier 1965.

116. AHUE, BAC 62/1980, volume 7, folio 150, doc. Conseil T/206/64 final, 14 avril 1964. 
les impôts pour limiter la demande et réduire les déficits (point 5), appliquer une politique de crédit restrictive (point 7) et s'efforcer de mettre en œuvre une politique des revenus. La croissance économique étant forte, l'accent est mis sur le contrôle de l'inflation et l'équilibre des balances des paiements. Sur le plan de la procédure, la recommandation n'a aucun caractère contraignant : le point 14 prévoit simplement des rapports réguliers de la Commission sur l'application de ces mesures.

La mise en œuvre des décisions d'avril 1964 est d'ailleurs très difficile. Cela se perçoit avec le dossier italien. Marjolin souhaite profiter des difficultés financières et monétaires de l'Italie pour renforcer l'autorité de la Commission par la mise en œuvre de l'article 108. Comme la procédure d'attribution d'un concours mutuel n'est toujours pas définie, Marjolin se contente dans un premier temps de faire des recommandations de politique économique. Celles-ci sont adoptées par la Commission le 12 mai 1964 et envoyée dans une communication secrète au président du Conseil Italien ${ }^{117}$. Suivant la ligne définie dans la recommandation du 14 avril 1964, la Commission demande une politique restrictive : limitation de la progression des dépenses budgétaires, augmentation des impôts, restriction du crédit. Marjolin rencontre le président du Conseil Moro qui semble inscrire son action dans la ligne définie par la Commission ${ }^{118}$.

Mais le gouvernement Moro est renversé et l'Italie ne parvient pas à adopter un véritable plan de stabilisation. Marjolin envisage alors de demander à la Commission de proposer des mesures très fortes de solidarité envers l'Italie, fondées sur des facilités douanières des Cinq ${ }^{119}$. Le but est de soulager sa balance commerciale mais surtout d'affirmer clairement la solidarité de la Communauté avec l'Italie. Cette proposition de Marjolin montre clairement la finalité politique de son projet car des aides sont prévues alors que la politique de rigueur demandée n'est pas appliquée. Cependant, ces mesures paraissent peu réalistes. Une note française sur ces propositions de Marjolin souligne d'ailleurs que les Italiens n'ont rien demandé à ce propos ${ }^{120}$. En abandonnant son rôle d'expert impartial, au service de l'intérêt général de la conjoncture européenne, Marjolin prend ainsi le risque de discréditer son projet qui répond à des besoins réels des Six.

117. AHUE, procès-verbal de la $273^{\mathrm{e}}$ séance de la Commission du 12 mai 1964, folio 88 .

118. AHUE, procès-verbal spécial de la $278^{\mathrm{e}}$ séance de la Commission du 24 juin 1964.

119. AHUE, procès-verbal spécial de la $279^{\mathrm{e}}$ séance de la Commission du $1^{\mathrm{er}}$ juillet 1964.

120. AMINEFI, archives privées de Lattre, carton 2, liasse 10, chemise 14, note P. Colmant, 16 juillet 1964. 
Le bilan des décisions des 13,14 et 15 avril 1964 en matière de coordination des politiques économiques et monétaires est donc très ambivalent. D'un côté Marjolin a réussi à obtenir un renforcement de l'arsenal institutionnel consacré à la coordination des politiques économiques. Les observateurs français, au Quai d'Orsay comme au CNPF, considèrent d'ailleurs que ces décisions constituent un succès pour le commissaire français ${ }^{121}$. Cependant, Marjolin n'a pas réussi à obtenir d'engagements contraignants, que ce soit en termes de recommandation de politiques conjoncturelles ou de consultations préalables à un changement de parité. Les États membres résistent à toute tentative de coordination effective comme l'illustre le cas italien.

\section{CONCLUSION : L'UEM, UNE AMBITION ANCIENNE ET COMPLÉMENTAIRE DE LA PEMT}

Dès son entrée en fonction en 1958, Marjolin avait tenté d'accroître les prérogatives de la CEE en matière monétaire. Après l'échec de ses deux plans de 1958 et la restauration de la situation française, le vice-président français est devenu plus prudent. Il a d'abord profité d'un contexte favorable, reprenant à son compte tant l'idée de comité de politique conjoncturelle que la doctrine élaborée par les Six dans les négociations du SMI, fondée sur l'équilibre des balances des paiements et un rôle important accordé aux banques centrales dans la régulation du système.

Il a ensuite lancé un projet ambitieux qui est le complément direct du projet de politique économique à moyen terme, dont il reprend la méthode. Marjolin ne cherche pas à obtenir des délégations de souveraineté spectaculaires à la Commission par un nouveau traité ou par un règlement ambitieux, comme le règlement 17/62. Il n'oppose pas le pôle intergouvernemental et le pôle supranational mais veut diviser le premier en multipliant les comités de hauts fonctionnaires. Ces derniers devraient progressivement intégrer la dimension communautaire à leur action et ainsi européaniser leurs actions nationales. Le passage progressif de discussions non contraignantes a posteriori à des consultations obligatoires a priori doit concrétiser institutionnellement cette européanisation.

La méthode institutionnelle est donc la même que pour la coordination des politiques économiques à moyen terme mais les réseaux sont différents.

121. AN, 5 AG1, volume 248, note de René de Saint-Légier du 20 avril 1964 ; AMAEF, DECE 1298, note de Maurice Ulrich du 22 avril 1964 ; Jean Louis, discours prononcé lors de l'assemblée générale du CNPF du 16 juin 1964, in Bulletin du CNPF, n² 242, juillet 1967, p. 22-26. 
Marjolin s'appuie en effet sur des chocs extérieurs (dossier britannique, crise du SMI) pour faire progresser son projet, sur la communauté des banquiers centraux qui a développé un embryon d'identité monétaire européenne, et sur le réseau Triffin-Monnet. La doctrine de Marjolin tient compte notamment de certaines exigences allemandes en matière de rigueur budgétaire et de surveillance étroite de l'inflation.

Marjolin définit ses idées dans la communication du 19 juillet 1963, partiellement appliquée dans les décisions des 14 et 15 avril 1964. Trois comités sont créés tandis que le Comité monétaire voit ses prérogatives s'accroître. Enfin une recommandation contenant un objectif chiffré du maximum de progression des dépenses publiques est adoptée. Cependant, Marjolin ne parvient pas à obtenir de délégations de souveraineté effectives. La CEE ne joue aucun rôle dans la crise de la balance des paiements italienne de 1964 ; aucun progrès réel ne semble donc avoir été effectué depuis la réévaluation du deutschmark de 1961. De plus, la Commission souffre d'un conflit interne croissant entre l'Europe économique volontariste de Marjolin et les partisans d'une intégration économique ordolibérale.

\section{LE CONFLIT ENTRE L'EUROPE ORGANISÉE ET L'EUROPE ORDOLIBÉRALE}

Face au développement de ce projet volontariste d'Europe organisée de Marjolin, les défenseurs d'une interprétation ordolibérale de l'intégration européenne réagissent de manière négative. Pour ces derniers, la CEE pourrait servir à diminuer les interventions perturbatrices des autorités publiques et privées sur le marché. Pour Marjolin au contraire, les interventions désordonnées des différents acteurs publics et privés des Six doivent être coordonnées. Le marché doit être corrigé et orienté, et pas simplement régulé. C'est l'Europe volontariste, fondée sur une organisation de l'économie à partir de choix politiques clairs, face à une Europe arbitre qui repose au contraire sur une neutralité des interventions publiques dans l'économie.

Ce conflit doctrinal débouche sur des accrochages récurrents au sein de la Commission européenne entre les deux commissaires, Robert Marjolin et Hans von der Groeben, et leurs DG, DG II et DG IV. De 1959 à 1964, les conflits concernent les deux projets respectivement mis en valeur dans les deux services, la programmation européenne et la politique de la concurrence. À partir de 1964, la concentration des entreprises s'impose comme un nouveau sujet de controverse. 


\section{A. UNE OPPOSITION CROISSANTE \\ ENTRE DEUX CONCEPTIONS ÉCONOMIQUES (1959-1964)}

Très rapidement, un décalage entre les deux conceptions de la construction européenne se fait jour entre deux commissaires aux compétences proches.

\section{Une rivalité structurelle.}

Les responsabilités attribuées à Marjolin et à von der Groeben concernent tous les deux l'action économique à caractère général. Nicole Condorelli-Braun souligne le contraste entre les deux hommes : d'un côté, Hans von der Groeben avait une « haute silhouette [qui] lui donnait l'allure d'un diplomate prussien. $\mathrm{Au}$ contraire, Robert Marjolin avait l'air d'un intellectuel bien français... ${ }^{122}$. On peut également opposer le chrétien-démocrate allemand au socialiste français planificateur. Par ailleurs, selon les archives allemandes étudiées par Katja Seidel, une première répartition des compétences avait attribué la politique de la concurrence à Marjolin dans un très vaste département économique et financier ${ }^{123}$. Mais à la demande de Bonn, la politique de la concurrence a été érigée en département indépendant.

Enfin, l'opposition de principe entre les deux hommes peut également être issue de leurs ambitions et de leur dynamisme propre. Marjolin et von der Groeben sont des spécialistes des négociations économiques européennes, tous deux issus de grands pays de la CEE qui ont chacun développé une voie économique propre, à la fois originale et pleine de succès. Ils arrivent sans doute à Bruxelles avec des idées précises sur ce qu'ils souhaitent faire, en tout cas avec des ambitions plus importantes que d'autres commissaires secondaires ou épisodiques. Ils s'entourent d'ailleurs de conseillers issus du monde académique afin de renforcer leur expertise technique et leur capacité de proposition. Von der Groeben s'appuie notamment sur Mestmäcker et Marjolin sur Triffin et Uri. Leurs projets européens respectifs suscitent de fortes critiques réciproques.

\section{Les critiques réciproques des travaux entrepris au sein de la Commission.}

À la base de la démarche volontariste de Marjolin figure la nécessité de réunir des informations macroéconomiques suffisamment nombreuses et précises

122. Nicole Condorelli-Braun, Commissaires et juges..., op. cit., p. 162.

123. Katja Seidel, «Establihing an Economic Constitution for Europe... », p. 133-135. 
pour pouvoir servir de base à un processus de coordination. Cette démarche initiale suscite la méfiance des ordolibéraux allemands. Elle s'exprime d'abord au sein du comité de politique conjoncturelle, où Müller-Armack s'oppose aux projets de Marjolin de multiplier les études macroéconomiques ${ }^{124}$. Au sein de la Commission ensuite, ce sont les travaux du groupe Uri qui posent problème. Marjolin souhaite donner une large diffusion au rapport de 1962 et pose la question de sa publication par la Commission ${ }^{125}$. Von der Groeben y est opposé. Il obtient que le rapport soit publié sous la seule responsabilité des experts et que l'avant-propos de la Commission soit amendé ${ }^{126}$.

De son côté Marjolin commence à émettre des doutes sur la démarche adoptée par son collègue pour développer la politique de la concurrence. En septembre 1960, au moment de la présentation de la proposition de von der Groeben qui inspira le règlement 17/62, Marjolin critique certains aspects du projet, comme le système de la déclaration obligatoire ou le caractère incomplet du règlement (il ne concerne ni l'article 86, ni certains types d'accords particulièrement visés par la législation française comme les accords d'exclusivité) ${ }^{127}$. Le vice-président français se rallie toutefois au règlement en soulignant son progrès par rapport au texte antérieur, en l'espèce la création d'un Comité consultatif composé de représentants des États membres ${ }^{128}$. Selon les notes manuscrites d'Émile Noël, Marjolin précise : « les interventions des gouvernements sont seulement d'information et de consultation. Donc pleine liberté de la Commission maintenue. Dans cette perspective, une association limitée des gouvernements est bénéfique et [illisible], convergence des critères appliqués sur plan national et européen. Harmonisation national/européen utile et nécessaire, et système von der Groeben de consultation peut la développer ${ }^{129} \gg$. Bien que schématiques, ces notes d'Émile Noël sont très utiles pour comprendre la démarche institutionnelle de Marjolin : il s'agit de mettre en avant une logique de coopération et même

124. AMINEFI, B 17.688, compte rendu de la $7^{\mathrm{e}}$ réunion du comité de politique conjoncturelle du 12 septembre 1961.

125. AHUE, BAC 62/1980, volume 3, folio 236, note de la Commission, 28 juin 1962 ; AHUE, BAC 62/1980, volume 3, folio 234, procès-verbal de la $194^{\mathrm{e}}$ réunion de la Commission, 18-19 juillet 1962.

126. AHUE, BAC 62/1980, volume 3, folio 212 , procès-verbal de la $201^{\mathrm{e}}$ réunion de la Commission du 10 octobre 1962.

127. AHUE, EN 722, notes manuscrites d'Émile Noël sur la $116^{\mathrm{e}}$ session de la Commission, réunion du 14 septembre 1960 ; notes manuscrites d'Émile Noël sur la $117^{\mathrm{e}}$ session de la Commission, réunion du 21 septembre 1960.

128. AHUE, EN 1269, note Richard pour Noël, 24 octobre 1960 ; AHUE, EN 722, notes manuscrites d'Émile Noël sur la session de la Commission du 26 octobre 1960.

129. AHUE, EN 722, notes manuscrites d'Émile Noël sur la session de la Commission du 26 octobre 1960. 
d'interpénétration des administrations nationales et communautaires, pour que l'intérêt européen imprègne progressivement les fonctionnaires nationaux. On retrouve la méthode de l'européanisation, qu'il souhaite appliquer à ce même projet de règlement qui est interprété au contraire dans un sens beaucoup plus centralisateur par von der Groeben. Au-delà des controverses institutionnelles, c'est bien une opposition de doctrine économique qui commence à se manifester à partir de 1962 .

\section{Le débat intellectuel (1962-1964).}

Le grand colloque de Rome de 1962 sur la programmation économique a été l'occasion pour Marjolin et les milieux favorables à la planification de critiquer l'orientation de la politique de la concurrence communautaire, alors que les imperfections du règlement 17/62 commencent à apparaître. Dans son discours de doctrine, tout en encourageant le développement de la politique de la concurrence, il la soumet clairement aux impératifs définis par la programmation: «Le programme aura notamment pour rôle de guider les autorités qui, dans la Communauté, ont pour tâche de dire dans quelle mesure les pratiques commerciales restrictives peuvent être maintenues dans certains cas et pour une durée déterminée, en raison des exigences du développement économique ${ }^{130} \gg$. L'action de la DG IV se trouve donc directement encadrée.

Un peu plus loin, Marjolin affirme : « Parlant au nom de la Commission du Marché commun, je peux dire que ce n'est pas de notre faute si la législation communautaire sur les positions dominantes et les concentrations n'est pas plus vigoureuse qu'elle n'est; nous sommes décidés à appliquer le traité tel qu'il est, en ce qui me concerne personnellement, je le dis ici pour la suite de la discussion, je serais favorable à une législation antitrust beaucoup plus forte que celle que nous avons et qui se rapprocherait de la législation américaine ${ }^{131} \gg$. En apparence, Marjolin associe donc programmation et politique de la concurrence dans la même recherche d'une efficacité économique maximale. Mais ce plaidoyer en faveur d'une politique de la concurrence communautaire forte ne doit pas être confondu avec une défense du règlement 17/62. Le commissaire français demande en effet une politique plus forte envers les positions dominantes et les concentrations, or c'est justement un domaine que le règlement 17/62 ignore délibérément (en dehors de dispositions secondaires) pour se concentrer sur

130. Robert Marjolin, « Rapport général », in La programmation économique européenne..., op. cit., p. 24.

131. La programmation économique européenne..., op. cit., intervention de Robert Marjolin lors de la séance du 30 novembre 1962 au matin. 
la lutte contre les ententes. Marjolin reprend ici la critique traditionnelle des milieux français inquiets d'une distorsion de concurrence entre l'application des articles 85 et 86 .

Cette offensive suscite une réaction des ordolibéraux. Au sein du gouvernement allemand, c'est Ludwig Erhard en personne qui sonne la charge contre le projet de Marjolin seulement quelques jours après le colloque de Rome, par un discours très vif au Parlement européen le 20 novembre $1962^{132}$. Son offensive est relayée notamment par une intervention d'Alfred Müller-Armack au comité de politique conjoncturelle de juillet $1963^{133}$.

Les membres de la Commission proches de ce réseau ordolibéral allemand émettent des critiques plus feutrées. C'est notamment le cas de von der Groeben, qui s'exprime lors d'un grand colloque organisé en Allemagne en 1963 sur la planification, justement pour discuter de ce concept nouveau en RFA, où il est très critiqué ${ }^{134}$. Von der Groeben place tout d'abord des limites claires à la programmation européenne : elle ne doit jamais être impérative ni sectorielle, mais simplement concerner des prévisions globales ${ }^{135}$. Surtout, il insère tous les projets de politique économique européenne, y compris la programmation, dans le cadre libéral de la politique de la concurrence qui est celui du traité de Rome ${ }^{136}$. Dans un témoignage de 2003, von der Groeben refuse certes de considérer qu'il avait un conflit avec Marjolin, avec lequel ses rapports personnels étaient bons, mais il reconnaît que les ambitieux projets économiques du commissaire français créaient de vifs débats au sein de la Commission, en particulier avec ses services ${ }^{137}$.

Un débat intellectuel oppose donc tenants et adversaires du projet de programmation européenne. Cette opposition s'exprime naturellement et de manière plus directe au sein de la Commission européenne.

132. Parlement Européen, Comptes rendus in extenso des séances, 1963/III, n 60, séances du 19 au 23 novembre 1962, séance du mardi 20 novembre 1962, p. 51-56.

133. AMINEFI, B 17.688, compte rendu de la $14^{\mathrm{e}}$ session des 8 et 9 juillet 1963 du comité de politique conjoncturelle.

134. "Vorwort der Herausgebers », in Alfred Plitzko (éd.), Planung Ohne Planwirtschaft, Kyklos, Bâle, 1964, p. V-VIII.

135. Hans von der Groeben, «Wettbwerb und Programmierung als Instrumente der Wirtschaftspolitik im Gemeinsamen Markt », in A. Plitzko (éd.), Planung..., op. cit., p. 195 et p. 198.

136. Ibid., p ; 191 et p. 194.

137. AO/AHUE, interview de Hans von der Groeben le 16 décembre 2003 par Wilfried Loth et Véronika Heyde, p. 9 et p. 31. 


\section{La critique du projet de politique économique à moyen terme.}

Entre le projet présenté par Marjolin lors du colloque de la fin 1962 et la communication de la Commission au Conseil de juillet 1963, de notables différences apparaissent. Elles s'expliquent par les débats au sein du collège des commissaires. Les principales modifications sont opérées entre la réunion de la Commission du 17 juillet $1963^{138}$, où une première version de communication est présentée, et la session suivante des 24 et 25 juillet $1963^{139}$, où la version définitive, qui engage l'ensemble de la Commission, est adoptée. À cette occasion, la DG IV développe ses critiques du projet de Marjolin.

C'est tout d'abord le directeur général de la DG IV Verloren van Themaat qui estime que les ambitions de coordination des politiques économiques de cette communication sont excessives ${ }^{140}$. En interne, une note du directeur des aides de la DG IV, le français Armand Saclé, est plus précise ${ }^{141}$. Il estime que son domaine de compétence, les aides d'État, est directement menacé par le projet. La DG IV entreprend ensuite une étude plus détaillée d'une version de la communication de Marjolin présentée le 17 juillet $1963^{142}$. Elle contient de nombreuses critiques manuscrites. La DG IV doute de la fiabilité des études prévisionnelles, qui sont à la base du fondement technocratique du projet. Elle s'inquiète de l'extension des études sectorielles, car elles pourraient servir de base à un élargissement des compétences du Comité. Plus généralement, elle déjoue les précautions utilisées par Marjolin pour présenter son projet comme complémentaire de la politique de la concurrence.

Dans le collège des commissaires, l'opposition entre Marjolin et von der Groeben se manifeste lors des sessions de juillet $1963^{143}$. Le commissaire allemand est celui qui demande le plus grand nombre de modifications. Il obtient ainsi la transformation de l'ancien paragraphe 18 de la version du 10 juillet $1963^{144}$. Il portait sur le lien entre études prospectives et établissement d'objectifs macroéconomiques et était gratifié du commentaire manuscrit : «Ce n'est pas très sérieux » dans le document de la DG IV annotant le projet initial de

138. AHUE, procès-verbal de la $236^{\mathrm{e}}$ réunion de la Commission du 17 juillet 1963.

139. AHUE, procès-verbal de la $237^{\mathrm{e}}$ réunion de la Commission des 24-25 juillet 1963.

140. AHUE, BAC 62/1980, volume 7, folio $\mathrm{n}^{\circ} 405$, note de $\mathrm{P}$. Verloren van Themaat à $\mathrm{F}$. Bobba, 10 juillet 1963.

141. AHUE, BAC 62/1980, volume 7, folio ${ }^{\circ} 408$, note de A. Saclé au DG P. Verloren van Themaat du 16 juillet 1963.

142. AHUE, BAC 62/1980, volume 7, folio $\mathrm{n}^{\circ} 381$, projet de communication de la Commission au Conseil, 10 juillet 1963, doc. II/COM (63) 271.

143. AHUE, procès-verbaux des $236^{\mathrm{e}}$ et $237^{\mathrm{e}}$ session de la Commission des 17 et 24-25 juillet 1963 , respectivement points 16 et 37.

144. AHUE, BAC 3/1978, volume 1067, folio $\mathrm{n}^{\circ} 272$. 
Marjolin $^{145}$. La nouvelle rédaction du paragraphe 18 établit clairement que les études ne sauraient en aucune manière être considérées comme des objectifs pour les acteurs privés.

Les domaines de Marjolin et de von der Groeben sont indissolublement liés et en même temps strictement contradictoires dans la doctrine économique qu'ils défendent. Par-delà les conflits initiaux portant sur les premiers projets défendus par les deux camps, l'opposition se transforme tout en se perpétuant avec l'émergence d'un nouveau dossier, celui de la concentration des entreprises de la CEE.

\section{B. LA POURSUITE DES CONFLITS DOCTRINAUX : LE DOSSIER DE LA CONCENTRATION (1964-1966)}

À partir de 1964, les deux projets commencent à s'appliquer de manière parallèle, la politique de la concurrence avec la décision " Grudig-Consten » (septembre 1964) et la coordination des politiques économiques avec les décisions d'avril 1964. Profitant d'une dynamique intellectuelle favorable, le commissaire français s'emploie alors à réorienter la politique de la concurrence d'une vision ordolibérale vers une acception plus pragmatique à partir de 1964 , en profitant du débat sur la concentration lancé par l'UNICE.

\section{Les réflexions de l'UNICE sur la concentration.}

Les années 1964 et 1965 sont marquées par un réinvestissement par le patronat de la thématique de l'organisation économique de l'Europe par le biais de la thématique de la concentration. La libéralisation accélérée du commerce international (baisse du TEC, Dillon Round et futur Kennedy Round) renforce considérablement la compétition internationale, et notamment l'influence des entreprises américaines en Europe. Elles profitent de l'unification commerciale des marchés des Six pour s'y établir en profitant de leur puissance sans commune mesure avec celle de leurs concurrentes européennes. La seule solution serait de favoriser la concentration des entreprises européennes, par des fusions ou au moins par des ententes. Or la politique répressive de la DG IV en matière d'ententes semble freiner ces regroupements. De plus, von der Groeben manifeste la volonté de doter la Commission d'un pouvoir de contrôle des concentrations, et plus seulement des ententes ${ }^{146}$. En août 1963, il lance une série de consultations

145. AHUE, BAC 62/1980, volume 7, folio $\mathrm{n}^{\circ} 387$, projet de communication de la Commission au Conseil, 10 juillet 1963, doc. II/COM (63) 271.

146. AHUE, BAC 26/1969, volume 601, note de von der Groeben pour Marjolin, 5 juillet 1963. 
de professeurs sur les moyens d'appliquer respectivement les articles 85 et 86 au contrôle des concentrations ${ }^{147}$. Le risque pèse d'une action répressive de la DG IV dans ce domaine.

L'UNICE se mobilise alors. En février 1964, les présidents des fédérations nationales de l'UNICE manifestent clairement la nécessité de mener une contreoffensive intellectuelle en présentant une interprétation globale des articles 85 et 86 qui insiste sur la nécessité de favoriser la coopération et la concentration entre les entreprises ${ }^{148}$. L'UNICE parvient à s'imposer dans le débat public sur cette question en diffusant une note sur la taille comparée des entreprises européennes et américaines en mars $1965^{149}$, qui s'inspire d'une étude déjà diffusée en France fin $1964^{150}$. Constatant l'accélération des fusions aux États-Unis, la note souligne la faiblesse de 1'Europe des Six en matière de structures industrielles. Sur les 500 plus grandes entreprises mondiales, 306 sont américaines, 53 britanniques, 38 japonaises. Face à elles se dressent 72 entreprises de l'Europe des Six (plus deux anglo-hollandaises) dont 33 allemandes et 25 françaises. Dans le secteur automobile par exemple, le chiffre d'affaire de la première entreprise américaine (General Motors) est neuf fois plus élevé que celui de la première entreprise européenne (Volkswagen). L'étude conclut sur la nécessité impérative d'encourager les concentrations en Europe non pas par une action dirigiste des pouvoirs publics mais par un aplanissement des obstacles légaux et administratifs.

Cette note est publiée à un moment opportun pour l'UNICE car elle s'impose comme un document de référence dans un débat sur la concentration qui commence à être évoqué dans les institutions européennes. Lors du Conseil du 2 février 1965 par exemple, von der Groeben fait référence aux vœux des milieux économiques d'encourager la concentration pour faire face à la concurrence américaine ${ }^{151}$. La mobilisation rapide de l'UNICE peut s'expliquer par le fait que cette thématique de la concentration suscite moins de controverses que la politique de la concurrence car elle constitue simplement une question de principe, et pas une prise de position sur une négociation en cours. Marjolin s'appuie sur cette contribution positive et ambitieuse à l'organisation

147. ASGCI, 1990.0452, article 23, lettre de la Commission européenne, DG IV à Boegner, 26 août 1963.

148. ACNPF, 72 AS 1544, compte rendu de la réunion des présidents UNICE, 14 février 1964.

149. AHUE, BAC 26/1969, volume 601, lettre de H.J. de Koster au président Walter Hallstein du 3 mars 1965 ; ASGCI, 1979.0791, volume 101, lettre de la CEE envoyant ce document au SGCI, 16 mars 1965.

150. AMAE, DECE 1261, intervention de Georges Villiers dans la Correspondance économique du 5 septembre 1964.

151. ASGCI, 1988.0516, article 4, compte rendu du Conseil du 2 février 1965. 
économique de l'Europe pour conduire l'opposition à la DG IV dans le dossier de la concentration.

\section{L'inflexion apparente de la politique de la concurrence.}

En 1965, face à cette offensive sur le front de la concentration et dans un contexte de développement de la politique économique à moyen terme, von der Groeben prononce un grand discours au Parlement européen le 16 juin 1965, où il tente de réaffirmer son leadership en matière de définition de l'organisation économique de la $\mathrm{CEE}^{152}$. Intitulé « La politique de la concurrence, partie intégrante de la politique économique dans le Marché commun », le discours affirme que la politique de la concurrence doit jouer un rôle majeur car « les mesures de la Commission ne se limitent nullement à des interventions ponctuelles dans le cas d'espèce, elles tendent au contraire, comme je l'ai exposé aujourd'hui, toujours davantage vers des réglementations générales ». Cela s'inscrit dans la vision ordolibérale de l'Europe arbitre, car von der Groeben veut faire de la politique de la concurrence une véritable constitution économique pour l'Europe. Il évoque ensuite l'action publique comme une nécessité mais qui doit être sévèrement contrôlée : «Les interventions reconnues nécessaires doivent être coordonnées et aménagées de telle sorte qu'elles n'affectent le libre jeu du marché que dans la mesure absolument indispensable ». C'est le rôle de la politique économique à moyen terme de réaliser ce processus de rationalisation, donc d'appliquer sectoriellement (aux autorités publiques) les principes généraux définis par la politique de la concurrence. Il termine sa conclusion sur une note consensuelle : la politique économique à moyen terme et la politique de la concurrence ne sauraient s'opposer. Cette observation paraît logique car il subordonne la première à la seconde. La politique de la concurrence donne un cadre doctrinal tandis que la politique économique à moyen terme est chargée de promouvoir les règles de concurrence dans les domaines résiduels qui ne la connaissent pas encore (le secteur public).

Par la suite, à la réunion de la Commission du 19 mai 1965, von der Groeben annonce un mémorandum sur la question de la concentration ${ }^{153}$. Marjolin demande et obtient d'être associé aux travaux. La DG IV cherche à élaborer un document destiné à fixer une doctrine économique et à trouver les moyens juridiques (à partir des articles 85 et 86) d'une action communautaire dans ce

152. AMAE, RPUE 615, discours de Hans von der Groeben devant le Parlement européen, 16 juin 1965.

153. AHUE, BAC 26/1969, volume 601, procès-verbal de la réunion de la Commission du 19 mai 1965. 
domaine. Une première version est présentée en septembre 1965 mais la DG II multiplie les critiques de fond ${ }^{154}$. Elle reproche à certaines parties rédigées par la DG IV leur caractère superficiel sur le plan économique ${ }^{155}$. Pour la DG II, le document élude le problème fondamental des rapports entre la politique de la concurrence et la concentration, et celui de la taille optimale. Il semble que la DG IV ne veuille pas limiter sa marge de manœuvre future en la matière en fixant par avance une doctrine d'intervention trop rigide. Même après son adoption le $1^{\text {er }}$ décembre 1965, Franco Bobba, le directeur général de la DG II, critique le communiqué de presse résumant ce document, estimant qu'il insiste trop sur la troisième partie (moyens de surveiller la concentration par les articles 85 et 86) et pas assez sur la première (justifications économiques de la concentration) ${ }^{156}$. Les conflits continuent par la suite entre les deux directeurs généraux, Bobba (DG II) et Verloren van Themaat (DG IV), le premier accusant notamment la DG IV d'avoir diffusé un document contenant des études réalisées en fait par la DG II ${ }^{157}$.

Le dossier de la concentration, qui émerge seulement à partir de 1964, montre la profondeur du conflit doctrinal entre la DG II de Marjolin et la DG IV de von der Groeben. La nouveauté réside plutôt dans le rôle moteur qu'a réussi à prendre l'UNICE dans ce débat intellectuel. La thématique de l'insuffisante concentration des entreprises européennes face à leurs concurrentes américaines devient rapidement consensuelle au sein des milieux économiques et de nombreux décideurs européens. Elle ne parvient pourtant pas à apaiser les oppositions entre modèles économiques qui s'expriment au sein de la Commission.

Dans les années 1964 et surtout 1965, à ce débat économique se superposent des controverses politiques sur les meilleurs moyens de faire progresser l'intégration politique. La figure du président Hallstein, qui apparaissait peu dans ces débats économiques, s'impose alors sur le devant de la scène. Ses ambitions contredisent directement la stratégie de Marjolin, conduisant à une tension croissante jusqu'à la crise de la chaise vide.

154. AHUE, BAC 26/1969, volume 602, procès-verbal de la $329^{\mathrm{e}}$ réunion de la Commission du 15 septembre 1965 , point VI.

155. AHUE, BAC 26/1969, volume 602, folio 3, note DG II-D du 3 septembre 1965 ; AHUE, BAC 26/1969, volume 602, folio 30, note DG II-D du 26 septembre 1965 ; AHUE, BAC 26/1969, volume 602, folio 22, note DG II-D du 11 octobre 1965.

156. AHUE, BAC 26/1969, volume 603, folio 13, note de DG II-D signée Franco Bobba, 18 janvier 1966.

157. AHUE, BAC 26/1969, volume 603, folio 21, note de Bobba à Verloren van Themaat, 2 février 1966 ; idem folio 46, note de Verloren van Themaat à Bobba, 8 mars 1966. 


\section{L'AFFRONTEMENT ENTRE MARJOLIN ET HALLSTEIN : LA CRISE DE LA CHAISE VIDE}

La crise de la chaise vide a fait l'objet de très nombreuses études historiques fondées sur des sources multiples ${ }^{158}$. Elles ont en commun de se concentrer principalement sur les États membres ${ }^{159}$, en considérant la Commission européenne comme un acteur homogène, uni derrière Hallstein, ou au contraire divisé suivant des clivages nationaux. Ainsi, lorsque les dissensions en son sein sont évoquées à propos du projet Hallstein de mars 1965 qui mena à la chaise vide, elles sont généralement implicitement expliquées par la nationalité française des deux commissaires Marjolin et Rochereau ${ }^{160}$. Or il est possible de démontrer que les réactions de Marjolin, peu étudiées en tant que telle par l'historiographie ${ }^{161}$, sont liées non pas à sa défense d'un intérêt national français mais à sa volonté de défendre un projet d'intégration européenne différent de celui d'Hallstein. Ce projet de Marjolin se fonde sur la promotion de ses projets de politique économique à moyen terme et de coordination des politiques économiques et monétaires. Ils reposent tous deux sur le développement d'une méthode progressive d'européanisation des esprits qui s'apparente à la logique néofonctionnaliste. Or, entre la fin 1964 et le début de 1965, juste avant la crise de la chaise vide, la doctrine néofonctionnaliste du commissaire européen français Robert Marjolin s'est opposée frontalement à stratégie fédéraliste du président de la Commission européenne Walter Hallstein.

158. Pour plus de précisions sur les aspects théoriques : Laurent Warlouzet, « Relancer la CEE avant la chaise vide : néofonctionnalistes $v s$ fédéralistes au sein de la Commission européenne (19641965) », in Revue d'histoire de l'intégration européenne, 2008, 14-1, p. 69-86.

159. Les études par pays les plus récentes se trouvent principalement dans deux recueils de contributions : Wilfried Loth (éd.), Crisis and Compromises : The European project, 1963-1969, Bruylant, Bruxelles, 2001 ; Jean-Marie Palayret, Helen Wallace, Pascaline Winand (éd.), Visions, Votes and Vetoes. The Empty Chair Crisis and the Luxembourg Compromise. Forty Years On, Bruxelles, Peter Lang, 2006. L'étude de Piers Ludlow inclut la perspective de la Commission européenne mais sans étudier les différentes lignes qui s'affrontent en son sein : Piers Ludlow, The European Community and the Crises of the 1960s. Negotiating the Gaullist Challenge, Routledge, Londres, 2006, p. 40-70. Enfin Philippe Bajon termine une thèse sur la chaise vide ; voir : Philippe Bajon, «The Empty Chair Crisis, 1965-1966 from a French Perspective », in Morten Rasmussen, Ann-Christina Knudsen, Jens Rungen Poulsen (éd.), The Road to a United Europe. Interpretations of the Process of European Integration, Peter Lang, Bruxelles, à paraître en 2010.

160. Jean-Marie Palayret, «De Gaulle Challenges the Community : France, the Empty Chair Crisis and the Luxembourg Compromise », in J.-M. Palayret, H. Wallace, P. Winand (éd.), Visions..., op. cit., p. 52 et 63 ; Wilfried Loth, « Hallstein and de Gaulle : the Disastrous Confrontation », in Wilfried Loth, William Wallace, Wolfgang Wessels, Walter Hallstein. The Forgotten European?, St Martin's Press, Londres, 1998, p. 141.

161. Hormis : Gérard Bossuat, « Robert Marjolin dans la tourmente de la chaise vide », in Institut de France (éd.), Robert Marjolin. Colloque du 9 décembre 2003, Institut, Paris, 2004, p. 66-82. 
Les fédéralistes adoptent une démarche institutionnelle de nature juridique et politique : ils souhaitent faire progresser l'intégration européenne par des traités internationaux spectaculaires, qui manifestent clairement et publiquement un transfert de souveraineté ${ }^{162}$. La dimension populaire est importante : le peuple doit être consulté et associé à la démarche.

$\mathrm{Au}$ contraire les néofonctionnalistes sont guidés par un certain optimisme rationalisateur ${ }^{163}$. Ils insistent sur la création d'institutions supranationales qui sont nécessaires pour créer et orienter le spill-over, cette dynamique qui étend progressivement les délégations de souveraineté d'un secteur à l'autre. L'idée consiste à mettre en commun des compétences dans un domaine technique, puis de proche en proche, de parvenir aux domaines les plus politiques. Les néofonctionnalistes sont donc plus prudents que les fédéralistes. Ils défendent une approche plus progressive, élitiste et technocratique.

La définition de la doctrine européenne de Walter Hallstein à la lumière de cette opposition divise les historiens. Ainsi, Matthias Schönwald estime qu'Hallstein a été très influencé par la doctrine fédérale allemande qui a guidé son action en 1965 et $1966^{164}$. Au contraire Jonathan White souligne la force des liens existants entre l'école néofonctionnaliste et Walter Hallstein. S'appuyant sur les papiers Hallstein et le témoignage de l'un de ses collaborateurs, il montre que le président de la Commission connaissait manifestement ces doctrines en $1965^{165}$. Or, l'étude des archives montre qu'Hallstein a agi au premier semestre 1965 de manière nettement fédéraliste, provoquant l'hostilité de Marjolin, resté fidèle à une méthode qui peut être qualifiée de néofonctionnaliste. Cette différence se perçoit nettement dès l'étude des trois projets de relance de la CEE des années 1964-1965.

\section{A. LES TROIS PROJETS DE RELANCE DE LA CEE}

L'échec du projet intergouvernemental français du plan Fouchet en 1962 et les tensions internes à la Communauté depuis le rejet de la candidature britannique en 1963 ont laissé la CEE dans un état d'incertitude quant à son

162. Le fédéralisme est entendu dans son sens le plus ambitieux et pas sous la forme dite « gradualiste » : René Schwok, Théories de l'intégration européenne, Montchréstien, Paris, 2005, p. 31.

163. Voir les ouvrages classiques néofonctionnalistes : Ernst Haas, The Uniting of Europe. Political, Social and Economic Forces, 1950-1957, Stanford UP, Stanford, 1958 ; Leon Lindberg, The Political Dynamics of European Economic Integration, Stanford UP, Stanford, 1963.

164. Matthias Schönwald, «Walter Hallstein and the « Empty Chair» Crisis 1965/66», in Wilfrid Loth (éd.), Crisis and Compromises, op. cit., p. 157-171.

165. Jonathan White, «Theory Guiding Practice : the Neofunctionalists and the Hallstein EEC Commission », in Revue d'histoire de l'intégration européenne, 2003/1, p. 111-131. 
avenir que trois projets de relance tentent de combler. La RFA tout d'abord cherche à occuper la place de moteur que la France avait un temps pu représenter en soutenant un projet d'Europe politique. Marjolin ensuite, développe progressivement son projet d'union économique et monétaire. Walter Hallstein enfin, prend brutalement l'offensive en mars 1965 avec ses propositions de nature fédéraliste.

\section{Le projet du gouvernement allemand : Europe politique et Europe libérale.}

Au début de 1963 et jusqu'à la crise de la chaise vide, la RFA est l'un des pays moteur de la CEE. Les ministres libéraux et atlantistes du gouvernement allemand - le ministre de l'Économie Erhard et le ministre des Affaires étrangères Schröder - profitent du discrédit de la France pour tenter de relancer la CEE ${ }^{166}$. La RFA relance les discussions communautaires par un discours prononcé par Gerhard Schröder au Conseil du 2 avril 1963, puis par un mémorandum déposé le 19 avril $1963^{167}$. D'autres propositions suivent en 1964 et $1965^{168}$.

Toutes ces tentatives de relance allemande de la CEE mettent l'accent sur la nécessité d'un renforcement majeur de la dynamique économique libérale, notamment par les négociations du Kennedy round ou l'accélération de la libération interne des échanges ${ }^{169}$. En matière institutionnelle, le gouvernement allemand est plus prudent. Dès le programme de travail du 19 avril 1963, la RFA affirme l'une de ses priorités : améliorer et rationaliser le processus de décision au Conseil ${ }^{170}$. Il s'agit de hiérarchiser les dossiers pour que le Conseil ne se perde pas dans les dossiers techniques et puisse donner les impulsions sur les grands dossiers économiques. Le mémorandum du 5 novembre 1964 prévoit même de créer à côté de la CEE une organisation chargée de développer la coopération intergouvernementale entre les Six en matière de politique étrangère, de défense et de culture. L'Europe politique intergouvernementale est clairement relancée par cette proposition. Si le plan allemand n'a pas les ambitions révisionnistes du plan Fouchet - car il ne menace pas les institutions communautaires - il

166. Piers Ludlow, Negotiating the Gaullist Challenge..., op. cit., p. 19-20.

167. AMAE, RPUE 1144, télex Boegner du 19 avril 1963 : programme de travail des communautés de la RFA.

168. AMINEFI, B 17.684, exposé de la délégation allemande au Conseil, doc. CEE du 4 février 1964 ; AHUE, EN 380, « Propositions allemandes sur la politique européenne », doc. S/752/64.

169. AHUE, EN 380, «Propositions allemandes sur la politique européenne », 5 novembre 1964, doc. S/752/64.

170. AMAE, RPUE 1144, télex Boegner du 19 avril 1963 : programme de travail des communautés de la RFA. 
reste intergouvernemental. Le projet d'Europe politique est particulièrement défendu par le nouveau chancelier Erhard ${ }^{171}$. Ce projet semble bénéficier d'une dynamique positive après les entretiens franco-allemands des 19 et 20 janvier $1965^{172}$, même s'il ne débouche sur aucune réalisation concrète.

La RFA se positionne également sur le dossier monétaire. De multiples projets de relance de l'Europe monétaire sont développés à cette période. Le ministre des Finances français Valéry Giscard d'Estaing lance cette thématique de manière très vague dans des entretiens bilatéraux franco-allemands en mars $1964^{173}$. Plus concrètement, la RFA, dans son mémorandum du 5 novembre 1964, appelle à une coordination accrue des politiques nationales. Dans la ligne doctrinale «monétariste » des Allemands, elle met l'accent sur deux points : la coordination des politiques budgétaires d'une part, et l'élaboration de « règles objectives pour éviter les déséquilibres monétaires dans la Communauté » qui « devraient être respectées par les banques d'émission comme lignes directrices de la politique monétaire ${ }^{174} »$. Le gouvernement allemand reprend donc à son compte une partie des projets de Müller-Armack de 1959.

Pour les défenseurs d'une Europe économique ambitieuse comme Robert Marjolin, cette relance allemande est particulièrement ambiguë. Si elle autorise une reprise salutaire des travaux communautaires après le veto du 14 janvier 1963, elle atrophie la capacité d'initiative de la Commission en proposant une CEE très modeste tant sur les plans économiques que politico-institutionnels. Le projet du commissaire français est plus ambitieux.

\section{La relance du projet d'union économique et monétaire de Robert Marjolin.}

Au début de 1965, Robert Marjolin relance son projet d'Europe économique et monétaire par deux discours importants le 19 janvier 1965, l'un au Parlement européen et l'autre au sein de la Commission européenne.

Le discours au Parlement européen du 19 janvier 1965 fait partie des discours rituels du commissaire à l'Économie sur la situation conjoncturelle de

171. Ulrich Lappenküper, « « Ein Europa der Freien un der Gleichen ». La politique européenne de Ludwig Erhard (1963-1966)», in W. Loth (dir.), Crisis and Compromises..., op. cit., p. 76-77 et 83.

172. DDF 1965-I, doc. $\mathrm{n}^{\circ} 35$, télégramme de Couve de Murville du 21 janvier 1965 ; AAPD, 1965-I, docs $n^{\circ} 26$ et $n^{\circ} 27$, Gespräch des Bundeskanzlers Erhard mit Staatspräsident de Gaulle im Rambouillet, 20 janvier 1965.

173. Benedikt Schoenborn, La mésentente apprivoisée : de Gaulle et les Allemands, 1963-1969, PUF, Paris, 2007, p. 117-118.

174. AHUE, EN 380, « Propositions allemandes sur la politique européenne », 5 novembre 1964, doc. S/752/64. 
la Communauté ${ }^{175}$. Cependant, après une première partie descriptive, Marjolin rentre dans des développements prospectifs plus ambitieux. Il lie ses préoccupations en matière de programmation européenne à son projet de coordination des politiques conjoncturelles et monétaires : « Nous devons nous efforcer de définir certaines normes, applicables à la progression des dépenses publiques et du volume du crédit et qui seraient applicables, non plus seulement à court terme, comme c'était le cas des recommandations du Conseil d'avril 1964, mais à moyen terme ${ }^{176} »$. Marjolin annonce ici sa volonté d'encadrer les politiques nationales par des critères définis à Six et dont l'application devrait être soumise à une surveillance commune.

Pour atteindre cet objectif ambitieux, peu de mesures sont préconisées hormis la poursuite des travaux du CPEMT et la définition de normes applicables aux politiques budgétaires et de crédit. En conclusion, Marjolin souligne la « signification politique » de son programme, tout en soutenant le principe d'une méthode progressive qu'il explicite clairement : « Les plus hauts fonctionnaires des États, en matière économique, financière et monétaire, se réunissent maintenant régulièrement avec les représentants de la Commission et, avec une efficacité que nous n'aurions pas osé espérer il y a quelques mois, analysent, comparent, confrontent, opposent leurs expériences, en même temps que les décisions, législations, réglementations, pratiques administratives des différents États. Inévitablement, dès maintenant, alors que nous sommes dans une période de clair-obscur entre la souveraineté encore étendue des États et celle naissante de l'Europe unie, il résulte de ces discussions prolongées une certaine coordination des politiques économiques nationales ${ }^{177}$ ». Refusant tout transfert de souveraineté brutal, Marjolin compte sur une européanisation progressive des esprits des décideurs publics. Il affirme désormais publiquement sa méthode, qui s'apparente à une description du shift of loyalty néofonctionnaliste, les élites administratives apprenant à ne plus penser seulement à une échelle nationale mais de plus en plus à l'échelle européenne.

Dans son discours à la Commission du 19 janvier $1965^{178}$, Marjolin reprend la même méthode mais l'applique cette fois-ci plus précisément au domaine monétaire. Le vice-président de la Commission européenne veut établir à long

175. AHUE, collection de discours, Robert Marjolin devant le Parlement européen le 19 janvier 1965.

176. AHUE, collection de discours, Robert Marjolin devant le Parlement européen le 19 janvier 1965, p. 27.

177. AHUE, collection de discours, Robert Marjolin devant le Parlement européen le 19 janvier 1965 , p. 34-35.

178. AFJM, ARM 32/1, note du 25 janvier 1965, exposé de Marjolin lors de la $302^{\mathrm{e}}$ session de la Commission le 19 janvier 1965. 
terme une union monétaire au sein de la CEE. Les monnaies resteraient nationales mais les taux de change seraient fixes. Pour y arriver, Marjolin défend toujours une méthode progressive. Il affirme explicitement qu'il ne faut pas définir un plan par étapes mais recourir à un " processus d'évolution continu » qui peut être long. Il cite d'ailleurs l'exemple des États-Unis, où le Federal Reserve System n'a été établi qu'en 1913. La Commission doit utiliser deux outils, la libération des mouvements de capitaux et les progrès de la coordination des politiques économiques nationales. Ces deux éléments permettront de progresser vers une fixité des changes de facto. Peu de propositions concrètes sont effectuées hormis la nécessité de progresser en matière de consultation préalable en matière de taux de change et dans la définition de " normes auxquelles doivent être soumises les politiques suivies dans les États membres » selon l'expression de Boyer de la Giroday, un collaborateur de Marjolin qui avait préparé ses réflexions ${ }^{179}$.

On retrouve la méthode prudente et éminemment néofonctionnaliste de Marjolin : la libération des mouvements de capitaux doit créer une contrainte extérieure qui diminue l'indépendance nationale et accroît l'intérêt de l'échelle communautaire, elle-même renforcée par un approfondissement du processus de coordination. L'européanisation des esprits reste à la base du processus. La priorité est à la convergence progressive des décideurs nationaux des Six entre eux et avec les institutions communautaires, dans le cadre des comités de hauts fonctionnaires coordonnés par la DG II.

Marjolin conserve la même attitude tout au long du premier semestre de 1965. Il encourage le renforcement progressif de la coordination des politiques nationales. Les Etats membres adoptent le $1^{\mathrm{er}}$ avril 1965 une procédure de consultation préalable en cas de modification des parités définie par le Comité monétaire le 14 décembre 1964, sans obligation contraignante ${ }^{180}$. En parallèle, le commissaire français soutient les travaux du CPEMT, que la crise de la chaise vide ne semble pas affecter au début. Marjolin intervient longuement lors sa septième réunion, tenue le 23 juillet $1965^{181}$. Il propose que «soit annexée au projet de programme une description des politiques économiques à moyen terme que les gouvernements des États membres se proposent de suivre au cours de la période

179. AFJM, ARM 32/1, « Monnaie, intégration et CEE », 9 janvier 1965, point 4.

180. AJFM, ARM 23/3/8, avis du Comité monétaire du 14 décembre 1964 ; AHUE, procès-verbal spécial de la réunion de la Commission du 3 février 1965, point 19 ; AHUE, EN 243, note d'Émile Noël du 2 mars 1965 pour Hallstein ; AFJM, ARM 23/3/15, note Bobba pour Marjolin, doc. DG II/ $\mathrm{RdK} / \mathrm{jt} / 15 / \mathrm{VII} / 66$.

181. AHUE, BAC 27/1985, volume 10, compte rendu de la $7^{\mathrm{e}}$ réunion du CPEMT du 23 juillet 1965. 
1966-1970, et que chaque gouvernement adresse au Comité un mémorandum à ce sujet ». Marjolin n'a donc pas abandonné ses ambitions malgré la chaise vide. Il compte faire du CPEMT une véritable force de propositions et obliger les États à se positionner par rapport à celles-ci.

Ainsi lors du premier semestre 1965, Marjolin continue de développer son projet d'Europe organisée fondé sur l'émergence progressive d'une union économique et monétaire. Le rapprochement des politiques économiques à moyen terme est à la base de ce processus, qui doit être complété par une coordination de plus en plus étroite des politiques conjoncturelles et monétaires. La démarche est très prudente : Marjolin cherche à aboutir à un consensus entre les responsables économiques par une européanisation de leurs conceptions. Cette démarche néofonctionnaliste prudente se heurte au projet fédéraliste développé par le président de la Commission européenne.

\section{Les ambitions fédéralistes d'Hallstein.}

Walter Hallstein développe des projets de nature fédéralistes pour l'Europe car il s'inspire de l'exemple de la RFA ${ }^{182}$, et des réflexions de nature assez fédéraliste développées dans les réseaux transnationaux chrétiens-démocrates auquel il participe ${ }^{183}$. Assez prudent dans les débuts de la CEE, il commence à adopter une méthode plus ambitieuse à partir de 1964 comme en témoigne l'introduction du document « Initiative $1964^{184} »$, issu des services du président Hallstein lui-même ${ }^{185}$.

« Initiative 1964 » se présente comme un plan de travail de la Commission pour les mois à venir. L'introduction du document expose clairement la doctrine de Walter Hallstein dès le point 1 : "Les Communautés "économiques" [...] constituent déjà un début de réalisation et pas seulement une préparation de 1'"union politique" ». Au point 2, il est précisé que l'union politique signifie deux choses. Tout d'abord, les compétences communautaires doivent être étendues à la politique étrangère, la politique culturelle et la défense. Cette doléance peut s'expliquer par les nombreux plans d'Europe politique qui ont

182. M. Schönwald, "Walter Hallstein and the "Empty Chair" Crisis 1965/66... », op. cit., p. $159-160$.

183. W. Kaiser, Christian Democracy..., op. cit., p. 304.

184. AHUE, procès-verbal spécial de la $287^{\mathrm{e}}$ session de la Commission du 30 septembre 1964 , document « Initiative 1964 », COM(64)400.

185. AHUE, procès-verbal spécial de la $286^{\mathrm{e}}$ session de la Commission du 23 septembre 1964 , point 6. La forte implication personnelle d'Hallstein est confirmée par des indiscrétions britanniques : PRO, T 312/1890/24, lettre de la délégation britannique auprès de la CEE (N.J.Barrington) à R.S. Symons (Treasury) R, Brussels, 11 décembre 1964. 
été discutés au cours de l'année 1964, et qui prévoyaient généralement de créer des structures intergouvernementales de coopération dans ces trois domaines, ce qui menacerait clairement le leadership de la Commission européenne en matière d'intégration européenne des Six. Ensuite, l'union politique doit passer par « l'amélioration de la structure institutionnelle », c'est-à-dire la fusion des exécutifs et des Communautés, mais aussi et surtout le renforcement du Parlement européen. Hallstein refuse de se contenter du programme fixé par les États à l'occasion de la fusion des exécutifs, qui se limite pour l'essentiel à une opération de rationalisation administrative plus que de renforcement politique. On retrouve dans l'introduction du mémorandum « Initiative 1964 » de nombreuses propositions qui annoncent celles de la Commission en mars 1965. La grande différence tient dans la prudence de la méthode car Hallstein se contente de déclarations de principe.

À partir du début de 1965, Hallstein se radicalise car la période est à la fois pleine d'opportunités et de menaces pour la Commission européenne. Sur le plan économique tout d'abord, les succès obtenus dans le domaine agricole le sont au prix de négociations toujours plus intenses et éprouvantes. L'ambivalence de la PAC, source de tensions et pilier de la dynamique communautaire, ressort nettement en 1965 : un accord financier sur la PAC doit être conclu avant le $1^{\text {er }}$ juillet 1965 pour achever la création de cette politique. La tentation est donc grande de faire pression sur ceux qui ont le plus intérêt à cette politique pour obtenir d'eux des concessions avant que la PAC ne soit définitivement mise sur les rails. C'est le calcul qui est envisagé par Narjes, le chef de cabinet d'Hallstein, dans une note à ce dernier du 2 mars $1965^{186}$. Dans un entretien avec Couve de Murville, il a clairement fait valoir que le succès de la négociation financière dépendait de concessions françaises en termes de renforcement des compétences communautaires. Il fait suivre cette remarque de considérations rassurantes sur les possibilités d'accord dans ce domaine ${ }^{187}$. Peut-être les informations régulières en provenance de l'Auswärtiges Amt pour Hallstein entretenaient-elles un certain optimisme au cabinet du président de la Commission ${ }^{188}$. Le contexte général semble également favorable à une pression sur la France en raison de la perspective de l'élection présidentielle de la fin 1965 qui pourrait limiter la marge de manœuvre de Charles de Gaulle.

Sur le plan institutionnel ensuite, les négociations sur le traité de fusion (finalement signé le 8 avril 1965) ont montré que cinq des six États membres

186. AHUE, Papiers Hallstein, 1119, note de Narjes à Hallstein, 2 mars 1965.

187. AHUE, Papiers Hallstein, 1119, note de Narjes à Hallstein, 2 mars 1965.

188. AHUE, Papiers Hallstein, 1186, télégramme de l'Auswärtiges Amt depuis l'ambassade allemande aux Pays-Bas, signé Berger, 5 avril 1965, « de Gaulles europäische politik ». 
étaient hostiles à la délégation de nouvelles prérogatives aux institutions européennes ${ }^{189}$. De même les projets d'Europe politique lancés en 1964 par l'Allemagne démontrent que la France n'est pas le seul pays à vouloir développer la coopération politique européenne en dehors de la CEE.

Enfin, sur le plan des rapports de force, le fort investissement des États membres dans la construction européenne n'est plus forcément un bon signe. Piers Ludlow a montré comment au cours du premier semestre 1965, chacun des trois grands pays, France, RFA et Italie, a cherché à promouvoir ses intérêts nationaux de manière parfois inhabituellement offensive pour les deux derniers ${ }^{190}$. Face à ce retour en force de logiques intergouvernementales, la Commission se doit de réagir pour Hallstein comme le montrent ses discours du début de 1965 où il loue le rôle moteur de la Commission européenne ${ }^{191}$, et où il souligne l'importance de la naissance d'un véritable droit communautaire ${ }^{192}$. L'ordre juridique communautaire a d'ailleurs été considérablement renforcé par les arrêts Van Gend \& Loos (5 février 1963) et Costa/Enel (15 juillet 1964) qui établirent respectivement l'effet direct du droit communautaire et sa suprématie sur le droit national ${ }^{193}$. Professeur de droit, Hallstein devait être particulièrement conscient de cette dynamique. Face à ce contexte à la fois stimulant et menaçant, Hallstein passe à une offensive plus fédéraliste.

C'est devant le Parlement européen, le 24 mars 1965, que le président de la Commission européenne présente ses propositions pour résoudre le problème $\mathrm{du}$ financement de la $\mathrm{PAC}^{194}$. Ce triptyque célèbre repose sur trois éléments imbriqués. Tout d'abord, le financement de la PAC devra être garanti par la création de « ressources propres » à la Communauté provenant des droits prélevés sur les produits agricoles et industriels à la frontière de la CEE. Comme ces ressources devraient rapidement dépasser les seuls besoins de la PAC, la Commission devrait en disposer seule pour développer les autres politiques communautaires. Fort logiquement, ce pouvoir supplémentaire accordé à la Commission au détriment des parlements nationaux, dont le vote du budget est l'une des principales prérogatives, devrait faire l'objet d'un contrôle.

189. La seule exception est la Hollande : P. Ludlow, Negotiating the Gaullist Challenge..., op. cit., p. 46.

190. P. Ludlow, Negotiating the Gaullist Challenge..., op. cit., p. 68.

191. AHUE, collection de discours Walter Hallstein, discours du 25 mars 1965, « La Commission, nouvel élément dans la vie internationale ».

192. AHUE, collection de discours Walter Hallstein, discours du 19 février 1965, « Les véritables problèmes de l'intégration européenne $»$.

193. J. Weiler, "The Transformation of Europe... », op. cit., p. 2413-14.

194. Détail de ces propositions in Wilfried Loth, «La crise de la chaise vide », in Michel Dumoulin (dir.), La Commission européenne..., op. cit., p. 97. 
Le pouvoir du Parlement européen en matière budgétaire devrait alors être considérablement renforcé. Il acquiert un pouvoir d'amendement qui lui permettrait d'adopter le budget amendé à la majorité simple si la Commission et seulement deux États membres l'acceptent. Le Conseil perdrait donc son monopole et même sa prééminence en matière budgétaire.

Ce discours de mars 1965 reprend les ambitions de l'introduction du mémorandum « Initiative 1964 » en les concrétisant. Surtout, ces propositions marquent le passage d'Hallstein d'une logique néofonctionnaliste à une logique fédéraliste. Certes, le plan du président de la Commission repose sur une démarche néofonctionnaliste, par le passage de l'intégration économique à l'intégration politique. Mais l'ampleur même de ces propositions témoigne plutôt d'une logique fédéraliste : le Parlement européen devrait acquérir par l'onction du suffrage universel et ses pouvoirs supplémentaires un véritable statut de représentant du peuple européen. En retour la Commission européenne s'érigerait en véritable gouvernement européen avec un pouvoir budgétaire propre. Dans la nouvelle procédure budgétaire présentée, la Commission deviendrait un arbitre entre le Parlement et le Conseil, ce dernier serait ainsi ravalé au rang de seconde chambre, analogue à un Sénat européen. Les incertitudes sur l'interprétation du traité de Rome seraient ainsi définitivement levées et le caractère fédéral de la CEE clairement affirmé. Si l'objectif est fédéral, la méthode l'est aussi. En effet, Hallstein veut obtenir ce changement non pas par des transformations progressives, mais par un accord décisif au plus haut niveau, dicté par les circonstances (la négociation sur la PAC), et qui nécessitera une modification du traité de Rome suivie d'une ratification parlementaire ${ }^{195}$, toutes caractéristiques d'une initiative éminemment fédérale. Il présente son plan devant le Parlement européen, c'est-à-dire, dans son esprit, aux représentants du peuple européen. De plus, une fois ce plan dévoilé, Hallstein refuse tout compromis. Il a maintenu l'intégralité de son plan jusqu'au matin du $1^{\text {er }}$ juillet $1965^{196}$. Il a également cherché à convaincre Erhard de la nécessité d'abandonner ses projets d'Europe politique au profit de son plan du 24 mars $1965^{197}$. Cette tactique montre clairement qu'Hallstein ne se considérait pas dans une négociation classique de règlement communautaire, qui donne lieu à des adaptations par la Commission de sa proposition initiale en fonction des réactions du Conseil. Dans le cas des propositions du 24 mars 1965, la Commission n'est plus l'arbitre à la recherche d'un consensus mais un acteur politique doté d'une légitimité supérieure aux

195. Pierre Gerbet, La construction de l'Europe, Imprimerie Nationale, Paris p. 275.

196. AFJM, ARM 21/1/16 et 17, notes manuscrites sur les réunions de la Commission des 23 juin 1965 et 29 juin 1965.

197. Philippe Bajon, « The Empty Chair Crisis... », op. cit., p. 9, note 16. 
autres qui indique la voie à suivre, qui propose un nouvel accord politique de relance de la dynamique européenne.

Face à cet ambitieux projet fédéraliste, la démarche progressive et néofonctionnaliste de Marjolin se trouve affaiblie, ce qui contribue à dégrader les rapports entre les deux commissaires européens.

\section{B. LES OPPOSITIONS AU SEIN DE LA COMMISSION EUROPÉENNE}

Si les rapports entre Marjolin et Hallstein sont étroits au début de la CEE, ils ont tendance à se distendre pour dégénérer en opposition frontale en 1965.

\section{Les rapports entre Marjolin et Hallstein en 1958-1962 : une convergence apparente.}

L'entente entre le président Hallstein et son vice-président Marjolin semble bonne voire même excellente dans les débuts de la CEE. Dans le dossier de la ZLE tout d'abord, une convergence de fond peut s'observer entre Marjolin, qui a été l'un des plus précoces opposants français à ce projet, et Hallstein, qui craint pour l'indépendance de la dynamique communautaire de la $\mathrm{CEE}^{198}$. De même, c'est le commissaire français qui rédige les introductions des troisième et quatrième rapports généraux de l'activité de la CEE de 1960 et 1961, qui ont un caractère éminemment politique ${ }^{199}$. C'est également à cette même époque, en décembre 1961, que Jean Rey, commissaire belge aux relations extérieures, se plaint amèrement du rôle majeur joué par Marjolin dans la conduite de la Commission européenne auprès du président Hallstein ${ }^{200}$. Il est soutenu dans ce constat par von der Groeben, lui-même proche de Rey ${ }^{201}$. Dans des témoignages postérieurs, von der Groeben et Jean-François Deniau ont également confirmé la prépondérance de ce tandem Marjolin-Hallstein dans les débuts de la Commission européenne $e^{202}$.

198. Voir le chapitre III.

199. AHUE, EN 240, note EN pour Hallstein du 2 mai 1962.

200. Yves Conrad, «Évolution de l'organisation administrative de la Commission et de la question du siège. Un long chemin vers la fusion des exécutifs (1960-1967) », in A. Varsori (éd.), Inside the European Community..., op. cit. p. 84-85 ; Yves Conrad, « Jean Rey : un Européen “de cœur” à l'“optimisme modéré” », in Michel Dumoulin (dir.) La Commission européenne..., op. cit., p. 117-118.

201. Hans von der Groeben, Europäische Integration aus historischer Erfahrung. Ein Zeitzeugengespräch mit Michael Gehler, Discussion Paper C108, Zentrum für Europäischen Integrationsforschung, Bonn, 2002, p. 29.

202. Hans von der Groeben, "Walter Hallstein as President of the Commission », in W. Loth et al. (dir.), Walter Hallstein..., op. cit., p. 105-6; AO/AHUE, Interview de Jean-François Deniau par Gérard Bossuat et Anaïs Legendre les 3 et 10 novembre 2004, p. 21-22 et p. 28. 
Toutefois, la convergence entre les deux hommes semble reposer plus sur une convergence en termes d'objectifs politiques généraux que sur des choix institutionnels et économiques. Hallstein paraît assez proche des réseaux ordo-libéraux. Ainsi, c'est grâce à l'économiste ordolibéral Wilhelm Röpcke qu'Adenauer le nomme à la tête de la délégation allemande pour négocier la CECA en $1950^{203}$. De plus, si Hallstein a défendu le projet de Marjolin de programmation économique contre Erhard lors d'une célèbre passe d'arme au Parlement européen, le 20 novembre 1962, il a surtout répondu sur le plan politique ${ }^{204}$. Il se défend contre toute tentative de « centralisation administrative » en affirmant au contraire son ambition « fédéraliste ", c'est-à-dire à la fois politique (par opposition à technocratique) et décentralisée. Sur le plan économique, Hallstein défend de manière théâtrale l'intervention de l'État dans l'économie, contre les « nombreuses variantes des doctrines libérales ${ }^{205}$. Pourtant, sa conception du rôle de l'État dans l'économie est assez proche de celle des ordolibéraux. Ainsi, il termine son discours en citant un économiste ordolibéral, Walter Eucken, dans un passage où il défend la notion de "plan » mais suivant une définition très générale, qui peut s'appliquer à n'importe quelle prévision effectuée par une entreprise ${ }^{206}$. Ce sont donc plus les ambitions politiques du projet qui sont défendues plus que sa philosophie économique.

Enfin, après la « lune de miel » des années 1958-1962 207 , lorsque la CEE avançait sans heurts, des signes de dissensions entre Marjolin et Hallstein se manifestent à l'occasion des premières grandes négociations intergouvernementales tendues. Le passage de la première étape au premier janvier 1962 donne lieu à une opposition entre les deux hommes. Hallstein fait en effet voter le passage à la seconde étape au sein de la Commission contre Marjolin, Mansholt et Caron $^{208}$. Le commissaire français estimait que le passage d'étape ne pouvait être accepté dans la mesure où la PAC n'était pas adoptée ${ }^{209}$. La thèse d'Ann-Christina Knudsen confirme la division de la Commission entre Marjolin et Hallstein sur la PAC suivant des lignes correspondant à

203. W. Loth, « Walter Hallstein : un Européen déterminé... », op. cit., p. 85.

204. Parlement Européen, comptes rendus in extenso des séances, 1963/III, $n^{\circ}$ 60, séances du 19 au 23 novembre 1962, séance du mardi 20 novembre 1962, p. 51-56 (intervention d'Erhard) et 65-71 (intervention d'Hallstein).

205. Ibid., p. 67.

206. Ibid., p. 71.

207. Selon l'expression employée par Robert Marjolin dans ses mémoires : R. Marjolin, Le travail d'une vie..., op. cit.,p. 304.

208. AHUE, MK 20, lettre de Max Kohnstamm à Jean Monnet, 5 janvier 1962.

209. AHUE, EN 733, notes manuscrites d'Émile Noël sur la réunion de la Commission des 21-23 décembre 1961. 
l'opposition entre France et RFA au Conseil ${ }^{210}$. On ne peut conclure de ce vote l'idée que Marjolin était irréductiblement opposé à Hallstein mais que la « lune de miel » qui se termine en 1962 ne concernait peut-être pas que les rapports entre les Six entre eux et avec la Commission, mais aussi les rapports au sein de la Commission européenne. À partir de la fin de 1964 en tout cas, les deux hommes développent des stratégies fondamentalement différentes.

\section{L’opposition de stratégie à partir de la fin $\mathbf{1 9 6 4}$ jusqu'à la chaise vide.}

En 1964, Marjolin veut se concentrer sur son projet de rapprochement des politiques économiques et monétaires des Six. Une note de janvier 1964 révèle qu'il semble hostile à toute initiative politique car la situation est bloquée, de Gaulle campant sur ses positions restrictives ${ }^{211}$. Pourtant, au même moment, Hallstein souhaite relancer la dynamique politique européenne par le mémorandum « Initiative $1964 »$.

Dès lors, Marjolin manifeste sa réticence envers « Initiative 1964 ». En juillet 1964 ainsi, le cabinet d'Hallstein écrit à Bobba, le directeur de la DG II, pour lui demander un plan de mise en commun des réserves des $\mathrm{Six}^{212}$, afin de l'inclure dans un futur document « Initiative $1964 »$. Or rien de tel n'est inclus dans ce mémorandum. Ce dernier ne contient, dans le domaine monétaire, que des répétitions de passages entiers du programme d'action de 1962 ainsi que l'assurance de la présentation par la Commission de proposition dans ce domaine $^{213}$. Cette absence n'est pas étonnante car Marjolin n'était pas très enthousiaste envers cette idée de fonds de réserve. Les archives britanniques sont beaucoup plus directes sur la divergence entre Marjolin et Hallstein. Selon la délégation britannique auprès des communautés européennes, Hallstein avait prévu un texte très ambitieux pour la partie monétaire d'《 Initiative 1964 ». Marjolin l'a obligé à en diminuer radicalement le contenu car il souhaite rester prudent dans ce domaine, d'où la déception d'Hallstein ${ }^{214}$.

Par la suite, Hallstein veut obliger Marjolin à prendre position dans le débat sur la réforme du SMI, relancé par la conférence de presse de Charles de Gaulle

210. A.-C. Knudsen, Defining..., op. cit., p. 403-404 et p. 413. A.-C. Knudsen, Farmers on Welfare..., op. cit., p. 229.

211. AHUE, MK 26, note du 10 janvier 1964.

212. AHUE, papiers Hallstein, 1247, note de Meyer, cabinet Hallstein à Bobba, 24 juillet 1964.

213. AHUE, procès-verbal spécial de la $287^{\circ}$ séance de la Commission du 30 septembre 1964 , annexe, folio 331, doc. « Initiative 1964 », communication de la Commission au Conseil.

214. PRO, T 312/1890/24 et 30, lettres de la délégation britannique à Bruxelles au Treasury, 11 décembre 1964 et 19 janvier 1965. 
du 4 février $1965^{215}$. Les notes prises par Émile Noël lors des séances de la Commission européenne des 17 février montrent clairement un débat entre Hallstein et Marjolin sur le SMI. Hallstein estime important que la Commission «montre sa présence » alors que Marjolin répond simplement que la possibilité existe de consulter le Comité monétaire ${ }^{216}$. Jean Rey soutient Hallstein ${ }^{217}$ mais Marjolin ne prononce finalement qu'un discours très modéré sur cette question sensible ${ }^{218}$.

L'autre grand opposant traditionnel à Marjolin est von der Groeben. Or von der Groeben considérait le développement de la politique de la concurrence comme un élément de progrès vers l'intégration politique ${ }^{219}$. En 1965, il fait partie de ceux qui défendent le principe d'une offensive politique de la Commission européenne. Lors d'une réunion du 28 janvier 1965 sur les propositions agricoles que la Commission européenne doit préparer, Mansholt s'oppose à von der Groeben $^{220}$. Le premier prévoyait de n'agir que sur les prélèvements agricoles alors que von der Groeben pensait utiliser aussi les droits de douane, formule qui a été finalement adoptée par Hallstein. Mansholt n'y est pas hostile par principe mais hésite pour des raisons tactiques. Marjolin est sur la même ligne. Il estime politiquement imprudent de réclamer tant de réformes en une seule fois $^{221}$ et exprime ses réticences à Mansholt ${ }^{222}$. C'est le chef de cabinet de von der Groeben, Ernst Albrecht, qui apparaît particulièrement offensif dans les réunions entre commissaires européens sur ce thème, en raison des fréquentes absences de son commissaire pour raisons de santée ${ }^{223}$. Il défend les propositions de son commissaire face aux réticences de Marjolin ${ }^{224}$, s'appuyant sur des documents sur les ressources propres préparés par la DG IV elle-même alors que ce domaine ne relève pas de sa compétence ${ }^{225}$. Le rôle d'Albrecht dans la

215. Sur le contexte : Robert Solomon, Le Système monétaire international..., op. cit., p. 45-50.

216. AHUE, EN 779, notes manuscrites d'Émile Noël sur la $306^{\mathrm{e}}$ réunion de la Commission européenne du 17 février 1965.

217. AFJM, ARM32/1/24, lettre de Rey à Marjolin, 25 février 1965.

218. AHUE, collection de discours, Robert Marjolin devant le Parlement européen le 23 février 1965 .

219. ANCPF, 72 AS 450, compte rendu de l'UNICE d'une rencontre avec von der Groeben le 9 juillet 1963.

220. AFJM, ARM 21/1/10, note JF, 28 janvier 1965.

221. AFJM, ARM 21/1/15, note de Marjolin sur le financement de la PAC, 22 février 1965.

222. AFJM, ARM 25/1/24, déjeuner avec Mansholt, 18 février 1965.

223. AHUE, EN 779, notes manuscrites d'Émile Noël sur la $307^{\mathrm{e}}$ réunion de la Commission, 24 février 1965. Jusqu'en mai 1965, von der Groeben est fréquemment absent. Il est remplacé par Albrecht lors des réunions de la Commission.

224. AFJM, ARM 21/1/20, notes manuscrites sur une réunion du 25 février 1965.

225. AFJM, ARM 21/1/29, note DG IV, doc. 1279/IV/65; ARM 21/2/1, note DG IV, « Les finances de la Communauté économique européenne à partir de 1967 », 23 avril 1965. 
radicalisation de la position d'Hallstein est d'ailleurs attesté par de nombreux témoignages français ${ }^{226}$. De manière surprenante, ce n'est donc pas Mansholt qui paraît être la figure dominante dans cette discussion sur les propositions de règlements agricoles mais un groupe d'Allemands chargé de la politique de la concurrence, proche du président de la Commission.

Marjolin semble isolé à la Commission face à ses collègues sensibles au «prestige politique » de la proposition Hallstein ${ }^{227}$. Le futur discours d'Hallstein au Parlement européen est discuté à la Commission européenne lors des séances des 22 et 31 mars 1965. Le principal opposant d'Hallstein est Marjolin ${ }^{228}$. Ce dernier conseille de ne pas demander l'accroissement du pouvoir du Parlement. Hallstein estime au contraire qu'il faut profiter de la fenêtre ouverte par la négociation agricole. Le président de la Commission refuse ensuite toute atténuation des propositions de la Commission lors de la réunion du 23 juin 1965 et estime encore le 29 juin 1965 que « le moment du package deal n'est pas venu $^{229}$ », sans doute par une surestimation du soutien qu'il pouvait attendre des États membres et notamment du gouvernement allemand ${ }^{230}$.

Par la suite, après le déclenchement de la crise de la chaise vide, Marjolin critique très durement l'attitude du président de la Commission en privé. Dans une note de Jean Flory, son chef de cabinet, le commissaire français souligne certains passages qui insistent sur le caractère non communautaire de la démarche d'Hallstein ${ }^{231}$. Au lieu de régler chaque dossier séparément, il les a liés entre eux et est ainsi entré dans une logique de package deal qui est en fait intergouvernementale. Dès lors, il critique les nouvelles propositions de la Commission définies en juillet 1965 et particulièrement celles avancées par von der Groeben qui sont une « apologie de la Commission ${ }^{232}$ selon lui.

Enfin, l'approfondissement de la crise de la chaise vide condamne le CPEMT car les délégués français ne participent plus à ses réunions. Le 17 décembre 1965, le président du Comité, Langer explique qu'il est impossible de parvenir

226. AO/Fondation Charles de Gaulle, Jean-Pierre Brunet, entretien du 13 février 1991 ; $\mathrm{AO} /$ Comité pour l'histoire économique et financière de la France, Armand Saclé, cassette 11, entretien du 12 mai 1992.

227. AFJM, ARM 21/1/22, note de Jean Flory du 9 mars 1965.

228. AHUE, EN 780, notes manuscrites d'Émile Noël sur la $311^{\mathrm{e}}$ session de la Commission européenne du 22 mars 1965.

229. AFJM, ARM 21/1/16 et 17, notes manuscrites sur les réunions de la Commission des 23 juin 1965 et 29 juin 1965 .

230. Wilfried Loth, « Hallstein and de Gaulle... », op. cit., p. 147.

231. AFJM, ARM 21/3/17, note de Jean Flory du 13 juillet 1965.

232. AFJM, ARM 21/3/17, note de Jean Flory du 13 juillet 1965 ; AFJM, ARM 21/3/28, note de Marjolin, 22 juillet 1965. 
à un avant-projet de programme pour la fin de l'année 1965 comme cela avait été envisagé initialement ${ }^{233}$. Le CPEMT a tenu une réunion par mois, précédé d'une réunion des suppléants, et a engagé de nombreux travaux ${ }^{234}$ mais il n'a pu surmonter l'absence de volonté politique des États membres. Alors que Marjolin voulait en faire un organe de proposition et de surveillance, il s'est contenté de devenir un cénacle d'étude. Sa démarche néofonctionnaliste achoppe sur le manque de volonté politique des États membres, préalable indispensable à une européanisation des esprits qui suppose la formation d'un consensus.

\section{CONCLUSION : CONFRONTATIONS ET ÉCHECS DES PROJETS D'EUROPE LES PLUS VOLONTARISTES}

La fin de l'année 1964 et le premier semestre 1965 sont marqués par un affrontement entre deux projets européistes au sein de la Commission européenne. Celui de Marjolin reposait sur une démarche néofonctionnaliste progressive, économique et technocratique. Le projet d'Hallstein, élaboré en coopération avec son cabinet et celui de von der Groeben, préconisait au contraire une rupture politique. Un nouvel accord de nature fédérale était nécessaire pour relancer l'union politique et enterrer définitivement les projets concurrents. Il fallait impérativement profiter de la fenêtre d'opportunité que donnait la négociation de la PAC pour agir. Au premier semestre 1965, Hallstein abandonne clairement la prudence néofonctionnaliste.

La crise de la chaise vide ne peut toutefois se réduire aux résultats d'une controverse au sein de la Commission, ni d'ailleurs à un affrontement binaire entre Hallstein et de Gaulle. Cependant l'étude de cette opposition permet de souligner l'originalité et la force des deux visions d'Hallstein et de Marjolin, et donc leur indépendance d'esprit par rapport à leurs gouvernements respectifs. Bien au contraire les deux commissaires ont cherché à forcer la main de leurs autorités nationales avec leurs projets d'intégration européenne. Cette opposition démontre également la rupture induite par l'offensive d'Hallstein par rapport à la prudence de la dynamique néofonctionnaliste antérieure, et donc la faiblesse de la Commission, divisée sur la stratégie à suivre.

La crise de la chaise vide marque l'échec de l'ensemble des projets européens développés en 1964-1965. Le projet allemand d'Europe politique est au point mort. Le projet révisionniste gaulliste a échoué dans ses dimensions les plus ambitieuses. Du côté de la Commission, le projet néofonctionnaliste de Marjolin

233. AMAE, RPUE 693, lettre de Langer au Conseil, 17 décembre 1965.

234. AHUE, BAC 62/1980, volume 144, folio 2046, doc. 15/671/II, note DG II de la fin 1965. 
est remis en cause car il repose sur la construction progressive d'un consensus qu'il paraît difficile de reconstituer après une crise aussi grave. Enfin le projet fédéraliste d'Hallstein a été condamné car il n'était véritablement soutenu par aucun des États membres.

Ce processus d'emballement fédéral d'une dynamique européenne essentiellement néofonctionnaliste a déjà eu lieu quinze ans auparavant. En 19501951, la démarche néofonctionnaliste de Jean Monnet a permis de mettre en place une organisation économique, la CECA. Les mouvements fédéralistes, déçus par la CECA, ont ensuite repris l'ascendant sur les néofonctionnalistes et relancé la dynamique politico-institutionnelle qui a débouché sur la CED et la CPE. La crise du 30 août 1954 comme celle déclenchée le $1^{\text {er }}$ juillet 1965 ont mis fin à ces deux emballements fédéralistes, mais aussi à la dynamique néofonctionnaliste qui la précédait.

Après la chaise vide, le projet volontariste de Marjolin se perpétue mais a perdu sa dynamique. Il est relancé par son successeur, Raymond Barre, vers des dimensions plus macroéconomiques mais toujours en continuité avec les efforts antérieurs.

\section{LE PROJET MACROÉCONOMIQUE DE RAYMOND BARRE}

Après la crise de la chaise vide, Robert Marjolin continue à promouvoir ses projets de coordination des politiques économiques et monétaires dans un contexte difficile. À partir de 1967, son remplaçant, Raymond Barre, s'appuie sur son héritage et sur un contexte monétaire international troublé pour développer ses propres propositions en février 1968 puis en février 1969, après les deux crises françaises de mai et novembre 1968.

\section{A. DES RÉFLEXIONS PRUDENTES}

En 1966 et 1967, le débat sur la coordination des politiques économiques et monétaires reste entretenu par Marjolin puis par son successeur Barre mais selon des modalités assez discrètes en raison d'un contexte difficile.

\section{La persistance du débat sur la coordination des politiques économiques (1966-1967).}

Marjolin reste attaché à son projet de coordination des politiques économiques. Dans le domaine de la PEMT, il multiplie les travaux, notamment pour 
définir une politique régionale européenne avec une communication ambitieuse en $1965^{235}$. Mais le gouvernement français définit en 1966 une position très claire envers la PEMT ${ }^{236}$. D'un côté, elle doit être soutenue car elle correspond à la doctrine française d'une intégration économique européenne volontariste, ne reposant pas seulement sur le libéralisme régulé. D'un autre côté, toutes les délégations de souveraineté notables doivent être refusées. Le CPEMT doit être considéré comme une enceinte de préparation des discussions à mener au sein du Conseil, le seul organe apte à discuter de la coordination des politiques économiques.

En matière de coordination des politiques conjoncturelles, Marjolin relance aussi l'initiative et propose dès le Conseil du 14 juin 1966 d'instaurer une coordination permanente par l'adoption systématique de recommandations de politique conjoncturelle deux fois par $\mathrm{an}^{237}$. Lorsqu'un " clignotant », c'est-à-dire un indicateur marquant un problème conjoncturel (récession, inflation, déficit de la balance des paiements), s'allumera, les Six devront examiner « dans les plus brefs délais », les propositions de la Commission. Sans contraindre les États directement, Marjolin veut donc les obliger à se concerter régulièrement.

Cependant, les États membres semblent réticents ${ }^{238}$. Ils refusent de donner aux recommandations une forme trop directe et contraignante. Toutefois, les ministres des Finances italiens et français, Colombo et Debré reconnaissent l'intérêt économique d'une telle procédure. Colombo affirme clairement : «Une recommandation peut être utile à chaque gouvernement pour appliquer une politique impopulaire ${ }^{239} »$. Dans un contexte de lutte contre l'inflation, il peut être intéressant de se prévaloir des recommandations de la Commission européenne pour appliquer une politique impopulaire de réduction de la demande.

Debré lui-même affirme à de nombreuses reprises sa volonté d'une coordination plus étroite des politiques économiques et financières des Six. Il cherche à constituer un front commun des Six dans les débats sur la réforme du FMI, notamment en fixant des conditions drastiques pour l'émission de droits de tirage supplémentaires. Il s'agit de défendre la doctrine française fondée sur

235. Laura Grazi, L'Europa e le citta. La questione urbana nel processo di integrazione europea (1957-1999), Il Mulino, Bologne, 2006, p. 23-78; AHUE, BAC 27/1985, volume 8, « Première communication de la Commission sur la politique régionale dans la Communauté économique européenne », doc. SEC (65) 1170 final, 11 mai 1965.

236. ASGCI, 1979.0791, volume 67, note SGCI du 10 octobre 1967, « La politique économique à moyen terme ».

237. AMAEF, DECE 1296, note SGCI, Dromer, du $1^{\text {er }}$ juillet 1966.

238. AMINEFI, B 17.688, compte rendu manuscrit du Conseil du 20 décembre 1966.

239. AMINEFI, B 17.688, compte rendu manuscrit du Conseil du 20 décembre 1966. 
l'opposition à l'émission de liquidités trop importantes par les États-Unis, en essayant de l'européaniser autant que faire se peut. Il parvient à certains succès car les Six s'accordent sur une position commune à la réunion des ministres des Finances des Six de Munich d'avril $1967^{240}$.

Dans le domaine précis de la coordination des politiques économiques, il expose publiquement sa doctrine lors du Conseil CEE du 4 juillet $1967^{241}$. Sceptique envers toute construction institutionnelle supranationale, il en appelle à la bonne volonté des États membres, qui devraient discuter de ces questions de manière approfondie au Conseil. En conséquence, il demande à ses collègues « de marquer par un communiqué la solidarité croissante de leurs économies [...] et leur accord, enfin, pour se concerter aussi souvent qu'il le faudra pour obtenir par une meilleure coordination un taux de croissance élevé dans l'ensemble du Marché commun ${ }^{242} \gg$. Debré exprime à la fois sa conception gaulliste et intergouvernementale de l'intégration européenne et son inscription dans les aspirations traditionnelles de la politique européenne de la France, fondée sur une forte coordination des politiques économiques. Les idées du ministre français sont partagées par certains hauts fonctionnaires de son ministère comme Maurice Pérouse et René Larre, directeurs successifs du Trésor, ou Jean Saint-Geours, le directeur de la Prévision, qui se montrent favorables à une coordination accrue, mais essentiellement intergouvernementale ${ }^{243}$.

Marjolin ne parvient pas à surmonter les réticences des États membres. Bien plus, il doit affronter des oppositions au sein même de la Commission en avril 1967 : « M. von der Groeben souligne le « gap » entre les efforts accomplis et les procédures arrêtées en matière de coordination et la réalité. Le risque existe d'une « oeceisation » de l'action communautaire ${ }^{244} »$. Suit une intervention de Marjolin résumée par Émile Noël en une phrase : «M. Marjolin relève vivement les propos de M. von der Groeben ce qui conduit ce dernier à en atténuer la portée $\mathrm{e}^{24} \gg$. Le commissaire allemand critique clairement le manque de réussite de son collègue français. Il estime que sa méthode est trop

240. AMINEFI, B 62124, communiqué de presse à l'issue de la $26^{\mathrm{e}}$ réunion des ministres des Finances réunis à Munich les 17 et 18 avril 1967.

241. AMINEFI, B 17.688, télex Boegner sur le Conseil des 3 et 4 juillet 1967.

242. AMINEFI, B 17.688, télex Boegner sur le Conseil des 3 et 4 juillet 1967.

243. Larre remplace Pérouse à la direction du Trésor en 1967; AMINEFI, B 17.688, note du Trésor signée Pérouse, 20 décembre 1966; AMINEFI, B 17.688, note de Jean Saint-Geours pour le ministre, 30 juin 1967 ; AN, 86 AJ, note de René Larre du 12 octobre 1967.

244. AHUE, EN 210, note sur la « Réception de M. Van Lennep, président du Comité monétaire », séance de la Commission du 6 avril 1967.

245. AHUE, EN 210, note sur la «Réception de M. Van Lennep, président du Comité monétaire », séance de la Commission du 6 avril 1967. 
prudente et se limite finalement à de simples études. La référence à l'OECE comme un contre-modèle sert à la fois à souligner l'échec de Marjolin en tant que commissaire européen mais aussi à rappeler les limites de l'action économique de l'OECE dont Marjolin était secrétaire général. Ces controverses ont certainement dû peser dans la décision de Marjolin de quitter la Commission européenne en mai 1967, alors même qu'il aurait eu des chances de rester à ce poste encore quelque temps ${ }^{246}$. Il revient à l'université et devient professeur à la faculté de droit et de sciences économiques de Paris tout en acceptant de nombreuses missions de conseil auprès de grandes multinationales britanniques et américaines ${ }^{247}$.

Robert Marjolin a déployé une grande énergie dans la défense de ses ambitions de coordination des politiques économiques. Reprenant sa méthode néofonctionnaliste des années 1962-1965, il cherche à obtenir des délégations de souveraineté progressives pour obliger les États membres à se consulter et donc à européaniser leurs réflexions. Il souhaite mettre en place une discipline économique et financière européenne qui se rapproche à certains égards de réflexions contemporaines. La logique des « clignotants » est la même que celle des « critères de convergence » du traité de Maastricht : il s'agit de définir collectivement des normes de bonne gestion dont la transgression entraînera un examen communautaire. De même, l'utilisation des recommandations de politique économique de la Commission pour justifier des politiques nationales impopulaires commence dès cette époque. Paradoxalement, plusieurs éléments du déficit démocratique dont souffre l'Union européenne sont déjà en place alors que les délégations de souveraineté n'ont pas été effectuées.

Marjolin a échoué dans son œuvre d'européanisation des esprits. Il est confronté à des États-nations qui ont nettement imposé leur leadership après la crise de la chaise vide. L'intransigeant ministre français Michel Debré souhaite développer la coordination des politiques économique et financière des Six mais il ne parvient pas à trouver une voie institutionnelle acceptable car il refuse toute évolution supranationale. La convergence entre des ambitions de la Commission nécessairement prudentes, et un volontarisme des États membres difficile à traduire de manière institutionnelle reste le problème central du commissaire européen en charge des affaires économiques et financières. C'est à Raymond Barre de relever ce défi après Robert Marjolin.

246. AN, 5 AG 1, volume 32, note de Dromer pour de Gaulle, 13 septembre 1967.

247. Il devint conseiller de la Royal Dutch Shell puis membre du conseil d'administration en 1969. Par ailleurs, Marjolin fut membre du conseil consultatif de la Chase Manhattan Bank à partir de 1967, puis conseiller pour IBM, American Express et General Motors : Robert Marjolin, Le travail d'une vie..., op. cit., p. 378-383. 


\section{L'arrivée de Barre à la Commission européenne.}

Nouveau vice-président de la Commission européenne en charge des affaires économiques et financières, Raymond Barre accède à ce poste après de nombreuses tergiversations du gouvernement français. Pierre Châtenet, un ancien ministre et président d'Euratom, initialement pressenti, refuse le poste pour rejoindre la direction de la nouvelle Commission des opérations de bourse (COB). Maurice Pérouse, le directeur du Trésor, avait également été contacté mais il a préféré rejoindre la Caisse des dépôts et consignations ${ }^{248}$. La fonction de commissaire européen reste donc toujours aussi peu prestigieuse et assimilée à une simple charge de haut fonctionnaire international.

Barre a un profil relativement proche de celui de Marjolin. S'il n'a pas occupé de postes dans la haute fonction publique française et internationale, il est, comme son prédécesseur, un économiste qui s'investit dans l'action publique sans entrer dans le jeu politique classique. De Gaulle avait d'ailleurs pensé à un autre professeur d'économie engagé en politique, Jean-Marcel Jeanneney, pour remplacer Marjolin après que ce dernier se soit présenté aux législatives sous les couleurs socialistes en $1962^{249}$. Né en 1924, treize années après Marjolin, Barre obtient l'agrégation d'économie du supérieur dès 1950. Contrairement à son aîné, il embrasse une carrière classique de professeur d'université. Il entre dans l'action publique en devenant directeur de cabinet du ministre de l'Industrie Jean-Marcel Jeanneney de 1959 à 1962. Ce passage au cœur de l'action gouvernementale lui permet de devenir un des experts officiels des exécutifs gaullistes.

La doctrine économique de Barre est difficile à définir. Auteur d'une thèse sur le facteur temps dans l'économie, il y brasse de multiples théories ${ }^{250}$. Élève et admirateur de Perroux ${ }^{251}$, c'est aussi un traducteur d'Hayek, il semble s'intéresser au renouvellement des idées de l'économie classique, sans toutefois rejeter le keynésianisme comme le fait Rueff ${ }^{252}$. Il est moins séduit par les idées planificatrices que Marjolin et paraît plus proche des néolibéraux. Cependant, à l'image de Marjolin qui travaillait à la fois pour l'économiste néoclassique Charles Rist et le socialiste Léon Blum en 1936, Barre est un intellectuel

248. AFNSP, 4 DE 12, note manuscrite de Pérouse à Debré, 26 mai 1967 ; AFNSP, 4 DE 6, lettre de Michel Debré à Charles de Gaulle, 16 juin 1967.

249. Éric Kocher-Marboeuf, Le praticien et le général. Jean-Marcel Jeanneney et Charles de Gaulle, 1958-1969, Comité pour l'histoire économique et financière de la France, Paris, 2003, p. 628.

250. Raymond Barre, La période dans l'analyse économique. Une approche de l'étude du temps, société d'édition d'enseignement supérieur, Paris, 1950.

251. Henri Amouroux, Monsieur Barre, Robert Laffont, Paris, 1986, p. 44.

252. F. Denord, Néolibéralisme version française..., op. cit., p. 249. 
pragmatique aux idées larges, soucieux de faire le lien entre ses recherches théoriques et l'action publique sans dogmatisme. La principale différence par rapport à Marjolin est donc politique car l'engagement de Barre se fait au sein des réseaux gaullistes ${ }^{253}$ et pas socialistes.

Fort de cette double expérience de professeur d'économie et d'expert « officiel » des gouvernements gaullistes, Barre doit affronter un contexte paradoxal en matière de coordination des politiques économiques et monétaires.

D'un côté, à l'échelle des Six, le développement de la CEE (union douanière, PAC) semble justifier un renforcement naturel de l'intégration économique et monétaire pour de nombreux hauts fonctionnaires comme le président hollandais du Comité monétaire, Emile van Lennep ${ }^{254}$, ou encore le directeur français de la Prévision Jean Serisé, qui souhaite poursuivre les travaux engagés par Marjolin autour des « clignotants $^{255}$ ». De même le président du gouvernement luxembourgeois Pierre Werner veut s'inspirer du programme défini par Marjolin pour que soient définies des opérations monétaires nécessitant une consultation préalable obligatoire ${ }^{256}$. Selon lui, « les Six devraient préciser leurs engagements réciproques pour le maintien de relations fixes entre leurs monnaies », coordonner leur attitude au sein du FMI et créer un " fonds européen de coopération monétaire ». Werner se montre donc très ambitieux car le contexte est favorable aux réflexions sur le renforcement de la coopération monétaire européenne.

À l'échelle internationale en effet, l'instabilité croissante du système monétaire international (SMI) et la demande d'adhésion de la Grande-Bretagne suscitent des débats intenses. Confrontée à des problèmes récurrents de déficits de la balance des paiements, la Grande-Bretagne a bénéficié de la solidarité internationale à plusieurs reprises dans les années soixante. Londres doit cependant accepter une dévaluation de la livre de $14 \%$ le 18 novembre 1967. Dans la perspective de l'adhésion britannique, le problème de la solidarité monétaire européenne est donc de plus en plus important.

Ce double contexte peut constituer une opportunité pour la relance de la coopération monétaire des Six. C'est d'ailleurs l'optique du ministre des Finances Michel Debré. Dans l'une des premières lettres qu'il envoie à Barre après la nomination de ce dernier à Bruxelles, il réaffirme son soutien à une

253. Selon Henri Amouroux, Barre soutenait de Gaulle depuis 1947, l'ayant rencontré pour la première fois en 1949 : H. Amouroux, Monsieur Barre..., op. cit., p. 58-59.

254. AHUE, EN 210, note sur la « Réception de M. Van Lennep, président du Comité monétaire », séance de la Commission du 6 avril 1967.

255. AMINEFI, B 17.689, note de Jean Serisé pour le ministre, 9 février 1968.

256. AMINEFI, B 50.478, dossiers de M. Pietra, discours Pierre Werner, janvier 1968. 
coordination forte des politiques conjoncturelles, sur une base intergouvernementale, la Commission devant assurer une fonction d'animation ${ }^{257}$. Son ambition est relancée par sa volonté de mobiliser les Six contre les États-Unis. Après l'échec de sa tentative de création d'un front commun contre l'approche américaine de réforme du SMI, il mène une nouvelle offensive contre les mesures protectionnistes envisagées par le président américain Johnson pour résoudre les problèmes de balance des paiements américaine. Le 6 janvier 1968, il écrit à de Gaulle une note très explicite ${ }^{258}$. Face aux « abus de la politique américaine », il se demande : « Peut-on imaginer que la coordination des politiques économiques européennes permettrait d'éviter ces incidents? ». En dépit des déceptions récentes, il affirme : «C'est ce qu'il faudrait et c'est sans doute notre seule chance $^{259} »$. Il se propose donc de tout faire pour constituer un front commun des Six et lance son initiative, sans succès, lors de la réunion des ministres des Finances des Six de février $1968^{260}$. Pour Debré, la coordination doit reposer non pas sur des procédures institutionnelles, mais sur une volonté politique, initiée par la perception d'une solidarité face à une menace extérieure.

Dans un contexte favorable au renforcement de la coordination des politiques monétaires, Barre tente de prendre l'initiative avec un premier mémorandum présenté en février 1968.

\section{Le mémorandum Barre de février 1968.}

Lors de la réunion des ministres des Finances des 26 et 27 février 1968, Raymond Barre présente un document secret intitulé « Mémorandum sur l'action de la Communauté dans le domaine monétaire ${ }^{261} »$. Ce document est issu d'un double constat. D'une part, les discussions sur les suites des projets engagés par Marjolin sont dans l'impasse. La réunion du comité de politique conjoncturelle du 14 février 1968 montre que le groupe d'experts sur le système des « clignotants » constitué le 18 octobre 1966 reste paralysé par les réticences des États membres ${ }^{262}$. Il est donc temps de relancer les discussions sur de nouvelles bases. D'autre part, Barre semble vouloir profiter des intentions offensives

257. AFNSP, 4 DE 6, lettre à Barre du 2 octobre 1967.

258. AFNSP, 4 DE 7, note du 6 janvier 1968 de Debré à Charles de Gaulle.

259. AFNSP, 4 DE 7, note du 6 janvier 1968 de Debré à Charles de Gaulle.

260. AN, Daney de Marcillac, volume 15, compte rendu de la réunion des ministres des Finances des 26-27 février 1968.

261. «Mémorandum sur l'action de la Communauté dans le domaine monétaire (présenté par M. R. Barre, vice-président de la Commission des Communautés européennes, à la conférence des ministres des Finances des 26 et 27 février 1968) ».

262. AMINEFI, B 17689, compte rendu de la $33^{\mathrm{e}}$ réunion du Comité de politique conjoncturelle du 14 février 1968. 
de Debré face aux États-Unis. Dans un entretien avec un haut fonctionnaire français le 12 janvier 1968, il évoque sa peur d'une déstabilisation du SMI à cause de l'attitude américaine pour justifier un renforcement de la solidarité monétaire européenne ${ }^{263}$.

Le mémorandum de Barre de février 1968 est fondé sur une démarche prudente. Au lieu d'utiliser la voie d'une communication au Conseil par exemple, il évite tout débat public et même toute discussion au sein de la Commission en diffusant un document court (une page et demie), secret et réservé aux seuls ministres des Finances ${ }^{264}$. Le secret semble d'ailleurs avoir été bien conservé car, hormis les articles d'Ivo Maes ${ }^{265}$, ce document est très rarement évoqué aujourd'hui encore. Le mémorandum propose d'étudier quatre mesures :

- 1. Une « déclaration des pays membres qu'ils ne procéderont que d'un commun accord à une modification des rapports de parité entre leurs monnaies » ;

- 2. Des dispositions pour éliminer les fluctuations du taux de change entre les monnaies des Six ;

- 3. La mise en place d'un « dispositif de concours mutuel [...] par exemple sous la forme d'un réseau multilatéral d'ouvertures de crédits réciproques »;

- 4. La définition d'une unité de compte européenne à utiliser le plus largement possible ${ }^{266}$.

La continuité avec Marjolin est nette. La cible reste la stabilité des taux de changes, indispensable pour ne pas remettre en cause les premières réussites de la CEE (union douanière, PAC). Pour l'assurer, Barre adopte, comme Marjolin, une méthode communautaire fondée sur une surveillance réciproque et des contraintes institutionnelles. Enfin, en matière de concours mutuel, Barre, comme son prédécesseur, ne parle pas de fonds européen à constituer mais préfère la solution plus décentralisée de la coordination des interventions des banques centrales.

La procédure d'application s'inspire aussi largement des méthodes de Marjolin. Barre s'inscrit dans son héritage en faisant référence aux mesures

263. AN, 5 AG1, volume 48, note du 12 février 1968 sur un entretien ce jour avec Raymond Barre.

264. Jean-Claude Paye, «Vers le Plan Werner. Le rôle de la Commission des Communautés, 19671973 », in Le rôle des ministères des Finances et de l'Économie dans la construction européenne (1957-1978), tome II, Comité pour l'histoire économique et financière de la France, Paris, p. 115.

265. Ivo Maes, " Projets d'intégration monétaire à la Commission européenne au tournant des années 1970 », in É. Bussière et al. (dir.), Milieux économiques et intégration européenne au XX ${ }^{e} .$. ? op. cit., p. 35-50.

266. J.-C. Paye, « Vers le Plan Werner... », op. cit., p. 115. 
prises depuis 1964. Il propose de confier l'étude de ces mesures au Comité monétaire et au Comité des gouverneurs des banques centrales. Barre se place donc directement dans la continuité de Marjolin, dont il veut relancer l'entreprise en utilisant la même méthode, fondée sur un large recours à des comités de hauts fonctionnaires censés " européaniser » les réflexions des États membres. Il abandonne les ambitions politiques et sociales planificatrices de Marjolin et concentre le processus de coordination sur les aspects macroéconomiques.

Les réactions aux propositions de Barre sont très mesurées. Fort classiquement les Néerlandais et les Allemands estiment que le mémorandum n'est pas assez précis sur les efforts de rapprochement et de discipline des politiques économiques $^{267}$. En France, l'hostilité est également de mise mais pour des raisons différentes. Larre, le directeur du Trésor affirme, dans des accents qui rappellent ceux de son ministre, que : «Dans le domaine monétaire et notamment dans le domaine monétaire international, les autres gouvernements européens prennent volontiers leurs consignes à Washington ${ }^{268} \ldots$ ». Dès lors, tous les efforts de renforcement de la solidarité monétaire européenne sont inacceptables si les Six ne s'entendent pas au préalable sur une attitude commune face aux États-Unis. Larre est hostile à toute délégation de souveraineté dans ce domaine. Lors de la réunion des six ministres des Finances, Debré a tenu la même ligne, en voulant faire porter le débat sur la solidarité des Six face aux États-Unis ${ }^{269}$. Après la réunion, il écrit directement à Raymond Barre pour lui manifester sa déception face au mémorandum, jugé trop supranational et pas assez hostile aux Etats-Unis ${ }^{270}$. Pour Debré, il est impossible de renforcer institutionnellement une solidarité européenne qui n'existe pas dans les esprits, en raison des divergences face aux États-Unis.

Le mémorandum de février 1968 est donc un échec pour Barre, mais le commissaire a cependant affirmé à cette occasion son autonomie face au gouvernement français et sa fidélité envers la partie non planificatrice du programme de Marjolin. Il profite des troubles monétaires issus de mai 1968 pour relancer les discussions sur la solidarité monétaire des Six.

267. Ivo Maes, Macroeconomic and Monetary Thought at the European Commission in the 1960s, EUI-RSCAS Working Papers, $\mathrm{n}^{\circ}$ 1, 2004.

268. AMINEFI, B 62124, note de Larre pour le Ministre, 22 février 1968.

269. AN, Daney de Marcillac, volume 15, compte rendu de la réunion des ministres des Finances des 26-27 février 1968.

270. AFNSP, 4 DE 7, lettre du 29 février 1968 de Michel Debré à Raymond Barre. 


\section{B. LES PROJETS MONÉTAIRES RELANCÉS PAR LA CRISE FRANÇAISE}

À partir de mai 1968, les difficultés financières françaises relancent le débat sur la coopération monétaire européenne, d'abord autour des mesures d'assistance à la France, ensuite lors de la crise monétaire de novembre 1968 et enfin avec le plan Barre de février 1969.

\section{La crise de mai 1968.}

La crise de mai 1968 a eu deux conséquences immédiates sur la politique européenne de la France. D'une part, les hausses de salaires, les pertes de production et les mesures de relance de l'économie ont relancé l'inflation et aggravé les déficits commercial et budgétaire. D'autre part, le crédit politique de la France est atteint par l'impression de vacance du pouvoir qui a pu être ressentie à certains moments de la crise. La France n'est plus en position motrice dans le dossier de la coordination des politiques économiques et monétaires. Elle devient au contraire demandeuse de dérogations.

Très rapidement, dès le 18 mai 1968 Michel Debré s'inquiète des conséquences possibles de ces troubles sur les obligations européennes, notamment l'échéance du premier juillet 1968, date d'achèvement du Marché commun (suppression totale des droits de douane internes, mise en place définitive du tarif extérieur commun $)^{271}$. Pour éviter des mesures trop brutales, il demande une forte retenue dans les négociations salariales mais il est écarté des négociations de Grenelle ${ }^{272}$.

Dès le 29 mai 1968 (deux jours après les accords de Grenelle du 27 mai 1968 et en pleine vacance du pouvoir présidentiel), des premières mesures de contrôle des changes et de tirage sur le FMI sont prises $^{273}$. En matière commerciale, les débats restent ouverts. Le 10 juin 1968, le Premier ministre (Pompidou), le ministre des Affaires étrangères (Couve de Murville) et le ministre de l'Économie et des Finances (Debré) fixent les premières mesures. Ils décident " comme le souhaite d'ailleurs le patronat», de respecter l'échéance du premier juillet 1968, ce qui montre la profondeur de la conversion des milieux économiques et politiques au libre-échange ${ }^{274}$. C'est également l'état d'esprit qui prévaut dans un service autrefois fer de lance des dispositifs protectionnistes,

271. AN, 5 AG1, 49, note de Debré à de Gaulle, 18 mai 1968.

272. Michel Debré, Trois républiques pour une France, Mémoires, t. IV, 1962-1969, Gouverner autrement, Albin Michel, Paris, 1993, p. 211.

273. AMAE, DECE 736, télégramme au départ, Brunet, pour tous les postes diplomatiques, 4 juillet 1968.

274. AN, 5 AG1, volume 36, note Prate du 11 juin 1968. 
la DREE. Son directeur, Jean Chapelle, conseille à son ministre d'adopter une politique d'importation libérale car la pression extérieure est nécessaire pour $l^{\prime}$ « adaptation et la rationalisation » à long terme ${ }^{275}$. Il faut donc résister aux appels protectionnistes. Par contre, une politique " vigoureuse » de soutien aux exportations doit être menée, notamment par le soutien à la prospection commerciale. C'est le sens des mesures spécifiques envisagées le 10 juin 1968. Elles concernent surtout des décisions que la France envisageait avant la crise mais ne pouvait pas se permettre de prendre comme des mesures d'aide sectorielles à l'électroménager et au textile. Boegner transmet à la Commission cette position française, fondée sur trois éléments : le respect de l'échéance tarifaire du premier juillet 1968, l'annonce de mesures éventuelles de protection envers les importations (dans certains secteurs, au titre de l'article 226) et d'aides aux exportations (notamment par un taux de réescompte privilégié) ${ }^{276}$.

La Commission réagit prudemment car ces mesures sont partielles et elles ne sont pas précédées d'une démonstration juridique de leur compatibilité avec le traité de Rome $^{277}$. En conséquence, sa réponse est plutôt négative ${ }^{278}$. Pourtant, les mesures françaises annoncées le 25 juin 1968 reprennent celles prévues le 10 juin 1968, et ne sont pas justifiées par une référence à un article précis du traité de Rome ${ }^{279}$. La consultation de la Commission n'a donc pas été prise en compte. Finalement, par une décision du 28 juin 1968 et une lettre à Debré du 5 juillet 1968, le président Rey lance officiellement la procédure de l'article $108^{280}$. Le recours à l'article 108 permet à la Commission de « redonner une apparence de régularité à l'ensemble de l'opération ${ }^{281} »$ car, comme en mai 1958, la procédure n'a pas été respectée : la France a en effet pris des mesures de manière unilatérale avant de les soumettre à la Commission alors qu'elle aurait dû attendre les recommandations de la Commission. La Commission comme les autres pays membres avaient critiqué l'attitude unilatérale de la France plus que le fond des mesures prises ${ }^{282}$.

275. AMAE, DECE 736, note du directeur de la DREE, Jean Chapelle, au ministre, 13 juin 1968.

276. AHUE, procès-verbal normal de la $40^{\mathrm{e}}$ session de la Commission du 12 juin 1968, point IV ; AMAEF, DECE 736, télégramme au départ, Brunet pour Boegner, 11 juin 1968.

277. AMAE, DECE 736, note EC, 14 juin 1958 ; AMAEF, DECE 736, télégramme à l'arrivée, Boegner, 13 juin 1968.

278. AHUE, procès-verbal de la $40^{\mathrm{e}}$ réunion de la Commission, 16 juin 1968, point XXXVIII.

279. AN, 5 AG1, volume 29, note de Prate pour le général de Gaulle, 25 juin 1968 ; AMINEFI, B

17.689, «Aide-mémoire remis le 25 juin 1968 ».

280. AMINEFI, B 17.689, lettre de Jean Rey, président de la Commission, à Debré, ministre de l'Économie et des Finances, 5 juillet 1968, et premières recommandations (doc. COM (68) 555).

281. AMAE, DECE 736, note SCE EC, 11 juillet 1968.

282. AMAE, DECE 736, note SCE, EC, 2 juillet 1968. 
Finalement le 23 juillet 1968, la Commission autorise la France à prendre des mesures de sauvegarde ${ }^{283}$. Il s'agit globalement d'une validation a posteriori des décisions françaises. La Commission s'est contentée d'augmenter un peu les contingents prévus (et de refuser un contingent mineur, sur la laine cardée, mesure qui ne fut d'ailleurs pas respectée par la France ${ }^{284}$ ) et de demander un rapport sur la mise en œuvre de ces mesures.

Dans l'application des mesures de sauvegarde, la France reste relativement modérée. Ainsi, elle lève dès le 4 septembre 1968 le contrôle des changes, provoquant une heureuse surprise chez ses partenaires ${ }^{285}$. En fait, selon Alain Prate, conseiller économique du général de Gaulle : " Il a été relativement facile, à la fin du mois de mai dernier, d'élaborer une nouvelle réglementation des changes, mais il n'existait pratiquement plus de services capables d'en contrôler l'application. Les Douanes elles-mêmes, dont les tâches courantes ont été accrues par la forte progression du trafic de marchandises et du nombre de voyageurs, n'ont pratiquement rien fait pour contrôler l'application des textes ${ }^{286} »$. Dans un monde ouvert, l'application des mesures restrictives devient beaucoup plus difficile. Dans le cas plus précis des sorties de devises par anticipation du paiement des importations, il affirme que « le contrôle de cette interdiction suppose une immense administration qui n'existe plus ». Les pratiques administratives ont donc considérablement évolué en dix ans et se sont profondément adaptées à la libération des échanges, considérée dans les années cinquante comme une contrainte à orienter, et dorénavant comme un fait intangible auquel il faut s'adapter.

Le recours par la France à l'article 108 en juin-juillet 1968 suite aux troubles de mai intervient juste dix années après la première intervention de la Commission au titre de l'article 108 en mai 1958. Les mesures prises par la France montrent le chemin parcouru en dix années en termes de mentalités. Les décideurs politiques et administratifs français ne recherchent plus d'exception globale au processus de libération des échanges. Le respect de l'échéance du premier juillet (achèvement du Marché commun) est accepté pas tous et seules

283. AMAE, DECE 736, lettre de Jean Rey, président de la Commission européenne, à Michel Debré, ministre des Affaires étrangères français, du 23 juillet 1968, décision de la Commission COM (68) 650 ; AMAE, DECE 736, note EC du 23 juillet 1968.

284. ASGCI 2000.0298, volume 9, télex du 22 août 1968 de Boegner qui souligne d'ailleurs la modération dont fait preuve la Commission dans ce dossier de la laine cardée.

285. Éric Bussière, « La France et les débats au sein du Comité monétaire à l'époque du Plan Werner. Automne 1968-Printemps $1971 »$, in Le rôle des ministères des Finances et l'Économie dans la construction européenne (1957-1978), tome I, Comité pour l'histoire économique et financière de la France, Paris, 2002, p. 354.

286. AN, 5 AG1, 37, note Prate du 14 novembre 1968. 
des mesures limitées sont prises. Par contre, l'apprentissage de l'européanisation du traitement des troubles financiers semble plus difficile. Comme en 1958, la procédure de l'article 108 n'a pas été respectée. Alors que la Commission aurait dû prendre l'initiative de recommandations, elle se trouve obligée de valider $a$ posteriori les mesures prises par la France. De plus, l'absence de justifications juridiques précises des mesures françaises manifeste la maladresse de l'administration française et son manque d'expertise juridique dans ce domaine, certes récent, du droit communautaire. Surtout, cet épisode marque le retour pour la France à une période de faiblesse financière et monétaire après dix années de franc fort. Enfin, la crise française ne s'est pas traduite par une coopération des Six très aboutie. Cela relance les débats sur le renforcement de la solidarité monétaire européenne, jusqu'à la prochaine crise monétaire française.

\section{La crise de novembre 1968.}

Après la crise de mai 1968, le nouveau gouvernement de Maurice Couve de Murville estime en septembre 1968 que la crise financière et monétaire est passée. En conséquence, un budget d'expansion est établi, avec un très fort déficit budgétaire, combiné avec une suppression du contrôle des changes ${ }^{287}$. En complément, la France lance une initiative européenne pour renforcer la solidarité monétaire européenne en cas de nouveaux troubles. Au Comité monétaire du 4 septembre 1968, le représentant français demande la « mise en place d'une solidarité monétaire dans le domaine des réserves ${ }^{288}$ ». Selon lui, les instruments internationaux actuels (dans le cadre du FMI, des accords entre banques centrales) sont insuffisants.

Cette offensive est un succès car, à la réunion suivante des ministres des Finances, en septembre 1968, le Comité monétaire est chargé d'étudier les progrès possibles en matière de coordination des politiques monétaires ${ }^{289}$. Barre en profite pour relancer les projets anciens de la DG II en proposant une amélioration des procédures de consultations préalables, la définition d'une procédure de concours mutuel et l'élimination des fluctuations de change entre les $\operatorname{Six}^{290}$. Un autre document du 7 novembre 1968 émanant de la Commission insiste sur la continuité entre les décisions de 1960 (création du comité de politique conjoncturelle), de 1964 (création du Comité des gouverneurs et du

287. A. de Lattre, La politique économique française de 1945 à 1970..., op. cit., p. 204.

288. É. Bussière, «La France et les débats au sein du Comité monétaire... », op. cit., p. 354.

289. AMINEFI, B 62.168, compte rendu du Comité monétaire du 15 octobre 1968.

290. Éric Bussière, «La France et les débats au sein du Comité monétaire... », op. cit., p. 356. 
Comité de politique budgétaire) et les décisions à prendre sur l'instauration de consultations préalables obligatoires ${ }^{291}$.

Les Six restent toutefois très prudents. La France souhaite renforcer la coordination des politiques monétaires mais sans s'engager dans des réformes institutionnelles trop contraignantes comme une consultation obligatoire ${ }^{292}$. Surtout, dans un contexte monétaire international tendu, elle entend mettre l'accent sur la coordination de l'action des Six dans le débat sur la réforme du SMI.

Cependant, la conjoncture financière et monétaire se dégrade en France. Une spéculation intense contre le franc se développe à partir du début novembre 1968. Le 12 novembre 1968, des mesures sévères de restrictions du crédit sont prises $^{293}$. Le ministre des Affaires étrangères Michel Debré envisage d'aller plus loin en proposant un nouveau plan Rueff analogue à celui de décembre $1958^{294}$. Il s'agirait de prendre des mesures sévères d'assainissement des finances publiques, voire une dévaluation même si ce n'est pas directement évoqué dans les archives. Quelques jours plus tard, le 15 novembre, Prate évoque l'hypothèse d'un accord franco-allemand sur une « remise en ordre limitée des parités monétaires » au sein de l'Europe des Six, c'est-à-dire une réévaluation du mark et une dévaluation du franc français, accompagnée par un plan de « rétablissement durable de l'économie française ${ }^{295}$ ». Il serait défini par « un petit groupe d'éminents spécialistes, comprenant, par exemple, M. Goetze et M. Massé ». Le parallèle avec le comité Rueff est donc évident dans la méthode mais aussi dans les personnes, car Goetze a joué un grand rôle dans l'élaboration du plan Rueff.

La situation s'aggrave. Les décisions prises le 12 novembre 1968 relancent la spéculation sur le franc, obligeant à une fermeture du marché du franc le 20 novembre 1968, et à un rétablissement d'un contrôle des changes plus sévère que celui de mai 1968 le 24 novembre $1968^{296}$. Pendant ce temps, des réunions de concertations internationales s'organisent. La RFA refuse de réévaluer et se contente de prendre des mesures de renchérissement de ses exportations

291. AMINEFI, B 62.168, note des membres de la Commission, 7 novembre 1968.

292. AMINEFI, B 62.168, note française pour la réunion des suppléants du Comité monétaire du 8 novembre 1968 ; AMINEFI, B 62.168, compte rendu des débats du Comité monétaire du 8 novembre 1968.

293. AN, 5 AG1, volume 37, note Prate du 12 novembre 1968.

294. AN, 5 AG1, volume 37, note Prate du 12 novembre 1968.

295. AN, 5 AG1, volume 37, note Prate du 15 novembre 1968 ; AN, 5 AG1, volume 36, note Prate du 18 novembre 1968 .

296. AN, 5 AG1, volume 37, note J. Chabrun du 25 novembre 1968 ; A. de Lattre, La politique économique française..., op. cit., p. 204-9. 
et de diminution du coût des importations ${ }^{297}$. Barre est ensuite consulté par de Gaulle, à qui il conseille de ne pas dévaluer et de prendre des mesures d'austérité financière ${ }^{298}$. Il assure également le président français de la possibilité d'obtenir rapidement des crédits internationaux en cas de difficultés ${ }^{299}$. Convaincu par Barre, puis par Jean-Marcel Jeanneney, de Gaulle maintient la parité du franc. Le 26 novembre 1968 est décidé un plan de stabilisation. Le déficit budgétaire est largement réduit, la fiscalité est alourdie et l'encadrement du crédit prolongé.

La Commission européenne ayant été en partie à l'origine de ces mesures, elle accepte dès le 4 décembre les mesures françaises, avec une réserve mineure, en se référant à l'article $108^{300}$. La mention de l'article 108 est d'ailleurs toute théorique car là encore, comme en mai 1958 et en mai 1968, la France a d'abord pris des mesures unilatérales qu'elle a fait accepter a posteriori alors que c'est la Commission qui aurait dû exprimer en premier ses recommandations.

La crise française de novembre 1968 démontre la profondeur des difficultés françaises. Le refus du général de Gaulle de dévaluer alors qu'une partie de son gouvernement et de son administration l'y incitait marque la priorité des considérations de prestige politique sur celles de la stabilité financière, comme en 1956-1957 lorsque Guy Mollet se refusait à dévaluer pour des raisons idéologiques. En termes de coopération économique et monétaire européenne, la crise a tendu considérablement les relations franco-allemandes, tout en relançant le débat sur le renforcement de la solidarité monétaire entre les Six.

\section{Le plan Barre de février 1969.}

La crise monétaire de novembre 1968 relance les débats sur la coordination des politiques économiques et monétaires de manière très large. Les projets sont nombreux, Jean Monnet ou Valéry Giscard d'Estaing ${ }^{301}$ reprennent des propositions anciennes tandis que Hans von der Groeben développe un projet très

297. Sur la crise monétaire franco-allemande, voir un compte rendu détaillé et fondé sur archives in B. Schoenborn, La mésentente apprivoisée..., op. cit., p. 129-138.

298. AHUE, procès-verbal spécal de la $57^{\mathrm{e}}$ réunion de la Commission, sessions des 20 et 23 novembre 1968.

299. É. Kocher-Marboeuf, Le praticien et le général..., op. cit., p. 1044 sur Barre, p. 1039-1049 plus généralement sur le rôle de Jeanneney.

300. AMAEF, DECE 724, décision de la Commission du 4 décembre 1968, doc. COM (68) 941 ; ABDF, 1489.2002.05, volume 222, note DGSE, relations avec l'étranger, MEF, 17 décembre 1968.

301. B. Schoenborn, La mésentente apprivoisée..., op. cit., p. 128 et 139. 
fédéraliste ${ }^{302}$. De son côté, Raymond Barre transmet un nouveau mémorandum aux États membres le 5 décembre $1968^{303}$. Il est centré sur deux mesures.

D'une part, une coordination permanente des politiques économiques des États membres doit être mise en place. Pour Barre, « il importe moins de créer des institutions ou des procédures nouvelles que de recourir effectivement aux instances communautaires existantes, d'utiliser les procédures déjà établies et de procéder à des consultations préalables sur les grandes options de la politique économique des États membres ou sur les décisions à prendre dans le domaine économique et financier ${ }^{304}$. Le mémorandum souligne ainsi que la crise monétaire de novembre 1968 a été résolue dans des enceintes plus large que celles de la CEE et que le Comité monétaire n'a pas pu se réunir comme l'avait demandé la Commission. De même, lorsque le Comité monétaire avait enfin pu se tenir, les quatre représentants des pays non concernés par la crise avaient critiqué l'absence de coordination par le Comité monétaire, certains mettant directement en cause la RFA ${ }^{305}$.

D'autre part, il est indispensable d'instituer un « mécanisme de coopération monétaire » entre les Six qui s'appuierait sur l'article $108^{306}$. Le mémorandum souligne « que le mécanisme envisagé ne saurait en aucun cas constituer un moyen permettant à un des États participants de poursuivre une politique de facilité qui s'écarterait de la ligne tracée en $\operatorname{commun}^{307} \gg$. L'instauration de ce mécanisme est donc directement liée au respect du premier objectif, une coordination étroite des politiques économiques. Enfin, la Commission annonce de nouvelles propositions pour février 1969.

Le mémorandum du 5 décembre 1968 trace donc une voie prudente fondée sur un équilibre entre une forte coordination des politiques économiques impliquant nécessairement une convergence vers des objectifs de stabilité - et, en contrepartie, l'instauration d'une solidarité monétaire réelle.

Le plan Barre du 12 février 1969, intitulé : " mémorandum sur la coordination des politiques économiques et la coopération monétaire au sein de la

302. AN, 1987.0451, volume XII, « Problèmes de politique monétaire européenne. Pour l'établissement graduel d'un système monétaire européen », note sous forme de tiré à part édité par la CEE, extrait de mélanges en l'honneur du professeur Schmölders (Geldtheorie und Geldpolitik - Günter Schmölders zum 65. Geburstag, Berlin, 1968).

303. AMINEFI, B 17.689, mémorandum du 5 décembre 1968, doc. SEC (68) 3958 final.

304. AMINEFI, B 17.689, mémorandum du 5 décembre 1968, doc. SEC (68) 3958 final.

305. Éric Bussière, «La France et les débats au sein du Comité monétaire... », op. cit., p. 353 ; AMINEFI, B 62.168, note DD, signé Larre, Directeur du Trésor, 10 janvier 1969.

306. AMINEFI, B 17.689, mémorandum du 5 décembre 1968, doc. SEC (68) 3958 final.

307. AMINEFI, B 17.689, mémorandum du 5 décembre 1968, doc. SEC (68) 3958 final. 
Communauté $^{308} »$, marque une étape décisive dans la naissance de l'union économique et monétaire par l'équilibre qu'il propose entre ces deux éléments. Il débute par un exposé des motifs classique qui souligne la perte de la souveraineté des États en matière monétaire du fait de l'ouverture de l'union douanière et de l'indépendance croissante des grandes multinationales. Il préconise ensuite trois actions, qui s'inscrivent, selon le mémorandum, dans la continuité de la ligne de la Commission depuis le programme d'action de 1962.

Tout d'abord, une « convergence des orientations nationales à moyen terme » doit être assurée ${ }^{309}$. S'appuyant sur le premier programme de politique économique à moyen terme qui avait révélé les « contradictions » des politiques nationales, il demande l'établissement d'objectifs communs dans un certain nombre de domaines comme le taux de croissance et le taux d'inflation. Pour ce dernier indicateur d'ailleurs, une grande convergence doit être recherchée pour assurer la cohésion de l'union douanière et agricole récemment constituée. Ainsi, paradoxalement, Barre utilise la politique économique à moyen terme tant décriée par les Allemands pour remplir un objectif défendu ces derniers : assurer une convergence des pays membres de la CEE vers la politique de gestion financière rigoureuse pratiquée outre-Rhin.

Une fois ce cadre commun planté, il est nécessaire d'aboutir à des « politiques économiques à court terme concertées ${ }^{310} »$. Le but est de prévenir les déséquilibres par une consultation permanente. Concrètement, Barre demande aux États membres d'adopter un projet de décision du Conseil annexé au mémorandum. Il se place ouvertement dans la continuité de la déclaration de 1964 adoptée à l'initiative de Marjolin. Elle prévoyait la nécessité de consultation préalable en matière de modification de taux de change sous réserve d'une procédure à définir. Cette fois, le projet de décision prévoit un domaine très large de concertations possibles. Les consultations devront concerner les « décisions, mesures ou prises de position [...] qui ont une incidence sur les économies des autres États membres », soit «l'évolution des prix, des revenus et de l'emploi ; la politique budgétaire globale... ». Les consultations auraient lieu au sein des comités monétaires, de politique conjoncturelle et de politique budgétaire. Enfin et surtout, l'article 3 stipule que : "Les États membres n'adoptent les décisions, mesures ou prises de position susvisées qu'après intervention des consultations prévues à l'article premier à moins que les circonstances ne s'y

308. AHUE, procès-verbal spécial de la $67^{\mathrm{e}}$ réunion de la Commission du 12 février 1969, annexe II : doc. $\operatorname{COM}(69) 150$ : « Mémorandum de la Commission au Conseil sur la coordination des politiques économiques et la coopération monétaire au sein de la Communauté ».

309. Ibid., points 8, 9 et 16 .

310. Ibid., points 11,21 et 22 . 
opposent ». Si la fin de l'article préserve une certaine souplesse, son début marque la volonté d'imposer une véritable coordination contraignante et ex ante des politiques économiques. Barre poursuit la logique de Marjolin (consultations dans le cadre de comités de hauts fonctionnaires) en l'accentuant. Il cherche à profiter des deux crises françaises de 1968 pour obtenir des délégations de souveraineté décisives.

Le dernier élément est la création d'un « mécanisme de coopération monétaire $^{311} »$. Des accords de mise à disposition de fonds à court terme devront être passés. L'utilisation de ces fonds obtenus automatiquement est plafonnée et limitée à trois mois en l'absence d'accord des institutions communes. Ces dernières devraient également pouvoir accorder un concours financier à moyen terme. Dans la continuité de Marjolin, Barre refuse donc de créer un FER et se contente d'accords ad hoc entre les institutions monétaires. Afin de donner une valeur ajoutée à la coopération monétaire à Six par rapport à la coopération internationale, les fonds sont donc débloqués automatiquement mais dans des limites strictes. Dans sa conclusion, Barre insiste sur le lien fort qui existe entre la coordination des politiques économiques et la mise en œuvre d'un mécanisme monétaire. Autrement dit, nul ne peut prétendre à un soutien monétaire s'il n'a fait l'effort de progresser vers les objectifs économiques définis en commun.

Les réactions à ce mémorandum ambitieux sont réticentes. Les gouverneurs des banques centrales sont très prudents et insistent sur la convergence des politiques économiques ${ }^{312}$. En France, une première analyse du directeur du Trésor, René Larre, se montre favorable en principe au soutien monétaire à court terme mais hostile à l'extension de la consultation préalable pour la coordination des politiques économiques ${ }^{313}$. Elle reste dans la logique de la position française " monétariste » traditionnelle, qui consiste à obtenir une solidarité monétaire sans discipline économique particulière. Au contraire, lors du Comité monétaire des 27 et 28 février 1969, la plupart des représentants des partenaires de la France ont insisté sur la nécessité d'une convergence accrue des objectifs de politique économique par la définition d'une attitude commune envers l'inflation ${ }^{314}$. Lors du débat, le mécanisme de coopération monétaire a été très critiqué. Le caractère automatique de l'aide a été mis en cause. Pour éviter qu'un pays assisté ne retarde les réformes nécessaires, " plusieurs membres

311. Ibid., points 11,21 et 22 .

312. I. Maes, « Projets d'intégration monétaire à la Commission européenne... », op. cit., p. 43.

313. AMAE, RPUE 692, note CP, signée Larre, 24 février 1969.

314. AMINEFI, B 62168, note sur les débats au Comité monétaire des 27 et 28 février 1969, 6 mars 1969, doc. OR II/15/69 ; AMINEFI, B 62168, note française sur les débats au Comité monétaire des 27 et 28 février 1969. 
ont proposé de préciser les sanctions en cas de non-respect de l'obligation de consultations $^{315}$ ». Cette dernière précaution semble directement viser les pays les plus fragiles comme la France. Le Comité monétaire du 28 février 1969 se termine par la même opposition entre « économistes » et « monétaristes ${ }^{316}$ ». Le choix est donc clairement politique.

Une relance politique est nécessaire pour surmonter ces divergences de fond entre « monétariste » français et « économistes » allemands. Le contexte évolue de toute façon radicalement avec le départ du général de Gaulle du pouvoir le 28 avril 1969, de nouvelles tensions sur le mark en mai 1969 puis la dévaluation française (août 1969) et la réévaluation allemande (octobre 1969). Ces préalables politiques et monétaires permettent une relance des discussions sur la coopération économique et monétaire tout au long des années 1970.

\section{Des AMBitions RÉElLES DE BARRE EN MATIÈRE ÉCONOMIQUE ET MONÉTAIRE}

Les projets défendus par le nouveau commissaire aux affaires économiques et financières Raymond Barre s'inscrivent donc dans la continuité des projets de son prédécesseur Robert Marjolin. Comme ce dernier, il associe politique économique à moyen terme d'une part, politique conjoncturelle et politique monétaire d'autre part dans un projet global. Il maintient une voie intermédiaire entre les préoccupations françaises d'une solidarité monétaire et la vision allemande fondée sur la surveillance des politiques économiques nationales, pour limiter l'inflation et les déficits de balance des paiements. Enfin, il adopte la même méthode institutionnelle que son prédécesseur, mettant au centre de la dynamique européenne les comités de hauts fonctionnaires et refusant de créer des institutions nouvelles comme un FER.

Cependant, Barre a réorienté les réflexions antérieures de Marjolin. Profitant d'un contexte général de crise monétaire à l'intérieur et à l'extérieur de la Communauté, il a pu lancer des imitatives ambitieuses. Sur le fond, il s'est concentré sur la coordination des politiques macroéconomiques et a abandonné les aspects sectoriels qui pouvaient apparaître comme les éléments les plus dirigistes des projets de Marjolin. Au fur et à mesure des crises monétaires françaises, Barre devient plus audacieux. Après son mémorandum secret de

315. AMINEFI, B 62168, note sur les débats au Comité monétaire des 27 et 28 février 1969, 6 mars 1969.

316. Éric Bussière, « La France et les débats au sein du Comité monétaire... », op. cit., p. 355. 
février 1968 largement oublié, il dévoile un plan plus ambitieux, qui fit date dans l'histoire de l'unification monétaire européenne, en février 1969.

Barre doit cependant composer avec la vigueur d'un projet français concurrent animé par Debré. Il repose sur une coordination des politiques économiques et monétaires forte mais fondée uniquement sur la volonté des États. Dans cette perspective, la solidarité entre les Six doit être assurée non pas par des institutions ou des procédures, mais par la commune perception de la menace américaine. L'isolement de la France gaulliste dans ce constat condamne cependant cette vision. Il faut attendre le départ du général de Gaulle pour que les discussions puissent être relancées.

\section{CONCLUSION : LE PROJET MARJOLIN D'EUROPE VOLONTARISTE ET SA POSTÉRITÉ}

Les ambitions du commissaire européen Robert Marjolin se traduisent par un plan global et ambitieux, dont la réalisation a été handicapée par les faiblesses de la position de son promoteur, mais qui a une réelle postérité.

Le projet de Marjolin d'Europe volontariste est fondé sur une double doctrine économique et politico-institutionnelle. Sur le plan économique, le projet s'inspire de la conviction scientiste des planificateurs français pour défendre la nécessité d'une confrontation globale de tous les éléments de l'activité économique, afin de leur donner une cohérence. Son volontarisme est particulièrement ambitieux, notamment lorsqu'il prévoit de réorienter les capitaux disponibles vers les besoins collectifs. D'un autre côté, il reste toujours attaché aux lois du marché et surtout à la nécessité de maintenir des équilibres financiers et monétaires aptes à générer une croissance saine. Il est en particulier très attentif à limiter l'inflation et les déficits publics, et il cherche à obtenir la confiance des banques centrales.

En termes de doctrine politico-institutionnelle, le projet de Marjolin se caractérise par une grande progressivité. Marjolin a certainement été influencé par son expérience de secrétaire général de l'OECE, par l'échec de ses deux projets d'union économique et monétaire de 1958 et par ses entretiens infructueux avec l'ombrageux président français. Il a sans doute également tiré la leçon du règlement 17/62, dont les difficultés d'application montrent la nécessité d'une collaboration étroite avec les administrations nationales et avec les milieux économiques. Marjolin développe donc un projet qui vise à obtenir des transferts de souveraineté de manière progressive, par une européanisation continue de l'esprit des fonctionnaires nationaux associés au travail de concertation. Des 
procédures de consultation effectuées de plus en plus en aval de la décision, et de plus en plus contraignantes doivent être développées. Au lieu de chercher des délégations de souveraineté radicales vers les institutions supranationales, Marjolin tente de diviser le pôle intergouvernemental et de le communautariser. C'est par la conversion des mentalités que le développement d'un consensus européen se fera, et qu'il aboutira naturellement à renforcer la Commission européenne, guide et arbitre de l'intérêt économique européen. Ce projet de nature technocratique et économique a cependant souffert de nombreuses faiblesses qui l'ont empêché de s'imposer.

Les limites du projet de Marjolin sont en effet très nombreuses et moins présentes chez son successeur, Raymond Barre. Elles tiennent à l'idéalisme de certains aspects de son programme, aux conflits internes à la Commission européenne et à des rapports difficiles avec le gouvernement français.

Une partie du projet d'Europe organisée de Marjolin est marquée du sceau d'un certain idéalisme scientiste caractéristique du début des années soixante. L'apogée de la planification indicative et la critique du matérialisme de la société de consommation se conjuguent pour nourrir les discours du commissaire français d'ambitions humanistes très volontaristes, comme la concentration des ressources sur les investissements collectifs. Barre apparait à cet égard plus pragmatique, poursuivant les efforts entrepris en matière de politique économique tout en les mettant au service de ses ambitions de coordination macroéconomique. Il profite aussi d'un contexte de crise monétaire française et internationale qui renforce ses initiatives.

La position de Marjolin au sein de la Commission européenne apparaît très forte dans la période 1958-1962. Il profite du soutien d'Hallstein et du gouvernement français, mais aussi d'une DG II efficace qui peut compter sur un réseau de relations privilégiées avec un certain nombre d'institutions comme le Comité monétaire ou les réunions officieuses des ministres des Finances. Après 1962, les conflits de doctrine économique avec le réseau de von der Groeben tendent les rapports au sein de l'organe communautaire. À partir de la fin 1964, cette opposition économique se double d'une controverse politico-institutionnelle qui divise profondément la Commission à l'aube de la crise de la chaise vide.

Enfin et surtout, Marjolin n'a pas le soutien du gouvernement français. Pourtant, il développe un projet d'Europe organisée qui s'inscrit pleinement dans les préférences françaises de long terme face à l'intégration économique européenne. L'ouverture des marchés y est ainsi complétée par un processus de rapprochement volontariste des politiques économiques et monétaires nationales. Mais le gouvernement gaulliste ne peut se satisfaire des ambitions institutionnelles de Marjolin. Les mauvais rapports personnels du commissaire 
français avec de Gaulle, ainsi que la concurrence du projet européen intergouvernemental de Debré limitent ses marges de manœuvres même si Marjolin trouve des soutiens au sein de l'administration française. Là aussi, Barre peut s'appuyer sur des réseaux gaullistes plus forts pour renforcer son autorité. Mais la convergence avec le gouvernement français reste limitée comme le prouvent, in fine, les réactions à ses plans de 1968-1969. L'Europe organisée reste finalement plus l'apanage des deux commissaires français que du gouvernement français.

La postérité du projet d'Europe organisée de Marjolin est certaine mais très contrastée en fonction des deux versants de son action.

Les idées de planification économique, tout d'abord, ont rapidement disparu en raison de l'évolution du contexte idéologique général, qui condamne rapidement ces thématiques. Ce mouvement est déjà visible sous Barre. Par contre, des ambitions sectorielles développées au sein de ce projet global de programmation européenne ont connu un certain succès dans les années 1970, avec les projets de politique industrielle et de politique régionale. L'idée d'Europe organisée par les autorités publiques reste donc forte, mais elle s'exprime de manière beaucoup plus sectorielle, en particulier dans les domaines marginaux par rapport au marché, que générale.

Par contre, les idées de coopération monétaire ont connu un développement paradoxal, qui annonce moins les années 1970 que les années 1980 et 1990. Les idées de Marjolin reposent en effet non pas sur la création d'institutions nouvelles, comme le FER, évoqué de manière récurrente dans les années 1960 et 1970, mais sur la coordination étroite et accrue des hauts fonctionnaires, ministres et gouverneurs de banques centrales, autour de la définition de critères de surveillance des politiques économiques. Cette thématique séduit Marjolin, Barre mais aussi d'autres observateurs comme Van Lennep. Elle annonce les critères de convergence du traité de Maastricht. De plus, Marjolin comme Barre mettent l'accent sur une doctrine économique qui paraît assez proche des exigences des " économistes ». Elle pose comme un axiome la nécessité d'une conversion à une politique économique fondée sur une inflation faible et prépare ainsi la conversion de la France à la rigueur allemande en 1976 puis en 1983. Marjolin, puis Barre, ont donc contribué à la formation d'un consensus européen autour d'une méthode institutionnelle et d'une doctrine économique, préalable indispensable à l'union monétaire. Dans les années 1960, leurs idées sont toutefois très éloignées des préoccupations du gouvernement français, qui développe à partir de 1964 ses réflexions sur l'Europe organisée vers une autre direction, celle de la politique industrielle. 



\section{CHAPITRE VII}

\section{LES PROJETS DE POLITIQUE INDUSTRIELLE COMMUNAUTAIRE (1965-1969)}

Alors que les projets d'Europe organisée de Marjolin avaient une dimension plutôt macroéconomique, c'est une nouvelle forme d'Europe volontariste plus spécifique qui se développe à partir du milieu des années soixante, la politique industrielle. Elle désigne les mesures prises par les autorités publiques pour renforcer la structure industrielle, c'est-à-dire accroître la productivité des entreprises, leur puissance financière, commerciale et de recherchedéveloppement, par des moyens plus ou moins incitatifs. Elle répond à l'intensification de la concurrence internationale dans les années 1960, issue des progrès de la libération internationale des échanges (CEE, GATT) et de la diffusion massive d'innovations techniques arrivées à maturité (informatique). Si le Marché commun semble devenir rapidement une réalité commerciale et agricole, les entreprises européennes restent de dimension nationale et paraissent mal armées pour relever les deux défis évoqués précédemment.

Se pose alors le problème de l'adoption de mesures de renforcement de la structure industrielle à l'échelle européenne par les autorités publiques. Une politique industrielle peut s'appuyer sur de simples mesures d'achèvement du Marché commun (suppression des obstacles non tarifaires), sur des mesures incitatives (législatives ou fiscales) au renforcement des structures industrielles, ou sur des mesures sectorielles (notamment dans les secteurs de pointe ou en déclin) plus ciblées, passant éventuellement par une mobilisation de capitaux (aides, prêts).

La politique industrielle communautaire se définit progressivement à partir de la fin 1964 et d'une première tentative française de promouvoir cette thématique en 1965. Après la crise de la chaise vide, en 1966 et en 1967, de multiples acteurs se mobilisent en France et à la Commission européenne autour d'une relance de cette ambition, qui intervient effectivement en 1966-1968 mais dont l'élan est rapidement brisé. 


\section{LE PREMIER PROJET FRANÇAIS DE POLITIQUE INDUSTRIELLE EUROPÉENNE DE 1965}

L'évolution des réflexions françaises internes sur la politique industrielle, puis l'échec d'une première tentative partielle d'action communautaire dans le dossier des investissements américains provoquent des réflexions à la fin de 1964 sur la nécessité de lancer une politique industrielle communautaire globale. La présidence française de la CEE au premier semestre 1965 donne l'occasion aux décideurs français de lancer des initiatives dans ce domaine.

\section{A. LA RELANCE DE LA POLITIQUE INDUSTRIELLE FRANÇAISE VERS L'INTERNATIONAL}

À partir de 1959, la France entre de plain-pied dans l'ère du libre-échange international. L'État doit repenser ses modalités d'incitation à la modernisation de ses structures industrielles. En parallèle, le renouvellement des élites après la deuxième guerre mondiale se traduit par une nouvelle étape avec l'arrivée au pouvoir de hauts fonctionnaires formés par l'ENA, qui s'implantent progressivement dans le monde des entreprises, et le remplacement des patronshéritiers par les patrons-managers ${ }^{1}$. Par ailleurs, la fin de la guerre d'Algérie marque la conclusion de la parenthèse de la décolonisation, ultime vestige de la reconstruction de la France sur de nouvelles bases après 1945.

Ces ruptures sont complétées dans le domaine politique par l'arrivée au poste de Premier ministre de Georges Pompidou le 14 avril 1962. L'intérêt de l'ancien directeur de la banque Rothschild pour ces dossiers paraît évident et a été largement souligné dans l'historiographie pour la période où il était président de la République ${ }^{2}$. Certes, son prédécesseur Michel Debré avait déjà mené une politique industrielle active ${ }^{3}$ mais il est resté majoritairement concentré sur le lourd dossier algérien. L'intérêt de Pompidou pour les dossiers industriels se

1. Youssef Cassis, Big Business : the European Experience in the $X X^{\text {th }}$ Century, Oxford UP, Oxford, 1997, p. 126 ; évolution nuancée in Pierre Bourdieu, Monique de Saint Martin, "Le patronat », Actes de la recherche en sciences sociales, 1978 , vol. 20, $\mathrm{n}^{\circ}$ 1, p. 3-82.

2. Pascal Griset, «Entre pragmatisme et ambition : la politique industrielle de Georges Pompidou face au contexte des années $1970 »$, in Éric Bussière (dir.), Georges Pompidou et la mutation économique de l'Occident, PUF, Paris, 2003, p. 283-296; Bernard Esambert, « La politique industrielle de Georges Pompidou et l'Europe », in Maurice Vaïsse (dir.), Georges Pompidou et l'Europe, Complexe, Bruxelles, 1995, p. 505-516.

3. Éric Kocher-Marboeuf, «L'expansion industrielle au service de l'ambition nationale », in Michel Debré Premier ministre (1959-1962), PUF, Paris, 2005, p. 203-214. 
perçoit dans son approche de la candidature britannique. Lors des réunions interministérielles sur la question, il se montre moins hostile à Londres que Couve de Murville et Wormser, et fait porter le débat sur les problèmes de concurrence industrielle, alors que les intervenants se concentrent sur l'agriculture ${ }^{4}$.

À partir de 1964, des réflexions plus spécifiques se développent sur la relance de la politique industrielle française et débouchent sur trois grandes actions. Tout d'abord, des groupes de travail sectoriels sont constitués pour réfléchir à la thématique du lien entre compétitivité internationale et nécessité d'une concentration industrielle. Le plus important est le groupe Clappier, du nom du sous-gouverneur de la Banque de France qui le préside. Considéré comme une personnalité favorable à la construction européenne, il est chargé par Pompidou de constituer un groupe qui étudiera plus précisément la situation de certains secteurs de l'industrie chimique et du gros matériel d'équipement ${ }^{5}$. Il devra rendre un rapport comportant des propositions d'actions de restructuration permettant d'accroître la compétitivité de ces branches. Pompidou justifie ces études par le fait que le gouvernement a fait l'objet de sollicitations d'aides par ces secteurs. Il souhaite vraisemblablement rompre avec une politique ancienne d'aides spécifiques au coup par coup pour définir une véritable stratégie industrielle à moyen terme. Le premier rapport sur les grands produits intermédiaires de la chimie organique est terminé dès juin $1965^{6}$. Il préconise des concentrations nationales sous la tutelle d'un « conciliateur privé » qui agirait en relation avec le ministère de l'Industrie, ainsi que des mesures fiscales et des incitations à la recherche scientifique. Les concentrations européennes sont aussi évoquées, mais uniquement pour une étape ultérieure.

Ensuite et de manière plus générale, l'ensemble du processus de planification française est réorienté vers la thématique de la compétitivité internationale, qui devient le thème central du cinquième Plan. Ce choix semble provenir du Premier ministre Georges Pompidou. Ses directives pour l'élaboration du cinquième Plan reposent sur le « renforcement de la compétitivité de nos entreprises industrielles et agricoles exposées à la concurrence dans le Marché commun ${ }^{7} »$. L'objectif de concentration des unités de production est explicitement mentionné.

4. AN, 5 AG1, volume 24, compte rendu de réunions sur les affaires européennes des 24 mai 1962 et 31 juillet 1962 .

5. ACNPF, 78 AS 8, lettre de Georges Pompidou à Bernard Clappier, 20 juillet 1964.

6. AN, 5 AG 2, volume 1003, note de R. Montjoie, cabinet de Georges Pompidou, 2 juin 1965.

7. AN, 540 AP, volume 8, projet de lettre de Georges Pompidou au commissariat général au Plan, 17 décembre 1964. 
Enfin, à la suite de cette réorientation globale du Plan, des groupes de travail transversaux sont lancés pour réformer en profondeur l'action de l'État. Dans une lettre du 24 juillet 1965 à Georges Pompidou, le général de Gaulle demande lui-même la création de groupes d'études chargés d'étudier la réforme des relations entre administrations, sociétés nationales et entreprises privées ${ }^{8}$. Ils doivent être constitués de personnalités issues de l'administration mais aussi du secteur privé, certaines devant être choisies, selon Dromer (citant ensuite le général de Gaulle), « pour susciter une certaine agitation intellectuelle "dans des domaines ou le conservatisme et la routine ont trop souvent tenu lieu de réflexions et de politique $"$ " $»$. De Gaulle semble vouloir réutiliser la méthode du comité Rueff dans le secteur industriel pour définir une nouvelle méthode de l'action publique modernisée et adaptée au cadre de la concurrence internationale.

Ces comités sont mis en place par le Conseil des ministres du 2 mars 1966. François-Xavier Ortoli, commissaire général au Plan, devient rapporteur du comité du développement industriel. Il est ensuite remplacé par Montjoie, son successeur au Plan, lorsqu'il devient ministre en 1967. Ortoli et Montjoie sont deux proches collaborateurs de Pompidou, ses deux principaux conseillers en matière économique à son cabinet de Matignon ${ }^{10}$. Les deux autres comités sont chargés des entreprises publiques (rapporteur : Simon Nora) et de la réforme des administrations (rapporteur : Claude Lasry) ${ }^{11}$. En complément, des mesures sont prises pour encourager la concentration. La loi du 12 juillet 1965 aménage la fiscalité pour faciliter les fusions ${ }^{12}$. Elle semble avoir renforcé le processus de concentration des entreprises françaises, même si ce mouvement est difficile à mesurer ${ }^{13}$. Par ailleurs, l'État montre l'exemple et fusionne une grande partie des compagnies pétrolières nationales en 1965 avec la création de l'ERAP, ou certaines banques publiques avec la création de la BNP en 1966. Dans le secteur privé, il intervient en 1965 pour favoriser le rachat de Tréfimétaux par

8. AN, $540 \mathrm{AP}$, volume 7, lettre de Charles de Gaulle à Georges Pompidou, 24 juillet 1965 et Charles de Gaulle, Lettres, notes et Carnets, tome X : janvier 1964-juin 1966, Plon, Paris, 1987, p. 181-182.

9. AN, 5 AG1, volume 31, note de Jean Dromer à Charles de Gaulle, 19 septembre 1966.

10. Éric Roussel, Georges Pompidou, Tempus, Paris, 2004, p. 132, 152 et 199.

11. AN, 5 AG1, volume 31, note de Jean Dromer à Charles de Gaulle, 19 septembre 1966.

12. Denis Woronoff, Histoire de l'industrie en France. Du XVI siècle à nos jours, Seuil, Paris, 1994 , p. 560.

13. La coupure de 1965 est attestée par Frédéric Jenny, qui reconnaît toutefois la difficulté de l'exercice : Frédéric Jenny, « Du contrôle des prix à la politique de la concurrence en France. L'alliance difficile de considérations économiques et politiques », in Annales de l'économie publique, sociale et coopérative, octobre 1981, p. 484. 
son concurrent Péchiney, qui intervient finalement en 1967, afin de renforcer la consolidation du champion national de l'aluminium ${ }^{14}$.

Ainsi, à partir de 1964 se développent des réflexions autour d'une relance de la politique industrielle de l'État français sur de nouvelles bases. Les habitudes dirigistes de l'économie fermée et réglementée sont abandonnées. L'intervention de l'État devient plus ciblée et orientée vers l'impératif de compétitivité internationale, par la promotion de la concentration sur une base nationale. À l'échelle européenne pourtant, les initiatives françaises empruntent d'abord une voie plus défensive, celle du contrôle des investissements directs américains.

\section{B. L'ÉCHEC D'UNE APPROCHE PARTIELLE : LES INVESTISSEMENTS DIRECTS ÉTRANGERS (1963-1965)}

Les investissements directs étrangers (IDE), particulièrement ceux en provenance des États-Unis, ont des effets ambivalents sur l'économie française. D'un côté, ils sont recherchés car ils représentent une source de capitaux mais aussi d'innovations technologiques et managériales. D'un autre côté, ils peuvent aboutir à des prises de contrôle d'entreprises françaises importantes ce qui peut être problématique en terme d'indépendance nationale. Dans un premier temps, en 1958-1959, les décideurs français recherchent les IDE américains ${ }^{15}$. Ces derniers étaient autrefois attirés par la Grande-Bretagne car elle appartenait à deux zones préférentielles, l'OECE et le Commonwealth. Avec la création réussie de la CEE et l'échec des négociations ZLE, la France devient un espace plus intéressant pour ces investissements américains.

Cependant, certains industriels sont opposés à cette attitude ouverte car ils ont peur d'une concurrence plus frontale des entreprises américaines. Il s'agit en particulier des industriels de l'automobile, qui craignent l'installation de filiales des entreprises américaines en Europe. En 1963, Renault et Fiat en particulier engagent plusieurs actions visant à renforcer le contrôle des IDE américains par la Commission européenne ${ }^{16}$. Ils la soutiennent notamment lorsqu'elle oblige le gouvernement belge à renoncer à son prêt bonifié à Ford,

14. Stéphane Bieganski, «La politique des champions nationaux dans le discours et dans le geste : tentative de définition », in Ivan Kharaba, Anne Dalmasso, Philippe Mioche, Philippe Raulin, Denis Woronoff (dir.) Politiques industrielles d'hier et d'aujourd'hui, en France et en Europe, éditions universitaires de Dijon, Dijon, 2009, p. 99.

15. AINDUS, 1977.1386, article 24, lettre du ministre de l'Industrie au ministre des Finances, 8 novembre 1958 .

16. Sigfrido Ramirez, Public Policies... op. cit., p. 687-688. 
qui souhaite installer une usine à Anvers ${ }^{17}$. Il s'agit de la reprise d'une stratégie ancienne déjà déployée lors de la négociation du traité de Rome ${ }^{18}$.

Lorsque Valéry Giscard d'Estaing devient ministre des Finances, en 1962, il veut lancer une grande action communautaire de surveillance des IDE américains. Il demande que la Commission fasse des propositions pour contrôler les éventuelles positions dominantes acquises par les IDE américains ${ }^{19}$. Il justifie sa demande par des considérations liées au passage sous contrôle extérieur de secteurs « importants ou sensibles », en citant l'exemple original du commerce du vin. Cependant, André de Lattre, le directeur du Finex, considère que le problème des IDE américains est négligeable ${ }^{20}$. Dans une note rédigée à la demande du ministre sur les moyens de les contrôler, il souligne qu'ils ne représentent qu'un volume assez modeste. Ils ne sont pas concentrés dans les secteurs " clés » (comme en témoigne l'exemple du « commerce du vin » mentionné plus haut), sont souvent très anciens, et s'avèrent la plupart du temps utiles pour moderniser les industries françaises. En dépit de ce constat initial, de Lattre envoie à son ministre des suggestions pour progresser vers un contrôle communautaire des IDE.

Les justifications économiques d'une offensive contre les IDE américains paraissent donc assez ténues, même si les journaux parlent de plus en plus du problème à partir de 1963 avec la prise de contrôle de Simca par Chrysler, puis l'affaire Bull de $1964^{21}$. L'offensive française s'inscrit donc aussi dans une stratégie de politique intérieure. À la réunion des ministres des Finances des Six à Baden-Baden, en mars 1963, Valéry Giscard d'Estaing relance l'offensive avec des arguments plus pertinents comme le différentiel de taille considérable entre les entreprises américaines et européennes ${ }^{22}$. Peu soutenu par ses pairs, le ministre des Finances obtient cependant que Marjolin conduise

17. Ibid., p. 688-692.

18. Ibid., p. 510-525.

19. AMINEFI, B 62164, exposé de Valéry Giscard d'Estaing à la $12^{\mathrm{e}}$ réunion des Minefi, 9-10 juillet 1962 ; voir aussi les déclarations de Valéry Giscard d'Estaing au Wall Street Journal, note d'information du 6 février 1963 du cabinet du ministre des Affaires étrangères (AMAEF, RPUE 565).

20. AMINEFI, B 62124, note signée de Lattre, 9 janvier 1963.

21. General Electric avait proposé de racheter $20 \%$ de Bull en difficulté en 1963 à cause de l'échec commercial du « Gamma $60 »$. Le gouvernement refuse dans un premier temps mais il ne parvient pas à monter une opération alternative, permettant finalement à General Electric de prendre totalement le contrôle de Bull. Voir Pascal Griset, « Nous ne vieillirons pas ensemble UNIDATA et la coopération industrielle franco-allemande au début des années 1970 », in Éric Bussière et al. (dir.), Milieux économiques et intégration européenne au XX siècle. La crise des années 1970..., op. cit., p. 293-294.

22. AMINEFI, B 17738, projet de procès-verbal de la réunion des ministres des Finances CEE de Baden-Baden, 10 avril 1963 ; AMINEFI, B 62164, note « extrait du compte rendu de la réunion d'information du $1^{\text {er }}$ avril $1963 »$. 
des études sur ce sujet. Le mémorandum de la Commission rendu le 17 mai 1963 reste assez prudent ${ }^{23}$. S'il constate une possibilité de menace de position dominante américaine dans certains secteurs, il conclut que des mesures de restrictions des IDE seraient in fine dommageables. La discussion à la réunion des ministres des Finances qui suit s'avère donc décevante ${ }^{24}$. Marjolin reconnaît que le problème est modeste et mal connu. C'est Giscard d'Estaing qui doit se faire l'avocat d'une solution communautaire, mais il se heurte au scepticisme des Allemands et des Hollandais. Il abandonne donc son offensive, même s'il reste très sensible à ce dossier. Le $1^{\text {er }}$ janvier 1965 , il demande à ses services de transmettre directement à son cabinet toutes les affaires nouvelles d'IDE. Une note interne au ministère commentant cette décision souligne que cette attitude relève de "motifs plus politiques et psychologiques que techniques ${ }^{25} \gg$. Leniveau des IDEreste en effetstablemaisquelquesprises de contrôle spectaculaires ont agité la presse.

L'offensive française de 1962-1963 en matière d'IDE américains a donc été la première tentative d'organiser économiquement la CEE dans le secteur industriel, au-delà de la stricte approche commerciale. On ne peut cependant parler de politique industrielle à proprement parler car ses motivations semblent relever plus d'une stratégie de politique intérieure, qui fait écho à une rhétorique gaulliste antiaméricaine. Certaines notes internes du ministère des Finances montrent d'ailleurs la faiblesse des arguments économiques d'une telle action. Cependant, si cette politique européenne a été un échec, elle a sans doute contribué à faire évoluer les réflexions sur les possibilités d'utiliser la CEE pour traiter de problèmes purement industriels.

\section{LA PRISE DE CONSCIENCE DE LA NÉCESSITÉ D'UNE POLITIQUE INDUSTRIELLE GLOBALE (FIN 1964)}

La politique européenne de la France connaît un certain nombre de déconvenues entre 1962 et 1964. Après l'échec du plan Fouchet, c'est désormais la RFA qui multiplie les initiatives dans le dossier de l'Europe politique. Ensuite, si la France a obtenu la PAC en 1962, elle doit concéder dès 1964 des prix élevés à la RFA qui obèrent à long terme l'équilibre financier de cette politique. Surtout, le gouvernement français assiste impuissant au développement d'une Europe

23. AMINEFI, B 62164, DG II, doc. II/5388/63, 17 mai 1963.

24. AMINEFI, B 62124, procès-verbal de la réunion des ministres des Finances des Six des 10 et 11 juin 1963 .

25. AMINEFI, B 62164, note sur la réunion des conseillers financiers du 25 février 1965. 
ordolibérale ambitieuse avec le règlement 17/62 et ne joue aucun rôle dans les projets d'Europe organisée de Marjolin.

Face à ces évolutions, les responsables français en charge de la politique européenne de la France commencent à définir une nouvelle stratégie d'action. En septembre 1964, le représentant permanent Boegner constate la nécessité de relancer les travaux sur l'union économique non agricole ${ }^{26}$. Selon lui, il est nécessaire de se concentrer sur un petit nombre de sujets afin d'appliquer la méthode volontariste de la PAC à d'autres secteurs économiques. À la fin de l'année 1964, le SGCI organise une série de réunions qui définissent une première approche française de la politique industrielle européenne ${ }^{27}$. Selon une note, ces réunions témoignent d'une mobilisation spontanée d'un petit groupe de hauts fonctionnaires. Il comprend sans doute François-Xavier Ortoli, le secrétaire général du SGCI qui est également directeur de cabinet de Pompidou de 1962 à 1966, et ancien directeur général à la Commission européenne (DG III, 1958-1961). Il a certainement dû jouer un rôle clé, avec Pompidou qui commande en même temps à ses services une note sur les moyens d'encourager les fusions ${ }^{28}$.

La stratégie définie au cours de ces réunions repose sur la prise de conscience d'un décalage de puissance entre les entreprises européennes et américaines ${ }^{29}$. Face à ce qui est désigné comme la " colonisation » américaine, il est nécessaire de réagir. Comme les tentatives de promotion d'une attitude des Six en matière d'IDE ont échoué, il est nécessaire d'adopter une autre méthode en se concentrant sur le renforcement des structures industrielles européennes, qui est une thématique plus positive. Trois outils complémentaires sont retenus ${ }^{30}$. Le premier repose sur l'intégration négative, c'est-à-dire la suppression des obstacles au sein du Marché commun et l'harmonisation du cadre juridique et fiscal. La seconde approche est plus volontariste car elle repose sur les moyens d'encourager les concentrations européennes. Plusieurs outils sont évoqués,

26. AMINEFI, B 17.684, télégramme de Boegner du 24 septembre 1964.

27. ASGCI, 1979.0791, volume 101, note JCS, SGCI, 24 novembre 1964.

28. AN, 5 AG 2, volume 1003, note de R. Montjoie, cabinet de Georges Pompidou, 20 novembre 1964.

29. ASGCI, 1979.0791, volume 101, note JCS, SGCI, 24 novembre 1964 ; ASGCI, 1979.0791, volume 101, note du 4 décembre 1964 sur la réunion du 28 novembre 1964, JCS, SGCI ; ASGCI, 1979.0791, volume 101, note du 11 décembre 1964 sur la réunion du 5 décembre 1964, JP, SGCI ; ASGCI, 1979.0791, volume 101, « Essai sur les structures industrielles », note SGCI, décembre 1964, note de $\mathrm{p}$.

30. ASGCI, 1979.0791, volume 101, note SGCI, « Le Marché commun industriel », 30 décembre 1964 ; ASGCI, 1979.0791, volume 101, note JP, SGCI, du 31 décembre 1964, " Adaptation des structures industrielles au Marché commun ». 
certains incitatifs (faciliter les contacts entre les industriels, encourager les investissements), d'autres accordant des privilèges (accès au marché des capitaux, marchés publics réservés), d'autres enfin plus interventionnistes (prêts européens). Enfin, une action spécifique en matière de politique de la recherche scientifique et technique doit être menée pour rationaliser les efforts européens en les coordonnant.

Sur le plan institutionnel, les réflexions sont beaucoup plus prudentes et refusent toutes délégations de souveraineté majeures aux institutions communautaires. Ces réflexions ne sont donc pas guidées par un idéalisme européiste. Elles sont en phase avec celles de Georges Pompidou qui entendait favoriser les fusions nationales pendant une période limitée, sans doute pour assurer une consolidation de l'industrie française avant qu'elle ne se tourne vers l'extérieur $^{31}$. C'est la stratégie des " champions nationaux » par des concentrations à l'échelle française, qui s'oppose à celle, plus traditionnelle dans le patronat, des ententes ${ }^{32}$.

Une évolution parallèle s'observe au sein du patronat européen au même moment, et débouche sur des initiatives au sommet de l'UNICE au début de 1965. Le Néerlandais de Koster estime ainsi en février 1965 qu'une « véritable politique industrielle est devenue indispensable ${ }^{33} »$. Elle « devrait entraîner un renforcement de la position concurrentielle des entreprises sur le plan européen comme sur le plan international, par la création d'un climat favorable aux investissements industriels qui permette aux entreprises de se développer jusqu'à leurs dimensions optimales $\gg{ }^{34}$. C'est ensuite un document du BDI, le syndicat allemand, présenté à la même réunion, qui insiste sur la réorientation de la politique de la concurrence vers le « renforcement de la capacité concurrentielle de l'industrie européenne » par une tolérance accrue envers les ententes et concentrations. Le patronat européen, et pas seulement français, se prononce donc très largement en faveur de la création d'une politique industrielle européenne ${ }^{35}$. Dans son esprit, il ne s'agit pas de susciter un dirigisme européen qu'il abhorre, mais de créer un cadre juridique et fiscal favorable aux ententes et surtout aux concentrations. Tout au long de l'année 1965, cette

31. AN, 5 AG 2, volume 1003, note de R. Montjoie, cabinet de Georges Pompidou, 20 novembre 1964.

32. ASGCI, 1988.0577, volume 40, réunion du groupe 1985 le 24 juin 1965, compte rendu du 9 juillet 1965 par R. Fraisse ; plus généralement : Stéphane Bieganski, « La politique des champions nationaux... ", op. cit., p. 87-100.

33. ACNPF, 72 AS 1544, réunion des présidents UNICE du 25 février 1965 à Paris.

34. ACNPF, 72 AS 1544, réunion des présidents UNICE du 25 février 1965 à Paris.

35. ACNPF, 72 AS 1544, réunion des présidents UNICE du 25 février 1965 à Paris ; ACNPF, 72 AS 1544, réunion des présidents UNICE du 27 mai 1965. 
thématique de la politique industrielle par l'encouragement à la concentration reste au cœur des débats de l'UNICE comme en témoigne la note sur l'insuffisante dimension des entreprises européennes par rapport à leurs concurrentes américaines, largement diffusée auprès des décideurs européens en mars $1965^{36}$. De leur côté, les décideurs français réfléchissent aux initiatives concrètes qui pourraient être lancées dans le cadre de la CEE.

\section{LA PRÉSIDENCE FRANÇAISE DE 1965}

\section{ET LE LANCEMENT DE LA POLITIQUE INDUSTRIELLE}

À la faveur de la présidence française de 1965, les décideurs français diffusent le 14 janvier 1965 un programme de travail pour la Communauté européenne pour le premier semestre de $1965^{37}$. Il comprend deux dossiers nouveaux liés à la politique industrielle : la " définition d'un droit européen des sociétés » et « la possibilité d'établir une politique commune en matière de recherche scientifique et technique ».

L'initiative française dans le domaine de la politique industrielle intéresse au plus haut point la Commission européenne selon Boegner. Il souligne que la France à « intérêt à l'encourager dans cette voie. Maintenant que l'on entrevoit, en dépit des difficultés qui restent à surmonter, l'achèvement de la politique agricole commune, il y a fort à parier que l'adaptation des industries des six pays aux nécessités de la concurrence mondiale deviendra l'une des grandes affaires du Marché commun au cours des prochaines années ${ }^{38} \gg$. Boegner est donc convaincu de l'enchaînement logique inéluctable entre la PAC et la politique industrielle. Il ne s'agit pas de créer une nouvelle politique commune sur le modèle de la PAC mais de déployer le même volontarisme politique. Finalement, le 4 mars 1965, la France diffuse un mémorandum « sur l'élaboration d'une politique commune de la recherche scientifique et technique $»(\mathrm{PRST})^{39}$, puis, le 24 mars 1965, une note proposant la création d'un statut de société européenne

36. AHUE, BAC 26/1969, volume 601, lettre de H.J. de Koster au président Walter Hallstein du 3 mars 1965 ; ASGCI, 1979.0791, volume 101, lettre de la CEE envoyant ce document au SGCI, 16 mars 1965.

37. ASGCI 1990.0638, volume 23, note SGCI, 14 janvier 1965 et note du Conseil CEE de la part de la France du 21 janvier 1965, doc. R/32/65.

38. AMINEFI, B 17.701, télex Boegner, REP, 18 février 1965.

39. AMAEF, RPUE 685, « Note du gouvernement français sur l'élaboration d'une politique commune de la recherche scientifique et technique », 4 mars 1965. 
est diffusée aux $\mathrm{Six}^{40}$. Ces deux dossiers lancés en mars 1965 correspondent à des réflexions déjà anciennes menées en France.

La politique de la recherche scientifique et technique (PRST) se concentre sur le processus du passage de la recherche fondamentale à un produit commercialisable. Le retard des Six sur les États-Unis en la matière commence à être mis en valeur vers 1964, en particulier en France à la faveur de l'affaire Bull. Elle s'inscrit dans un effort gaulliste de promotion de la capacité de recherche nationale comme fondement de l'indépendance nationale, depuis la création de la DGRST (direction générale de la Recherche scientifique et technique) en novembre $1958^{41}$. C'est d'ailleurs un proche du général de Gaulle, Gaston Palewski (son ancien directeur de cabinet en 1946 et l'un des fondateurs du RPF) qui, en tant que ministre chargé de la Recherche scientifique, lance en mars 1964 la réflexion sur la PRST ${ }^{42}$. Palewski veut profiter d'un contexte favorable, la fusion des trois exécutifs européens, pour remédier à une carence du traité de Rome et mobiliser les Six dans ce secteur crucial afin de sauvegarder « l'indépendance » de la CEE (sous-entendu face aux États-Unis). Couve de Murville est plus prudent car il désapprouve l'idée de lancer un débat sur la fusion des exécutifs et des traités ${ }^{43}$.

Une réunion est organisée au SGCI en mai 1964 pour définir des propositions françaises ${ }^{44}$. Palewski avait proposé trois mesures : une confrontation des programmes de recherche des Six (afin de les coordonner et d'éviter les doubles emplois), l'établissement d'un régime uniforme d'aides à la recherchedéveloppement, et le lancement d'actions concertées. Seule la première idée est retenue. La seconde est considérée comme dangereuse en raison de l'attitude négative de la Commission européenne (DG IV) en la matière, qui fait craindre une " censure communautaire ». La troisième pose le problème des financements et des délégations de souveraineté. Finalement deux propositions d'études

40. ASGCI, 1988.0577, volume 37, note du gouvernement français aux Six du 24 mars 1965, doc. $\mathrm{R} / 327 / 65$.

41. Voir les témoignages réunis dans un numéro des Cahiers de la Fondation Charles de Gaulle et notamment : Pierre Piganiol (ancien délégué général à la DGRST), « L'exemple de la DGRST », in Cahiers de la Fondation Charles de Gaulle, 2003, p. 117-142; Alain Chatriot, «Introduction », in Alain Chatriot et Vincent Duclerc (dir.), Quel avenir pour la recherche ?, Flammarion, Paris, 2003, p. 172.

42. AMAE, DECE 1487, lettre du ministre de la recherche scientifique et des questions atomiques et spatiales, Gaston Palewski, au ministre des Affaires étrangères, Maurice Couve de Murville, 3 mars 1964.

43. AMAE, DECE 1487, lettre du ministre des Affaires étrangères, Maurice Couve de Murville, au ministre de la recherche scientifique et des questions atomiques et spatiales, Gaston Palewski, 28 mars 1964.

44. AMINEFI B 44.246, note SGCI du 30 juillet 1964 sur une réunion du 28 mai 1964. 
sont retenues ${ }^{45}$. Tout d'abord, une confrontation des programmes de recherche doit être menée dans le cadre du CPEMT pour déterminer les doublons et les possibilités de coordination. Ensuite, des études devront être menées par la CEE pour recenser les secteurs où l'effort européen est insuffisant. Le but est de mettre en valeur la portée de la menace américaine dans ces secteurs, afin de mobiliser les Six vers des actions communes à définir.

Le mémorandum sur l'élaboration d'une PRST reprend ces deux propositions ${ }^{46}$. Il part de la nécessité de compléter le traité de Rome en raison du « risque de voir le fossé technologique entre l'Europe et les États-Unis s'accroître ». La note reste très évasive sur les procédures institutionnelles. Les références à la CPEMT ont même disparu de la note finale par rapport aux versions antérieures ${ }^{47}$. En dépit de son titre, la note française propose moins une politique commune qu'une harmonisation des politiques nationales. Enfin, il faut souligner la longueur du processus séparant les propositions de Palewski en mars 1964 de leur traduction concrète et largement édulcorée en mars 1965. Il avait été décidé de repousser l'initiative qui devait avoir lieu initialement fin $1964^{48}$, sans doute en raison des négociations sur la PAC (accord sur le prix des céréales le 15 décembre 1964).

Quoi qu'il en soit, ces propositions semblent répondre à un besoin véritable car elles donnent lieu rapidement à des décisions institutionnelles. Lors du COREPER du 18 mars 1965, les Six chargent la Commission et le CPEMT de faire des propositions au Conseil pour octobre $1965^{49}$. Le groupe PREST (politique de la recherche scientifique et technique) est finalement constitué très rapidement dans le cadre du CPEMT. Présidé, à la demande expresse de la France ${ }^{50}$, par le délégué général à la recherche scientifique et technique français André Maréchal, il tient sa première réunion le 14 juin $1965^{51}$. Trois études sont lancées : l'une sur la PRST en général, une confrontation des programmes et une dernière sur les aides à la recherche. Les travaux s'orientent donc dans une direction correspondant globalement à celle du mémorandum français. Le groupe doit faire un rapport pour octobre 1965 qui pourrait inclure des « premières

45. AMAE, DECE 1487, note du SGCI du 17 septembre 1964 et note MU du 24 septembre 1964.

46. AMAE, RPUE 685, « Note du gouvernement français sur l'élaboration d'une politique commune de la recherche scientifique et technique », 4 mars 1965.

47. AMAE, DECE 1487, lettre du ministre des Affaires étrangères (FS) au SGCI, $1^{\text {er }}$ février 1965 et AMAEF, RPUE 685, note SGCI du 20 février 1965.

48. AMAE, DECE 1487, note FS (DAEF) du 16 mars 1965.

49. AMAE, RPUE 685, note SGCI, Dromer du 14 mai 1965.

50. AMAE, RPUE 685, note du SGA de SGCI Jean Dromer au REP, 9 juin 1965.

51. AMAE, RPUE 685, compte rendu de la réunion du groupe PREST, 14 juin 1965. 
indications sur les axes possibles de la recherche industrielle à promouvoir au niveau des Six ». Le groupe PREST est donc relativement ambitieux. Il peut donner lieu à un véritable travail de coordination des politiques nationales mais le déclenchement de la crise de la chaise vide deux semaines après sa première réunion obère gravement son travail.

La thématique de la société européenne est plus ancienne que celle de la PRST. Le Conseil de l'Europe avait déjà étudié la question en $1952^{52}$. Le but est de faciliter les regroupements et collaborations entre les sociétés européennes tout en évitant une concurrence législative et fiscale intracommunautaire contreproductive. Il s'agit donc à la fois de renforcer l'interpénétration des entreprises au sein du Marché commun, pour le transformer en véritable union économique, mais aussi de renforcer sa structure industrielle, ce second objectif devenant de plus en plus important avec l'ouverture croissante à la concurrence internationale.

Le contexte est favorable car une première fusion véritablement européenne a eu lieu entre les firmes photographiques Agfa et Gevaert au début de 1964, mais leur regroupement fonctionnel est limité par les contraintes législatives ${ }^{53}$. $\mathrm{Au}$ SGCI, Jean Dromer, le secrétaire général adjoint, demande au cabinet du Premier ministre de tenir un comité interministériel pour définir une position française sur le sujet ${ }^{54}$. Dromer reproche aux travaux entrepris de s'enliser dans des discussions d'experts juridiques ayant comme seule finalité l'harmonisation des législations et pas la création d'un statut économiquement avantageux, qui seul encouragerait à des concentrations ${ }^{55}$. Il demande donc l'établissement rapide d'un statut de « société commerciale de type européen » qui s'ajouterait aux lois nationales, afin de ne pas attendre la fin d'un long processus d'harmonisation. Il prendrait la forme d'une loi identique dans tous les pays. Cela traduit un glissement dans la conception de l'intégration économique européenne. Comme le processus d'harmonisation est trop lent pour être parallèle à la libération des échanges, il est nécessaire de passer à une nouvelle méthode, plus intergouvernementale, le vote d'une loi identique dans tous les pays, au lieu de créer un droit communautaire autonome qui surplombe les droits nationaux.

52. ASGCI 1988.0577, volume 37, lettre de la Commission au REP, 12 mai 1960.

53. La société belge Gevaert et la société allemande Agfa ont créé deux nouvelles sociétés communes, l'une en Belgique et l'autre en Allemagne, qui ont les mêmes dirigeants et se réunissent alternativement dans l'un ou l'autre pays : Jacques et Colette Nême, Économie européenne, PUF, Paris, 1970, p. 262.

54. ASGCI, 1988.0577, volume 37, note SGCI, GB (introduction par Jean Dromer), 15 juillet 1964 ; AMINEFI, B 17.683, note SGCI du SGA Dromer, 20 janvier 1965.

55. AMINEFI, B 17.683, note SGCI du SGA Dromer, 20 janvier 1965. 
Les démarches de Dromer portent leurs fruits car dans le cadre du programme de travail de la présidence française pour 1965, un mémorandum français sur la création d'un statut de « société commerciale de type européen » est déposé le 24 mars $1965^{56}$. Il conseille de mettre en place un projet de loi identique dans tous les États membres pour faciliter la coopération et la concentration entre les entreprises européennes. Pour élaborer ce projet de loi, un groupe de travail intergouvernemental, mais avec la participation de la Commission, devrait être rapidement constitué. La proposition française répond à un besoin exprimé par les milieux économiques, notamment l'UNICE qui discute depuis l'automne 1964 du problème de la société européenne ${ }^{57}$.

Très rapidement, la France obtient la création d'un groupe de travail au mois d'avril 1965 malgré les réticences de la Commission qui avait déjà engagé des travaux d'harmonisation législative de son côtés8. Le groupe tient sa première réunion le 24 mai $1965^{59}$. Cette première réunion est marquée par une opposition entre la France et la Commission sur la méthode de l'harmonisation législative ${ }^{60}$. La seconde affirme que le choix n'est pas encore fait entre une convention portant une loi uniforme et un instrument communautaire (directive, règlement), alors que la France défend clairement la première solution. Les autres États membres sont sceptiques. De toute façon la crise de la chaise vide brise cette initiative.

Ainsi les réflexions sur la nécessité de renforcer la structure industrielle face à la compétition internationale, les leçons de l'échec de l'approche trop politique adoptée dans le dossier de l'IDE, et le contexte général de la construction européenne (libéralisation internationale accrue, nécessité de progresser après la PAC) se conjuguent pour soutenir une réflexion sur la création d'une politique industrielle européenne. Lancée par le gouvernement français, elle répond à des besoins européens comme en témoignent les débats de l'UNICE mais aussi le succès rapide des deux initiatives françaises. La forme prise par la politique industrielle promue par la France explique d'ailleurs en partie sa réussite à court terme : le gouvernement français a choisi, sous l'impulsion

56. ASGCI, 1988.0577, volume 37, note française proposant une société commerciale de type européen, 24 mars 1965.

57. ACNPF, 72 AS 1544, comptes rendus des réunions des présidents (UNICE) des 10 septembre 1964 et 27 mai 1965.

58. ASGCI, 1988.0577, volume 37, télex de la REP (Boegner) du 27 avril 1965.

59. AHUE, procès-verbaux spéciaux de la $307^{\mathrm{e}}$ session de la Commission du 24 février 1965 (point 21) et de la $308^{\mathrm{e}}$ session du 3 mars 1965 (folio 288) ; ASGCI, 1988.0577, volume 37, projet d'instructions au représentant permanent, 19 mai 1965.

60. ASGCI, 1988.0577, volume 37, télex Boegner du 26 mai 1965, compte rendu de la réunion du groupe de travail. 
d'un groupe de fonctionnaires du SGCI, de mettre en avant des dossiers précis mais charnières : une mesure générale favorisant les concentrations - la société européenne - et une initiative sectorielle dans un domaine d'avenir - la PRST. Son pragmatisme a assuré une mise en œuvre rapide de ses propositions, brisée par la chaise vide. Cet épisode démontre les contradictions entre les objectifs économiques et politiques de la France, et repousse à 1966 la relance des réflexions sur la politique industrielle.

\section{LES RÉFLEXIONS SUR LA POLITIQUE INDUSTRIELLE COMMUNAUTAIRE EN FRANCE}

Après la crise de la chaise vide, la relance de la politique industrielle provient de la conjonction de deux facteurs : l'émergence d'un courant qui souhaite réviser l'orientation de la politique européenne de la France au sein des décideurs français, et le volontarisme français en matière de politique industrielle, tant à l'échelle nationale qu'au niveau de la Communauté.

\section{A. L'ÉMERGENCE D'UN COURANT RÉVISIONNISTE AU SEIN DES RESPONSABLES FRANÇAIS (1965-1967)}

Le style brutal et conflictuel du général de Gaulle en matière de politique européenne suscite des critiques croissantes au sein des décideurs français. Un courant révisionniste souhaitant modifier les priorités de la politique européenne de la France émerge en réaction à deux épisodes particulièrement destructeurs pour le crédit extérieur de la France : la crise de la chaise vide et le rejet de la seconde candidature britannique.

\section{La chaise vide : l'émergence d'un courant révisionniste.}

La crise de la chaise vide a représenté une rupture majeure dans la pratique des discussions communautaires. Cette épreuve de force est très rapidement contestée par les milieux économiques. Dans une note du 15 juillet $1965^{61}$, le CNPF manifeste son opposition envers la stratégie gaulliste. Énumérant la liste des travaux qui vont être retardés, il s'attarde plus particulièrement sur la politique industrielle et ses différents éléments (société européenne,

61. AFJM, ARM 21/3/22, note du CNPF, 15 juillet 1965, « La crise du 30 juin et ses conséquences $»$. 
PRST, etc.), c'est-à-dire la réalisation de l'union économique en parallèle de l'union douanière, justement l'un des objectifs de la France. Enfin, il souligne que cette crise risque de retarder la modernisation des structures industrielles françaises, elle-même largement dépendante de l'incitation donnée par la construction européenne. Cette note a été envoyée au commissaire français Robert Marjolin, vraisemblablement pour qu'il tente d'infléchir la position française ${ }^{62}$. Dans des déclarations publiées dans sa revue, Patronat français, le CNPF continue de développer une attitude critique ${ }^{63}$. Enfin, le CNPF soutient les initiatives de l'UNICE sur ce dossier. Le compte rendu de la réunion des présidents du 6 octobre 1965 souligne d'ailleurs qu'il « existe un étonnant parallélisme entre les positions des différentes fédérations : fidélité au traité de Rome, et attachement au fonctionnement normal des institutions communautaires en soulignant le rôle essentiel de la Commission, nécessité de poursuivre, parallèlement à l'union douanière, l'union économique ${ }^{64} »$. Le CNPF s'inscrit pleinement dans cette dynamique européenne de mobilisation contre l'attitude française.

Au sein de l'administration française, les principaux responsables de la politique européenne de la France réagissent de manière très prudente à la crise de la chaise vide. Déjà, une note du SGCI du 26 mai 1965 avait montré que la France ne pourrait obtenir de satisfactions dans le domaine agricole sans quelques évolutions institutionnelles ${ }^{65}$. Par la suite, les notes du SGCI du début de juillet 1965 insistent sur la dépendance juridique et institutionnelle de la France. Elles plaident pour une grande prudence tandis que le Quai d'Orsay est plus offensif ${ }^{66}$.

À partir du moment où la crise de la chaise vide s'annonce comme étant inscrite dans la durée, les critiques du SGCI se font plus directes. Elles émanent tout d'abord du groupe qui a mis en valeur à la fin de 1964 la thématique de la politique industrielle. L'un des animateurs de ce groupe rédige le 28 juillet 1965 une note qui demande une réorientation complète de la politique européenne de la France ${ }^{67}$. Elle montre le caractère illogique d'une politique européenne fondée sur l'agriculture car ce secteur représente moins de $10 \%$ de la production, tandis

62. AFJM, ARM 21/3/22, note du CNPF, 15 juillet 1965, " La crise du 30 juin et ses conséquences ».

63. Patronat français, août $1965, \mathrm{n}^{\circ} 254$, p. 2 ; Patronat français, février $1966, \mathrm{n}^{\circ} 259$, discours de Jean Louis à l'assemblée générale de janvier 1966, p. 5-9.

64. ACNPF, 72 AS 789, conseil général du CIFE, 6 octobre 1965.

65. ASGCI, 1990.0646, volume 6, note du SGCI du 26 mai 1965.

66. Voir le chapitre IV.

67. ASGCI, 1979.0791, volume 101, note SGCI, JP, 28 juillet 1965.

ASGCI, 1979.0791, volume 101, note JP, SGCI, du 31 décembre 1964. 
que les exportations françaises sont à $80 \%$ industrielles. L'enjeu majeur est de renforcer la structure industrielle du pays, en utilisant les projets de politique industrielle développés à l'échelle de la CEE. À défaut, la CEE deviendra une simple zone de libre-échange européenne puis atlantique. La note est donc très critique dans la mesure où elle démontre l'illogisme de la politique gaulliste : la concentration sur la PAC et la chaise vide risquent en effet de faire renaître le spectre de la ZLE que de Gaulle avait écarté en 1958.

Le 8 septembre 1965, une note du SGCI plus générale reprend ces idées et en tire les conséquences politiques ${ }^{68}$. Comme aucune autre alternative (protectionnisme, libre-échange intégral, accords bilatéraux) n'est satisfaisante, « malgré ses insuffisances, le Marché commun institue un cadre dans lequel on peut s'efforcer d'atteindre les objectifs de développement et d'autonomie de nos industries en dégageant progressivement les principes d'une union économique $^{69} \gg$. Une note du SGCI contenant les mêmes idées est envoyée à Dupont-Fauville, le directeur de cabinet du nouveau ministre de l'Économie et des Finances Michel Debré, en janvier 1966, en prévision d'un Conseil interministériel pour les affaires européennes ${ }^{70}$. Elle a été transmise au niveau du gouvernement par l'intermédiaire d'un nouveau ministre, peut-être pour insuffler un cours différent à l'action politique.

Cette attitude révisionniste du SGCI touche aussi d'autres pans de 1'administration française. Au commissariat au Plan, Massé souligne que, en dépit des événements du 30 juin, « la France ne pourrait échapper à la concurrence internationale qu'en s'enfermant, c'est-à-dire en renonçant à un grand destin ${ }^{71} »$. La division agricole du commissariat général au Plan produit une note très critique envers la PAC, qui est envoyée au cabinet du ministre des Finances ${ }^{72}$. Le soutien exclusif par les prix et la fixation de ces derniers à un niveau trop élevé n'assure pas d'incitation à l'augmentation de la productivité, fait courir un risque d'inflation et produit un transfert de revenus vers les régions agricoles les plus riches. Annonçant très largement les réformes de la PAC de la fin des années 1980, la note plaide pour un plafonnement des soutiens aux productions excédentaires (des stocks excédentaires de beurre gérés par la Commission

68. AMINEFI, B 17.684, note SGCI sur l'évolution de l'industrie française dans le Marché commun, 8 septembre 1965 .

69. AMINEFI, B 17.684, note SGCI sur l'évolution de l'industrie française dans le Marché commun, 8 septembre 1965 .

70. ASGCI, 1990. 0638, volume 24, note SGCI, $1^{\text {er }}$ octobre 1965.

71. AN, 540 AP, volume 7, lettre de Massé à Georges Pompidou, 8 juillet 1965.

72. AN, 540 AP, volume 7, note du 28 octobre 1965, commissariat général au Plan, division agricole. 
existent déjà à cette époque ${ }^{73}$ ), la baisse des prix et le passage d'un soutien par les prix à des aides directes.

D'un autre côté, face à ces réflexions révisionnistes, un groupe gaulliste défend l'orientation traditionnelle de la politique européenne de la France. Il est particulièrement bien représenté à la DAEF du Quai d'Orsay, toujours fidèle à une ligne gaulliste orthodoxe. Dans son appréciation sur la chaise vide son directeur, Olivier Wormser, se concentre sur les aspects institutionnels et agricoles $^{74}$. Une fois les concessions obtenues dans ce cadre, la France pourra accepter en retour la relance du dossier GATT. L'optique reste donc traditionnelle et concentrée sur un échange entre des débouchés pour les produits agricoles français contre des facilités pour les produits industriels allemands. De même, pour l'adjoint et successeur de Wormser, Jean-Pierre Brunet, l'analyse des conséquences de la crise ne provoque aucune remise en question de la politique européenne de la France mais se concentre plutôt sur la culpabilité comparée de la Commission et de l'Allemagne dans le déclenchement de la crise ${ }^{75}$.

En dépit des divisions de l'administration française, la crise de la chaise vide a entraîné un début de remise en cause de la priorité donnée à la PAC dans la politique européenne de la France. Les projets de politique industrielle sont au contraire mis en valeur. Cette dynamique s'accentue par la suite.

\section{De la chaise vide à la seconde candidature britannique (1966-1967).}

Après la crise de la chaise vide, le courant révisionniste progresse, en particulier grâce à Jean Dromer, devenu secrétaire général du SGCI (1966-1967) et toujours conseiller économique du général de Gaulle (1964-1967), et par le nouveau ministre des Finances Michel Debré (1966-1968). Les critiques se concentrent sur la PAC, qui paraît maintenant mieux assurée après les accords de la mi-1966 sur son financement.

Deux aspects sont particulièrement visés. Les prix trop élevés résultant de la PAC constituent le premier défaut. Debré s'oppose plusieurs fois à Edgar Faure, le ministre de l'agriculture, sur ce point ${ }^{76}$. Il écrit directement à Pompidou et à de Gaulle en 1966 pour se plaindre du niveau trop élevé des prix agricoles car cela crée des tensions inflationnistes et un transfert de revenus vers les agriculteurs

73. AHUE, procès-verbal spécial de la $335^{\mathrm{e}}$ session de la Commission du 25 octobre 1965 , point 18 ; AN, 5 AG 1, volume 36, note Prate du 7 mai 1968.

74. AMAE, POW 36, folio 278, note d'Olivier Wormser, 13 octobre 1965.

75. AMAE, DECE 1114, folio 1, note de Jean-Pierre Brunet, $1^{\text {er }}$ février 1966.

76. AN, 5 AG1, volume 28, note de Jean Dromer pour Charles de Gaulle, 10 mars 1966. 
les plus riches comme les céréaliers ${ }^{77}$. Dans sa note de juillet 1966 où il tire le bilan de la PAC pour de Gaulle, Dromer critique une PAC fondée uniquement sur le soutien aux prix, qui est l'inverse d'une politique agricole " cohérente » car elle n'incite pas suffisamment aux réformes de structure indispensables ${ }^{78}$.

La seconde faille de la PAC est son mode de gestion, qui échappe très largement aux arbitrages économiques généraux. Dès le 2 mai 1967, Dromer écrit ainsi à de Gaulle pour lui rappeler la nécessité d'une procédure interministérielle pour la détermination des grandes orientations de la $\mathrm{PAC}^{79}$. Il cherche ainsi à replacer la politique agricole dans une perspective économique globale. Debré est beaucoup plus direct. Dans une lettre manuscrite à Dromer, il écrit : « Je suis abasourdi d'apprendre que mardi les ministres de l'Agriculture discuteront de questions financières. Comment cet ordre du jour a-t-il pu être accepté ? À quel titre les ministres de l'agriculture s'en occupent-ils ? Enfin quelles instructions ont-elles été données à la délégation ? Et que dois-je faire ? J'ai bien envie de faire un incident ${ }^{80}$ ». Au-delà du goût de Debré pour la provocation, qui est bien dans la tradition gaulliste, la note critique le processus de décision spécifique à la PAC. Les ministres de l'agriculture des Six ont en effet multiplié les réunions parallèles où ils ont pris des décisions qui relèvent normalement du Conseil des ministres des Six. Cet isolement se perçoit également au niveau du COREPER, où un Comité spécial agriculture (CSA) a été créé en 1960 pour traiter spécifiquement ce dossier ${ }^{81}$.

Face à ce double constat d'échec, des pistes de réforme sont proposées. Le 20 juin 1967, Debré rédige une note à l'attention du général de Gaulle (non envoyée) où il préconise deux réformes radicales de la $\mathrm{PAC}^{82}$. La Commission devrait avoir l'obligation de consulter les gouvernements des États membres, et pas seulement les ministres de l'agriculture, avant toute proposition de prix. De plus, la détermination des prix des produits agricoles ne doit plus être laissée aux seuls ministres de l'agriculture car, en général, le Conseil est obligé de valider leurs décisions.

77. AFNSP, 4 DE 4, lettre de Michel Debré à Georges Pompidou du 4 juillet 1966 ; lettre de Michel Debré au général de Gaulle du 15 septembre 1966.

78. AN, 5 AG1, volume 48, note de Jean Dromer pour Charles de Gaulle, 26 juillet 1967.

79. AN, 5 AG1, volume 32, note de Jean Dromer pour Charles de Gaulle, 2 mai 1967.

80. AFNSP, 4 DE 6, lettre de Michel Debré à Olivier Guichard, 28 mai 1967.

81. Ann-Christina Knudsen, Morten Ramussen, « A European Political System in the Making 1958-1970 : The Relevance of Emerging Committee Structures », in Journal of European Integration History, 2008/1, p. 51-67.

82. AFNSP, 4 DE 6, projet de lettre de Michel Debré à Charles de Gaulle, 20 juin 1967. 
Le cabinet de Debré est particulièrement critique envers l'action du nouveau ministre de l'agriculture Edgard Faure. Ce dernier a affirmé dans un discours qu'il était possible d'augmenter le revenu agricole tout en maintenant des petites exploitations, c'est-à-dire sans gain de productivité ${ }^{83}$. Le commentaire est cinglant: " C'est ce que l'on dit depuis les premiers jours de la III ${ }^{\mathrm{e}}$ République. Mais Méline disait aussi [...] que les usines de Billancourt allaient bientôt fermer parce que le marché de l'automobile était saturé. [...] Même si nos partenaires du Marché commun acceptent de financer pour une part nos excédents agricoles, ce financement n'est pas sans limite, il coûte aux négociateurs français des concessions sur d'autres points. Il faut d'ailleurs relever que les problèmes agricoles d'aujourd'hui sont très largement le fruit du choix fait au début du siècle, choix prétendument social, en réalité d'un conservatisme aveugle, dont le fruit a été un retard d'évolution technique et structurelle de deux générations ${ }^{84} \gg$. Tous les éléments du révisionnisme sont présents dans cette note : la PAC est économiquement illogique, socialement néfaste et politiquement coûteuse en termes de crédit de la France auprès de ses partenaires européens.

Tirant les conséquences de ces critiques, Dromer écrit au Premier ministre Georges Pompidou, en septembre 1966 pour lui demander une réorientation de la politique européenne de la France car « tout notre effort depuis cinq ans a porté sur l'agriculture et c'est pour obtenir la politique agricole commune que nous avons souvent mené les Six à la crise ouverte. Or, le produit agricole français représente moins de $10 \%$ du produit national ${ }^{85} \ldots »$. Dromer revient ensuite à l'objectif fondamental de la politique extérieure de la France gaulliste, celui d'assurer son indépendance. Or l'indépendance économique « ne s'exprime pas en termes agricoles. C'est dans la vie industrielle, dans le domaine de la recherche, dans les investissements techniques, dans la finance, que se forge la puissance économique des pays modernes ${ }^{86} »$. Dès lors, la solution est claire, si la France veut relancer l'Europe vers la voie de la puissance, elle doit se concentrer sur la promotion de l'union économique et industrielle. À défaut, la CEE sera une simple zone de libre-échange augmentée d'une PAC irrationnelle, où la RFA et bientôt la Grande-Bretagne voire les États-Unis seront plus influents que la France. La France doit être « le moteur d'une politique industrielle, économique et financière au profit de l'Europe indépendante,

83. AN, $540 \mathrm{AP}$, volume 9, note J Weil, cabinet du ministre des Finances, 20 mai 1966.

84. AN, 540 AP, volume 9, note J Weil, cabinet du ministre des Finances, 20 mai 1966.

85. AN, 5 AG 2, volume 1003, note du secrétaire général du SGCI, Jean Dromer, du 27 septembre 1966.

86. AN, 5 AG 2, volume 1003, note du secrétaire général du SGCI, Jean Dromer, du 27 septembre 1966. 
comme il l'a été pour la politique agricole commune ». Dromer replace donc la politique économique de la France face à la CEE dans le prisme gaulliste du renforcement de la puissance nationale.

La note s'efforce de définir un programme réaliste. Dromer constate que : «nos partenaires des Six ont beaucoup évolué à ce sujet depuis quelques années et les menaces de concurrence américaine les inquiètent aujourd'hui ${ }^{87} \gg$. Dans une note rédigée peu après, il plaide pour une « action systématique pour replacer entre les mains des États la responsabilité des initiatives, des programmes, des orientations et des priorités ${ }^{88} »$. Seul le volontarisme intergouvernemental peut assurer une relance efficace, mais cela ne signifie pas qu'il faille se couper de la dynamique communautaire. Au contraire, il faut mettre en place dans les communautés « des commissaires et des fonctionnaires français, conscients de cette orientation et susceptibles par leurs qualités professionnelles et leur volonté politique, d'appliquer une décision gouvernementale en ce sens $\gg$. La Commission européenne est donc perçue clairement comme un maillon indispensable de cette relance, à laquelle elle doit participer par le biais d'un réseau décisionnel français bipolaire, établi à Paris et à Bruxelles, mais suivant in fine les consignes de Paris. Ainsi, le SGCI de Dromer défend au même moment un programme d'harmonisation fiscal beaucoup plus ambitieux que celui du service en charge de la question au ministère des Finances, la direction générale des Impôts ${ }^{89}$, et plaide pour une harmonisation qui ne serait pas limitée à la TVA mais concernerait aussi la fiscalité directe sur les entreprises car c'est un élément important de la politique industrielle, à travers les incitations aux investissements ou aux concentrations ${ }^{90}$.

Ainsi, après la fin de la crise de la chaise vide et les accords sur la PAC en 1966, le courant révisionniste français gagne en puissance. Le nouveau ministre des Finances Michel Debré est séduit par certains de ses thèmes comme la remise en cause des équilibres de la PAC. La figure centrale reste Jean Dromer, qui propose une réorientation fondamentale de la politique européenne de la France vers la promotion de l'union économique et industrielle, au détriment d'une union commerciale et agricole déjà réalisée et très imparfaite. Il n'hésite pas à remettre en cause la politique européenne de la France menée jusqu'ici. La seconde candidature britannique contribue à renforcer le camp révisionniste.

87. AN, 5 AG 2, volume 1003, note du secrétaire général du SGCI, Jean Dromer, du 27 septembre 1966.

88. AMAEF, DECE 1117, « Problèmes actuels des Communautés européennes », note du SGCI, 12 octobre 1966.

89. Frédéric Tristram, Une fiscalité pour la croissance..., op. cit., p. 571-3.

90. AN, 86 AJ, volume 84, note SGCI, HZ, du 28 mars 1966 ; AMAE, RPUE 635, note du SGCI du 9 décembre 1964. 


\section{Les divisions lors de la seconde candidature britannique (1967-1968).}

Le gouvernement travailliste d'Harold Wilson dépose une nouvelle candidature britannique le 11 mai 1967. Elle est repoussée par de Gaulle le 27 novembre 1967. Contrairement au premier veto de 1963, le second a un impact beaucoup plus destructeur pour le crédit politique du président français à l'échelle de l'Europe ${ }^{91}$, mais aussi au sein de l'administration française.

La seconde candidature déposée en 1967 contient, à la différence de la première, une forte composante industrielle. Les milieux économiques britanniques et notamment la CBI (Confederation of British Industry) soutiennent cette candidature car elle permet d'envisager un renforcement des structures industrielles britanniques face à la concurrence américaine ${ }^{92}$. Le gouvernement travailliste lance le slogan de la " communauté technologique ». La Grande-Bretagne bénéficie en effet d'une industrie puissante dans certains secteurs de pointe (aéronautique, informatique). À l'heure où les Six discutent de la création d'une politique commune en matière de recherche scientifique et technique, l'apport de la Grande-Bretagne serait décisif dans la concurrence avec les États-Unis. Le ministre de l'Industrie Olivier Guichard avait d'ailleurs mis en valeur l'intérêt industriel de la candidature britannique face à des ministres, et à un président de la République, très majoritairement sceptiques lors du Conseil des ministres du 10 mai $1967^{93}$. De plus, la puissance économique britannique a décliné tandis que la CEE s'est largement affirmée depuis la première candidature. C'est d'ailleurs très largement l'analyse du CNPF. Hostile à l'adhésion britannique en 1961, le CNPF y est plus favorable en $1967^{94}$.

Ces arguments économiques sont repris par un petit groupe de hauts fonctionnaires, déjà identifié par Laurence Badel, qui sont séduits par la perspective d'un rapprochement entre la Grande-Bretagne et la $\mathrm{CEE}^{95}$. Il s'agit tout d'abord de Jean Wahl, conseiller commercial de l'ambassade de France à Londres, et

91. Piers Ludlow, «A Short-Term Defeat: The Community Institutions and the Second British Application to join the EEC », in Oliver Daddow (éd.), Harold Wilson and European Integration. Britain's Second Application to join the EEC, Frank Cass, Londres, 2003, p. 135-150.

92. Neil Rollings, «The Confederation of British Industry and European Integration in the $1960 \mathrm{~s} »$, in O. Daddow (éd.), Harold Wilson..., op. cit., p. 115-134.

93. Selon les propos rapportés par Alain Peyrefitte : Alain Peyrefitte, C'était de Gaulle, tome III, 1966-1968, Fayard, Paris, 2001 p. 271.

94. Jean Louis, « Situation et progrès du Marché commun », in Patronat français, $\mathrm{n}^{\circ} 275$, juillet 1967 , compte rendu de l'assemblée générale du 13 juin 1967.

95. Laurence Badel, « Le rôle tenu par le poste d'expansion économique de Londres dans le processus d'adhésion du Royaume-Uni au Marché commun (1966-1971) » in Le rôle des ministères des Finances et de l'Économie dans la construction européenne (1957-1978), Comité pour l'histoire économique et financière de la France, Paris, 2002, p. 247-250. 
de Dominique de la Martinière, son collègue conseiller financier ${ }^{96}$. Ce dernier écrit même à son ministre Michel Debré en personne pour lui montrer à la fois que l'évolution de la position britannique est sous-estimée, et que le problème des balances sterling est surestimé et devrait être réglé par une approche communautaire $^{97}$. La Martinière compare explicitement la situation actuelle du Royaume-Uni à celle de la France à la fin des années cinquante. L'ampleur de ses engagements extérieurs ne l'a pas empêché de participer pleinement au Marché commun, une fois le redressement du plan Rueff effectué. Cette action d'influence porte d'ailleurs ses fruits car Michel Debré affirme à propos de la note de Dominique de la Martinière sur le sterling qu'elle « correspond assez à mon sentiment. Je suis naturellement persuadé qu'il existe encore un courant vers le rattachement plus étroit de l'économie anglaise à l'américaine, mais l'évolution inverse est sensible ${ }^{98} \ldots$.. Leurs idées influencent également Jean Dromer qui met en avant les avantages industriels d'une adhésion britannique, sans sous-estimer les inconvénients qu'elle représenterait par ailleurs, dans une note globale analysant ce dossier ${ }^{99}$.

Ce groupe doit d'ailleurs être élargi à Michel Albert, un inspecteur des finances détaché à la Commission européenne (DG II) et qui correspond directement avec Jean Dromer et avec Jean-René Bernard (le second ayant remplacé le premier au secrétariat général du SCGI en 1967 ${ }^{100}$ ). Michel Albert est cependant moins favorable à une candidature britannique en tant que telle qu'à une relance vigoureuse de la politique industrielle européenne sur des bases supranationales. Cette vision européiste n'était pas partagée par tous les membres du groupe. Jean Wahl par exemple conseille, après le rejet de la candidature britannique, de conclure avec Londres des accords sectoriels. Ils devraient concerner en particulier les secteurs de pointe et comporter des éléments douaniers (accords sur des réductions de tarifs douaniers et de contingents) et des éléments d'organisation de la production (coordination de la recherche, des investissements, de la production) ${ }^{101}$. On retrouve dans cette note le schéma de l'écheveau d'accords sectoriels devant tenir lieu de ZLE qui avait été

96. ASGCI 1990.0639, volume 73, note Wahl du 12 avril 1967 ; ASGCI 1990.0639, volume 73, lettre de Dominique de la Martinière au ministre, 23 mai 1967.

97. AN, 80 AJ, volume 80, note D. de la Martinière, 4 juillet 1967 ; AN, 86 AJ, volume 80, Note D. de la Martinière, 2 janvier 1967.

98. AFNSP, 4 DE 8, lettre de Michel Debré à Étienne Burin des Roziers, 12 juin 1967.

99. AN, 86 AJ, volume 80, note de Jean Dromer, 4 janvier 1967.

100. ASGCI, 1990.0639, volume 73, lettre de Michel Albert à Jean-René Bernard, 27 octobre 1967. Il envoie une note qu'il a écrite le 17 mai 1967.

101. ASGCI, 1990.0639, volume 73, note de Jean Wahl du 6 décembre 1967, « Intérêt et orientation d'un éventuel arrangement entre la Grande-Bretagne et le Marché commun ». 
développé par les Français à la fin 1958, ou même des éléments du projet Loucheur de 1927 reposant sur un parallélisme entre la conclusion d'ententes et un processus de libéralisation commerciale ${ }^{102}$.

Le second veto à la Grande-Bretagne a heurté les convictions de ce groupe de hauts fonctionnaires. Ils ne défendaient pas une adhésion de la Grande-Bretagne de manière inconditionnelle et systématique mais estimaient que le dossier méritait d'être examiné sérieusement en raison des opportunités économiques qu'elle présentait. Une note de réflexion du cabinet de Michel Debré qui circule en mars 1968 se demande d'ailleurs si un dossier économique sur la candidature britannique ne devrait pas être constitué pour ne pas laisser cette question aux mains des seuls diplomates ${ }^{103}$.

En 1968, le flambeau du révisionnisme est repris par Alain Prate, nouveau conseiller économique du général de Gaulle après le départ de Jean Dromer, en 1967. La cible principale reste la PAC. Dans deux notes de mars 1968, Prate estime que les très importants transferts financiers dont a bénéficié la France dans le cadre de la PAC ont non seulement été très coûteux sur le plan politique à l'échelle des Six, mais qu'en plus ils n'ont pas réglé les problèmes agricoles ${ }^{104}$. Les prix trop élevés de certains produits ont en effet abouti à une concentration des financements vers les exploitations qui en avaient le moins besoin. Prate constate par ailleurs que les sommes consacrées dans le budget français à la politique agricole n'ont pas diminué en dépit de ces transferts financiers considérables. Enfin, il appelle à prendre exemple sur la Grande-Bretagne en matière de politique industrielle car il souligne l'intérêt de l'expérience de l'IRC (Industrial Reorganisation Corporation), une institution qui intervient directement dans l'industrie britannique pour encourager sa rationalisation et sa concentration ${ }^{105}$.

Peu après, en 1969, Lionel Stoleru, un ingénieur des mines et futur ministre appelle lui aussi à revoir les priorités européennes de la France. Il observe que la priorité accordée à la PAC a conduit à une augmentation de la part des exportations agricoles au détriment de celles des produits industriels à plus forte valeur ajoutée. Il en conclut : "À lire ces données, on ne peut s'empêcher de comparer la position de la France vis-à-vis de ses cinq partenaires à celle

102. Laurence Badel, « Le rôle tenu par le poste d'expansion économique... », op. cit., p. 247.

103. AN, 540 AP, volume 14, note du cabinet du ministère des Finances, 8 mars 1968.

104. AN, 5 AG1, volume 35, note Prate du 16 mars 1968 ; AN, 5 AG1, volume 35, note Prate du 26 mars 1968.

105. AN, 5AG1, volume 36, note Prate du 22 juillet 1968 ; AN, 5AG1, volume 38, note de Prate du 27 janvier 1969. 
de ces pays sous-développés qui commercent avec les pays industriels en leur envoyant des minerais et des produits agricoles en échange de biens manufacturés $^{106} ! »$. Il appelle au contraire à développer une politique industrielle forte à l'échelle française et européenne, en finissant sur un constat d'évidence selon lui : « pas d'Europe industrielle sans l'Angleterre » ${ }^{107}$. Les fondamentaux de la politique gaulliste, la priorité à la PAC et le rejet de la Grande-Bretagne, sont donc rejetés dans cet ouvrage qui paraît certes après le départ du pouvoir du général de Gaulle, mais qui émane d'une figure émergente du groupe des " fonctionnaires modernisateurs », par ailleurs ancien membre du comité de développement industriel d'Ortoli.

La volonté de remettre en cause la PAC est partagée par de nombreux autres fonctionnaires de premier plan en 1968. Au ministère des Finances, on se demande si la politique agricole ne devrait pas être réorientée d'une politique de soutien au marché vers une politique structurelle de reconversion et de modernisation des exploitations ${ }^{108}$. Pierre Lelong de son côté, ancien membre du cabinet de Georges Pompidou et influent sur ce dernier en matière agricole ${ }^{109}$, envoie au Premier ministre une note où il préconise une « remise en cause de l'ensemble de la PAC, qui devrait être alors, sinon supprimée, du moins profondément modifiée " pour que le soutien aux marchés soit remplacé par une politique des structures ${ }^{110}$. Dans le cadre d'un grand débat interne au gouvernement et à l'administration française sur la réorientation de la politique agricole, le SGCI produit une note assez mesurée où il pose la question du passage progressif d'un soutien exclusif par les prix à l'introduction d'aides directes ${ }^{111}$. Un conseil restreint sur l'agriculture se tient en effet le 10 octobre $1968^{112}$. Il aboutit au constat de la nécessité de réformer la PAC, afin notamment de baisser les prix. Mais les avantages acquis par la France doivent être préservés et la politique structurelle, si elle doit être remise à plat, doit rester nationale. Cela limite les marges de manœuvre à l'échelle des Six mais démontre en tout cas que la PAC telle qu'elle a été définie entre 1962 et 1966 est jugée déséquilibrée et inefficace y compris par son principal bénéficiaire.

106. Lionel Stoleru, L'impératif industriel, Seuil, Paris, 1969, p. 14.

107. Ibid., p. 275-276.

108. AN, 540 AP, volume 14, note du cabinet du ministère des Finances, 8 mars 1968.

109. Bernard Bruneteau, Les paysans dans l'État..., op. cit., p. 182-184 et p. 194-198.

110. AMINEFI, 1 A 76, note de Pierre Lelong au Premier ministre, 17 mai 1968.

111. AMINEFI, B 17.703, note SGCI, YG, du 24 juillet 1968.

112. AN, 5 AG1, volume 30, Conseil restreint sur les affaires agricoles du 10 octobre 1968, schéma de relevé de décisions. Voir aussi la note de préparation du Conseil pour Charles de Gaulle de G. Carrère très critique sur la PAC, 5 octobre 1968. 


\section{La force du courant révisionniste.}

Les épisodes de la chaise vide et du second veto à la Grande-Bretagne se sont révélés traumatisants pour une partie de l'administration française car ils ont affaibli le crédit politique de la France en Europe tout en révélant les failles de sa politique européenne. Un révisionnisme des bases de la politique européenne gaulliste se développe. Il est fondé sur une critique de plus en plus radicale de la PAC pour deux raisons : elle monopolise tout le crédit diplomatique de la France pour un secteur au poids économique mineur et déclinant, et elle est économiquement inefficace. La France devrait au contraire, selon ce courant révisionniste, se concentrer sur les dossiers de la politique industrielle et de l'union économique en général. La seconde candidature britannique permet d'aboutir au rejet d'un nouveau dogme, celui du refus absolu d'envisager l'adhésion britannique. Ce courant révisionniste est alimenté par les réflexions de nombreux hauts fonctionnaires français, à partir des constats initiaux effectués par Jean Dromer. Ces idées semblent recevoir un accueil attentif du nouveau ministre des Finances Michel Debré. Ce groupe défend, avec plus ou moins de vigueur et selon des modalités variées (Albert étant plus supranational par exemple), la réorientation de la politique européenne de la France du secteur agricole vers le secteur industriel. La relance de la politique industrielle en France à partir de 1966 soutient ces ambitions.

\section{B. LE VOLONTARISME FRANÇAIS \\ EN MATIÈRE DE POLITIQUE INDUSTRIELLE (1966-1967)}

La politique industrielle bénéficie d'une forte impulsion en France à partir de 1966. Grâce à un groupe de fonctionnaires «modernisateurs », les réflexions s'européanisent et débouchent, en 1967, sur des initiatives françaises marquantes en termes de politique industrielle européenne, en particulier sous l'impulsion de Michel Debré.

\section{La relance de la politique industrielle nationale en 1966.}

À partir de 1966, l'arrivée au ministère de l'Économie et des Finances du volontariste Michel Debré ${ }^{113}$ permet une mise en application des idées de politique industrielle. Cette dernière repose sur un principe général : la France ne peut

113. Florence Descamps, « Michel Debré et la réforme du ministère des Finances : continuités et innovations, 1938-1968 », in Michel Debré, un réformateur aux Finances, 1966-1968, Paris, Comité pour l'histoire économique et financière de la France, 2005, p. 145-155 et les autres contributions de ce colloque. 
assurer sa croissance qu'en supportant la concurrence internationale ${ }^{114}$. Debré souhaite que soient développés des mécanismes pour encourager la recherche scientifique et technique d'une part, et l'encouragement aux concentrations d'autre part. Les deux pistes déjà lancées à l'échelle des Six au début de 1965 (PRST et société européenne) sont donc étudiées de nouveau. Debré explore la piste de la création d'un organisme d'État qui serait chargé de prendre des participations dans les entreprises pour les restructurer, sur le modèle de ce qui existe en Grande-Bretagne (l'IRC: Industrial Reorganisation Corporation lancée en 1966 par le nouveau gouvernement travailliste) et en Italie (avec l'IRI : Istituto per la Ricostruzione Industriale $)^{115}$. Surtout il met en place les trois comités de réforme qui avaient été annoncés par de Gaulle à l'été 1965, en particulier le comité de développement industriel présidé par Ortoli ${ }^{116}$. Doté d'un mandat assez large, il se concentre rapidement sur la question de l'incitation aux fusions et concentrations d'entreprises ${ }^{117}$. Ortoli s'efforce de définir une méthode efficace mais non dirigiste ${ }^{118}$. Il plaide pour l'organisation d'un large dialogue avec les industriels de chaque secteur, pour faire émerger un consensus sur les opérations de concentration nécessaires et les aides de l'Etat (octrois privilégiés de marchés publics, aide à l'exportation, assouplissement du contrôle des prix $)^{119}$. Debré rencontre lui-même les industriels du secteur mécanique pour leur exposer cette méthode double : les industriels consentent à des opérations de rationalisation et de concentration contre des aides discrètes de l'État ${ }^{120}$.

Cette méthode sectorielle a été appliquée d'une manière plus spectaculaire dans le domaine de l'industrie de l'informatique avec le célèbre plan Calcul lancé en juillet $1966^{121}$. Il repose sur la création de deux outils, une délégation à l'informatique qui s'apparente à une administration de mission, et une compagnie commune aux principales entreprises françaises du secteur, la CII.

114. AFNSP, 4 DE 32, note de Michel Debré du 29 janvier 1966.

115. AFNSP, 4 DE 32, note de Michel Debré du 2 février 1966 ; AFSNP, 4 DE 31, « note générale d'instruction » de Michel Debré pour son cabinet, 15 avril 1966.

116. AFNSP, 4 DE 32, note de Michel Debré du 2 février 1966.

117. AN, 5 AG 1, volume 31, note de Jean Dromer du 29 mars 1966.

118. AMINEFI, B 52.380, note du 20 avril 1966 sur la réunion du 14 avril 1966 du comité de développement industriel ; AINDUS, 1991.0817, volume 6, compte rendu du 8 décembre 1966 de la deuxième réunion du groupe spécialisé mécanique du 2 décembre 1966 ; note Colonna pour le ministre du 31 août 1966.

119. AINDUS, 1991.0817, volume 6, note Colonna pour le ministre du 21 septembre 1966.

120. ACNPF, 78 AS, volume 7, note sur un entretien avec Debré du 23 mai 1966 d'une délégation patronale.

121. Sur le plan calcul : Yves Bouvier, La Compagnie générale d'électricité... op. cit., p. 571-577; Pascal Griset (dir.), Informatique, politique industrielle, Europe : entre plan Calcul et Unidata, Institut d'histoire de l'industrie, Paris, 1998. 
Cette compagnie reçoit, sous le contrôle de la délégation de l'informatique, de très importants subsides de l'État. En retour, elle doit développer une gamme d'ordinateurs indépendante de la technologie américaine.

La philosophie est donc interventionniste et modernisatrice, mais vise aussi à stimuler le secteur privé national. Lors d'un entretien entre le ministre Michel Debré et l'industriel Ambroise Roux, directeur général de la CGE, Roux insiste sur la nécessité d'avoir une « assurance de production et de vente permettant un prix de revient et une clientèle assurée ${ }^{122}$. Lorsque Debré insiste sur la nécessité d'une rationalisation des industries du secteur. Roux en convient et souligne que cela permettra de nouer plus facilement des accords avec les entreprises américaines (c'est d'ailleurs ce que fit la CGE après la fin du plan calcul en 1974-1975 ${ }^{123}$ ). La perspective européenne est donc largement absente de ces entretiens, alors même que des idées de coopération entre la France et la Grande-Bretagne en la matière avaient été développées en $1965^{124}$. Le plan calcul manifeste l'apogée d'une vision d'indépendance nationale obtenue par un volontarisme étatique forcené.

L'année 1966 permet un véritable lancement de la politique industrielle française à la faveur du retour au pouvoir de Michel Debré. Deux objectifs principaux sont recherchés : l'encouragement à la concentration des entreprises et le développement de la recherche scientifique et technique. La perspective reste toutefois plus nationale que communautaire mais une nouvelle génération de hauts fonctionnaires cherche à l'infléchir en l'européanisant.

\section{Une nouvelle génération de « modernisateurs ».}

Emmanuel Chadeau et Michel Margairaz ont identifié un groupe de fonctionnaires « modernisateurs » qui réunissaient quelques caractéristiques communes comme un discours dichotomique (opposant l'avant et l'après 1945) et un attrait pour la compétence technocratique économique ${ }^{125}$. Ils ont connu leur apogée en France entre 1945 et 1952 et se sont ensuite largement divisés face au traité de Rome $^{126}$. Le projet de programmation européenne avait paru réconcilier un temps tous les « fonctionnaires modernisateurs » autour d'un projet d'intégration économique européenne tout à la fois ambitieux et vague ${ }^{127}$.

122. AFNSP, 4 DE 3, lettre de Debré du 17 mars 1966, compte rendu d'un entretien du 15 mars 1966.

123. Yves Bouvier, La Compagnie générale d'électricité, op. cit., p. 575-577.

124. AMAE, POW 7, folio 238, note DB, 9 mars 1966.

125. Emmanuel Chadeau, «Les modernisateurs de la France et l'économie du $\mathrm{XX}^{\mathrm{e}}$ siècle. Note sur quelques ouvrages d'histoire immédiate ", in Bulletin de l'IHTP, septembre 1982, p. 22-35; Michel Margairaz, L'État, les finances et l'économie..., op. cit., notamment p. 1338-1340.

126. Voir le chapitre I.

127. Voir le chapitre VI. 
L'échec de la programmation européenne et le passage aux problématiques de la politique industrielle permettent l'émergence, autour des années 1964-1967, d'une nouvelle génération de fonctionnaires modernisateurs constituée d'un petit groupe d'inspecteurs des finances âgés d'environ $40 \mathrm{ans}^{128}$ : principalement Jean Dromer, François-Xavier Ortoli, Jean Saint-Geours, Michel Albert et Alain Prate. Comme leurs aînés, ils sont marqués par une confiance dans la compétence technocratique économique et une volonté de stimuler un patronat jugé trop frileux. À cet égard, ils évoquent souvent la nécessité de créer un « choc psychologique ». Cependant, ils se singularisent par la mise en valeur d'une autre coupure que celle de leurs aînés car ils insistent sur celle de 19571958. À cette date, la France est passée symboliquement d'un monde dirigiste à l'ère de la compétition internationale. Comme elle n'en a pas encore tiré toutes les conséquences, en particulier du fait du poids de considérations agricoles archaïques dans la politique économique, il est nécessaire de parachever les réformes de 1957-1958 (traité de Rome, plan Rueff) pour la faire entrer de plain-pied dans le monde de la compétition industrielle internationale.

Contrairement à leurs prédécesseurs des années cinquante, ces nouveaux « modernisateurs » sont hostiles au dirigisme dans la mesure où ils souhaitent rationaliser l'action de l'État en la limitant à la création d'un cadre incitatif, sauf pour quelques secteurs stratégiques où une intervention plus directe est nécessaire. Ils paraissent également moins sensibles aux thématiques de la planification, qui avaient séduit un grand nombre de hauts fonctionnaires dans la première partie des années soixante. Surtout, ils inscrivent leurs réflexions dans le cadre d'une concurrence internationale pleinement acceptée. Cela les conduit à vouloir européaniser les réflexions de politique industrielle développées en 1966. L'approche générale de Dromer et celle plus spécifique de Saint-Geours et d'Ortoli peuvent être différenciées. Elles sont complétées par des réflexions plus communautaires développées par des Français basés à la Commission comme Michel Albert et Alain Prate.

Jean Dromer, tout d'abord, est un inspecteur des finances qui s'est spécialisé très tôt dans les affaires européennes. Après un mémoire d'étude à l'ENA sur "Les échanges extérieurs français dans le cadre du Marché commun » sous la direction de Jean-François Deniau ${ }^{129}$, lui-même fervent défenseur de l'intégration économique européenne, il devient membre de la délégation française pour la négociation du traité de Rome. Il passe ensuite par plusieurs cabinets

128. Albert est né en 1930, Dromer en 1929, Ortoli en 1925, Prate en 1928, Saint-Geours en 1925.

129. ASGCI, 1991.004, volume 2, rapport d'élèves de l'ENA sur «Les échanges extérieurs français dans le cadre du Marché commun ", juillet 1957. Parmi les élèves de ce travail collectif se trouve Jean Dromer. 
et devient notamment le conseiller pour les affaires économiques et financières du ministre des Affaires étrangères Couve de Murville de 1961 à 1964. À partir de 1964, il est à la fois conseiller technique à la présidence de la République et secrétaire général adjoint (1963-1966) puis secrétaire général (1966-1967) du SGCI.

Il développe une vision libérale fondée sur la nécessité de poursuivre la suppression des obstacles artificiels à la concurrence à l'intérieur de l'économie française ${ }^{130}$. À l'échelle européenne, il manifeste un grand volontarisme, appelant à une action vigoureuse de la France en matière industrielle afin d'inciter aux « regroupements nécessaires par-dessus des frontières qui n'existeront bientôt plus ${ }^{131} »$. Il s'agit donc d'impulser un véritable changement de mentalité économique. La politique industrielle telle que l'envisage Dromer consiste surtout à créer un cadre favorable pour les entreprises européennes et leur concentration par une harmonisation juridique et fiscale ${ }^{132}$. Son libéralisme est visible également en matière financière. Alors que la direction du Trésor s'oppose au projet de la Commission de troisième directive sur la libération des mouvements de capitaux (car elle aboutirait à accroître la place des entreprises étrangères sur un marché financier qui reste très étroit, et à diminuer le contrôle du Trésor sur les émissions et les placements de titre ${ }^{133}$, Dromer conseille au contraire d'être plus souple dès 1964-1965 ${ }^{134}$. À partir de 1966, il lie plus explicitement les réformes internes du marché financier (troisième directive) et la politique industrielle en considérant que la pression communautaire impose une ouverture inéluctable du marché parisien, dont il faut tirer parti pour le renforcer, et faciliter ainsi le financement des entreprises françaises ${ }^{135}$.

Dromer ne fait preuve d'aucun idéalisme européiste. Ainsi, s'il reconnaît que le cadre des Six doit être privilégié, il estime que le choix des partenaires doit être adapté à chaque secteur ${ }^{136}$. Il cite notamment la Grande-Bretagne - avec

130. AN, 5 AG1, volume 28, note de Jean Dromer du 3 juin 1966.

131. AN, 5 AG1, volume 28, note de Jean Dromer du 3 juin 1966 ; AN, 5 AG1, volume 32, note de Jean Dromer, 18 mars 1967.

132. AN, 5 AG1, volume 28, note de Jean Dromer du 3 juin 1966.

133. AMAE, RPUE 565, note SGCI du 2 juin 1964 ; AMINEFI, B 62160, note signée Pérouse et de Lattre, 12 février 1965 ; sur l'opposition du Trésor, voir aussi : Laure Quenouëlle-Corre, « Les réformes bancaires et financières de 1966-1967 », in Michel Debré, un réformateur aux Finances, 1966-1968, Comité pour l'histoire économique et financière de la France, Paris, 2005, p. 88 et 93.

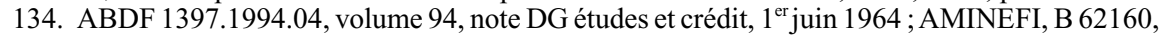
note Dromer, SGA, au cabinet du ministre, Serisé, $1^{\text {er }}$ mars 1965.

135. ASGCI, 1989.0642, volume 6, note SGCI du 10 octobre 1966 ; AN, 5 AG1, volume 28, note Dromer du 2 novembre 1966. Sur ce conflit à propos de la troisième directive : Laurent Warlouzet, Quelle Europe économique pour la France..., op. cit., p. 834-838.

136. AFNSP, 4 DE 32, note du $1^{\text {er }}$ décembre 1966 de Dromer pour Dupont-Fauville. 
laquelle la France coopère de manière privilégiée dans l'aéronautique notamment, l'URSS - la Grande Commission franco-soviétique est lancée à la même époque, et même les États-Unis. Il ne s'agit donc pas de mener une croisade antiaméricaine dans une Europe unie sous la direction éclairée de la France, idée qui est présente par exemple chez Debré. De plus, les coopérations envisagées doivent rester intergouvernementales et $a d$ hoc, c'est-à-dire strictement limitées à une opération précise ${ }^{137}$. Très favorable au projet de société européenne, il encourage la formation de groupes industriels véritablement européens dans le secteur privé ${ }^{138}$. Il combine donc une approche institutionnelle intergouvernementale, une séduction pour des accords sectoriels ad hoc, car à géométrie variable, et une vision supranationale de la structure industrielle européenne.

La même ambition à la fois volontariste, européenne et intergouvernementale se retrouve chez Jean Saint-Geours (directeur de la Prévision) et François-Xavier Ortoli (commissaire général au Plan). Si les deux hommes sont inspecteurs des finances, leur parcours est très divergent. Saint-Geours a été membre du cabinet de Pierre Mendès France en 1954-1955 puis est passé par le SEEF (1962-1964) avant de devenir le premier directeur de la Prévision (1965-1968). Membre du club Jean Moulin, il a donc plutôt le profil d'un mendésiste planificateur ${ }^{139}$. Après être passé par divers cabinets sous la $\mathrm{IV}^{\mathbb{E}}$ République, Ortoli a quant à lui acquis une position importante grâce à son passage par l'administration communautaire, où il était directeur général du Marché intérieur (DG III). Il est ensuite devenu secrétaire général du SGCI (1961-1966) et surtout, en parallèle, directeur de cabinet du Premier ministre Georges Pompidou (1962-1966) dont il est très proche $\mathrm{e}^{140}$. Cette proximité avec le pouvoir gaulliste lui ouvre les portes de la direction du commissariat général au Plan en 1966-1967.

En dépit de leurs parcours politiques divergents, les deux hommes se rapprochent autour d'un programme commun de modernisation de la France, qui passe par la politique industrielle européenne. En avril 1967, ils présentent une note commune sur « la coopération industrielle dans l'Europe des Six » au Premier ministre Georges Pompidou et au ministre de l'Économie et des Finances Michel Debré ${ }^{141}$. Cette note est constituée de plusieurs documents qui cherchent à encourager à la fois les concentrations industrielles et la recherche

137. AFNSP, 4 DE 32, note du $1^{\text {er }}$ décembre 1966 de Dromer pour Dupont-Fauville.

138. AMINEFI, B 17.683, note SGCI du SGA Dromer, 20 janvier 1965 ; ASGCI 1988.0577, volume 40, compte rendu de la réunion du groupe 1985 le 24 juin 1965.

139. Sur Jean Saint-Geours : Aude Terray, Des francs-tireurs aux experts..., op. cit., p. 305-312 et p. 407-419.

140. Éric Roussel, Georges Pompidou, Tempus, Paris, 2004, p. 132, 152 et 199.

141. AFNSP, 4 DE 12, lettre manuscrite de Jean Saint-Geours pour Michel Debré, 28 avril 1967. 
scientifique et technique. L'une d'elle reconnaît que si « le risque d'une certaine prééminence de l'industrie allemande ne doit pas être négligé [...] il n'existe pour nous que si nous ne faisons pas l'effort économique et politique nécessaire à l'échelon national alors que dans l'autre sens, la perspective d'une suprématie anglo-saxonne est une certitude dans tous les pays de la $\mathrm{CEE}^{142}$ ». Il s'agit donc de reconnaître explicitement le passage d'une logique industrielle nationale à une logique européenne. Le danger de la puissance allemande ne disparaît pas mais s'atténue devant le danger américain.

Ortoli et Saint-Geours plaident plus spécifiquement pour une coordination des politiques nationales dans les secteurs de pointe et les secteurs en déclin, en collaboration avec les industriels ${ }^{143}$. En matière de recherche scientifique et technique, des actions concertées et mêmes communes devraient être développées ${ }^{144}$. Enfin « pour certains secteurs industriels d'avenir, où l'État est par nécessité fortement engagé, la volonté de construction d'une véritable industrie européenne là où une activité exclusivement nationale paraît trop aléatoire, trop lente, trop peu efficace, ou trop lourde financièrement $\gg s^{\prime} i m p o s e^{145}$. Si le vocabulaire semble très communautaire, les mesures proposées le sont moins. Ortoli et Saint-Geours proposent ainsi, dans le domaine de l'informatique, d'étudier la possibilité d'étendre le plan calcul à la RFA ${ }^{146}$. En dépit de la rhétorique européiste, la logique reste donc bien essentiellement intergouvernementale. Il s'agit de mobiliser les États membres par l'adoption d'une déclaration volontariste qui devra déboucher, dans un second temps, sur un calendrier de travail entre les $\mathrm{Six}^{147}$. Ainsi, dans une note à Debré sur la politique industrielle française, Saint-Geours estime que de nombreux outils incitatifs existent déjà et que le problème est maintenant essentiellement psychologique ${ }^{148}$. La vision proposée par Ortoli et Saint-Geours est donc plus sectorielle et plus interventionniste que celle de Dromer. Elle souhaite mobiliser les États membres

142. AFNSP, 4 DE 12, «Les problèmes du développement industriel et de la recherche en France et en Europe. Projet de conclusion (doc. II) », annexe à la lettre du 28 avril 1967.

143. AFNSP, 4 DE 12, "Écart technologique et structures industrielles (Note de réflexion) », annexe à la lettre du 28 avril 1967 ; « projet de mémorandum (doc. III) », annexe à la lettre du 28 avril 1967.

144. AFNSP, 4 DE 12, «Les problèmes du développement industriel et de la recherche en France et en Europe. Projet de conclusion (doc. II) », annexe à la lettre du 28 avril 1967.

145. AFNSP, 4 DE 12, « Projet de mémorandum (doc. III) », annexe à la lettre du 28 avril 1967.

146. AFNSP, 4 DE 12, « Note complémentaire. Essai d'analyse des problèmes de structure industrielle par secteurs », annexe à la lettre du 28 avril 1967.

147. AFNSP, 4 DE 12, «Les problèmes du développement industriel et de la recherche en France et en Europe. Projet de conclusion (doc. II)», annexe à la lettre du 28 avril 1967.

148. AFNSP, 4 DE 12, note de Saint-Geours pour le ministre, 30 juin 1967. 
dans la création d'une véritable industrie européenne mais dans une logique intergouvernementale.

Le relais de ces réflexions françaises est assuré à Bruxelles par Michel Albert, inspecteur des finances et militant européen actif, par ailleurs membre du club Jean Moulin ${ }^{149}$. Il est détaché à Bruxelles comme directeur des structures et du développement économique à la DG II (1966-1969). Juste après ces notes de Saint-Geours et d'Ortoli d'avril 1967, Michel Albert envoie à Jean Dromer, qu'il a côtoyé au secrétariat général du comité Rueff-Armand ${ }^{150}$, une note très ambitieuse sur la politique industrielle européenne ${ }^{151}$. Elle part du constat que : " en dépit de succès insignes, le Marché commun apparaît comme un échec sur le plan industriel. Ce ne sont pas des entreprises européennes qui construisent l'Europe industrielle, mais bien des entreprises américaines... ». Dès lors, pour répondre au "défi des entreprises américaines », il faut lancer une véritable politique industrielle européenne. Albert constate les limites des formules intergouvernementales qui sont soit limitées dans leur portée (programmes nationaux ou bilatéraux), soit très fragiles et peu efficaces car fondées sur un engagement renégociable périodiquement et sur le principe du juste retour (programmes multilatéraux). Pour Albert, la seule solution est de mettre en place une politique véritablement communautaire fondée sur deux éléments, le cadre juridique de la société européenne, et une coordination des politiques nationales dans un très grand nombre de secteurs, devant aboutir in fine à une spécialisation nationale. Le problème des justes retours serait ainsi supprimé car les États pourraient recevoir des compensations entre les secteurs. Une initiative politique européenne solennelle devrait être prise. Elle devrait lancer des travaux communautaires et en même temps assurer un " déblocage psychologique » pour les industriels, selon l'idée déjà promue par Dromer, Saint-Geours et Ortoli. Dromer reprend à son compte cette note et l'envoie à de Gaulle le 5 juillet $1967^{152}$.

Cette thématique du « Défi Américain » est particulièrement promue par Jean-Jacques Servan-Schreiber, qui fait paraître un célèbre ouvrage au titre

149. AO, interview de Michel Albert par Laurent Warlouzet, 16 décembre 2009 ; Michel Albert y a écrit un livre intitulé Le socialisme et l'Europe publié au Seuil (collection Jean Moulin) en 1965 sous le pseudonyme de Claude Bruclain.

150. Il semble l'avoir précédé à ce poste selon les informations données par le Who's who in France, 1991-1992, Lafitte, Paris, 1991.

151. AN, 5 AG1, volume 32, note de Dromer du 17 mai 1967. Selon la lettre qui l'accompagne, elle a été « dictée » par Michel Albert.

152. AN, 5 AG1, volume 32, note de Dromer pour Charles de Gaulle, 5 juillet 1967. 
homonyme en $1967^{153}$, traduit en anglais dès $1969^{154}$ et qui eut un grand retentissement en France et en Europe. Il a été écrit justement avec la collaboration essentielle mais discrète de Michel Albert ${ }^{155}$. Le Défi Américain appelle les Européens à se mobiliser dans ce qui est présenté comme une véritable guerre économique. Face au danger des investissements directs américains, les Européens doivent réagir. Or si «L'Europe a créé un marché, elle n'a pas créé une puissance ${ }^{156} /$, l'ouvrage appelle donc à cesser de mener des politiques industrielles nationales. Plus précisément, certaines réformes assez consensuelles sont encouragées comme l'adoption d'un statut de société européenne, la concentration des entreprises européennes ou la modernisation de leurs méthodes de gestion $^{157}$. De manière plus originale, le livre, comme dans la note de Michel Albert de mai 1967, appelle à un rapprochement avec la Grande-Bretagne qui est l'une des clés de la puissance industrielle du Marché commun dans les secteurs de pointe ${ }^{158}$. Toujours dans la continuité de cette note, Le Défi américain plaide pour un plan calcul européen sans logique du juste retour et avec une unité de commandement ce qui revient à « faire du fédéralisme dans le secteur clé de l'industrie ${ }^{159} »$. La notion de fédéralisme est d'ailleurs souvent présente dans cet ouvrage qui défend le développement du recours au vote à la majorité ou au suffrage universel pour établir une " certaine autorité fédérale européenne ${ }^{160}$ ». Le choix du fédéralisme devrait contribuer non pas à dessaisir la France de ses pouvoirs mais au contraire à augmenter ses leviers d'influence car « si l'on ne compense pas la libération des échanges par des politiques communes », la France sera soumise soit à la force aveugle des marchés, soit à celle des multinationales américaines ${ }^{161}$. La voie européenne est donc le seul chemin de l'indépendance économique. Ainsi, par l'intermédiaire du Défi américain, qui devient rapidement un ouvrage incontournable, Albert développe son projet de politique industrielle européenne commune et pas seulement coordonnée.

Le dernier défenseur de cette approche, Alain Prate, a passé la majeure partie de sa carrière à Bruxelles. Inspecteur des finances, il appartient à la délégation française chargée de négocier le traité de Rome puis part tout de suite à

153. Jean-Jacques Servan-Schreiber, Le Défi américain, Denoël, Paris, 1967.

154. Jean-Jacques Servan-Schreiber, The American Challenge, Atheneum, New York, 1969.

155. AO/AHUE, interview de Michel Albert par Éric Bussière, Ghjiussepu Lavezzi, et Émilie Willaert, le 18 décembre 2003, p. 9.

156. Jean-Jacques Servan-Schreiber, Le Défi américain..., op. cit., p. 116.

157. Ibid., p. 122 et p. 171 .

158. Ibid., p. 180 et p. 190.

159. Ibid., p. 185.

160. Ibid., p. 193-195.

161. Ibid., p. 196. 
Bruxelles à la DG II de Marjolin. Il suit tous les projets de programmation européenne comme directeur de la division Structure économique et développement (1961-1965). Il devient ensuite directeur général de la DG III Marché intérieur (1965-1967) puis remplace Dromer comme conseiller économique du président de la République (1967-1969). Dans les années 1966-1967, c'est un promoteur enthousiaste d'une politique industrielle européenne qu'il conçoit naturellement comme très communautaire. Le 12 septembre 1966, il rédige en tant que directeur général pour le Marché intérieur une note qui est directement à l'origine des projets du commissaire européen Colonna di Paliano de politique industrielle ${ }^{162}$. Il développe une vision globale, qui associe création d'un cadre commun et coordination des politiques sectorielles. Il cherche à obtenir un transfert de souveraineté des Etats membres vers la Commission européenne. Il envoie sa note sur la politique industrielle de septembre $1966 \mathrm{au}$ Quai d'Orsay ${ }^{163}$. De retour à Paris au cabinet du général de Gaulle, il continue de développer une approche très volontariste. Ainsi dans une note de novembre 1967 sur la coopération européenne dans le domaine des industries de pointe, il part de la nécessité pour l'Europe de prendre conscience du défi posé par la domination américaine ${ }^{164}$. Soulignant les premiers efforts de la CEE en matière de définition d'une politique industrielle européenne, il insiste sur la nécessité de manifester dans ce dossier industriel le même volontarisme que celui qui a été déployé pour la PAC.

Enfin, il faut noter que cette ambition de développer une politique industrielle européenne se diffuse même au sein des services restés fidèles à une politique européenne gaulliste de stricte observance comme la DAEF du Quai d'Orsay ${ }^{165}$. Selon son témoignage, lorsque Jean-Pierre Brunet a pris son poste de directeur de la DAEF en 1966, il aurait affirmé à de Gaulle, qui le recevait au titre de sa récente nomination, que la priorité de la CEE était désormais, après la PAC, le développement d'une politique industrielle commune ${ }^{166}$. Ce témoignage est confirmé par un entretien avec son homologue allemand Lahr du 3 avril $1967^{167}$. Il commence cette discussion bilatérale rituelle entre les deux hommes par l'affirmation de la nécessité, reconnue en France, d'appliquer le volontarisme

162. AMAE, RPUE 685, note d'Alain Prate, doc. 11.590/III/66 du 12 septembre 1966.

163. AMAE, RPUE 685, note d'Alain Prate, doc. 11.590/III/66 du 12 septembre 1966.

164. AN, 5AG 1, volume 33, note d'Alain Prate du 22 novembre 1967.

165. Sur la culture politique gaulliste de la DAEF et de ses deux directeurs successifs, Olivier Wormser (1954-1966) et Jean-Pierre Brunet (1966-1975), voir le chapitre IV.

166. AO/Association Georges Pompidou, entretien d'Armelle Demagny avec Jean-Pierre Brunet du 26 avril 2002, $2^{\mathrm{e}}$ Cassette, face B, entretien du 26 avril 2002.

167. AMAE, Papiers directeurs Jean-Pierre Brunet, volume 43, compte rendu des entretiens entre Brunet et Lahr du 3 avril 1967. 
déployé pour la PAC à la création d'une « politique industrielle commune ». S'il est difficile de faire de Jean-Pierre Brunet, diplomate gaulliste orthodoxe, un fonctionnaire " modernisateur ", sa défense, qui apparaît sincère, de cette thématique de la politique industrielle européenne en 1966-1967 montre qu'elle apparaît pour beaucoup d'observateurs comme la nouvelle priorité française une fois la PAC établie.

Un groupe de fonctionnaires «modernisateurs » plus libéraux et européens que leurs prédécesseurs des années 1945-1952 émerge donc clairement en 19661968. Il promeut une politique industrielle ambitieuse, dans laquelle la France devrait jouer un rôle de premier plan. Les mesures préconisées sont centrées sur la création d'un cadre juridique et fiscal chez Jean Dromer et sont plus sectorielles chez Jean Saint-Geours et François-Xavier Ortoli. Elles sont toutes fondées sur la dynamique intergouvernementale, même si Michel Albert et Alain Prate développent des projets plus communautaires, fondés sur la mobilisation d'une Europe unie contre le « Défi américain ». Leurs réflexions marquent l'apogée du volontarisme économique gaulliste, qui combine libéralisme et conscience de la nécessité pour l'État d'orienter des acteurs économiques encore frileux dans la voie de la modernisation. Ce groupe diffuse une rhétorique de la politique industrielle communautaire qui trouve un écho chez certains ministres comme Michel Debré.

\section{La promotion d'une approche européenne de la politique industrielle par Debré en 1967.}

Immédiatement après le semi-échec des élections législatives de mars 1967, le gouvernement Pompidou se relance par la prise d'une série d'ordonnance dans le domaine économique et social. Le ministre de l'Économie et des Finances Michel Debré joue un rôle de premier plan dans cette relance et choisit de l'inscrire dans la perspective européenne. Il s'appuie sur les analyses du groupe des « modernisateurs » comme Saint-Geours et Ortoli, dont la grande note sur la politique industrielle européenne envoyée à Debré et Pompidou date du 28 avril $1967^{168}$. Cependant, Ortoli devient rapidement ministre dans le nouveau gouvernement. Chargé de l'équipement et du logement, il n'intervient plus dans ce dossier. Consulté par Debré, Saint-Geours continue de son côté d'envoyer à son ministre des notes axées sur l'adaptation de l'industrie à la concurrence internationale et sur l'incitation à la concentration ${ }^{169}$. Jean Dromer conseille

168. AFNSP, 4 DE 12, lettre manuscrite de Jean Saint-Geours pour Michel Debré, 28 avril 1967.

169. AFNSP, 4 DE 12, note de Jean Saint-Geours du 30 juin 1967 de 20 pages. 
également au général de Gaulle de prendre des mesures destinées à faciliter les concentrations ${ }^{170}$.

Le processus de décision est très rapide. Dans son discours comme dans ses instructions à son cabinet en mai 1967, Debré choisit de mettre l'accent sur l'importance de l'échéance de 1968 en termes de libération des échanges, et donc sur l'adaptation de l'industrie à la concurrence internationale par un mouvement de concentration ${ }^{171}$. Dès le 19 juin 1967 se tient un comité restreint qui décide de prendre des mesures d'encouragement aux fusions à la fois sur le plan fiscal, mais aussi sur le plan juridique ${ }^{172}$. Finalement à la fin du mois de septembre 1967 sont prises une série d'ordonnances sur l'encouragement aux fusions, le renforcement de la concurrence au sein du marché français ${ }^{173}$ et la réforme des marchés financiers (réformes Debré-Haberer). En six mois, de très profondes transformations ont donc été entreprises. Certaines d'entre elles s'inscrivent largement dans la perspective d'une politique industrielle européenne.

En parallèle, un nouvel acteur de ce volontarisme industriel émerge, le nouveau ministre de l'Industrie Olivier Guichard. C'est un fidèle du général de Gaulle (il fut son chef de son cabinet en 1947-1948) et de Georges Pompidou (il fut son adjoint à la direction du cabinet du général de Gaulle en 1958 puis membre du cabinet du Premier ministre de 1962 à 1967). Il fait preuve rapidement d'un grand volontarisme européen en matière industrielle ${ }^{174}$, ce qui lui vaut parfois quelques frictions avec l'ombrageux Michel Debré. Guichard demande ainsi très rapidement à ce que le ministère de l'Industrie ait un représentant au groupe de travail sur la société européenne ${ }^{175}$ mais aussi au CPEMT ${ }^{176}$, car

170. AN, 5 AG1, volume 32, note de Jean Dromer pour Charles de Gaulle du 25 juillet 1967.

171. AN, 540 AP, volume 10, note du cabinet du ministre des Finances, 13 mai 1967, AN, 540 AP, volume 10, note de Michel Debré à son cabinet, 16 mai 1967.

172. AN, $540 \mathrm{AP}$, volume 10, compte rendu du Conseil restreint sur les ordonnances, 19 juin 1967.

173. Création des MIN (Marchés d'Intérêts Nationaux), renforcement de la politique de la concurrence française : Dominique Brault, L'État et la concurrence en France, Économica, Paris, 1987, p. 40.

174. Confirmé par le témoignage de Robert Toulemon, à l'époque à la Commission européenne, interview par l'auteur le 6 décembre 2005. On peut également comparer les notes préparant les audiences du général de Gaulle avec son ministre de l'Industrie : en 1966, Marcellin est reçu pour parler des mines et l'énergie alors qu'en 1967, c'est la concentration industrielle dans la perspective de la compétition internationale qui est évoquée avec Guichard: AN, 5 AG1, volume 32, note de H. Deniau pour Charles de Gaulle du 8 janvier 1967 ; AN, 5 AG1, volume 32, note H. Deniau pour Charles de Gaulle, 5 octobre 1967.

175. ASGCI, 1988.0577, volume 38, lettre du ministre de l'Industrie Olivier Guichard au SGCI, 8 mai 1967.

176. ASGCI, 1979.0791, volume 65, lettre du ministre de l'Industrie au Premier ministre, 4 décembre 1967. 
les deux représentants sont issus du ministère de l'Économie et des Finances, mais Debré s'y oppose ${ }^{177}$.

À partir de janvier 1968, Guichard prononce des discours très volontaristes en matière de politique industrielle nationale et européenne, dont certains font l'objet d'études au sein de la Commission européenne ${ }^{178}$. Guichard défend une politique industrielle européenne très ambitieuse et reposant sur deux pôles ${ }^{179}$. Le premier et le plus classique serait la création d'un cadre fiscal et juridique harmonisé et incitant aux concentrations. Le second reposerait sur un « accord général sur les perspectives industrielles de la Communauté » tant au niveau des gouvernements que des entreprises. Guichard propose de définir des « actions communes » dans des domaines où la nécessité d'une action communautaire est reconnue, comme la société européenne ou la recherche scientifique et technique, mais aussi dans des domaines moins consensuels comme la politique envers les IDE ou des actions sectorielles communes.

La logique des projets de politique industrielle développés par Debré et Guichard reste intergouvernementale. Le but est d'affirmer le rôle directeur de l'État-nation dans la modernisation de l'économie et le renforcement de la puissance française. Cette dimension nationale se perçoit notamment dans le dossier de la concurrence industrielle italienne, particulièrement virulente dans le domaine de l'électroménager. Déjà en 1963, la Commission avait accordé à la France, au titre de l'article 226, la possibilité d'appliquer une taxe compensatoire sur les réfrigérateurs italiens pendant une période limitée, afin de faciliter la restructuration du secteur ${ }^{180}$. En juin 1967 les fabricants français, par la voie de Thomson, demandent une nouvelle fois le soutien du gouvernement français contre des pratiques concurrentielles italiennes déloyales, fondées sur des aides aux exportations et sur une tolérance de l'administration envers les fraudes fiscales ${ }^{181}$. La démarche des industriels français s'appuie sur une consultation européenne, organisée dans le cadre du syndicat de la construction électrique animé par l'ancien secrétaire général de l'OECE René

177. AFNSP, 4 DE 7, lettre de Michel Debré à Olivier Guichard, 4 décembre 1967.

178. AHEU, BDT $118 / 83$, volume 807 , note d'information du ministère de l'Industrie sur le discours du ministre prononcé le 26 avril 1968 .

179. ASGCI, 1988.0577, volume 50, transmission à J. R. Bernard du discours que Guichard doit prononcer le 25 janvier 1968.

180. AINDUS, 1991.0817, volume 2, note de M. Colonna (ministère de l'Industrie français) à R. Barre (commissaire européen), 19 janvier 1968.

181. AINDUS, 1991.0817, volume 9, note sur la concurrence italienne dans l'électroménager transmise par une lettre du vice-président et directeur général de la compagnie française Thomson Houston-Hotchkiss Brandt, P. Richard, le 2 juin 1967, au ministre de l'Industrie. 
Sergent ${ }^{182}$, et des lettres de soutien des organisations professionnelles allemandes, néerlandaises et belges ${ }^{183}$. Le patronat européen est donc à la recherche d'une régulation forte de la concurrence, qui concerne plus les obstacles non douaniers aux échanges que les ententes.

Cette requête est immédiatement appuyée par Debré et Guichard ${ }^{184}$. Debré élargit le problème par des notes de septembre et octobre 1967 qui accusent l'Italie de bénéficier indûment d'un traitement de faveur dans le cadre du Marché commun ${ }^{185}$. Il demande donc au général de Gaulle et à Georges Pompidou une offensive globale contre l'Italie qui concernerait aussi bien le domaine industriel que le domaine agricole (renégocier la clé de répartition financière), et se traduirait par des entretiens bilatéraux avec Rome mais aussi avec l'Allemagne et enfin à Six.

Finalement, la France dépose auprès de la Commission une nouvelle demande de recours à l'article 226 dans le domaine de l'électroménager en novembre 1967 , afin de permettre la concentration de l'industrie nationale ${ }^{186}$. Le gouvernement français encourage fortement les constructeurs français à se rapprocher en échange d'une action contre l'Italie, suivant la logique sectorielle incitative déjà appliquée ailleurs (aides de l'État contre la rationalisation du secteur). Le commissaire Colonna di Paliano refuse finalement d'accorder à la France le recours à l'article $226^{187}$. La France profite ensuite de ses difficultés de mai 1968 pour revenir à la charge sur ce dossier.

L'exemple italien montre combien le projet de politique industrielle européenne de Debré et Guichard repose sur une logique intergouvernementale d'affrontement de puissance. La CEE est perçue comme un cadre de coopération naturel, mais pas exclusif. Ainsi, face aux difficultés pour faire avancer les dossiers dans le cadre des Six, les décideurs français sont

182. Polytechnicien, René Sergent a une expérience de fonctionnaire financier versé dans les problèmes internationaux (attaché financier à Londres, 1947-1952) et de fonctionnaire international (secrétaire général adjoint de l'OTAN de 1952 à 1954, secrétaire général de l'OECE de 1955 à 1960) avant de devenir vice-président délégué du Syndicat général de la construction électrique (1960-1969).

183. AINDUS, 1991.0817, volume 9, note sur la concurrence italienne dans l'électroménager transmise par une lettre du vice-président et directeur général de la compagnie française Thomson Houston-Hotchkiss Brandt, P. Richard, le 2 juin 1967, au ministre de l'Industrie.

184. AFNSP, 4 DE 6, copie d'une lettre manuscrite de Michel Debré à Olivier Guichard, 9 juillet 1967 ; AINDUS, 1977.1386, article 56, lettre d'Olivier Guichard à Michel Debré, 11 décembre 1967.

185. AFNSP, 4 DE 6, lettre de Michel Debré remise à de Gaulle le 14 septembre 1967 ; AFNSP, $4 \mathrm{DE}$ 6, copie d'une lettre de Michel Debré à Georges Pompidou et Olivier Guichard du 19 octobre 1967.

186. AMAE, RPUE 1146, lettre à la Commission du 16 novembre 1967.

187. ASGCI, 1977.1467, article 53, note sur les $23^{\text {e }}$ (30 au 31 janvier et $1^{\text {er }}$ février 1968) et $26^{\mathrm{e}}$ réunions de la Commission (21 février 1968). 
tentés de se replier sur le cadre franco-allemand. Entre 1965 et 1968 d'ailleurs, deux institutions spécifiques sont créées pour lancer une coopération économique concrète en termes de politique industrielle, le bureau industriel francoallemand (1965-1967) puis le comité franco-allemand de coopération économique (1967-1968) $^{188}$. Par ailleurs, de nombreuses coopérations industrielles ad hoc sont menées à des échelles différentes, que ce soit le projet franco-britannique du Concorde ${ }^{189}$ ou les multiples projets à géométrie variable conduits dans le domaine de l'aéronautique militaire ${ }^{190}$. L'ambition de politique industrielle de Debré se développe donc suivant une approche associant le nationalisme gaulliste et un cadre communautaire perçu comme une échelle naturelle, mais pas exclusive, du déploiement des actions économiques françaises.

\section{Conclusion : des réseaux dynamiques à l'échelle nationale.}

La relance de la politique industrielle française puis européenne s'effectue en 1966-1967 grâce à l'activisme du nouveau ministre de l'Économie et des Finances Michel Debré. Il s'appuie sur le ministre de l'Industrie Olivier Guichard et sur une nouvelle génération de fonctionnaires " modernisateurs ». Ils définissent une forme d'interventionnisme économique qui associe libéralisme et fortes incitations étatiques, affirmation de la puissance nationale et insertion dans un cadre communautaire. Ce groupe exprime toutefois des visions différentes de l'intégration européenne, certains affichant un européisme prononcé (Michel Albert), la majorité se servant de la construction européenne comme d'un levier pour réclamer des réformes structurelles nationales et accroître l'efficacité de ces dernières en les envisageant d'emblée dans un cadre communautaire.

Cette doctrine a des conséquences immédiates et radicales en termes de politique intérieure (plan calcul), mais beaucoup plus limitées en matière européenne. La stratégie reste en effet purement intergouvernementale et peine à s'incarner dans une stratégie institutionnelle adaptée au fonctionnement du système communautaire. Elle aboutit même parfois à contredire complètement

188. Toutefois, ces tentatives ne débouchent sur rien de tangible en raison des divergences d'approches économiques ; sur cette coopération, voir : Laurent Warlouzet, « La dimension industrielle du couple franco-allemand : les tentatives de créer une coopération bilatérale institutionnalisée entre 1965 et 1969 », in Jean-François Eck, Stefan Martens, Sylvain Schirmann (dir.), L'économie, l'argent et les hommes. Les relations franco-allemandes de 1871 à nos jours, Comité pour l'histoire économique et financière de la France, Paris, 2009, p. 287-307.

189. Frances Lynch, «A Treaty too Far? Britain, France, and Concorde, 1961-1964 », in Twentieth Century British History, 13-3, 2002, p. 253-276.

190. David Burigana, Pacal Deloge, « La cooperazione europea a una svolta ? Armamenti e aeronautica fra Allenza atlantica e Comunita europea (1967-1977)», in Antonio Varsori (dir.), Alla origini del persente. L'Europa occidentale nell crisi degli anni'70, Franco Angeli, Milan, 2006, p. 193-220. 
la dynamique communautaire comme dans le cas de l'offensive anti-italienne. La politique industrielle européenne ne peut donc être lancée que grâce à l'activisme d'un autre groupe d'acteurs présents au sein même de la Commission européenne.

\section{LE LANCEMENT DE LA POLITIQUE INDUSTRIELLE COMMUNAUTAIRE (1966-1968)}

Après l'Europe de la concurrence et les projets macroéconomiques de Marjolin, une troisième approche de l'Europe économique est lancée par la Commission européenne en 1966 avec la politique industrielle.

\section{A. UNE NOUVELLE FORCE MOTRICE À LA COMMISSION EUROPÉENNE (1966-1967)}

Profitant d'un contexte européen favorable à des initiatives en matière de politique industrielle, un groupe constitué de responsables français et italiens défini à la Commission européenne une nouvelle stratégie en la matière.

\section{Un contexte européen favorable.}

Les réflexions au sein de la Commission européenne sur la politique industrielle sont favorisées par la fusion des exécutifs des trois communautés (traité du 8 avril 1965) car les prérogatives de politique industrielle sont beaucoup plus développées à la CECA que dans la CEE. Le président de la Haute Autorité, Dino del Bo, réfléchit d'ailleurs, en mars 1965, aux moyens de développer une vision autonome de la politique industrielle dans le secteur sidérurgique afin d'imprimer la marque de la CECA dans la future Commission unique ${ }^{191}$. En France, Jean Dromer préconise de demander un approfondissement des politiques communes dans le domaine économique et industriel à l'occasion de la fusion $^{192}$. Ces idées font l'objet de réunions au SGCI au sein du même groupe qui a développé les réflexions sur le développement d'une politique industrielle européenne fin $1965^{193}$.

191. AHUE, CEAB 2, volume 3697, « Note à mes collègues » de Dino del Bo, président de la Haute Autorité de la CECA, 26 mars 1965.

192. AMINEFI B 16.677, note du SGCI, Dromer, du 17 mai 1965.

193. AMINEFI B 16.677, note du SGCI, JP, du 14 juin 1965, suite de la réunion SGCI du 2 juin 1965. 
Finalement, le traité de fusion des exécutifs est minimaliste sur ce point. Un traité de fusion des Communautés (et pas seulement des exécutifs) est bien envisagé pour le compléter mais se perd dans les arcanes des débats institutionnels. Toutefois, la Commission est réorganisée. Une direction générale « affaires industrielles » (DG III) et une direction générale « recherche générale et technologie » (DG XII), qui comprend une direction PRST, naissent en juillet 1967.

Les États européens sont de plus en plus sensibles à la thématique de la politique industrielle à partir de 1966. Le contexte général de la CEE s'y prête. Les travaux reprennent rapidement après la crise de chaise vide et aboutissent à une série d'accords décisifs entre mai et juillet 1966 sur la PAC et le GATT. Les contentieux les plus urgents sont donc soldés, ce qui permet aux Six de s'interroger sur les développements futurs de la Communauté à partir de la rentrée $1966^{194}$.

La France exprime son volontarisme en la matière par la voie de son nouveau ministre Michel Debré et par le groupe des fonctionnaires « modernisateurs ». Elle peut s'appuyer sur un nouveau chancelier, Kurt-Georg Kiesinger, plus proche de Paris qu'Erhard et sensible à la thématique de la PRST ${ }^{195}$. Du côté britannique, le Premier ministre Harold Wilson veut profiter de la puissance technologique de l'industrie britannique dans de très nombreux domaines (aéronautique, informatique) pour séduire les Six. Ainsi, Londres sollicite directement Paris en 1965 et en 1966 pour établir une coopération bilatérale en matière d'électronique et en termes de coordination de leurs politiques de recherche scientifique et technologique d'une manière générale ${ }^{196}$. La menace de la candidature britannique devient donc, dans la perspective du développement d'une politique industrielle et technologique communautaire, une opportunité à prendre en compte. Ce contexte favorable est exploité par un groupe basé à la Commission qui se mobilise sur la thématique de la politique industrielle.

\section{Un groupe franco-italien volontariste à la Commission européenne.}

La DG III joue un rôle central dans la promotion de la politique industrielle en particulier à partir du moment où sa tutelle est assurée par le dynamique commissaire italien Colonna di Paliano. Il succède à deux commissaires

194. P. Ludlow, The European Community and the Crises of the 1960s..., op. cit., p. 106-109 et p. 125.

195. Henning Türk, Die Europapolitik der Grossen Koalition, 1966-1969, Oldenbourg, Munich, 2006, p. 98 ; AMAE, Papiers directeurs Jean-Pierre Brunet, volume 54, compte rendu des entretiens du 13 janvier 1967 entre le chancelier Kiesinger et le Premier ministre Georges Pompidou.

196. AMAE, POW 7, folio 238, note DB, 9 mars 1966. 
italiens ayant rapidement quitté leur poste, Piero Malvestiti, parti à la CECA, et Guiseppe Caron, qui préfère revenir au Sénat italien. Guido Colonna di Paliano est un spécialiste des affaires européennes. Ancien collaborateur de Marjolin à l'OECE $^{197}$, il assuma des fonctions à l'OTAN mais reste un diplomate spécialiste des questions économiques ${ }^{198}$. Il retrouve donc Marjolin à la Commission entre 1964 et 1967 dans un domaine très complémentaire. Les affaires économiques et financières (Marjolin) privilégient une vision macroéconomique et le marché intérieur (Colonna) une approche microéconomique.

Au moment où Colonna exerce son magistère, la DG III a toujours été dirigée par des Français, anciens élèves de l'ENA : François-Xavier Ortoli (1958-1961), Pierre Millet (1961-1965) et Alain Prate (1965-1967). Ces deux derniers sont venus à ce poste depuis la direction des structures économiques de la DG II. À ce titre, ils avaient participé à la mise au point de la politique économique à moyen terme.

Colonna a d'ailleurs personnellement choisi Prate comme directeur général, justement pour ses liens avec Marjolin et pour renforcer la réflexion économique d'une DG qui se concentrait trop sur une approche juridique selon lui ${ }^{199}$. Il semble que Colonna souhaite réorienter sa direction vers un travail plus volontariste après des premières années consacrées à la résolution de problèmes techniques de nature commerciale comme la fixation du tarif extérieur commun et les problèmes douaniers ${ }^{200}$.

Cette ambition croissante de la DG III se heurte bientôt à la susceptibilité de la DG IV. En février 1965 par exemple, alors que la DG IV avait entrepris des études sur l'application de l'article 37 (monopoles nationaux à caractère commercial), Colonna obtient que le dossier revienne à la DG III, ce qui suscite des réserves d'Albrecht (le chef de cabinet de von der Groeben qui représente son commissaire absent) $)^{201}$. De même lors de la séance du 8 décembre 1965, un front commun entre Marjolin et Colonna (représenté par son chef de cabinet) se constitue face à von der Groeben tant sur le dossier de la société européenne que sur celui du déséquilibre géographique dans les recrutements à la DG IV ${ }^{202}$.

197. Robert Marjolin, Le travail d'une vie..., op. cit., p. 194.

198. Nicole Condorelli-Braun, Commissaires et juges..., op. cit., p. 96.

199. AHUE, papiers Hallstein, volume 1248, lettre de G. Colonna di Paliano à W. Hallstein du 11 février 1965.

200. AHUE, papiers Hallstein, volume 1248, lettre de G. Colonna di Paliano à W. Hallstein du 26 novembre 1964.

201. AHUE, procès-verbal spécial de la $307^{\mathrm{e}}$ session de la Commission européenne du 24 février 1965 , point 17 .

202. AHUE, procès-verbal spécial de la $340^{\mathrm{e}}$ session de la Commission européenne du 8 décembre 1965 , points 10 et 13 . 
Avec la fusion des Communautés, le groupe autour de Colonna évolue mais reste très proche du réseau Marjolin. En 1967, Colonna conserve la DG III dans la nouvelle commission mais celle-ci s'intitule désormais « affaires industrielles ». Elle est dirigée par Robert Toulemon, un inspecteur des finances lui aussi proche de Marjolin (il fut son chef de cabinet en 1962 avant de devenir directeur à la DG relations extérieures). Le conseiller principal attaché à la DG III est le Luxembourgeois Fernand Braun, ancien promoteur à la programmation européenne ${ }^{203}$. Les deux directions majeures en matière de politique industrielle sont la direction $\mathrm{A}$ dite « études et politique industrielle » et la direction $\mathrm{C}$ sectorielle. Cette dernière est confiée à l'italien Stefano Ponzano tandis que la première revient à Jean Flory, ancien chef de cabinet-adjoint (1958-1962) puis chef de cabinet (1962-1966) de Marjolin. De son côté, la DG II reste toujours dirigée par un italien (Ugo Mosca succède à Franco Bobba - un des plus importants négociateurs italien du traité de $\mathrm{Rome}^{204}$ ) et avec Michel Albert maintenu à la tête de la direction "structure et développement industriel ». Enfin, une DG « recherche générale et technologie » est créée. En son sein, le directeur pour la politique de la recherche scientifique et technique est le français Pierre Maillet, un ancien du SEEF et de la direction des études économiques de la CECA.

Ainsi un front commun à la DG II et à la DG III se crée contre l'Europe ordolibérale de la DG IV. Une grande partie du personnel de la DG III est composée d'anciens collaborateurs directs de Marjolin comme Millet, Prate, Toulemon, Flory ou Braun. Les Italiens sont très présents dans ces réseaux : le commissaire Colonna bien sûr mais aussi les directeurs généraux de la DG II et un directeur important de la nouvelle DG III « affaires industrielles ». La tradition interventionniste de la politique industrielle italienne (notamment par le biais de l'IRI) ${ }^{205}$ explique sans doute une certaine communion doctrinale avec les Français sur la nécessité de mener une politique industrielle européenne volontariste. Cette convergence franco-italienne à la Commission va à l'encontre de la tendance observée au sein du Conseil, si l'on s'en tient à la volonté du ministre Michel Debré de mener une offensive globale contre l'Italie au sein de

203. ASCGI 1979.0791, volume 264, note sur le CES du 7 janvier 1961 ; ASCGI 1979.0791, volume 264, note CEE sur les débats lors de la XVession du CES, 27 au 27 mars 1961.

204. Elena Calandri, «L'administration italienne pendant les dix premières années de la Communauté économique européenne. Prédominance de la diplomatie et conflits de compétence », in L. Badel et al. (dir.), Les administrations nationales..., op. cit., p. 262 et 270.

205. Ferrucio Ricciardi, «L'absence de plan en Italie : mythe ou réalité ? Interventionnisme d’État et politique industrielle entre fascisme et république (années 1930-années 1960) », in Ivan Kharaba et al. (dir.), Politiques industrielles..., op. cit. p. 43-58; Valerio Castronovo, « La stratégie du conglomérat : l'État banquier et entrepreneur en Italie », in Entreprises et histoire, $n^{\circ}$ 1, avril 1992, p. 17-21. 
la CEE. Ce groupe franco-italien s'attelle à définir rapidement un projet global de politique industrielle.

\section{Le projet global de Colonna (1966-1967).}

Devenu directeur général de la DG III à la demande expresse de son commissaire Colonna pour approfondir les réflexions économiques de son service, Prate se met immédiatement au travail. Il peut s'appuyer sur une triple expérience. Tout d'abord, sa direction générale a déjà traité des dossiers industriels. C'était elle qui s'occupait des difficultés sectorielles justifiant l'usage de l'article 226, auquel l'Italie a souvent eu recours. Elle a également cherché à développer une approche communautaire du problème de la construction navale, en proposant une directive d'harmonisation des politiques d'aide en avril $1965^{206}$. Ensuite, Prate profite de son expérience à la DG II. Comme directeur de la direction structure économique et développement depuis 1961, il a dû suivre de près les développements de la politique économique à moyen terme. Enfin, comme inspecteur des finances et «fonctionnaire modernisateur» de la nouvelle génération, il ne devait sans doute pas ignorer les réflexions en cours en France depuis la fin de 1964 sur la politique industrielle.

Dès le 24 mars 1965, une première note sur la politique industrielle est envoyée à Colonna ${ }^{207}$. Faisant référence notamment aux travaux de l'UNICE, la note reste focalisée sur le problème de la concentration. À partir de la fin 1966, le contexte devient de nouveau favorable au lancement d'une initiative majeure en matière de politique industrielle. Alain Prate diffuse alors une note très dense datée du 12 septembre 1966 sur la politique industrielle ${ }^{208}$. Elle sert de base à la communication à la Commission européenne prononcée par Colonna di Paliano le 27 février $1967^{209}$. Après des discussions au sein du collège des commissaires, un " mémorandum sur la politique industrielle de la Communauté », issu de cette communication est adopté le 4 juillet $1967^{210}$. Prate l'a élaboré en relation

206. Éric Bussière, « L'improbable politique industrielle », in Michel Dumoulin (dir.), La Commission européenne, 1958-1972..., op. cit., p. 472-473.

207. AHUE, BDT 118/83, volume 807, « Note adressée à M. Colonna di Paliano en date du 24.3.65».

208. AHUE, BDT 118/83, volume 807, note signée Prate, doc. 11.590/III/66, 12 septembre 1966.

209. AHUE, BAC 144/1992, volume 682, communication de M. Colonna di Paliano du 27 février 1967, « Problèmes de la politique industrielle », doc SEC (67) 672. Voir aussi : Éric Bussière, «L'improbable politique industrielle... », op. cit., p. 474-476.

210. AHUE, BDT 118/83, volume 807, " Mémorandum sur la politique industrielle de la Communauté », doc SEC (67) 1201 final, 4 juillet 1967. 
étroite avec la DG II, notamment en consultant celui qui l'a remplacé comme directeur des structures et du développement économique, Michel Albert ${ }^{211}$.

Ces trois documents sont fondés sur un double constat. Tout d'abord, l'intégration économique européenne doit s'engager dans une dynamique nouvelle. L'intégration négative, c'est-à-dire la suppression des obstacles aux échanges, a beaucoup progressé mais n'est pas suffisante pour renforcer la structure industrielle communautaire. Le but de la CEE n'est pas simplement de former une union commerciale, mais bien de créer une union économique, par un processus parallèle d'intégration négative et positive. Le second facteur d'évolution est la menace des entreprises américaines. Certes, les investissements américains en Europe sont globalement bénéfiques mais, du fait de la dimension des entreprises américaines, émergent parfois des « positions dominantes, dépendantes de centres de décision situés dans des pays tiers ${ }^{212} »$. En plus d'être un modèle, les États-Unis deviennent une menace, ils posent un « défi » à surmonter.

Les propositions des trois documents sont triples : achèvement du marché intérieur, politique sectorielle et incitation à la concentration. L'équilibre entre les trois évolue cependant entre la note de Prate de septembre 1966 d'une part, la communication de février 1967 et le mémorandum d'avril 1967 d'autre part.

La note de Prate se concentre sur l'achèvement du Marché commun industriel car c'est la prérogative première de la DG III qui est encore celle qui s'occupe du « marché intérieur » jusqu'en 1967, avant d'être en charge des « affaires industrielles ». Les mesures qu'il préconise concernent donc l'harmonisation législative et fiscale, la suppression des entraves techniques aux échanges, et l'encouragement aux concentrations par un cadre juridique et fiscal incitatif (notamment le statut de société européenne). Enfin, on perçoit assez fortement l'héritage de la programmation européenne chez Prate car il insiste beaucoup sur une harmonisation poussée des politiques macroéconomiques. Les autres mesures (PRST, coordination des politiques d'aides aux secteurs en déclin) sont décrites de manière plus rapide.

La communication de Colonna à la Commission en février 1967 et le mémorandum de juillet 1967 présentent deux différences majeures par rapport à la note initiale de Prate. Tout d'abord, ils s'intéressent moins à l'achèvement du marché intérieur et la nécessité de coordonner les politiques macroéconomiques

211. AHUE, BAC 118/83, volume 807, note de la DG II du 17 février 1967 pour Prate. La signature semble indiquer que le document est de Michel Albert.

212. AHUE, BDT 118/83, volume 807, note signée Prate, doc. 11.590/III/66, 12 septembre 1966. 
disparaît. Les deux documents de 1967 insistent sur les actions communes à caractère général à engager pour renforcer les entreprises européennes (incitations aux fusions, etc.) et sur l'encouragement à la recherche-développement (améliorer la circulation de l'information, développer des centres de recherches européens). Les actions sectorielles, que ce soit dans les secteurs de pointe ou en déclin, sont traitées de manière plus rapide. En matière de secteurs de pointe, toutes les décisions précises sont renvoyées au groupe PREST du CPEMT. Le mémorandum se veut donc plus spécifiquement orienté vers des mesures de politique industrielle à caractère général. Le but est de créer un cadre juridique, fiscal et financier donnant de fortes incitations aux entreprises européennes pour renforcer leur compétitivité.

La deuxième différence est une insertion plus évidente de la politique industrielle dans la politique de la concurrence et le respect de l'indépendance des entreprises ${ }^{213}$. Reprenant le thème du « déblocage psychologique » présent dans des notes françaises contemporaines de Dromer ${ }^{214}$, le discours d'introduction à la communication de février insiste sur la nécessité de faire prendre conscience aux industriels « de leur communauté d'intérêt au niveau européen ${ }^{215} »$. De plus, le mémorandum de juillet 1967 fait une place plus grande aux évolutions de la politique de la concurrence dans les réformes attendues ${ }^{216}$. Enfin, une définition consensuelle de la politique industrielle est adoptée : «Par politique industrielle on entend un ensemble de problèmes et d'actions dont la plupart sont en cours. L'objet du mémorandum ci-joint est d'établir un lien logique entre ces différentes actions. L'objectif de la politique industrielle de la Communauté est le développement de la capacité concurrentielle des entreprises communautaires ${ }^{217} »$.

Le but de ce paragraphe est clairement de désamorcer les débats doctrinaux sur le terme de "politique industrielle », qui peut effrayer les plus libéraux. Le résultat est d'ailleurs probant. La première réflexion du président Hallstein après le discours de Colonna présentant sa communication à ses collègues de la Commission le 2 mars 1967 insiste sur cet aspect : " [Le] premier mérite du document est de démystifier et de rationaliser les termes "politique industrielle" " . Cependant, à cette même réunion, d'autres commissaires comme von der Groeben ou Rey sont plus critiques sur l'approche de Colonna. Marjolin

213. Éric Bussière, «L'improbable politique industrielle... », p. 476-477.

214. AN, 5 AG1, volume 28, note de Jean Dromer du 3 juin 1966.

215. AHUE, BAC 144/1992, volume 682, doc. G (67) 92, «Résumé du déroulement de la discussion dans la Commission sur les problèmes de la politique industrielle (séance du 2 mars 1967)».

216. AHUE, BDT 118/83, volume 807, " Mémorandum sur la politique industrielle de la Communauté », doc SEC (67) 1201 final, 4 juillet 1967, p. 13.

217. AHUE, BAC 144/1992, volume 682, communication de M. Colonna di Paliano du 27 février 1967, « Problèmes de la politique industrielle », doc. SEC (67) 672. 
quant à lui soutient pleinement les ambitions de Colonna. Fidèle à son credo, il insiste sur une coordination accrue des politiques économiques et financières ${ }^{218}$. Lors des réunions des chefs de cabinets, ce sont les représentants de Rey et de von der Groeben qui présentent et obtiennent le plus de modifications ${ }^{219}$. On retrouve ainsi les lignes de fractures qui s'étaient déployées à l'époque de la chaise vide. Ces critiques expliquent sans doute l'abandon des thématiques de la programmation macroéconomique.

Ces projets du groupe franco-italien de la Commission européenne s'inscrivent directement dans les réflexions des « fonctionnaires modernisateurs » français, en particulier Jean Dromer. Sa note de juin $1966^{220}$ semble inspirer partiellement celle de Prate de septembre 1966 - d'ailleurs diffusée au sein de l'administration française ${ }^{221}$, qui en retour influence la note de Dromer de décembre $1966^{222}$. Les réflexions d'Albert sont également proches de celles de Prate, même si Albert insiste plus encore sur le défi américain et surtout sur la nécessité de mener une politique sectorielle européenne concentrée sur quelques points forts ${ }^{223}$. Or les documents de Prate et de Colonna ont abandonné tout volontarisme en matière sectorielle. De même, la note commune de Saint-Geours et d'Ortoli du 28 avril 1967 insistait beaucoup sur la définition de politiques des structures sectorielles avec les industriels européens ${ }^{224}$. Le mémorandum de Colonna se révèle sur ce point paradoxalement beaucoup plus prudent que les notes de certains fonctionnaires « modernisateurs » français. Les difficultés des études sectorielles et des tentatives de politique sectorielle menée dans le cadre de la construction navale ont sans doute dû également refroidir les ambitions de la DG III, qui se concentre sur les mesures transversales.

Le groupe Colonna présente donc, avec le soutien de Marjolin et le relais des fonctionnaires «modernisateurs » français, un programme global de politique industrielle. Il rassemble des initiatives et projets antérieurs dans un ensemble cohérent, fondé sur la nécessité de faire passer la CEE d'une union commerciale

218. AHUE, BAC 144/1992, volume 682, doc. G(67) 92, « Résumé du déroulement de la discussion dans la Commission sur les problèmes de la politique industrielle (séance du 2 mars 1967) ».

219. AHUE, BAC 144/1992, volume 682, note d'Émile Noël, compte rendu du 13 mars 1967 de la réunion des chefs de cabinet du 8 mars 1967 ; AHUE, BAC 144/1992, volume 682, note du secrétaire exécutif, 6 avril 1967.

220. AN, 5 AG1, volume 28, note de Jean Dromer du 3 juin 1966.

221. AMAE, RPUE 685, note signée Prate, doc. 11.590/III/66, 12 septembre 1966.

222. AFNSP, 4 DE 32, note du $1^{\text {er }}$ décembre 1966 de Dromer pour Dupont-Fauville.

223. AN, 5 AG1, volume 32, note Dromer du 17 mai 1967. Selon la lettre qui l'accompagne, elle a été « dictée » par Michel Albert; AHUE, BAC 118/83, volume 807, note de la DG II du 17 février 1967 pour Prate.

224. AFNSP, 4 DE 12, "Écart technologique et structures industrielles (Note de réflexion) », annexe à la lettre du 28 avril 1967. 
à une union économique, dans un contexte de forte concurrence américaine. Délaissant l'approche de la PEMT, le mémorandum privilégie quatre mesures, l'achèvement du Marché commun, la création d'un cadre incitatif pour les concentrations européennes, la PRST et, de manière plus indirecte, les politiques sectorielles (dans les secteurs en déclin et les secteurs de pointe). Colonna tente d'appliquer son programme entre 1966 et 1968.

\section{B. LES INITIATIVES DE POLITIQUE INDUSTRIELLE DE 1966-1968}

Le groupe franco-italien de la Commission ainsi que les représentants du gouvernement français tentent de mettre en œuvre la politique industrielle en particulier dans deux domaines, la société européenne et la PRST. Le succès de la politique industrielle contribue même à réorienter la politique de la concurrence.

\section{Inciter aux concentrations : la société européenne.}

Le dossier de la société européenne avait été lancé par la France au début de 1965. Mais la crise de la chaise vide a brisé cette initiative. Les travaux reprennent en novembre $1966^{225}$. La délégation française s'efforce d'obtenir des résultats rapides. Un groupe de travail présidé par Sanders, doyen de la faculté de droit de Rotterdam, est réuni pour réaliser un rapport sur le sujet ${ }^{226}$. Cependant, la RFA pose un nouveau problème celui de l'extension au statut de société européenne des obligations en matière de cogestion ${ }^{227}$. Le problème de l'attractivité de ce nouveau statut de société européenne se pose s'il ne comporte aucun avantage pour les entreprises mais au contraire des obligations supplémentaires. La RFA bloque les discussions à la fin de 1967 à cause de ce problème de la cogestion, qui provoque des divisions au sein même du gouvernement allemand ${ }^{228}$. Enfin, l'accès au statut de société européenne constitue une deuxième difficulté. Certains membres du groupe de travail ont proposé que des entreprises des pays tiers puissent en bénéficier, ce qui irait à l'encontre de l'objectif français du renforcement d'une structure industrielle

225. ASGCI, 1988.0577, volume 37, télex de Boegner des 30 septembre, 7 octobre 1966 et 17 novembre 1966.

226. ASGCI, 1988.0577, volume 37, note REP pour DAEF/SCE du 5 juin 1967.

227. ASGCI, 1988.0577, volume 38, compte rendu de la réunion des 15 et 16 février 1967, 22 février 1967.

228. ASGCI, 1988.0577, volume 38, télex Boegner du 20 décembre 1967 sur le COREPER du 15 décembre 1967. 
européenne indépendante ${ }^{229}$. À partir de juin 1967, la candidature britannique fait peser une nouvelle inconnue sur les travaux et tend les discussions entre les Cinq et le délégué français ${ }^{230}$. Après le rejet de la candidature britannique, les Pays-Bas refusent de reprendre ces travaux au prétexte qu'ils contribueraient à accroître le fossé avec la Grande-Bretagne ${ }^{231}$. L'opposition franco-hollandaise sur ce point combinée à la position allemande radicale sur le problème de la cogestion bloque les travaux en $1968^{232}$. La Commission tente de relancer les travaux en octobre $1968^{233}$ mais les Pays-Bas refusent tout progrès. Ils se trouvent isolés au sein des six gouvernements car la majorité souhaite la reprise des travaux ${ }^{234}$.

Pour dépasser ce blocage communautaire, déjà prévisible à la mi-1967, une solution nationale est envisagée. En juillet 1967, Jean Dromer plaide pour une initiative unilatérale de la France, qui créerait dans sa législation un statut de "société d'intérêt européen » associé à des avantages fiscaux ${ }^{235}$. Il s'agit d'accorder un traitement discriminatoire à certaines opérations favorables au renforcement de la structure industrielle communautaire comme des fusions d'entreprises, sur le plan national et européen, ou la création de filiales communes. Les avantages seraient réservés à des entreprises contrôlées par des ressortissants de la CEE, et dont le centre décisionnel y serait situé ${ }^{236}$. La notion d' « intérêt communautaire » est donc définie de manière très explicite et restrictive, pour exclure toutes les filiales des entreprises américaines. Le gouvernement français prend d'ailleurs des mesures pour faciliter la coopération entre les entreprises en créant en août 1967 les « groupements d'intérêt économique » (GIE) ${ }^{237}$. Le GIE est un statut intermédiaire entre l'association et la société anonyme et vise à favoriser la coopération entre les entreprises ${ }^{238}$. L'accord doit correspondre à certains objectifs comme la promotion des exportations ${ }^{239}$.

229. ASGCI, 1988.0577, volume 38, instructions pour la réunion du 19 janvier 1967, 18 janvier 1967.

230. ASGCI, 1988.0577, volume 38, télex Boegner du 15 juin 1967.

231. AMAE, DECE 732, télégramme de Boegner, 7 mai 1968 ; AMINEFI, B 40.478, note Trésor, 25 janvier 1968 .

232. ASGCI, 1979.0791, volume 271, note SGCI du 5 janvier 1968 ; note du ministère de l'Industrie du 25 avril 1968.

233. AMAE, DECE 732, lettre de Hans von der Groeben à Michel Debré, 11 octobre 1968.

234. ASGCI, 1988.0577, volume 37, télex Boegner, 18 octobre 1968.

235. AN, 5 AG1, volume 32, note de Dromer pour de Gaulle, 25 juillet 1967.

236. AMAE, DECE 732, note du MAE, BD, 19 août 1967.

237. AN, 1987.0451, volume 1, note SGG du 29 août 1967 : conseils restreints des 28 et 29 août 1967.

238. AFNSP, 4 DE 31, note de Jacques Delmas, inspecteur des finances, 31 octobre 1967.

239. L'inspiration est la législation allemande de la concurrence, qui encourage les ententes à l'exportation : AFNSP, 4 DE 40, lettre du ministre de la Justice (Foyer) à Debré, 23 août 1966. 
Il est destiné aux PME qui ne veulent pas fusionner, ou aux grandes entreprises qui préparent une fusion dans un second temps. Il se place donc clairement dans la logique de l'Europe organisée défendue par les milieux économiques.

Dromer veut aller plus loin. Il présente un texte de projet d'ordonnance créant un statut de « société d'intérêt européen ». Le Quai d'Orsay et le ministère des Finances sont hostiles au principe d'une initiative unilatérale car elle risquerait de contrarier les efforts entrepris à Six mais aussi à deux, dans le cadre francoallemand $^{240}$. Le projet de Dromer est donc rejeté.

Cette tentative de Dromer montre combien le statut de société européenne était important aux yeux des défenseurs de la politique industrielle européenne. Elle constituait un élément fondamental dans la création d'un environnement juridique et fiscal non seulement homogène mais surtout incitant à la concentration des entreprises européennes. La méthode unilatérale défendue par Dromer montre son pragmatisme et son absence d'idéalisme européen : l'efficacité devant être privilégiée, la voie communautaire peut être momentanément contournée si elle s'avère inefficace. Mais le dossier de la société européenne est paralysé par des obstacles techniques et surtout politiques insurmontables, comme le problème de l'accès des tiers au statut de société européenne et des privilèges à leur accorder. Le but est-il de maximiser l'homogénéité du Marché commun et son efficacité économique pour y faciliter l'action des entreprises, quelle que soit leur origine, ou de renforcer les structures industrielles dans un souci d'indépendance communautaire ? Ce dilemme se pose également pour la PRST.

\section{L'approche sectorielle : la PRST.}

La crise de la chaise vide a interrompu brutalement la dynamique en matière de PRST. En 1966 le groupe Maréchal reprend ses travaux et dépose un premier rapport intérimaire en mai ${ }^{241}$. Il propose d'encourager les échanges d'information, de coordonner les productions, voire même de lancer des programmes communs, ce qui pose le problème des délégations de souveraineté. Le second débat porte sur l'échelle de coopération. Le cadre des Six permettrait de renforcer l'unité de la Communauté face aux États-Unis mais il apparaît illogique pour beaucoup de se priver du potentiel britannique en matière de haute technologie, le plus important d'Europe, d'autant que les Six ont

240. AN, 1987.0451, volume 1, compte rendu des réunions interministérielles des 22 et 25 août 1967, notes SGG (RM) des 24 et 25 août 1967 ; AN, 5 AG1, volume 48, note de J.-P. de Longevialle à J.-R. Bernard, 14 décembre 1967.

241. AMAE, RPUE 685, note de Maréchal du 12 mai 1966. 
l'habitude de coopérer avec Londres en la matière (par exemple la France en matière aéronautique). La plupart des responsables français partisans de la création d'une PRST propre aux Six ne sont ainsi pas hostiles à l'extension de certains programmes à des tiers ${ }^{242}$.

Au cours de l'année 1966, les débats progressent peu car les institutions communautaires paraissent paralysées par des rivalités entre les trois exécutifs, notamment entre la Commission européenne et la Commission de l'Euratom ${ }^{243}$. C'est donc des États membres que provient la relance des travaux. Fanfani, le ministre des Affaires étrangères italien propose en septembre 1966 devant le Conseil de l'OTAN que les États-Unis aident les Européens à rattraper leur retard technologique ${ }^{244}$. Le plan italien est très ambitieux. Il propose de créer à partir de l'OTAN une nouvelle institution dotée d'un " organe international exécutif » qui organiserait à la fois des coopérations technologiques à l'échelle atlantique et des transferts de technologie depuis les États-Unis. Fanfani fait d'ailleurs référence à un nouveau « plan Marshall ». Par ailleurs, le discours du Premier ministre britannique Harold Wilson du 14 novembre 1966 sur la Communauté technologique, même s'il est assez vague ${ }^{245}$, renforce l'actualité du débat. Lors du Conseil des 6 et 7 décembre 1966, il est finalement décidé, grâce au volontarisme des Belges et des Italiens, de relancer le débat communautaire sur ce dossier ${ }^{246}$. Des échanges ont lieu dans le cadre du Conseil au début de 1967 mais seuls les Belges et les Italiens sont alors demandeurs ${ }^{247}$. Les Français mais aussi les Allemands soulignent que le cadre de l'OTAN, proposé par Fanfani, est inadapté 248 .

La Commission tente de relancer les travaux en matière de PRST avec le mémorandum du 20 mars 1967 commun aux trois exécutifs communautaires puis le mémorandum Colonna du 4 juillet $1967^{249}$. Ils demandent que le Conseil

242. Par exemple : AFNSP, 4 DE 32, note du $1^{\text {er }}$ décembre 1966 de Dromer pour Dupont-Fauville.

243. Éric Bussière et Arthe Van Laer, «Recherche et technologie ou la « sextuple tutelle» des États sur la Commission, « éternelle mineure » », in Michel Dumoulin (dir.), Histoire de la Commission européenne..., op. cit., p. 509-511.

244. Lorenzo Mechi, Francesco Petrini, « La Comunità europea nella divisione internazionale del lavoro : le politiche industriali, 1967-1978 », in Antonio Varsori (dir.), Alla origini del persente. L'Europa occidentale nell crisi degli anni'70, Franco Angeli, Milan, 2006, p. 255-256.

245. J. John Young, « Technological Cooperation in Wilson's Strategy for EEC Entry » in Oliver Daddow (éd.), Harold Wilson..., op. cit., p. 100.

246. AMINEFI, B 17.701, télex Boegner du 13 juin 1967.

247. Eric Bussière et Arthe Van Laer, « Recherche et technologie... », op. cit., p. 514.

248. AMAE, RPUE 685, note du Conseil du $1^{\text {er }}$ février 1967 sur le COREPER du 23 février 1967.

249. AMAE, RPUE 685, «Mémorandum sur les problèmes que pose le progrès scientifique et technologique dans la Communauté européenne », 20 mars 1967; AHUE, BDT 118/83, volume 807, «Mémorandum sur la politique industrielle de la Communauté », doc. SEC (67) 1201 final, 4 juillet 1967. 
charge le CPEMT d'une étude sur ces trois approches. Justement, le groupe de travail du CPEMT chargé de la PRST, le groupe PREST, termine son rapport à l'été $1967^{250}$. Il préconise des mesures dans trois domaines mentionnés par le mémorandum interexécutif : mesures générales en faveur de la recherche scientifique et technique, coordination des aides nationales par la création de contrats de recherche et de marchés publics communs, confrontation des programmes nationaux. Il détermine six secteurs prioritaires (informatique et télécommunications, transports, métallurgie, océanographie, météorologie, nuisances - pollution sonore, de l'air et de l'eau) mais aucune procédure institutionnelle précise.

Dans le même temps, entre mars et juillet 1967, certains responsables français commencent à se mobiliser. La grande note de Saint-Geours et d'Ortoli à Debré et Pompidou sur l'encouragement aux concentrations européennes et à l'innovation date du 28 avril $1967^{251}$. Elle demande une forte coordination des politiques sectorielles dans les secteurs de pointe, en liaison avec les industriels, sur le modèle de ce qui se pratique en France depuis la relance de la politique industrielle de 1966. Jean Dromer au SGCI demande une attitude plus volontariste en matière de $\mathrm{PRST}^{252}$. Le représentant permanent Jean-Marc Boegner est quant à lui également favorable à une relance de la PRST mais sur une ligne clairement intergouvernementale : un comité scientifique devrait être établi dans le cadre du Conseil pour faire des études de nature sectorielle sur les coopérations possibles ${ }^{253}$. Ensuite, des programmes de coopérations ad hoc, spécifiques à chaque secteur et à échelle variable - pouvant inclure des pays extérieurs aux Six - devraient être établis. Boegner refuse donc le principe d'un financement communautaire et d'une politique commune ou globale qui permettrait de faire disparaître la logique du « juste retour », comme Michel Albert l'avait envisagé.

La déclaration de candidature britannique de mai 1967 et le volontarisme du gouvernement français permettent de relancer les discussions. En juin 1967, le COREPER décide de réserver une session du Conseil d'octobre 1967 à la promulgation d'une déclaration solennelle sur la $\mathrm{PRST}^{254}$. Une résolution assez générale est adoptée par le Conseil du 31 octobre $1967^{255}$. Elle part d'un constat

250. AMAE, RPUE 685, note DGRST, 5 juillet 1967 ; Éric Bussière et Arthe Van Laer, « Recherche et technologie... », op. cit., p. 514-515.

251. AFNSP, 4 DE 12, lettre manuscrite de Jean Saint-Geours pour Michel Debré, 28 avril 1967.

252. AMAE, RPUE 685, télex de Dromer (SGCI) pour Boegner (REP), 22 juillet 1967.

253. Sur la position de Boegner : AMAE, RPUE 685, note PhL (REP) du 27 juin 1967 ; AMINEFI, 1 A 45, compte rendu de la réunion du 5 juillet 1967, note SGCI du 28 juillet 1967.

254. AMAE, RPUE 685, note PhL (REP) du 27 juin 1967 sur le COREPER du 23 juin 1967.

255. AMAE, DECE 735, résolution du Conseil du 31 octobre 1967, doc. R/1548/67 du 6 novembre 1967. 
partagé du retard technologique européen par rapport aux États-Unis. Elle prend en compte la possibilité de « faire participer d'autres États européens » à ces coopérations. Trois types de travaux, correspondant aux trois approches, générale, sectorielle et intergouvernementale, sont envisagés. Tout d'abord, la résolution appelle à continuer les travaux portant sur la création d'un cadre incitatif (société européenne, harmonisation fiscale, brevet européen). Ensuite, le groupe Maréchal devra étudier les possibilités de coopérations sectorielles existant dans les six domaines identifiés par lui et dans d'autres secteurs (des sous-groupes seront d'ailleurs créés rapidement). Enfin, le groupe Maréchal devra poursuivre la confrontation des politiques nationales pour étudier leurs possibilités de coordination. Il devra travailler en étroite coopération avec le COREPER. Boegner est satisfait de cette déclaration qui reste générale mais qui marque l'expression d'une volonté commune ${ }^{256}$. La tutelle du COREPER sur ces travaux est par ailleurs affirmée.

Le second veto français à la candidature britannique, le 27 novembre 1967 , bouleverse ces perspectives de coopération. Les Cinq se réunissent sans la France les 14 et 19 décembre 1967 tandis que le Conseil du 19 décembre 1967 donne lieu à des démonstrations d'aigreur envers Paris ${ }^{257}$. Lors de ce Conseil, les Pays-Bas et l'Italie décident de suspendre leur participation aux travaux du groupe PREST afin de ne pas creuser le décalage entre les Six et le Royaume-Uni dans ce dossier nouveau, qui n'est pas explicitement prévu par le traité de Rome ${ }^{258}$. Les Néerlandais sont les plus virulents. Ils reprennent même partiellement la stratégie française de « chaise vide » en refusant de se faire représenter à certaines réunions d'experts ${ }^{259}$. La Commission envisage alors de tenir ces réunions sans les Néerlandais mais Boegner considère que la France ne peut soutenir cette approche rigoriste de la Commission ${ }^{260}$. En effet, cela équivaudrait à une condamnation a posteriori de la politique française de " chaise vide ». Le groupe Maréchal est donc bloqué. André Maréchal demande à être déchargé de sa présidence. Il est remplacé en janvier 1968 par Pierre Aigrain, un scientifique et haut fonctionnaire ${ }^{261}$.

256. AMAE, DECE 735, télégramme à l'arrivée de la REP du 2 novembre 1967.

257. Piers Ludlow, Negotiating the Gaullist Challenge., op. cit., p. 143-144.

258. AMAE, RPUE 685, note du 25 mars 1968.

259. AMAE, DECE 735, télex de la REP du 6 février 1968.

260. AMAE, DECE 735, télex de la REP du 6 février 1968.

261. AN, 5 AG1, volume 34, note de Bailly du Bois, 29 janvier 1968 : Aigrain est un ancien professeur des universités en sciences, directeur scientifique de la DRME (ministère des Armées, 1961-1965) puis directeur des enseignements supérieurs (ministère de l'Éducation nationale, 1965-1968). 
La crise de mai 1968 donne des arguments à Alain Prate, conseiller économique du général de Gaulle, pour soutenir une relance de la PRST en juillet $1968^{262}$. Partant de cette nécessité absolue d'une gestion saine des finances publiques, il estime impératif une révision drastique des efforts dans le domaine des secteurs de pointe. Pour ne pas condamner le potentiel de la France, une seule solution existe, celle d'une politique commune à l'échelle européenne. Pour éviter de sombrer dans le problème du juste retour : « La seule issue serait qu'un programme cohérent portant sur l'ensemble de la recherche scientifique et des industries de pointe soit établi pour plusieurs années, ce qui permettrait de compenser les avantages et inconvénients que chaque pays y trouve ${ }^{263} \gg$. Prate s'inspire de réflexions antérieures, notamment celles de Michel Albert dans sa note de mai $1967^{264}$. Cela ne signifie pas que la Commission européenne doit recevoir tous les pouvoirs mais que la méthode des coopérations intergouvernementales au coup par coup, prônée par exemple par Jean-Marc Boegner ${ }^{265}$, est inefficace selon lui.

Les milieux économiques se montrent demandeurs d'une reprise des travaux en matière de PRST. L'UNICE publie le 19 juillet 1968 un mémorandum sur les « possibilités d'une politique de la recherche dans la Communauté266 ». Il appelle à une politique véritablement communautaire de la recherche, dépassant le principe du « juste retour ». Il insiste également sur la nécessité d'adapter la politique de la concurrence pour qu'elle tolère les accords portant sur la recherche-développement. Enfin, le mémorandum estime que la solution française du GIE (groupement d'intérêt européen) devrait être développée à l'échelle européenne. Elle permettrait de favoriser une première forme de coopération entre les entreprises européennes en attendant la création du statut de société européenne qui devrait faciliter les concentrations indispensables. Le mémorandum de l'UNICE est donc particulièrement ambitieux et communautaire, en adaptant le schéma de l'Europe organisée par les ententes au contexte du moment.

Devant cet intérêt envers la PRST, des négociations à Six sur une reprise des travaux du groupe PREST sont menées à l'automne 1968. Les Pays-Bas acceptent de reprendre les travaux s'il est admis que les pays candidats

262. AN, 5 AG 1, volume 36, note d'Alain Prate du 5 juillet 1968.

263. AN, 5 AG 1, volume 36, note d'Alain Prate du 5 juillet 1968.

264. AN, 5 AG1, volume 32, note Dromer du 17 mai 1967. Selon la lettre qui l'accompagne, elle a été « dictée » par Michel Albert.

265. AMAE, RPUE 685, note PhL (REP) du 27 juin 1967 ; AMINEFI, B 17.701, télex Boegner du 13 juin 1967.

266. AHUE, BAC 118/1986, volume 1393, folio 193, mémorandum de 1'UNICE, 19 juillet 1968. 
puissent prendre part aux coopérations envisagées, ce que la France accepte ${ }^{267}$. Le nouveau ministre des Affaires étrangères Michel Debré refuse toutefois que la Grande-Bretagne soit admise directement au sein du groupe PREST ${ }^{268}$. Ce compromis permet au Conseil du 10 décembre 1968 de décider la reprise des travaux du groupe PREST après presque une année d'interruption ${ }^{269}$. Le groupe doit dorénavant rendre son rapport au Conseil sur les actions prévues dans les domaines identifiés précédemment pour le 15 mars 1969, un an après la date prévue initialement ${ }^{270}$. Les travaux avancent cependant de manière satisfaisante car le rapport est terminé pour l'échéance fixée ${ }^{271}$. Mais les obstacles politiques restent vifs. Le départ du général de Gaulle du pouvoir un mois plus tard permet de lever certaines hypothèques et d'assister à une véritable relance sous la présidence de Georges Pompidou, avec l'adoption de la résolution COST (coopération européenne dans le domaine des sciences et techniques) en novembre 1969 dans un cadre plus large que celui de la CEE, puis une nouvelle référence à la PRST dans le communiqué final de la conférence de La Haye de décembre $1969^{272}$.

La PRST est un domaine de coopération à la fois consensuel et problématique. Les milieux économiques et la plupart des décideurs publics de l'Europe des Six reconnaissent la nécessité d'améliorer l'efficacité des programmes par une intensification de la coopération à l'échelle européenne et internationale. Cependant les divergences sont nombreuses tant sur l'ampleur des délégations de souveraineté que sur l'échelle de coopération. En dépit de ces difficultés, la thématique de la politique industrielle progresse et tend à réorienter la politique de la concurrence communautaire.

\section{La réorientation du projet ordolibéral : encouragement à la concentration et à la coopération.}

L'accent mis à partir de 1965 sur le renforcement des structures industrielles européennes face à la concurrence internationale ébranle encore un peu plus la doctrine ordolibérale de la DG IV. Le principal soutien de l'Europe ordolibérale, la RFA, évolue d'ailleurs dans ses conceptions. En 1968 un projet de loi amendant la loi sur la concurrence allemande pour favoriser les ententes entre les PME est déposé, tandis que le débat est de plus en plus favorable à

267. Éric Bussière et Arthe Van Laer, « Recherche et technologie... », op. cit., p. 516.

268. AMAE, DECE 735, télégramme de Boegner du 6 novembre 1968.

269. AMAE, RPUE 686, télégramme SGCI pour REP du 8 janvier 1969.

270. AMINEFI, 1 A 45, note d'information sur les travaux du groupe PREST, 27 février 1969.

271. AMAE, RPUE 686, note PhL du 20 mars 1969.

272. Éric Bussière et Arthe Van Laer, "Recherche et technologie... », op. cit., p. 516-518. 
la concentration ${ }^{273}$. En matière de politique de la concurrence communautaire, le gouvernement allemand dépose en avril 1967 un document de travail qui demande à la Commission de porter un intérêt particulier à la question de la concentration $^{274}$.

Face à cette évolution générale et aux difficultés internes de la DG IV dans l'application du règlement 17/62, von der Groeben continue de mettre l'accent sur les règlements d'exemptions par catégories. Plus généralement, il fait évoluer le discours de la Commission vers une rhétorique plus pacifiée, insistant sur sa tolérance envers les accords rationalisateurs ${ }^{275}$. Il est remplacé en 1967 par Emmanuel Sassen, un ancien ministre néerlandais et membre de la Commission de l'Euratom, lié au réseau transnational chrétien-démocrate favorable à l'Europe communautaire $^{276}$. Le nouveau directeur général est Ernst Albrecht, l'ancien chef de cabinet de von der Groeben. La continuité semble donc de mise même si, au début de 1968, l'administration française pense pouvoir faire changer radicalement l'approche de la DG IV. Au SGCI, Dominique Brault, plaide pour une suppression large de la notification préalable afin de rapprocher le système communautaire du système français : la Commission recevrait beaucoup moins de notifications mais pourrait toujours agir, de son plein gré ou sur plainte, contre les accords jugés néfastes, au lieu d'exempter a priori certaines ententes sur des critères généraux. Brault insiste sur l'insertion de la politique de la concurrence dans les exigences de la politique industrielle dans la perspective de la fusion des traité ${ }^{277}$.

Cependant, Albrecht reste sur la logique ancienne de la DG IV, infléchie dans un sens plus pragmatique : la Commission compte publier une communication destinée à clarifier sa doctrine pour les entreprises, puis la compléter par quelques décisions individuelles assurant une jurisprudence ${ }^{278}$. C'est effectivement la voie adoptée par la Commission qui publie le 29 juillet 1968 une communication sur « la coopération entre entreprises ${ }^{279} »$. Elle a pour but de fournir des indications aux entreprises sur l'interprétation de l'article 85. Il est

273. Jean François-Poncet, La politique économique de l'Allemagne occidentale, Sirey, Paris, p. $365-366$.

274. ASGCI, 1979.0791, volume 280, mémorandum allemand sur la politique de la concurrence, 17 avril 1967.

275. ASGCI, 1990.0452, volume 23, note de Dominique Brault pour la DG Prix, 3 mai 1967.

276. Wolfram Kaiser, Christian Democray..., op. cit., p. 199, 202 et 270.

277. ASGCI, 1988.0516, volume 2, note SGCI, Brault, 22 mars 1968.

278. ASGCI, 1990.0646, volume 7, note SGCI à Clément, 17 mai 1968.

279. «Communication relative aux accords, décisions et pratiques concertées concernant la coopération entre entreprises ", in Journal Officiel des Communautés Européennes (JOCE) n ${ }^{\circ} \mathrm{C} 75 \mathrm{du}$ 29 juillet 1968, p. 3 . 
aussi précisé explicitement que cette communication vise à éviter des notifications inutiles. Elle affirme la position de principe favorable de la Commission envers plusieurs types d'ententes : accords entre PME si elles ont une fonction de rationalisation, accords de recherche-développement (sous réserve que des licences soient ensuite concédées), de vente sous certaines conditions (service après-vente), etc. La référence aux accords de recherche-développement est particulièrement importante dans le cadre du développement de la PRST. D'ailleurs, la Commission prend en août 1968 une décision individuelle d'exemption au titre de l'article $85 \$ 3$ d'un accord de coopération technique et de recherchedéveloppement ${ }^{280}$. Enfin dans un discours prononcé le 12 décembre 1968 justement sur la politique industrielle, le nouveau commissaire à la concurrence Emmanuel Sassen affirme sa volonté d'obtenir un règlement d'exemptions pour les accords visés par la communication de juillet $1968^{281}$. Ainsi, la Commission, qui s'est vue refusée par le Conseil le pouvoir de décider seule d'exemptions par catégories, tente de reconquérir cette prérogative de manière indirecte, par une « pseudo-legislative action ${ }^{282}$ » qui s'appuie sur des outils juridiquement non contraignants (communication) et des décisions de jurisprudence.

L'attitude plus modérée de la Commission européenne est également relevée par le patronat européen. Dans le cadre de la coopération franco-allemande institutionnelle, le CNPF et le BDI ont multiplié les réunions d'experts dans le domaine de la politique de la concurrence ${ }^{283}$. Ce travail influence même les décideurs administratifs car il pousse les administrations des deux pays à chercher des points de convergence en la matière sur la base d'un texte commun préparé par les deux organisations patronales ${ }^{284}$. Les experts administratifs des deux pays se mettent finalement d'accord sur une position commune reposant sur l'extension du régime des exemptions par catégories à de nombreux accords, soit une position proche de celle de la Commission européenne ${ }^{285}$. Le patronat continue donc de jouer un rôle d'expert influent auprès des administrations, mais il se montre moins hostile à la politique de la DG IV.

280. Décision A.C.E.C-Berliet, in Journal Officiel des Communautés Europeénnes, $(J O C E) n^{\circ} 201$ du 12 août 1968.

281. AHUE, BDT118/83, volume 808 , discours de M. Sassen, commissaire à la concurrence, le 12 décembre 1968 sur « la politique industrielle dans la Communauté européenne », p. 13.

282. Walter van Gerven, «Twelve years of EEC Competition Law revisited », in Common Market Law Review, 1974-1, p. 42.

283. ASGCI, 1990.0646, volume 6, lettre de D. Brault à P.O. Lapie, 13 juin 1968.

284. ASGCI 1990.0646, volume 12, compte rendu de la réunion du 23 octobre 1968 au CNPF.

285. ASGCI, 1979.0791, volume 207, lettres du SCGI (SGA Zalieski) au ministère de l'économie allemand (Kartte), 28 octobre 1968 et 17 décembre 1968. 
La Commission fait ainsi évoluer son application de la politique de la concurrence. Si elle conserve une doctrine ordolibérale qui conditionne une approche juridique du problème de la concurrence (utilisation des règlements d'exemption), elle accepte d'avoir une attitude plus ouverte envers les problèmes de la concentration et de la coopération, tenant ainsi compte des débats sur la politique industrielle et sur la PRST. La politique industrielle se déploie donc suivant un schéma à la fois ambitieux et pragmatique, mais elle a du mal à se concrétiser. Ces incertitudes contribuent à limiter son impact et à une réorientation des réflexions françaises dans les dernières années du pouvoir gaulliste.

\section{VERS LES ANNÉES 1970 : LIBÉRALISATION ET NORMALISATION}

À la fin des années de Gaulle, les difficultés de la mise en œuvre de la politique industrielle et, plus généralement, la paralysie de la CEE à cause de l'hypothèque britannique conduisent à une remise en cause des bases de la politique européenne de la France. Les spécificités de l'approche gaulliste volontariste tendent à s'émousser. Les conceptions économiques se libéralisent tant chez le patronat français qu'au sein de l'appareil administratif. De même, sur le plan européen, les réflexions les plus volontaristes ne sont pas abandonnées mais la thématique de l' " achèvement » du Marché commun, qui relève du libéralisme régulé, s'impose naturellement. Les désillusions de la politique extérieure gaulliste dans les années 1968-1969 conduisent finalement à une normalisation de la politique européenne de la France.

\section{A. L'ÉVOLUTION DU CNPF VERS UNE POSITION PLUS LIBÉRALE}

La libéralisation des réflexions est visible à la tête du CNPF. En juin 1966, le CNPF élit son second président, Paul Huvelin, un polytechnicien, président de Kléber-Colombes ${ }^{286}$. Huvelin est certes proeuropéen mais cette position était devenue plus courante en $1966^{287}$. Villiers au contraire avait fait preuve d'un véritable militantisme proeuropéen dès l'immédiat après-guerre et notamment en 1956-1958 ${ }^{288}$. Une normalisation de l'attitude face à la CEE se produit donc, même si la doctrine de l'intégration économique reste la même. Elle reste fondée

286. AO, interview de François Ceyrac réalisée par l'auteur le 10 mai 2004.

287. Ibid.

288. AO, interview de François Ceyrac réalisée par l'auteur le 10 mai 2004. AO/Fondation Charles de Gaulle, entretiens de François Ceyrac avec Daniel Desmarquest le 3 décembre 1996. 
sur la défense d'un progrès parallèle de la libération des échanges et de l'harmonisation des politiques économiques, c'est-à-dire, en 1968, la suppression des obstacles non tarifaires aux échanges et les mesures à prendre au titre de la politique industrielle si elles ne sont pas dirigistes (adaptation de la politique de la concurrence, société européenne, etc. ${ }^{289}$.

Huvelin prend la tête du CNPF en compagnie d'une équipe dont émerge la figure d'Ambroise Roux, qui remplace Emmanuel Mayolle à la tête de la commission des relations économiques internationales. Également polytechnicien, Ambroise Roux a dirigé le cabinet de Jean-Marie Louvel, le ministre du Commerce et de l'Industrie (1952-1955) avant de faire carrière à la CGE, dont il devient directeur général en 1966. Roux n'est pas connu pour ses opinions européistes, bien au contraire selon le témoignage de Robert Toulemon ${ }^{290}$. Cette dimension apparaît d'ailleurs lors de l'entretien entre Roux et Debré de mars 1966 à propos du plan calcul où Roux affirme sa volonté de se tourner vers les États-Unis pour des alliances ultérieures ${ }^{291}$. L'arrivée de Huvelin et de Roux manifeste également une autre rupture, l'arrivée des patrons-managers, qui remplacent les patrons-héritiers.

Sur le plan de la doctrine économique, la nouvelle équipe du CNPF est divisée. Huvelin est proche de Marcel Demonque qui avait soutenu l'ouvrage Pour une réforme de l'entreprise que François Bloch-Lainé avait publié en 1963, et où il plaidait pour un renforcement du rôle des syndicats et de l'État dans les entreprises ${ }^{292}$. Villiers lui-même ne lui avait pas réservé un accueil hostile ${ }^{293}$. Huvelin semble proche du groupe patronal qui accorde une grande importance à l'action de l'État dans l'économie, et qui s'était notamment manifesté par une défense de la planification française dans le débat sur la CPEMT ${ }^{294}$.

Au contraire, le groupe libéral qui s'était déjà manifesté lors de la préparation de l'assemblée générale extraordinaire du 14 mai $1958^{295} \mathrm{~s}$ 'affirme de manière plus nette. Il regroupe Henri Fayol, Jean Louis et Pierre de Calan. C'est ce groupe de trois personnes (et d'autres dont Jean-Maxime Lévêque, ancien conseiller économique du général de Gaulle et proche de Pierre de Calan ${ }^{296}$ ) qui est à

289. AN, 5 AG1, volume 34, note d'Alain Prate pour Charles de Gaulle, 10 janvier 1968.

290. AO, interview de Robert Toulemon réalisée par l'auteur le 6 décembre 2005.

291. AFNSP, 4 DE 3, lettre de Debré du 17 mars 1966.

292. François Bloch-Lainé, Pour une réforme de l'entreprise, Paris, Seuil, 1963.

293. Bernard Brizay, Le patronat. Histoire, structure, stratégie du CNPF, Paris, Seuil, 1975, p. 106.

294. Voir le chapitre VI.

295. Voir le chapitre II.

296. ACNFP, 72 AS 1376, note RL pour Mayolle et Roux, $1^{\text {er }}$ février 1965. 
l'origine de l'ouvrage Renaissance des libertés économiques et sociales de 1963 où Pierre de Calan prend le contre-pied du livre de François Bloch-Lainé en affirmant la responsabilité unique du dirigeant dans l'entreprise et l'effacement nécessaire de l'État ${ }^{297}$. Pierre de Calan et Henri Fayol entendent par ailleurs réagir contre la tendance d'une partie du patronat à tolérer une intervention très forte de l'État dans l'économie ${ }^{298}$. Le « groupe Fayol» se montre particulièrement actif dans la promotion d'une rupture idéologique qui met l'accent sur la réhabilitation du profit et de l'entreprise privée ${ }^{299}$.

C'est ce groupe qui est à l'origine de la célèbre « charte libérale » adoptée par l'assemblée générale du CNPF le 19 janvier $1965^{300}$. La charte part du constat de l'accentuation inéluctable de la concurrence internationale. Elle demande en conséquence des réformes radicales de la politique économique de l'État français : suppression de la politique des prix dirigiste, adoption d'une politique des finances publiques saine, etc. L'État est décrit comme prédateur en raison de son poids sur le marché financier ou des privilèges dont bénéficient les entreprises publiques.

Ce texte doctrinaire très offensif provoque des remous au CNPF. Si Ambroise Roux l'approuve, le débat sur la charte provoque la démission du bureau du CNPF de Marcel Demonque ${ }^{301}$. Le groupe Fayol veut même aller plus loin et partir de cette charte libérale pour mener une action de dénonciation systématique et documentée de toutes les interventions néfastes de l'État dans l'économie $^{302}$. Ces réflexions débouchent sur l'édition d'une brochure en 1967 qui critique certains éléments de la planification française, sans remettre en cause son principe ${ }^{303}$. Dans un autre domaine, Pierre de Calan multiplie les discours

297. AO/Comité pour l'histoire économique et financière de la France, interview de Pierre de Calan avec Aude Terray, 1988, retranscrites, tome IV, p. 63 ; Pierre de Calan, Renaissance des libertés économiques et sociales, Paris, Plon 1963.

298. AO/Comité pour l'histoire économique et financière de la France, interview de Pierre de Calan avec Aude Terray, 1988, retranscrites, tome IV, p. 54-55; Henri Fayol, « préface », in Pierre de Calan, Renaissance..., op. cit., p. 7.

299. ACNPF, 72 AS 1202, extrait des décisions du Bureau du 11 mai 1964 ; lettre de René Norguet à Emmanuel Mayolle, 4 juin 1964.

300. ACNPF, 98 AS 157, déclaration adoptée par l'assemblée générale du CNPF le 19 janvier 1965 ; François Denord, Néolibéralisme version française..., op. cit., p. 273-5. 114.

301. Bernard Brizay, Le patronat. Histoire, structure, stratégie du CNPF, Seuil, Paris, 1975, p. 110-

302. ACNPF, 72 AS 1202, extrait de la réunion de la commission de politique économique générale du 17 mai 1965 .

303. AN, 5 AG1, volume 34, note de Prate au général de Gaulle, 10 janvier 1968 ; brochure De la forme et des méthodes d'un plan national dans un système d'économie de marché par Louis Devaux, octobre 1967, citée in Bernard Brizay, Le patronat..., op. cit., p. 159-161 ; «Planification et économie de marché », in Patronat français, ${ }^{\circ}$ 267, décembre 1967, p. 7-10. 
sur les « entraves administratives à la vie des entreprises ». Avec le soutien enthousiaste de $\mathrm{Fayol}^{304}$, il dénonce en particulier la réglementation des prix, celle du marché financier et surtout le soutien implicite d'une partie du patronat, " victime terriblement consentante », à cet interventionnisme excessif ${ }^{305}$. Sur ce plan, la position de Roux est d'ailleurs particulièrement ambiguë car il multiplie les discours libéraux ${ }^{306}$ tout en profitant de la manne publique pour gérer la $\mathrm{CGE}^{307}$.

L'action de ce groupe se perçoit également à l'échelle européenne, au sein du CIFE. Roux y mène depuis octobre 1964 une campagne en faveur de la défense de l'entreprise privée et dénonçant le dirigisme étatique ${ }^{308}$. Il obtient le soutien du CIFE pour lancer des travaux sur ce thème juste avant la proclamation de la «Charte libérale » du CNPF, en janvier $1965^{309}$. Une table ronde d'experts doit se pencher sur la « position dans chaque pays de l'entreprise privée face à la mainmise progressive de l'État sur l'économie ${ }^{310}$. Cependant les débats sont très difficiles ${ }^{311}$. Le document initial est finalement fortement amendé et le CIFE décide de le réserver à un usage interne en décembre $1967^{312}$. En parallèle, Robert Pelletier, l'expert du CNPF pour les questions de prix, tente de relancer les discussions à l'échelle de l'UNICE sur la politique des prix $^{313}$. Le CNPF obtiendrait ainsi une condamnation de la politique des prix française. Cependant, certaines délégations restent réticentes et les travaux s'avèrent décevants du point de vue français ${ }^{314}$.

L'incapacité du patronat européen réuni au sein du CIFE à prendre une position commune sur un tel sujet marque bien les limites de l'action patronale européenne. En septembre 1968, Villiers, lui-même à l'origine du CIFE, pose

304. ACNPF, 72 AS 1355, lettre de Fayol et Pierre de Calan, 5 décembre 1967.

305. ACNPF, 72 AS 1365, exposé lors de l'assemblée générale du 12 décembre 1967 ; AMINEFI, B 55896, note du 10 octobre 1968 de la DG commerce intérieur et prix, service du marché intérieur.

306. Ambroise Roux, «L'économie française face aux dernières échéances du Marché commun », in Patronat français, $n^{\circ} 264$, juillet 1966, p. 16-20.

307. Yves Bouvier, La Compagnie générale d'électricité..., op. cit., p. 524-613.

308. ACNPF, 72 AS 789, compte rendu du conseil général du CIFE du 28 octobre 1964.

309. ACNPG, 72 AS 1412, lettre de René Arnaud, secrétaire général du CIFE, aux fédérations, 14 janvier 1965.

310. ACNPG, 72 AS 1412, lettre de René Arnaud, secrétaire général du CIFE, aux fédérations, 14 janvier 1965.

311. ACNPF, 72 AS 789, compte rendu du conseil général du CIFE du 4 novembre 1966.

312. ACNPF, 72 AS 789, compte rendu du conseil général du CIFE du 6 décembre 1967.

313. ACNPF, 72 AS 1316, aide-mémoire sur la réunion UNICE « politique des prix » du 19 janvier 1967.

314. ACNPF, 72 AS 1316, note de Pelletier pour Maneval, 16 juin 1967 ; aide-mémoire sur la réunion UNICE « politique des prix » du 19 janvier 1967. 
la question du maintien en activité de cet organisme, alors que le cadre de l'UNICE paraît s'imposer ${ }^{315}$. À l'occasion du départ en retraite de René Arnaud, le secrétaire général du CIFE, ce poste est supprimé en $1969^{316}$. Par ailleurs, les milieux économiques privés sont concurrencés par l'émergence du CEEP, le Centre européen des entreprises publiques. Se voulant l'équivalent de l'UNICE pour les entreprises publiques, il développe son activité à partir de $1964^{317}$. Le CEEP a été lancé avec le soutien du président de l'IRI et ancien commissaire italien Guiseppe Petrilli ${ }^{318}$, et celui du gouvernement français qui a incité ses nombreuses entreprises publiques à y participer ${ }^{319}$. Il manifeste donc la force du réseau dirigiste franco-italien, la section allemande ayant d'ailleurs été constituée avec retard en raison des réticences du gouvernement allemand ${ }^{320}$, alors en pleine période de privatisation. En tout cas, l'émergence du CEEP constitue une nouvelle concurrence pour l'UNICE dans la représentation des milieux économiques, en raison du poids très important des entreprises publiques dans l'économie, en particulier en France et en Italie.

Progressivement, entre 1963 et 1967, le CNPF devient de plus en plus libéral et moins spécifiquement européen à la faveur d'un changement de génération et d'une banalisation de la construction européenne, qui est désormais plus consensuelle. La tolérance envers la planification indicative laisse la place à une critique plus vive du dirigisme étatique au sein d'un groupe animé par Fayol, de Calan et Roux. L'accent est mis sur les réformes internes alors que l'action européenne reste toujours très difficile à organiser. Cette évolution du CNPF est contemporaine d'une évolution similaire observable au sein de l'administration française.

\section{B. LES MUTATIONS DE LA POLITIQUE ÉCONOMIQUE FRANÇAISE}

À partir de la fin de 1967, les conceptions économiques des décideurs administratifs français évoluent tant sur le plan macroéconomique que dans le domaine de la politique industrielle. Tout d'abord, la remise en cause de la

315. ACNPF, 72 AS 789, lettre de Georges Villiers aux présidents des fédérations, 16 septembre 1968.

316. ACNFP, 72 AS 789, rapport pour Villiers sur la réforme du CIFE, compte rendu du conseil général du 29 mai 1969.

317. ASGCI, 1988.0577, volume 40, note sur le CEEP, 3 octobre 1964.

318. AHUE, EN 208, lettre d'Émile Noël pour Narjes, 14 juin 1965.

319. ASGCI, 1988.0577, volume 40, note sur le CEEP envoyée à Dromer, SGCI le 17 juillet 1967. Voir aussi : ASGCI, 1988.0577, volume 40, note SGCI (GB) du 29 mars 1965 ; ASGCI, 1988.0577, volume 40, note SG du SGCI (Bernard) du 2 février 1968.

320. ASGCI, 1988.0577, volume 40, note du CEEP sans date : les activités du CEEP en 1967. 
planification par les milieux économiques gagne l'administration. De nombreux services du ministère des Finances demandent sa réforme. La direction du Budget critique un plan trop rigide, idéaliste et qui n'incite pas à une gestion rigoureuse des finances publiques ${ }^{321}$. En janvier 1968 la direction du Trésor partage cette critique et y ajoute l'insuffisante prise en compte de la contrainte extérieure $^{322}$.

Au ministère des Finances, ces préoccupations de modernisation libérale se traduisent par une attention accrue portée à la rationalisation de la décision plus qu'à la planification, entamée dès la création de la direction de la prévision en 1965 par Valéry Giscard d'Estaing ${ }^{323}$. Le projet qui devint ensuite la procédure de « rationalisation des choix budgétaires » (RCB) est lancé au ministère de l'Économie et des Finances en $1965^{324}$. Elle a pour but de comparer le but et l'efficacité économique des moyens dont dispose l'État et est mise en œuvre progressivement à la fin des années soixante. Par ailleurs, le rapport Nora sur l'amélioration de la gestion des entreprises publiques est rendu en $1968^{325}$. Il conseille de les rapprocher des exigences du marché en termes de gestion interne et de prix pratiqués. Les réflexions de Nora, lui-même ancien conseiller de Pierre Mendès France, sont d'ailleurs partagées par un grand nombre de « fonctionnaires modernisateurs ». François Bloch-Lainé dirige en 1967-1968 un groupe de travail qui aboutit à un livre (Pour nationaliser l'Etat, Paris, Seuil, 1968). Abandonnant la thématique de la planification, il se concentre sur des logiques de contractualisation, d'autonomisation et de responsabilisation des agents économiques ${ }^{326}$. La planification globale et systématique cède la place à une volonté de rationalisation gestionnaire et managériale.

Enfin, la politique industrielle s'oriente de manière plus exclusive vers la création de « champions nationaux ». Ainsi, lors d'un comité interministériel de mai 1968 consacré aux moyens de favoriser les fusions internationales, le Premier ministre Georges Pompidou « s'est interrogé sur l'opportunité ou au

321. AN, 540 AP, note du directeur du Budget au directeur de cabinet du ministre des Finances, 18 décembre 1967.

322. AN, 540 AP, note du directeur du Trésor au directeur de cabinet du ministre des Finances, 10 janvier 1968 .

323. Témoignage de Jean Saint-Geours : François Fourquet (éd.), Les comptes de la puissance : histoire de la comptabilité nationale et du Plan, Éd. Recherches, Paris, 1980, p. 309-310, voir aussi p. 292-293.

324. Sur la RCB : Aude Terray, Des francs-tireurs aux experts..., op. cit., p. 439-482.

325. Rapport sur les entreprises publiques, rapporteur : Simon Nora, avril 1967, Paris, La Documentation française, $1968,132 \mathrm{p}$.

326. Florence Descamps, «François Bloch-Lainé et la réforme de l'État : de l'action au magistère moral, 1946-1996 », in Michel Margairaz (dir.), François Bloch-Lainé, fonctionnaire, financier, citoyen, Paris, Comité pour l'histoire économique et financière de la France, 2005, p. 215. 
contraire les inconvénients qu'il pouvait y avoir pour les entreprises françaises, au stade actuel de leur évolution économique, d'instituer un régime favorisant les fusions intracommunautaires. Dans cette affaire, la bonne position n'estelle pas de gagner du temps ${ }^{327}$ ? ». Dans la perspective du Premier ministre, le mouvement de concentration européen ne doit intervenir qu'une fois la concentration terminée à l'échelle française. De même, si Alain Prate multiplie les schémas ambitieux de relance de la politique industrielle communautaire, il adopte une position plus nationale lorsqu'il est confronté aux dossiers concrets. Lorsque Fiat menace de racheter Citroën à l'automne 1968, Prate s'alarme et échafaude divers scenarii permettant de conserver à l'entreprise son caractère français ${ }^{328}$. D’une manière générale les décideurs français cherchent les moyens de s'opposer à cette opération tout en observant les prescriptions du traité de Rome, qui interdit toute discrimination envers une entreprise du Marché commun $^{329}$. L'Europe est confrontée à une relance des politiques industrielles nationales, marquées par exemple par le regroupement par le gouvernement italien de son industrie chimique ${ }^{330}$ ou les fusions suivant des lignes nationales dans l'automobile (Volkswagen-NSU-Audi et Fiat-Lancia en 1969) ${ }^{331}$. Ces orientations annoncent les principales caractéristiques de la politique industrielle du président Pompidou (1969-1974), très ambitieuse sur le plan national ${ }^{332}$ mais exclusivement intergouvernementale sur le plan communautaire ${ }^{333}$.

La politique économique française connaît ainsi une nouvelle inflexion vers 1967-1968. Après avoir accepté difficilement le libre-échange entre 1955 et 1959 , les décideurs français ont adopté le très fort volontarisme gaullien entre 1960 et 1966 en embrassant les thématiques de la planification triomphante, puis de la politique industrielle. La perspective évolue sensiblement vers une doctrine tout aussi volontariste, mais plus libérale et plus rationalisatrice. Ces réorientations pèsent sur la politique économique de la France envers la CEE, qui commence à être redéfinie à la fin de 1968.

327. ASGCI, 1979.0791, volume 273, compte rendu du comité interministériel du 13 mai 1968.

328. AN, 5 AG1, volume 38, note d'Alain Prate du 2 octobre 1968.

329. Sigfrido Ramirez, Public Policies..., op. cit., p. 763.

330. Jean-François Grevet, Au cour de la révolution automobile : l'industrie du poids lourd du plan Pons au regroupement Berliet-Saviem. Marchés, industrie et État en France, 1944-1974, thèse université Lille III, dir. Jean-Pierre Hirsch, 2005, p. 467-468.

331. Sigfrido Ramirez, Public Policies..., op. cit., p. 785.

332. Pascal Griset, « Entre pragmatisme et ambition... », op. cit., p. 283-296.

333. Voir notamment le mémorandum français de 1970 sur la politique industrielle : Robert Toulemon, Jean Flory, Une politique industrielle pour l'Europe, PUF, Paris, 1974, p. 102-4. 


\section{LA POLITIQUE EUROPÉENNE DE LA FRANCE RÉORIENTÉE VERS L'UNION ÉCONOMIQUE}

Les difficultés de la politique industrielle européenne à partir de novembre 1967 puis du couple franco-allemand à partir des crises de mai et novembre 1968 conduisent les décideurs français à réfléchir à une stratégie économique européenne différente.

Le départ des « fonctionnaires modernisateurs » de l'administration en 1968 et 1969 est un signe marquant de cette évolution. Jean Saint-Geours et Jean Dromer rejoignent des banques nationalisées (respectivement le Crédit lyonnais et la BNP), à la faveur d'un grand mouvement de nomination encouragé par Michel Debré pour dynamiser ce secteur ${ }^{334}$. Michel Albert rejoint le groupe L'Express de Jean-Jacques Servan-Schreiber ${ }^{335}$. François-Xavier Ortoli devient ministre de l'Économie et des Finances en 1968. Il souhaite renforcer la politique industrielle française ${ }^{336}$ mais se montre très peu favorable à sa dimension européenne selon le témoignage de Robert Toulemon ${ }^{337}$. Une fois parvenu au pouvoir politique, son volontarisme européen semble s'émousser.

Cette évolution des réseaux de décideurs facilite une réorientation des priorités française de la politique industrielle vers la thématique de l'« union économique ». Ce mouvement commence à l'été 1968 avec la préparation des rencontres franco-allemandes de septembre 1968. Celles de février 1968 avaient donné lieu à de grands espoirs mais la multiplicité des sujets traités, les fréquentes divergences doctrinales et les difficultés françaises issues de mai 1968 ont refroidi les ardeurs. Les fonctionnaires français soulignent la nécessité d'établir des priorités entre les trop nombreux dossiers évoqués ${ }^{338}$. Ils estiment que les dossiers de la politique industrielle doivent céder le pas à ceux de l'union économique, c'est-à-dire de la suppression des entraves techniques aux échanges et de certains éléments d'harmonisation juridique et fiscale. La dégradation de la balance commerciale française depuis quelques années, surtout depuis les événements de mai 1968, contribue à relancer l'intérêt des décideurs français pour la suppression des entraves techniques aux échanges, qui sont perçues

334. Sur Dromer : AFNSP, 4 DE 8, note de Dromer à Debré du $1^{\text {er }}$ mai 1967. Sur Saint-Geours : AFNSP, 4 DE 12, copie d'une lettre manuscrite de Debré à Saint-Geours, 24 décembre 1967.

335. Il devient vice-président du groupe L'Express Union.

336. AN, 5 AG 1, volume 49, note pour Charles de Gaulle sur l'audition d'Ortoli, 7 janvier 1969.

337. AO, entretien de Robert Toulemon avec l'auteur le 6 décembre 2005.

338. ASCGI, 1979.0791, volume 207, note de synthèse du SGCI du 30 août 1968 ; compte rendu manuscrit d'une réunion de hauts fonctionnaires du 5 septembre 1968. 
comme le moyen de lutter contre le protectionnisme déguisé des Allemands, l'une des sources de leur excédent commercial bilatéral ${ }^{339}$. Cette thématique est récurrente chez les décideurs français dans les années soixante ${ }^{340}$. Elle se nourrit d'exemples retentissants, comme par exemple le refus d'homologation de la Dauphine Renault (modèle sorti en 1956) pour des raisons techniques jugées abusives $^{341}$.

L'union économique désigne ainsi plutôt l'achèvement du Marché commun par la création d'un cadre législatif et fiscal harmonisé, sachant que ce mouvement d'unification ne doit toucher que les dispositions les plus discriminantes pour l'exercice d'une libre concurrence effective. Au contraire la politique industrielle ne vise pas simplement à instaurer une concurrence non faussée mais à renforcer les structures industrielles par des actions incitatives. La perspective de l' « union économique » entendue au sens d' « achèvement » du Marché commun est donc plus limitée.

Lorsque Michel Debré, le nouveau ministre des Affaires étrangères, présente son plan de relance de la CEE lors des Conseil des ministres des 4 et 5 novembre 1968, il insiste surtout sur l'union économique ${ }^{342}$. Les trois premiers points mis en valeur sont l'harmonisation des législations douanières, la suppression des entraves techniques aux échanges et celle de «certains » obstacles fiscaux ${ }^{343}$. Les problématiques de la politique industrielle sont reléguées à une partie ultérieure. D'ailleurs, tous les thèmes de coopération cités par Debré (recherche technologique, brevets, société européenne), sauf l'adaptation de la politique de la concurrence, sont immédiatement contestés par les Pays-Bas. Luns estime en effet que ces problèmes « devraient être traités en contacts étroits avec les pays candidats ${ }^{344} \gg$. De facto, en raison de l'hypothèque britannique, les seuls éléments d'une relance à très court terme se trouvent donc dans l'achèvement du Marché commun. La note du SGCI de mars 1969 qui dresse un premier bilan de l'application du "plan français de renforcement des Communautés » insiste d'ailleurs sur les progrès des discussions dans les domaines de

339. AN, 5 AG1, volume 58, note du SGCI de septembre 1968 sur les entraves techniques aux échanges.

340. Laurent Warlouzet, " La dimension industrielle du couple franco-allemand... », op. cit., p. 287-307.

341. Jean-François Eck, « Les politiques industrielles en France et en Allemagne après 1945 : essai de comparaison », in Ivan Kharaba et al. (dir.), Politiques industrielles d'hier et d'aujourd'hui..., op. cit., p. 65.

342. ASGCI, 1990.0638, volume 23, télégramme de la REP, 6 novembre 1968.

343. ASGCI, 1990.0638, volume 23, télégramme de la REP, 6 novembre 1968.

344. ASGCI, 1990.0638, volume 23, télégramme de la REP, 6 novembre 1968. 
l'harmonisation des législations douanières et sur un programme général d'élimination des entraves techniques aux échanges ${ }^{345}$.

Ainsi, en raison des difficultés nationales et communautaires de la période allant du second veto de novembre 1967 à la crise monétaire de novembre 1968, la France réoriente sa politique économique européenne vers le dossier plus pragmatique de l'« union économique », entendu au sens de l'« achèvement » du Marché commun. Les incitations au renforcement de la structure industrielle s'effacent devant l'établissement d'un cadre homogène. Une orientation parallèle tend à se développer au sein de la Commission européenne.

\section{L'ÉVOLUTION DES AMBITIONS DE LA COMMISSION EUROPÉENNE}

Alors que la période transitoire du Marché commun s'achève le $1^{\text {er }}$ juillet 1968, la Commission cherche à relancer la dynamique communautaire avec la thématique consensuelle de l'" achèvement » du Marché commun. En mars 1968, la Commission adopte un programme général d'élimination des entraves techniques aux échanges ${ }^{346}$ qui est immédiatement soutenu par de nombreux commissaires européens ${ }^{347}$. Cette thématique s'impose à partir de ces années 1968-1969 au cœur de l'agenda communautaire jusqu'à sa concrétisation avec l'Acte unique de 1986.

$\mathrm{Au}$-delà du thème consensuel de l'achèvement, Colonna reste toujours très ambitieux en matière de politique industrielle. Le 7 mai 1968, Colonna présente une nouvelle communication à la Commission sur « la politique industrielle de la Communautééc8 $\gg$. Par rapport au mémorandum de juillet 1967, la continuité des thématiques est évidente car la communication de mai 1968 se concentre sur deux mesures, l'incitation aux concentrations et les mesures sectorielles dans les secteurs de pointe et en déclin. Cependant, trois évolutions majeures doivent être soulignées. Tout d'abord, un accent très fort est mis sur la rationalisation tant des actions publiques que des méthodes de gestion des entrepreneurs publics et privés, suivant une démarche déjà observée en France. Ensuite, entre l'incitation à la concentration et les mesures sectorielles, la priorité change. Elle passe du premier au second type de mesures entre le mémorandum de juillet 1967 et la communication de mai 1968. Le discours du 30 avril 1968 souligne que

345. AMAE, DECE 734, note du SGCI du 21 mars 1969.

346. ASGCI, 1977.1467, volume 53, note sur la réunion de la Commission des 5-6 et 8 mars 1968.

347. AHUE, collection de discours, rapport de Colonna di Paliano du 30 avril 1968 ; co-rapport de Colonna di Paliano sur « L'union douanière à parfaire », 24 avril 1969.

348. AHUE, BDT 118/83, volume 807, communication de M. Colonna di Paliano, 7 mai 1968, doc. SEC (68) 1571. 
la concentration n'est pas un remède absolu et que les petites et moyennes entreprises doivent aussi être encouragées ${ }^{349}$. D'ailleurs la communication de Sassen de juillet 1968 tend à encourager les accords entre les petites et les moyennes entreprises ${ }^{350}$. Enfin, le respect des lois du marché est réaffirmé ${ }^{351}$. Les actions devraient être moins directes (création d'organismes communautaires) qu'indirectes : les politiques nationales devraient être largement et profondément coordonnées dans de très nombreux secteurs, et ce depuis la recherchedéveloppement jusqu'aux débouchés publics.

La communication de Colonna délaisse donc les thématiques de l'incitation à la concentration, sans doute en raison des difficultés des travaux comme ceux de la société européenne, qui restent toujours bloqués malgré leur utilité indiscutable. Au contraire les travaux sur la PRST sont plus récents, plus ambitieux et bloqués essentiellement par des préalables politiques plus que par des raisons techniques insurmontables (comme la société européenne avec la cogestion). La levée de l'hypothèque britannique paraissant inéluctable à moyen terme, les travaux dans ce domaine devraient être naturellement débloqués. Lorsque le nouveau directeur général de la DG affaires industrielles, Robert Toulemon, présente à son commissaire le plan d'un document global sur la politique industrielle, il insiste d'ailleurs particulièrement sur ces aspects sectoriels ${ }^{352}$. La définition des possibilités d'actions pour les secteurs d'avenir dépend en partie, "d'une évaluation des dégagements à attendre de l'agriculture et des secteurs en déclin [...], afin de mieux mesurer l'effort que devra accomplir la Communauté en matière de création de nouveaux emplois industriels ${ }^{353} »$. Dans la veine des " fonctionnaires modernisateurs », Toulemon demande une réorientation des priorités budgétaires de l'action communautaire et nationale, de l'agriculture et des secteurs en déclin, vers les secteurs de pointe. Il affirme par ailleurs un européisme militant, qui s'affirme dès les années $1960^{354}$. Il représente, avec Jean Flory, son collaborateur direct en tant que directeur à la politique industrielle au sein de sa DG, la continuité avec les réseaux Marjolin. Toulemon et Flory continuent ainsi à promouvoir la politique industrielle communautaire au début

349. AHUE, collection de discours, rapport de Colonna di Paliano, 30 avril 1968, doc. 7870/ CAB/68/F, p. 22.

350. "Communication relative aux accords, décisions et pratiques concertées concernant la coopération entre entreprises ", in Journal Officiel des Communautés européennes (JOCE) $\mathrm{n}^{\circ} \mathrm{C} 75$ du 29 juillet 1968, p. 3.

351. AHUE, BDT 118/83, volume 807, communication de M. Colonna di Paliano, 7 mai 1968, doc. SEC (68) 1571.

352. AHUE, BDT 118/83, volume 808, note de Toulemon à Colonna di Paliano, 22 novembre 1968.

353. AHUE, BDT 118/83, volume 808, note de Toulemon à Colonna di Paliano, 22 novembre 1968.

354. AHUE, BDT 118/83, volume 808, note de Toulemon du 24 juin 1964. 
des années $1970^{355}$, en tandem avec leurs commissaires italiens successifs, Guido Colonna di Paliano (1967-1970) puis Altiero Spinelli (1970-1976).

Les ambitions de la Commission européenne perdurent donc, tant dans le domaine de la politique industrielle que dans d'autres dossiers (union économique et monétaire, politique régionale, etc.) mais elles se recentrent sur la thématique consensuelle de l' " achèvement ». L'exécutif communautaire se montre donc plus prudent, d'autant plus que le contexte du gaullisme finissant est difficile.

\section{E. LA REMISE EN CAUSE DES BASES \\ DE LA POLITIQUE GAULLISTE (FIN 1967-1969)}

Les bases de la politique extérieure du général de Gaulle sont remises en cause entre la fin 1967 et son départ du pouvoir en avril 1969. Le président français connaît une série de désillusions à toutes les échelles.

Sur le plan politique tout d'abord, la crise de mai et novembre 1968 remettent en cause l'autorité du général de Gaulle sur le plan intérieur et, plus généralement, celui de la France dans les négociations internationales. À l'échelle des Six ensuite, le second veto à la Grande-Bretagne a durablement affecté le crédit français car Londres a posé beaucoup moins de conditions à son entrée et avait réussi à obtenir une attitude assez bienveillante de la Commission européenne, à la différence de la première candidature ${ }^{356}$. Les conséquences du second veto sont donc beaucoup plus destructrices sur la France que le premier car l'élargissement devient un prérequis à tout nouveau progrès dans l'intégration, comme le montrent les blocages des travaux sur la PRST. L'élargissement à la Grande-Bretagne semble de plus en plus inévitable, et de Gaulle lui-même semble être conscient de la nécessité de se rapprocher de Londres comme en témoigne l'affaire Soames ${ }^{357}$.

Enfin, sur le plan mondial, entre la fin de 1967 et la mi-1968, la France connaît une série de désillusions ${ }^{358}$. Sa position en matière de réforme du SMI,

355. Robert Toulemon, Jean Flory, Une politique industrielle pour l'Europe, PUF, Paris, 1974 ; plus généralement, voir : Philippe Mioche, «Construction européenne et politiques industrielles : les possibilités de rencontre », in I. Kharaba et al. (dir.) Politiques industrielles..., op. cit., p. 125-142.

356. Piers Ludlow, «A Short-Term Defeat : The Community Institutions and the Second British Application to join the EEC » in Oliver Daddow (éd.), Harold Wilson..., op. cit., p. 139-142.

357. Voir le chapitre IV.

358. Garret Martin, «Grandeur et dépendances. The dilemmas of Gaullist Foreign Policy, September 1967 to April 1968 », in Piers Ludlow (éd), European integration and the Cold War : OstpolitikWestpolitik, 1965-1973, Routledge, Londres, 2007, p. 36-52. 
qui avait paru s'imposer au sein des Six à la mi-1967, est devenue largement minoritaire à la fin de l'année et au début de 1968. Par ailleurs, la politique menée depuis 1965 de confrontation avec les États-Unis et de rapprochement avec le bloc de l'Est n'a pas provoqué les effets escomptés. De Gaulle n'a pas réussi à dépasser l'opposition idéologique binaire de la guerre froide. Son espoir de voir les pays de l'Est s'émanciper progressivement de la tutelle soviétique est brisé par l'intervention militaire à Prague à l'été $1968^{359}$. Les événements de Prague contribuent d'ailleurs à tendre les relations franco-allemandes, déjà dégradées par l'Ostpolitik de Willy Brandt ${ }^{360}$. Bien plus, la rhétorique antiimpérialiste qui est à la base du succès de la politique gaulliste ${ }^{361}$ connaît des revers à partir du printemps 1968. Les événements de mai 1968 font apparaître de Gaulle comme un conservateur et pas comme un révolutionnaire, tandis que l'arrivée au pouvoir de Nixon aux États-Unis se traduit par un changement de politique au Vietnam et un rapprochement avec la France.

Ces échecs en termes de politique extérieure induisent une volonté de dresser le bilan de la politique gaulliste dès l'arrivée au pouvoir de Georges Pompidou. Les hauts fonctionnaires des Finances et du SGCI pressent le nouvel exécutif de définir rapidement la position française sur des sujets essentiels comme la PRST ou l'union économique et monétaire ${ }^{362}$, signe de l'absence de réflexions en matière d'intégration européenne depuis le plan Debré de novembre 1968. Une réunion se tient en septembre 1969 sous la conduite de Simon Nora, du cabinet du Premier ministre Chaban-Delmas, pour « voir si nous pouvons nous dégager des habitudes de pensée conditionnées depuis des années par le souci de respecter des lignes politiques et diplomatiques très précises, et dégager des objectifs qui correspondent à nos véritables intérêts économiques ${ }^{363} \gg$. Il s'agit donc clairement de réévaluer les dogmes de la politique gaulliste pour les adapter à des objectifs économiques de l'époque, plus qu'à des intérêts censés être permanents.

Les réorientations de la politique européenne autorisées par l'arrivée au pouvoir de Georges Pompidou sont bien connues et se traduisent notamment

359. Georges-Henri Soutou, «The linkage between European Integration and détente. The contrasting approaches of de Gaulle and Pompidou, 1965 to $1974 »$, Piers Ludlow (éd), European integration and the Cold War..., op. cit., p. 19-21.

360. Benedikt Schoenborn, La mésentente apprivoisée..., op. cit., p. 353-354.

361. Maurice Agulhon, De Gaulle. Histoire, symbole, mythe, Plon, Paris, 2000, p. 128-130.

362. ASGCI, B 62161, note de Jean-René Bernard (SGCI) du 26 juin 1969; AMINEFI, B 62168 , note CP, Trésor, 10 juillet 1969 , signée Larre.

363. AMAE, papiers Jean-Pierre Brunet, volume 61, note Sellières (DAEF) du 25 septembre 1969. 
par une acceptation rapide de l'élargissement à la Grande-Bretagne ${ }^{364}$. Elles s'inscrivent dans ce mouvement général visant à tirer les leçons des échecs multiples de la période allant de la fin 1967 à 1969. L'exceptionnalisme de la politique européenne de la France ou le « Gaullist challenge ${ }^{365}$ » touche à sa fin. La politique européenne de la France se normalise, tandis que les réflexions économiques se libéralisent.

\section{CONCLUSION : LES TENTATIVES DE POLITIQUE INDUSTRIELLE}

La politique industrielle communautaire a été développée entre 1965 et 1969 suivant une chronologie heurtée, qui traduit tout à la fois la force de cette nouvelle dynamique et les faiblesses qui l'empêchent de se concrétiser.

Sur le plan chronologique, la politique industrielle communautaire a été lancée une première fois au début de 1965 par le gouvernement français. Grâce au soutien de nombreux acteurs européens, elle a pris un départ rapide mais cette dynamique a été interrompue par la crise de la chaise vide. Après une relance timide en 1966, la politique industrielle a connu son apogée en 1967 avec la relance des travaux sur la société européenne, le mémorandum Colonna de juillet 1967 et enfin la résolution du Conseil sur la PRST en octobre 1967. Là encore, une nouvelle initiative politique française, le second veto à la Grande-Bretagne, condamne ces travaux. Ils sont relancés progressivement en 1968-1969 mais souffrent de la persistance de l'hypothèque britannique.

Cette politique industrielle repose sur quatre éléments : une politique d'environnement visant à achever l'union économique (harmonisation fiscale, suppression des entraves techniques aux échanges), des incitations plus spécifiques à la concentration (société européenne) et à la recherche scientitifque et technique, et enfin des politiques sectorielles dans les secteurs de pointe ou en déclin. Elle tire sa force de l'étendue de ses soutiens et de sa souplesse doctrinale.

364. Voir notamment : Maurice Vaïsse (éd.), Georges Pompidou et l'Europe, Complexe, Paris, 1995 ; Éric Bussière (éd.), Georges Pompidou et la mutation économique de l'Occident, PUF, Paris, 2003 ; Katrin Rücker, Le triangle Paris-Bonn-Londres et le processus d'adhésion britannique au Marché commun, 1969-1973 : quel rôle pour le trilatéral au sein du multilatéral ?, thèse IEP Paris, dir. Wolfgang Krieger et Maurice Vaïsse, 2009.

365. Piers Ludlow, The European Community and the Crises of the 1960s. Negotiating the Gaullist challenge, Routledge, Londres, 2005 ; James Ellison, The United States, Britain and the transatlantic crisis : rising to the Gaullist challenge, 1963-1968, Palgrave Macmillan, Basingstoke, 2007, 263 p. 
Les réseaux d'acteurs à la source de la promotion de la politique industrielle tout d'abord, sont multiples. D'un côté, un groupe de nouveaux « fonctionnaires modernisateurs $\gg$ français soutient une politique industrielle nationale volontariste mais pas dirigiste, orientée vers l'objectif de compétitivité internationale et qui s'insère naturellement dans le cadre de la CEE, mais sans européisme pour la plupart d'entre eux. Contrairement à la génération précédente de "fonctionnaires modernisateurs », la coupure essentielle pour eux n'est pas 1945 mais 1957-1958. Ils paraissent disposer de relais au plus haut niveau de l'État notamment chez le ministre des Finances Michel Debré et le Premier ministre Georges Pompidou. D'un autre côté, un réseau transnational se constitue autour d'un groupe franco-italien présent à la Commission à la DG II, placée sous la tutelle de Marjolin, et à la DG III du très énergique commissaire italien Colonna di Paliano. On retrouve ce réseau franco-italien lors de la création du CEEP ou dans les initiatives de politique industrielle prises après 1969 , preuve d'une certaine unité doctrinale entre les deux côtés des Alpes autour d'un rôle fort de l'État dans la modernisation des structures économiques. Ce réseau franco-italien ne s'étend cependant pas au niveau des gouvernements car Debré y est fondamentalement hostile et cherche en parallèle à mener une offensive contre le protectionnisme fiscal italien. Enfin, le patronat européen soutient cette réorientation de l'Europe économique des préoccupations agricoles et commerciales vers les dossiers des structures industrielles. C'est d'ailleurs le patronat européen qui lance et soutient de nombreux débats communautaires comme le contrôle des IDE (Renault en 1959), la société européenne (UNICE, 1960) ou la concentration (UNICE, 1965).

La deuxième force de la politique industrielle est d'ailleurs sa souplesse doctrinale. Comme le souligne le mémorandum de la Commission de juillet 1967, elle consiste à reprendre sous un vocable unique un grand nombre de travaux en cours ou projetés. Il s'agit en fait de provoquer un choc psychologique chez les acteurs économiques européens, publics et privés, en leur faisant prendre conscience de la nécessité de passer de l'union douanière à l'union économique par le renforcement des structures industrielles européennes. Les promoteurs de la politique industrielle cherchent explicitement à éviter les débats doctrinaux qui ont paralysé l'Europe ordolibérale et l'Europe organisée de Marjolin. Ils mettent en avant le fait que la politique industrielle répond à des problèmes spécifiques nouveaux comme le gap technologique ou la gestion de secteurs en déclin depuis peu. De plus, pour le courant révisionniste français qui se développe avec la chaise vide, la politique industrielle permet de tirer les leçons d'une politique européenne gaulliste qui a abouti à une PAC déséquilibrée. 
Cependant les facteurs de dynamisme de la politique industrielle constituent aussi des sources de faiblesse. Sur le plan des acteurs tout d'abord, la longue maturation de la politique industrielle l'a condamnée à être reléguée au second plan car les contentieux antérieurs restent toujours prioritaires. Ainsi, les bases de la politique européenne de la France des années 1958-1963 (priorité à la $\mathrm{PAC}$, rejet de la Grande-Bretagne, révisionnisme institutionnel) conditionnent toujours l'attitude française même lorsque la thématique de la politique industrielle commence à être considérée comme une priorité. La chaise vide et le second rejet de la Grande-Bretagne condamnent deux initiatives de politique industrielle soutenue par la France.

Par ailleurs, le débat sur les pouvoirs à accorder à la Communauté n'est jamais tranché. En particulier le volontarisme européen mais strictement intergouvernemental de Debré et de certains fonctionnaires modernisateurs (Dromer, Ortoli) s'accommode mal avec les ambitions de la Commission, elles aussi issues de compromis entre des lignes divergentes. La promotion d'initiatives unilatérales de la France (GIE) ou bilatérales traduit bien cette volonté de ne pas s'en tenir exclusivement à la voie communautaire.

Enfin, le problème politique de l'échelle de coopération n'est également jamais résolu car il renvoie à la finalité de la construction européenne. Vise-t-elle à constituer une entité homogène susceptible de manifester son indépendance et sa puissance (Europe volontariste), ou seulement à créer une zone de coopération économique performante (Europe arbitre) ? Les deux principaux ressorts de la construction européenne se retrouvent dans ce débat, l'objectif de lutte contre le déclin de l'Europe se retrouvant dans le premier projet, alors que le second repose avant tout sur l'exigence de paix. Toutes ces inconnues pèsent sur le développement d'une thématique certes assez consensuelle mais qui a du mal à s'incarner dans une politique commune effective. 


\section{CONCLUSION GÉNÉRALE}

L'étude du choix de la CEE par les décideurs français permet de mettre en valeur trois nouveautés saillantes. Tout d'abord, le succès de la CEE n'était pas inévitable. Il s'est construit en particulier grâce au contre-modèle de la zone de libre-échange, qui met en valeur les avantages du Marché commun. Ensuite, le modèle économique de la CEE n'est pas fondé sur l'échange entre des exportations agricoles françaises et des exportations industrielles allemandes, mais au contraire sur un débat constant entre plusieurs projets d'intégration économique, soutenus par plusieurs réseaux d'acteurs nationaux et transnationaux concurrents. Ces oppositions entre des Europe arbitre et des Europe plus volontaristes s'inscrivent dans des schémas de long terme. Enfin, de Gaulle n'est pas un acteur tout-puissant mais un dirigeant contesté, y compris dans son propre camp, aux prises avec un système institutionnel complexe qu'il n'arrive pas à dominer, comme en témoigne le semi-échec de la crise de la chaise vide. D'une manière générale, les décideurs politiques et administratifs parisiens doivent composer avec des acteurs communautaires influents, y compris français comme le commissaire Robert Marjolin, mais aussi avec des milieux économiques dont l'expertise s'avère indispensable sur certains dossiers.

Plus précisément, cette étude permet de mieux comprendre tout à la fois le succès de la dynamique institutionnelle de la CEE, les vives controverses auxquelles ont donné lieu les débats sur son orientation économique, et enfin les failles du processus de décision français.

\section{LE SUCCÈS DE LA DYNAMIQUE INSTITUTIONNELLE DE LA CEE}

Entre les débuts de sa définition en 1955 et son douzième anniversaire au printemps 1969, la CEE s'impose comme l'organisation de coopération européenne de référence. Elle doit ce succès à une dynamique duale, à une logique institutionnelle de nature cumulative et à un processus d'européanisation en profondeur.

\section{A. UNE DYNAMIQUE COMMUNAUTAIRE}

La CEE repose sur deux piliers, intergouvernemental et supranational, qui ne fonctionnent efficacement que lorsqu'une dynamique communautaire les 
anime, c'est-à-dire lorsqu'aucun acteur ne tente d'imposer sa vision à ses partenaires.

Ce double pilier a connu un certain nombre de réussites. D'un côté, la Commission a une capacité d'entraînement véritable, jouant un rôle beaucoup plus important que certaines études ne le reconnaissent ${ }^{1}$. Dans la négociation du règlement 17/62, par exemple, elle a réussi à obtenir beaucoup plus de prérogatives que la plupart des États membres ne semblaient prêts à lui en accorder. D'un autre côté, les États membres ont souvent fait preuve d'un grand volontarisme communautaire, en particulier la France. Les décideurs français ont constamment défendu une libération des échanges perçue comme stimulante si elle est régulée par les institutions communautaires. Cette inclination a parfois conduit les responsables français à être divisés. Ainsi sur la politique de la concurrence, certains fonctionnaires souhaitent utiliser l'intégration comme un levier de réforme, notamment pour accroître la concurrence sur le marché intérieur. En termes de coordination des politiques économiques et monétaires, Marjolin et Debré sont tous les deux volontaristes mais leurs visions institutionnelles sont antithétiques.

Cependant, cette dynamique communautaire a souvent fait défaut. Le nationalisme gaulliste est souvent stigmatisé mais il n'est pas le seul en cause, car la promotion vigoureuse, voire agressive, des intérêts nationaux n'est pas l'apanage de la France ${ }^{2}$. La stratégie de boycott des Néerlandais en 1968 est peut-être l'exemple le plus manifeste de la contradiction entre un discours européiste et une politique européenne d'obstruction. De plus, les États membres ont soutenu l'affirmation du Conseil dans le système institutionnel, en particulier par l'officialisation du COREPER, non prévue dans le traité de Rome. Cela explique finalement le semi-échec du général de Gaulle avec la crise de la chaise vide : il n'obtient dans le compromis de Luxembourg que des engagements non contraignants et consensuels, de nombreux États membres refusant d'abandonner le droit de veto dans des dossiers sensibles même s'ils n'osent pas le dire publiquement.

D'autre part, le défaut de comportement communautaire est aussi le fait de la Commission. Lorsque Hallstein lance son projet en mars 1965, et surtout le maintient sans l'adapter jusqu'au 30 juin 1965, alors qu'aucun État membre ne défend son programme, il discrédite la Commission. Cette dernière n'a d'influence que lorsqu'elle s'insère dans une dynamique communautaire, en

1. A. Moravcsik, The Choice for Europe..., op. cit., p. 7-9.

2. P. Ludlow, Negotiating the Gaullist Challenge..., op. cit., p. 207-208. 
mettant son expertise au service de la définition de projets susceptibles de trouver une majorité au sein des États membres ${ }^{3}$.

Sur le plan chronologique, cette dynamique communautaire s'est affaiblie progressivement en deux étapes à partir de 1962, en raison des coups d'éclats répétés du président de Gaulle, des tensions nées de la définition progressive de la PAC, mais aussi de la meilleure maîtrise par les décideurs nationaux des institutions communautaires. Marjolin parvient cependant à lancer avec un certain succès ses projets de programmation européenne et de coordination des politiques monétaires, tandis que Paris soutient un projet de politique industrielle à la fois précis et novateur. La crise de la chaise vide bloque les deux dynamiques. Par la suite, si la politique industrielle est relancée, elle est irrémédiablement affectée par le second veto de 1967.

À la lumière de ce constat, la CEE à Six peut difficilement être considérée comme une période idéale, celle d'une communauté ambitieuse et irrémédiablement pervertie par l'entrée de la perfide Albion en 1973. Seule la « lune

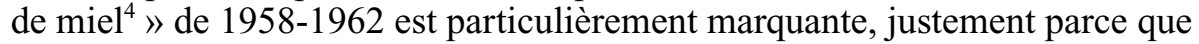
les éléments les plus déstabilisants pour le système communautaire ne se sont pas encore manifestés. Pourtant, en dépit de ces obstacles, la CEE a largement profité d'une logique institutionnelle cumulative.

\section{B. UNE LOGIQUE INSTITUTIONNELLE CUMULATIVE}

Le phénomène de path-dependency ${ }^{5}$ désigne les contraintes de long terme, en général imprévisibles, entraînées par des choix institutionnels sous-estimés à l'origine. Cette logique se manifeste dès 1956 car les choix institutionnels effectués par les décideurs français pendant la négociation du traité de Rome, et validés par de Gaulle en juin 1958, ont eu une influence qui a largement dépassé celle que de nombreux responsables français, majoritairement sceptiques sur l'application de la CEE à cette époque, anticipaient. Les prérogatives de la Commission ont été très largement utilisées dans des voies qui n'avaient pas été prévues, tout au moins du côté français, comme la politique de la concurrence. A contrario d'autres domaines comme la politique des transports ou de l'énergie se sont moins développés que ce qui avait pu être imaginé. Surtout les pouvoirs

3. Piers Ludlow, «A supranational Icarus ? Hallstein, the early Commission and the search for an independant role ", in Antonio Varsori (éd.), Inside the European Community. Actors and Policies in the European Integration 1957-1972, Bruylant, Bruxelles, 2006, p. 53.

4. R. Marjolin, Le Travail d'une vie..., op. cit., p. 304.

5. P. Pierson, « The Path to European Integration... », op. cit., p. 123-163. 
donnés à la CJCE ont permis de créer une véritable communauté juridique avec un droit communautaire supranational propre dès les années 1963-1964. Lors de la crise de la chaise vide, les décideurs français découvrent tardivement leur dépendance juridique et économique vis-à-vis des institutions communautaires. Enfin, même si les prérogatives que la Commission a pu se voir reconnaître en matière de politique de la concurrence par le règlement 17/62 ne lui ont pas beaucoup servi dans les années 1960, elles ont constitué la base indispensable au fort développement de ce domaine de compétence dans les années 1980.

Cependant, cette logique institutionnelle cumulative est également un élément de faiblesse pour le système institutionnel de la CEE. Elle crée des rigidités structurelles, qui rendent les réformes difficiles. Ainsi, une fois que la PAC a été définie sur des bases financières déséquilibrées entre 1962 et 1964, il a été très difficile de revenir dessus par la suite. En matière de politique de la concurrence, les choix institutionnels parfois malheureux de 1962 n'ont pu être réglés que très difficilement par la suite.

Sur le plan politique, enfin, cette logique cumulative repose sur des délégations de souveraineté progressives et discrètes qui ne sont pas validées par les opinions publiques nationales, mais sont au contraire entretenues par une dynamique d'essence technocratique. Elle participe donc de ce qui allait être appelé par la suite le " déficit démocratique », c'est-à-dire le manque de lisibilité du processus institutionnel. Cette logique cumulative renforce la complexité $\mathrm{du}$ jeu des acteurs au sein du système communautaire.

\section{LES ACTEURS DANS LE SYSTÈME COMMUNAUTAIRE : DIVISIONS, RÉSEAUX ET EUROPÉANISATION}

Au sein du système communautaire, aucun acteur institutionnel (État-nation, Commission européenne, etc.) ne parvient à conserver son unité, surtout dans les dossiers économiques. Ils sont divisés en réseaux d'acteurs nationaux et, de plus en plus, transnationaux, qui défendent des visions concurrentes de l'avenir économique, institutionnel et politique de l'Europe. Cette situation s'applique tant à la IV République qu'à la France gaulliste, mais aussi à la Commission européenne. Ses divisions sont largement liées à son mode de désignation : à la différence d'un gouvernement élu sur une liste commune ou autour d'un candidat, et uni par un projet politique, la Commission est une juxtaposition d'individus nommés par leurs gouvernements respectifs. Entre 1958 et 1969 s'affrontent en particulier un réseau allemand ordolibéral et fédéraliste, des réflexions plus néofonctionnalistes et planistes autour de Marjolin, et un groupe franco-italien promoteur de la politique industrielle. 
Ces acteurs se regroupent dans des réseaux, parfois développés à l'initiative de la Commission européenne. Ils constituent des sources d'information pour leurs membres, des vecteurs pour influencer le processus de décision et, enfin, des lieux de socialisation autour de valeurs communes. Se développe alors un processus d' " européanisation » qui désigne la convergence des décideurs et des experts vers des valeurs et des pratiques communes à l'ensemble de l'Europe. Ce phénomène se perçoit concrètement par exemple dans l'activisme de Langer, l'ancien opposant à la programmation devenu un très actif président du CPEMT. Le réseau intellectuel devient progressivement un ensemble de penseurs et de décideurs indispensables à l'application d'une politique publique, un « policy-network ». Cette dimension est présente également au sein du réseau ordolibéral, très largement allemand mais qui convertit à ses valeurs d'autres membres de la DG IV comme le Français Saclé.

Enfin, les patronats européens tentent de s'ériger en réseau transnational. Ils ont cependant du mal à définir une position commune et une tactique efficace, comme le montre leur échec dans la négociation du règlement 17/62. Le patronat est divisé autour de plusieurs modèles d'Europe organisée. Les Français restent très attachés à une structure économique fondée sur des entreprises moyennes et indépendantes, qui s'associent par le biais d'ententes. Au contraire, les Allemands se tournent très tôt vers la thématique des concentrations. Ils parviennent néanmoins à s'unir autour de la défense de quelques thématiques consensuelles comme la dénonciation d'une politique de la concurrence trop théorique ou la mise en valeur de la taille insuffisante des entreprises européennes. Cette émergence du patronat européen comme groupe de pression transnational prépare l'émergence de nouvelles formes de lobbying dans les années 1980, autour de groupes plus limités mais plus cohérents comme 1'European Roundtable of Industrialists (ERT) ${ }^{6}$.

Au sein de l'administration française, l'européanisation est visible car les réflexions sur la politique économique intérieure française prennent de plus en plus en considération le cadre du Marché commun, même si les actions proposées sont strictement nationales. À cet égard, la CEE semble se substituer progressivement au Plan comme horizon de référence. De même, l'européanisation des pratiques est visible lorsque les décideurs français décident de respecter autant que faire se peut l'échéance de l'ouverture du Marché commun au premier juillet 1968 malgré les évènements de Mai 1968. Ils éprouvent des

6. Maria Green Cowles, « Setting the Agenda for a New Europe : The ERT and EC 1992 », in Journal of Common Market Studies, 33, 4, décembre 1995, p. 501-526. 
difficultés à imposer un retour au protectionnisme en raison du démantèlement de tout un pan dirigiste de l'administration.

Cette européanisation est toutefois limitée à la fois par le faible succès des politiques communes dans les années 1960, mais aussi par la persistance d'autres échelles mentales de coopération qui restent très présentes. Ainsi la Grande-Bretagne apparaît souvent comme un partenaire industriel et stratégique naturel. Par ailleurs, l'européanisation n'est pas forcément que le fait des institutions de la CEE. La diffusion d'une culture commune au sein de la communauté des banquiers centraux européens a été permise par l'expérience de l'UEP, même si elle a été sans doute renforcée par la création du comité des gouverneurs par Marjolin. Enfin, les stratégies industrielles restent concentrées sur la création de « champions nationaux », dont le marché intérieur est certes devenu européen mais dont la structure est nationale ${ }^{7}$.

Ainsi, la CEE n'a pas seulement transformé la répartition des pouvoirs mais a également contribué à faire évoluer les mentalités, voire les pratiques. Cependant, cette dynamique se combine avec de très forts débats sur son orientation économique.

\section{LES MODÈLES ÉCONOMIQUES D’EUROPE EN DÉBAT}

L'interprétation économique du traité de Rome a donné lieu à de très vives controverses tout au long des années 1960. Les débats s'orientent autour de l'opposition entre l'Europe arbitre et l'Europe volontariste. Leur étude permet de mettre en valeur des acteurs et des projets très largement sous-estimés. Ces débats n'ont pas empêché la CEE de devenir un choix de modernisation économique consensuel pour la plupart des décideurs français.

\section{A. EUROPE ARBITRE ET EUROPE VOLONTARISTE}

La CEE ne peut se comprendre comme un simple traité de commerce, complété par des clauses agricoles. Au contraire, le traité de Rome développe une véritable ambition d'intégration économique qui s'est développée suivant deux schémas de long terme, l'Europe arbitre et l'Europe volontariste.

L'« Europe arbitre » est fondée sur la régulation forte mais neutre de la libéralisation des échanges. Elle repose sur l'idée que le libre-échange est

7. J.-C. Defraigne, De l'intégration nationale à l'intégration continentale, op. cit., p. 183-216. 
souhaitable, car porteur de croissance économique et vecteur de paix. Cependant, l'ouverture des marchés doit être contrôlée pour s'assurer de la réciprocité des engagements et éviter des déséquilibres trop importants. Les autorités publiques, qu'elles soient européennes ou nationales, doivent conserver une certaine neutralité dans leur action. Elles doivent éviter les interventions discrétionnaires, susceptibles de favoriser de manière excessive un secteur ou une entreprise, y compris pour des raisons politiques, sociales ou d'équilibre régional. Elles doivent s'efforcer d'agir comme un juge impartial, comme un arbitre. Cette conception de l' «Europe arbitre » se rapproche de la vision de la CEE/UE comme d'un « État régulateur ${ }^{8}$ ». Cette conception a été développée pour décrire l'Union européenne des années 1980 et 1990, dont les prérogatives de surveillance des marchés se renforcent considérablement alors que les fonctions anciennes des États keynésiens interventionnistes s'émoussent. Les institutions européennes sont donc envisagées comme des autorités productrices d'instruments de régulations influents, car neutres politiquement.

Cette conception est visible dans le mouvement continu de libération des échanges sous le contrôle de procédures communautaires qui marque les années soixante. Elle est soutenue par les décideurs français, qui cherchent parfois à l'utiliser comme pour l'harmonisation fiscale avec la TVA, ou l'offensive contre les taxes italiennes en 1966-1967. Elle est relancée par l'ouverture du Marché commun au premier janvier 1968 avec le chantier de l' « achèvement », la lutte contre les obstacles non douaniers aux échanges qui ne trouve finalement sa concrétisation qu'avec l'Acte unique de 1986. L'exemple le plus abouti est l'Europe ordolibérale à travers la politique de la concurrence. Par extension, les exigences de coordination stricte des politiques économiques dans une optique de lutte contre l'inflation et des déficits publics rejoignent cette volonté d'encadrer les initiatives du politique par des normes strictes et intangibles. Elles annoncent la politique de la concurrence toute-puissante des années 1990 et le pacte de stabilité et de croissance de 1996.

Au contraire, l' « Europe volontariste » repose sur la notion de choix politique. Les autorités nationales et européennes doivent privilégier certains secteurs ou entreprises (en crise ou au contraire d'avenir), des catégories sociales ou même des régions (notamment celles qui sont défavorisées). L'instrument n'est plus la loi et sa sanction, mais des transferts financiers, sous forme d'aides, de subventions, d'avantages divers. Cette approche est justifiée par la volonté de donner aux autorités publiques un rôle moteur dans la stimulation de

8. Giandomenico Majone, "The Rise of the Regulatory State in Europe ", in West European Politics, vol. 17/3, septembre 1994, p. 77-101. 
l'économie, en particulier dans une perspective de concurrence avec d'autres régions du monde. Alors que l'Europe arbitre repose sur l'idée de paix, celle d'Europe volontariste prend appui sur le refus du déclin.

La construction européenne est alors perçue comme un démultiplicateur de la puissance nationale. Il ne s'agit pas simplement de réguler des conflits potentiels et de s'insérer dans un ordre mondial libéral, mais d'affirmer une identité saillante et discriminante. Cette vision constitue le pendant économique du projet d' « Europe puissance », lui-même largement fondé sur l'« Europe européenne » du général de Gaulle ${ }^{9}$. Dans cette optique, l'Europe devrait constituer un acteur à la fois indépendant et déterminé à promouvoir ses propres intérêts sur la scène internationale.

Cette conception de l' " Europe volontariste » se concrétise avec les projets de coordination des politiques économiques et monétaires développés par Robert Marjolin, puis par les projets de politique industrielle. Si Marjolin veut encourager l'« Europe arbitre » par une libération des échanges régulée et une surveillance des politiques économiques destinées à limiter l'inflation et les déficits, c'est pour la mettre au service de ses ambitions de développement économique et social. La finalité reste l' " Europe volontariste ». Ces ambitions perdurent bien au-delà de 1969, avec de multiples projets de politique industrielle et d'Europe sociale, ou avec le développement de la politique régionale à partir de 1975. L'étude de cette opposition de long terme entre « Europe arbitre » et « Europe volontariste » permet de revaloriser des acteurs longtemps ignorés.

\section{B. REVALORISER DES ACTEURS ET DES PROJETS SOUS-ESTIMÉS}

Alors que les feux de l'histoire restent majoritairement braqués sur Charles de Gaulle et Jean Monnet sur cette période, l'étude des débats économiques permet de mettre en valeur des personnages et des projets sous-estimés mais influents sur le long terme. C'est particulièrement le cas de Robert Marjolin. Il joue un rôle fondamental dans la négociation des clauses économiques du traité de Rome, puis dans son application. Il développe un projet de planification européenne particulièrement ambitieux et surtout très influent politiquement. La planification indicative est en effet à l'apogée de son prestige entre 1960 et 1965 dans le monde, ce que son rapide déclin par la suite a fait oublier.

9. Conférence de presse tenue le 23 juillet 1964 : La vision gaulliste de l'Europe puissance repose cependant sur une inégalité entre la France - pays leader, et ses partenaires. Cette caractéristique ne se retrouve pas forcément dans les autres projets d'Europe volontariste. 
Sur le plan de la méthode historique, il est d'ailleurs important d'étudier les échecs, même s'ils sont largement passés sous silence par les témoins. Ainsi, Marjolin parle très peu de cette ambition planificatrice dans ses mémoires ${ }^{10}$. De même, le diplomate Jean-Pierre Brunet affirme que si « l'idée [de politique industrielle] est excellente [...] il ne faut pas en parler parce que cela a échoué $^{11} \gg$. De fait, l'historiographie est largement muette sur ces thématiques. Or elles ont joué un grand rôle dans les réflexions des décideurs lorsqu'elles ont été négociées. Elles continuent d'influencer la construction européenne sur le long terme. L'échec du règlement 17/62 prépare le succès de la DG IV dans les années 1980, tandis que les projets de coordination des politiques économiques et monétaires de Marjolin sont largement repris par Barre, qui en expurge les éléments les plus planificateurs. Marjolin paraît alors bien plus influent dans ce domaine que les multiples propositions de fonds de réserve soutenues par le comité d'action de Jean Monnet. L'union économique et monétaire a d'ailleurs repris certaines idées développées par les deux commissaires français, notamment l'exigence d'une forte convergence des politiques économiques et l'attention à l'européanisation des procédures et des décideurs.

Si Marjolin fait figure de leader dans la promotion d'une « Europe volontariste » supranationale, Michel Debré est son pendant intergouvernementaliste. Intéressé depuis longtemps par la construction européenne, réformateur infatigable, « hypergaulliste » attaché au rayonnement français, Debré cherche tous les moyens pour utiliser le système communautaire au profit des intérêts français : l'harmonisation fiscale, la politique industrielle, la lutte contre le protectionnisme discret de ses voisins ou la promotion d'une approche commune dans le débat sur la réforme du SMI.

Enfin, le rôle du CNPF peut être lui aussi revalorisé, surtout pour la période 1956-1958. À cette date, le président proeuropéen du CNPF Georges Villiers impulse un mouvement de soutien au projet de marché commun qui compte dans la lente conversion des décideurs français à la CEE. Son opposition à la ZLE pour des raisons économiques, partiellement relayée par d'autres organisations patronales européennes (LECE, Confindustria), montre aux responsables français tout l'intérêt de la CEE. Elle leur donne également des arguments solides pour ralentir la négociation ZLE et obtenir finalement une rupture à l'amiable, qui préserve l'unité des Six. Plus généralement, les débats au CNPF sont révélateurs de l'évolution des idées économiques. Alors que la

10. R. Marjolin, Le Travail d'une vie..., op. cit., p. 342-343.

11. AO/Association Georges Pompidou, entretien d'Armelle Demagny avec Jean-Pierre Brunet, $2^{\mathrm{e}}$ Cassette, face B, 26 avril 2002. Jean-Pierre Brunet a été directeur de la DAEF de 1966 à 1975. 
planification et le corporatisme de la politique de la concurrence française apparaissent comme des modèles au début de la période, ils sont de plus en plus critiqués à partir de la charte libérale de 1965. L'évolution au CNPF anticipe ainsi celle des hauts fonctionnaires, qui remettent en cause de plus en plus directement la planification à partir de 1968.

Enfin, l'étude des dossiers économiques permet de mettre en valeur l'existence de solidarités transnationales indépendantes des relations diplomatiques. Ainsi, un groupe transnational franco-italien s'est naturellement constitué à la Commission pour promouvoir la programmation et la politique industrielle, alors que les deux gouvernements ne constituent quasiment jamais un front commun dans les négociations européennes. Debré souhaite même développer une offensive spécifique anti-italienne. Au contraire, les décideurs français et allemands s'opposent souvent sur le plan économique en raison de l'opposition structurelle existant entre ces deux pays sur ces questions, antagonisme surmonté par la volonté politique des deux gouvernements. Au-delà de ces relations bilatérales, la CEE s'impose de toute façon comme le cadre naturel de la modernisation économique de la France.

\section{LA CEE COMME CHOIX DE MODERNISATION POUR LES DÉCIDEURS FRANÇAIS}

Selon Alan Milward, les États-nations européens se sont refondés après les crises des années trente et de la guerre sur un nouveau consensus qui supposait un élargissement de leurs fonctions, notamment la formation d'un Etatprovidence ${ }^{12}$. La construction européenne a été l'un des éléments qui a permis d'assurer leur renforcement. Sans reprendre toutes les conclusions d'Alan Milward $^{13}$, il est possible d'appliquer cette théorie à la France de l'après 1955. À partir de cette date, la fin de la période de la reconstruction semble proche en Europe, ce qui suppose un retour prochain à une libéralisation des échanges et des paiements à l'échelle mondiale. Or la France a su fonder un nouveau consensus national après 1945, et ce en dépit des divisions nées de Vichy, de la guerre froide ou des drames coloniaux. Il repose sur un rôle central reconnu à l'État dans la régulation des rapports économiques et sociaux. Le retour à une libéralisation internationale des échanges brutale peut menacer ce fragile équilibre. La CEE apparaît bientôt comme la seule possibilité de préserver ce

12. A. Milward, The European Rescue of the Nation-State..., op. cit., p. 3-5.

13. Notamment le postulat que la construction européenne est animée par des déterminants plus économiques que politiques et le rôle négligeable qu'il attribue aux institutions communautaires. 
consensus national en le faisant évoluer. Elle manifeste l'acceptation pleine et entière d'une rupture qui date en fait des années 1945-1948, avec l'insertion dans un monde libre-échangiste du GATT et du FMI, mais qui a été largement occultée par la reconstruction. L'engagement dans la CEE marque l'abandon d'une culture économique teintée de radicalisme, fondée sur un rôle éminent donné aux indépendants (artisans, commerçants, agriculteurs, petits chefs d'entreprises) et le protectionnisme colonial, avec le passage vers un modèle plus influencé par les exemples américain et allemand (modèle du grand marché avec des entreprises importantes, société de salariés, impératif de l'exportation).

Ce processus est progressif. En 1955 et 1956, une majorité de décideurs français est hostile au Marché commun. Les « fonctionnaires modernisateurs » n'arrivent pas à combiner le libre-échange avec leurs réflexions dirigistes. À partir du milieu de 1957, la négociation de la ZLE montre à la France que la CEE est moins une menace qu'une protection contre une libéralisation non régulée. L'alternative est l'isolement diplomatique et la tutelle financière. Cela permet également de comprendre la conversion des gaullistes à la CEE. Ils font cependant clairement la distinction entre le choix économique de la CEE et les formes d'organisation politique de l'Europe et du monde, qui restent à négocier.

Le cadre souple de la CEE permet à tous les projets de modernisation économique de la France de s'y retrouver. Les libéraux non européistes (Goetze, Rueff) sont séduits par l'Europe libérale, voire par l'Europe ordolibérale pour certains. Les planificateurs sont intéressés par les projets de programmation européenne, y compris ceux qui sont hostiles à la libération des échanges (Gruson). Enfin, la nouvelle génération des fonctionnaires modernisateurs, qu'ils soient européistes (Albert, Toulemon) ou pas, plutôt libéraux (Dromer) ou défendant des projets sectoriels interventionnistes (Saint-Geours), s'engage dans la promotion de la politique industrielle. Ces derniers voient la construction européenne comme le cadre naturel dans lequel doivent s'inscrire les profondes réformes structurelles dont la France a besoin. La CEE devient consensuelle auprès de tous ces groupes non pas par idéalisme mais par un choix de raison : c'est le meilleur levier de modernisation pour la France.

Ces différentes lignes se rejoignent autour de certaines idées-forces, qui définissent les permanences françaises face à l'intégration économique européenne. Les décideurs français réclament une libéralisation des échanges compensée par une forte régulation. Elle traduit un manque de confiance dans l'ouverture des marchés lié à des facteurs de court terme (crises financières de 1956-1958 et de 1968), de moyen terme (protectionnisme en vigueur depuis les années trente), voire de long terme (tradition colbertiste). La régulation 
doit s'exprimer à la fois sous la forme de l'Europe-arbitre, par la surveillance des comportements non concurrentiels en particulier chez les voisins, et par l'Europe volontariste autour de projets mobilisateurs qui s'inscrivent dans une tradition de fort interventionnisme public. Enfin, la CEE offre un cadre institutionnel permettant d'améliorer l'efficacité de certaines politiques économiques nationales, et en même temps d'assurer une pression extérieure pour faciliter des réformes intérieures nécessaires.

Cependant, cette doctrine française repose sur des éléments très généraux, plus que sur une véritable stratégie d'influence au sein des institutions communautaires. Dans ce domaine, la complexité et les failles du processus de décision français limitent son influence.

\section{LES FAILLES DU PROCESSUS DE DÉCISION FRANÇAIS}

La sous-estimation de la dynamique institutionnelle de la CEE a marqué la politique officielle de la France pendant toute la période. Elle se caractérise globalement par une absence de ligne politique claire sur l'intégration économique. Cette lacune est issue de la position paradoxale de Charles de Gaulle, qui a entraîné le développement d'une contestation interne croissante de sa politique européenne.

\section{A. L'ABSENCE DE POLITIQUE D'INTÉGRATION ÉCONOMIQUE}

La politique du gouvernement français face à l'intégration économique est très largement réactive. Le rapport Spaak puis la ZLE surprennent les décideurs français, tout comme l'Europe ordolibérale. Même les projets développés par les Français de Bruxelles, comme la coordination des politiques économiques et monétaires, ne font pas l'objet d'une position française officielle claire à leurs débuts. Pendant la négociation du traité de Rome, les représentants français se sont concentrés sur l'obtention de garanties négatives qui ne sont finalement pas utilisées, les décideurs français initiant même une accélération du rythme de libération des échanges au sein du Marché commun. Par la suite, la PAC a été définie sans tenir compte de ses implications en termes de structures économiques ou de ses équilibres financiers à long terme. Certes, en matière de politique industrielle, la France a dégagé en 1965 des priorités claires en mettant l'accent sur deux domaines charnières et relativement consensuels, la société européenne et la PRST. En conséquence, elle a obtenu un certain succès politique. Mais il est trop tard car la logique cumulative de l'intégration 
économique européenne soumet cette dernière à des dossiers non réglés, qui ont ruiné par deux fois (crise de la chaise vide et second rejet britannique) les initiatives en matière de politique industrielle.

Cette carence est liée à l'absence de réflexion aboutie des dirigeants français en matière d'intégration économique européenne, tant chez de Gaulle que chez Mollet ou Pineau. Guy Mollet a joué un rôle déterminant pour imposer le Marché commun à une administration hostile et à un parlement potentiellement frondeur sur ces questions. Cependant, le fait qu'il soit séduit par l'Europe franco-britannique montre qu'il n'a pas compris la spécificité du modèle d'intégration économique européenne porté par la CEE. Ce dernier ne pouvait en effet se combiner avec le projet britannique de ZLE. C'est paradoxalement la même faiblesse qui condamne la réflexion, pourtant très aboutie et documentée, que Pierre Mendès France propose dans son discours de janvier 1957, où il développe une vision cataclysmique d'une France soumise à la dictature du Marché commun. Il se rend d'ailleurs compte de son erreur de jugement et se convertit rapidement à la CEE par la suite.

Sur le plan institutionnel, la centralité du processus de décision à Paris a pu représenter une force, notamment lorsque le pouvoir politique a imposé à l'administration le rapport Spaak ou le plan Rueff, mais a également été une source de faiblesse pour comprendre la nature fondamentalement décentralisée d'un système communautaire complexe. Marjolin en a profité pour développer un vaste réseau transnational centré sur Bruxelles, qui incluait beaucoup de fonctionnaires français. De même, l'action du patronat français paraît très mal coordonnée avec celle de l'administration, en particulier dans le cas de la négociation du règlement 17/62. L'influence française sur l'intégration économique n'est donc pas uniquement parisienne, et ce même sous de Gaulle. Ce dernier apparaît paradoxalement comme l'un des pères de la CEE.

\section{B. De GAulle, PÈRE INVOlOnTAIRE DU SUCCÈS DE LA CEE}

Charles de Gaulle peut être considéré comme un «père » de la CEE (au sens des « pères de l'Europe ${ }^{14}$ ») tout comme Jean Monnet, même si sa paternité est largement involontaire. C'est bien le président du Conseil français qui accepte la CEE de manière irréversible en juin 1958. Il permet son application par la

14. Robert Frank, «Les pères de l'Europe : une difficile typologie », in Paul F. Smets (éd.), Les Pères de l'Europe : cinquante ans après. Perspectives sur l'engagement européen, Bruylant, Bruxelles, 2001, p. 13-26. 
France en imposant un plan Rueff très radical. Il obtient ainsi un rejet de la ZLE non traumatisant pour l'Europe des Six en novembre-décembre 1958. Sans de Gaulle, la ZLE serait vraisemblablement entrée en fonction et aurait très largement diminué l'importance prise par les institutions communautaires. La Grande Europe libérale aurait ainsi pu ravaler la CEE au rang d'organisation technique subalterne, surtout avec l'essor du GATT dans les années soixante. Figure charismatique, doté d'une très forte légitimité en France, il soutient ensuite constamment la défense du libéralisme régulé et d'une Europe volontariste si elle n'est pas supranationale.

Cependant, le général de Gaulle souffrait de faiblesses objectives pour influencer la direction de l'intégration économique européenne. Âgé pendant la majeure partie de la période de plus de 70 ans, militaire de formation et de carrière, accaparé comme président de la République par des dossiers bien plus urgents, de Gaulle ne pouvait pas tout contrôler et n'avait pas le temps de maîtriser tous les complexes dossiers communautaires. Bien plus, il n'a pas compris la dynamique de la CEE, assimilée à un simple « traité de commerce » provisoire. Le fonctionnement communautaire de ses institutions comme leur caractère cumulatif a donc été ignoré. En conformité avec cette vision restrictive de la CEE, les premiers projets économiques globaux (Europe ordolibérale et Europe organisée de Marjolin) n'ont pas fait l'objet chez lui de prise de position claire. Il n'a pas réussi à imposer sa vision institutionnelle comme en témoignent l'échec du plan Fouchet et les conclusions mitigées de la crise de la chaise vide. La Commission est certes moins flamboyante après 1966, mais le système institutionnel communautaire est résilient et de nouvelles initiatives sont lancées. Elles débouchent sur des réalisations dès les années soixante-dix (Europe monétaire, politique régionale, réformes institutionnelles) et sur la relance Delors en 1985-1992.

En 1969, lorsque de Gaulle quitte le pouvoir, la CEE est l'organisation de coopération économique européenne de référence alors même que l'OECE pouvait prétendre jouer ce rôle jusqu'en 1958. Même dans le domaine des discussions diplomatiques et stratégiques, aucune autre institution européenne n'a pu être créée en dépit des nombreux débats lancés par le plan Fouchet. Avec la PAC, de Gaulle a soutenu une dynamique qui a fortement renforcé les prérogatives des institutions supranationales à court terme. En ne s'opposant pas à la politique de la concurrence, il a commis la même erreur sur le plus long terme. De Gaulle est bien un père involontaire du succès de la CEE. Cette ambiguïté pèse lourdement sur les rapports entre les Français et la dynamique communautaire. 


\section{DES ÉLITES PROEUROPÉENNES \\ FACE À UNE VISION GAULLISTE PLUS POPULAIRE}

La politique du général de Gaulle face à la CEE a rapidement fait l'objet d'une forte contestation interne. Tout d'abord l'agressivité de son révisionnisme institutionnel et son style essentiellement déclaratoire apparaissent inefficaces. Le volontarisme politique forcené du leader français a pu fonctionner de manière spectaculaire dans un contexte où c'est surtout l'incarnation et l'affirmation d'une identité nationale forte qui comptent, comme en 19401944 ou en mai 1958. Mais cette tactique ne fonctionne pas dans le cadre de la CEE, qui observe une logique communautaire et des méthodes très juridiques. La diplomatie " déclaratoire » devient non seulement inefficace mais même contre-productive lorsqu'il s' agit de bâtir des coalitions variables en fonction des sujets, et de développer une argumentation technique. Ainsi, la ligne divergente exprimée par le SGCI pendant la crise de la chaise vide montre que ce ne sont pas les objectifs de la France sur le fond qui sont contestés - empêcher toute dérive supranationale - mais la méthode utilisée.

Ensuite, la concentration sur la PAC est considérée comme particulièrement néfaste. Elle mobilise tout le crédit politique de la France sur un secteur à l'importance économique décroissante. De plus, elle aboutit à des résultats contre-productifs, en alourdissant le processus de décision communautaire, en relançant l'inflation et en organisant un transfert financier vers les agriculteurs les plus riches. Enfin, le rejet a priori de la Grande-Bretagne est de moins en moins accepté après le veto de 1967.

Le réseau contestataire se développe au sein de différentes administrations, au SGCI, dans certains services du commissariat au Plan et du ministère des Finances, ou même dans le propre cabinet du général de Gaulle, tandis que la DAEF du Quai d'Orsay reste fidèle à l'orthodoxie gaulliste. Plus généralement se manifeste un mouvement de conversion des élites à la CEE, visible par exemple dans les milieux économiques, par réalisme beaucoup plus que par fédéralisme militant.

Cependant, cette rhétorique gaulliste séduit l'opinion publique française, transportée par ce discours anti-impérialiste qui redonne une fierté à la France après le traumatisme de $1940^{15}$. Elle se manifeste aujourd'hui par les thématiques de l'Europe-puissance et la critique d'une Europe trop technocratique et régulatrice, loin du volontarisme politique et économique gaullien. C'est la conséquence du succès d'une logique libérale et néofonctionnaliste qui vise

15. M. Agulhon, De Gaulle..., op. cit., p. 128-130. 
explicitement à encadrer la marge de manœuvre des populations européennes, coupables de dérives nationalistes meurtrières dans les années 1930. C'est la même dynamique qui a permis le développement de nouvelles doctrines économiques développées à l'époque (économie sociale de marché, keynésianisme) pour encadrer un marché qui paraît incapable de s'autoréguler sans crises graves. Le déficit démocratique constitue donc à la fois la sanction logique d'un succès institutionnel et politique, et la limite de cette dynamique. Les années 1955-1969 sont la matrice de ces débats de fond sur l'orientation politique et économique de l'intégration européenne. 
SOURCES ET BIBLIOGRAPHIE 



\section{SOURCES}

\section{ARCHIVES DE L'EXÉCUTIF FRANÇAIS}

\section{ARCHIVES NATIONALES (PARIS ET FONTAINEBLEAU)}

- IV République : F60, vol. 3082-83 et 3112-14 : négociation du traité de Rome, 1955-57.

- Fonds Charles de Gaulle (5 AG1) : vol. 24, 28, 30 à 38, 48-49, 75, 248 et 249 : conseils restreints et notes des conseillers

- Fonds Georges Pompidou (5AG2) : vol. 1001 à 1005 : Georges Pompidou, Premier ministre.

- Fonds privés déposés aux archives nationales :

- 540 AP, vol. 1 à 18 : Jean Daney de Marcillac.

- 56 AJ, vol. 80 et 84 : papiers de Jean-René Bernard, 1964-67.

\section{ARCHIVES DU SGCI (FONTAINEBLEAU)}

- 1977.1467, vol. 53-54; 1990.0568, vol. 385 ; 1990.0638, vol. 4, 22-26 : CEE.

- 1977.1471, vol. 60-61, 63-64, 67 et 69 : négociation ZLE.

- 1979.0791, vol. 65-68, 73, 79, 279-285 : PEMT.

- 1979.0791, vol. 99-101, 219-220 ; 1988.0577, vol. 37-39 : CEE, politiques économiques.

- 1979.0791, vol. 261-266, 271 et $273 ; 1988.0516$, vol. 1, 2, 4, 6 : politique de la concurrence.

- 1988.0577, vol. 40 et $50 ; 1989.0642$, vol. 2 : politique industrielle.

- 1990.0638, vol. 50-52 et $55 ; 1990.0641$, vol. 13, 16, 18 : institutions CEE.

- 1990.0639, vol. 73 et 78 : Grande-Bretagne, 1967-1970.

- 1991.0004, vol. 1-4 : dossiers Deniau, 1956-1958.

- 2000.0298, vol. 9 : politique commerciale intracommunautaire. 


\section{ARCHIVES DU MINISTÈRE DES AFFAIRES ÉTRANGÈRES (PARIS ET NANTES)}

- Fonds de la représentation permanente (RPUE) déposé à Nantes : communautaires.

- 29-32, 49-50, 118, 121, 123, 189, 197, 245-246 : institutions - 565, 608-609, 613-619, 635, 685-687, 692-696, 1144, 1146 : économie et monnaie.

- 1149-1150 : ZLE.

- Papiers d'agents (Paris) :

- papiers privés Olivier Wormser, vol. 1-2 : correspondance, 1956-1961.

- papiers privés René Massigli, vol. 91 et 94 : correspondance, 1945.

- Cabinet Couve de Murville : dossiers 50, 52, 57, 60, 63-66, 282.

- Coopération économique (DECE), 1955-1960 :

- 613-629, 631-34, 636-37 : CEE.

- 660-662, 671, 673-675, 679-681 : dossiers économiques

- 711-715 et 717 : questions sociales.

- 701, 740-744, 751-757 (sauf 755), 780 et 783-790 : Grande-Bretagne et ZLE.

- Coopération économique (DECE), 1961-1966

- 1109-1117, 1135, 1257-1261, 1265-1269, 1296-1298, 1487 : CEE.

- 1413-1416 : rapports avec la Grande-Bretagne, 1963-1966.

- Coopération économique (DECE), 1967-1975 : vol. 698, 724, 727-732, 735-737, 739, 938.

- Papiers directeurs Olivier Wormser : vol. 2-3, 6-8, 31-46, 77-78.

- Papiers directeurs Jean-Pierre Brunet : vol. 53-55, 57 et 62.

\section{ArChives du Ministère Des FinANCES (SAVIGNY-LE-TEMPLE)}

- 1A 39, 44-46, 76, 89, 103, 229, 410, 422, 437-441, 443, 450 : dossiers des cabinets des ministres

- B 55896-55898, 55908-55912, 57628-32 : DG Prix

- B 12526, 17701, 62164 : politique industrielle, recherche, investissements étrangers.

- B 17676-17690, 17703, 17740, 25343, 61240, 62161 : CEE, 1958-68.

- B 17712, 25341, 62128, 62168 : Comité monétaire, UEM.

- B 17722-723, 17730 : politique de la concurrence. 
- B 17735-36, 62160 : libération des mouvements de capitaux.

- B 17738, 50478, 62124 : réunions des ministres des Finances.

- 3 A 68 et B 44246-44248, 50500, 62175-76, 64423-24 : ZLE, Grande-Bretagne.

- B 52380-81 : Direction de la Prévision (politique industrielle).

- Papiers privés d'André de Lattre.

\section{ARCHIVES DU MINISTÈRE DE L'INDUSTRIE (FONTAINEBLEAU)}

- 1977.1386, vol. 24, 35, 43, 52 et 56 : inspection générale, affaires extérieures.

- 1977.1386, vol. 184, 193, 202, 260, 261 : directions sectorielles, 1955-1967.

- 1991.0817, vol. 1 et 2 : directeur de la DIMEE (Marc Colonna), 1966-1968.

- 1991.0230, vol. 2 : Groupements d'intérêts économiques.

- 1977.1520, vol. 49 ; 1977.1525, vol. 3 ; 1977.1529, vol. 99 : coopération européenne.

\section{ARCHIVES DE LA BANQUE DE FRANCE (PARIS)}

- 1397.1994.04, vol. 95-97 et 99 : DG études, CEE, mouvements de capitaux.

- 1489.2002.05, vol. 46, 222, 224, 226 et 245 : DG services étrangers, comité des gouverneurs, mouvements de capitaux, CEE.

\section{ARCHIVES BRITANNIQUES (NATIONAL ARCHIVES)}

Archives du cabinet (CAB), du Premier ministre (PREM), du Board of Trade (BT), du Foreign Office (FO) et du Treasury (T).

- CAB 130/120 et 130/123 : réunions du cabinet, 1956-1958.

- PREM 11/1352 et 11/2671 : entretiens de 1956 et de 1958.

- BT 205/264 : rapports d'activités du Board of Trade.

- BT 241/1897 : politique industrielle.

- FO 371/122029, 122037, 122039, 122052 : négociations du Marché commun, 1956.

- FO 371/128338, 128360, 128364, 134501, 142440, 142441 : Marché commun, ZLE, 1957.

- FO 371/150289, 182368 ; T 230/373, 312/1890 : CEE. 
- T 234/378 et 379, 337/6, 337/7, 337/8, 337/49 : ZLE, 1958.

- T 236/4822, 237/198 : retour à la convertibilité de la livre, 1958.

\section{ARCHIVES COMMUNAUTAIRES (INSTITUTIONS ET FONDS PRIVÉS)}

\section{ARCHIVES DE LA COMMISSION EUROPÉENNE}

- BAC 25/1980, vol. 294 ; BAC 89/1983, vol. 9 et 11 : rapports avec les organisations patronales.

- BAC 26/1969, vol. 601-3 ; 1/1971, vol. 79-81 ; 28/1980, vol. 18, 38-9 ; $31 / 1984$, vol. $768-69 ; 71 / 1988$, vol. $107 ; 144 / 1992$, vol. 115 et 141 : politique de la concurrence.

- BAC 26/1969, vol. 717-19 ; BAC 3/1978, vol. 990 : politique monétaire.

- BAC 26/1969, vol. 743-57 ; BAC 3/1978, vol. 92 : institutions CEE.

- BAC 3/1978, vol. 1067 ; BAC 62/1980, vol. 136, 144 et 148 ; BAC 27/1985, vol. 1-13 ; BAC 144/1992, vol. 108 et 118 : PEMT.

- BAC 61/1982, vol. 1-12 : négociation ZLE (1957-1959).

- BAC 62/1980, vol. 2-4, 7, 9 et 140 ; BDT 118/83, vol. 807 et 815 ; BAC 118/1986, vol. 1393 ; BAC 144/1992, vol. 682 ; CEAB 1, vol. 1260 ; CEAB 2, vol. 3697 : politique industrielle.

- Procès-verbaux de la Commission : 1958-1969.

- Discours des commissaires Colonna di Paliano, Hallstein et Marjolin.

\section{ARCHIVES DU CONSEILS ET PAPIERS PRIVÉS}

- Archives du Conseil : dossier CM2 1964, vol. 434-438 : réunions du Conseil de 1964.

- Archives de la Commission/Papiers Hallstein :

- vol. 1114, 1169, 1211-1213, 1220 : RFA.

- vol. 1119 : cabinet.

- vol. 1186-1187 : crise de la chaise vide.

- vol. 1229 et 1775 : France.

- vol. 1245-1248 : relations avec les DG II et III

- Fonds Émile Noël (EN)

- vol. 8, 343, 377, 1588 : crise de 1965. 
- vol. 21, 304-305, 313-314 et 2390 : fusion des exécutifs.

- vol. 185-186, 1260 : correspondance.

- vol. 206-210, 238-245, 249, 651, 2383-1284 : relations avec les cabinets des commissaires.

- vol. 349, 379 et 1180 : traité de Rome, 1957-1958.

- vol. 350-351, 380, 1863 : relations avec les États.

- vol. 721-722, 732-733, 777-781 : réunions de la Commission.

- vol. 1269-1271, 1276, 2381, 2409 : relations au sein de la Commission.

- Fonds Pierre Uri : vol. 54-56; 80-84, 92 et 112.

- Fonds Max Kohnstamm : vol. 20 et 26.

- Négociations du traité de Rome (CM3) : vol. 236, 238, 393-394.

\section{ARCHIVES DÉPOSÉES À LA FONDATION JEAN MONNET (LAUSANNE)}

- Fonds Jean Monnet :

- AMK C 14/3, 14/9, 16/4, 33/1, 33/2, 33/4 : correspondance.

- AMK 13/5 : comité d'action.

- AMK 50/1, 50/4, 50/8 : industrie et ententes.

- AMK 62/1, 62/2 : politique monétaire.

- Fonds Robert Marjolin : Rome.

- ARM 13/1,13/5, 15/1,15/4 à 15/5, 18/1 à 18/5 : négociation du traité de

- ARM 19/2, 20/1,21/1, 21/2, 21/3, 21/4 : CEE.

- ARM 23/2, 23/3, 24/2, 32/1 : politique économique et monétaire.

- ARM 25/1, 25/2 : entretiens.

\section{ARCHIVES PATRONALES}

\section{ARCHIVES DU CNPF (ROUBAIX)}

- 72 AS 132, 821 : organisations professionnelles.

- 72 AS 350, 1315-1316, 1355, 1364, 1505, 1590 : la France et le Marché commun.

- 72 AS 450, 1358, 1365, 1379, 1381-1382 : politique de la concurrence. 
- 72 AS 1388, 1389, 1460, 1503-1504, 1544 : concurrence, CNPF et UNICE (19581965).

- 72 AS 789, 801, 803,809, 812, 817 : réunions CIFE et conférences internationales.

- 72 AS 1412 : programmation européenne, 1962-1965.

- 72 AS 846-848, 1201-1202 et 1204 : assemblées générales, 1956-1958.

- 78AS 6-8 : archives FIMTM, Comité des industries exposées (rapport Clappier), 1964-1967.

- 83AS 1, 13, 15 : archives du centre de recherche du CNPF (CRC), 1964-1965.

- 98AS 67 : CNPF (deuxième versement), divers 1961-1969.

- 98AS 157 : bureau et comité directeur de 1953 à 1969 (CNPF).

FONDS DE LA LECE (LOUVAIN-LA-NEUVE)

- Vol. 653-655 : ZLE.

- Vol. 657 et 668 : politique de la concurrence CEE.

- Vol. 669-670 : divers CEE, 1965-1966.

\section{ARCHIVES PRIVÉES FRANÇAISES}

\section{ARCHIVES DE LA FNSP (PARIS)}

- Fonds Maurice Couve de Murville : CM7 à CM9 (correspondance).

- Fonds Michel Debré, Premier ministre (2 DE) :

- 2 DE 12-13 : notes au cabinet.

- 2 DE 14, 29-30 : correspondance.

- 2 DE 36-37 : économie.

- 2 DE 69-70 : affaires étrangères.

- Fonds Michel Debré, ministre des Finances (4 DE) :

- 4 DE 3 à $8,10,12$ : : correspondance.

- $4 \mathrm{DE} 31$ à 33 : politique économique.

- 4 DE 39 à 42 : entreprises (intéressement, faillites, fusions, GIE).

- 4 DE 65 : déplacements. 


\section{ARCHIVES DE PAUl RAMADIER (RoDEZ)}

- $52 \mathrm{~J} 47$ : activité politique 1958.

- 52 J 92, 97, 161 : politique économique, 1955-1957.

- 52 J 114-116 : Marché commun.

\section{ARCHIVES ORALES}

\section{ENTRETIENS DU PROGRAMME D'HISTOIRE DE LA COMMISSION}

Transcription disponible sur Internet (site des archives historiques de l'UE à Florence)

- ALBERT Michel, entretien le 18 décembre 2003 avec Éric Bussière, Ghjiussepu Lavezzi et Émilie Willaert.

- AlBRECHT Ernst, entretien le 4 mars 2004 avec Jan Van der Harst et Veronika Heyde.

- BARRE Raymond, 20 février 2004, entretien avec Marie-Thérèse Bitsch, Éric Bussière et Ghjiseppu Lavezzi.

- DENIAU Jean-François, 3 et 10 novembre 2004, entretiens avec Gérard Bossuat et Anaïs Legendre.

- FLORY Jean, 3 décembre 2003, entretien avec Éric Bussière, Marie-Thérèse Bitsch et Anaïs Legendre.

- RABIER Jacques-René, 8 janvier 2004, entretien avec Yves Conrad, Julie Cailleau

- TOULEMON Robert, 17 décembre 2003, entretien avec Gérard Bossuat, Éric Bussière et Anaïs Legendre.

- SACLÉ Armand, 28 janvier 2004, entretien avec Éric Bussière, Véronika Heyde et Laurent Warlouzet.

- Von DeR GROEBen Hans, 16 décembre 2003, entretien avec Wilfried Loth et Véronika Heyde

ENTRETIENS DÉPOSÉS AU COMITÉ POUR L'HISTOIRE ÉCONOMIQUE ET FINANCIÈRE DE LA FRANCE (IGPDE)

- Les voix des Finances. De hauts fonctionnaires racontent la vie économique de la France, 1945-1969, recueil de témoignages, CD-Rom et livret, 2006 : notamment les entretiens réalisés par le Comité pour l'histoire économique et financière de la France avec Claude Pierre-Brossolette, Philippe Huet, Alain Prate et Roger Goetze. 
- BERNARD Jean-René, 13 octobre et 6 novembre 1997, entretiens avec Anne de Castelnau.

- De Calan Pierre, 1988, entretiens avec Aude Terray, retranscrits.

- ClAPPIER Bernard, 1990, entretiens avec Fabrice Demarigny.

- SACLÉ Armand, 14 et 21 avril, 12, 19 et 26 mai 1992, entretiens avec Laurence Badel.

\section{ENTRETIENS RÉALISÉS PAR L'ASSOCIATION GEORGES POMPIDOU}

- BRUNet Jean-Pierre, 12 et 26 avril, 17 mai 2002, entretiens avec Armelle Demagny.

- CEYRAC François, 8, 21, 28 février 1994, entretiens avec Jean-Pierre Williot.

\section{ENTRETIENS DÉPOSÉS À LA FondATION CHARLES DE GAULLE}

- CeYrac François, 1996, entretien avec Daniel Desmarquest le 3 décembre 1996.

- ORTOLI François-Xavier, 1994, entretien avec Daniel Desmarquest.

\section{ENTRETIENS DÉPOSÉS AU MINISTÈRE DES AFFAIRES ÉTRANGÈRES}

- BRUNET Jean-Pierre, 1991, entretiens avec Catherine Oudin et Maurice Vaïsse.

- VALÉRY François, 1990, entretiens avec Catherine Oudin et Maurice Vaïsse.

\section{ENTRETIENS RÉALISÉS PAR L'AUTEUR}

- Administration française et communautaire : Armand Saclé le 28 janvier 2004 (dans le cadre du programme d'histoire de la Commission), Robert Toulemon le 6 décembre 2005, Michel Albert le 16 décembre 2009.

- CNPF : François Ceyrac le 10 mai 2004, Robert Pelletier le 4 avril 2005.

\section{SOURCES IMPRIMÉES}

\section{PÉRIODIQUES ET PUBLICATIONS OFFICIELLES}

- Le Monde : divers numéros consultés de 1955 à 1969.

- Bulletin du CNPF (à partir de 1957, devient CNPF en 1957, puis Patronat français en 1960). 
- Bulletin de la Communauté économique européenne (devient le Bulletin des Communautés européennes en 1967), 1958-1969.

- Rapport général sur l'activité de la Communauté économique européenne (devient le Rapport général sur l'activité des Communautés européennes en 1967), Luxembourg, Office de publications des communautés européennes, 1959-1969.

- Le mouvement économique en France, 1949-1979. Séries longues macroéconomiques, INSEE, Paris, 1981.

\section{PUBLICATIONS DE DOCUMENTS ORIGINAUX}

- Site ina.fr et ena.lu.

- Akten zur Auswärtigen Politik der Bundesrepublik Deutschland. Munich, Oldenbourg : consultés pour les années 1965 (éd. 1996), 1967 (éd. 1998) et 1968 (éd. 1999).

- Documents diplomatiques français, Imprimerie nationale \& Peter Lang, Paris \& Bruxelles, 1987-2006 : consultés pour les années 1955-1966.

- BRUNETEAU Bernard, Histoire de l'idée européenne au premier vingtième siècle à travers les textes, Colin, Paris, 2006.

- BussiÈRE Éric, DuMOULIN Michel (textes réunis par), Les cercles économiques et l'Europe au XX' siècle, Peter Lang, Bruxelles, 1992.

- De GaUlLe Charles, Lettres, notes et carnets, Plon, Paris, 1985-1987.

- Hoeren Thomas, Schulze Reiner (éd.), Dokumente zum Europaïschen Recht, Band 3 : Kartellrecht (bis 1957), Springer, Berlin, 2000.

- MEndÈs France Pierre, CEuvres complètes, tome IV, Pour une République moderne, 1955-1962, Gallimard, Paris, 1987.

- RuefF Jacques, Euvres complètes. Politique économique, tome III, Plon, Paris, 1980 .

\section{ARTICLES ET OUVRAGES D’ÉPOQUE SUR LE MARCHÉ COMMUN}

- Deniau Jean-François, Le Marché commun, Paris, PUF, 1958.

- HALLSTEIN Walter, «Wirtschaftliche Integration als Faktor politischer Einigung », in MEYER Fritz, GREISS Franz (éd.), Wirtschaft, Gesellschaft und Kultur : Festgabe für Alfred Müller-Armack, Duncken \& Humblot, Berlin, 1961, p. 267-278.

- DE LATTRE André, La politique économique française de 1945 à 1970, Les cours de droit, Paris, 1972.

- MARJOLIN Robert, "Coopération intergouvernementale et autorités supranationales », in Revue économique, 1958, vol 9, n² 2, p. 267-277.

- Marchal André, L'Europe solidaire, tome I, Cujas, Paris, 1964. 
- Meynaud Jean, Le Marché commun : essai de présentation générale, Centre d'études économiques de l'EPHE, Paris, 1957.

- NÊME Jacques et Colette, Économie européenne, PUF, Paris, 1970.

- PERrouX François, L’Europe sans rivages, PUF, Paris, 1954.

- RUEFF Jacques, «Introduction : une mutation dans les structures politiques : le marché institutionnel des Communautés européennes », in Revue d'économie politique, $1958, n^{\circ} 1$, p. 1-11.

- Servan-SchreIBer Jean-Jacques, Le Défi américain, Denoël, Paris, 1967.

- StOLERU Lionel, L'impératif industriel, Seuil, Paris, 1969.

- TRIFFIN Robert, Europe and the Money Muddle, Oxford UP, Londres, 1962.

- VEDEL Georges, «Mythes de l'Europe et Europe des mythes », in Revue du Marché commun, $\mathrm{n}^{\circ} 39$, septembre 1961, p. 305-307. 


\section{BIBLIOGRAPHIE}

La bibliographie contient les livres les plus utilisés pour ce travail à l'exclusion des manuels portant sur l'histoire de France, l'histoire de l'intégration européenne, l'histoire des relations internationales et l'histoire économique. Elle est volontairement sélective. Toutes les références figurant dans les notes de bas de page ne sont pas reprises. De même, certains articles et ouvrages historiques lus mais $n$ 'apportant pas de contribution à notre étude n'ont pas été signalés. Une bibliographie plus détaillée figure dans la thèse originale.

\section{MÉMOIRES ET BIOGRAPHIES}

\section{MÉMOIRES}

- CARRÉ DE MALBERG Nathalie (textes établis, présentés et annotés par), Entretiens avec Roger Goetze, haut fonctionnaire des finances. Rivoli-Alger-Rivoli, 1937-1958, Comité pour l'histoire économique et financière de la France, Paris, 1997.

- DeBRÉ Michel, Trois républiques pour une France, Albin Michel, Paris, 19841988.

- Delors Jacques, Mémoires, Plon, Paris, 2004.

- Deniau Jean-François, Mémoires de 7 vies, tome II, Croire et oser, Plon, Paris, 1997.

- Froment-Meurice Henri, Vu du Quai. Mémoires 1945-1983, Fayard, Paris, 1998.

- HALlSTEIN Walter, L’Europe inachevée, Robert Laffont, Paris, 1970.

- De Gaulle Charles, Mémoires d'espoir. Le renouveau, 1958-1962, Plon, Paris, 1970.

- De Gaulle Charles, Mémoires d'espoir. L'effort, 1962-..., Plon, Paris, 1970.

- De LATTRE André, Servir aux Finances, Comité pour l'histoire économique et financière de la France, Paris, 1999.

- FRANCK Louis, 697 Ministres. Souvenir d'un directeur général des prix, 1947-1962, Comité pour l'histoire économique et financière de la France, Paris, 1989.

- LEMAIGNEN Robert, L'Europe au berceau. Souvenirs d'un technocrate, Plon, Paris, 1964. 
- LÉVÊQUE Jean-Maxime, En première ligne, Albin Michel, Paris, 1986.

- MARJOLIN Robert, Le travail d'une vie. Mémoires 1911-1986, Robert Laffont, Paris, 1986.

- Massigli René, Une comédie des erreurs, 1943-1956, Plon, Paris, 1978.

- Monnet Jean, Mémoires, Fayard poche, Paris, 1976.

- MÜLLER-ARMACK Alfred, Auf dem Weg nach Europa. Erinnerungen und Ausblicke, C.E. Poeschel, Stuttgart, 1971.

- PISANI Edgar, Le général indivis, Albin Michel, Paris, 1974.

- RUEFF Jacques, Combats pour l'ordre financier. Mémoires et documents pour servir à l'histoire du dernier demi-siècle, Plon, Paris, 1972.

- URI Pierre, Penser pour l'action. Un fondateur de l'Europe, Odile Jacob, Paris, 1991.

- VILLIERs Georges, Témoignages, éditions France-empire, Paris, 1978.

- Von Der Groeben Hans, Combat pour l'Europe. La construction de la Communauté européenne de 1958 à 1966, Office de publication des Communautés européennes, Luxembourg, 1985.

- VON DER GROEBEN Hans, Europäische Integration aus historischer Erfahrung. Ein Zeitzeugengespräch mit Michael Gehler, Discussion Paper C108, Zentrum für Europäischen Integrationsforschung, Bonn, 2002.

- WERNER Pierre, Itinéraires luxembourgeois et européens, 2 tomes, éditions SaintPaul, Luxembourg, 1991.

\section{BIOGRAPHIES ET OUVRAGES COLLECTIFS CONSACRÉS À UN PERSONNAGE}

- Association Georges Pompidou (éd.), Georges Pompidou, un politique, PUF, Paris, 2001.

- Amouroux Henri, Monsieur Barre, Robert Laffont, Paris, 1986.

- Berstein Serge (dir.), Paul Ramadier, la République et le socialisme, Complexe, Bruxelles, 1990.

- Bossuat Gérard, « Christian Pineau face aux crises internationales (1956-1958)», in Aglan Alya, Lefebvre Denis (dir.), Christian Pineau, de Buchenwald aux traités de Rome, Bruno Leprince, Paris, 2004, p. 71-114.

- DUCHÊNE François, Jean Monnet, The first statesman of interdependence, Norton, New-York, 1994.

- Dumoulin Michel, Spaak, Racine, Bruxelles, 1999.

- EsAmBert Bernard, Pompidou capitaine d'industries, Odile Jacob, Paris, 1994. 
- FeIERTAG Olivier, Wilfrid Baumgartner. Un grand commis des finances à la croisée des pouvoirs (1902-1978), Comité pour l'histoire économique et financière de la France, Paris, 2006.

- Ferrant Catherine, Sloover Jean (éd.), Robert Triffin. Conseiller des princes, témoignages et documents, Ciaco, Bruxelles, 1990.

- Guillaume Sylvie, Antoine Pinay ou la confiance en politique, FNSP, Paris, 1984.

- Jouve Edmond, Le général de Gaulle et la construction de l'Europe, 1940-1966, 2 volumes, LGDJ, Paris, 1966.

- Kocher-Marboeuf Éric, Le patricien et le général : Jean-Marcel Jeanneney et Charles de Gaulle, 1958-1969, 2 volumes, Comité pour l'histoire économique et financière de la France, Paris, 2003.

- Lacouture Jean, De Gaulle. Tome III : Le souverain (1959-1970), Seuil, Paris, 1986.

- Margairaz Michel, « Christian Pineau et son expérience des Finances et de l'économie : un modernisateur réformateur et réformiste (1934-1950) », in AGLAN Alya, Lefebvre Denis (dir.), Christian Pineau : de Buchenwald aux traités de Rome, Bruno Leprince, Paris, 2004, p. 53-70.

- MÉnager Bernard, Ratte Philippe, ThiÉBault Jean-Louis, Vandenbussche Robert, WaLlon-LedUCQ Christian-Marie (éd.), Guy Mollet. Un camarade en République, PUL, Lille, 1987.

- Michel Debré, un réformateur aux Finances, 1966-1968, Comité pour l'histoire économique et financière de la France, Paris, 2005.

- Margairaz Michel (dir.), Pierre Mendès France et l'économie. Pensée et action, Odile Jacob, Paris, 1989.

- MARgairaz Michel (dir.), François Bloch-Lainé, fonctionnaire, financier, citoyen, Comité pour l'histoire économique et financière de la France, Paris, 2005.

- Peyrefitte Alain, C'était de Gaulle, 3 tomes, Fayard, Paris, 1994-2001.

- RIONDEL Bruno, Maurice Faure, un artisan de la construction européenne, thèse dir. Robert Frank, Paris I, 1997.

- Roussel Éric, De Gaulle, NRF Gallimard, Paris, 2002.

- Roussel Éric, Georges Pompidou, Tempus, Paris, 2004.

- Roussel Éric, Jean Monnet, Fayard, Paris, 1996.

- UlRICH-PIER Raphaële, René Massigli (1888-1988). Une vie de diplomate, Peter Lang, Bruxelles, 2006. 


\section{LA FRANCE ET L'INTÉGRATION EUROPÉENNE}

\section{LA FRANCE DANS LES RELATIONS INTERNATIONALES}

- Agulhon Maurice, De Gaulle. Histoire, symbole, mythe, Plon, Paris, 2000.

- Bozo Frédéric, Deux stratégies pour l'Europe : De Gaulle, les États-Unis et l'Alliance atlantique, 1958-1969, Plon, Paris, 1996.

- FRANK Robert, La hantise du déclin. La France 1920-1960 : finances, défense et identité nationale, Belin, Paris, 1994.

- GIAUQUE Jeffrey Glen, Grand designs and visions of unity : the Atlantic powers and the reorganization of Western Europe, 1955-1963, University of North Carolina Press, Londres, 2002.

- MARTIN Garret, « Grandeur et Dépendances : The dilemmas of Gaullist Foreign Policy, September 1967-April $1968 »$, in LuDLOW Piers (éd.), Ostpolitik-Westpolitik : European Integration and the Cold War in Europe, 1965-1973, Routledge, Londres, p. 36-52.

- Soutou Georges-Henri, «The linkage between European Integration and détente. The contrasting approaches of de Gaulle and Pompidou, 1965 to 1974 », in LUDLOW Piers (éd.), European integration and the Cold War : Ostpolitik-Westpolitik, 1965-1973, Routledge, Londres, 2007, p. 11-35.

- Soutou Georges-Henri, La Guerre de cinquante ans. Le conflit Est-Ouest, 19431990, Fayard, Paris, 2001.

- Soutou Georges-Henri, STEINERT Marlis, « Ordre européen et construction européenne, $\mathrm{XIX}^{\mathrm{e}}-\mathrm{XX}^{\mathrm{e}}$ siècles » in Relations internationales, $\mathrm{n}^{\circ}$ 90, été 1997, p. 127-143.

- VAÏ̈SSE Maurice, « Europe européenne ou Europe atlantique ? Les conceptions de Charles de Gaulle », in Dumoulin Michel (dir.), L'Union européenne et les États-Unis, Peter Lang, Bruxelles, p. 89-110.

- VAïsse Maurice, La Grandeur. Politique étrangère du général de Gaulle, 19581969, Fayard, Paris, 1998.

- VANKE Jeffrey, « Charles de Gaulle's Uncertain Idea of Europe », in DiNAN Desmond (éd.), Origins and Evolution of the European Union, Oxford UP, Oxford, 2006, p. 141165 .

\section{OUVRAGES GÉNÉRAUX SUR LA FRANCE ET L'INTÉGRATION EUROPÉENNE}

- Bossuat Gérard, La France, l'aide américaine et la construction européenne, 1944-1954, 2 volumes, Comité pour l'histoire économique et financière de la France, Paris, 1992 
- Bossuat Gérard, L'Europe des Français, 1943-1959 : la IV République aux sources de l'Europe communautaire, Publications de la Sorbonne, Paris, 1996.

- Bossuat Gérard, Faire l'Europe sans défaire la France. 60 ans de politique d'unité européenne des gouvernements et des présidents de la République française (1943-2003), Peter lang, Bruxelles, 2005.

- Dulphy Anne, Manigand Christine, La France au risque de l'Europe, Colin, Paris, 2006.

- LYNCH Frances, France and the international economy. From Vichy to the Treaty of Rome, Routledge, Londres, 1997.

- PARSOns Craig, A Certain Idea of Europe, Cornell UP, Ithaca, 2003.

\section{LA FRANCE : OUVRAGES SPÉCIALISÉS}

- Association Georges Pompidou (éd.), Georges Pompidou et l'Europe, Complexe, Bruxelles, 1995.

- Bossuat Gérard, « La France et la zone de libre-échange. Le jeu du pouvoir politique et des intérêts économiques (1956-1959) », in CIAMPANI Andrea (dir.), L'altra via per l'Europa. Forze sociali e organizzazione degli interessi nell'integrazione europea (1947-1957), F. Angeli, Milan, 1995, p. 350-382.

- BossuAT Gérard, « Le choix de la petite Europe par la France (1957-1963). Une ambition pour la France et pour l'Europe », in Relations internationales, n 82, été 1995, p. 213-235.

- Bossuat Gérard, «Les trois visages de Monnet », in SMETs Paul (éd.), Les Pères de l'Europe : cinquante ans après, Bruylant, Bruxelles, 2001, p. 27-54.

- Bossuat Gérard, "Les eurosocialistes de la SFIO », in BossuAT Gérard (dir.), SAUNIER Georges (collab.), Inventer l'Europe. Histoire nouvelle des groupes d'influence et des acteurs de l'unité européenne, Peter Lang, Bruxelles, 2003, p. 409-430.

- GIRAUlt René, « La France entre l'Europe et l'Afrique », in SERRA Enrico (dir.), La relance européenne et les traités de Rome, Bruylant, Bruxelles, 1989, p. 351-378.

- KIPPING Matthias, La France et les origines de l'Union européenne. Intégration économique et compétitivité internationale, Comité pour l'histoire économique et financière de la France, Paris, 2002.

- KOCHER Éric, Le rôle de la France dans les négociations des traités de Rome. Un aspect de la relance 1954-1957, maîtrise dir. René Girault, Paris I, 1989.

- Soutou Georges-Henri, « Michel Debré, une vision mondiale pour la France », in BERSTEIN Serge, Milza Pierre, SiRINELli Jean-François (dir.), Michel Debré Premier ministre, PUF, Paris, 2005, p. 398-416. 


\section{L'ALLEMAGNE ET LES RELATIONS FRANCO-ALLEMANDES}

- COMMun Patricia, « La contribution d'Alfred Müller-Armack à l'initiation d'un ordre économique libéral en Europe de 1958 à 1963 », in BITSCH Marie-Thérèse (dir.), Le couple France-Allemagne et les institutions européennes. Une postérité pour le plan Schuman, Bruylant, Bruxelles 2001, p. 171-190.

- FRANÇOIS-PONCET Jean, La politique économique de l'Allemagne occidentale, Sirey, Paris, 1970.

- GerBer David, Law and competition in XX ${ }^{\text {th }}$ Century Europe. Protecting Prometheus, Oxford, Clarendon Press, 1998.

- JoLY Hervé, Patrons d'Allemagne. Sociologie d'une élite industrielle 1933-1989, Presses de Sciences Po, Paris, 1996

- LAPPENKÜPER Ulrich, «"Ein Europa der Freien un der Gleichen". La politique européenne de Ludwig Erhard (1963-1966) », in LOTH Wilfried (dir.), Crisis and Compromises : The European project, 1963-1969, Bruylant, Bruxelles, 2001, p. 65-91.

- NEUMANN Wolfgang, UTERWEDDE Henrik, Industriepolitik : ein deutsch-französischer Vergleich, Leske Verlag, Leverkusen, 1986.

- Schoenborn Benedikt, La mésentente apprivoisée : de Gaulle et les Allemands, 1963-1969, PUF, Paris, 2007.

- SouTOU Georges-Henri, L'Alliance incertaine. Les rapports politico-stratégiques franco-allemands, 1954-1996, Fayard, Paris, 1996.

- TÜRK Henning, Die Europapolitik der Grossen Koalition, 1966-1969, Oldenbourg, Munich, 2006.

- UTERWEDDE Henrik, Wirtschaft im Vergleich. Wirtschaftsstruktur und politik in Frankreich und der Bundesrepublik, Max Niemeyer Verlag, Tübingen, 1979.

- WARLOUZET Laurent, « La dimension industrielle du couple franco-allemand : les tentatives de créer une coopération bilatérale institutionnalisée entre 1965 et 1969 », in ECK Jean-François, MARTENS Stefan, SCHIRMANN Sylvain (dir.), L'économie, l'argent et les hommes. Les relations franco-allemandes de 1871 à nos jours, Comité pour l'histoire économique et financière de la France, Paris 2009, p. 287-307.

- WiLKENS Andreas (éd.), Die deutsch-frazösischen Wirtschaftbeziehungen, 19451960. Les relations économiques franco-allemandes, 1945-1960, Jan Thorbecke Verlag, Sigmaringen, 1997. 


\section{HISTOIRE DE L'INTÉGRATION EUROPÉENNE : ACTEURS}

\section{ÉTUDES MULTINATIONALES}

- GILLINGHAM John, European Integration, 1950-2003. Superstate or New Market Economy?, Cambridge UP, Cambridge, 2003.

- KAISER Wolfram, «Transnational networks in European governance : the informal politics of integration », in KAISER Wolfram, LEUCHT Brigitte, RASMUSSEN Morten (éd.), The History of the European Union. Origins of a trans- and supranational polity, 1950-1972, Routledge, Londres, 2008, p. 12-33.

- KAISER Wolfram, Christian Democracy and the Origins of the European Union, Cambridge UP, Cambridge, 2007.

- KÜsters Hanns Jürgen, Fondements de la CEE, Office de publication des communautés, Luxembourg, 1990 [1982].

- Leboutte René, Histoire économique et sociale de la construction européenne, Peter Lang, Bruxelles, 2009.

- LuDLOw Piers, The European Community and the Crises of the 1960s. Negotiating the Gaullist challenge, Routledge, Londres, 2005.

- MiLward Alan, The European Rescue of the Nation-State, Routledge, Londres, 1992.

- MoRAVCSIK Andrew, The Choice for Europe. Social Purpose and State Power from Messina to Maastricht, UCL Press, Londres, 1999.

- PoIDEVIn Raymond, SPIERENBURg Dirk, Histoire de la Haute Autorité de la CECA, Bruylant, Bruxelles, 1993.

\section{LA GRANDE-BRETAGNE}

- CAMPs Miriam, Britain and the European Community, 1955-1963, Princeton UP, Princeton, 1964.

- ELLISON James, Threatening Europe : Britain and the creation of the European Community, 1955-1958, Macmillan Press, Houndmills, 2000.

- FRANK Robert, « France-Grande-Bretagne : la mésentente commerciale (19451958) » in Relations internationales, $\mathrm{n}^{\circ}$ 55, automne 1988, p. 323-339.

- GeHLER Michael, «Das Scheitern der Großen Freihandelszone 1958 und die Gründung der EFTA 1959/60 », in GEHLER Michael (éd.), Vom gemeinsamen Markt zur europäischen Unionsbildung. 50 Jahre Römische Verträge 1957-2007, Böhlau, Vienne, 2009, p. 243-282.

- KAISER Wolfram, Using Europe, abusing the Europeans. Britain and European Integration, 1945-1963, Macmillan Press, Basingstoke, 1996. 
- KAISER Wolfram, «Culturally Embedded and Path Dependent : Peripheral Alternatives to ECSC/EEC « core Europe » since 1945 », in Revue d'histoire de l'intégration européenne, 2001, p. 11-36.

- LuDLOw Piers, Dealing with Britain. The Six and the first UK application to the EEC, Cambridge UP, Cambridge, 1997

- LudLow Piers, «A Short-Term Defeat: The Community Institutions and the Second British Application to join the EEC » in DADDOW Oliver (éd.), Harold Wilson and European Integration. Britain's Second Application to join the EEC, Frank Cass, Londres, 2003, p. 135-150

- MiLWARD Alan, The Rise and Fall of a National Strategy, 1945-1963, Whitehall History Publishing, Londres, 2002.

- PARR Helen, Britain's Policy towards the European Community, 1964-1967. Harold Wilson and Britain's World Role, Routledge, Londres, 2005.

\section{AUTRES PAYS}

- CALANDRi Elena, «L'administration italienne pendant les dix premières années de la Communauté économique européenne. Prédominance de la diplomatie et conflits de compétence ", in BADEL Laurence, LUDLOW Piers, JEANNESSON Stanislas (dir.), Les administrations nationales et la construction européenne. Une approche historique (1919-1975), Peter Lang, Bruxelles, 2005, p. 259-286.

- Duchenne Geneviève, Dujardin Vincent, Dumoulin Michel (dir.), Rey, Snoy, Spaak, fondateurs belges de l'Europe, Bruylant, Bruxelles, 2007.

- FAURI Francesca, «Italy and the Free Trade Area Negotiations, 1956-1958 », in Revue d'histoire de l'intégration européenne, p. 48-66.

- Winand Pascaline, Eisenhower, Kennedy and the United States of Europe, St. Martin's Press, New-York, 1993.

\section{MILIEUX COMMUNAUTAIRES : COMMISSAIRES ET FONCTIONNAIRES EUROPÉENS}

- BossuAT Gérard, «Émile Noël : un grand serviteur de l'Europe communautaire », in DuMOULIN Michel (dir.), La Commission européenne, 1958-1972. Histoire et mémoire d'une institution, Communautés européennes, Bruxelles, 2007, p. 213-227.

- Bossuat Gérard, «La culture de l'unité européenne des élites françaises aux Communautés européennes », in VARSORI Antonio (éd.), Inside the European Community. Actors and Policies in the European Integration, 1957-1972, Bruylant, Bruxelles, 2006, p. 55-78. 
- CARBonell Mauve, Des hommes à l'origine de l'Europe. Biographies des membres de la Haute Autorité de la CECA, Publications de l'université de Provence, Aix-enProvence, 2008.

- Condorelli-Braun Nicole, Commissaires et juges dans les Communautés européennes, LGDJ, Paris, 1972.

- CONRAD Yves, « Jean Rey : un Européen « de cœur » à l' « optimisme modéré » », in DuMOULIN Michel (dir.), La Commission européenne, 1958-1972. Histoire et mémoire d'une institution, Communautés européennes, Bruxelles, 2007, p. 115-130.

- DuMOulin Michel, «L'administration », in DuMOulin Michel (dir.), La Commission européenne, 1958-1972. Histoire et mémoire d'une institution, Communautés européennes, Bruxelles, 2007, p. 229-250.

- Fontaine Pascal, Le Comité d'action des États-Unis d'Europe de Jean Monnet, Centre de recherches européennes, Lausanne, 1974.

- Lотн Wilfrid, «Walter Hallstein : un Européen déterminé », in DuMOULIN Michel (dir.), La Commission européenne, 1958-1972. Histoire et mémoire d'une institution, Communautés européennes, Luxembourg, 2007, p. 83-94.

- Loth Wilfrid, Wallace William, Wessels Wolfgang (éd.), Walter Hallsein. Der vergessene Europäer? Europa Union Verlag, Bonn, 1995.

- MANGENOT Michel, «La revendication d'une paternité : Les hauts fonctionnaires français et le «style» administratif de la Commission européenne (1958-1988) », in Pôle Sud, 2001, vol. 15, n 1, p. $33-46$

- MANGenot Michel, « Le Conseil d'État et l'institutionnalisation du système juridique communautaire », intervention au colloque CRPS-CURAPP/Groupe Polilexes Les juristes et la construction d'un ordre politique européen, Amiens, $1^{\mathrm{er}}$ avril 2004.

- Migani Guia, «The commissioner Robert Lemaignen and the African States : the Origins of the European Development Policy (1958-1961) », in ELVERT Jürgen, SALEWSKI Michael (éd.), Historische Mitteilungen, Band 18, Franz Steiner, Stuttgart, 2005, p. 150-161.

- SCHÖNwALD Matthias, «Walter Hallstein et les institutions des Communautés européennes », in BITSCH Marie-Thérèse (dir.), Le couple France-Allemagne et les institutions européennes. Une postérité pour le plan Schuman, Bruylant, Bruxelles, 2001, p. 151-168.

- SCHRÖDER Corinne, WILSON Jérôme, " Europam Esse Construendam : Pierre Pescatore und die Anfänge der Europaïschen Rechtsordnung », in ELVERT Jürgen, SALEWSKI Michael (éd.), Historische Mitteilungen, Band 18, Franz Steiner, Suttgart, 2006, p. 162-174.

- SEIDEL Katja, «Gestalten statt Verwalten : Der Beitrag von Europabeamten zur Europäischen Integration », in ELVERT Jürgen, SALEWSKI Michael (éd.), Historische Mitteilungen, Band 18. 2005, Franz Steiner, Stuttgart, 2006, p. 136-149. 
- VAUCHEZ Antoine, « Une élite d'intermédiaires. Genèse d'un capital juridique européen, 1950-1970 », in Actes de la recherche en sciences sociales, $\mathrm{n}^{\circ}$ 166-167, février 2007, p. 3-13.

- WILSON Jérôme, « Jurisconsultes et conseillers d'État : aux origines de l'ordre juridique communautaire » in Revue d'histoire de l'intégration européenne, 2008-2, p. 35-55.

\section{LES MILIEUX ÉCONOMIQUES}

- BADEL Laurence, Un milieu libéral et européen. Le grand commerce français, 19251948, Comité pour l'histoire économique et financière de la France, Paris, 1999.

- BADEl Laurence, Bussière Éric, Dumoulin Michel, RANIERI Ruggero, «Cercles et milieux économiques » in FRANK Robert, BOSSUAT Gérard (dir.), Les identités européennes au $X X^{e}$ siècle. Diversités, convergences, solidarités, Publications de la Sorbonne, 2004, Paris, p. 13-45.

- BÜHRER Werner, «Le Bundesverband der Deutschen Industrie, le ministère fédéral de l'Économie et l'intégration européenne (1958-1972) », in Le rôle des ministères des Finances et de l'Économie dans la construction européenne (1957-1978), Comité pour l'histoire économique et financière de la France, Paris, 2002, p. 53-70.

- BusSIÈRE Éric, DUMOULIN Michel, « L'émergence de l'idée d'identité économique européenne d'un après-guerre à l'autre », in GIRAULT René (dir.), Identité et conscience européenne au XX siècle, Hachette, Paris, 1994, p. 67-105.

- CASsis Youssef, Big business : the European experience in the twentieth century, Oxford UP, Oxford, 1997.

- DuMOULIN Michel, « Milieux patronaux belges et construction européenne autour de 1960 », in BUSSIÈRE Éric, DUMOULIN Michel, SCHIRMANN Sylvain (dir.), Europe organisée, Europe du libre-échange? Fin XIX -années 1960, Peter Lang, Bruxelles, p. 148-164.

- Dumoulin Michel, DutrIEU Anne-Myriam, La Ligue européenne de coopération économique (1946-1981), Peter Lang, Berne, 1993.

- ECK Jean-François, Les entreprises françaises face à l'Allemagne de 1945 à la fin des années 1960, Comité pour l'histoire économique et financière de la France, Paris, 2003.

- GREVET Jean-François, Au cour de la révolution automobile : l'industrie du poids lourd du plan Pons au regroupement Berliet-Saviem. Marchés, industrie et État en France, 1944-1974, thèse de doctorat, dir. Jean-Pierre Hirsch (Lille III), 2005.

- KIPPING Matthias, Rollings Neil, « Networks of Peak Industrial Federations. The Council of Directors of European Industrial Federations and the Council of European Industrial Federations », in DuMOULIN Michel (éd.), Réseaux économiques et construction européenne, Peter Lang, Bruxelles, 2004, p. 277-300. 
- LoEB Nicole, Le patronal industriel belge et la CEE, ULB, Bruxelles, 1965.

- Mioche Philippe, «Le patronat français et les projets d'intégration économique européenne dans les années cinquante », in TRAUSCH Gilbert (éd.), Die Europaïsche Integration vom Schuman-Plan bis zu den Verträgen von Rom, Nomos Verlag, BadenBaden, 1993, p. 241-257.

- Moguen Marine, L'ouverture des frontières européennes dans les années cinquante. Fruit d'une concertation avec les industriels ?, Peter Lang, Bruxelles, 2002.

- MoRIVAL Yohann, L'intégration européenne du Conseil national du patronat français (1949-1966), mémoire de master, dir. Michel Offerlé, EHESS-ENS, 2009.

- PETRINI Francesco, Il Liberismo a una dimensione. La confindustria el 'integrazione europea 1947-1957, Franco Angeli, Milan, 2005.

- RAMIREZ-Perez Sigfrido, Public Policies, European Integration and Multinational Corporations in the Automobile Sector. The French and Italian Cases in a comparative perspective 1945-1973, thèse, dir. Bo Strath, European University Institute, 2007.

- Rollings Neil, British Business in the Formative Years of European Integration, 1945-1973, Cambridge UP, Cambridge, 2007.

- SEgRETo Luciano, « L'UNICE et la construction européenne (1947-1969) », in VARSORI Antonio (éd.), Inside the European Community. Actors and Policies in the European Integration, 1957-1972, Bruylant, Bruxelles, 2006, p. 195-208.

- SzOKOLOCZY-SYLLABA Janos, Les organisations professionnelles françaises et le Marché commun, Colin, Cahiers de la FNSP n 133, Paris, 1965.

\section{HISTOIRE DE L'INTÉGRATION EUROPÉENNE : THÉMATIQUES}

\section{QUESTIONS POLITIQUES, JURIDIQUES \\ ET INSTITUTIONNELLES (SAUF CRISE DE LA CHAISE VIDE)}

- BITSCH Marie-Thérèse (CONRAD Yves collab.), « Le collège des commissaires : un nouveau type d'autorité publique », in DuMOUlin Michel (dir.), La Commission européenne, 1958-1972. Histoire et mémoire d'une institution, Communautés européennes, Bruxelles, 2007, p. 189-212.

- Dumoulin Michel, «Les travaux du Comité intérimaire pour le Marché commun et Euratom », in VARSORI Antonio (éd.), Inside the European Community. Actors and Policies in the European Integration, 1957-1972, Bruylant, Bruxelles, p. 23-35.

- KNUdSEN Ann-Christina, RASMUSSEN Morten, «A European Political System in the Making 1958-1970 : The Relevance of Emerging Committee Structures », in Journal of European Integration History, 2008/1, p. 51-67 
- LuDLOW Piers, «A Supranational Icarus ? Hallstein, the early Commission and the search for an independant role ", in VARSORI Antonio (éd.), Inside the European Community. Actors and Policies in the European Integration, 1957-1972, Bruylant, Bruxelles, 2006, p. 37-54.

- LUDLOW Piers, « Mieux que six ambassadeurs. L'émergence du COREPER durant les premières années de la CEE », in BADEL Laurence, JEANNESSON Stanislas, LUDLOW Piers (dir.), Les administrations nationales et la construction européenne. Une approche historique (1919-1975), PIE-Peter Lang, Bruxelles, 2005, p. 337-356.

- LudLow Piers, « Decision Making in the 1960s EEC. Three case-studies ", in LOTH Wilfrid (dir.), La gouvernance supranationale dans la construction européenne, Bruylant, Bruxelles, 2005, p. 115-134.

- MolLIN Gerhard Th., « La « Commission Hallstein » 1958-1967 : aux frontières d'un « gouvernement supranational » », in LOTH Wilfried (dir.), La gouvernance supranationale dans la construction européenne, Bruxelles, Bruylant, 2005, p. 58-61.

- PALAYRET Jean-Marie, «Les décideurs français et allemands face aux questions institutionnelles dans la négociation des traités de Rome, 1955-1957 », in BITSCH Marie-Thérèse (dir.), Le couple France-Allemagne et les institutions européennes. Une postérité pour le Plan Schuman, Bruylant, Bruxelles, 2001, p. 105-150.

- RAMUSSEN Morten, « Supranational governance in the making: Towards a European political system », in KAISER Wolfram, LEUCHT Brigitte, RAMUSSEN Morten (éd.), The History of the European Union. Origins of a trans- and supranational polity, 1950-1972, Routledge, Londres, 2008, p. 34-55.

- RAMUSSEN Morten, «The Origins of a Legal Revolution. The Early Hsitory of the European Court of Justice », in Revue d'histoire de l'intégration européenne, 2008/2, p. 91-86.

- WILSON Jérôme, «Aux origines de l'ordre juridique communautaire » in Annales d'études européennes de l'université catholique de Louvain, vol. 7, 2003-2004, p. 11-33.

\section{CRISE DE LA CHAISE VIDE}

- BOSSUAT Gérard, « Robert Marjolin dans la tourmente de la chaise vide », in Institut de France (éd.), Robert Marjolin, Institut, Paris, 2004, p. 66-82.

- Loth Wilfried, "La crise de la chaise vide », in Dumoulin Michel (dir.), La Commission européenne, 1958-1972. Histoire et mémoire d'une institution, Communautés européennes, Bruxelles, 2007, p. 95-114.

- LuDLOW Piers, «The Eclipse of the Extremes. Demythologising the Luxembourg Compromise. » in LOTH Wilfrid (éd.), Crisis and Compromises : The European project, 1963-1969, Bruylant, Bruxelles, 2001, p. 247-264. 
- LudLow Piers, « De-Commissioning the Empty Chair Crisis : the Community Institutions and the Crisis of 1965-1966 », in PALAYRET Jean-Marie, WALLACE Helen, WinAND Pascaline (éd.), Visions, Votes and Vetoes. The Empty Chair Crisis and the Luxembourg Compromise. Forty Years On, Peter Lang, Bruxelles, 2006, p. 79-96.

- PALAYRET Jean-Marie, « De Gaulle Challenges the Community : France, the Empty Chair Crisis and the Luxembourg Compromise », in PALAYRET Jean-Marie, WALLACE Helen, Winand Pascaline (éd.), Visions, Votes and Vetoes. The Empty Chair Crisis and the Luxembourg Compromise. Forty Years On, Peter Lang, Bruxelles, 2006, p. 45-78.

- SCHÖNWALD Matthias, « Walter Hallstein and the «Empty Chair» Crisis 1965/66», in LoTH Wilfried (éd.), Crisis and Compromises : The European project, 1963-1969, Bruylant, Bruxelles, 2001, p. 157-171.

- WHITE Jonathan, «Theory Guiding Practice : the Neofunctionalists and the Hallstein EEC Commission », in Revue d'histoire de l'intégration européenne, 2003/1, p. 111131.

\section{MARCHÉ COMMUN, HARMONISATION FISCALE ET SOCIALE}

- ASBEEK-BRUCE Wendy, Tariffs, trade and European integration, 1947-1957 : from study group to Common Market, St Martin Press, New-York, 1997.

- BUSSIÈRE Éric, «Un marché pas encore tout à fait commun », in DUMOULIN Michel (dir.), La Commission européenne, 1958-1972. Histoire et mémoire d'une institution, Commission européenne, Bruxelles, 2007, p. 299-312.

- Gerbet Pierre, La naissance du Marché commun, Complexe, Bruxelles, 1987.

- TRISTRAM Frédéric, « Le ministère français des Finances et l'harmonisation fiscale européenne dans les années soixante », in Le rôle des ministères des Finances et de l'Économie dans la construction européenne (1957-1978), tome I, Comité pour l'histoire économique et financière de la France, Paris, 2002, p. 471-488.

- RANIERI Ruggero, "The origins and achievements of the EEC Customs Union (1958-1968) », in VARSORI Antonio (éd.), Inside the European Community. Actors and Policies in the European Integration 1957-1972, Bruylant, Bruxelles, 2006, p. 257282.

- RYE Lise, «The Rise and Fall of the French Demand for Social Harmonization in the EEC, 1955-1966 », in RÜCKER Katrin, WARLOUZET Laurent (éd.), Quelle(s) Europe(s)? Nouvelles approches en histoire de l'intégration européenne, Peter Lang, Bruxelles, 2006, p. 155-168.

\section{LA POLITIQUE DE LA CONCURRENCE EN EUROPE (SAUF FRANCE)}

- BARJOT Dominique (dir.), International Cartels Revisited. Vues nouvelles sur les cartels internationaux (1880-1980), éditions du Lys, Caen, 1994. 
- Berger Françoise, "Les milieux économiques et les États face aux tentatives d'organisation des marchés européens dans les années $1930 »$, in BUSSIÈRE Éric, Dumoulin Michel, SchirmanN Sylvain (dir.), Europe organisée, Europe du libre-échange? Fin XIX siècle-Années 1960, Peter Lang, Bruxelles, 2006, p. 71-106.

- BUSSIÈRE Éric, «La concurrence», in DUMOULIN Michel (dir.), La Commission européenne, 1958-1972. Histoire et mémoire d'une institution, Communautés européennes, Bruxelles, 2007, p. 313-328.

- CInI Michelle, Mc Gowan Lee, Competition Policy in the European Union, Macmillan Press, Londres, 1998.

- DENORD François, « Néo-libéralisme et «économie sociale de marché» : les origines intellectuelles de la politique européenne de la concurrence (1930-1950) » in Histoire, économie et société, $\mathrm{n}^{\circ}$ spécial, 2008/1, p. 23-34.

- Dubors Jean-Pierre, Les mécanismes de l'autorité à l'intérieur de la DG de la concurrence de la Commission des Communautés européennes, DES, dir. Paul Reuter, Cujas, 1970.

- EnCAOUa David, Guesnerie Roger, Politiques de la concurrence, rapport du Conseil d'analyse économique, Documentation française, Paris, 2006.

- FrANCK Louis, La libre concurrence, PUF, Paris, Que sais-je ?, 1967.

- GERBER David, Law and competition in XX ${ }^{\text {th }}$ Century Europe. Protecting Prometheus, Clarendon Press, Oxford, 1998.

- HACHEZ-LEROY Florence, L'aluminium français : l'invention d'un marché, 19111983, CNRS éditions, Paris, 1999, p. 161.

- HAMBLocht Sybille, « Die Entstehung der Verordnung 17 von 1962 im Rhamen der EWG-Wettbewerbspolitik », in Europarecht, novembre 2002, p. 877-897.

- HoussiauX Jacques, Concurrence et Marché commun, Génin, Paris, 1960.

- LEUCHT Brigitte, «Tracing European Mentalities : Free Competition in Post-World War II Transatlantic Europe », in BITSCH Marie-Thérèse, LOTH Wilfrid, BARTHEL Charles (éd.), Cultures politiques, opinions publiques et intégration européenne, Bruylant, Bruxelles, 2007, p. 337-353.

- LEUCHT Brigitte, SEIDEL Katja, «Du traité de Paris au règlement 17/1962 : ruptures et continuités dans la politique européenne de concurrence, 1950-1962 », in Histoire, économie et société, 2008/1, p. 3546.

- MC GowAN Lee, WILKS Stephen, «The first supranational policy in the European Union : Competition Policy », in European Journal of Political Research, 1995, p. 141169.

- RAMIREZ Sigfrido, «Antitrust ou anti-US ? L'industrie automobile européenne et les origines de la politique de la concurrence de la CEE », in BUSSIÈRE Éric, DUMOULIN Michel, SchirmanN Sylvain (dir.), Europe organisée, Europe du libre-échange? Fin XIX'e-années 1960, Peter Lang, Bruxelles, p. 203-228. 
- Revue du Marché commun, supplément au numéro de juillet 1959 sur les journées d'études de Caen des 8-10 mai 1959, «La libre concurrence dans les pays du Marché commun ».

- SCHWEITZER Heike, Parallels and Differences in the Attitudes towards Single-Firm Conduct: What are the Reasons? The History, Interpretation and Underlying Principles of Sec. 2 Sherman Act and Art 82 EC, EUI Working Paper LAW n 2007/32.

- SEIDEL Katja, «Establishing an Economic Constitution for Europe : DG IV and the Origins of a Supranational Competition Policy », in KAISER Wolfram, LEUCHT Brigitte, RASMUSSEN Morten (éd.), The History of the European Union. Origins of a trans- and supranational polity, 1950-1972, Routledge, Londres, 2008, p. 129-147.

- VAN GERVEN Walter, "Twelve years of EEC Competition Law revisited », in Common Market Law Review, 1974, 1, p. 38-61.

- WARLOUZET Laurent, « La France et la mise en place de la politique de la concurrence communautaire (1957-1964) », in BUSSIĖRE Éric, DUMOULIN Michel, SCHIRMANN Sylvain (dir.), Europe organisée, Europe du libre-échange? Fin XIX'-années 1960, Peter Lang, Bruxelles, p. 175-202.

\section{PROGRAMMATION ET PLANIFICATION EN EUROPE (SAUF FRANCE)}

- Denton Geoffrey, Forsyth Murray, MaClenNan Malcolm, Economic Planning and Policies in Britain, France and Germany, George Allen, Londres, 1968.

- GRAZI Laura, L'Europa e le citta. La questione urbana nel processo di integrazione europea (1957-1999), Il Mulino, Bologne, 2006.

- La programmation économique européenne et la programmation économique nationale dans les pays de la CEE, Actes du colloque de Rome, 30 novembre au 2 décembre 1962, Vallechi, Rome, 1963.

- PlitzKo Alfred (éd.), Planung Ohne Planwirtschaft, Kyklos-Verlag, Bâle, 1964.

- RICCIARDI Ferrucio, «L'absence de plan en Italie : mythe ou réalité ? Interventionnisme d'État et politique industrielle entre fascisme et république (années 1930-années 1960) », in Kharaba Ivan, Dalmasso Anne, Mioche Philippe et al. (dir.), Politiques industrielles d'hier et d'aujourd'hui, en France et en Europe, PU de Dijon, Dijon, 2009, p. 43-58.

- SHONFIELD Andrew, Modern Capitalism. The changing Balance of Public and Private Power, Oxford UP, 1965.

- Von DeR GRoeben Hans, « Wettbewerb und Programmierung als Instrumente der Wirtschaftspolitik im Gemeinsamen Markt», in PLITZKo Alfred (éd.), Planung Ohne Planwirtschaft, Kyklos-Verlag, Bâle, 1964, p. 191-198. 


\section{LA POLITIQUE INDUSTRIELLE}

- BUSSIÈRE Éric, «L'improbable politique industrielle », in DUMOULIN Michel (dir.), La Commission européenne, 1958-1972. Histoire et mémoires d'une institution, Commission européenne, Bruxelles, 2007, p. 471-486.

- BussiÈre Éric, DUMOULIN Michel, WiLlAERT Émilie (dir.), La Banque de l'Union européenne. La BEI, 1958-2008, Imprimerie Centrale, Luxembourg, 2008.

- BUSSIÈRE Éric, VAN LAER Arthe, «Recherche et technologie ou la « sextuple tutelle » des États sur la Commission, éternelle mineure », in Dumoulin Michel (dir.), La Commission européenne, 1958-1972. Histoire et mémoire d'une institution, Commission européenne, Bruxelles, 2007, p. 507-522.

- DEFRAIGNE Jean-Christophe, De l'intégration nationale à l'intégration continentale. Analyse de la dynamique d'intégration supranationale européenne des origines à nos jours, L'Harmattan, Paris, 2004.

- ECK Jean-François, « Les politiques industrielles en France et en Allemagne après 1945 : essai de comparaison », in KHARABA Ivan, DALMASSO Anne, MIOCHE Philippe et al. (dir.), Politiques industrielles d'hier et d'aujourd'hui, en France et en Europe, PU de Dijon, Dijon, 2009, p. 59-71.

- GRISET Pascal (dir.), Informatique, politique industrielle, Europe : entre plan Calcul et Unidata, Institut d'Histoire de l'Industrie, Paris, 1998.

- GRISET Pascal, « «Nous ne vieillirons pas ensemble», UNIDATA et la coopération industrielle franco-allemande au début des années $1970 »$, in BUSSIÈRE Éric, DUMOULIN Michel, SCHIRMANN Sylvain (dir.), Milieux économiques et intégration européenne au XX $X^{e}$ siècle. La crise des années 1970. De la conférence de La Haye à la veille de la relance des années 1980, Peter Lang, Bruxelles, 2006, p. 287-314.

- LABORIE Léonard, «Les grands réseaux techniques et l'intégration européenne. Le cas des Postes et des Télécommunications (1945-1959) », in RÜCKER Katrin, WARLOUZET Laurent (éd.), Quelle(s) Europe(s)? Nouvelles approches en histoire de l'intégration européenne, Peter Lang, Bruxelles, 2006, p. 321-336.

- MECHI Lorenzo, PETRINI Francesco, « La Comunità europea nella divisione internazionale del lavoro : le politiche industriali, 1967-1978 », in VARSORI Antonio (dir.), Alla origini del persente. L'Europa occidentale nell crisi degli anni'70, Franco Angeli, Milan, 2006, p. 251-283.

- Mioche Philippe, «Construction européenne et politiques industrielles : les possibilités de rencontre », in KHARABA Ivan, DALMASSO Anne, MIOCHE Philippe et al. (dir.), Politiques industrielles d'hier et d'aujourd'hui, en France et en Europe, PU de Dijon, Dijon, 2009, p. 125-142.

- VAN LAER Arthe, « Liberalization or Europeanization? The EEC Commission's Policy on Public Procurement in Information Technology and Telecommunications (1957-1984) », in Revue d'histoire de l'intégration européenne, 2006, vol. 12, $\mathrm{n}^{\circ} 2$, p. 107-130. 
- YounG John, « Technological Cooperation in Wilson's Strategy for EEC Entry » in DADDOW Oliver (éd.), Harold Wilson and European Integration. Britain's Second Application to join the EEC, Frank Cass, Londres, 2003, p. 95-114.

\section{QUESTIONS FINANCIÈRES ET MONÉTAIRES}

- Bossuat Gérard, «Questions sur l'identité monétaire européenne à travers les positions de Jean Monnet, Robert Triffin et Pierre Mendès France », in BUSSIÈRE Éric, DuMOULIN Michel (éd.), Milieux économiques et intégration européenne, Artois presses université, Arras, 1998, p. 105-114.

- BotTEX Agnès, « La mise en place des institutions monétaires européennes (19571964) », in BUSSIËRE Éric, FEIERTAG Olivier (dir.), Banques centrales et convergences monétaire en Europe (1920-1971). Histoire, économie et sociétés, 1999, n 4, p. 753774.

- BUSSIÈRE Éric, "Les tentatives d'une politique économique et monétaire », in DuMOULIN Michel (dir.), La Commission européenne, 1958-1972. Histoire et mémoire d'une institution, Communautés européennes, Bruxelles, 2007, p. 405-424.

- BussiÈRE Éric, «La France et les débats au sein du Comité monétaire à l'époque du plan Werner. Automne 1968-Printemps $1971 »$, in Le rôle des ministères des Finances et de l'Économie dans la construction européenne (1957-1978), tome I, Comité pour l'histoire économique et financière de la France, Paris, 2002, p. 351-374.

- BUSSIÈRE Éric, « La Banque de France et la réforme du système monétaire international : entre impératifs nationaux et solidarité des banques centrales européennes (1963-1968) », in BUSSIĖRE Éric, FEIERTAG Olivier (dir.), Banques centrales et convergences monétaires en Europe (1920-1971). Histoire, économies et sociétés, $\mathrm{n}^{\circ} 4,1999$, p. 797-814.

- ChELINI Michel-Pierre, «Le plan de stabilisation Pinay-Rueff, $1958 »$ in Revue d'histoire moderne et contemporaine, 48-4, octobre-décembre 2001, p. 102-123.

- DicKhaus Monika, « La politique extérieure de la Banque centrale allemande après $1958 »$, in FEIERTAG Olivier, MARGAIRAZ Michel (dir.), Politiques et pratiques des banques d'émission en Europe (XVII $-X X^{e}$ siècle). Le bicentenaire de la Banque de France dans la perspective de l'identité monétaire européenne, Albin Michel, Paris, 2003, p. 767-786.

- Feiertag Olivier, "Les banques d'émission et la croissance économique en Europe (1945-1973) », in FeIERTAG Olivier, MARGaIraZ Michel (dir.), Politiques et pratiques des banques d'émission en Europe (XVII ${ }^{e}-X X^{e}$ siècle). Le bicentenaire de la Banque de France dans la perspective de l'identité monétaire européenne, Albin Michel, Paris, 2003, p. 595-622. 
- FEIERTAG Olivier, « banques centrales et relations internationales au $\mathrm{XX}^{e}$ siècle : le problème historique de la coopération monétaire internationale », in Relations internationales, $\mathrm{n}^{\circ} 100$, hiver 1999, p. 355-376.

- FEIERTAG Olivier, « La France, la CEE et le système monétaire international : les accords généraux d'emprunt ou l'émergence de l'Europe monétaire, 1958-1962 », in Le rôle des ministères des Finances et de l'Économie dans la construction européenne (1957-1978), tome I, Paris, Comité pour l'histoire économique et financière de la France, 2002, p. 277-306.

- FForde John, The Bank of England and Public Policy, 1941-1958, Cambridge UP, Cambridge, 1992.

- Institut Charles de Gaulle, 1958 : la faillite ou le miracle économique. Le plan de Gaulle-Rueff, Économica, Paris, 1986.

- KAPLAN Jacob, Schleiminger Günther, The European Payments Union. Financial Diplomacy in the 1950s, Clarendon Press, Oxford, 1989.

- LYNCH Frances, «De Gaulle's First Veto. France, the Rueff Plan and the Free Trade Area », in Contemporary European History, 9, 1, 2000, p. 111-135.

- MAES Ivo, «Projets d'intégation monétaire à la Commission européenne au tournant des années 1970 », in BussIËRE Éric, DUMOULIN Michel, SCHIRMANN Sylvain (dir.), Milieux économiques et intégration européenne au XX siècle. La crise des années 1970. De la Conférence de La Haye à la veille de la relance des années 1980, Peter Lang, Bruxelles, 2006, p. 35-50.

- MAES Ivo, Macroeconomic and Monetary Thought at the European Commission in the 1960s, EUI-RSCAS Working Papers, $\mathrm{n}^{\circ}$ 1, 2004.

- MiLWARD Alan, «The European Monetary Agreement », in TRAUSCH Gilbert (éd.), Die Europaïsche Integration vom Schuman-Plan bis zu den Verträgen von Rom, Nomos Verlag, Baden-Baden, 1993, p. 115-128.

- PAYE Jean-Claude, «Vers le Plan Werner. Le rôle de la Commission des Communautés, 1967-1973 », in Le rôle des ministères des Finances et de l'Économie dans la construction européenne (1957-1978), tome II, Comité pour l'histoire économique et financière de la France, Paris, p. 113-122.

- PITMAN Paul, «Le retour à la convertibilité monétaire en Europe occidentale et le redressement financier français ", in LÉVY-LEBOYER Maurice, PLESSIS Alain, AGLIETTA Michel, DE BoISSIEU Christian (dir.), Du franc Poincaré à l'écu, Comité pour l'histoire économique et financière de la France, Paris, 1993, p. 449-470.

- SchWAAG Sylvia, « Currency convertibility and European Integration : France, Germany and Britain », in Deighton Anne, MiLWARD Alan (éd.), Widening, deepening and acceleration: The European Economic Community, 1957-1963, Bruylant, Bruxelles, 1999, p. 89-106. 


\section{RELATIONS ÉCONOMIQUES EXTÉRIEURES}

- AUBOURG Valérie, « Entre intégration régionale, vision atlantique et perspective mondiale : Pierre Uri, la CEE et la libéralisation commerciale internationale à la veille du Kennedy Round », in BossuAT Gérard (dir.), L'originalité des communautés européennes dans le processus de mondialisation. L'Europe et la mondialisation, Soleb, Paris, 2006, p. 42-63

- Bossuat Gérard, «Le projet de la Commission pour les relations extérieures de la Communauté économique européenne, 1958-1972, la « mondialisation en question » », in BOSSUAT Gérard (dir.), L'originalité des communautés européennes dans le processus de mondialisation. L'Europe et la mondialisation, Soleb, Paris, 2006, p. 10-41.

- BossuAT Gérard, LEGENDRE Anaïs, « Le rôle de la Commission dans les relations extérieures », in DuMOULIN Michel (dir.), La Commission européenne, 1958-1972. Histoire et mémoire d'une institution, Communautés européennes, Bruxelles, 2007, p. 351-390.

- Coppolaro Lucia, Trade and Politic across the Atlantic : the European Economic Community (EEC) and the United States of America in the GATT Negotiations of the Kennedy Round (1962-1967), thèse dir. Alan Milward, Institut universitaire européen de Florence, 2006.

- Migani Guia, La France et l'Afrique subsaharienne, 1957-1963 : histoire d'une décolonisation entre idéaux eurafricains et politique de puissance, Peter Lang, Bruxelles, 2008.

- TURPIN Frédéric, «L'association Europe-Afrique : une « bonne affaire » pour la France dans ses relations avec l'Afrique. (1957-1975) ", in BITSCH Marie-Thérèse, BOSSUAT Gérard (dir.), L'Europe unie et l'Afrique. De l'idée d'Eurafrique à la Convention de Lomé I, Bruylant, Bruxelles, 2005, p. 345-360.

- WARLOUZET Laurent, «La Commission européenne face au défi de la « Grande Europe » : la négociation de la zone de libre-échange en 1958 », in BOSSUAT Gérard, DEIGHTON Anne (dir.), Les Communautés européenne, acteurs de la sécurité mondiale? Soleb, Paris, 2007, p. 364-381.

\section{PAC}

- KnUdSen Ann-Christina, Defining the Common Agricultural Policy. A Historical Study, thèse IUE (Florence), dir. Alan Milward, 2001.

- KNUDSEN Ann-Christina, Farmers on Welfare. The Making of Europe's Common Agricultural Policy, Cornell UP, Ithaca, 2009.

- KNUDSEN Ann-Christina, «European Integration in the Image and the Shadow of Agriculture », in DiNAN Desmond (éd.), Origins and Evolution of the European Union, Oxford UP, Oxford, 2006, p. 191-217 
- LuDLOW Piers, "The Making of the CAP : Towards a Historical Analysis of the EU's First Major Policy », in Contemporary European History, 2005-3, p. 347-371.

- LUDLOW Piers, «The Green Heart of Europe ? The Rise and Fall of the CAP as the Community's Central Policy, 1958-1985 », in PATEL Kiran (éd.), Fertile Ground for Europe? The History of European Integration and the Common Agricultural Policy since 1945, Nomos, Baden-Baden, 2009, p. 79-96.

- NoËL Gilbert, «Les finalités de la politique agricole commune (1958-1972). Marché et cohésion économique et sociale », in VARSORI Antonio (éd.), Inside the European Community. Actors and Policies in the European Integration, 1957-1972, Bruylant, Bruxelles, 2006, p. 283-300.

- NoËL Gilbert, «Le rôle des institutions dans le développement de la politique agricole commune (1968-1975) », in BUSSIÈRE Éric, DUMOULIN Michel, SCHIRMANN Sylvain (dir.), Milieux économiques et intégration européenne au XX $X^{e}$ siècle. La crise des années 1970. De la Conférence de La Haye à la veille de la relance des années 1980, Peter Lang, Bruxelles, 2006, p. 195-224.

- PATEL Kiran, Europäisierung wider Willen : Die Bundesrepublik Deutschland in der Agrarintegration der EWG, 1955-1975, Oldenbourg, Münich, 2009.

- PATEL Kiran, « Europeanisation à contre coeur. West Germany and agricultural Integration, 1950-1975 », in PATEL Kiran (éd.), Fertile Ground for Europe? The History of European Integration and the Common Agricultural Policy since 1945, Nomos, Baden-Baden, 2009, p. 139-160.

- PATEL Kiran, «Veto Player $\mathrm{N}^{\circ} 1$ ? Germany and the Creation of the EEC's Common Agricultural Policy, 1957-1964 », in GEHLER Michael (éd.), From Common Market to European Union Building. 50 Years of the Rome Treaties, 1957-2007, Böhlau, Cologne, 2009, p. 349-370.

- WARLOUZET Laurent, « The Deadlock : The choice of the CAP by de Gaulle and its impact on French EEC policy (1958-1969) », PATEL Kiran (éd.), Fertile Ground for Europe? The History of European Integration and the Common Agricultural Policy since 1945, Nomos, Baden-Baden, 2009,p. 99-118.

\section{INTERPRÉTATIONS DE SCIENCES-POLITIQUES}

- BURLEY Anne-Marie, MATTLI Walter, «Europe Before the Court : A Political Theory of Legal Integration », in International Organization, 47(1), hiver 1993, p. 41-76.

- HaAs Ernst B., The Uniting of Europe. Political, Social and Economic Forces, 1950-1957, Stanford UP, Stanford, 1958.

- HAAs Peter M., «Introduction : Epistemic Communities and International Policy Coordination », in International Organization, 1992, p. 1-36.

- HofFMANN Stanley, « Obstinate or Obsolete ? The Fate of the Nation-State and the Case of Western Europe », in HoffMAnN Stanley (éd.), Conditions of World Order, Simon and Schuster, New-York, 1970, p. 110-163. 
- LindBerg Leon, The Political Dynamics of European Economic Integration, Stanford UP, Stanford, 1963.

- Majone Giandomenico, La Communauté européenne : un État régulateur, Montchrestien, Paris, 1996.

- PIERSON Paul, «The Path to European Integration : A Historical Institutionalist Analysis », in Comparative Political Studies, 29(2), 1996, p. 123-163.

- Puchala Donald, « Of Blind Men, Elephants and International Integration », in Journal of Common Market Studies, 10/3, 1972, p. 267-284.

- WEILER Joseph, «The transformation of Europe », in The Yale Law Journal, vol. 100, p. 2403-2479.

\section{HISTOIRE ÉCONOMIQUE FRANÇAISE}

\section{HISTOIRE ÉCONOMIQUE GÉNÉRALE}

- BARJOT Dominique, "L'histoire économique de la France aux XIX ${ }^{\mathrm{e}}$ et $\mathrm{XX}^{\mathrm{e}}$ siècles » in BARJOT Dominique (coord.), Où va l'histoire économique?, numéro spécial d'Historiens et Géographes, mai 2002, p. 165-180.

- BUSSIÈRE Éric (dir.), Georges Pompidou et la mutation économique de l'Occident, PUF, Paris, 2003.

- DAUMAS Jean-Claude, "Redynamiser l'histoire économique en France », in Entreprises et histoire, ${ }^{\circ}$ 52, 2008/3, p. 7-17.

- KUISEL Richard, Le capitalisme et l'État en France. Modernisation et dirigisme au XX siècle, Gallimard, Paris, 1984 [1981].

- MARGAIRAZ Michel, L'État, les finances et l'économie. Histoire d'une conversion, 1932-1952, 2 vol., Comité pour l'histoire économique et financière de la France, Paris, 1991.

- MARSEILLE Jacques, Empire colonial et capitalisme français. Histoire d'un divorce, Albin Michel, Paris, 1984.

- Prate Alain, Les batailles économiques du général de Gaulle, Plon, Paris, 1978.

\section{HISTOIRE}

\section{DE L'ADMINISTRATION ET DE L'ÉTAT}

- BADEL Laurence, « La direction des relations économiques extérieures (DREE). Origines, culture, logique (1920-1970) », in BADEL Laurence, JEANNESSON Stanislas, LUDLOW Piers (dir.), Les administrations nationales et la construction européenne, Peter Lang, Bruxelles, 2005, p. 169-206. 
- BADEL Laurence, « Le Quai d'Orsay, la Grande-Bretagne et l'élargissement de la Communauté (1963-1969). Aspects fonctionnel et culturel », in CATALA Michel (dir.), Cinquante ans après la déclaration Schuman. Histoire de la construction européenne, Presses académiques de l'Ouest, Nantes, 2001, p. 235-260.

- BADEL Laurence, «Le rôle tenu par le poste d'expansion économique de Londres dans le processus d'adhésion du Royaume-Uni au Marché commun, 1966-1971 », in Le rôle des ministères des Finances et de l'Économie dans la construction européenne (1957-1978), tome I, Comité pour l'histoire économique et financière de la France, Paris, 2002, p. 229-266.

- BossuAT Gérard, "Les hauts fonctionnaires du ministère des Finances français et la construction européenne, 1948-1974 », in Le rôle des ministères des Finances et de l'Économie dans la construction européenne (1957-1978), tome I, Comité pour l'histoire économique et financière de la France, Paris, 2002, p. 142-187.

- Bossuat Gérard, «La culture de l'unité européenne des élites françaises aux Communautés européennes », in VARSORI Antonio (éd.), Inside the European Community. Actors and Policies in the European Integration, 1957-1972, Bruylant, Bruxelles, 2006, p. 79-94.

- BOUVIER Jean, BLOCH-LAINÉ François, La France restaurée, 1944-1954 : dialogue sur le choix d'une modernisation, Fayard, Paris, 1986.

- DE CASTELNAU Anne, «Le SGCI : une réponse administrative aux défis européens », in BADEL Laurence, JEANNESSON Stanislas, LUDLOW Piers (dir.), Les administrations nationales et la construction européenne. Une approche historique (1919-1975), Peter Lang, Bruxelles, p. 307-336.

- De CASTElnaU Anne, « Le rôle du SGCI dans les relations de la France avec le Marché commun, 1956-1961 ", in Le rôle des ministères des Finances et de l'Économie dans la construction européenne (1957-1978), tome I, Comité pour l'histoire économique et financière de la France, Paris, p. 207-228.

- Chadeau Emmanuel, « Les modernisateurs de la France et l'économie du $\mathrm{XX}^{\mathrm{e}}$ siècle. Note sur quelques ouvrages d'histoire immédiate ", in Bulletin de l'IHTP, septembre 1982, p. 22-35.

- CHELINI Michel-Pierre, Inflation, État et opinion en France de 1944 à 1952, Comité pour l'histoire économique et financière de la France, Paris, 1998.

- DESCAMPS Florence, « François Bloch-Lainé et la réforme de l'État : de l'action au magistère moral, 1946-1996», in MARGAIRAZ Michel (dir.), François Bloch-Lainé, fonctionnaire, financier, citoyen, Comité pour l'histoire économique et financière de la France, Paris, 2005, p. 157-232.

- Descamps Florence, « Michel Debré et la réforme du ministère des Finances : continuités et innovations, 1938-1968 », in Michel Debré, un réformateur aux Finances, 1966-1968, Comité pour l'histoire économique et financière de la France, Paris, 2005, p. 145-182. 
- GAÏTI Brigitte, «Les modernisateurs dans l'administration d'après-guerre. L'écriture d'une histoire héroïque », in Revue française d'administration publique, $\mathrm{n}^{\circ} 102$, avriljuin 2002, p. 295-306.

- GERBET Pierre, «L'élaboration des politiques communautaires au niveau national français », in RIDEAU Joël, GERBET Pierre, TORRELli Maurice, CHEVALIER Michel (dir.), La France et les Communautés européennes, LGDJ, Paris, 1975, p. 379-398.

- MANGENOT Michel, Une Europe improbable. Les hauts fonctionnaires français dans la construction européenne, 1948-1992, thèse de sciences politiques, dir. Brigitte Gaïti, IEP de Strasbourg, 2001.

- MANGENOT Michel, «La formation à l'Europe des hauts fonctionnaires des Finances français entre économie mondiale et planification nationale ", in Le rôle des ministères des Finances et de l'Économie dans la construction européenne (1957-1978), tome I, Comité pour l'histoire économique et financière de la France, Paris, 2002, p. 119-142.

- OSMONT Matthieu, «Europe politique versus Europe économique ? Rivalités et répartition des rôles dans les dossiers européens entre la direction des Affaires politiques et la direction des Affaires économiques et financières au Quai d'Orsay (1955-1974) », in AfFinIto Michele, MigANI Guia, Wenkel Christian (dir.), Les deux Europes, actes du III colloque international RICHIE, Peter Lang, Bruxelles, 2009, p. 197-212.

- QueNOUËLle-CORRE Laure, La direction du Trésor 1947-1967. L'État-banquier et la croissance, Comité pour l'histoire économique et financière de la France, Paris, 2000 .

- TRISTRAM Frédéric, Une fiscalité pour la croissance. La direction générale des Impôts et la politique fiscale en France de 1948 à la fin des années 1960, Comité pour l'histoire économique et financière de la France, Paris, 2005.

- TERRAY Aude, Des francs-tireurs aux experts. L'organisation de la prévision économique au ministère des Finances. 1948-1968, Comité pour l'histoire économique et financière de la France, Paris, 2002.

- WARLOUZET Laurent, « Le Quai d'Orsay face au traité de Rome. La direction des Affaires économiques et financières (DAEF) de 1957 à 1975 », in BADEL Laurence, JEANNESSON Stanislas, LUDLOW Piers (dir.), Les administrations nationales et la construction européenne, Peter Lang, Bruxelles, 2005, p. 139-168.

\section{PATRONAT FRANÇAIS}

- BounIÉ Jean-Paul, Le CNPF et l'Europe, Georges Lang, Paris, 1969.

- Bourdieu Pierre, DE SAINT MARTIN Monique, «Le patronat ", in Actes de la recherche en sciences sociales, 1978, vol. 20, $\mathrm{n}^{\circ} 1$, p. 3-82.

- Bouvier Yves, La Compagnie générale d'électricité : un grand groupe industriel et l'État. Technologies, hommes et marchés. 1898-1992, thèse, dir. Pascal Griset, Université Paris IV-Sorbonne, 2005. 
- BRIZAY Bernard, Le patronat : histoire, structures, stratégie du CNPF, Seuil, Paris, 1975.

- ERHMANN Henry, Organized Business in France, Princeton UP, Princeton, 1957.

- GARrigues Jean, Les patrons et la politique. De Schneider à Seillière, Perrin, Paris, 2002.

- HodeIR Catherine, Stratégies d'Empire. Le grand patronat colonial face à la décolonisation, Belin, Paris, 2003.

- LEFRANC Georges, Les organisations patronales en France du passé au présent, Payot, Paris, 1976.

- MeYnaud Jean, Les groupes de pression en France, Cahiers de la FNSP n 95 , Colin, Paris, 1958.

- TOUCHELAY Béatrice, « Les difficultés d'adaptation des industriels du CNPF aux nouvelles formes du lobbying politique entre 1946 et $1969 »$, in ANCEAU Éric, BARJOT Dominique, DARD Olivier, MUSIEDLAK Didier (dir.), Industrie et politique en Europe occidentale (XIX $X^{\mathrm{e}}$ et $X X^{\mathrm{e}}$ siècles), PUPS, Paris, p. 383-397.

- WeBER Henri, Le parti des patrons. Le CNPF 1946-1990, Seuil, Paris, 1986.

\section{HISTOIRE DES IDÉES}

- Clouet Stéphane, De la rénovation à l'utopie socialiste. Révolution constructive, un groupe d'intellectuels socialistes des années 1930, Presses Universitaires de Nancy, Nancy, 1991.

- DARD Olivier, «Économie et économistes des années trente aux années cinquante : un tournant keynésien ? », in Historiens et Géographes, $n^{\circ}$ 361, 1998, p. 173-195.

- DENORD François, Néo-libéralisme version française. Histoire d'une idéologie politique, Démopolis, Paris, 2007.

- Rosanvallon Pierre, "Histoire des idées keynésiennes en France » in Revue française d'économie, vol. 2-4, automne 1987, p. 22-56.

- SCHIRMANN Sylvain, "La CFDT et l'organisation des marchés européens au cours des années 1960 », in BuSSIÈRE Éric, DUMOULIN Michel, SCHIRMANN Sylvain (dir.), Europe organisée, Europe du libre-échange? Fin XIXْ-années 1960, Peter Lang, Bruxelles, p. 243-250.

\section{LA PLANIFICATION}

- FOURQUET François (éd.), Les comptes de la puissance : histoire de la comptabilité nationale et du Plan, Recherches, Paris, 1980.

- GRuson Claude, Origines et espoirs de la planification en France, Dunod, Paris, 1968. 
- MC ARTHUR John, SCOTT Bruce, L'industrie française face aux plans, Harvard ausculte la France (Industrial planning in France), Les éditions d'organisation, Paris 1970.

- MARGAIRAZ Michel, «Planification et politiques industrielles des années 1940 aux années 1960 : les trois figures du Plan », in KHARABA Ivan, DALMASSO Anne, Mioche Philippe et al. (dir.), Politiques industrielles d'hier et d'aujourd'hui, en France et en Europe, PU de Dijon, Dijon, 2009, p. 25-42.

- Mioche Philippe, Le plan Monnet, genèse et élaboration, 1941-1947, PUPS, Paris, 1987.

- Mioche Philippe, CAZEs Bernard (dir.), Modernisation ou décadence. Contribution à l'histoire du plan Monnet et de la planification en France, Publ. de l'université de Provence, Aix-en-Provence, 1990.

- Rousso Henry (dir.), De Monnet à Massé. Enjeux politiques et objectifs économiques dans le cadre des quatre premiers plans (1946-1965), Éd. CNRS, Paris, 1986

- Rousso Henry (dir.), La planification en crise (1965-1985), Éd. CNRS, Paris, 1987.

- TERRAY Aude, Des francs-tireurs aux experts. L'organisation de la prévision économique au ministère des Finances. 1948-1968, Comité pour l'histoire économique et financière de la France, Paris, 2002.

\section{LA POLITIQUE DE LA CONCURRENCE}

- ADAMS William, Restructuring the French Economy. Governement and the Rise of Market Competition since World War II, The Brookings Institution, Washington DC, 1989.

- BraUlt Dominique, L'État et la concurrence en France, Économica, Paris, 1987.

- CHATRIOT Alain, « Les ententes : débats juridiques et dispositifs législatifs (19231953). La genèse de la politique de la concurrence en France », in Histoire, économie et sociétés, numéro spécial, 2008/1, p. 7-22.

- DUMEZ Hervé, JEUNEMAîTRE Alain, Diriger l'économie. L'État et les prix en France, 1936-1986, L'Harmattan, Paris, 1989.

- JENNY Frédéric, « Du contrôle des prix à la politique de la concurrence en France. L'alliance difficile de considérations économiques et politiques », in Annales de l'économie politique, sociale et coopérative, 1981-1984, octobre-décembre 1981, p. 477490.

- KIPPING Matthias, «Concurrence et compétitivité. Les origines de la législation anti-trust française après $1945 »$ in Études et documents, IV, Comité pour l'histoire économique et financière de la France, 1994, p. 429-455. 


\section{LA POLITIQUE INDUSTRIELLE}

- BIEGANSKI Stéphane, «La politique des champions nationaux dans le discours et dans le geste : tentative de définition », in Kharaba Ivan, DALMASSO Anne, Mioche Philippe et al. (dir.), Politiques industrielles d'hier et d'aujourd'hui, en France et en Europe, PU de Dijon, Dijon, 2009, p. 87-100.

- Chatriot Alain, DUCLERC Vincent (dir.), Quel avenir pour la recherche?, Flammarion, Paris, 2003.

- ESAMBERT Bernard, «La politique industrielle de Georges Pompidou et l'Europe », in Maurice Vaïsse (dir.), Georges Pompidou et l'Europe, Complexe, Bruxelles, 1995, p. 505-516.

- GRISET Pascal, «Entre pragmatisme et ambition : la politique industrielle de Georges Pompidou face au contexte des années $1970 »$, in Éric Bussière (dir.), Georges Pompidou et la mutation économique de l'Occident, PUF, Paris, 2003, p. 283-296.

- GRISET Pascal, PÉBEREAU Georges, L'industrie, une passion française, Paris, PUF, 2005.

- KOCHER-MARBOEUF Éric, «L'expansion industrielle au service de l'ambition industrielle », in BERSTEIN Serge, MilZA Pierre, SIRINELLI Jean-François (dir.), Michel Debré Premier ministre, PUF, Paris, 2005, p. 203-214.

- « Le général de Gaulle et la recherche scientifique et technique », Cahiers n ${ }^{\circ} 12$ de la Fondation Charles de Gaulle, 2003.

\section{LA POLITIQUE AGRICOLE}

- BRUNETEAU Bernard, Les paysans dans l'État : le gaullisme et le syndicalisme agricole sous la $V^{\mathcal{C}}$ République, L'harmattan, Paris, 1994.

- CÉPÈDE Michel, WEIL Gérard, L'agriculture, PUF, Paris, 1965.

- KeELER John, The Politics of Neocorporatism in France. Farmers, the State, and Agricultural Policy-making in the Fifth Republic, Oxford UP, Oxford, 1987.

- LYNCH Édouard, «Le moment Debré et la genèse d'une nouvelle politique agricole », in BERSTEIN Serge, Milza Pierre, Sirinelli Jean-François (dir.), Michel Debré Premier ministre, PUF, Paris, 2005, p. 215-234.

- Meynaud Jean, La révolte paysanne, Payot, Paris, 1963.

- Wright Gordon, Rural Revolution in France. The Peasantry in the Twentieth Century, Stanford UP, Stanford, 1964. 


\section{INDEX DES NOMS DE PERSONNES}

L'indexation porte sur le texte, à l'exclusion des notes et annexes.

A

Adenauer (Konrad) 48, 49, 84, 148, $154,160,162,163,164,185,187$, $191,248,391$.

Aigrain (Pierre) 472.

Albert (Michel) 441, 444, 447, 451, 452, 454, 458, 462, 464, 466, 471, $473,484,503$.

Albrecht (Ernst) 282, 393, 461, 475.

Allais (Maurice) 173.

Armengaud (André) 318, 323.

Arnaud (René) 297, 481.

Aron (Raymond) 342.

\section{B}

Barre (Raymond) 257, 258, 259, 265, 339, 396, 399, 400, 401, 402, 403, 404, 408, 410-417, 501.

Baumgartner (Wilfrid) 174, 176-178, 183, 184, 257, 265, 306, 363.

Beaurepaire (Claude) 34, 39, 67, 80, 316, 317.

Beddington-Behrens (Edward) 130.

Bekaert (Léon) 285.

Bernard (Jean-René) 265, 441.

Bernard (Paul) 54.

Beyen (Johan-Willem) 81.

Bichelonne (Pierre) 57.

Bidault (Georges) 147.

Bloch-Lainé (François) 72, 478, 479, 482.

Blum (Léon) 198, 340, 400.

Bobba (Franco) 379, 392, 462.
Boegner (Jean-Marc) 249, 319, 323, 406, 426, 428, 471-473.

Boël (René) 130.

Böhm (Franz) 286.

Boris (Georges) 27.

Bosquet (Maurice) 56 .

Bourgès-Maunoury (Maurice) 101, 102, 139.

Boussac (Marcel) 108.

Boyle (Edward) 122.

Brandt (Willy) 8, 489.

Brault (Dominique) 475.

Braun (Fernand) 462.

Brunet (Jean-Pierre) 111-113, 115, 261, 453, 454, 501.

\section{C}

Cahan (Philip) 130.

Calan (Pierre de) 57, 58, 108, 478, 479, 481.

Calvet (Pierre) 183.

Camu (Louis) 349.

Carbonnel (Éric de) 114.

Carli (Guido) 137, 140, 152.

Caron (Giuseppe) 391, 461.

Carstens (Karl) 49, 80.

Ceyrac (François) 110.

Chaban-Delmas (Jacques) 45, 238, 489.

Chapelle (Jean) 406.

Châtenet (Pierre) 257, 400.

Chauvel (Jean) 128. 
Churchill (Winston) 48.

Clappier (Bernard) 24, 61, 65, 78, 80, 84, 421.

Colombo (Emilio) 397.

Colonna di Paliano (Guido) 453, 457, 460-467, 470, 486-488, 491.

Colthoff (Albert Rom) 278, 279.

Coty (René) 36.

Couve de Murville (Maurice) 13, 42, $147,148,150,151,153,161,165$, $212,215,224,228,251,259,260$, 262-266, 387, 405, 408, 421, 429, 448.

\section{D}

Debré (Michel) 13, 145, 148, 224, $231,232,234,236,245,247,256-$ 260, 262-266, 293, 295, 306, 315, 321, 343, 397-399, 401-406, 409, 415, 417, 420, 435-439, 441, 442, 444-446, 449, 450, 454-458, 460, $462,471,474,478,484,485,491$, 492, 494, 501, 502.

Del Bo (Dino) 459.

Delcourt (Jean-Paul) 133, 212.

Del Marmol (Charley) 283, 297, 299, 300, 311.

Delors (Jacques) 343, 506.

Demonque (Marcel) 349, 478, 479.

Deniau (Jean-François) 56, 82, 97, 99, 111-113, 118, 189, 190, 214, 256, 390, 447.

Deringer (Arved) 287, 315, 318, 323, 335.

De Staercke (Roger) 300.

Dillon (Douglas) 162.

Donnedieu de Vabres (Jacques) 38, $115,123,127,133-135,213,234$, 255.

Dreyfus (Pierre) 56, 99, 126, 154, 213.

Dromer (Jean) 250, 256, 258, 265, 422, 431, 432, 436-439, 441, 442, $444,447,448,450,451,453,454$,
$459,465,466,468,469,471,484$, 492, 503.

Dulles (John Foster) 47.

Dupont-Fauville (Antoine) 435.

\section{E}

Eccles (David) 158, 159, 164, 165.

Eden (Anthony) 48.

Emminger (Otto) 364.

Erhard (Ludwig) 48, 62, 128, 134, $164,173,178,179,185,188,227$, $248,272,275,279,282,294,352$, $374,382,389,460$.

Esteva (Pierre) 362.

Etzel (Franz) 179, 360.

Eucken (Walter) 282, 391.

\section{F}

Fabra (Paul) 349.

Fabre (Robert) 277, 279, 280, 283, 302.

Fanfani (Amintore) 470.

Faure (Edgar) 69, 436, 438.

Faure (Maurice) 31, 36, 38, 40, 44, $45,79,82,108,118,124,127,128$, $134,135,148,188,212,216,260$, 318.

Fayol (Henri) 104, 105, 478-481.

Flory (Jean) 394, 462, 487.

Fontanet (Joseph) 293, 294, 306, 309, 310, 314, 318, 333.

Franck (Louis) 32, 183, 257.

François-Poncet (André) 52.

François-Poncet (Jean) 111.

\section{G}

Gaillard (Félix) 27, 81, 101, 102, 104, $106,107,117,126,132,133,135$, $139,140,152,166,195,204,209$, 212.

Gaudet (Michel) 117.

Gaulle (Charles de) 8, 15, 102, 107, 143-147, 149-151, 154, 155, 158, $159,161-163,166,172,173,175$, 
177-180, 184, 185, 195, 196, 200, 202-205, 208, 209, 211-213, 215, 223-228, 238-248, 257, 258-267, $315,321,343,387,392,400,407$, 410, 414, 415, 417, 422, 435-437, $442,443,453,455,457,473,477$, 488, 489, 493, 494, 495, 500, 505, 506, 507.

Gaulle (Philippe de) 223.

Genière (Renaud de la) 111.

Giscard d'Estaing (Edmond) 54 .

Giscard d'Estaing (Valéry) 231, 265, $266,305,306,383,410,424,425$, 482.

Goetze (Roger) 31-33, 73, 83, 97, 151, 153, 176, 184, 204, 215, 225, 409, 503.

Gruson (Claude) 72, 73, 346, 347, 503.

Guéna (Yves) 257.

Guichard (Olivier) 440, 455, 456, 457, 458.

Günther (Eberhard) 282, 287.

Gutmann (Francis) 34, 66.

\section{H}

Haberer (Jean-Yves) 455.

Hallstein (Walter) 48, 136, 137, 160, 187-190, 195, 202, 209, 216, 252, $262,282,283,291,379-382,386-$ $395,416,465,494$.

Hayek (Friedrich von) 400.

Heathcoat-Amory (Derrick) 169, 170, $178,179$.

Hommey (Bertrand) 79.

Houphouët-Boigny (Félix) 116.

Huet (Philippe) 252.

Huvelin (Paul) 348, 477, 478.

Iveroth (Axel) 131.

Jacobsson (Per) 177.
Jeanneney (Jean-Marcel) 231, 257, 287, 294, 306, 337, 400, 410.

Juvigny (Pierre) 39 .

\section{K}

Kervin de Lettenhove (Albert) 346, 347, 354.

Keynes (John Maynard) 340.

Khrouchtchev (Nikita) 49, 163.

Kiesinger (Kurt-Georg) 460.

Kojève (Alexandre) 65, 183, 342.

Koster (H.J. de) 427.

\section{L}

Lafond (Henri) 54.

Lagrange (Maurice) 117.

Lahr (Rolf) 453.

La Martinière (Dominique de) 441.

Lamfallussy (Alexandre) 349.

Langer (Wolfram) 354, 497.

Lapie (Pierre-Olivier) 257-259, 295.

Larre (René) 398, 404, 413.

Lartisien (Raymond) 279, 284, 293, 299, 305, 306, 310, 311, 314, 315, $320,333,348,354$.

Lasry (Claude) 422.

Lattre (André de) 177, 363.

Leclerc (Édouard) 293.

Lecourt (Robert) 250.

Lefaucheux (Pierre) 57, 274.

Lelong (Pierre) 443.

Lemaignen (Robert) 53, 116, 257 , 305.

Lévêque (Jean-Maxime) 478.

Levi Sandri (Lionello) 354.

Lippmann (Walter) 340.

Lloyd (Selwyn) 121.

Loucheur (Louis) 442.

Louis (Jean) 53, 66, 105, 176, 478.

Louvel (Jean-Marie) 478.

Luns (Josef) 485. 


\section{M}

Macmillan (Harold) 47, 60, 61, 63, 67, $80,121,122,151,158,159,161$, 164, 167, 170, 171, 179, 212.

Maillet (Pierre) 462.

Malvestiti (Piero) 461.

Mansholt (Sicco) 239, 354, 391, 393, 394.

Marchal (André) 287, 345.

Marcille (Yves) 295, 320.

Maréchal (André) 430, 472.

Marjolin (Robert) 14, 16, 38, 43, 44, $49,56,61,65,67,76,78-81,83$, 86, 97-101, 116-118, 121, 160, 174, 188, 190, 191, 195-203, 209, 210, 212, 214-216, 256-258, 279, 291, 339-342, 345-349, 351-386, 390404, 412-417, 419, 424-426, 434, $453,459,461,462,465,466,487$. 491, 493-496, 498, 500, 501, 506.

Martino (Gaetano) 61.

Marx (Karl) 341.

Massé (Pierre) 343, 344, 347, 348, 354, 409.

Massigli (René) 24, 38, 73, 85, 261.

Mattei (Franco) 283.

Maudling (Réginald) 122, 128, 138, $151,158,160,161,166,170,188$, 203.

Mayer (René) 119.

Mayolle (Emmanuel) 348, 478.

Méline (Jules) 438.

Mendès France (Pierre) 8, 27, 35-37, $59,63,68-72,74,77,86,97,111$, 449, 482, 505.

Mestmäcker (Ernst-Joachim) 286, 371.

Meyer (Fritz) 282.

Meynaud (Jean) 345.

Mille (Jean) 111, 113, 245, 255, 307.

Millet (Pierre) 345, 461, 462.

Minoli (Eugenio) 312.

Missoffe (François) 318, 320.
Mitterrand (François) 45.

Mollet (Guy) 19, 22, 31, 34-38, 41, 43-51, 62, 69, 76-78, 80, 81, 82, $86,97-99,101,117,133,147,204$, 208, 210, 212, 213, 215, 261, 295, 410, 505.

Monnet (Jean) 14, 27, 36, 79, 81, 83, $84,86,99,103,117,126,197,200$, $212,274,341-343,345,356,360$, 366, 370, 396, 410, 500, 501, 505.

Montjoie (René) 422.

Moro (Aldo) 368 .

Mosca (Ugo) 462.

Müller-Armack (Alfred) 48, 160, 190, 272, 274, 275, 308-310, 333, 357, $372,374,383$.

\section{$\mathbf{N}$}

Narjes (Karl-Heinz) 387.

Nixon (Richard) 489.

Noël (Émile) 14, 82, 117, 372, 393, 398.

Nora (Simon) 422, 482, 489.

\section{O}

Ortoli (François-Xavier) 118, 189, 190, 256, 264, 302, 422, 426, 443, 445, 447, 449-451, 454, 461, 466, 471, 484, 492.

\section{$\mathbf{P}$}

Palewski (Gaston) 429, 430.

Pelletier (Robert) 480.

Pérouse (Maurice) 257, 398, 400.

Perroux (François) 400.

Petrilli (Giuseppe) 481.

Peyrefitte (Alain) 85, 111, 112, 215, 224, 238, 246-249.

Pflimlin (Pierre) 103, 106, 132, 133, 135, 139.

Pierre-Brossolette (Claude) 83.

Pinay (Antoine) 147, 174, 175, 179, 184, 195, 196, 227, 234, 265. 
Pineau (Christian) 35-38, 62, 63, 64, $77,78,86,97,98,123,124,139$, 197, 208, 212, 213, 215, 239, 340, 342, 505.

Pisani (Edgar) 238.

Poincaré (Raymond) 173.

Poinso-Chapuis (Germaine) 272.

Pompidou (Georges) 8, 264, 265, 405, 420-422, 426, 427, 436, 438, 443, $449,454,455,457,471,474,482$, 483, 489, 491.

Ponzano (Stefano) 462.

Prate (Alain) 111, 113, 118, 225, 265, $346,407,409,442,447,452,454$, 461, 462, 463, 464, 466, 473, 483.

Proudhon (Pierre-Joseph) 341 .

\section{$\mathbf{R}$}

Rabier (Jacques-René) 118, 287.

Rabot (Louis-Georges) 118, 119.

Ramadier (Paul) 31, 45, 61, 63, 68, 69, 72, 80, 83, 86, 97, 215.

Rey (Jean) 189, 390, 393, 406, 465, 466.

Reynaud (Paul) 173.

Ricard (Pierre) 53.

Rist (Charles) 340, 400.

Rochereau (Henri) 380.

Röpcke (Wilhelm) 391 .

Roux (Ambroise) 446, 478-481.

Rueff (Jacques) 119, 168, 172-176, 181, 184, 210, 215, 349, 400, 503.

\section{$\mathbf{S}$}

Saclé (Armand) 118, 119, 256, 375, 497.

Sadrin (Jean) 31, 32, 67, 73, 82, 97, 99, 128, 183, 192.

Saint-Geours (Jean) 398, 447, 449451, 454, 466, 471, 484, 503.

Saltes (Jean) 74, 183.

Sanders (Pieter) 467.

Sassen (Emmanuel) 475, 487.

Savary (Alain) 77.
Schröder (Gerhard) 382.

Schumacher (Hermann) 282, 287, 327.

Schuman (Robert) 24, 78, 147.

Sergent (René) 47, 130, 136, 457.

Serisé (Jean) 401.

Sermon (Lucien) 129, 130, 278.

Servan-Schreiber (Jean-Jacques) 451, 484.

Shonfield (Andrew) 344.

Snoy et d'Oppuers (Jean-Charles) 278.

Soames (Christopher) 226, 263, 488.

Soustelle (Jacques) 160.

Spaak (Paul-Henri) 25, 40, 44, 81.

Spinelli (Altiero) 488.

Stoleru (Lionel) 442.

\section{T}

Teitgen (Pierre-Henri) 119.

Toulemon (Robert) 462, 478, 484, 487, 503.

Triffin (Robert) 192, 197, 200, 356, 360, 361, 364, 366, 370, 371.

\section{$\mathbf{U}$}

Ulrich (Maurice) 249, 256.

Uri (Pierre) 14, 27, 72, 81, 197, 200, $212,214,282,346,356,371$.

\section{V}

Valéry (François) 31, 63, 64, 73, 85, 111, 112, 124, 139, 165, 215, 261.

Van der Schueren (Jacques) 300, 309, 314.

Van Lennep (Emile) 401, 417.

Van Scherpenberg (Hilger) 164.

Vedel (Georges) 38, 82 .

Verloren van Themaat (Pieter) 119, 282, 283, 287, 290, 294, 297, 298, 302, 312, 316, 317, 327, 375, 379.

Verret (Alexandre) 38, 133, 212.

Villiers (Georges) 51-54, 59, 66, 86, 97, 99, 104, 107, 109, 110, 116, 176, 213, 293, 310, 320, 477, 478, 480, 501. 
Vitry d'Avaucourt (Raoul de) 312, 313.

Von Brentano (Heinrich) 48, 160.

Von der Groeben (Hans) 27, 232-234, 269, 281, 282, 286, 289, 290-292, 296, 298-305, 307-315, 318, 319, $325,328,330,331,334-336,370-$ $379,390,393,394,398,410,416$, 461, 465, 466, 475.

\section{W}

Wahl (Jean) 119, 440, 441.

Werner (Pierre) 401.
Wertheimer (H.W.) 298.

Wilson (Harold) 440, 460, 470.

Wolff (Pieter de) 346, 347.

Wormser (Olivier) 24, 25, 27, 31, 33, 38-40, 42, 64, 73, 84, 94, 101, 103, 115, 124-127, 132, 133, 134, 137, 148-150, 152-159, 166, 183, 190, 195, 200, 204, 213, 215, 260-262, 421, 436. 


\section{INDEX DES INSTITUTIONS}

L'indexation porte sur le texte, à l'exclusion des notes et annexes. Non significative, l'entrée « CEE » n'a pas été retenue

A

AELE (Association européenne de libre-échange) 131.

AME (Accord monétaire européen) $171,180,181,185,192,200,201$, 364.

Assemblée parlementaire européenne (puis Parlement européen) 99, 305, $308,311,315,318,319,334,335$, $337,374,378,383,387-389,391$, 394.

\section{B}

BDI (Bundesverband der Deutschen Industrie) 276, 277, 427, 476.

BEI (Banque européenne d'investissement) 90, 91, 92.

BKA (Bundeskartellamt) 271, 272, 282, 284, 286, 291, 324, 332, 336.

\section{C}

CBI (Confederation of British Industry) 440.

CCI (Chambre de commerce internationale) 116, 280, 291, 296, 297, 298, 303, 304, 311-313, 333, 337.

CECA (Communauté européenne du charbon et de l'acier) 7, 8, 150, $187,214,226,246,258,273,274$, 276, 277, 282, 286, 294, 295, 391, 396, 459, 461, 462.
CED (Communauté européenne de défense) 7, 23, 32, 36, 77, 87, 91, 93, 96, 99, 111, 144, 396.

CEEP (Centre européen de l'entreprise publique) 481, 491.

CEPES (Comité européen pour le progrès économique et social) 348 .

CES (Comité économique et social de la CEE) 305, 308, 334, 337.

Chambre syndicale de la sidérurgie française 40.

Chambre syndicale des constructeurs d'automobiles 55 .

CIFE (Conseil des fédérations industrielles européennes) 52, 130, 131, 277, 278, 480, 481.

CJCE (Cour de justice des communautés européennes) 87,88 , 99, 250, 251, 290, 314, 322, 496.

CNPF (Conseil national du patronat français) $15,35,43,51-54,58-60$, $65,66,79,80,86,97,101,104-$ $105109,110,112,116,126,128$, $131,140,153,176,186,208,213$, $229,231,276,277,279,281,293$, 297, 300-302, 306, 307, 310, 311, $313-315,319,320,333,334,349$, $369,433,434,440,476-481,501$, 502 .

COB (Commission des opérations de bourse) 400 . 
Comité d'action pour les États-Unis d'Europe 36, 84, 342, 362, 501.

Comité de politique budgétaire 365 , 367, 409.

Comité de politique conjoncturelle 367, 369, 372, 374, 402, 408.

Comité des gouverneurs 201, 365, 367, 404, 408, 498.

Comité monétaire 37, 46, 90, 93, 192, 199, 358, 359, 361, 366, 367, 370, $385,393,401,404,408,411,413$, 414, 416.

Comité Rueff 106, 169, 174, 176, 183, 409, 422.

Comité Rueff-Armand 179, 451.

Comité spécial agriculture 437.

Comité Verret 39, 40, 42, 65, 124.

Commission européenne 9, 10, 14, 30, $87,88,90,115-119,128,136,137$, $139,140,143,155,156,160,163$, $165,167,177,186-191,194-196$, 198-204, 209, 211, 216, 230, 231, 233-235, 239, 241, 245, 246, 249$258,262,263,269,274,275,278-$ 284, 286-342, , 345-354, 358-361, 365-380-, 383-395, 397, 399, 402, 403, 406-408, 410-412, 416, 419, $423,424,426,428-430,432,434-$ 437, 439, 441, 447, 448, 453, 456, 457, 459-468, 470, 472-477, 486, 488, 491, 492, 494-497, 502, 506.

Commonwealth 48, 61-63, 71, 95, $121,122,127,212,423$.

Commonwealth Office 47.

Confédération internationale des syndicats libres 352 .

Confindustria 131, 284, 320, 501.

Conseil CECA 87.

Conseil CEE 14, 30, 34, 49, 87, 88, $90,114,137,138,152,159,163$, 164, 189, 194, 195, 199, 200, 228, 231-233, 245, 249, 250, 253, 274, 275, 289, 291, 301, 302, 304-301, $313,315,318,319,321,322,325$,
$326,331,334,335,337,338,349$, 352-354, 358, 365, 366, 367, 375, $377,382,384,389,392,397,398$, 403, 412, 422, 430, 437, 440, 462, 470-472, 474, 476, 485, 494.

Conseil de l'Europe 7, 35, 82, 99, 117, 431.

Conseil d'État 117, 148.

COREPER (Comité des représentants permanents) $114,245,249,250$, $255,326,331,335,353,430,437$, 471, 472, 494.

Cour d'appel de Paris 251, 330.

CPC (Comité de politique conjoncturelle) 357,358 .

CPE (Communauté politique européenne) 87, 91, 93, 99, 396.

CPEMT (Comité de politique économique à moyen terme) 350 , 354, 367.

\section{D}

DAEF (Direction des Affaires économiques et financières du ministère des Affaires étrangères) 27, 31, 41, 42, 63-66, 73, 84, 86, $94,101,115,124,125,134,140$, $148,149,153,154,156,157,159$, $161,234,236,260,261,436,453$, 507.

Direction de la Prévision (ministère des Finances) 398, 401, 449, 482.

Direction des Douanes (ministère des Finances) 32.

Direction des Finances extérieures (ministère des Finances) 32, 67, 82, 183, 192.

Direction des Prix (ministère des Affaires économiques) $32,39,174$, 273, 292, 317.

Direction du Budget (ministère des Finances) 31, 32, 83, 482. 
Direction du Trésor (ministère des Finances) 31, 257, 398, 400, 404, 413, 448, 482.

DREE (Direction des Relations économiques extérieures du ministère des Affaires économiques) $24,61,65,74,78$, 116, 118, 183, 340, 406.

\section{$\mathbf{E}$}

Euratom 38, 43, 59, 79, 83, 84, 145, $148,150,342,400,470,475$.

\section{F}

FIB (Fédération des industries belges) 300, 309, 323, 333.

FIMTM (Fédération des industries mécaniques et transformatrices de métaux) 33, 40, 51, 57, 58, 73, 108, 110.

FMI (Fonds monétaire international) 7, 23, 103, 167, 169, 170, 177, 181, 201, 208, 216, 359, 360, 361, 366, 397, 401, 405, 408, 503.

FSE (Fonds social européen) 90.

\section{G}

GATT (General agreement on tariffs and trade) $7,22,23,121,122,136$, $140,150,157-160,162-165,167$, $174,175,181,185,188,201,204$, 208, 212, 216, 229, 252, 419, 436, $460,503,506$.

Groupement syndical des constructeurs français d'automobile 55.

\section{H}

Haute Autorité de la CECA 40, 69, 85, $87,93,99,117,118,246,257,258$, 274, 277, 294, 295, 307, 341, 342, 459.

\section{I}

IRC (Industrial Reorganisation Corporation) 442, 445.

IRI (Istituto per la Ricostruzione Industriale) 445, 462, 481.

\section{L}

LECE (Ligue européenne de coopération économique) 129,130 , 140, 280, 501.

\section{M}

Ministère français de l'Industrie 40, 74, 125, 127, 153, 183, 203, 235, 258, 292, 316, 329, 421, 455.

Ministère français des Affaires étrangères $14,27,31,34,38,41$, $54,66,71,73,85,94,111,114$, $115,124,147,148,212,213,234$, 249-251, 258, 261, 262, 266, 295, 330, 369, 434, 436, 453, 469, 507.

Ministère français des Affaires sociales 32,39 .

Ministère français des Finances et des Affaires économiques 14, 31, 72, $74,183,345,362,425,439,443$, 444, 456, 469, 482, 489, 507.

\section{$\mathbf{O}$}

OCDE (Organisation pour la coopération et le développement économique) 359.

OECE (Organisation européenne de coopération économique) $7,22,28$, 42, 46, 47, 53, 56, 62, 69, 78, 81, 84-87, 93-96, 99, 102, 114, 116, $119,120,122,123,124,126,130$, $131,136,137,138,140,156,162-$ $165,167,172,174,175,178,180-$ $182,184,185,192,195-197,201$, 204, 216, 226, 341, 342, 355, 357, 399, 415, 423, 456, 461, 506. 
OIT (Organisation internationale du travail) 39 .

OTAN (Organisation du Traité de l'Atlantique Nord) 59, 146, 151, $158,205,461,470$.

\section{$\mathbf{P}$}

PAC (Politique agricole commune) 12, 201, 225, 228, 236-241, 245, 249, 266, 267, 319, 335, 363, 387-389, $391,395,401,403,425,426,428$, 430, 432, 435-439, 442-444, 453, 454, 460, 491, 495, 496, 504, 506, 507.

PEMT (Politique économique à moyen terme) 349-352 355, 356, 362, 369, $378,380,385,396,412,414,461$, 463, 467.

Plan Beyen 24, 25, 40, 99.

Plan Rueff 105, 167, 168, 169, 174, 177-185, 203-205, 207, 208, 210, $211,213,225,227,230,337,358$, 409, 441, 447, 505, 506.

PRST (Politique de la recherche scientifique et technique) 428-430, 433, 434, 445, 460, 464, 467, 469, 470, 471, 473-477, 487-490, 504.

\section{$\mathbf{R}$}

REP (Représentation permanente de la France auprès de la CEE) 14, 114, 194, 255, 256, 306, 327, 329.

\section{$\mathrm{S}$}

SGCI (Secrétariat général du comité interministériel pour les questions de coopération économique européenne) $14,39,56,112,114$, $115,119,133,140,213,232,235$, $236,249,252,255,256,258,264$, 292, 307, 309, 315-317, 346, 426, $429,431,433-436,439,443,448$, 449, 459, 471, 475, 485, 489, 507.

Syndicat général de l'industrie cotonnière française 57, 108, 110.

\section{$\mathbf{U}$}

UEP (Union européenne des paiements) $23,103,167,171,177$, $178,180,181,185,192-194,196-$ 201, 216, 364, 498.

UNICE (Union des industries de la Communauté européenne) 15, 60, 276, 279, 280, 283-285, 294, 296$304,311,313,320,323,330,333$, $348,352,376,377,379,427,428$, 432, 434, 463, 473, 480, 481, 491.

\section{Z}

ZLE (Zone de libre-échange) 19, 46, 47, 49, 59, 61-68, 71, 73, 77, 78, 80, 84-86, 94-99, 112, 117, 118, 120-140, 143, 145, 146, 150-161, 163-172174, 175, 178-182 184191, 193, 197, 201-204, 208-216, 221, 229, 239, 243, 245, 260, 261, $278,279,282,337,356,357,358$, 390, 423, 435, 441, 501, 503, 504, $505,506$. 


\section{TABLE DES MATIÈRES}

Avant-propos....................... V

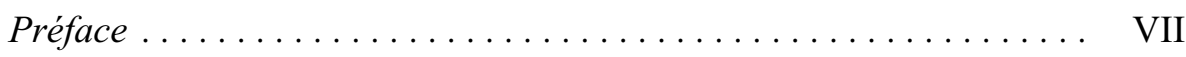

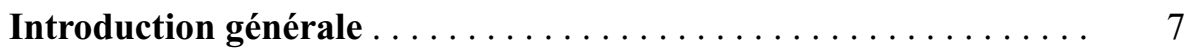

\section{PREMIÈRE PARTIE \\ LA FRANCE FACE À LA RÉORGANISATION \\ DE L'EUROPE : LES DÉFIS DU MARCHÉ COMMUN \\ ET DE LA ZLE (1955-1958)}

Chapitre premier. La CEE sans enthousiasme (1955-Mars 1957) . . .

I. L'invention d'un Marché commun hypothétique

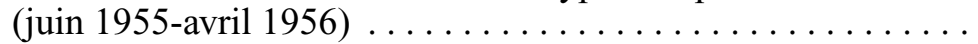

A. La France face à la construction européenne : opportunités et contraintes. ................ 2

1. La France au cœur des constructions européennes ...... 22

2. Les décideurs français méfiants face au projet de Marché commun..................... 23

3. Les ambiguïtés de la conférence de Messine ........ 25

4. Le mémorandum français d'octobre $1955 \ldots \ldots \ldots \ldots \ldots 26$

B. Le rapport Spaak : les équilibres du Marché commun . . . . . 27

C. La surprise et l'hostilité de l'administration française ..... 30

1. Le rapport Spaak et le mémorandum français

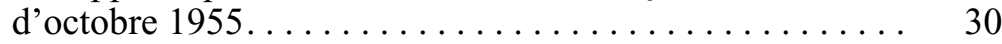

2. L'hostilité de l'administration au rapport Spaak ....... 30

3. La contre-proposition de l'administration française

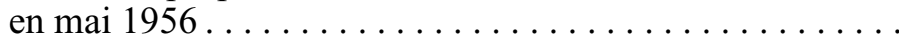


II. Le choix de la CEE par le gouvernement Mollet. . . . . . . . . 35

A. Le difficile choix politique du Marché commun

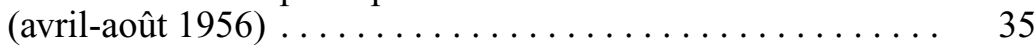

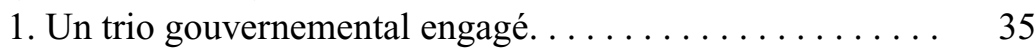

2. Le primat du pouvoir politique sur l'administration ..... 36

3. La reprise en main de l'administration . .......... 38

4. L'échec sur le fond des opposants internes au Marché commun . . . . . . . . . . . . . . . . . . . . 39

B. L'évolution vers une position française plus modérée (septembre-novembre 1956) . . . . . . . . . . . 43

1. La définition d'une position réaliste en septembre 1956. . 43

2. La ZLE et la place de la Grande-Bretagne dans la coopération européenne. ............. 46

3. Le «tournant» de Suez. . . . . . . . . . . . . . . . . 48

C. Le patronat divisé face au Marché commun :

le rôle de Georges Villiers . . . . . . . . . . . . . . . 50

1. Le soutien du CNPF au Marché commun ........... 51

2. Le lobbying d'experts de l'automobile dans la négociation finale ................ 55

3. La force de l'opposition patronale à la libération des échanges ....................... 57

4. Les libéraux peu enthousiastes envers le Marché

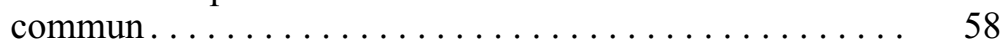

5. De l'influence de l'acteur patronal ............. 59

III. Un Marché commun toujours menacé

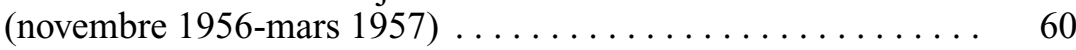

A. La ZLE : complément ou alternative $? \ldots \ldots \ldots \ldots \ldots \ldots$

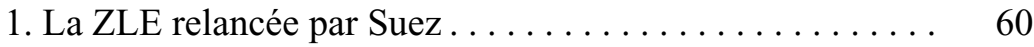

2. Une mobilisation naturelle en faveur de la ZLE ....... 63

3. L'émergence d'un groupe hostile à la ZLE ......... 65

B. Des opposants au Marché commun très influents ........ 68

1. Les décideurs politiques : Ramadier et Pierre Mendès France . . . . . . . . . . . . . . . . 68

2. Le Marché commun en porte-à-faux face à la logique des « fonctionnaires modernisateurs $» \ldots \ldots \ldots \ldots \ldots$. . . . 
C. La complémentarité des promoteurs du Marché commun . . 76

1. L'ambiguiité de la défense du Marché commun par Mollet ...................... 76

2. Le rôle central de Robert Marjolin ............. 78

3. Les autres promoteurs du Marché commun dans l'administration ................... 81

D. Les autres modèles d'Europe. . . . . . . . . . . . . . 83

E. Conclusion : des promoteurs du traité de Rome

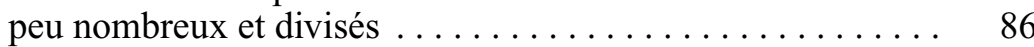

IV. Le traité de Rome face aux positions françaises . . . . . . . . 87

A. L'équilibre du traité de Rome . . . . . . . . . . . . 87

1. Un système institutionnel mixte . . . . . . . . . . 87

2. Une union économique potentielle $\ldots \ldots \ldots \ldots \ldots \ldots . \quad 88$

B. Le décalage face aux revendications françaises . . . . . . . 91

1. L'absence de contre-proposition française. . . . . . . . 92

2. Une difficile application de la CEE . ............ 93

3. La menace de la ZLE sur la vision française de la CEE .. . 94

V. Conclusion : la France et la négociation du traité de Rome. . . . 96

A. La contrainte extérieure impose l'option européenne ...... . 96

B. Le rôle décisif des promoteurs du Marché commun . . . . . . 96

C. L'intérêt économique et institutionnel de la CEE pour la France . . . . . . . . . . . . . . . . 98

Chapitre II. La crise française, la CEE et la ZLE (avril 1957-mai 1958) . . . . . . . . . . . . . . . . . . . . . . 101

I. La crise de la IV République.................. 101

A. Les difficultés financières et le crédit international de la France . . . . . . . . . . . . . . . . . . . . . . . 101

B. Le volontarisme du gouvernement Gaillard . . . . . . . 102

C. L'offensive du CNPF : l'assemblée générale extraordinaire du 13 mai $1958 \ldots \ldots \ldots \ldots \ldots \ldots \ldots$. . . . . . . . . . 104

D. La crise finale de la IV République. . . . . . . . . . 106

II. L'acceptation de la CEE . . . . . . . . . . . . . . . . 107

A. Le ralliement d'une majorité du patronat à la CEE. . . . . . . 107

1. La dernière opposition active : le secteur cotonnier . . . . . 107 
2. L'action de rassemblement du CNPF en faveur de la CEE. . . . . . . . . . . . . . . . . . . . . . . . . . . . 109

B. L'adaptation rapide des décideurs publics . . . . . . . . 111

1. L'évolution des fonctionnaires spécialisés dans les affaires

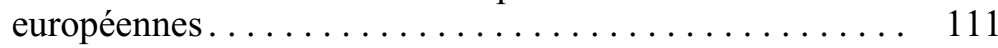

2. L'adaptation de l'organisation administrative ........ 113

C. L'absence de stratégie d'influence des jeunes institutions

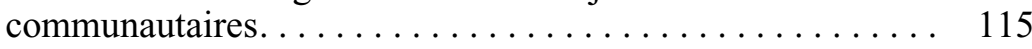

1. Les commissaires européens français . . . . . . . . 116

2. L'administration communautaire et la place des fonctionnaires français . . . . . . . . . . . 117

III. La pression de la négociation ZLE. . . . . . . . . . . . . . . 120

A. Les débuts de la négociation intergouvernementale de la ZLE. . . . . . . . . . . . . . . . . . . . . . 120

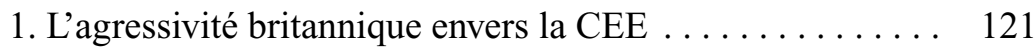

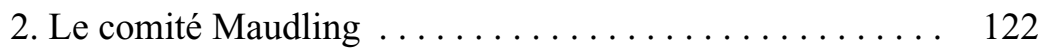

B. Une méfiance croissante envers la ZLE. . . . . . . . . 123

1. Christian Pineau et l'impératif de la ZLE ......... 123

2. La définition rapide d'une position restrictive par l'administration .................... 124

3. Une mobilisation patronale influente en France ... . . . . 126

4. Les divisions révélatrices du patronat européen . . . . . . . 129

C. La tentative de prise en main de la négociation

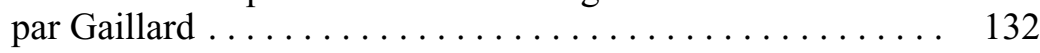

1. L'investissement de l'exécutif (janvier 1958) . . . . . . . 132

2. L'élaboration difficile du mémorandum français....... 133

3. Le mémorandum de la Commission (mars 1958) . . . . . 136

4. Vers une position commune des Six . . . . . . . . . 137

IV. Conclusion : une contrainte internationale croissante . . . . . . 139

Chapitre III. De Gaulle et la rupture dans les négociations européennes (Mai-Décembre 1958) . . . . . . . . . . . . . . . . 143

I. La rupture politique nationale : le retour au pouvoir

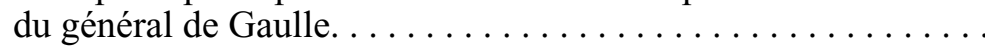


A. Des conceptions européennes relativement favorables à la CEE en juin $1958 \ldots \ldots \ldots \ldots \ldots \ldots \ldots \ldots \ldots \ldots$

B. La position de force du président du Conseil de Gaulle . . . . 146

II. La rupture européenne : la fin de la ZLE . . . . . . . . . . . . . . 149

A. Le renforcement de la position française (juin-octobre 1958) 149

1. L'acceptation de la CEE et la nouvelle position sur la ZLE . . . . . . . . . . . . . . . . . . . . . . . . . . . . . . 149

2. La nouvelle position française sur la ZLE. . . . . . . 151

3. Les progrès des négociations sectorielles . . . . . . . 153

4. Vers une position commune des Six . . . . . . . . 154

B. La rupture de la négociation ZLE (octobre-décembre 1958) . 156

1. La stratégie de la rupture (octobre-début novembre 1958). 156

2. La rupture des négociations (14 novembre 1958) . . . . 159

3. La communautarisation de la rupture (novembre-décembre 1958)................. 161

4. L'indécision britannique et la rupture finale du 15 décembre 1958. . . . . . . . . . . . . . . . . 164

5. Conclusion : l'échec de la ZLE en $1958 \ldots \ldots \ldots \ldots \ldots 166$

III. La rupture européenne et mondiale : le plan Rueff . . . . . . . . 167

A. Une nouvelle initiative britannique : l'opération Unicorn . . 169

B. La réaction française : le comité Rueff et les décisions du 18 novembre $1958 \ldots \ldots \ldots \ldots \ldots \ldots \ldots \ldots \ldots \ldots$

C. Le débat sur le plan Rueff et la convertibilité . . . . . . . . 175

D. Les décisions françaises : du 10 au 31 décembre $1958 \ldots \ldots$.

E. Le processus de décision du plan Rueff . . . . . . . . . 181

F. La rupture du plan Rueff et la ZLE . . . . . . . . . . . . . 184

IV. L'affirmation de la Commission européenne en 1958 . . . . . . 186

A. La défense de l'intégrité de la CEE

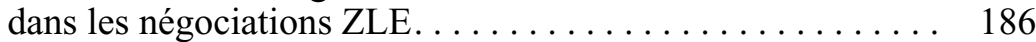

1. L'enjeu de la négociation ZLE pour la jeune Commission européenne . . . . . . . . . . . . . . . 186

2. L'affirmation rapide de la Commission Hallstein ....... 187

3. Au service d'une approche communautaire de la ZLE . . . 189

4. La convergence apparente entre la France et la Commission. . . . . . . . . . . . . . . . 
B. Renforcer l'Europe monétaire par la crise française . . . . . 191

1. Marché commun et union monétaire : un lien évident

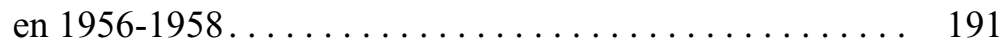

2. Le débat au début de 1958 : visions allemandes et britanniques . . . . . . . . . . . . . . . . . . 193

3. La communautarisation de la crise française de mai 1958 . 194

4. Le premier projet d'union économique et monétaire . . . . 197

5. Le second projet d'union économique et monétaire . . . . 200

C. Conclusion : une affirmation réussie

de la Commission européenne. . . . . . . . . . . . . 202

V. Charles de Gaulle et les nouveaux équilibres en France et en Europe .

Conclusion de la première partie. La France face à la réorganisation de la coopération économique européenne (1955-1958) . . . . . . . 207

I. La crise française . . . . . . . . . . . . . . . . . 207

A. Les deux ruptures principales : le rapport Spaak et le plan Rueff

B. Les temps des négociations européennes et de la crise française . . . . . . . . . . . . . . . . . 208

C. Crise et réforme du modèle français par la CEE. . . . . . . 209

II. La conversion de la France à la CEE . . . . . . . . . . . . 210

A. La CEE, dernier levier d'influence internationale

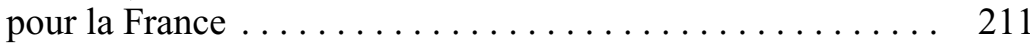

B. Les vecteurs internes de la conversion . . . . . . . . . . 212

C. De la profondeur de la conversion. . . . . . . . . . . . 213

III. Le succès du modèle flexible de la CEE . . . . . . . . . . . . . . 214

A. Des interprétations multiples de la CEE . . . . . . . . . 214

B. L'influence positive de la ZLE sur la CEE. . . . . . . . . . 215

C. La mise en place réussie de la CEE. . . . . . . . . . . 216 


\section{DEUXIÈME PARTIE LES EUROPE ÉCONOMIQUES EN DÉBAT : LES DÉCIDEURS FRANÇAIS ET LA CEE (1959-1969)}

\section{Chapitre IV. Les bases de la politique européenne}

de la France gaulliste (1959-1969) . . . . . . . . . . . . . . . . . . . 223

I. Des objectifs économiques ciblés, voire limités . . . . . . . 224

A. Le Marché commun : un «traité de commerce » . . . . . . 225

B. L'encouragement à la libération des échanges. . . . . . . . . 227

C. Le consensus français autour d'une libéralisation régulée . . 229

D. L'acceptation d'une Europe-arbitre . . . . . . . . . . . . . 233

E. La PAC : une priorité politique mal maîtrisée........ 236

II. Une ambition politique et institutionnelle irréaliste. . . . . . . . 242

A. Les handicaps de la vision gaulliste pour la politique européenne . . . . . . . . . . . . . . . 242

B. Une politique révisionniste agressive . . . . . . . . . 244

C. Les limites de la politique révisionniste française : la crise de la chaise vide . . . . . . . . . . . . . . . . 247

D. Contrôler et influencer l'administration communautaire . . . 254

E. L'autorité incontestée du général de Gaulle en matière de politique européenne. . . . . . . . . . . . . 259

III. Conclusion : forces et faiblesses de la France gaulliste...... 266

Chapitre V. L'Europe ordolibérale : la politique de la concurrence (1958-1965).

I. Une nouvelle politique publique à l'échelle du Marché commun . . . . . . . . . . . . . . . . . . . . . . 269

A. Les enjeux de la politique de la concurrence en 1957. . . . . 269

1. Des pratiques nationales diverses . . .......... 271

2. Les dispositions du traité de Rome . . . . . . . . . . . . . 273

B. Une mobilisation patronale précoce (1956-1957) . . . . . 276

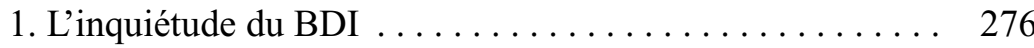

2. Les divisions internes au patronat européen ......... . 277

3. L'UNICE mobilisée mais sans doctrine. . . . . . . . . . . . 279 
C. La constitution d'un réseau autour de la Commission

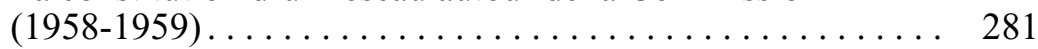

1. Le groupe ordolibéral de la Commission . . . . . . . . 281

2. Les divisions persistantes de l'UNICE ........... 283

3. Les deux Europe organisées du patronat.......... 285

4. Le débat intellectuel . . . . . . . . . . . . . . . . . 286

II. Une mobilisation française inefficace face à la Commission . . 288

A. Juin 1959-Juin 1960 : impatience et mobilisation de la Commission . . . . . . . . . . . . . . . . . . . . 288

1. La nécessité d'un changement de stratégie ......... . 288

2. Une proposition de règlement ambitieuse . . . . . . . 290

B. Le décalage des décideurs français (1958-1960). . . . . . . 292

1. Une réflexion minimaliste et concentrée sur la circulaire Fontanet (1958-1960) . . . . . . . . . . . . . . . . . . 292

2. L'obsession française de la concentration de l'industrie allemande. . . . . . . . . . . . . . . . . . . . . . . . . . . . 294

C. L'impossible lobbying européen du patronat (1959-1960) . . 296

1. La faiblesse structurelle de l'UNICE dans les débats initiaux . . . . . . . . . . . . . . . . . . 296

2. L'offensive belge de l'été $1960 \ldots \ldots \ldots \ldots \ldots \ldots . \ldots 299$

3. Le patronat face aux propositions de von der Groeben. ... 301

III. Le règlement 17/62 : succès et échecs de l'Europe ordolibérale. 304

A. La dynamique communautaire de la négociation (fin 1960-mi-1961) . . . . . . . . . . . . . . . . . . . . 304

1. La réaction française à la proposition de la Commission . . 304

2. La proposition passe l'étape du Conseil des ministres ... . 307

3. La contre-offensive du CNPF par l'UNICE ......... 311

4. L'action des acteurs patronaux et administratifs français . . 313

B. La dernière étape des négociations et le règlement 17/62

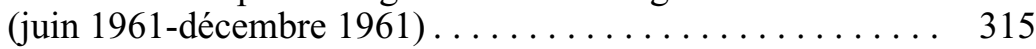

1. Les divisions de l'administration française face aux ambitions de la Commission. . . . . . . . . . 315

2. Le soutien de l'Assemblée (septembre-octobre 1961) ... 318

3. Le dernier effort du CNPF. . . . . . . . . . . . . 320

4. Le revirement du gouvernement français . . . . . . . . 321 
5. Le règlement 17/62 : une victoire pour la Commission . . 322

C. L'impossible application du règlement $17 / 62 \ldots \ldots \ldots \ldots . . \ldots 324$

1. Le problème de masse : l'afflux des notifications (1962-1964) ......................... 324

2. La crise de confiance de la DG IV (1963-1964) ...... 326

3. La sortie de crise $(1964-1965) \ldots \ldots \ldots \ldots \ldots \ldots \ldots 330$

IV. Conclusion : succès et limites du projet d'Europe ordolibérale. . 332

A. La division des opposants . . . . . . . . . . . . . . 333

B. La Commission européenne au cœur du système institutionnel communautaire ..................... 334

C. Ambition et échec d'un projet ordolibéral

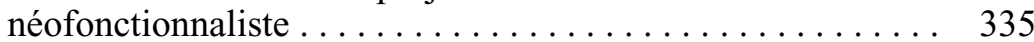

D. La définition tardive d'une approche française de la politique de la concurrence. . . . . . . . . . . . 337

Chapitre VI. L'Europe « organisée » de Marjolin . . . . . . . . . . . . . 339

I. La coordination des politiques économiques à moyen terme . . 339

A. La doctrine économique et européenne du commissaire Robert Marjolin. . . . . . . . . . . . 339

B. La constitution d'un réseau de promotion de la programmation européenne . . . . . . . . . . . . 342

1. Un contexte favorable : la relance de la planification indicative ........................... 342

2. Le développement d'un réseau planificateur européen ... 345

3. La promotion de l'idée de programmation . . . . . . . . 347

C. L'adoption de la « politique économique à moyen terme » . . 349

1. La proposition de la Commission du 25 juillet 1963 . . . . 349

2. La négociation au Conseil (juillet 1963-avril 1964) ..... . 352

3. La mise en œuvre de la PEMT (1964-1965) . . . . . . . . 354

D. Conclusion : la cohérence du projet de Marjolin. . . . . . . . 355

II. La coordination des politiques conjoncturelles et monétaires . . 356

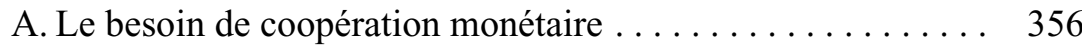

1. Le dernier avatar de la négociation ZLE : le comité de politique conjoncturelle ............... 357

2. La coopération des Six et le SMI ........... 358 
3. Les réflexions de Marjolin, de Triffin et de Jean Monnet (1959-1961) . . . . . . . . . . . . . 360

B. Le projet d'union économique et monétaire de Marjolin . . . 363

1. La définition du projet (fin 1962-début 1963)........ 363

2. Le lancement du projet : la communication

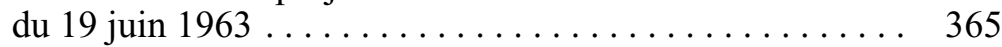

3. Le débat à Six et les décisions des 13-15 avril 1964 . . . . 366

C. Conclusion : l'UEM, une ambition ancienne et complémentaire de la PEMT.

III. Le conflit entre l'Europe organisée et l'Europe ordolibérale. . . 370

A. Une opposition croissante entre deux conceptions économiques $(1959-1964) \ldots \ldots \ldots \ldots \ldots \ldots \ldots \ldots$. . . . . . . 371

1. Une rivalité structurelle . . . . . . . . . . . . . 371

2. Les critiques réciproques des travaux entrepris au sein de la Commission . . . . . . . . . . . . . . . . 371

3. Le débat intellectuel (1962-1964) . . . . . . . . . . . . 373

4. La critique du projet de politique économique à moyen terme .

B. La poursuite des conflits doctrinaux : le dossier de la concentration $(1964-1966) \ldots \ldots \ldots \ldots \ldots \ldots \ldots$

1. Les réflexions de l'UNICE sur la concentration ....... . 376

2. L'inflexion apparente de la politique de la concurrence ... 378

IV. L'affrontement entre Marjolin et Hallstein :

la crise de la chaise vide. . . . . . . . . . . . . . . . . 380

A. Les trois projets de relance de la CEE. . . . . . . . . . 381

1. Le projet du gouvernement allemand : Europe politique et Europe libérale. ....................

2. La relance du projet d'union économique et monétaire de Robert Marjolin . . . . . . . . . . . . . . . 383

3. Les ambitions fédéralistes d'Hallstein. . . . . . . . . 386

B. Les oppositions au sein de la Commission européenne . . . . 390

1. Les rapports entre Marjolin et Hallstein en 1958-1962 : une convergence apparente . . . . . . . . . . . . 390

2. L'opposition de stratégie à partir de la fin 1964 jusqu'à la chaise vide. . . . . . . . . . . . . . . 
C. Conclusion : confrontations et échecs des projets d'Europe les plus volontaristes . . . . . . . . . . . . 395

V. Le projet macroéconomique de Raymond Barre . . . . . . . . . 396

A. Des réflexions prudentes . . . . . . . . . . . . . . . 396

1. La persistance du débat sur la coordination des politiques économiques (1966-1967) . . . . . . . . . . . . . . . . 396

2. L'arrivée de Barre à la Commission européenne...... 400

3. Le mémorandum Barre de février 1968 . . . . . . . . . . 402

B. Les projets monétaires relancés par la crise française. . . . . 405

1. La crise de mai $1968 \ldots \ldots \ldots \ldots \ldots \ldots \ldots \ldots \ldots 4 \ldots \ldots \ldots$

2. La crise de novembre $1968 \ldots \ldots \ldots \ldots \ldots \ldots \ldots \ldots 40 . \ldots \ldots$

3. Le plan Barre de février $1969 \ldots \ldots \ldots \ldots \ldots \ldots \ldots .410$

C. Des ambitions réelles de Barre en matière économique

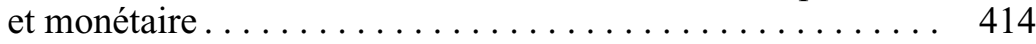

VI. Conclusion : le projet Marjolin d'Europe volontariste et sa postérité

Chapitre VII. Les projets de politique industrielle communautaire (1965-1969).

I. Le premier projet français de politique industrielle européenne de 1965 .

A. La relance de la politique industrielle française vers l'international.

B. L'échec d'une approche partielle : les investissements directs étrangers (1963-1965)

C. La prise de conscience de la nécessité d'une politique industrielle globale (fin 1964).

D. La présidence française de 1965 et le lancement de la politique industrielle.

II. Les réflexions sur la politique industrielle communautaire en France . . . . . . . . . . . . . . . . . . . . . . . . . .

A. L'émergence d'un courant révisionniste au sein des responsables français (1965-1967).

1. La chaise vide : l'émergence d'un courant révisionniste . .

2. De la chaise vide à la seconde candidature britannique (1966-1967) 
3. Les divisions lors de la seconde candidature britannique (1967-1968) . . . . . . . . . . . . . . . . . . . 440

4. La force du courant révisionniste . . . . . . . . . . . . . 444

B. Le volontarisme français en matière de politique industrielle $(1966-1967)$. . . . . . . . . . . . . . . . . . . . . 444

1. La relance de la politique industrielle nationale en 1966 . . 444

2. Une nouvelle génération de « modernisateurs » . . . . . . 446

3. La promotion d'une approche européenne de la politique industrielle par Debré en 1967 . . . . . . . . . . . . 454

4. Conclusion : des réseaux dynamiques à l'échelle

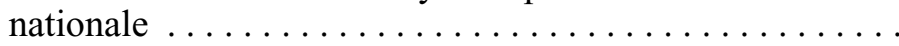

III. Le lancement de la politique industrielle communautaire (1966-1968)

A. Une nouvelle force motrice à la Commission européenne

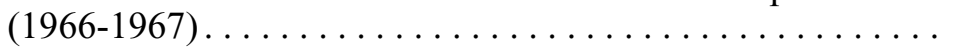

1. Un contexte européen favorable .

2. Un groupe franco-italien volontariste à la Commission européenne. ......................

3. Le projet global de Colonna (1966-1967) . . . . . . . . 463

B. Les initiatives de politique industrielle de 1966-1968. . . . . 467

1. Inciter aux concentrations : la société européenne ..... 467

2. L'approche sectorielle : la PRST . . . . . . . . . . . 469

3. La réorientation du projet ordolibéral : encouragement à la concentration et à la coopération . . . . . . . . . 474

IV. Vers les années 1970 : libéralisation et normalisation . . . . . . 477

A. L'évolution du CNPF vers une position plus libérale . . . . . 477

B. Les mutations de la politique économique française. . . . . . 481

C. La politique européenne de la France réorientée

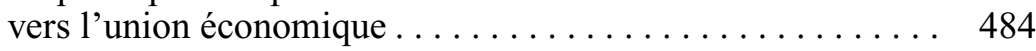

D. L'évolution des ambitions de la Commission européenne. . . 486

E. La remise en cause des bases de la politique gaulliste

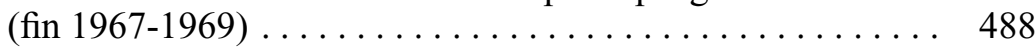

V. Conclusion : les tentatives de politique industrielle........ 490 
Conclusion générale

Sources et bibliographie . . . . . . . . . . . . . . . . . . . . . 509

Sources ........................... 511

Bibliographie............................ 521

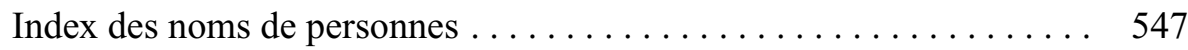

Index des institutions $\ldots \ldots \ldots \ldots \ldots \ldots \ldots \ldots \ldots \ldots \ldots$

Table des matières. . . . . . . . . . . . . . . . 551 



\section{DANS LA MÊME COLLECTION}

BossuAT (Gérard), La France, l'aide américaine et la construction européenne, 1944-1954

BussiÈRE (Éric), La France, la Belgique et l'organisation économique de l'Europe, 1918-1935

KiPPING (Matthias), La France et les origines de l'Union européenne. Intégration économique et compétitivité internationale

SCHIRMANN (Sylvain), Crise, coopération économique et financière entre États européens, 1929-1933

L'Europe face à la mondialisation. Quelles politiques communautaires pour demain? 50 ans de construction européenne

Colloque du 26 mars 2007 organisé par la Direction Générale du Trésor et de la Politique Économique (DGTPE) et l'Institut d'Études Politiques de Paris en partenariat avec Les Échos

De l'estime au cadastre en Europe. Les systèmes cadastraux aux XIX et $X X^{e}$ siècles

Colloque des 20 et 21 janvier 2005 sous la direction de Florence Bourillon et Nadine Vivier 
Milieux économiques et intégration européenne au $X X^{e}$ siècle. La relance des années quatre-vingt (1979-1992)

Colloque du $1^{\text {er }}$ décembre 2005 sous la direction scientifique d'Éric Bussière, Michel Dumoulin, Sylvain Schirmann

La mobilisation du territoire. Les districts industriels en Europe occidentale du XVII au XX siècle

Colloque des 5 et 6 février 2004 sous la direction de Michel Lescure

Le rôle des ministères des Finances et des ministères de l'Économie dans la construction européenne (1957-1978)

Colloque des 26, 27 et 28 mai 1999 sous la direction de Raymond Poidevin et René Girault

Les banques en Europe de l'Ouest de 1920 à nos jours

Colloque des 7 et 8 octobre 1993

Le Plan Marshall et le relèvement économique de l'Europe

Colloque des 21, 22 et 23 mars 1991 sous la direction de René Girault et Maurice Lévy-Leboyer 
Retrouvez tous les titres des Éditions du Comité pour l'histoire économique et financière de la France et les activités de recherche de l'Institut de la gestion publique et du développement économique sur le site internet: www.recherche.igpde.fr 

Formaté typographiquement par DESK (53) :

0243012211 -desk@desk53.com.fr

Achevé d'imprimer en octobre 2011 


